\title{
"Walking the Talk"? \\ An Ethnography of Biculturalism at Te Papa
}

By

Tanja Schubert-McArthur

\author{
A thesis \\ submitted to Victoria University of Wellington in fulfilment of the \\ requirements for the degree of Doctor of Philosophy in Anthropology \\ Victoria University of Wellington \\ 2014
}




\begin{abstract}
This thesis examines the implications of a bicultural framework for the everyday interactions of Māori and non-Māori staff at the Museum of New Zealand Te Papa Tongarewa (TP thereafter). The research addresses gaps in the New Zealand literature on biculturalism, which has not hitherto explored the internal dynamics of cultural organisations in depth, as well as issues in the international literature of anthropology, museum studies and related fields to do with museums, indigenous people and cultural identity. The central research question is: how does biculturalism work in practice at TP? The approach is qualitative using mixed-methods, based on twelve months intensive fieldwork behind the scenes at New Zealand's national museum. Drawing on 68 interviews and participant observations with 18 different teams across the organisation, the thesis explores how biculturalism is enacted, negotiated, practised and envisioned on different stages within the complex social institution that is the museum.
\end{abstract}

Rather than seeing TP as a single bicultural entity, my analysis suggests that TP is a convoluted amalgam of several stages encompassing 'contact zones' where Māori and non-Māori engage to varying degrees. I propose that TP's marae is the centre stage for Māori activities and rituals that serve a number of functions: to position people through mechanisms of inclusion and exclusion, display power, facilitate intercultural dialogue, empower Māori, and transform non-Māori through meaningful experiences. Throughout the thesis, I argue that biculturalism is neither an innocent aspiration nor a means to an end, but an ongoing struggle and negotiation process.

The importance of ethnography to the anthropological enterprise and museum studies research is reaffirmed through this study; not only does this ethnographic study provide insights into museum practices, but also the complex processes of 'grappling with biculturalism', interactions between diverse museum staff as well as positioning of indigenous peoples in settler societies. 


\section{Preface}

I was born and raised in the South West of Germany and lived most of my life in a small village near Stuttgart in what I would call a very monocultural German, middle class setting. From my teenage years onwards I was fortunate to encounter different cultures and world views on my travels through Europe and Australia, which led me to study anthropology. My methodological approach stems from my academic studies in Germany and New Zealand (NZ thereafter). Prior to my immigration to NZ I completed a Magister degree (entails both bachelor and master's) at Tübingen University in Germany in Empirische Kulturwissenschaft, an academic discipline that is also known as European ethnology, cultural anthropology or folklore studies.

During my studies in Wellington in 2003 I met Ryan, who was born in NZ to his Pākehā mum and Australian dad. After living in Germany together for several years, we got married in 2006 and decided to return to NZ. Although I felt well prepared to live in Wellington having researched recent German emigrants to NZ in my master's thesis (Schubert-McArthur 2007; see also 2009), I still struggle with positioning myself in NZ society, where I am often mistaken for a Pākehā with my blond hair and fair skin, yet picked as a foreigner because of my accent and sometimes find myself identifying with Māori, whose cultural values are close to my heart.

Just after I had immigrated to NZ in December 2006 my first job happened to be at TP. Probably because I frequently encountered cultural differences in my bi-national marriage and in my everyday life in NZ, I was curious how intercultural interaction at TP was managed and enacted by its staff members.

\section{My Own Journey Through Te Papa}

In the job interview for a position at TP as a research assistant in the Visitor and Market Research Team I learned that TP offers te reo Māori classes, so I started a beginners' course. Besides learning the basics of the Māori language I gained an understanding and 
appreciation of the Māori culture and made friends with staff across the organisation. When I came to a point where the one hour per week seemed not enough to improve my Māori language skills I signed up for Māori 101 at Victoria University.

A couple of months after I had started work at TP I applied for the role of Events supervisor and from then on I held two casual positions at TP mainly working front-ofhouse with and for the visitors. Having two managers, one Māori and one Pākehā, I experienced firsthand how their support, or lack of, influenced my own behaviour within the bicultural organisation. When I heard about the waiata sessions I wanted to join, but found it very difficult to 'hit it off' with some Māori. The turning point, I think, was performing as part of the TP kapa haka Team, Ngā Whetu Ririki, at the Regional Kapa Haka Competition, when they realised that I was not just an onlooker but a full member. As my confidence dealing with the Māori staff grew, the relationship became a lot friendlier. In hindsight, I'm wondering if my own anxiety contributed to the tense relationship at the beginning.

My joining the taonga pūoro group was completely coincidental: I bumped into the organiser in the lift and he invited me to the next practice. From then on I received email invitations and despite my lack of experience playing any instrument I felt accepted and guided to be become a valued member of the team. My involvement with taonga pūoro since January 2010 has allowed me to experience pōwhiri ${ }^{1}$ from a different viewpoint, standing on the porch of the marae rain or shine to welcome the manuhiri. It has also opened my eyes to the huge commitment some - mainly Māori staff members have carrying the responsibilities of karanga, whaikōrero, taonga pūoro and waiata.

\footnotetext{
${ }^{1}$ I use the term 'pōwhiri' as it is used at Te Papa to describe all ceremonial rituals for visitors conducted on the marae, including staff inductions, tangi and repatriation ceremonies, whereas Salmond (2009) uses hui to describe these gatherings and defines pōwhiri as a distinct part of the hui, namely the 'action chant of welcome' (2009:118) that is performed by the hosts as the visitors advance the marae and only 'given for important groups' (2009:119). The meaning of pōwhiri has changed significantly since Salmond's observation in 1975, "[n] owadays, however, the word pōwhiri is often used to mean every aspect of welcoming visitors" (Barlow 2005:100).
} 
If I was still perceived as 'young thing from Germany doing some study' up until this point, giving birth to my son and becoming a mother enhanced my standing. When I stayed with the taonga pūoro group at Hongoeka Marae in Plimmerton for the wānanga in March 2011 with my four-week-old baby, I experienced the Māori concepts of manaakitanga, whanaungatanga and aroha firsthand. After seven years at TP and having shared so many experiences and events good and bad with TP staff I feel part of the whānau nowadays, although I still have to push myself to collect a skirt before every performance as my inner-self just wants to hide in the back-row and observe rather than participate. I have learned that in the Māori world it is not just about the performance, it is about standing together and supporting each other.

An eye-opener for me was a conference on re-ethnicisation of indigenous peoples held in Germany, where experts reported cases from Africa, North and South America and the Pacific. I had prepared a paper that was quite sceptical of the implementation of biculturalism at TP, but after three conference days of hearing how poorly indigenous peoples are treated in other countries (constantly thinking "this would not be possible in New Zealand!"), I changed my presentation completely. In the end I emphasised that TP has contributed to a better understanding between cultures and provides a 'contact zone' where the bicultural concept can be performed and experimented with by staff. In contrast to most other museums worldwide TP has made an effort to empower Māori by providing space and resources so they can take control of their tangible and intangible heritage. The interest and enthusiasm from the conference attendees was overwhelming (to the extent that they held their next conference in NZ and visited TP), and changed my own perception significantly. In this regard I hope my work will not be misinterpreted as 'Te Papa bashing', but read as an attempt to understand the innerworkings of a bicultural institution by empathetically yet critically analysing its policy and practice. 


\section{Acknowledgements}

This study would not have been possible without the fruitful collaboration with TP, therefore the staff deserve my deepest felt thanks and gratitude for allowing me into their worklives and sharing their knowledge with me. Working alongside them and seeing their daily challenges I have gained lots of appreciation and respect for the passion and idealism of these museum practitioners. Special thanks to the late $\mathrm{Dr}$ Seddon Bennington for supporting my research interest, and to Dame Dr Claudia Orange and Arapata Hakiwai for being my liaison persons at TP. Joan Costello has sparked my interest in Māori culture and 'dragged' me along to noho marae, tēnā koe. Awhina Tamarapa not only gave me a lift to New Plymouth for the Museums Aotearoa conference 2010 , but also an invaluable insight into TP. Mere Boynton, Tracy Puklowski and Te Herekiekie Herewini allowed me into their teams when the project was still in its early stages; their trust meant a lot to me. I thank Rangimoana Taylor for his friendship and naming my son Tūmanako. I would like to thank all the people (in no particular order) who helped me to grasp the 'taniwha' TP by talking to me, finding resources or simply providing words of encouragement:

Victoria Boyak, Ken Gorbey, Jock Phillips, Jonathan Mane-Wheoki, Nikkie Rich, Ashley MacKenzie-White, Sue Piper, Michelle Hippolite, Roger Gascoigne, Chris Reed, Martin Lewis, Lynne Carmichael Allen, Sabine Schulte, Lucy Arthur, Carolyn RobertsThompson, Kim Gustavsson, Sonya Davis, Simon Whittaker, Hema Temara, Rhonda Paku, Dr Richard Nunns, Shane Pasene, Florence Liger, Jude Turner, Suzanne Tamaki, Megan Tamati-Quennell, Kukupa Tirikatene, Stephen Owen, Simon Harper, Alison Preston, Sean Mallon, Julie Noanoa, Lucinda Blackley, Michael Houlihan, Pamela Lovis, Catherine Halbleib, Sue Superville, Te Arikirangi Mamaku, Riria Hotere, Kahu Taumata, Te Taru White, Richard Wright, Lisa Ward, Kristelle Plimmer, Sarah Morris, Frith Williams, Jette Sandahl, Mark Donovan, William Yip, Lucy Trevalia, Jane Keig, Fiona Allen, Greg Ariell, Jay Houpapa, Erana Hemmingsen, Tamara Patten, Lucie Paterson, Khali Philip-Barbara, Michael Steele, Amber Aranui, Nicola Smith, 'Uncle' Tom Ward, Anna Wilson, Lisa Reweti, Priscilla Tugaga, Gavin Reedy, Roxan Mathys, Anna Andrews, Marlene Curyer, Janet Purdy, Shalesh Vasan, Moana Parata, Bridget MacDonald, Laura Feasley, Andrew Watt, Xandra Boswell, Emma Best, Chrissie Locke, Haley Hakaraia, Cliff Whiting, Dame Cheryll Sotheran, Hokimate Harwood, Grace Hutton, Graeme Whimp, 
Susana Woo, Roma Potiki, Puawai Cairns, Ross Edney, Dougal Austin, Matiu Baker, Adrienne Jansen, Giselle Stanton, Maraea Rihari, Chris Palin, Brighid Kelly, Vanessa Rogers, Liz Grant, Victoria Esson, Kylie Ngaropo, Elise Goodge, Paora Tibble, Shane James, Lucy Searanke, Anna Sheffield, Corinna Howland, Leimomi Oaks , Simon Jean, Mariska Kecskemeti, Gabby Lawson, Dr Huhana Smith, Jeff Fox, and all the other people at TP I had the pleasure to interact with! Please accept this thesis is a koha.

Kukupa Tirikatene once said to me: "You can create a situation of giving each person a mirror so they can look at themselves. That's your job! [...] Tēnā koe. Good luck to whatever you're doing. There is one thing you got to believe in - (whispers) yourself!" These words were an inspiration and blessing to me, especially at times when I felt inadequate to the task and like an intruder at TP. I sincerely hope that the participants will say in hindsight that my research agrees with Hirini Moko Mead's (2003:318) statement: "Processes, procedures and consultation need to be correct so that in the end everyone who is connected with the research project is enriched, empowered, enlightened and glad to have been a part of it."

The views and mistakes are mine alone and do not reflect TP or Victoria University. My thanks goes to Lauren Callow for helping me with transcribing interviews. My dear friend Rosina Hickman deserves a medal for hours upon hours of transcribing and proof-reading my drafts.

At Victoria University I owe thanks to many people: First and foremost my supervisors Prof Brigitte Bönisch-Brednich and Dr Conal McCarthy who have provided thorough feedback, been a sounding board for my ideas, and have supported me beyond the call of duty on this journey. The bond I established with Brigitte would be better reflected in the German term 'Doktormutter' as she has indeed been a 'mother-figure' for me. Conal, I owe you a beer or two. I am thankful to the academic staff and the Admin team at the School of Social and Cultural Studies and the wider Victoria University research community, especially Jeff Sissons who supervised me in the early stages and planted the seed for my interest in institutional thinking by pointing me to Mary Douglas' book How Institutions Think (1986). I thank the Postgraduate Students' Association for having me as their president in 2010 and the writing group for the lively discussions and moral 
support, namely Dr Catherine Trundle, Dr Lorena Gibson, Elisabeth Kosnik, Rachael Fabish, Dr Dionne Stevens, Dr Brownwyn McGovern and Tanja Rother. Special thanks to Jared Walton and Josh Barton for helping me with the final edit and Sunshine Prior for keeping me company during many nightshifts.

I am grateful for the Victoria University PhD Scholarship and the Top Achiever Scholarship from Tertiary Education New Zealand as well as to the School of Social and Cultural Studies for their grants that allowed me to complete this thesis and travel to overseas conferences. I would also like to thank the organisers of the ASA/ASAANZ conference (Auckland 2008), ICEE conference (Wellington 2008), the INTERCOM conference (Rotorua 2009), the Second International conference of the Inclusive Museum (Brisbane 2009), and 'Die neuen Wilden?' Symposium (Mainz 2012). I am especially thankful for the ongoing dialogue with Dr Steven Engelsmann, former director of the Leiden Museum Volkenkunde who encouraged my research early on. It was a privilege to be taken behind the scenes at several museums and 'thank yous' are owed to Dr Jenny Newell (American Museum for Natural History, New York), Dr Ingrid Heermann (Linden Museum, Stuttgart), Dr Malcolm Chapman (Manchester Museum) and Linda Wigley (former director Whangarei Museum). This whakataukī is for all the people who were part of this research project:

Hutia te rito

o te harakeke

Kei whea, te kāmako e ko

Ki mai ki ahau

He aha te mea nui

o tenei ao

Maku e ki atu

He tangata, he tangata, he tangata.
When the heart is torn

from the flax bush

where will the Bell bird sing?

You ask me

what is the greatest thing

on Earth

My reply is

it is people people people. 
My friends and extended family all over the world deserve my thanks for keeping in touch and helping me in many ways: My parents, Günther and Marita Schubert, have been incredibly supportive, despite being in Germany, and I would not have been able to do it, if they did not believe in me. Mama, thank you for being my biggest fan! Thank you to my sister Tina and her family who gave us their guest room in New York. I acknowledge my grandparents, without whom I would not be who I am, and fondly remember my late Opa Fritz, who passed away in 2013. 'Danke' to Rebecca Burke, Dr Angelika Dietz, Andreas von Normann, Dr Helena Heizmann and Dr Carmen Weith for their friendship.

To my husband Ryan: thank you for backing me through the highs and lows of doing a $\mathrm{PhD}$ and being my rock. If we can survive a PhD we can survive anything. I think I owe you a beer - or a small craft beer brewery! It has not always been easy doing a PhD with a toddler in tow, but I am forever thankful for all the babysitting and support from my 'Kiwi' family; thank you Susan, Malcolm, Sophie, Jordan McArthur and Fitzy. I dedicate this thesis to my son Max, who was born halfway through this bicultural journey, for he had to share his Mama with the PhD (and thought I lived at uni for a while) but grounded me by making me laugh every day. 
To my son

Maximilian James Tūmanako Schubert McArthur

and his grandparents

E toru ngā mea

Ngā mea nunui

E kì ana

Te Paipera

Whakapono

Tūmanako

Ko te mea nui

Ko te aroha
There are three

Great things

That are spoken of

In the Bible

Faith

Hope

And the greatest of all

Love 


\section{Contents}

Abstract $\quad$ i

$\begin{array}{ll}\text { Preface/Acknowledgements } & \text { ii }\end{array}$

Introduction 1

Chapter 1: Building Biculturalism 52

Chapter 2: Staging Biculturalism 95

$\begin{array}{ll}\text { Chapter 3: Doing Biculturalism } & 148\end{array}$

Chapter 4: 'Grappling' with Biculturalism 192

Chapter 5: Understanding and Imagining Biculturalism 239

$\begin{array}{ll}\text { Conclusion } & 271\end{array}$

$\begin{array}{ll}\text { Epilogue } & 285\end{array}$

$\begin{array}{ll}\text { Glossary } & 286\end{array}$

$\begin{array}{ll}\text { Appendix } & 293\end{array}$

$\begin{array}{ll}\text { Bibliography } & 320\end{array}$ 


\section{A note on the Māori language}

Many Māori words are in common usage in New Zealand English. Where they are not translated in the text, the reader is referred to the glossary. Translations are my own in line with published dictionaries, e.g. P.M. Ryan (2008 [1995]), Māori Dictionary online, except where otherwise stated. Māori texts have been edited to conform to modern conventions, including the addition of macrons.

\section{Abbreviations}

AGMANZ - Art Gallery and Museums Association of New Zealand

Board - Museum of New Zealand Te Papa Tongrewa Board

'Buckle Street' - used as a synonym for Te Papa before it moved to Cable Street CEO - Chief Executive Officer

Day One - used as a synonym for Te Papa's opening day (14 February 1998)

EBT - Egypt Beyond the Tomb (exhibition title)

ET - Education Team

ICOM - The International Council of Museums

NSTP - National Services Te Paerangi

NZ - Aotearoa New Zealand

NZJH - NZ Journal of History

TP - Museum of New Zealand Te Papa Tongarewa

Treaty - Treaty of Waitangi 1840 


\section{List of illustrations}

1. Durie’s bicultural continuum. Source: Durie 1998b.

2. Fleras and Spoonley's model of bicultural commitment. Source: Fleras/ Spoonley 1999.

3. Eagle's stages of the bicultural journey. Source: Eagle 2000.

4. Diverse understandings of biculturalism.

5. Demographics of TP staff in 2008.

6. Demographics of NZ population in 2006.

7. Māori staff numbers at TP (December 2010).

8. Interview Sample, ethnic diversity.

9. Interview Sample, gender diversity.

10. Interview Sample, employment status at TP at time of interview.

11. Interview Sample, duration of service at TP at time of interview.

12. International policy and legislation on indigenous people. Source: ICOM.

13. Whakataurangi Ake (Na Rangimoa - Ngati Apakura).

14. Buckle Street 'old museum' vs. Cable Street 'Te Papa'.

15. Section 4, Purpose of the Act. Source: The Museum of New Zealand Act 1992.

16. Corporate Principles. Source: Annual Report 2007/08.

17. The post-colonial field (very simplified). Source: Sissons 2005.

18. Mana Taonga Principle at TP. Source: Keynote Hippolite.

19. Biculturalism at TP as Pākehā stage and Māori stage.

20. Contact zones within TP. 
NEW ZEALAND

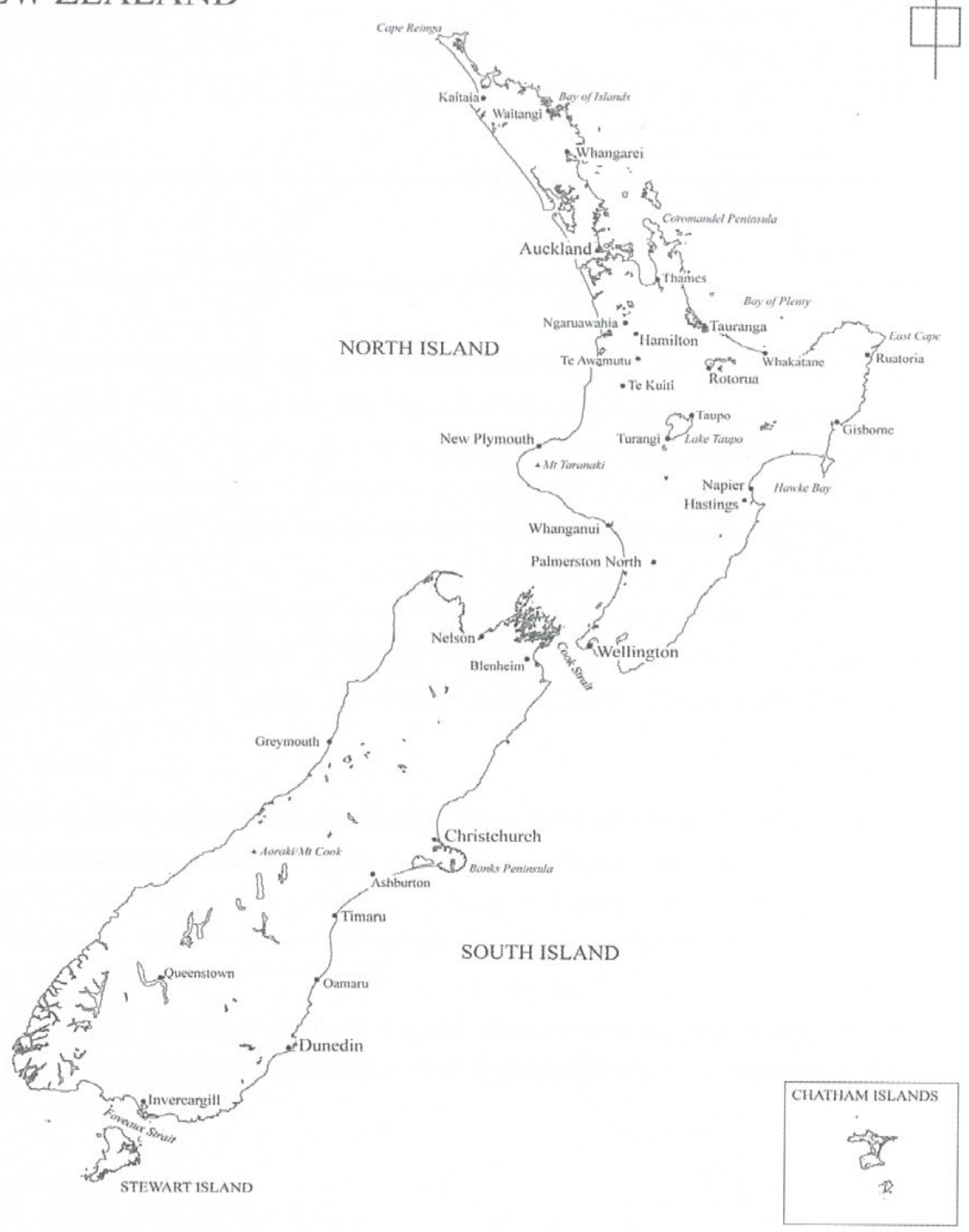


NEW ZEALAND

\section{AOTEAROA}

Simplified iwi (tribal) map

Source: Roger Neich and Te Warena Taua (Starzecka 1996: 159-160)

1 Te Aupōuri

Te Rarawa

2 Ngāpuhi

3 Ngãti Whătua

Te Kawerau-ā-Maki

Te Wai-o-Hua

4 Ngãi Tai

Ngâti Paoa

Ngāti Whanaunga

Ngāti Tamaterã

Ngãti Maru

5 Waikato

6 Ngãi Te Rangi

Ngâti Ranginui

Ngâti Haua

Ngāti Raukawa

7 Te Arawa

8 Ngăti Awa

Whakatōhea

9 Tühoe

10 Ngâi Tai

Te Whânau-a-A panui

11 Ngăti Porou

12 Rongowhakaata

Te Aitanga -a-Māhaki

13 Ngăti Maniapoto

14 Ngãti Tũwhareto

15 Ngãti Kahungunu

16 Ngāti Tama

Ngāti Mutunga

Ngāti Maru

Te Ati Awa

17 Taranaki

18 Ngāti Ruanui

Ngã Rauru

19 Te Ati-Haunui-a-Păpārangi

20 Ngāti Raukawa

Ngãti Apa

Rangităne

21 Muaūpoko

Ngāti Toa

Te Ati Awa

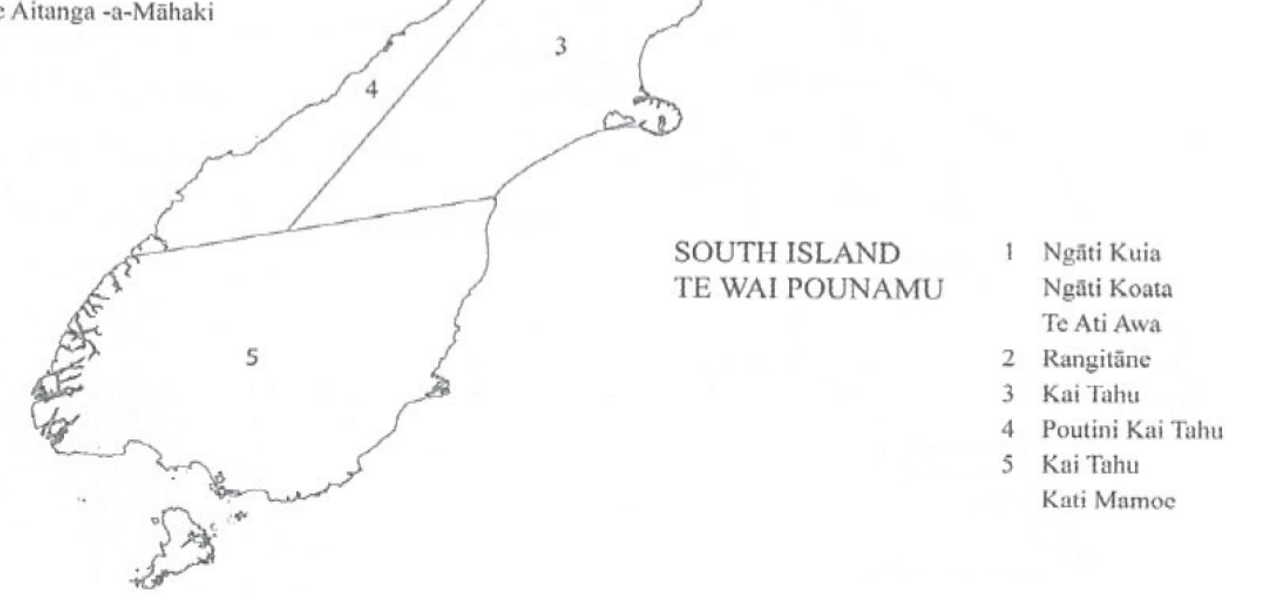

NORTH ISLAND

TE IKA A MAUI

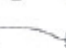

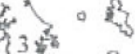

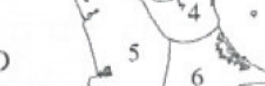

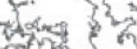
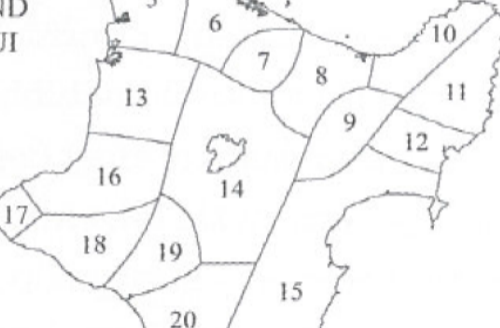

13 sist

Q
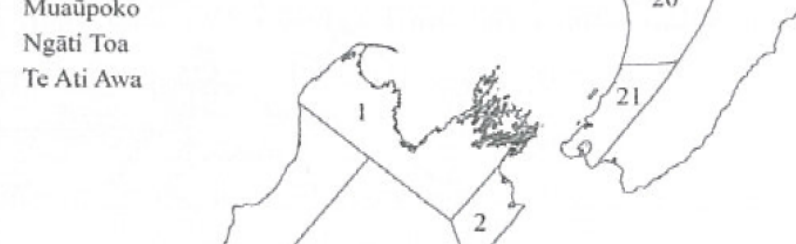


\section{Introduction}

\section{Opening Story}

When Seddon Bennington, the Chief Executive Officer (CEO) of TP, tragically died on a tramping trip in July 2009, his body lay in state inside the Museum and some staff members stayed the night to keep him company. A tangi (Māori funeral rite) was held for him where Māori leaders spoke and the next day a couple of hundred people attended his funeral, both held on Te Marae. I just got back from overseas in time to attend the funeral, but regretted missing the tangi. However, I was assured by some of my Pākehā colleagues that 'it doesn't really matter'2, as it was 'all in Māori' and since they do not understand te reo Māori, it seemed a long four hours of speeches to them. The following excerpt from my fieldnotes documents the discussion among the women in the Events Team that followed my question about how the tangi went:

Māori: It was good.

Pākehā: Well, you understand what they [Māori] were saying!

Māori: Yeah. How was it for you guys [non-Māori colleagues]?

New migrant: It's all in Mãori. I wanna understand!

Pākehā: Yeah, it was quite exclusive.

Mäori: But there was heaps of English! You know, Mãori is so rarely spoken 100 per cent, that [on the marae] is one of the seldom chances. And everyone who wanted could get up and speak. Maybe Mãori just speak longer (laughs).

This short discussion highlights some of the challenges associated with $\mathrm{TP}^{3}$ attempting to be a bicultural organisation, as well as its potential as a 'contact zone' (Clifford 1997) for staff to engage in intercultural dialogues. Moreover, it illustrates that the issues at stake cannot be described in black and white but in all shades of grey, and multiple perspectives need to be considered in order to understand the complexity of biculturalism.

\footnotetext{
2 Italics are used to set quotes from interviews or fieldnotes apart from other sources.

3 I sometimes use TP as a synecdoche or totum pro parte, where TP stands for a part of the organisation (e.g. management). The participants often referred to TP as if the organisation was a person (e.g. TP is growing up); I sometimes adopt this view, although in a metaphorical sense.
} 


\section{Introduction}

TP is internationally renowned as a world leader for museums collaborating with indigenous communities. Around the time of TP's opening in 1998, it received praise from museum professionals worldwide. Catherine Cole (1996:174), Canadian museum consultant, stated that "what's happening in New Zealand is a model for many of us"; American museum and tourism analyst, Barbara Kirshenblatt-Gimblett (1998b:14), argued that TP "is a bold and innovative venture that has to be taken very seriously from an international perspective"; Sir Neil Cossons, then Director of the British Science Museum, predicted that TP "will be a mould-breaker internationally" (Forsyth 2000:7). For Michael Ames (1996:208), TP has shown "that there is light at the end of the tunnel", and Anthony Wright (2000:6), Chair of Museums Aoetearoa and Director of the Canterbury Museum, testified:

Worldwide, there's no more completely well thought out model of the (for the moment) 'new' museum than our own Te Papa. The teams there have laboured mightily and produced an experience which has shaken the foundations of the museum world.

The people involved with the design and concept of TP were equally proud. Designer Robin Parkinson (1998:62) reported: “Te Papa is, in the best sense, the ultimate do-ityourself museum [...]. There is [...] nothing else like it in the world." American museum consultant Elaine Heuman Gurian (1998:74) stated that TP has been a "ray of hope" and Kaihautū Cliff Whiting (1998:68) said TP is 'setting standards' for the museum sector.

What sets TP apart from other museums is its unique bicultural concept, which acknowledges NZ's indigenous Māori culture as well as Pākehā culture derived from the European settlers. Biculturalism is immediately visible to visitors to TP when they enter the Museum ${ }^{4}$ : a host (perhaps a Māori ${ }^{5}$, but quite likely a Pākehā ${ }^{6}$ or new migrant) greets the visitor with the words "Kia ora, welcome to Te Papa"; ${ }^{7}$ as visitors wander

\footnotetext{
4 'Museum' with a Capital M refers to TP, whereas 'museum' refers to the institution in general.

5 Māori are the indigenous people of NZ and seen as an ethnic "group of persons bound together by common origin and interests" (Metge 1967:42).
} 
through the exhibitions or follow the signs to the toilet they will notice that introductory panels and signage around the Museum are bilingual in English and Māori; a whole exhibition is dedicated to the Treaty of Waitangi (Treaty, thereafter), NZ's 'founding document' that spells out a partnership between indigenous and nonindigenous inhabitants of NZ, and in the Iwi Gallery Māori tribal groups present themselves on their own terms. Visitors are often impressed to hear that TP has a Māori Kaihautū (leader) alongside the CEO, that Māori elders oversee tikanga Māori (cultural practices) and a significant number of Māori staff members work in all areas and ranks.

But how visible is biculturalism in the back-of-house areas: the office spaces, the collection rooms and Te Marae?8 How do staff put TP's bicultural concept into practice there? This thesis attempts to provide an insight into biculturalism in NZ 'on the ground' by exploring the inner workings of TP and the intercultural interactions of its staff using an ethnographic approach. In doing so, it seeks to address the gap in the literature on museums and source communities in general, and on TP in particular, which tends to focus on architecture and displays front-of-house or public expressions found in policy and websites. Much of the writing on TP has been superficial and lacks an in-depth understanding of its internal dynamics. On a popular level, TP has been celebrated as a role model for museums in postcolonial countries, but also criticised for being little more than an 'amusement arcade' (Dalrymple 1999:32) or "the cultural equivalent to a fast-food outlet" (Keith 2000:19). Interestingly, while visitors from overseas and the international press seem to love TP, its biggest critics are New Zealanders, especially Wellingtonians, not least its own employees. A common reply to my question of how genuinely TP commits to bicultural principles was: “Well, it's not perfect. They could do more!" While this is certainly true, one must acknowledge what TP has achieved on the

\footnotetext{
${ }^{6}$ Pākehā is the Māori term referring to non-Māori or New Zealanders of European descent. Due to their white-skin, Māori called the immigrants from the United Kingdom 'Pākehā'. "The name also refers to a patupaiarehe or fairy ... [and] can also signify a flea or a type of eel. But in my view the term as applied to white people did not derive from any of these alternative meanings. The word is not a term of denigration in Māori usage, but rather one of respect in associating the new settlers with supernatural beings or godlike people (at least in terms of their appearance)" (Barlow 2005: 87). It is not used for all non-Māori in NZ (e.g. Indians or Japanese), but reserved for those who have white skin. Therefore the term Pākehā is often used synonymous with New Zealand Europeans. For a critical discussion of the concept see (Kukutai 2009; McCreanor 2005; A. Bell 1996; King 1985; Pearson 1989; Spoonley 1986).

${ }^{7}$ As Māori words are in common usage in New Zealand English, I refer the reader to the glossary. Macrons indicate a double vowel in the Māori language and have been added, except in names, exhibition titles and quotations, where the original did not use macrons.

${ }^{8}$ Italics distinguish exhibition or book titles from the main text.
} 
bicultural front. Living in NZ it is easy to take biculturalism for granted or take up 'Te Papa bashing' (a national sport, as one informant told me), but it is a different story when one is confronted with the realities for indigenous peoples in other parts of the world, as I mentioned in the preface.

\section{Context, Aim and Scope of This Study}

This introduction situates the current study within the relevant literature, discusses the theoretical underpinnings and establishes the research methodology, before providing an overview of the chapters of this thesis. Since the 1980s biculturalism has been serving as the 'de facto' government policy in NZ (Kelsey 1996); around the same time the institution of the museum was radically transformed. In the 1990s TP was set up as a 'state experiment' to put this bicultural ideology into practice and educate the NZ public. Since then it has spearheaded the museum movement to collaborate with source communities, and particularly the indigenous Māori people. This thesis examines TP as a case study, because it is an excellent example of a national museum in a former settler colony, engaging with indigenous people in an organisational context.

There is a body of literature about museum representations of indigenous peoples, collaborative curatorship and biculturalism. To date, however, nobody has sufficiently examined the interactions of diverse museum staff working together within a bicultural framework. Therefore research that is grounded in museum practice and focuses on museum staff is greatly needed. The aim of this study is to investigate how a policy framework affects the intercultural relationships between staff in an organisation. Thus, the research is set back-of-house at the National Museum and focuses on Māori and non-Māori staff and TP's organisational rituals, rather than its exhibitions, visitors or community outreach.

One intended outcome of the study is to advance the critical analysis of biculturalism, by providing an insight into how biculturalism works (or does not work) in practice at TP. On a practical level, a second intended outcome of this study is to identify the complex politics of participation that facilitate or hinder engagement with Māori activities and rituals in an organisational context. A further concern is to determine to what extent 
Māori empowerment is possible in a museum which is inherently a Western institution. In writing this thesis, I hope to contribute to the broader debate about biculturalism in $\mathrm{NZ}$ and attempt to close the gap in the literature (discussed below) by asking, as does Tony Ballantyne (2012:62), "what ideological work does biculturalism perform within New Zealand's public sphere?" In a wider sense the research also seeks to make a contribution to anthropology, museum studies and related fields by refining the understanding of organisations, intercultural communication, rituals and performances as well as power, identity formation and sense of belonging. Ballantyne (2012:63) claims that "there is a desperate need to juxtapose narratives of nation with histories that are framed around different spatial units"; this thesis will try to do exactly this by analysing the bicultural workplace that TP claims to be.

At a time when the NZ government, together with iwi groups, 'imagine' a future for NZ through a constitutional review, and discuss the place of the Treaty within it, research that looks closely at TP, where the Treaty - in principle - already underpins every element of the institution, seems timely and valuable. As Moana Jackson, Māori lawyer and lecturer at Te Wānanga ō Raukawa, said recently, "Te Papa is a place of imagination", where one can dream beyond the reality that surrounds us. ${ }^{9}$ By viewing TP as an 'experiment' in biculturalism, I am interested in examining how the bicultural concept works out in practice: how do Māori and Pākehā build relationships? Who makes decisions based on which values? And who exercises power within this framework? ${ }^{10}$

\section{Literature Review}

This thesis is based in the discipline of anthropology but is interdisciplinary in nature, therefore it addresses the complexities of the topic by drawing on several bodies of literature. In order to examine the processes, practices and performances of biculturalism at TP, I survey literature from multiple disciplines, including anthropology, museum and heritage studies, organisational studies, political science,

\footnotetext{
9 Presentation by Moana Jackson at the 'Treaty Debate' on 24 January 2013 at TP.

10 The last question is inspired by Dr Matthew Palmer's presentation at the Treaty Debate on 24 January 2013 at TP.
} 
Māori studies and history. In the following literature review I discuss these in turn and identify useful theories and models for the current research.

\section{Museum Studies: Definitions, Interpretations and Concepts}

The term museum, despite being used in the vernacular, is 'intractable' according to Joachim Baur (2010:1) when it comes to defining it. According to Krzysztof Pomian (2007:16) when pope Sixtus IV gifted his collection to the Roman republic, the shift of the objects from the pope's residence to the capitol, the political centre, marked the birth of the first museum. Ever since then the question of what a museum is, has been the subject of constant debate: who is it for and what is its purpose? Tony Bennett (1995) gives an excellent account of the history of museums and how the institution as such has changed. Today the International Council of Museum's (ICOM) definition of museum (2007) is accepted by most museum professionals and scholars worldwide:

A museum is a non-profit, permanent institution in the service of society and its development, open to the public, which acquires, conserves, researches, communicates and exhibits the tangible and intangible heritage of humanity and its environment for the purposes of education, study and enjoyment.

Although museums have come a long way, from status symbols for aristocracy only accessible to certain elite circles to public institutions open to everyone, I concur with Bennett (1995), drawing on Foucault's idea of governmentality, that museums are an instrument to control publics through culture, hegemonic devices to sustain the status quo. On the other hand, some museums have played a significant role in challenging the status quo in their exhibitions by striving towards social justice and responsibility (Knell 2007).

Scholars tend to think of museums as Western inventions, but it is important to acknowledge that there is a tradition of museum-like institutions in many non-Western contexts, not least the Māori meeting house (Simpson 2007) and the whare tapere (Royal 1998). Although museums "were the premier colonial institutions - institutions that created the ordered representations that contained, objectified, and reduced the colonized world for paternalistic imperialism that characterized the $19^{\text {th }}$ and early $20^{\text {th }}$ centuries" (Boast 2011:64), more recently scholars have advanced the view that museums have reconstructed themselves as postcolonial institutions. The new 
museology (Vergo 1989) calls for museums to become educating, engaging places rather than authoritative research facilities, allowing multiple voices and ontologies. However, a critical analysis of the liberatory practices of the new museum is essential in former settler colonies such as NZ. Robin Boast (2011:64), drawing on Amy Lonetree (2006:642), argues that " $[t]$ he new museology is neoliberal in the sense that it assumes, as a core premise, the open exchange of information and the open access to information. It is abstract postmodern in that it assumes a critical ambiguity to definitive interpretations and positions within the museum". Furthermore, the core competencies of museums are remnants from colonial times: "they collect and they exhibit" (Ashley 2005:31). This suggests that despite attempts to include formerly marginalised peoples in museums (Dodd/Sandell 2001) and making room for diversity and difference (Sherman 2008), ultimately, the museum is still a Western institution.

Patricia Penn Hilden and Shari Huhndorf (1999) have a rather negative outlook on attempts to include indigenous voices in the museum which, in their view, is only a continuation of silencing the shameful stories of the colonial past that speak of violence and degradation. How is this possible, considering that "museum professionals are absolutely sincere in their desire to find an inclusive narrative - to allow the source community a real partnership" (Boast 2011:66)? Some scholars (Boast 2011; Bennett 1995 and 1998; Clifford 1997; Lonetree 2006) suggest that - often invisible hierarchical structures and barriers to accessing resources, within the 'structurally neocolonial' institution and museum profession are responsible for the discrepancy between aspiration and reality. I attempt to tackle these issues by dissecting the dynamics of policy and practice at TP.

Since the 1970s public pressure externally as well as a paradigm shift from within the institutions, have made a push to 'civilise' (Gurian 2006a), 'democratise' (Witcomb 2006; Hooper-Greenhill 1994) and 'decolonise' (Sully 2007) museums and their practices, bringing in multiple voices and breaking down barriers for marginalised (including indigenous) communities to visit museums and access 'their' collections. 
The metaphors used to describe museums are numerous. While the idea of the museum as vault, temple (Cameron 2004), mausoleum (Adorno 1983), ${ }^{11}$ graveyard (Groys 1997:9) and tomb (Kirshenblatt-Gimblett 1998a:57) primarily point to its historical function as collection depository, the museum as 'mirror of the nation' (Raffler 2008) or even the universe (Pommier 2006:63), suggests that the museum reflects the social system that surrounds it.

Georges Bataille (2005 [1929]:65f.) sees museums as "giant mirrors, in which human beings [can] finally view themselves from all angles". ${ }^{12}$ This view, however, has been critiqued, arguing that the museum does not merely put up a mirror, but rather reflects a distorted image of reality as its representations propose active interpretations of the world that are influenced by its position, context and political agendas (Bendix/Welz 2002). The notion of museums as distorting mirrors can be found in Mary Jo Arnoldi (1992) and Susan Crane (1997), while Patricia Davison (1999:145 f.) makes an attempt to justify the 'mirror' metaphor by seeing "museums as mirrors of power" where existing power structures are reproduced through emphasising some histories and silencing others; Sharon Macdonald (1997a) also uses the mirror metaphor in this context.

However, in contrast to this international literature, it seems to me that TP is not a mirror of NZ society, but actively (re)constructs that society, by modelling a 'New Zealand that could be' in many regards; this corresponds with the notion of the museum as a laboratory for 'civic experiments' (Healy/Witcomb 2006) and a 'site of transformation' (Golding 2009:49). As I discuss in chapter one, considering how TP was conceptualised as a genuinely bicultural institution by some of NZ's leading thinkers, it becomes evident that TP is as much an aspirational and imaginary place as it is a representation of NZ.

\footnotetext{
${ }^{11}$ Adorno (1983:175) writes: “The German word, 'museal' [museum-like], has unpleasant overtones. It describes objects to which the observer no longer has a vital relationship and which are in the process of dying. They owe their preservation more to historical respect than to the needs of the present. Museum and mausoleum are connected by more than phonetic association. They testify to the neutralization of culture. Art treasures are hoarded in them and their market value leaves no room for the pleasure of looking at them. Nevertheless, that pleasure is dependent on the existence of museums."

${ }^{12}$ My translation of the German quote: "riesenhafte Spiegel, in dem der Mensch sich endlich von allen Seiten anschaut".
} 
Anthony Shelton (2006:79) suggests:

Museums are a microcosm of the wider society in which inter-ethnic relations are played out through a struggle over interpretation and control of cultural resources. [...]It is the new, revitalized sub-discipline of anthropology that, through its dialectical engagement and transformation of its subject, has done much, and can be expected to do much more, in charting new courses not only for ethnographic but for other museum presentations too.

In analysing the way that museums actively produce culture, nations and peoples, I have found it useful to draw on theories from anthropology. The 'museum as stage' metaphor focuses on its expository aspects, representing or staging identity (Korff 2002:174) ${ }^{13}$ and led to the idea that museums act as 'identity factories' (Korff/ Roth 1990). Although this concept must also be questioned for its linear and top-down perception of museum production, which ignores the agency of the audience, I find the museum as stage image very useful to describe TP. Erving Goffman's (1959) model of 'back stage' and 'front stage' provides another analytical tool to take this idea further. Although all the above concepts fit TP to some extent, I have found the concept of 'museum as contact zone' (Clifford 1997) to be the most fruitful for my research; the key concepts of 'museum as stage' and 'museum as contact zone' are discussed later in this chapter.

The fields of museum research relevant to this study focus on the relationship between museums and source communities ${ }^{14}$ (Peers/Brown 2003; Karp/Mullen

Kraemer/Lavine 1992), the impact of national museums on identity formation (Knell/Macleod/Watson 2011; Kaplan 1996; Kaeppler 1994; Pomian 1992), intangible heritage (Alivizatou 2012; Stefano/Davis/Corsane 2012), the museum as an agent for social change (Janes/Conaty 2005; Hirsch/Silverman 2000; Knell et. al. 2010), museum ownership (Fitz Gibbon 2005) and governance (Malaro 1994; Butts 2007; Butts/Dell/Wills 2002; Soutar/Spedding 2000), museum practice (Hooper-Greenhill 2000; Sully 2007) and management (Moore 1998). I should note that this study does not focus on the fields of museum pedagogy, visitor research, outreach programmes,

\footnotetext{
13 Gottfried Korff draws on the Swabian idiom 'Bühne' which has two meanings: stage and attic. Both can be used to describe museums in terms of collecting and exhibiting objects.

14 'Source communities' in the museum context are groups of people (or descendents of those) who have a special connection to a particular museum through creation, donation, (former) ownership of objects in the museum collection. Thus, source communities are often consulted by museums about the care, display and future of these objects (Peers/ Brown 2003).
} 
community engagement and representations of indigenous peoples in exhibition displays. Instead, at the centre of this study are the daily practical interactions of indigenous and non-indigenous staff and how their professional identities shape and are shaped by a collaborative framework within the museum.

Sharon Macdonald's Behind the Scenes at the Science Museum (2002), one of the best museum ethnographies to date, was an inspiration for this thesis. "Museums, and perhaps especially national museums, are invested with all kinds of public ambitions and hopes," writes Macdonald (2002:258), "[t]hey are expected to represent the nation and its achievements, to tell 'us' who 'we' are, to identify and conserve significant items of material culture for posterity, to engage in scholarly work on the collections, and to bring education and enlightenment to as wide a population as possible." While Macdonald has museum visitors in mind, I argue that this statement is also true for the behind the scenes at TP. Moreover, "[m]useums have a crucial role not only in [...] managing cultural heritage," stresses Amareswar Galla (1996:94), "but also modelling community relations strategies".

Of the studies analysing the dynamic relationships between source communities and museums, those looking at museums and indigenous communities are particularly pertinent to this thesis. Moira Simpson's (2001 [1996]) comparative study covering several museums in Australia, the USA and the Pacific documents how museums react to the pressures of indigenous peoples with changing policy and practices, and sheds light on the contested issue of the repatriation of human remains. Giving an insight to NZ museums including TP, Conal McCarthy has published extensively about 'exhibiting Māori' (2007a; 2007b) and 'Museums and Māori' (2011); his findings have provided points of comparison for this study. Attempts to hand over authority to indigenous peoples have led to collaborative exhibition curatorship (Sciascia 2012; Shannon 2009; Brady 2009; Thompson Rand 2009; Barni/Herle 1998) and non-Western models of curatorial practices (Kreps 2003; 2006; Simpson 2007). These areas provide the starting point of this study, which focuses on the museum staff and the effects of the 'museum revolutions' (Knell 2007) on the ground, viewing museums as "site of 
decolonization" (Lonetree 2009:322) and a "tools of revitalization" (Sleeper-Smith 2009:4).

Museum employees, professional practice, staff development and training are underresearched areas, Patrick Boylan's $(1992 ; 2006)$ attempt to capture a global snapshot of the museum profession being an exception. This study intends to add to this literature by gathering data on the interactions 'on the ground' of professional and nonprofessional museum employees and how they 'learn the ropes' at TP. Several anthropologists have provided valuable ethnographies of museum staff: Jennifer Shannon (2009) investigates the construction of native voice at the National Museum of the American Indian (NMAI), and Cara Krmpotich and Laura Peers (2011) examine the relationship between the Pitt Rivers Museum at University of Oxford and the Haida First Nation in Canada as 'communities of practice' (Wenger 1998). ${ }^{15}$ Peter Vergo (1989:3) emphasises the importance of looking 'beyond the captions' and instead focusing on the people who produced them, taking into account the society that shaped their values. The museum sector is a rather young industry, which is still under formation (Sola 1992; Abasa 1995), and 'relatively unprofessionalised' yet, at times innovative, particularly in NZ (McCarthy 2011:17). Tomislav Sola (1992:110) stresses that "[t]he curious thing is that museum professionals have their minds dragged behind their actual practice. This also explains why we have to analyse institutions in order to make assertions concerning their professional staffs." I aim to analyse TP through the eyes of the staff members and their practices, as "[i]t is not usually credited that museum workers [...] are powerful and influential individuals", as Adrienne Kaeppler (1994:21) states, "[b]ut it is they who decide what stories are told or not told. It is their vision that is disseminated to the museum goer. It is they who can be a force in forging or discouraging national identity." The employees at TP therefore will be the focus of this ethnography.

According to Elaine Heuman Gurian (1995a:15) "the internal climate of [...] a museum its organizational culture - can help create a safer space for the public". Surprisingly,

\footnotetext{
15 'Communities of practice' are groups of people who share a profession or common (professional) interest, but do not necessarily work together in the same department or organisation; by sharing information and experiences they learn from each other (Wenger 1998).
} 
"few, if any" studies explore the impact of organisational culture within a museum on the educational experiences that visitors have (Griffin et.al 2007:153), therefore in order to change the institution of the museum, she deems it necessary to implement a safe and equal culture 'at home' among staff members. However, museum professionals, as James Clifford (1997:200) asserts, "are not free of colonial legacies of exoticism and neocolonial processes of commodification. Nor are they entirely confined by these repressive structures. [...] The historical possibilities of contact relations - negative and positive - need to be confronted." What Ivan Karp, Christine Mullen Kreamer and Steven D. Lavine (1992:3) say about the museum visitor is also true for museum staff:

When people enter museums they do not leave their cultures and identities in the coatroom. [...] They interpret museum exhibitions through their prior experiences and through the culturally learned beliefs, values, and perceptual skills that they gain through membership in multiple communities.

Keeping the importance of identity in mind, I use ethnic/cultural identity as a lens to look at the practices and interactions of TP staff. Identity is not an 'all-encompassing' entity, but is created through social events, "encounters and social settings where identities are made relevant by the people participating in them"(Karp/ Mullen Kreamer/ Lavine 1992:3). This emphasises the need to explore organisational culture and its rituals, a classic field of anthropology, a discipline to which I turn to explore now.

\section{Anthropology}

For this study I draw on the following fields of anthropology: museum anthropology, anthropology of organisations, anthropology of policy, politics of identity and recognition, intercultural relationships, ritual theory and food consumption. Museums and anthropologists, despite having been closely connected in the early history of anthropology, have had an awkward relationship since the 1920s when material culture became a 'dead duck' and the 'university period' began for anthropology (Ames 1986:27). However, Michael Ames (1986:32) argues that anthropologists should show more interest in museums today, examining "the museum itself, as an artefact of our society". He suggests studying "the organization of museums and their role in the community", as well as reading their "activities and programmes as cultural performance". The value of doing museum ethnography then, is to estrange "ourselves from ourselves" in order to see the culture we 'swim in' and "become the anthropologist 
of ourselves" (Halpin 1978:41). Mary Bouquet (2001:4) suggests that there is a need for anthropologists to go "into museums [...] to observe the changes going on behind the scenes". I embrace this outlook in analysing TP and believe that an anthropological lens can contribute in-depth understandings to the study of museums, thus enriching both anthropology and museum studies in the process.

The field of organisations is not traditionally occupied by anthropology, but anthropologists have been interested in organisations (Wright 1994; Jiménez 2007; Gellner/ Hirsch 2001) and policy (Shore/ Wright/ Però 2011) since the 1970s in order to reveal the politics of power in a quest to 'study up' (Nader 1972). Case studies of organisations are of particular interest to this study, such as Sharon Macdonald's ethnography of the Science Museum (2002), Andreas Wittel's study of the dynamics between corporate ideology and organisational culture (1996), and Irene Götz' ethnography situated at several branches of a franchise bakery in Germany (1997). Despite studying the microcosms of particular entities, they contribute to a better understanding of the society in which they are embedded. Few anthropologists have studied museums as organisations, but the museum ethnographies by Sharon Macdonald (see 1995, 1997a, 2001, 2002), Jennifer Shannon (2009), Richard Handler and Eric Gable (1997) among others, have demonstrated the value of doing ethnography in museums in order to reveal otherwise hidden processes, politics and dynamics between staff of different ranks. This thesis aims to contribute to this growing body of literature. TP is internationally recognised for its bicultural framework, and should therefore make an excellent fieldsite for studying on a small-scale what the future of NZ could look like.

Unlike other disciplines (political studies, management, policy studies and so on) anthropology understands the process of policy making ethnographically as part of a story and is particularly interested in how policy 'trickles down' from the top. According to Cris Shore and Susan Wright (2011:3f) policy needs to be problematised because "policies have agency" and function "as an instrument to rule" by organising and classifying people. Therefore, policy needs to be deconstructed by dissecting the decision-making process and the "new assemblages and subjects" that policies create. 
"Like the architecture and internal organisation of an institution, policies reflect the rationality and assumptions prevalent at the time of their creation", stress Shore and Wright (2011:3), "[h]owever, this is not to suggest that the ideas (or ideologies) that create and sustain policy agendas are in a way static or monolithic". Looking at TP's bicultural policy we need to keep in mind that policy itself introduces new classifications by ordering people in a 'social taxonomy', in this specific case into 'tangata whenua' and 'tangata tiriti' (people of the land, people of the Treaty).

The discourse of biculturalism is embedded in the wider discourse of identity politics (Giddens 1984; Bauman 2004; McIntosh 2005; Barcham 2000) and the politics of recognition of indigeneity in post-settler states (Sissons 2005; Povinelli 2002; Taylor 1994). An ongoing debate in such states concerns who is included or excluded from the definition of 'indigenous cultures' or who is 'authentic' or not (Kukutai 2011; Kuper 2003; Spoonley/Pearson/ Macpherson 1996; Fleras/Spoonley 1999). They all agree that the formation of Pākehā identity in NZ was a response to the Māori quest for selfdetermination. Rejecting attempts to quantify indigeneity by blood quantum ${ }^{16}$ with the intention to terminate 'full blood' indigenous over time, I borrow Sissons' (2005:15) definition of indigenous cultures, "as cultures that have been transformed through the struggles of colonized peoples to resist and redirect projects of settler nationhood". It becomes evident, then, that definitions of indigeneity exist primarily in contrast to a white, European, settler population, and that often its binary construct (nature-culture, rural-urban, traditional-modern among others) perpetuates primitivist connotations, demanding an oppressive 'indigenous authenticity' which, as Sissons (2005:37) remarks, is "racism and primitivism in disguise".

Several anthropological studies have shed light on 'race relations' in NZ and intercultural misunderstandings (Metge/Kinloch 1978; Metge 2010), as well as the interactions among school pupils (Doerr 2009), but there is little research about intercultural interactions between Māori and Pākehā in NZ organisations. Linguists

\footnotetext{
${ }^{16}$ The concept of blood quantum has sometimes been used (e.g. by the US Government) to recognise indigenous people, regulate tribal membership and manage access to financial and other benefits by excluding people who have less than an arbitrarily set percentage (often between $50 \%$ and $3 \%$ ) of 'indigenous blood'. Under this scheme the indigenous population is continuously decreasing through intermarriage.
} 
Meredith Marra and Jo Angouri (2011) examine the process of negotiating identity at NZ workplaces in a study of intercultural communications (see also Holmes/ Marra/ Vine 2011). Crown/Māori relationships have, however, been examined by academics from several disciplines in the contemporay NZ context (Hill 2009, 2004; Jackson 1988; Bell/Matthewman; Durie 1995) and the historical context (O'Malley 2012; Ward 1995 [1974]). As Richard Hill (2009:3) stresses, reciprocal relations of appropriation and reappropriation were at play:

From the beginning of colonisation, the state had sought to appropriate Māori organisational modes and energies for its own purposes. In turn, however, Māori were always adept at seeking to reappropriate the state's appropriations, while simultaneously engaging in other traditional and non-traditional forms of resistance and adaptation.

Thus, in line with this research, I see Māori not as passive objects of state policy and victims of colonial representation in museums, but rather indigenous people with agency who seek relationships with the Crown and the museum for advancing their own political agendas. My study will look at rituals and performances at TP in particular, as a microcosm of this larger social context, as a means of performing indigenous-settler power and resistance.

Rituals structure human lives. Arnold van Gennep (1960 [1909]) discovered that significant status changes in life (such as marriage, birth and death) are marked by rites of passage, following similar ritual patterns. The social order is out of balance throughout this transition and a ritual is needed as an equilibrium-producing system (Durkheim 1976 [1915]; Malinowski 1954 [1925]; Radcliffe-Brown 1964 [1922]). Thus the ritual provides security and reassurance in the face of social disturbance. Death is a prime example of this disruption of the social order and networks that are restored through ritual (Dickinson/ Leming 2010). However, rituals should be read as displays of politics and power, as David Ketzer (1988) suggests. Performance or 'social drama', according to Victor Turner (1980), is often an aspect of rituals. In addition, Goffman (1959) emphasises ceremonial aspects of everyday actions and Clifford Geertz (1973), Stanley Tambiah (1990) and Richard Schechner (1993) among others, stress the notion of 'cultural performance'. According to Ute Hüsken (2007) ritual failure can lead to 
better understanding of its performative elements. Rituals are a central part of TP's organisational culture; I will therefore analyse how identity formation and positioning is enacted in staged performances. Inspired by theatre studies, I am particularly interested in indigenous, postcolonial and participatory forms of theatre, in which utopian theatre or performances set out to address "issues of equity, healing, and social justice" (Denzin/ Lincoln/ L.T. Smith 2008:7).

Food consumption is another area of anthropological interest, because shared meals help construct identity (Simmel 1957; Tokarev 1971; Tolksdorf 2001; Augustynek 2010). Eating together can signify a 'reincorporation rite' (van Gennep 1960 [1909]) and plays an important role in creating social cohesion. Through consuming food together people "create and maintain their social relations", according to Mary Douglas (1984:10). Furthermore, Douglas sees a link between gifting and food, as "[h]ospitality is part of reciprocal exchanges". Kinship connections or how a person feels about other persons can be expressed through giving (or receiving) food, where food is the 'vehicle of communication' (Lévi-Strauss 1973). Giving away food creates a reciprocal asymmetry, yet "gifts of food are flows of life-giving substance" (Douglas 1984 [1973]:12), or in Bernd-Jürgen Warneken's words, it is 'an extension of the umbilical cord' that nurtured the baby in the womb. ${ }^{17}$ Lastly, Pierre Bourdieu (1984) sees dominance and subordination of the class system expressed through food consumption, reflecting and maintaining the social ranking of the class system. These theories help interpret food consumption at TP.

\section{Literature on Te Papa}

TP has been studied from many angles and academic viewpoints with some interesting publications coming from 'inside' TP written by its staff (Fitzgerald 2009; Gibson 2003; Legget 1995; Hakiwai 1999, 2005; Puklowski 2011; Nesus 2004; Gorbey 1991; ManeWheoki 1995; Bennington 2004, 2007; Tamarapa 1996a, 1996b, 2007; Paku 2009; H. Smith 2006, 2009). Although their writing has informed this research, it often remains at a descriptive level, especially when the main purpose for a publication is to explain TP's bicultural model to an international audience of museum practitioners, lacking

${ }^{17}$ Bernd-Jürgen Warneken, Seminar 'Essen als Kultur' [Eating as Culture], Ludwig-Uhland-Institut für Empirische Kulturwissenschaft, Universität Tübingen 2002. 
critical academic analysis. Many studies focus on the 'front stage' at TP, namely its exhibitions (for Signs of a Nation see Armstrong 2002; for concept design of Blood, Earth, Fire see Allan 2008; for Te Marae see Tamaira 2009a), and its visitors (Schorch 2010; C. Macdonald 2009; Davidson/Sibley 2011). In contrast this thesis goes behind the scenes shedding light on the complex relationships between Māori and Pākehā staff at the workplace - thereby contributing to the wider analysis of biculturalism and race relations in NZ.

Celine Carlisle (2003) is the only researcher who examines TP from an organisational perspective, providing a point of reference for this thesis. Other studies use a variety of approaches: cultural studies, museum studies, art history and art criticism. Kylie Message (2006) analyses TP as part of a study of new museums and the way they 'make culture'. TP has been criticised for being a "neat rhetorical solution" to racial inequality (Henare 2004:62) and a pedagogical device of NZ's government (McLeod 2013). Paul Williams $(2003 ; 2005 ; 2006 b)$ critiques TP's representation of biculturalism in the exhibition spaces as a celebration of NZ's natural beauty which implies unity of Māori and Pākehā that is not matched by the political reality outside the museum. Williams argues that TP's exhibitions evoke a cultural dualism within visitors that does not benefit Māori in a material sense and can be counterproductive to achieving economic equality by symbolically acknowledging Māori. Michael Goldsmith (2003) addresses TP's divided exhibition spaces, which result in separate spheres, 'sacred' Māori and 'profane' Pākehā, thereby creating 'double standards'. Ben Dibley (1996:i), on the contrary, examining TP's concept development prior to opening, calls TP “unique internationally in its aspiration to give material expression to a bicultural heritage and identity."A comparative study of the National Museum of Australia in Canberra and TP by James Gore (2002) interprets the new museums as an attempt at nation-building.

Almost all academic research conducted at TP drew on a relatively small range of secondary sources and a consequently subjective individual perspective based on their own visit to the institution; much of this critical literature has relied on expert interviews to investigate the topic (Carlisle 2003; McCarthy 2011; Waite 2009). My study, in contrast, adds an ethnographic account to the body of literature about TP, 
bringing together practice and theory (Labrum/McCarthy 2005). Having discussed the shortcomings of the existing literature about TP that focuses on the exhibitions, critiques modes of display or interprets TP's biculturalism as 'symbolic', it is evident that there is little attention to the complex and often contradictory realities of working in a museum. I attempt to examine the intercultural relationships of museum practitioners at TP on all levels and what biculturalism looks like, providing a more rounded and comprehensive internal perspective. With the exception of Carlise (2003) and McCarthy (2011) there is very little work on the 'personal side' of biculturalism. This thesis aims to address this issue by investigating the interpersonal staff relations at TP and how they enact (or suppress) biculturalism in museum practice. It will therefore incorporate recent research about intangible heritage (Alivizatou 2012) and performing heritage (Jackson/Kidd 2011), as well as social implications of cultural practices (Thode-Arora 2009). In the next section I introduce the theoretical framework and key concepts drawn from this literature review for my analysis.

\section{Theoretical Framework and Key Concepts}

From the literature review I chose the key concepts of 'museum as stage' and 'museum as contact zone' for my analysis of TP, drawing on theory in anthropology, sociology and dramaturgy. Furthermore, as my research analyses the discourse of biculturalism, I use political theory, Māori studies, legal studies, historical and anthropological theory to critically examine its employment in the public setting of a museum. Firstly, I provide a definition of culture. Secondly, I give an overview of biculturalism in NZ, including various models and my own working definition, before I discuss the stage concept and contact zone in more detail.

\section{Culture}

Clifford Geertz's (1973:89) definition of culture as "a system of inherited conceptions expressed in symbolic forms by means of which men communicate, perpetuate, and develop their knowledge about and attitudes toward life", suggests the existence of a coherent, holistic and essentialist culture; this concept has been deconstructed and is now deemed obsolete by many social scientists who have replaced it with more fluid 
and self-reflexive models of cultures in the plural (Marcus/ Fischer 1986; Kumoll 2005). Culture is not static but a continuous, dynamic process of negotiating the rules by which people, groups and societies organise their lives, communicate and differentiate themselves from others. Rather than being inherited, culture can be taught formally or acquired informally by absorbing the norms subconsciously; what is visible of culture is only the tip of the iceberg, thus it is necessary to reveal the underlying, hidden values and assumptions (Hall 1976). If culture is constructed and therefore unthinkable without addressing notions of power, hegemony and identity, it becomes a political category in which power relationships are enacted. I understand culture as a broad concept that is not reduced to 'high culture' (e.g. cultural artefacts, the fine arts) at TP but includes all cultural expressions and interactions of Māori and non-Māori staff in everyday life, such as language, rituals, food consumption, social activities, and meetings. Although the focus of my thesis is on Māori culture and rituals within TP as evidence of its bicultural concept (and because my active participation in the Māori activities became my lens), it is important to note that Pākehā are, of course, not without culture and rituals. Their culture is in fact so ingrained in the 'life' of the Museum (e.g. office procedures, meetings, newsletters, birthday celebrations, afterwork drinks, Christmas parties etc.) that it is often invisible and taken for granted.

\section{Biculturalism in an International Context}

The adoption of biculturalism, that is giving equal value to two cultures, as 'state policy' in NZ is best understood as part of a global trend in postcolonial countries to value cultural diversity in the 1970s and 1980s. The quest for self-determination grew stronger as indigenous peoples reclaimed their cultural identiy (Hendry 2005), and efforts of decolisation and demarginalisation led to radical political changes in state policy (Fleras 1999). Most postcolonial countries, such as the USA, Canada and Australia, favoured multiculturalism, reflecting their multi-ethnic immigrant demographics, but regarding their indigenous population, Canada experimented with self-governance (Maaka/ Fleras 2005). NZ, in contrast, was the only settler nation to introduce a bicultural framework which values indigenous Māori culture and (predominantly European) immigrant cultures equally. Despite these efforts, indigenous peoples around the globe still struggle for (cultural) survival (Coates 2004). 


\section{Biculturalism in New Zealand: Discourse, Understandings, Models}

$\mathrm{NZ}$ academics of multiple disciplines have written extensively about biculturalism. Some interpret biculturalism as a means of 'becoming bicultural' (Ritchie 1992) and 'reconciling' Māori and Pākehā that enhances people's ways of life (Vasil 2000 [1988]), whereas others emphasise that biculturalism has a mandate for power-sharing (Fleras/ Spoonley 1999), acknowledging the autonomy of Māori and Pākehā groups, or criticising its potential to appropriate Māori culture (Durie 1995; Poata-Smith 1996). Augie Fleras and Paul Spoonley (1999:236) call biculturalism a 'double-edged sword', as it aims to incorporate Māori values into public institutions, yet the sharing of power and resources is often limited to the effect that "power and authority remain firmly under Crown control" (Fleras/ Spoonley 1999:240).

It is sometimes argued that biculturalism constructs distinctly separate Māori and Pākehā identities while forgetting the complex overlaps and inter-relationships through intermarriage and 'economic interdependence' in reality (O'Sullivan 2007:22). However, as Raj Vasil (2000 [1988]:1) states, despite intermarriage, Māori and Pākehā still "constitute two different peoples". Perhaps 'middle ground', the concept that Vincent O’Malley (2012) uses to describe Māori/Pākehā encounters in NZ before 1840, is a more fitting metaphor. Richard White (1991:x), in his history of the Great Lakes region of North America, defines the middle ground as 'the place in between':

in between cultures, peoples, and in between empires [...]. On the middle ground diverse peoples adjust their differences through what amounts to a process of creative, and often expedient, misunderstandings. People try to persuade others who are different from themselves by appealing to what they perceive to be the values and practices of those they deal with, but from these misunderstandings arise new meanings and through them new practices - the shared meanings and practices of the middle ground.

In this regard, biculturalism could promote "new cultural formations and new understandings" of 'the other' (White 2006:13). I see biculturalism, drawing on Andrew Sharp (1995:122), as a "mode of inter-cultural contact" that is necessary in NZ if the Treaty is taken seriously (Sissons 1992:32). Brenda Tahi (1995:62) explains that most New Zealanders understand biculturalism as having "something to do with being able to understand and use, but not necessarily adopt, the concepts, customs and practices of a 
culture other than one's own." This raises the question of whether or not, or to what extent adopting the other's culture is appropriate or even desirable. Being bicultural is a fact for most Māori, as Sharp (1995:121) notes "if they want to prosper, [Māori have] no choice." Distinguishing between bicultural 'personae' or actors and bicultural 'persons' or beings, and bicultural public procedures, Sharp (1995:120) asks whether it is worthwhile to pursue all or any of them. He concludes that in his opinion it is not right to require everyone to become bicultural (Sharp 1995:122). However, C.L. Ten (1993) argues that being bicultural makes for more and better choices. It is important to research the bicultural relationships between Māori and Pākehā, because, as Dominic O’Sullivan (2007:21) claims “[p]ower relationships are, however, much more complicated than a binary Maori/Pakeha 'partnership' discourse suggests".

Another question is, whether biculturalism promotes intercultural understanding by bridging differences and promoting inclusion, or on the contrary, creates separatism by emphasising differences and "the potentially essentialist binary of a Maori/Pakeha relational politics" (K. Turner 1995:93). Paul Spoonley (1995:110) suggests that biculturalism results in "fictive ethnicity, or imagined community", particularly making Pākehā a 'political label' in their positioning to the tangata whenua. While Spoonley (1995:110) sees possibilities of the Māori aspiration of tino rangatiratanga within biculturalism, he notes that "[t]he stumbling block is a majoritarian political system that overrides iwi concern."

It must be noted, however, that "any striving for 'inclusion' in such an environment" as Ian Hugh Kawharu (2008:56) emphasises, can have detrimental side-effects, as it "has been a substantial disincentive for Maori to retain - or recover - a competence in their Maori values and culture at the same time". Māori scholars are critical of the concept of biculturalism and strive for autonomy rather than co-management, saying that "New Zealand places too much emphasis on the ideology of biculturalism."18 Analysing the incentive for states to support indigenous recognition, Sissons (2005:80) writes somewhat cynically that it is convenient for states to do so, "after all, it is relatively inexpensive and enhances the appearance of a national inclusiveness within which

${ }^{18}$ http://posttreatysettlements.org.nz/2011/06/post-treaty-settlements-website-launched-today/ (accessed 29 October 2012). 
illegitimate dispossession has become legitimate belonging for both indigenous people and post-settlers".

In chapter five I discuss biculturalism that evokes various imaginings, because, as Ballantyne (2012:201) states:

While it is important to recognise that biculturalism enabled the slow redress of Māori claims under the Treaty and a significant redistribution of resources and authority, it must also be seen as a national imaginary that allows the state to produce a partial and self-legitimating vision of the past.

James Liu and Chris Dibley (2004) ${ }^{19}$ argue that Pākehā tend to embrace symbolic biculturalism, such as allowing for cultural diversity, singing the national anthem in Māori and accepting kapa haka as part of NZ culture, but when it comes to resourcebased biculturalism, meaning the sincere sharing or ownership of resources and power, Pākehā tend to reject this as a 'step too far'. Looking at the dynamic relationship between indigenous peoples and settlers in former settler colonies, it is crucial to take into account the neo-liberal politics that frame the interaction. As this component is often masked in order to retain hegemonic control, yet pretends to accept indigenous peoples as equal partners, Povinelli calls this 'the cunning of recognition' (2002). While many see biculturalism as a positive development of recognising indigeneity and celebrating diversity within a nation state, others warn that is little more than 'cultural window-dressing' (Sissons 2005:81) with rarely any economic benefits.

O'Sullivan (2007) in his book Beyond Biculturalism reveals that biculturalism, in his opinion, is 'inherently colonial' and merely accepts Māori as 'the junior partner' in the bicultural partnership. Thus, O'Sullivan (2007:27) is rather suspicious of biculturalism as a tool to 'liberate' Māori, as he states: “The greatest limitation of the 'partnership' discourse is that it is not concerned with Maori development and advancement in Maori terms" and furthermore "[b]iculturalism is enthusiastically embraced by state institutions as a strategy for managing resistance" (O'Sullivan 2007:30). Ultimately, this

${ }^{19}$ For a critique of Liu/Sibley (2004) see Paul Callister's working paper (2011) 'Attitudes towards biculturalism in New Zealand: Asking the wrong questions, getting the wrong answers?' Available online at: http://callister.co.nz/attitudes-towards-biculturalism-in-new-zealand.pdf (accessed 28 January 2014). 
means that control still remains with the hegemony, in O'Sullivan's (2007:32) view, as "one step towards self-determination is permitted, but the next prevented". Selfdetermination on the other hand, also has different meanings and is sometimes "seen as an endpoint and sometimes as a means to an end" (Durie 2005:3).

Kawharu (2008:55) understands biculturalism as "a form of 'bilateral' inclusion if a 'full sharing' is also a reasonably full understanding of perspectives from both sides of the indigenous divide, rather than merely a tolerable level of mutual respect with little understanding." He stresses that "[a]t all events I have indeed found Eric Schwimmer's dual concept of biculturalism and inclusion helpful, however ineptly applied, in thinking about Maori ethnicity, the maintenance of group boundaries, trusteeship in development and much else besides." From this overview of the bicultural discourse in NZ I pay attention to the ambiguities of the concept, such as inclusion and exclusion, political aspirations of Māori and non-Māori, symbolic meanings and resource outcomes, when analysing biculturalism 'on the ground' among TP staff. In the next section I will introduce some useful academic models of biculturalism that will be tested in this thesis.

Three models are particularly helpful in understanding biculturalism as a dynamic development rather than a fixed framework: Mason Durie's bicultural continuum, Fleras/ Spoonley's model of bicultural commitment and Eagle's stages of the bicultural journey. Both Durie (1998b) and Fleras/ Spoonley (1999) link goals or principles with changing structural arrangements ranging from 'soft' to 'hard' or from 'mainstream' to 'Rangatiratanga'.

Box 1: Durie's bicultural continuum

Principles

\begin{tabular}{|c|c|c|c|c|}
\hline Homogeneity & Cultural pluralism & Participation & Partnership & Rangatiratanga \\
\hline \multicolumn{5}{|c|}{ Structural arrangements } \\
\hline $\begin{array}{l}\text { Unmodified } \\
\text { mainstream } \\
\text { institution }\end{array}$ & $\begin{array}{l}\text { A Maori } \\
\text { perspective }\end{array}$ & $\begin{array}{l}\text { Active Maori } \\
\text { involvement in } \\
\text { mainstream } \\
\text { institution }\end{array}$ & $\begin{array}{l}\text { Parallel Maori } \\
\text { development }\end{array}$ & $\begin{array}{l}\text { Independent } \\
\text { Maori institutions }\end{array}$ \\
\hline
\end{tabular}

Source: Durie 1998b:102-3. 
It is also interesting that Durie and Fleras/ Spoonley place a bicultural partnership somewhere in the middle of the journey towards Māori self-determination, whereas for Eagle (2000) it marks the endpoint.

Box 2: Fleras and Spoonley's model of bicultural commitment

\begin{tabular}{|l|l|l|l|l|l|}
\hline & 'Soft' & Moderate & Inclusive & Strong & 'Hard' \\
\hline Goals & $\begin{array}{l}\text { celebrating } \\
\text { Maoritanga }\end{array}$ & $\begin{array}{l}\text { improving } \\
\text { race } \\
\text { relations }\end{array}$ & partnership & $\begin{array}{l}\text { separate } \\
\text { but equal }\end{array}$ & $\begin{array}{l}\text { tino } \\
\text { rangatiratanga: } \\
\text { challenging the } \\
\text { system }\end{array}$ \\
\hline Structures & $\begin{array}{l}\text { removal of } \\
\text { discriminatory } \\
\text { barriers and } \\
\text { prejudice }\end{array}$ & $\begin{array}{l}\text { a Maori } \\
\text { perspective }\end{array}$ & $\begin{array}{l}\text { active Maori } \\
\text { involvement } \\
\text { and special } \\
\text { treatment }\end{array}$ & $\begin{array}{l}\text { parallel } \\
\text { institutions }\end{array}$ & $\begin{array}{l}\text { Maori models of } \\
\text { self- } \\
\text { determination }\end{array}$ \\
\hline $\begin{array}{l}\text { Policy } \\
\text { outcomes }\end{array}$ & mainstreaming & $\begin{array}{l}\text { te taha } \\
\text { Maori }\end{array}$ & responsiveness & devolution & He Putahitanga \\
\hline
\end{tabular}

Source: Fleras and Spoonley 1999, Table 7.2, 238.

Eagle's model is more simplistic going from monocultural to bicultural partnership in four steps.

Box 3: Eagle's stages of the bicultural journey

\begin{tabular}{|l|l|l|l|}
\hline 1 & 2 & 3 & 4 \\
Monocultural & $\begin{array}{l}\text { Decision to be } \\
\text { bicultural, Maori } \\
\text { perspective introduced }\end{array}$ & $\begin{array}{l}\text { Active iwi/Maori } \\
\text { involvement, } \\
\text { development of trust }\end{array}$ & Bicultural partnership \\
\hline
\end{tabular}

Where TP sits in relation to these models and whether or not it 'walks the talk' or puts the ideals into real operation are questions that this thesis attempts to answer. In the museum context there is an absence of a clear definition of biculturalism as Murphy (1999) notes and this vacuum is filled with conflicting ideas: "[t]o museums, biculturalism often is about bringing Māori and non-Māori together as one. For Māori the concept means something completely different" (Murphy 1999:10). While Pākehā often see an equal partnership as the goal of biculturalism, for Māori it is a step towards the ultimate goal of self-determination. Box 4 is my own attempt at ordering and illustrating the range of diverse understandings of biculturalism on multiple levels. 
Box 4: Diverse understandings of biculturalism

\begin{tabular}{|c|c|c|c|c|c|}
\hline & $\begin{array}{l}\text { Tokenism/ } \\
\text { 'window- } \\
\text { dressing' }\end{array}$ & $\begin{array}{l}\text { Improving } \\
\text { Pākehā skills } \\
\text { and tolerance } \\
\text { of Māori culture }\end{array}$ & $\begin{array}{l}\text { Māori } \\
\text { participation }\end{array}$ & $\begin{array}{l}\text { Resource-based } \\
\text { biculturalism; } \\
\text { cultural redress }\end{array}$ & $\begin{array}{l}\text { Tino } \\
\text { Rangatiratan } \\
\text { ga }\end{array}$ \\
\hline Strategy & $\begin{array}{l}\text { Use of } \\
\text { bicultural } \\
\text { names }\end{array}$ & $\begin{array}{l}\text { Bicultural } \\
\text { training for staff } \\
\text { (e.g.Māori } \\
\text { language } \\
\text { classes) }\end{array}$ & $\begin{array}{l}\text { Māori staffing; } \\
\text { Bicultural } \\
\text { rituals; mixing } \\
\text { elements from } \\
\text { both cultures }\end{array}$ & $\begin{array}{l}\text { Power-sharing; } \\
\text { genuine sharing } \\
\text { of resources }\end{array}$ & $\begin{array}{l}\text { Separate } \\
\text { Māori } \\
\text { institutions }\end{array}$ \\
\hline Vision & $\begin{array}{l}\text { Promoting } \\
\text { bilingualism }\end{array}$ & $\begin{array}{l}\text { Individuals } \\
\text { become } \\
\text { biculturally } \\
\text { competent }\end{array}$ & $\begin{array}{l}\text { Reconciliation; } \\
\text { cultural fusion }\end{array}$ & Co-management; & $\begin{array}{l}\text { Māori self- } \\
\text { determination }\end{array}$ \\
\hline Who benefits? & $\begin{array}{l}\text { Institutional } \\
\text { image }\end{array}$ & $\begin{array}{l}\text { Non-Māori and } \\
\text { some Māori }\end{array}$ & $\begin{array}{l}\text { Both Māori } \\
\text { and non-Māori } \\
\text { able to make } \\
\text { better choices }\end{array}$ & $\begin{array}{l}\text { Māori } \\
\text { empowerment } \\
\text { through material } \\
\text { gain }\end{array}$ & Māori \\
\hline Scholars & $\begin{array}{l}\text { Critique: } \\
\text { Sissons } \\
2005 ; \\
\text { O'Sullivan } \\
2007\end{array}$ & $\begin{array}{l}\text { Tahi 1995; } \\
\text { Ritchie 1992 }\end{array}$ & $\begin{array}{l}\text { Ten 1993; } \\
\text { White 2006; } \\
\text { Vasil 2000 } \\
\text { [1988] }\end{array}$ & $\begin{array}{l}\text { Sibley/Liu 2004; } \\
\text { Kawharu 2008; } \\
\text { Fleras/ Spoonley } \\
1999\end{array}$ & $\begin{array}{l}\text { Murphy 1999; } \\
\text { Spoonley } \\
1995\end{array}$ \\
\hline Understanding & $\begin{array}{l}\text { Superficial } \\
\text { ideology/ } \\
\text { theory }\end{array}$ & $\begin{array}{l}\text { 'beginner' } \\
\text { practice }\end{array}$ & $\begin{array}{l}\text { 'advanced' } \\
\text { practice }\end{array}$ & $\begin{array}{l}\text { Business } \\
\text { operation; full } \\
\text { sharing }\end{array}$ & $\begin{array}{l}\text { Aspiration for } \\
\text { Māori }\end{array}$ \\
\hline
\end{tabular}

Institutional

Change:

very little

radical

Control:

Pākehā

giving up control

Māori

3

5 steps:

1

2

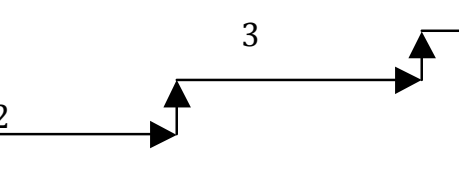

(1)

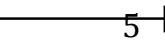

\section{Working Definition of Biculturalism}

As is evident from the previous discussion of various bicultural understandings, biculturalism is a messy term, sometimes used as a theory or ideology, sometimes a 
practice and sometimes an aspiration. Entering TP I had little understanding of the various connotations attached to biculturalism and not belonging to either the settlers or indigenes, I kept an open mind for an exploratory approach. While I have great admiration for TP putting into practice a bicultural model, I am also critical of the underlying ideological interests and imaginations. The more I got involved in the 'politics' at TP and the more I read about biculturalism, the more I became aware of its negative implications for Māori and my interest shifted towards asking 'how does TP's concept impact on Māori identity formation and the standing of indigenous peoples within the nation state?'

I suggest a critical reading of biculturalism as it might not be as innocent and harmonious as it seems at first glance. I agree with McCarthy (2011:244) that "biculturalism is best thought of as a phase in cultural resource management that leads from Pākehā control of Māori culture to self-determination". Rather than seeing biculturalism as a fixed and static state of being, in this research I explore it as a fluid concept or continuum. My working definition of biculturalism is that it is the acceptance of two cultures (indigenous Māori and Western Pākehā) as different but equal, as well as a commitment to share power and resources; it is not an end in itself, but an on-going negotiation process and a stepping-stone towards Māori self-determination.

\section{Museum as 'stage'}

Seeing the museum as 'theatre' or 'stage' enables us to examine the human interactions within it as 'performances'. In The Presentation of Self in Everyday Life (1959) Goffman illustrates how human interaction is guided by one's desire to make an impression on others around us. He uses theatre as a metaphor to highlight the strategies people use to express themselves through performances in certain settings, using masks, scripts and other expressive equipment in order to manipulate certain audiences. According to Goffman (1959:63) "life itself is a dramatically enacted thing", however, he adds the disclaimer "[a]ll the world is not, of course, a stage". Goffman distinguishes between 'front stage', where a presentation of self is performed, and 'back stage', where the actor can drop the mask. As this lens is particularly suited to study 'institutional social life' within confined physical spaces, such as buildings, I utilise Goffman's theory as a 
framework for analysing biculturalism at TP, both front stage and back stage. Given TP's diverse rituals on the marae and other 'stages', I believe this concept to be very useful. As Gyan Prakash (2012 [2004]:317) argues, we can see that the museum becomes "the stage for the enactment of history".

\section{Museums as 'contact zone'}

James Clifford (1997) coined the term 'museums as contact zones' in his writings about a consultation meeting between museum professionals and indigenous Tlingit people at the Portland Art Museum. What he observed in the museum's basement was much more than the consultation process that the museum had envisioned, it was in fact a meaningful encounter in a 'contact zone'. Clifford borrows the concept from Mary Louise Pratt (1992:6f.) who defines the 'contact zone' in relation to the 'frontier' as

the space of colonial encounters, the space in which peoples geographically and historically separated come into contact with each other and establish ongoing relations, usually involving conditions of coercion, radical inequality and intractable conflict.

I see TP as a 'contact zone' that is situated at the frontier which marks a boundary between indigenous and non-indigenous peoples; the contact zone is not a border but rather a starting point. Here fixed notions of imperialism and colonialism give way to diverse voices (Golding 2009:49) and the museum becomes a 'third space' (Bhabha 1994:56) where encounters take place and people are transformed through interaction (Taylor 1994:70-71). Similarly, Stephen Weil (2002:68) argues that museums can provide public spaces "in which diverse elements of the community might intermingle in ways not readily available elsewhere".

Museums can facilitate and accelerate processes of decolonisation, participation and negotiation when engaging in a relationship with 'the other', providing a 'contact zone'. Rather than seeing museums as static institutions, Clifford (1997:192) emphasises their adaptable and dynamic character, stating his vision for an ongoing shaping of the institution in dialogue or partnership with the peoples represented in them: "When museums are seen as contact zones, their organizing structure as a collection becomes an ongoing historical, political, moral relationship - a power-charged set of exchanges, of push and pull." However, seeing that museums have been developed by appropriating 
"exotic things, facts and meanings" (Clifford 1988:221), we must read the museum as "the instrument for undoing and redoing history" (Prakash 2012 [2004]:317).

The phrase 'museums as contact zones' has become synonymous with collaborative and inclusive programs in museums, particularly in exhibition development and collecting, and thus been promoted by many (Phillips 2005; Peers/ Brown 2003; Stanton 2003; Witcomb 2003). In their optimistic outlook on the concept, scholars have reduced it to the aspects of transculturation between the institution and the source communities, ideally creating an ongoing dialogue and empowering 'the other', thereby ignoring the notion that contact zone can also be a colonial instrument, as Boast (2011:62) rightly stresses. Although contact zones can function as cross-cultural mediators (Witcomb 2003), catalysts for new relationships (Peers/ Brown 2003:4) and spaces "of collaboration, discussion, and conflict resolution" (Boast 2011:60), they are also "asymmetric spaces of appropriation" (Boast 2011:63) and consequently need to be understood in their complexity and ambiguity.

While I certainly see the potential of museums as contact zones for establishing meaningful partnership between museums and source communities, I am also aware of its "dark underbelly" (Boast 2011:57; see Dibley 2005 for a critique of contact zone) that hides asymmetric power structures and unequal access to resources as well as the persistent tendency to appropriate and domesticate indigenous peoples. Therefore, I argue that the contact zone should also be read as a 'battle zone' where conflicts, controversies and contestations are articulated and 'fought out'. This reading of museum politics reflects the recent debate about 'who owns the past?' (Denzin/ Lincoln/ L.T. Smith 2008:566). It also raises questions about the ownership of cultural heritage and museum objects and the increasing calls from source communities for their repatriation. Clifford (1997:213) indeed suggested this dual view when he called on museums to loosen "their sense of centrality and [see] themselves as specific places of transit, intercultural borders, contexts of struggle and communication between discrepant communities". In this regard, museums - while trying to bridge gaps and cross borders - become the centre of 'culture wars' and the arena "where some of the most controversial and most difficult questions of the late $20^{\text {th }}$ century were fought 
out", as Macdonald (2011:55) states. In my view the concept of museum as contact zone is best suited to analysing the inner workings at TP, bearing in mind the above refinement of the concept. Joachim Baur (2010:41) calls this concept the "most prominent and ambitious suggestion for a description of the potential changes in and by the museum".

\section{Research Questions}

Now that the literature review has clarified the gap in the literature addressed by this research, and I have laid out the theoretical framework I employ, in this section I articulate the central research questions that have emerged. For some disciplines other than anthropology, this may appear to be a very general research interest rather than a specific question, but at the beginning of my exploratory research the overarching question was:

- How does biculturalism work at TP?

From this broad question several other questions emerged during my fieldwork and the literature review, including:

- How does the bicultural framework affect staff of diverse ethnic groups?

- $\quad$ How do staff enact biculturalism?

- What strategies do staff members use to position themselves within the workplace?

- What role do Māori activities and rituals play in TP’s day-to-day operation?

- Where do world views clash and how is conflict resolved?

- What implications does biculturalism have for staff?

- What is the significance of biculturalism for TP as an institution? 


\section{Methodology}

In this section, I discuss my methodological approach to this research. In order to grasp the complexity of TP as an organisation and to do justice to its various bicultural commitments, it seemed sensible to apply a holistic, interpretative, interdisciplinary and exploratory approach using multiple data-collection methods (Borman et al. 2007).

\section{Research Design: An Empirical Mixed-Methods Approach}

I applied qualitative methods and immersed myself in the world of the employees in order to illuminate the 'inner workings' of biculturalism at TP. Sharing and 'living' the same experiences as the employees is "invaluable for the contemporary understanding of work" (V. Smith 2005:229). Therefore, I decided to conduct ethnographic fieldwork which "reveal[s] to us things that we cannot know by conducting a survey, by interviewing individuals out of context, by doing archival research, or by performing experiments in carefully controlled settings" (V. Smith 2005:229). A combination of the following methods seemed appropriate:

- $\quad$ Ethnography and case study

- $\quad$ Semi-structured, open-ended and oral history interviews

- Participant and direct observation

- $\quad$ Autoethnography

- Document analysis

The triangulation of multiple methods helps to correct and verify the data gathered by cross-checking (Friebertshäuser 1997) and thus enables me to give a multi-layered portrayal of the organisation. For example, although the policies could be studied in a singular document analysis, the written material alone does not illuminate the decisionmaking processes behind them and hence a more in-depth method is needed to understand the underlying politics.

The imperative to use qualitative methods when trying to understand inter-personal relationships is even more evident when researching intra-organisational relations and cross-cultural interaction in the work environment. Empirical methods provide tools to 
conduct qualitative research based on observation and experience that is suited to understanding human behaviour. At the heart of my research project were the bicultural practices at the museum carried out by staff members. Although interviews provide a plethora of individual opinions, only in conjunction with observation can the researcher put the statements into perspective and interpret them correctly. I therefore agree with Gisela Welz (1998) that it is necessary to observe the physical actions of the participants in addition to their verbal statements in order to validate them or spot discrepancies.

\section{Ethnography and Case study}

Sharon Macdonald's ethnographic research in the Science Museum in London (2002) informed and shaped the methodological approach for my study and was an inspiration for me, as it demonstrated the value of an ethnography of the organisation behind the scenes. Being interested in the processes of collective identity formation and rituals among staff, ethnography seemed the best choice of method, "[b]ecause symbolic meaning and unfolding history are critical to any account of collective identity, there is perhaps no other substantive area for which ethnography is more suitable as a method of study" (van Maanen 2001:244).

I chose to do a case study of one organisation, rather than a comparison between different museums or organisations for two reasons. First of all, TP's commitment to biculturalism is outstanding in scale and effort, therefore it was impossible to find an appropriate match in NZ or overseas that would lend itself readily to comparison. Secondly, by focusing on a single institution my study was able to go beyond 'scratching the surface', as I was able to conduct a long-term ethnography that provided a fuller picture of a particular bicultural organisation. My empirical enquiry of TP adopted the method of case study because it has the potential for understanding a phenomenon thoroughly, as Arthur Bedeian (1984:30) states:

[t]he depth of penetration and understanding that it [case analysis] allows the researcher is unmatched by any other approach; it often leads to the discovery of significant facts that a researcher from 'outside' would not ordinarily look for or that might be purposefully hidden. 
The best case studies, according to John van Maanen and Ai-Yen Chen (1999:30), use a "variety of methods" and profit from "living with and living like those studied" in order to make the familiar strange (and vice versa) and open up new possibilities of interaction. An almost ideal situation, according to Bedeian (1984), occurs when the researcher also works within the organisation he or she investigates. Given that I was already a casual employee at TP when I started my PhD, I thought I was in an advantageous position to gain an insight into the institution and its organisational structure as 'one of them'.

Van Maanen advocates the understanding of case studies as narratives that "link events to events and thus provide historically situated tales of real people, in real places, doing real things and at real times" (van Maanen/Chen 1999:32). In my case study of TP I kept his suggestion in mind that

[c]ase studies of the careful and trustworthy sort [...] must treat theory lightly (borrowing as much as building) and make few (and usually tentative) generalizing claims for a given analysis may not travel very far (van Maanen/Chen 1999:39).

Thus document analysis was a secondary method to interpret and complement my empirical data, not the starting point or main focus; rather the analysis of documents evolved from my fieldwork.

\section{Interviews}

Interviews were long considered the 'silver bullet' in the social sciences (König 1974). Semi-structured, open-ended interviews seemed the best instrument for my data gathering as they are theme-orientated and thus comparable, but at the same time allow an open structure that is very close to an everyday conversation. Despite the closeness of semi-structured interviews to informal conversations, it is not an 'easy' technique, so the interviewer needs to be trained and prepare the questions well in advance (Friebertshäuser 1997). When I interviewed former staff members who were involved in conceptualising TP, I used narrative interviewing techniques and the interviews constituted oral history documents (Leavy 2011; Janesick 2010). Oral history as a method is also rooted in the oral traditions of Māori and can therefore be seen as an extension of their oral tradition preserving and passing on tribal memory (Selby/Laurie 
2005). Within the Treaty negotiation processes of the Waitangi Tribunal, over time the Crown and the Tribunal appreciated "oral-based testimony" by Māori claimants as integral evidence rather than 'exotica'(Hill/ Bönisch-Brednich 2007:169). Interviews are, however, a presentation of self (Goffman 1959) and should therefore be complemented with participant observations.

\section{Participant Observation}

Since my research is interested in the intercultural interactions among staff, participant observation seemed the best choice as it allows an understanding of the life-worlds of others (Knoblauch 2003; Carsten 2012; van Maanen 2007[1979]). Participant observation, according to Janet Carsten (2012), allows the researcher to become totally immersed in the field. This is especially useful in the study of organisations, because it forces the researcher to "come to grips [with] [...] what it means to be rather than to see a member of the organization" (van Maanen (2007[1979]:293]; emphasis added).

\section{Autoethnography}

I had not considered autoethnography as a method initially. However, seeing myself as a research participant and interpreting my journey through TP as an individual experience that related to some of my participants' experiences gave my research an additional dimension, offering a matrix to contrast the experiences of the participants with. Consequently, I decided that autoethnographic accounts were appropriate.

Bönisch-Brednich (2012) stresses that autoethnography is not so much a 'new' phenomenon - anthropologists have long used 'confessional tales' (van Maanen 1988:73) - as a new paradigm of conducting and writing ethnography. Ethnographers who traditionally studied 'the exotic other' abroad have shifted their focus to doing 'anthropology at home'; in this regard the researcher is both familiar with the researched and distanced as a member of the academic guild (Strathern 1987). In my case, it is questionable whether I am doing ethnography 'at home' or 'abroad', because on the one hand I am at the periphery of NZ society as a German immigrant, yet, on the other, I am an insider to TP as a staff member. 


\section{Te Papa at the Time of My Fieldwork}

TP's operational and capital budget is approximately NZD 46 million per annum (TP Annual Report 2009/10). About half the budget is funded by the government, whereas the other half is revenue generated by TP through commercial activities (car park, retail, hospitality, publishing, tours) and sponsors. Admission to the exhibitions is generally free of charge for visitors, with the exception of some short-term exhibitions.

\section{Te Papa's Governance and Organisational Structure}

At the very top of TP's hierarchy is the TP Board consisting of eight members who are appointed by and report to the Minister of Arts, Culture and Heritage. The Board members are frequently public figures appointed for their skills and experience in the public or private sector, and although Pākehā, Māori and new migrants are usually represented, there are no regulations in place to ensure, for example, Māori participation on the Board. In 2007/08 two of the eight Board members were Māori (TP Annual Report 2007/08). Beneath the Board, the CEO and the Māori director (Kaihautū) jointly lead the Museum. Despite appearing equal on TP's organisational chart (see Appendix 2; 3; 4), their responsibilities differ and only the CEO reports to the Board, making them an unequal match in practice (see discussion in chapter 5).

Until 2009 TP's workforce was divided into ten directorates, namely Marketing and Communications, Funds Development, Commercial, People and Strategy, Corporate Services, Experience, Pacific Cultures and History, Natural Environment, Mātauranga Māori, and Art and Collection Services. These directorates were further segmented into a large number of 'teams'. ${ }^{20}$ The ten directors, together with CEO and Kaihautū made up the 'TP leadership team' of twelve people, which included seven Pākehā, three Māori and two new migrants, of whom six were men and six were women in the year 2007/08; again, gender-parity or ethnic balance is not a given. Appendix 4 makes the complexity of TP's internal structure visible. TP underwent a restructure under CEO Bennington in 2009 reducing the number of directorates from ten to five, and another major restructure in 2011 under CEO Houlihan introducing a matrix structure to the

\footnotetext{
20 The team-based organisational philosophy was changed under Michael Houlihan's leadership in 2013 to a matrix structure thought to prevent 'working in silos' (personal observation of internal staff workshops and meetings in 2012).
} 
organisation. Because my fieldwork was predominantly carried out in 2009 and 2010, I refer to the directorates and teams that were in operation at the time.

During data collection TP had roughly 500 staff of whom about 350 were full time and 150 were part-time employees (Michelle Hippolite, personal communication 13 August 2010), plus over 50 casuals. In absence of official statistics of TP staff, I did my own count, analysing TP's organisational chart and the all staff mailing list. About 67 per cent were non-Māori or Pākehā New Zealanders, 21 per cent were new migrants who moved to NZ less than ten years ago and 12 per cent were of Māori descent. As box 5 and 6 show, the TP staff breakdown matches the national Census data closely. The percentage of Māori staff within a bicultural organisation might seem relatively small, but considering that Māori are a minority in NZ (14.6 per cent at the 2006 Census) ${ }^{21}$ and even more so in Wellington City (7.4 per cent) the TP staff demographics reflect national trends and settling patterns.

Box 5: Demographics of TP staff in 2008

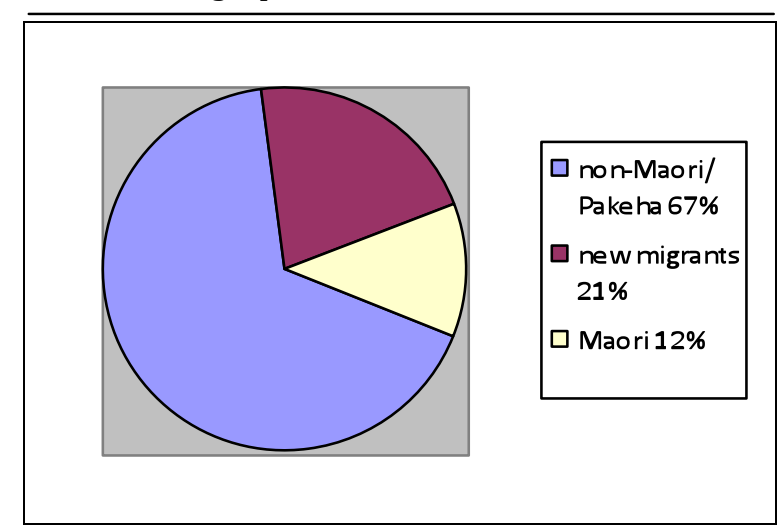

${ }^{21}$ http://www.stats.govt.nz/Census/2006CensusHomePage/QuickStats/quickstats-about-asubject/maori.aspx (accessed 14 October 2013). 


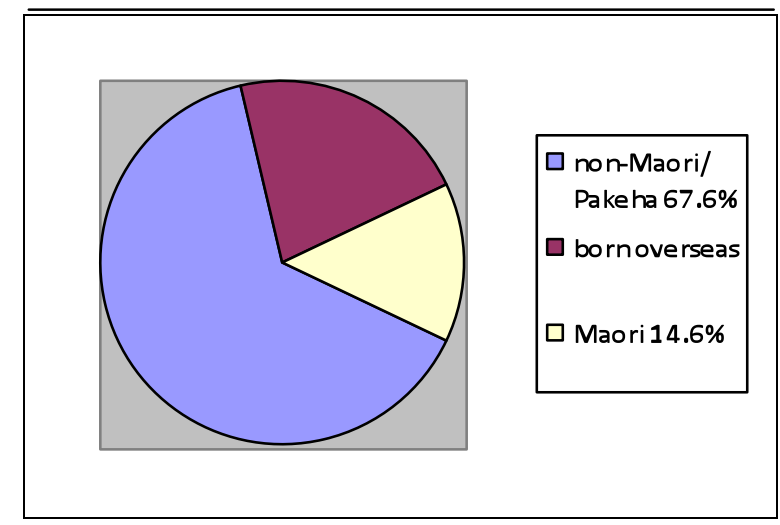

Note: Total comes to more than 100 per cent due to some people falling into more than one category.

Box 7 shows that the number of total staff and Māori staff varied between the chart and the list - mainly because the organisational chart did not list casual staff - yet both counts come up with a Māori staff percentage of roughly 12 per cent. This percentage parallels the most recent NZ Census ${ }^{22}$ (14.6 \% Māori in 2006), and counters the impression that Māori staff are overrepresented at TP.

Box 7: Māori staff numbers at TP (December 2010)

\begin{tabular}{|l|l|l|}
\hline & Organisational chart (without casuals) & Staff Mailing List (with casuals) \\
\hline Total staff number & 441 & 575 \\
\hline Māori staff number & 53 & 67 \\
\hline Māori Percentage & $12.02 \%$ & $11.65 \%$ \\
\hline
\end{tabular}

Adhering to the principles of Equal Employment Opportunities (EEO), TP strives for a diverse workforce and recruitment is based on best skills rather than ethnic make-up. Nevertheless, Māori are employed throughout TP at all hierarchical levels and contribute to TP's profile in diverse roles. Māori staff members are not spread out evenly (see Appendix 4, organisational chart 2008) but clustered in certain teams at the interface with the public (e.g. Hosts, Education team) or with Māori content (e.g. Mātauranga Māori team, Karanga Aotearoa/ Repatriation team). Other teams with a very high percentage of Māori staff (between 50 and 100 per cent) include National

\footnotetext{
${ }^{22}$ In the 2006 Census "European remained the largest of the major ethnic groups, with 2,609,592 people (67.6 percent of the population) in 2006. The Māori ethnic group is the second largest, with 565,329 people (or 14.6 percent)". http://www.stats.govt.nz/Census/2006CensusHomePage/QuickStats/quickstats-about-asubject/culture-and-identity/ethnic-groups-in-new-zealand.aspx (accessed 2 November 2012).
} 
Services Te Paerangi, the very successful outreach programme to other NZ museums and cultural centres, and the Iwi Relationships team.

The year 2009, when I officially began my fieldwork at TP, was in many regards an extraordinary year bringing many changes and challenges: following a restructuring of the leadership team almost the entire higher management level was replaced with new directors, the mana taonga principle was under review, TP's CEO Dr. Seddon Bennington died tragically on a tramping trip ${ }^{23}$ and consequently the institution was in a state of mourning and uncertainty. Nevertheless I was able to observe biculturalism in practice during those events, some of which brought the importance of biculturalism at TP to the fore.

\section{Sampling and Research Design}

I viewed TP hypothetically as an entity that consists of different back-of-house teams and front-of-house areas that are all interconnected through the bicultural framework. Rather than studying one aspect in isolation, I intended to gain as much insight as possible into bicultural practices at the workplace, both horizontally (across the frontof-house/ back-of-house division) and vertically (across the hierarchical levels), taking into account Goffman's (1959) concept of 'front stage' and 'back stage'. Given that in theory every segment of TP plays a role in putting biculturalism into practice, I assumed I would be able to observe bicultural practices, regardless of the team or area of the workplace within the Museum I chose for my research. Thus, for recruiting teams and interviewees my approach was exploratory, and as much participant-led as possible.

What may have seemed a vague and unfinalised methodological approach at the outset was in fact an intentionally open-ended exploration that has proven to be a virtue in other workplace ethnographies, as Helen Schwartzman (1993:15) reflects on the 'Hawthorne Study': "the most significant contribution of it is its demonstration of the value of allowing both research questions and methods to evolve and change during the

${ }^{23}$ http://www.stuff.co.nz/national/2594033/Te-Papa-boss-Seddon-Bennington-found-dead (accessed 16 July 2009$)$. 
course of the investigation". Therefore, the teams I conducted my fieldwork with were partly selected randomly and partly identified in partnership with the individual staff members I interviewed as one of my questions was 'what other team would you recommend for my research?' I assumed that respondents would make their recommendation for a particular team on the basis that in their view it either performed a very high standard of bicultural practice or, in their eyes, underperformed biculturally. These were both particularly interesting cases, because they went beyond the 'average team's daily reality, showing the cracks and conflicts in normal life and highlighting something that would not have been seen otherwise (Götz 1997).

\section{Entry to the Field}

It is a dilemma inherent in the study of organisations that the researcher relies heavily on the organisation that controls the researcher's access to resources and staff, the communication flow and the research schedule. Vicki Smith (2005:220) describes the "unique barriers to entry to the field", giving examples of researchers spending up to one year trying to gain relatively unrestricted access to a company and feeling "vulnerable to the inescapable realities of the corporate world" (V. Smith 2005:226) . David Gellner and Eric Hirsch (2001:5) argue that in terms of access issues, organisations bear similarities to 'gatekeepers' in non-Western contexts, because

boundaries and identities have to be negotiated, and the duration of stay and focus of research have to be cleared [...]. For the ethnographer, adaptability to the circumstances is essential, since, as Buchanan et al. (1988:56) remark, 'negotiating access for the purposes of research is a game of chance, not of skill'.

As I experienced these difficulties at TP early on and often stood helpless in the face of the powerful organisation, I was relieved to read that other researchers have encountered similar problems. I had to deal with the fact that gaining access to the field was beyond my control and remind myself that bureaucracies work slowly. My emotions and frustrations of this journey were reflected in my field diary, which at times was a collection of self-pity, aggression and disappointment. These episodes of setbacks however, tell more than just the story of my personal struggle during fieldwork; they also tell the story of organisational procedure, hierarchy and bureaucracy. I found that TP is very bureaucratic and inflexible in the ways it deals with 
official requests, as often individuals I approached had to follow the long line of command until approval was given.

\section{Gaining Permission}

On 9 September 2008 I had a meeting with the then CEO Seddon Bennington to propose my research. He was very supportive and welcomed my research on the basis that "Te Papa is a transparent institution". Despite this permission 'from the top', I ran into hurdles and gatekeepers when it came to actually observing teams behind the scenes. As well as having several meetings with my TP liaison persons, I also relied on personal contacts I already had 'from the bottom' and started my ethnography with my colleagues in the Events Team who welcomed my research. A formal 'memorandum of understanding' was drafted and signed by my liaison persons, my supervisors and myself once I started my fieldwork. Eleven months had passed since I first met with the CEO until I was officially allowed to study TP behind the scenes.

\section{Entry to the Teams}

In hindsight, entrance to teams was most difficult when there was no pre-existing relationship between the manager and me. My limited knowledge of some teams' working schedules and their internal structure also seemed to hinder my entry to specific teams. The same approach would work in one team but not in another: in the Māori collection I approached the collection manager directly rather than her manager; it backfired however, when I approached a scientist without asking his manager for permission first. Informal approach on a personal level was not successful in some cases where teams were structured very hierarchically, because it did not reproduce the organisational hierarchy and disrupted the chain of command. The thinking behind my decision to ask staff members directly was to ensure they would participate on their own terms and not just because their manager encouraged them. By unintentionally 'over-stepping' the - invisible - boundaries, I quickly learned how the bureaucratic apparatus works at TP. While all teams I approached agreed to be part of my research, my request to sit-in on a Board or Leadership team meeting was denied, as the content of their meeting was deemed to be too sensitive. 
Contrary to some management's concerns about my research, many staff welcomed my project and pushed me to look particularly at TP's Leadership team and Board of Trustees. ${ }^{24}$ While at first glance their intentions for allowing me into their teams seemed genuine and generous, closer examination revealed less altruistic reasons as I was sometimes used as a cheap administrator and snowed under with data entry or filing. However, the teams who made use of my voluntary work also allowed me to shadow them almost unrestrictedly, took me along to meetings or social get-togethers and showed their gratitude with a farewell present in the form of a shared meal (particularly in Māori or mixed teams) or a bottle of wine (particularly in non-Māori teams). While I understood my fieldwork as reciprocal taking and giving that ideally creates a win-win-situation for both parties, one participant put a different spin on my research, seeing it as a 'gift to the organisation' and calling my voluntary services a 'koha'.

\section{Data Collection}

I spent almost one year - from July 2009 till June 2010 - conducting fieldwork at TP, 'living with' 18 different teams across the whole organisation (see Appendix 6 for an overview). I stayed within each team between one day (two teams) and three weeks (one team), but most often between one week (eight teams) and two weeks (three teams). This was dependent firstly, on the team's size, their schedule and how long they were willing to accommodate me and secondly, on my own research schedule, other commitments and how much time I expected to require to gain an insight into each team. The teams had between two (Workforce Development, Conservation) and over 20 team members (host team). In large teams I was only able to observe a small number of individuals, whereas in smaller teams I made an effort to observe each member. In total I observed 74 staff over 104 days. This figure neither includes staff and other people I observed when they interacted with my participants, nor days I spent at TP in other capacities; including them the total number would be significantly higher.

\footnotetext{
24 One must be aware as a researcher of other people's agendas and not confuse 'welcoming' with 'instrumentalising' the researcher for their political aspirations (see Macdonald 1997a).
} 


\section{Participant and Direct Observation}

When I approached the team leaders via e-mail I asked to be allowed to

participate and observe the everyday operation and the daily activities of the team and conduct interviews with individual team members. [...] It would be great if I could accompany you and other team members to staff meetings, lunches and these kinds of things.

However, I left it up to the team members whether they took me along to their meetings and social functions or not. In some teams I was treated like a full team member and asked to participate, in other teams I was left to my own devices and largely excluded from their activities. Within the teams there was often one team member who became my 'mentor', introducing me to people, taking me along to meetings and allowing me to shadow them for a day. As the teams are quite busy there was always something I could help with: the tasks I was given reflected whether my role within the team was seen as merely a student who needed to be occupied or whether I was perceived as a colleague who generously gave up time to support the team. Another indicator for the kind of relationship each team formed with me was the farewell on my last day in the team. The farewell ranged from a verbal 'thank you and good bye' to fond hugs, morning tea rituals and lunch invitations.

TP's office space at Cable Street stretches over level two and three, and consists of several large open office spaces along the widow front facing the city. This means team members are grouped together in a square shape at their individual desks, sitting alongside or back-to-back to each other. Each square is only separated from the next team by chest-high dividing screens. While each desk is considered the territory of an individual staff member, the team's area is their communal territory often reflecting their personalities and particular style. In almost all the office-based teams I was given a spare desk that I could use as my own within their workspace. As I used my own laptop I was largely autonomous with the flexibility to move quickly. This also gave me the opportunity to 'escape' the open office for the library or the staff room sometimes, when I required privacy to type up field notes.

Working alongside the team members I had a good vantage point for unobtrusive, direct observation not just within the team, but often with the 'neighbouring team' just over 
the wall, seeing who interacted with whom, what they talked about, the rituals in each team etc. Although what I was able to observe and the degree of my participation was mostly participant-led, I also chose to attend certain events or social functions, and participated in Māori activities that were of interest to me before, during and after my fieldwork.

Between 2008 and 2012 I attended over 40 te reo Māori classes, more than 50 waiata and 35 taonga pūoro practices, 42 social functions (including Christmas functions, staff anniversaries and farewells or parties), 15 training sessions (including two staff inductions) and 18 all staff meetings. Furthermore, I participated in 42 pōwhiri, opening and closing blessings where I was sometimes performing in the kapa haka group and/ or playing taonga pūoro, and experienced sitting on the manuhiri side as well as the tangata whenua side. I stayed six times on marae outside TP for several nights, three times for Te Ataarangi hui 25 on national events, once at Te Herenga Waka Marae at Victoria University and twice at wānanga for TP staff on the kaupapa of taonga pūoro and flax weaving. Although I did not always participate or attend these events with my 'researcher hat' on, I did take mental notes and often typed up proper field notes afterwards, so that my experiences there informed and shaped my research and became part of my data. During my fieldwork period I took part in 54 meetings, accompanying my participants to internal meetings as well as meetings with external clients or iwi. I was also allowed to sit in on three job interviews for entry positions and take part in ten front-of-house tours and five back-of-house tours through different collection rooms with several tour groups. In 2008, before the fieldwork in teams, I did participant observation at the ten day long host training module for the new host intake.

\section{Interview Sample}

In addition to participant observation within the teams I interviewed individual staff members. The interviews were conducted between September 2008 and September 2012 with 68 'Te Papa people' from the hosts at the front door to the CEO at the top (see

\footnotetext{
25 "Hui is a general term in Māori for any kind of meeting, but when people say they have been to a hui, they are nearly always referring to a ceremonial gathering on a marae" (Salmond 2009:1). Te Ataarangi is a revitalisation of the Māori language movement that developed a particular teaching style which is offered around NZ, including at TP.
} 
Appendix 7). "[D]efining a museum professional is almost as difficult as defining a museum," writes Kenneth Hudson (2004:89), therefore I adopted a very broad approach, seeing TP staff as 'everyone who works at TP'. I made an effort to speak to staff of all ranks and professions, thus my sample included managers, conservators, curators, training facilitators, administrators, tour guides and scientists just to mention a few. I started with oral history interviews of influential former TP staff who could be informants regarding TP's conception and early days; then I moved on to current staff members, mainly recruited from the teams I also observed. Most interviews were conducted in 2010 when I was based at TP. My sample was selected randomly - team members could volunteer - and sometimes deliberately, if a particular era in the history of the organisation was to be covered. I aimed for a diverse cross-section of the organisation in terms of gender, age, ethnicity, rank, duration of employment and professional background.

My interview sample totalled 68 people and consisted of 25 men and 43 women. 34 were Pākehā (24 women and ten men), 24 Māori (13 women and eleven men) and ten new migrants (six women and four men) who had recently moved to NZ from overseas.

Box 8: Interview Sample, ethnic diversity

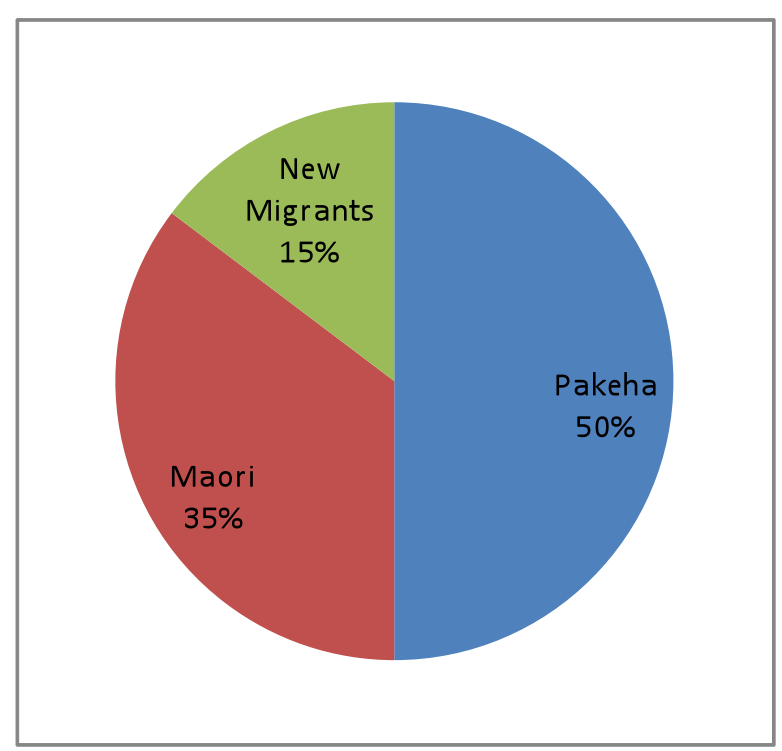


Box 9: Interview Sample, gender diversity

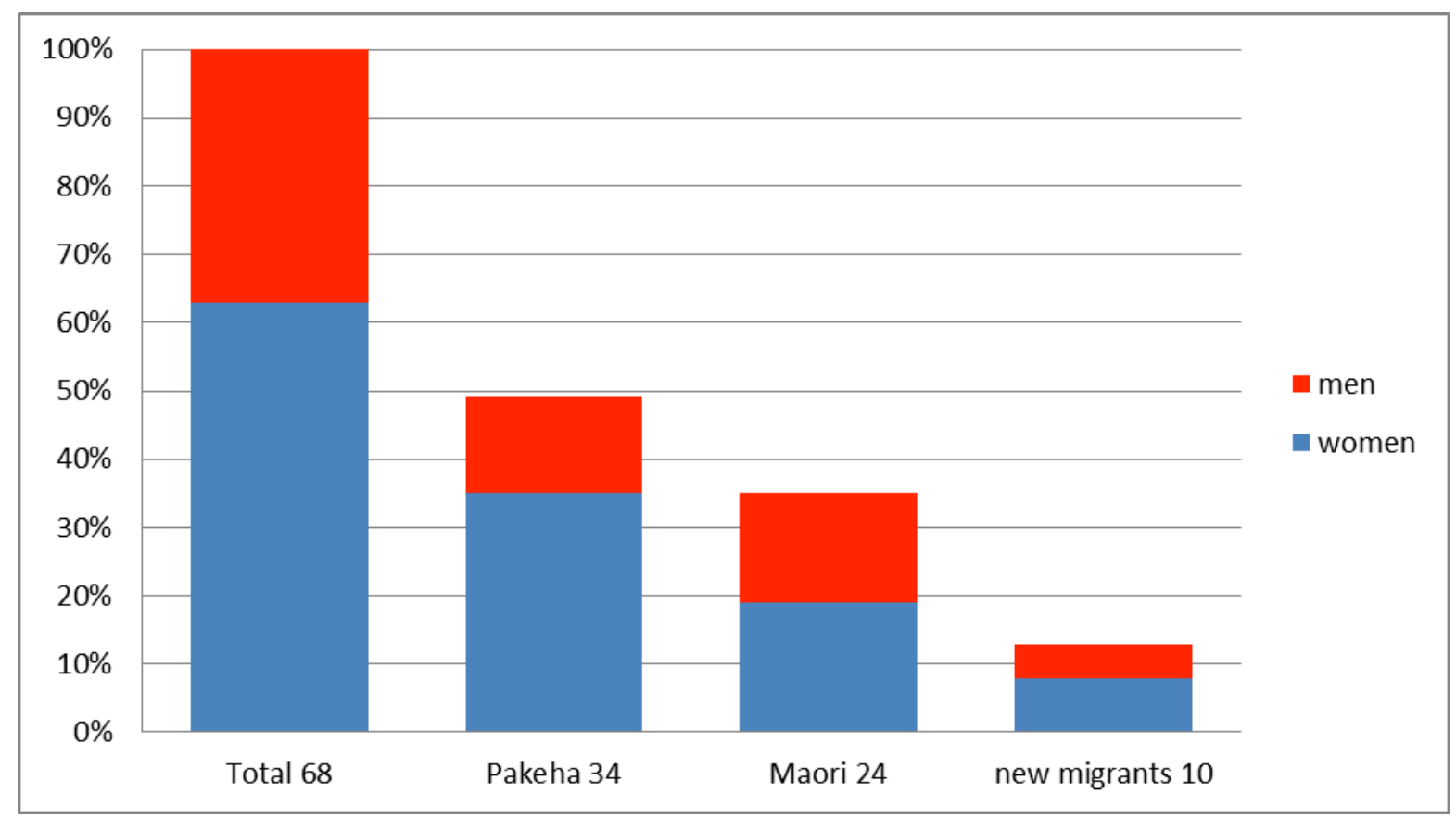

At the time of the interview twelve had already left the institution compared with 56 who were currently working at TP. In five cases the interview coincided with the staff member moving on to another role outside TP, in which case I was aware that my interview took on the nature of an exit interview and that the interviewee - depending on their reason for resignation - might view things in a negative light.

Box 10: Interview Sample, employment status at TP at time of interview

\begin{tabular}{|l|c|}
\hline Current staff & 56 \\
(About to leave TP) & $(5)$ \\
\hline Former staff & 12 \\
\hline
\end{tabular}

The current staff members' professional involvement with TP ranged from a selfacclaimed 'fossil', who had been there for 34 years, to one interviewee who was a complete newcomer with only two weeks TP work experience under her belt. Out of the 56 current TP staff members six (five of them Māori) had been working at TP and its predecessor in Buckle Street for over twenty years, four had been there more than ten years and eleven between six and ten years. The vast majority (35 interviewees) had entered the organisation less than ten years ago; out of those, 24 had worked at TP 
between two and five years, and eleven people had started their jobs less than one year ago.

Box 11: Interview Sample, duration of service at TP at time of interview

\begin{tabular}{|l|c|}
\hline Over 20yrs & 6 \\
\hline Over 10yrs & 4 \\
\hline 6-10yrs & 11 \\
\hline 2-5yrs & 24 \\
\hline Less than 1 yr & 11 \\
\hline
\end{tabular}

The diversity within my sample reflects a cross-section of TP's staff with approximately 10 per cent of the total staff interviewed. Towards the end of my fieldwork I ticked off all the people I had observed or talked to informally and noticed that there was hardly anyone working at TP who I had not interacted with in one way or another. While many staff members were wary of being observed, they were happy to talk to me in a formal interview; almost all interviewees chose a quiet location inside TP. The setting and the course of the interview followed the principle of equality between interview partners that is so important in the 'ero-epic dialogue' (Girtler 2001), whereby both partners are seen as 'learners' and not only the interviewer, but also the interviewee, can ask questions. My first question opened the conversation by asking 'Could you give me a brief overview of your career path so far and tell me what your role at Te Papa involves?' (Appendix 5). It was intended to give the interviewee a 'safe' question and generate a narrative that would often lead them back to their school years. From there they would offer the next topic, often without prompting, and connect this to biculturalism.

During the interviewing process the written interview questions (see Appendix 5) became more and more irrelevant as I used them less to navigate through the interview; instead the interview guide became a mere checklist to ensure that the main themes had been discussed. On average each interview took about 60 minutes, the shortest interview lasted 20 minutes and the longest 200 minutes. All interviews except one 
were electronically recorded with the participants' permission and transcribed verbatim.

\section{Data Analysis}

The data collection and analysis were not completely separate processes, but overlapped and informed each other. For instance, I conducted interviews with former staff members, transcribed them and started their analysis, while doing ethnography with current staff members of TP at the same time. The first step of analysis happened on a rather subconscious level during transcribing the first fifteen interviews verbatim myself. I then used an inductive approach that is associated with grounded theory (Glaser/ Strauss 1967), labelling emerging patterns and themes. I followed an iterative process of three activities: data reduction, data display and interpretation/verification (Miles/ Huberman 1994). For easier data processing, I had transferred most of my field notes, observation protocols and interview transcripts into electronic format and used NVivo, an analysis software suited for managing large bodies of qualitative data, for coding the material. The interview transcripts were consulted repeatedly during the process of developing themes and ultimately writing-up. Making meta notes and drawing diagrams as described by Kathleen Dewalt and Billie Dewalt (2002), proved a useful strategy to translate the themes into chapters.

\section{Ethics, Limitations - Some Considerations}

Doing fieldwork in NZ requires ethical considerations that take into account NZ's demographic structure (Tolich 2002), as it is quite easy to trace someone in such a bounded field site. Ethics approval for this research project was granted on 19 September 2008 by the Social and Cultural Studies Human Ethics Sub-committee at Victoria University (No. 15863). Confidentiality is problematic when researching a small community of about $500 \mathrm{TP}$ staff who know each other. I have addressed this issue by seeking written consent and giving the interview partners a choice to be named or not, as well as to check the parts of their transcripts used in this thesis. For information obtained during participant observation, I do not use names and emphasise that I am accountable for these very subjective impressions. Doing research 'at home' with 
participants, who are also my colleagues and in some instances my friends, is ethically not an easy task. I worried that my research and what I write about 'them' could alter our relationships. It was my intention to write an ethnography of TP as I experienced it myself and as I saw it through the narratives of my participants.

Due to the interviews touching on relational issues in the workplace, with many staff using them as an opportunity to vent frustrations, it is understandable that confidentiality issues were raised, especially where staff feared negative consequences for their jobs. High profile figures were happy to be fully named as they did not fear any negative consequences for their jobs due to their statements. In contrast, staff lower in the organisational hierarchy were conscious of possible negative implications and often preferred complete confidentiality. Therefore, I only use names from 'public figures' who gave their permission and use 'a Māori staff member' or 'a non-Māori staff member' to protect the identity of the participants who chose to remain anonymous.

\section{Negotiating the Roles of Employee and Researcher}

Before I embarked on my fieldwork in 2009, I already was a paid employee at TP. From 2007-2010 I worked as a research assistant for the Visitor and Market Research Team conducting exit interviews with visitors, and since 2007 I have been working as an Events supervisor ensuring that the public events (e.g. concerts, kapa haka performances, film screenings, discussion forums, children's activities etc) run smoothly ((see photos in Appendix 11). Since both roles were casual positions, amounting to an average of ten hours per week on a flexible roster basis, and saw me working front-ofhouse engaging with the public rather than back-of-house, they did not interfere much with my researcher role. In addition, my paid work was marked by wearing an Events uniform or carrying a box containing visitor surveys.

To avoid confusion I always asked for permission and made a verbal statement to all participants if I attended a work meeting or other activity for research purposes. Nevertheless, it was sometimes unavoidable to observe something while working or being told something as a colleague rather than a researcher. In these cases I had to carefully negotiate my research interest and my loyalty as a colleague, weighing up the 
relevance of stories or observations for my research and ethical considerations of protecting participants. While being an employee had the advantage of almost unrestricted access to back-of-house areas with my staff swipe card, and being able to contact other staff members more easily, it also placed constraints on my research: participants were suspicious of my multiple roles, being careful what they told me or acting differently when I was present; management kept a close eye on my movements around the building, trying to limit my research to certain areas and teams; and writing critically about delicate issues was difficult because I felt obliged to keep on good terms with my colleagues and management.

My ongoing engagement with TP has created a relationship of trust that enriches my research tremendously, yet also made me feel obliged to leave out material that was accessible to staff only, confidential or too controversial. Because my two paid roles were at entrance level, towards the bottom of the TP hierarchy, my status within the organisation was low at the beginning; any status gain was due to my research and active participation rather than my work capacity. Saying that, I think that seeing me in multiple roles, working on evenings and weekends, in addition to my fieldwork contributed to the participants taking me seriously as they testified my passion and effort at TP, which one Māori woman summed up as "Tanja is part of the furniture".

\section{Researching-Up}

A special form of the researcher's anxiety of the field (Devereux 1968; see also Lindner 1981) was expected to arise during my research. This is a phenomenon associated with 'researching up' (Warneken and Wittel 1997; Nader 1972), addressing the power imbalance in the relationship between the researcher and those researched. My own fear and self-understanding in relation to my interviewees was that they would see me as a young woman and inexperienced researcher, with a foreign accent, someone who lacks NZ specific knowledge and does not yet have a professional career.

However, during the course of my fieldwork I realised that even though I felt inferior to most interviewees by salary, life experience and often age, in terms of academic degree I was better qualified than all but a handful of staff who hold a PhD. Often when managers 
introduced me to other staff they would say: "This is Tanja, she is doing a Masters about biculturalism at TP - is it a Masters or PhD?" Their hesitation and the common assumption that I was a Master student suggests that they were more comfortable with this option. These incidents made me rethink the complex power-balance in the researcher/researched relationship that entails so much more than just professional rank. The categories of gender, age, sexual orientation, religion, race, social status, education and marital status are certainly important factors in shaping relationships between researcher and participants, which at TP were expanded on with the following criteria: time spent in NZ, time served at TP and the proficiency level in te reo Māori or the willingness to learn.

\section{Reflexivity: Being an Outsider and Kaupapa Māori Methodologies}

Being neither Māori nor Pākehā, but German, rendered me an outsider to NZ. Being also an anthropologist researching TP (see Ames 1986 for a discussion of why there are not many anthropologists in museums), was a double-stigma in the field at times.

Anthropologists in NZ had conducted 'salvage ethnography' to record and capture tribal cultures that were believed to be extinct. While white ethnographers and filmmakers believed they "were preserving 'tribal' identities" (Sissons 2005:148), they actually produced and perpetuated the ideology of the 'primitive savage' (see also Hill/ BönischBrednich 2007). However, during the course of my fieldwork, I became an insider at TP.

It occurred to me during my fieldwork, especially when confronted with other recent migrants or Pākehā who were ignorant of Māori culture and NZ politics, that I had in fact adapted to both Māori and Pākehā culture, through travelling the country, being married to a Pākehā and having family in the South Island; I had the privilege of staying on several marae around NewZealand, where I experienced differences between regions as well as variations in iwi tikanga and dialects. These experiences made me very aware that as a foreigner I was often ignorant and marginalised because I lacked NZ specific knowledge, but I was also exempt from carrying the 'cultural baggage' of NZ's colonial 
past. ${ }^{26}$ I acknowledge that factors such as the ethnicity, gender and class of the researcher, shape the research outcomes. A male or Māori researcher would have had a very different rapport with the participants and drawn other conclusions. However I believe that my limitations, as an outsider, were actually an advantage in many regards, as I took nothing for granted and observed with a 'fresh pair of eyes'. Certainly, as will be evident from this thesis, 'the researcher [has been] changed in the dialogic of research' (D. Smith 2006:2).

Conducting research with Māori as a non-Māori researcher is very difficult, given a history of Pākehā research exploiting Māori. In Linda Tuhiwai Smith’s (2006 [1999]:1) words, the term research itself "is probably one of the dirtiest words in the indigenous world's vocabulary. [...] It is implicated in the worst excesses of colonialism". Therefore, Māori call for kaupapa Māori research, conducted by Māori for Māori with the intention to achieve positive outcomes for Māori. Since the 1980s this has meant non-Māori were "ruled ineligible on things Maori" (Spoonley 1995:101; see also Awatere 1984) in NZ, because, as L.T. Smith (2006 [1999]:187) claims, "being Māori is an essential criterion for carrying out Kaupapa Māori research". The orthodoxy of this concept had a paralysing effect on Pākehā researchers (Tolich 2002), resulting in an excessive avoidance of Māori related topics altogether. As a non-Māori, I have to accept that I am unable to conduct kaupapa Māori research, however, I tried to conduct meaningful research that benefits indigenous peoples. I try to act on the performance turn in the humanities (Denzin 2003) by using interpretive research practices which

[t]urn the world into a series of performances and representations, including case study documents, critical personal experience narratives, life stories, field notes, interviews, conversations, photographs, recordings, and memos to the self. These performances create the space for critical, collaborative, dialogical work. They bring researchers and their research participants into a shared, critical space, a space where the work of resistance, critique, and empowerment can occur. (Denzin/ Lincoln/ L.T. Smith 2008:5)

Throughout my data collection and the writing-up I have made an effort to use the diverse narratives to create a rich tapestry of understanding. Furthermore, writing this ethnography I am aware that "a text is not a mirror; rather, a text is embedded in the narrative logics of science [...] and capitalism" (Denzin 1997:232) and that "[t]he reader

${ }^{26}$ I am grateful to Martin Tolich for the metaphor of 'cultural baggage' (personal communication 17 November 2010). 
and writer of the ethnographic or cultural text are coproducers of the very text that is being written and read" (Denzin 1997:240).

I also adhered to L.T. Smith's (2006 [1999]:120) demand that researchers show respect for Māori by exhibiting a willingness to listen, to be humble, to be cautious, to increase knowledge - and most importantly, to not "trample over the mana of people". Consequently, I hope that my study represents "indigenous persons honestly, without distortion or stereotype", and honours "indigenous knowledge, customs, and rituals" (Denzin/ Lincoln/ L.T. Smith 2008:2). The longer I worked at TP, the more I became an insider and now, after seven years, I believe I am able to say I am "practising anthropology in our own backyards" (Ames 1979:23).

\section{Outline of Chapters}

This thesis consists of five further chapters. In chapter one I critically examine the historical context of 'building TP' (part one) and how TP was constructed as a bicultural museum (part two). This includes an oral history of the making of TP by key players at the time, TP's bicultural framework in policy and the construction of a pan-tribal marae. Chapters two, three, and four focus on staff interactions following the path of a new (non-Māori) staff member being inducted into TP, welcomed with a pōwhiri (chapter two), through to doing biculturalism in their day-to-day work and becoming more bicultural (chapter three), grappling with biculturalism when world views clash (chapter four), and finally understanding biculturalism more deeply and making sense of this abstract concept (chapter five). In chapter five the discussion of the key findings is expanded by two 'unresolved issues' regarding co-governance and marae kawa at TP. Finally, the conclusion summarises the key findings, offers a reflective evaluation of the research and proposes areas for further research. 


\section{1 \\ Building Biculturalism}

\section{Introduction}

In this chapter I demonstrate how the political climate in NZ, particularly during the 1980s, in conjunction with a paradigm shift in museology, paved the way for conceptualising and building TP, a bicultural museum in a new location on the Wellington waterfront (see photos in Appendix 11). It is important to understand TP's history within a larger national and postcolonial context, as "[o]rganizations do not exist in a vacuum" (Gellner 2001:4). Worldwide transformations in museums with the call for the 'new museology', the claim for self-determination of first peoples around the globe and a 'political wind of change', were all factors that lead to the founding of TP. I provide a very brief overview of the historical and political events in NZ at the time and present a summary of the shift from a monocultural to a bicultural society (rather than a multicultural one) (Sissons 2005:66; McCarthy 2011). To the 'official' history I add an oral history of making TP.

This chapter is structured in two parts: part one is a historical account of constructing a bicultural museum and part two looks at TP's bicultural framework. In part one, historical records and academic literature are juxtaposed with an oral history of 'making TP', drawing on interviews with 'TP pioneers', including Ken Gorbey, Jock Phillips, Dame Cheryll Sotheran, Cliff Whiting and Richard Wright (see Appendix 8 for their roles within TP). In part two, I explore how biculturalism is 'built into' TP both figuratively, in terms of policy and governance, and literally, in terms of architecture, exhibition spaces, and most importantly, its marae (see photos in Appendix 11). The purpose of this chapter is to embed TP in the historical and contemporary context 
within NZ and internationally, and 'set the scene' for the reader. Overall I argue that TP is the product of a particular socio-political climate and was set up as an experiment for the bicultural state policy.

\section{PART I: CONSTRUCTING A BICULTURAL STAGE FOR THE NATION}

Firstly, I provide the historical and political context of NZ, starting with the signing of Te Tiriti o Waitangi/The Treaty of Waitangi (the Treaty) in 1840, which marks the official beginning of colonisation in NZ and is recognised today as NZ's 'founding document'. ${ }^{27}$

\section{Historical and Political context}

The Treaty was signed in 1840 by the majority of Māori chiefs and representatives of the British Crown at Waitangi. ${ }^{28}$ Basically, it granted the British Crown the right to purchase land and Māori the rights of British citizens. However, the understandings of both parties were different due to incorrect translations and interpretations of concepts, as Richard Hill (2009:222) states:

In Article One of the Maori version of the Treaty, 'kawanatanga' (governship) had been used as a translation for 'sovereignty'. This had meant, in Maori eyes, something less than the transfer of indivisible sovereignty to the Crown - the more so when taken alongside Article Two's guarantee of 'full authority'/ te tino rangatiratanga over land and other taonga/treasures to the Maori signatories, which was seen to imply 'more than mere possession' of tangible resources.

For about 100 years the significance of the Treaty was all but forgotten by Pākehā (Awatere 1984; Belich 2001b; Bell/ Matthewman 2004; Orange 2011 [1987]; Walker 1990a; Ward 1995 [1974]); in contrast, it was present in the collective memory of Māori and passed on to the next generation through oral history (Vasil 2000 [1988]:9; Hill 2009:153). Increasing numbers of Europeans settling on Māori land created conflict, Māori resistance and military intervention that led to land confiscation by the Crown

27 'The Treaty in brief', Ministry for Culture and Heritage website (accessed 27 January 2014).

${ }^{28}$ The signing of the Treaty in Waitangi was a major event (hence the name), but several other signings took place around the county, resulting in multiple copies of 'the Treaty'. It is important to note that some iwi did not sign at all and still consider themselves independent http://www.nzhistory.net.nz/politics/treaty/making-the-treaty/signing-the-treaty (accessed 26 April 2013). 
and ignited the 'New Zealand Wars' in the 1860s and 1870s, in which thousands were killed (see Belich 1986; Boast/Hill 2009). In 1877 Chief judge James Pendergast’s declaration that the Treaty was 'a simple nullity' prevented any breaches against it being legally dealt with (Walker 1990a; Orange 2011 [1987]). Hill (2004:15) notes that "the Crown suppression of Maori autonomy [rangatiratanga], and Māori resistance to this, became the most fundamental and ongoing relational nexus between state and indigenous people in New Zealand".

Colonisation changed the demographics and lifeworld of Māori rapidly and radically (see Belich 1996; Bertram 2009), and "[b]y 1900 Maori were destitute, depopulated and largely landless" (Hill/ Bönisch-Brednich 2007:167). Land loss, urbanisation and the suppression of the Māori language in the public sphere ${ }^{29}$ made it very difficult for the Māori culture; Ranginui Walker (1990a) described it as 'Ka whawhai tonu matou struggle without end'. Separate schools and other institutions were established for Māori, but as James Belich (2001a:x) asserts:

This was not apartheid: Māori had access to the mainstream equivalents, and these institutions existed, because Māori wanted them. [...] To my mind [...] [they] were a set of storm sails under which Māori culture and identity could survive the prevailing winds of socio-economic disadvantage and assimilationist rhetoric.

While the NZ government aimed for assimilation for much of the $20^{\text {th }}$ Century, "integration was the official government line in the Hunn Report of 1960" (McCarthy 2011:36; see Hill 2009:88ff for a discussion). These state policies were not beneficial for Māori who consequently fought for the recognition of their cultural values and rangatiratanga, as well as against the state goal of 'racial amalgamation' and producing "culturally homogenous citizens" (Sissons 2005:88, 97). Māori urbanisation was one of the most rapid worldwide, but nevertheless "Maori did not cease to 'be Maori'” (Hill 2009:39). While 46 per cent of the Māori population lived in urban centers in 1961, the figure of urban Māori rose rapidly to 70.2 per cent by 1971 (Statistics NZ 1986:29). The negative parameters of "urbanization and proletarization" were, as Sissons (2000:58)

${ }^{29}$ The Native School Act of 1867 made English the sole language at schools. This policy was vigorously enforced to the extent that some pupils were severely punished for speaking te reo Māori until the 1940s (Sissons 2005:94; Simon 2001:141-173). In 1969 Native schools were amalgamated into the public school system, but it was not until 1972 that te reo Māori was included in the school syllabus after 30,000 signatories presented a petition to Parliament. See Simon 2001 for a comprehensive discussion on the Native Schools System. 
stresses, accompanied by "a new ethnic activism, led initially by trade-unionists and later by Maori tertiary students" (see also Poata-Smith 1996:99; Roper 1990).

\section{Māori Activism and Cultural Revitalisation}

Māori activism of the 1970s marked the escalation of the "social and cultural turbulence that began in the 1960s" (Veracini 2001:15), heralding the Māori renaissance. The cultural revival in NZ was embedded in an international context of decolonisation and indigenous rights, and inspired by a global movement of human rights; Martin Luther King Jr.'s protest march to Washington D.C. for civil rights in 1963 became a catalyst for other oppressed peoples (Povinelli 2002:24). Scholars Walker (1990a), Hill and Bönisch-Brednich (2007:165) emphasise that "African American, Native American and other minority campaigns in the United States, for example, provided both moral empowerment and practical (often confrontational) tactics for young Maori radicals and their pakeha comrades". However, Māori resistance was also motivated by Parihaka, which was in fact, "very active resistance, although pacific in nature" (Riseborough 1989:3).

Inspired by the Black Power movement in the United States, Māori activists formed Ngā Tamatoa (The Young Warriors) groups in 1971 and voiced their anger about being oppressed and misrepresented (Poata-Smith 1996:102). Māori issues were now seen as linked to class and union politics. The Land March to Parliament and the occupation of Bastion Point (1977-78) ${ }^{30}$ are part of the collective memory of most New Zealanders, demarcating a turning point in race relations as well as the rise of 'Māori political consciousness' (Harris 2004; King 1983; Walker 1990a). The year 1981 marks a milestone in NZ history with the upheavals and protests surrounding the Springbok Tour (Richards 1999; Harris 2004). Protests against the 'all white' South African Rugby Team were aimed at the Apartheid regime, but at the same time the protests raised awareness of racism within NZ, and mobilised Pākehā and Māori alike to debate Māori self-determination.

\footnotetext{
30 When ancestral land in Auckland was threatened by the Government's housing development plans, Māori of Ngāti Whātua occupied the headland for 506 days to protest against land loss. The peaceful occupation ended when the Government sent in the army and police forces to clear the occupation site. 
The process of decolonisation was in full swing in this political climate as not only Māori, but also Pākehā had to position themselves and construct their identities in relation to 'the other' (King 1988; Spoonley 1986, 1991, 1995; Pearson/ Sissons 1997; Pearson 1989). Attempts to revitalise Māori culture and language included the Te Ataarangi movement ${ }^{31}$ that started in 1979, the establishment of Māori Studies departments and the building of marae at NZ universities. It also saw the parallel development of a Māori run education system with the first Māori university Te Wānanga o Raukawa opening in 1981. This was followed by Kōhanga Reo in 1982, and Kura Kaupapa in 1985 (Harris 2004; Bishop 1999). The development of Māori education initiatives has been criticised for being separatist (Doerr 2009), but has also helped Māori to revitalise their language and culture (Te Puni Kōkiri 1993).

In 1987 te reo Māori was recognised as an official language of NZ; Māori radio and Māori television (founded under the Māori Television Act of 2002 and a second station, Te Reo, launched in 2008) were established to revitalise the Māori language. With seven guaranteed Māori seats in Parliament since 1867and the foundation of the Māori Party in 2005, Māori seem to have maintained a robust presence in NZ society and public life compared to other indigenous peoples in post-settler states. ${ }^{32}$

\section{Economic Climate}

Britain's entry to the European Economic Community in 1973 meant that NZ largely lost its biggest export market, the United Kingdom. The Forth Labour Government, elected in 1984, implemented drastic changes (labelled 'Rogernomics', after finance minister Roger Douglas) to the social system, deregulated the labour market and promoted free trade (Roper 1993). The state tradition of "socialism without doctrines" was seen as no longer being affordable and the 'New Zealand experiment' in neoliberalism began (Larner 1997). Not surprisingly, New Zealanders feeling rejected by the 'motherland'

\footnotetext{
${ }^{31}$ Te Ataarangi method of teaching Māori language aims to provide a safe, supportive learning environment. http://www.teataarangi.org.nz/ (accessed 5 November 2012).

32 Sissons (2005:135) discussed the distribution of Māori seats in Parliament which are not allocated per capita of Māori citizens, but based on Māori who chose to enrol in the Māori electorate. With four of 76 seats in Parliament in 1867 Māori were underrepresented, and with seven of 120 seats in 1996 political influence of Māori is still limited. However, taking into account Māori Members of Parliament across the political spectrum, Māori are assured a voice in Parliament, despite its limited influence in a majoritarian democracy.
} 
had to re-interpret their national identity. As a result of this identity crisis, many New Zealanders changed their sense of place from the 'better Britain of the south seas' to a Pacific Island. As Kawharu (2008:53) argues: "While New Zealand is a member of the British Commonwealth with a dominant European culture, it is also undeniably located in the South Pacific with a growing indigenous and immigrant Polynesian population".

\section{Cultural Redress: The Waitangi Tribunal}

Addressing racial inequalities and the Māori-Crown relationship became a state priority, with the establishment of the Waitangi Tribunal (Hill: 2009). When the Tribunal was set up, it could only investigate claims of breaches of the Treaty since the passing of the Treaty of Waitangi Act on 10 October 1975. This changed in 1984 when the amendment to the Act gave the Waitangi Tribunal the authority to investigate retrospective claims dating back to 1840 (Hill 2009:165). The Treaty settlements acknowledge the Crown's wrong doings of the past through apology, monetary compensation, return of land to the iwi claimants and other social and cultural redress packages. The process is also instrumental in bringing the importance of the Treaty as a 'living document' (New Zealand 1990 Commission) back into public discourse; in fact, the Waitangi Tribunal has been called "the conscience of the nation" (Temm 1990:127). Hill and Bönisch-Brednich (2007) place the Waitangi Tribunal in an international context of 'transitional justice', stressing its potential for 'healing the past'. Processes of "moral reconstruction of political relationships through truth telling, reparations and forgiveness" (Amstutz 2005:16) gained momentum through the establishment of the Waitangi Tribunal. Nevertheless, "the wounds that were inflicted upon indigenes remain unhealed because they were so severe and traumatic in the first place. Transitional justice machinery is a necessary precondition for Māori attaining a position in New Zealand society, culture and politics that is acceptable to them" (Hill/ BönischBrednich 2007:165).

State acceptance of compensation for Treaty breaches and Māori claims that their tangata whenua status had been violated and needed restoring (Ward 1999; Hill/ Bönisch-Brednich 2007) resulted in the Waitangi Tribunal becoming a facet of 'nation building'. While the state made its intentions clear to encourage Māori to "move out of 
grievance mode and into development mode" (Graham 1997:58), through the settlement deeds Māori aspired to "full participation as a distinct people in modern New Zealand society" (Hill/ Bönisch-Brednich 2007:166). What Māori desired as an outcome was an ongoing partnership not only with the Crown, but with Pākehā more generally (Hill/ O’Malley 2000).

Moreover, the Waitangi Tribunal can be seen as a symbolic, performance-based redress (Benton/ Frame/ Meredith 2013), as Māori stage their regained autonomy in narratives that are only tangentially relevant for the hearings, yet create "new channels for expressing their long-standing autonomist aspirations" (Hill/ Bönisch-Brednich 2007:170). Judith Binney (1987:27) sees those indigenous oral narratives as attempts to counterbalance official written records, reclaim mana and validate the group, thus the stories were not so much directed at the judges or the audience, but the iwi members themselves. Therefore, the Waitangi Tribunal hearings are crucial in establishing Māori identity within an iwi framework.

While Pākehā often see Treaty settlements as a means to 'put the past behind us and move on', for Māori it is often a starting point for an ongoing partnership, or as it is now often phrased, a conversation. The Waitangi Tribunal was instrumental in establishing the Treaty's significance as the founding document of NZ and, as Hill (2009:223) argues, this was crucial "for 'a developing social contract' between Crown and Maori". Likewise, I see Treaty settlements and bicultural state policy not as an endpoint, but a necessary stage towards self-determination and equal race relations. The doctrine of biculturalism needed institutions like the Waitangi Tribunal and TP as part of a postcolonial cloak that the NZ state started weaving.

\section{New Zealand Society Today}

What is the state of Māori-Pākehā relations in NZ at the beginning of the $21^{\text {st }}$ century? Kawharu (2008:56) stresses:

Today, those who identify as Maori involve themselves in social and economic activities of the dominant New Zealand society without special regard for their ethnicity or that of others, by responding at the level of their capacities to the presence of incentives and to an absence of ethnic barriers to their doing so. It may therefore be argued that Maori are 
'included' in their wider society. Individuals are certainly not excluded of their perceived or asserted Maori identity (and Race Relations legislation provides a supportive check on that).

Although Māori achieved many milestones in NZ, they are over-represented in statistics for ill-health, poor housing, criminal activities, and have a short life expectancy (see McIntosh/ Mulholland 2011, Vol. 1).33 Despite rhetoric to the contrary, NZ is far from being an ideal for race relations as recent history proves: the Foreshore and Seabed Bill was passed into law on 17 January 2005, although it was "hugely unpopular among Maori" (Kawharu 2008:43). This 'turmoil of ethnic politics' saw the then-leader of the National Party Don Brash call for "an end to race-based law", and "one law for all" in his infamous Orewa speech in 2004, addressing race-relations in NZ, particularly the special status of Māori people. Sissons (2005:119) interprets this incident as proof, that “[i]ndividualized emancipation is by no means a forgotten 1970s option", reading 'emancipated' as "relieved of their special status".

In this climate of neo-conservative reaction against new found Māori assertiveness, and the grief Māori felt over their customary rights to the foreshore and seabed, the Māori Party was formed in 2004, at least in part to give Māori a stronger political voice. Kawharu (2008:54) reflects on the political climate in NZ at the time:

Three days after the [2005] election, Colin James, writing in the New Zealand Herald, claimed that the issue for the incoming Government was 'unification.' He said that 'there is a lot of healing to do. This is a divided nation.' And perhaps the biggest unification challenge was with the 'indigenous divide' where cultural pride is locked into material inequality.

This statement illustrates that a Māori-Pākehā divide remains in NZ society today and the reality is a far cry from "what New Zealanders believed were the "best race relations in the world'”34 (King 2003:415). Calls for sovereignty and self-determination from Māori have become stronger and more persistent. Nevertheless, biculturalism remains the official state policy. In the following section I therefore give an overview of the historical evolution of biculturalism and its political agenda.

33 "Māori life expectancy at birth is about 8.2 years lower than for non-Māori." http://www.stats.govt.nz/browse for stats/health/life expectancy/NZLifeTables_HOTP05-07.aspx (accessed November 2012).

34 According to King (2003:471), however, this perception does not match New Zealand reality. Hill and Bönisch-Brednich (2007:164) also unveil this phrase as 'national mythology' unable to withstand 'critical scrutiny'. 


\section{The Evolution of Biculturalism in New Zealand}

Biculturalism was not an invention of the 1980s, as Māori leader and Minister of Māori Affairs Sir Apirana Ngata already had proclaimed in the 1920s that Māoritanga could be a foundation for economic growth, and that Māori could select what they 'required of the culture of the Pākehā' (Ngata in Sorrenson 1986-8), while maintaining their culture through a revival of their songs, dance, carving, medicine, calendar and oratory traditions. In the late 1960s the NZ Government was under pressure to react to the increasingly outspoken Māori rights activists and sympathetic Pākehā who joined in the protests. A bicultural policy seemed the political solution for living together peacefully. The modern notion of biculturalism was reintroduced to NZ by Canadian anthropologist Eric Schwimmer. A symposium in 1968 "provided Schwimmer with an opportunity to break away from the assimilist-integrationist mantra that had been chanted for at least 100 years to justify government policy for the Maori people and to offer instead the dual concept of 'biculturalism and inclusion'" (Kawharu 2008:50). In Canada, the model seemed to work well from a Government point-of-view to give recognition to both the French and Anglophone Canadian population, thus it promised a model for co-existence of two cultures within one NZ nation.

Biculturalism is a challenging and highly contested concept in NZ. Although "[a] commitment to biculturalism has served as de facto Government practice since the late 1980s, following moves to acknowledge the Treaty as a founding document between partners" (Fleras/ Spoonley 1999:236), biculturalism is not always included in legislation. The term biculturalism is elusive and ambiguous, leaving space for misinterpretation (Sharp 1995). Likewise, the definitions and understandings of the principles of biculturalism vary enormously on a personal and institutional level (see chapter five).

Ballantyne (2012:60) argues that biculturalism was part of NZ's reimagining in the 1970s which was due to 'local developments' (political mobilisation of Māori) and 'global currents' (Britain joining the EEC in 1973). Biculturalism was both a radical step away from the assimilation policy and "a new approach to New Zealand's past: a Treatybased bicultural history" (Ballantyne 2012:60). In contrast Poata-Smith (1996:108) sees 
biculturalism as the "illusion of a partnership", including some Māori elites "while marginalising other, more radical demands". Biculturalism to date falls short of 'total decolonisation' (Awatere 1984) and might even have hindered Māori sovereignty (O’Sullivan 2007), however it "has become deeply entrenched in New Zealand public life" (Ballantyne 2012:60).

As a result of adopting a bicultural policy in 1984 (Poata-Smith 1996:108) NZ Government departments have become more 'user-friendly' and supportive of Māori culture on a symbolic level (Sissons 2005:80), mostly visible in official bilingualism; for example the inclusion of Māori names alongside the English names (such as Inland Revenue Te Tari Taake), the production of bilingual pamphlets, the display of Māori art within public buildings and the incorporation of Māori ceremonial rituals into official occasions. Although these institutional transformations have had positive spin-offs, namely employment opportunities for Māori, they have remained 'illusionary' for most Māori who are still at the periphery of political decision-making; in fact these changes created "new forms of oppressive authenticity" (Sissons 2005:80). Standardising the Māori language, for example, appropriates linguistic diversity, which might be "a small price to pay for greater recognition", yet "it is by no means an entirely innocent or positive development" (Sissons 2005:81). Dialogues between indigenous and postsettlers remain largely unequal exchanges, and biculturalism might be used to mask these inequalities or employed as 'window-dressing' (O'Sullivan 2007:30) for the state. Therefore, it is necessary to look "behind the masks of orthodoxy" (Sissons 2005:83) to see the real face of biculturalism, as I attempt in this thesis. If the socio-political climate in NZ and the rise of biculturalism as state policy were prerequisites for building TP, the radical transformation of the institution of the museum was no less important.

\section{The 'Museum Revolution'}

Museums in postcolonial countries worldwide undertook reforms in regards to their relationships with indigenous people and Government acts manifested these changes in legislation. McCarthy (2011:6) provides an overview of some international reforms that have had an impact on the museum sector: 
United States: Native Graves Protection and Repatriation Act 1990

Canada: Joint Task Force Report on Museums and First Peoples 1992

Aotearoa New Zealand: Mataatua Declaration 1993

Australia: Precious Possessions, New Obligations 1993, Continuous

Cultures,

Ongoing Responsibilities 2005

For lack of space I cannot discuss the implications of these changes in legislation in detail, but they are all evidence that issues of ownership, indigenous heritage and rights of self-determination have been addressed globally during the last twenty years. It should be noted that in many instances another twenty years of debate and lobbying predated these legal agreements. The changes that occurred in the political arena worldwide also happened in NZ at the same time. As a result, the institution of the museum was radically transformed in the 1980s with a demand for open access, a focus on audiences and new ways of exhibiting all referred to as the 'new museology'.

\section{The 'New Museology'}

Since the 1970s museums have been recognising their responsibility as an agent for social change within the nation state: "the museum [...] is or rather should be one of the most highly perfected tools that society has available to prepare and accompany its own transformation" (Varine 1985:4). The new museology promotes the idea of social inclusion in museums by using a multi-voiced approach, collaborating with audiences and consulting them about representation. Although the new museology is often seen as a 'new' phenomenon of the 1970s and 1980s, it "actually follows the tradition among museum people dating back to the nineteenth century of considering the museum as an educational institution in the service of society" (Hauenschild 1988:1). Varine (1976:127) notes that, "[a]t the center of this idea of a museum lie not things, but people". The concept of the new museology was made popular by Peter Vergo (1989) and led many museums to reflect on their role within society, and change accordingly.

TP embraced the concept of the new museology and has arguably been "the most farreaching experiment in new museological practices, and has correspondingly attracted the greatest attention" (Williams 2003:13-14). The authority, agency and ownership of 
museums and their collections, long taken for granted, have been criticised and became subject to change and ongoing debate. Hooper-Greenhill (1994:1) states the extent of the change museums went through:

The thrust of the shift is clear - museums are changing from being static storehouses for artefacts into active learning environments for people. This change in function means a radical reorganisation of the whole culture of the museum - staff structures, attitudes and work patterns must all mutate to accommodate new ideas and new approaches.

Museums, it was claimed, should be more inclusive, open to everyone and not only educational but also entertaining. This debate had an effect on many museums visible in the dropping of entrance charges and efforts to address new target audiences who were formerly marginalised. With this shift in museology TP's predecessor the National Museum in Buckle Street appeared very colonial, old-fashioned and static, hence it was felt that a new museum was needed. In the mid-1980s, the exhibition Te Maori ${ }^{35}$ marked the beginning of a new era for the relationships of Māori and museums in NZ. Te Maori experimented with new techniques for the display of taonga Māori and was groundbreaking in terms of indigenous control over their cultural heritage and perhaps provided a vision for TP (Hakiwai 2005), as discussed in the next section.

\section{The Te Maori Exhibition and Its Impact on the Museum Sector}

The evolution of NZ's museums and art galleries (Markham 1933; Thomson 1981; McCarthy/ Cobley 2009) and the detailed story of Te Maori have been discussed elsewhere (Mead 1986; McCarthy 2007a, 2007b, 2011). Therefore I will only briefly describe the 'quiet revolution' that the Te Maori exhibition initiated and its effects on museum practice.

Before Te Maori NZ museums housed Māori artefacts but showed little respect for cultural sensitivities in storing and exhibiting them. For example, tattooed heads, known as mokamokai or toi moko, were still exhibited in the 1940s; displaying their ancestors was insulting to Māori and kept many Māori away from museums (see Ranginui Walker in McCarthy 2011:27ff). Māori were suspicious of the museum as a

\footnotetext{
35 In accordance with the original exhibition title no macrons are added.
} 
'graveyard for taonga' and assumed that taonga in the collections were 'stolen'. ${ }^{36}$ During the 'Māori renaissance' Māori demanded ownership of and control over their cultural artefacts; at the same time museums aspired to be more accommodating of visitor needs in general and indigenous audiences in particular and started to collaborate with source communities.

The Te Maori exhibition toured the United States (New York, St Louis, Chicago and San Francisco) in 1984-85, before it returned to NZ in 1986 under the new title Te Maori: Te hokinga mai. The return home. Its international success drew 920,000 New Zealanders to visit the exhibition. Te Maori was seen as an advancement in the relationship between museums and Māori for two reasons: firstly Māori not only participated in the exhibition planning but were in a position of authority, and secondly, Māori artefacts were displayed as fine art rather than as 'curio' or ethnographic specimens (McCarthy 2011; Hakiwai 2005; Mead 1986). The recognition of Māori objects as taonga (treasures), living and breathing entities, was demonstrated by big opening ceremonies featuring karakia and kapa haka as well as specially employed Māori guides who interpreted the exhibition for visitors. According to Māori scholars Te Maori was a catalyst for Māori to rediscover their cultural heritage (Mead 1986) and engage with museums as equal partners; for the first time Māori had the power to "orchestrate and dictate the terms" (Hakiwai 2005:160) of exhibiting themselves.

Te Maori was the major catalyst for museum transformation in NZ and had many spinoffs that progressed institutional change, one being Māori staffing in museums. Before 1980 there were "[o]nly a lonely handful" (Tamarapa 1996a:161) of Māori staff in NZ museums - among them Mina McKenzie, who became the first Māori museum director at Manawatu Museum in 1978 (McCarthy 2011:41). A national training scheme to attract Māori to work in museums was set up in the early 1980s by Ken Gorbey, then director of the Waikato Museum (McCarthy 2011:42). The fact that many of the Māori staff who came into TP under this scheme still work there shows that the programme

\footnotetext{
${ }^{36}$ The general assumption that Māori artefacts were stolen is 'inaccurate' as most objects were in fact traded and "Māori elders may even have deposited taonga in museum collections with the express intention of sowing the seeds for later maintenance and revival" (McCarthy 2011:31).
} 
has indeed been successful. One of them was Shane Pasene who remembers vividly when Te Maori came to Buckle Street:

At that time there was a bit of a ground swell. You were starting to get in more Mãori people and [...] you could really put [it] down to Te Maori, [which] opened those doors, because of all that interaction. Te Maori was at Buckle Street and we had these iwi coming in and it was amazing to see these iwi on the paepae, handing over the paepae to the other one, all these challenges going out, doing hakas to each other, waiata, whaikōrero. So it was quite dynamic, something that you'd never get at the National Museum. So at the time it was - it's hard to explain really - certainly different. Mãori wasn't seen as a major part of the National Museum [before the Te Maori exhibition].

Carolyn Roberts-Thompson, another contemporary witness of Te Maori and long-term member of TP's staff, suggests that Te Maori created “this hype of activity and encouragement from lots of different tribal members and leaders in the country for Mãori to actually take up studying in that field", which brought her into the museum sector. The significance of Te Maori for Māori people is expressed in the following waiata Whakataurangi Ake by Pumi Taituha (Ngāti Maniapoto). ${ }^{37}$ When he viewed Te Maori, the "taonga on display especially Uenuku"38 impressed him so much, that this experience inspired him to "create this waiata to commemorate [the taonga]". It was first sung "when Tainui Waka took over tangata whenua status at Te Maori in 1987". In January 2012 it was sung again by TP staff and representatives from Tainui at a repatriation pōwhiri. ${ }^{39}$

\footnotetext{
${ }^{37}$ All references to this waiata are taken from a song sheet handed out by the Tainui iwi kaumātua to TP staff at waiata practice in January 2012.

38 Uenuku is currently on display in the Tainui exhibition at TP. See more about Uenuku who is worshipped as an atua by Māori in chapter four where I discuss tikanga Māori in museum conservation. ${ }^{39}$ I use the term 'pōwhiri' the way it is used at TP for ceremonies on the marae, including tangi and repatriations. As Anne Salmond (2009 [1975]) writes, these are 'rituals of encounter' and usually the first part of hui.
} 


\begin{tabular}{|l|l|}
\hline Whakataurangi ake & My unsatisfied longing \\
Te here i taku ate & Fills my heart \\
Pupu ake nei & Giving way to \\
Te mauri o te aroha & The spirit of sorrow \\
& As a bridge to those \\
Hei hongonga ki te iwi & That have disappeared \\
Kua whakangaro & To the night \\
Ki te pō & To the dark night \\
Te pō uriuri & To the night of no return \\
Ki te pō i oti atu & \\
Kei ngā whakaoati i herea & The binding oaths \\
Ki te rangi & To the heavens still stand \\
Hei huarahi atu & As a pathway for us \\
Tīhei mauri ora! & It is life! \\
\hline
\end{tabular}

Some argue that TP was "the offspring of Te Maori" (McCarthy 2011:96). It certainly was a 'brain-child' of the 1980s, reflecting not only the socio-political climate but also the neoliberal shift in the NZ economy. This climate of political change and a radical rethinking of the museum as a national institution became a fertile seed-bed for building TP as a 'state experiment': "All that was missing was a symbol to express all of this" (Williams 2006b:1).

TP was developed precisely to fill this void, as the "revalued Maori culture and emergent postcolonial Pakeha culture were the basis for the vision of a national bicultural institution" (Williams 2006b:2). TP could act as a waharoa (Puklowski 2011) for New Zealanders and international tourists, as well as being both 'customer focused' and 'commercially positive' (Corporate Principles, Annual Report 2007/08:14). While these cultural and economic policies do not necessarily oppose each other, Williams (2006b:4) emphasises the drive to make money: "The museum meant business, and Maori and Pakeha cultural identities were its assets". While neoliberal economics certainly had an impact on NZ identity and the making of TP, I suggest that other factors were more important, primarily the visions and influence of a number of powerful and well-connected individuals. In the following section I analyse how TP was constructed. 


\section{Constructing Te Papa}

In this section I explore how TP was conceptualised and constructed, including the shift from the 'old' to the 'new' museum, TP's architectural concept, and opening day celebrations. To start with I present an oral history, collected through interviews with contemporary witnesses in the making of TP.

\section{Making Te Papa: An Oral History}

In contrast to the 'official history' and 'top down' legitimisations for biculturalism, Ken Gorbey (Director of Museum Project 1992-1999) argues that it was a 'bottom-up triumph' closely connected to personalities: "That's the other side of biculturalism, that perhaps people need to look at more, it's the personal element". ${ }^{40}$ Gorbey suggests that the seed for building TP in the 'spirit of biculturalism' was planted long before the planning phase began in 1984 under Māori MP and Minister of Arts Peter Tapsell. ${ }^{41} \mathrm{~A}$ new generation of Māori and Pākehā academics and revisionist historians challenged their students to "come up with an alternative view to this perfect utopia called New Zealand", by their own account. In turn, these students, including Gorbey himself and others, such as David Butts, occupying key positions at regional museums, transformed these "heavily paternalistic" institutions into facilities by and for all New Zealanders, including Māori. Putting the radical ideas of their academic teachers into practice, "we created museums according to what we had heard in our university lectures with great naivety". The collaboration and negotiation processes they initiated with the local iwi were exemplary (see Butts 2003 for Wanganui and Tairawhiti museums; McCarthy 2011 for a complete record of these revolutionary acts around NZ museums). It was grassroots movements at small, provincial museums that paved the way for the shift at the national museum.

\footnotetext{
${ }^{40}$ All quotes are taken from my interview with Ken Gorbey (2 February 2009), unless stated otherwise. 41 "From 1984 to 1987 he was Minister of Internal Affairs, of Civil Defence, and for the Arts, and Associate Minister of Local Government and of Tourism." Sir Peter Tapsell was also the first Māori to become speaker of the House of Representatives in 1993. http://www.parliament.nz/enNZ/PB/Debates/Debates/4/d/7/50HansD 20120501 00000004-Obituaries-Hon-Sir-Peter-WilfredTapsell.htm (accessed 3 November 2012).
} 
According to Gorbey it was the Fourth Labour Government under David Lange in 1984 that dreamt up the idea of a 'Pacific cultural centre', then to be called 'Te Marae $o$ Aotearoa': "Peter Tapsell laid it on the line, he had said it shall be a bicultural institution. He didn't particularly go on and say what biculturalism would be. Because the Labour Government themselves were struggling with it." Because Tapsell did not specify what biculturalism would look like, Gorbey and Cliff Whiting (Kaihautū 1995-2000) "had to find out what that was." Both believed that biculturalism "is a statement in terms of [Māori] sovereignty" and involved iwi from the outset to "establish a relationship with them." Again, TP's development did not occur in isolation, as other institutions also adopted a bicultural model around that time, particularly Government departments, and the Anglican Church. ${ }^{42}$ However, TP was in the unique situation of being rebuilt from scratch and thereby able to integrate biculturalism better than other institutions.

A commitment to biculturalism featured early on in the making of TP. According to Whiting, "[o]ne of our first priorities was biculturalism. That was number one". However, developing TP's concept and putting it into operation was not a straightforward process. In 1988 Sir Wallace (Bill) Rowling, former prime minister (Labour 1974-75), was appointed as the chairman of TP's Development Board. The documentary film Getting to Our Place (Cottrell/ Preston 1999) gives an excellent insight into the lively discussions and cultural clashes that preceeded the birth of TP. A new understanding emerged among the project team, as Gorbey states: "The museum is part of the fabric of its own society, therefore it must reflect that society". The resulting 'customer focused approach' was not to everyone's liking; Gorbey remembers the reaction of Sir Wallace Rowling to making TP an inclusive museum: "[he] was terribly worried that we were bringing in the riffraff which of course we were. All New Zealanders, you know, includes the riffraff".

Developing TP's underlying principles, management adopted a new collection policy mana taonga - that gave Māori ownership over their taonga and saw the museum as guardian, as Cheryll Sotheran (first CEO 1993-2002) recalls:

\footnotetext{
${ }^{42}$ In 1992 the Anglican Church of Aotearoa, New Zealand and the Pacific allowed the three partners to order their own affairs under tikanga Māori, tikanga Pākehā, and tikanga Pasefika. Within New Zealand this means the church adopted a bicultural framework with a Māori and Pākehā diocese and bishops respectively. http://www.anglican.org.nz/About (accessed 5 November 2012).
} 
[W]e actually recorded in our collection policy that we did not own the Māori collections, we held them in trust and of course no other museum in the Western world would do that, because they'd say "they'll come and take them back" and I said, "if we cannot be a trusted partner to look after them properly - and that means putting them in the right context and telling stories that the iwi tells - we shouldn't have them". That was a hugely tough concept for my Board to accept and I don't think they ever fully did, but it's in there and in that spirit all the exhibitions and the taonga were driven by iwi, not by curators in the museum.

This shift was crucial at a time when iwi discussed repatriation, establishing their own cultural centres and considered boycotting NZ museums. Perhaps a bicultural concept was not so much a choice but a necessity, because if Māori were not included as equal partners, "there was talk of 'we'll have a separate Māori museum' and there was some people saying 'we're going to take our taonga out!'”, as Whiting remembers. With this threat by Māori in mind, adopting a bicultural model could be interpreted in hindsight as a concession to secure the Māori collections and prevent an autonomous Māori museum. Nevertheless, what Sotheran honestly envisioned was nothing less than genuine partnership: "it was not a matter of consultation, it was a genuine matter of shared power in a partnership [...] It certainly wasn't a soft, politically correct relationship [...] it wasn't warm and fuzzy, it was tough stuff!"

The bicultural concept was a challenge for NZ society, because biculturalism does not necessarily mean anything to many New Zealanders, as Gorbey observed: "there are elements of New Zealand society that just do not live biculturalism. When Mrs. Smith opens a dairy on the corner of the road, she's probably not too concerned about biculturalism". For Pākehā there is little need to be bicultural in their everyday life, whereas for most Māori it is an integral part of their lives, being surrounded by Pākehā culture and the English language. TP's tangata whenua and tangata tiriti concept was developed as a way around the problem of the status of non-Māori in a bicultural 'Aotearoa New Zealand', but it was contested and quite revolutionary at the time:

you've got to realise that at the time that Te Papa was being developed, there was a high degree of hostility in the community to an emphasis on Mâori things. And also a good deal of suspicion about the degree of immigration coming into New Zealand. So people were very keen that Te Papa be a celebration of Pākehā culture, $y^{\prime}$ know, old white New Zealand culture. (Jock Phillips, Conceptual Leader History 1994-1998) 
The biggest hurdle was not to convince TP's staff of the importance of biculturalism, but the general public. As Sotheran states, the most challenging factor was

[s]uspicion out there in the community. The Dominion [Post] right up until the time we opened ran a campaign that we were just trying to turn it into a Mãori museum, which was in some way a pejorative [campaign]. In my view it was racism, institutional racism pure and simple. You couldn't dress it up as anything else.

Most importantly, as Gorbey states, TP was "an institution which was essentially about experimenting with a new New Zealand culture". This is backed by Sotheran who stressed that the brief was to "establish what a bicultural museum in a bicultural nation would look like". Thus, this evidence suggests constructing TP was a bicultural experiment that was supposed to be an expression of biculturalism as state ideology with the goal of educating the NZ public, but more importantly, offering a conceptual framework for what it means to be a bicultural institution.

\section{Reaction from New Zealand Public: Te Papa, a 'State-Prescribed' Educator?}

TP was not a reflection of the NZ society of the time, but an aspiration for the future, as biculturalism then and now is not a reality of everyday life in NZ. In fact, some members of the public see TP as a state-prescribed remedy to pursue a bicultural agenda and educate the public.

Rosemary McLeod (2013) in her Dominion Post newspaper column complained that "Our Place (Pakeha-speak for TP) was never really our place. It has always been 'Their Space'”, although she leaves open whether she is referring to 'the museum experts' or 'Māori and Pacific cultures'. The reason for the discrepancy between TP's intention and visitor perception lies in TP's conception which avoided any input from the public, according to McLeod (2013):

[Bill Rowling] explained the great triumph had been having no public consultation to stuff things up and perhaps force compromise on his eager team. And that's how you get to Their Place. We had no ownership of it, other than through our pockets, but we would be made to like it by being told it was good for us. It was as if your parents chose your boyfriend.

This statement highlights the many problems connected with TP's mandate to educate New Zealanders and incorporate the state-prescribed bicultural agenda so the public 
could not ignore it. In order to understand the far-reaching implications of TP's development as a different kind of museum we need to revisit the 'old museum' in Buckle Street.

\section{Remembering Buckle Street}

The history of TP's precursor begins in 1865 with the opening of the Colonial Museum, near the Parliament Buildings in Wellington. In 1936 the Dominion Museum moved into a neoclassical building in Buckle Street, which housed the National Art Gallery as well as the museum.

There are a number of TP staff who worked at 'the old museum', as they call it, in Buckle Street. In their narratives they talk about TP "as antithesis of the authoritarian museum on the hill" that Buckle Street used to be. Given the tremendous changes the institution went through this is not surprising. Remembering the 'old museum' they often describe the 'stuffy' atmosphere, the cluttered collection rooms, the white middle-class visitors and the dated displays as a stark contrast to the buzz and interactivity of TP today. I never had the opportunity to visit 'the old museum' at Buckle Street, but Shane Pasene (Conservation Technician and longtime staff member) brings it to life with the following words:

It was very - what would you call it? - Ethnocentric! Like I said, Mãori came under ethnology at the time [...] You had everything in glass cabinets, showing how Māori made hāngi at that time, how they did bird snares, the Mãori 'as they were,' very much that sort of thing. There was no interaction. I mean you didn't have guides, you had security guards and all their purpose was to make sure people don't steal anything, so they weren't interacting with the crowds.

Pasene emphasises two major changes: a museological shift from displaying Māori culture ethnographically as a 'dying race' to exhibiting them as a 'living culture', and the introduction of hosts as the 'face of Te Papa' interpreting the museum to visitors and therefore museum staff being a vital part of the visitor experience. 
Box 14: Buckle Street 'old museum' vs. Cable Street 'Te Papa'

\begin{tabular}{|l|l|l|}
\hline & Buckle Street 'old museum' & Cable Street 'Te Papa' \\
\hline Governance & single director & dual leadership: CEO and Kaihautū \\
\hline Institution & museum and art gallery separate & museum and art gallery converged \\
\hline Costumer service & security guards & hosts \\
\hline $\begin{array}{l}\text { Exhibition } \\
\text { techniques }\end{array}$ & $\begin{array}{l}\text { glass cabinets } \\
\text { diorama displays } \\
\text { object-driven exhibitions } \\
\text { single voice }\end{array}$ & $\begin{array}{l}\text { hands-on exhibits } \\
\text { interactives } \\
\text { narrative-driven exhibitions } \\
\text { multiple voices }\end{array}$ \\
\hline Staff & few Māori staff & significantly more Māori staff (12\%) \\
\hline $\begin{array}{l}\text { Source } \\
\text { Communities }\end{array}$ & museum as authority & $\begin{array}{l}\text { communities exhibit themselves } \\
\text { (community gallery, iwi gallery), mana } \\
\text { taonga principle, iwi in residence }\end{array}$ \\
\hline
\end{tabular}

It was no easy task, changing the organisational culture among the museum workers to take them along on the 'huge leap' and transformation that was to come. Sotheran encouraged everyone to see it as an "opportunity, get on the waka because it's such a fantastic ride", but staff who did not fit in with the new museum found themselves marginalised or left out. With the old museum still open while TP was under development, Sotheran realised the mixed messages this sent to the public: "I had to close the museum on the hill much earlier and that was not so much an issue of resource but an issue of image. That its image was so different and its attitude was so different from what we were trying to create, this was proving to be a sheet anchor".

The physical move marked not only a shift in location but a major shift in museology. For the Wellington public this shift was made visible through the moving of taonga: streets would be closed for museum staff and iwi carrying taonga to the new museum accompanied by Māori warriors in traditional costumes. The following quote illustrates how the positioning of Māori in the new museum was physically enacted in the public sphere through Māori performances. Sotheran recalls that Māori, who were formerly marginalised in the museum, took on an important ceremonial role:

[T] hose rituals coming down from Buckle Street, it was like coming from the old to the new, but in a funny kind of way. For Mãori, it was like coming from the lack of ownership, the 'bad old' to the ownership in the new. And they took it so seriously that when we brought the waka down, which is a waka taua, which is a war canoe, and [...] Whanganui iwi brought it down, the whole idea of utu [compensation; revenge], which is of course embedded in the concept, was so strong that some of the Whanganui warriors actually attacked one of the cameramen in the crowd. It was incredibly powerful and dramatic. 
When TP was constructed between 1994 and 1998, the concept of biculturalism was literally built into its architecture, governance structure and day-to-day operation. When the 'old museum' at Buckle Street outgrew its capacity for exhibition space and collection store rooms, a new location was sought and found on the waterfront. The new building adds an iconic feature to the capital's townscape that was a lynchpin of the city's tourism strategy. There were many overlapping interests in creating a new museum to express a new national identity: to celebrate diversity, showcase NZ to the world and pay tribute to the Treaty as well as to promote Wellington as a tourist destination.

\section{Architecture and Space}

The rather unique situation to 'start from scratch' was an excellent opportunity not only to expand the exhibition and collection space but also to cement some of the newly developed museum concepts into the architecture. The building itself was designed by Auckland company Jasmax who won the initial competition and developed the building together with the Project Development team. It is not without irony that TP, the bicultural experiment, was set on reclaimed land that had to be compacted down first before it was stable enough to hold the national museum - and yet it still stands on shaky ground, literally and symbolically, in a city divided by the earthquake fault line. Aspirations for the new building were high, as Pete Bossley (1998:2), one of the architects notes:

[The design for Te Papa] powerfully express the total culture of New Zealand' and represent the 'bicultural nature of the country, recognising the mana and significance of each of the two mainstreams of tradition and cultural heritage, and provide the means for each to contribute effectively to a statement of the nation's identity'. [...] 'in all it does [it would] honour the principle of Te Tiriti o Waitangi the Treaty of Waitangi.

However, this client-produced brief proved to be challenging as Bossley (2008:90) remembers ten years after the opening: "There was input from all around the world and all round the country. The iwi groups and every cultural group had a crack at it - the government and local councils, everyone wanted to have a go." The finished building spans over 36,000 square metres of public floor space on six levels, which can be roughly divided into commercial opportunities on level 1, Papatūānuku (natural environment) on level 2, human impact on the environment on level 3, NZ cultures on 
level 4 and art on level 5 and 6 (see floor maps, Appendix 1). One of the key features is a vertical core through the middle of the building from the foyer to the ceiling representing 'the void' (or ihonui) and linking the floors visually. In addition to the exhibitions, TP houses a theatre for 350 people, several function rooms, two cafes, a gift shop, a children's store and a library front-of-house.

Right from the start the bicultural concept was a project priority and was to be reflected in the architecture of the building. It is a striking feature that the tangata whenua exhibitions are located at the harbourside of the building facing the rising sun, whereas the tangata tiriti exhibitions, reflecting the "pluralistic New Zealand side" (Ken Gorbey) are situated on the city side. This division was inspired by the settling patterns of Māori and Pākehā and create axes that run from 'city to sea' and 'from urban to natural' through the museum (Bossley 1998:10). The space that both divides and brings together the two mainstream cultures is a wedge-shaped exhibition area in the middle called Signs of a Nation representing the Treaty (see photo in Appendix 11). As it opens to the core of the building it also acts as a link to the natural environment section below. While cleverly planned, these layout features go largely unnoticed by the ordinary visitor as there is little signage explaining the architectural vision. ${ }^{43}$ Some of my participants did however refer to the architectural features when asked about bicultural aspects of TP. The most prominent and important bicultural space is Te Marae which is both a permanent exhibition and a functioning marae. I elaborate further on the challenges of developing Te Marae in a case study later in this chapter.

At opening day on 14 February 1998 the bicultural spirit was expressed in a Māori dawn ceremony, a culturally diverse programme with musicians and dance groups including kapa haka, and most importantly, a huge range of visitors who came to view 'the spectacle of ourselves' (Williams 2003) or how the 317 million NZD (Cottrell/ Preston 1999) of taxpayers' money had been spent. The new museum was officially opened by prominent New Zealander Sir Peter Blake and two children, one Pākehā and one Māori (Whiting's grandson). Richard Wright, a Māori staff member who was the

\footnotetext{
43 In my casual job as a research assistant conducting visitor exit interviews for TP's Visitor and Market Research Team I had the opportunity to talk to several hundred visitors over the years. Very rarely did visitors pick up on the concepts underlying the architecture. Almost all first-time visitors however, had difficulty navigating their way through the Museum and found the layout disorientating and confusing.
} 
Manager of the Project Office's Visitor Centre, took the day off work to be part of the crowd:

[It] brought a tear to my eye when I walked in and I saw Polynesian people sitting up in the Polynesian exhibition. A lot of Mãori people going over to the Mãori exhibition. [...] People [...] lined up for three hours to come into the museum, so just fantastic, looking up and seeing Museum of New Zealand Te Papa Tongarewa, that sign up there saying to people, 'hey come and look at your treasures'.

\section{PART II: FRAMING BICULTURALISM AT TE PAPA}

In this section I consider how biculturalism was built into TP internally, examining the framework of policies and concepts that guide museum practice and TP's governance structure. Furthermore, I give a brief overview of the front-of-house exhibitions and look at TP's marae in particular.

\section{Policy}

It took thirteen years from the initial concept to the opening of the new national museum. Following the 'Nga Taonga o Te Motu' report in 1985, the Project Development Team was formed in 1988. They formulated the concept in 1989 (revised in 1992) which climaxed with the opening in 1998 (McCarthy 2011:96). The Museum of New Zealand Act 1992 (the Act thereafter) required TP to be inclusive of the ethnic and cultural diversity of the peoples of NZ, including Māori. Interestingly, the wording of the Act does not mention biculturalism or the Treaty at all.

Box 15: Section 4, Purpose of the Act: 44

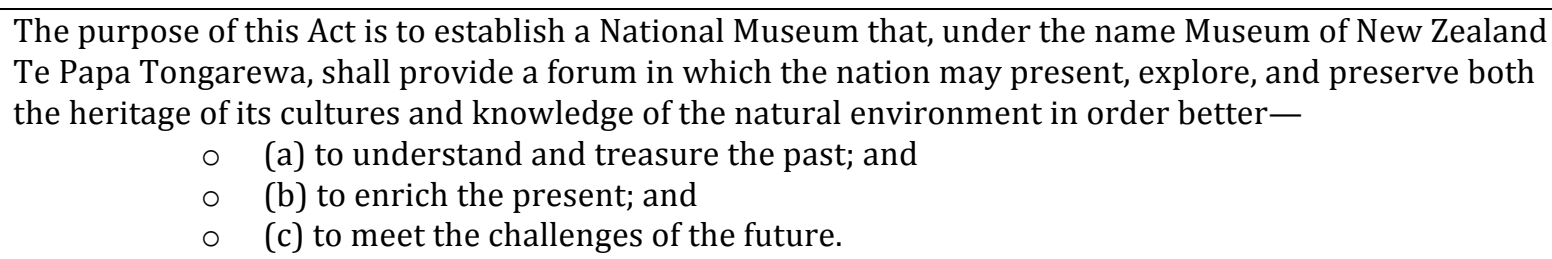

Source: The Museum of New Zealand Act 1992.

${ }^{44}$ http://www.legislation.govt.nz/act/public/1992/0019/latest/DLM260221.html\#DLM260221 (accessed 22 December 2011). 
However, TP's official publications ${ }^{45}$ and 'grey literature' 46 leave no doubt that it is a bicultural institution and state "Te Papa is bicultural" as the first corporate principle (Statement of Intent 2005/08:2).

Box 16: Corporate Principles

\begin{tabular}{|l|l|}
\hline Te Papa is bicultural & $\begin{array}{l}\text { Te Papa values and reflects the cultural heritage } \\
\text { and diversity of Tangata Whenua and Tangata } \\
\text { Tiriti. }\end{array}$ \\
\hline Te Papa acknowledges Mana Taonga & $\begin{array}{l}\text { Te Papa recognises the role of communities in } \\
\text { enhancing the care and understanding of } \\
\text { collections and taonga. }\end{array}$ \\
\hline Te Papa speaks with authority & $\begin{array}{l}\text { All of Te Papa's activities are underpinned by } \\
\text { scholarship drawing on systems of knowledge } \\
\text { and understanding, including mātauranga Māori. }\end{array}$ \\
\hline Te Papa is a Waharoa & $\begin{array}{l}\text { Te Papa is a waharoa (gateway) to New } \\
\text { Zealand's natural and cultural heritage and } \\
\text { provides a forum in which to explore and reflect } \\
\text { our national identity. }\end{array}$ \\
\hline Te Papa is committed to excellent service & $\begin{array}{l}\text { Te Papa seeks to meet the needs and } \\
\text { expectations of its audiences and communities. }\end{array}$ \\
\hline Te Papa is commercially positive & $\begin{array}{l}\text { Te Papa seeks to achieve successful financial } \\
\text { outcomes and offers experiences and products } \\
\text { that contribute to the sustainability of the } \\
\text { Museum. }\end{array}$ \\
\hline
\end{tabular}

Source: Annual Report 2007/08:14) ${ }^{47}$

The bicultural policy, first adopted in 1994 and reviewed in 2002, establishes the strategic framework in the following words:

45 “Te Papa is New Zealand's national museum, renowned for being bicultural, scholarly, innovative, and fun. Our success is built on our relationships with and ability to represent our community" http://www.tepapa.govt.nz/AboutUs/Pages/AboutTePapa.aspx (accessed 8 November 2012); "Mehr als alles andere bringt der marae das bikulturelle Prinzip Te Papas zum Ausdruck [The marae expresses Te Papa's bicultural principle more than anything]" (Te Papa Mehr als ein Museum! [Te Papa More than a museum] brochure in German); “Te Papa's modern, interactive, and narrative-based approach has attracted worldwide attention, as has its commitment to biculturalism" (Te Papa Explorer:25).

46 'Grey literature' is defined as printed material that is not published and might therefore lack basic information like author or date. Often these documents are only circulated internally (reports, e-mail notifications, 'Kupenga' - Te Papa Intranet etc.) and not produced with the public in mind, but many of them are accessible through Te Aka Matua, the TP library.

${ }^{47}$ http://tepapa.govt.nz/SiteCollectionDocuments/AboutTePapa/LegislationAccountability/Annual.Repo rt.20072008.pdf (accessed 19 December 2011).

These corporate principles were valid up until the Annual Report 2008/09 when the order of them changed. "Te Papa is a Waharoa", formerly number four, became the first corporate principle, while "Te Papa is bicultural" fell into second place (see Annual Report 2008/09:12) http://tepapa.govt.nz/SiteCollectionDocuments/AboutTePapa/LegislationAccountability/TePapaAnnual Report2008-09.pdf (accessed 19 December 2011). 
Biculturalism at Te Papa is the partnership between Tangata Whenua and Tangata Tiriti recognising the legislative, conceptual and Treaty framework within which the Museum operates as well as reflecting international developments. This framework provides the mandate for the Museum to express and celebrate the natural and cultural diversity of New Zealand. It acknowledges the unique position of Maori in Aotearoa New Zealand and the need to secure their participation in the governance, management, and operation of the Museum of New Zealand Te Papa Tongarewa. ${ }^{48}$

Not only does the policy acknowledge the Treaty, but also the 'unique position of Māori' in NZ; using the parameters of tangata whenua and tangata tiriti it creates a binary that sees Māori on one side, with all other ethnicities included on the other. The policy frames TP's operation as a bicultural partnership and envisions that biculturalism permeates every aspect of the institution. The policy document states how the policy will inform bicultural practices across TP:

- Te Papa's Collections, in the acquisition, management, conservation and study of the collections;

- The Te Papa Experience, in providing a diverse and changing programme of integrated activities and programmes founded on scholarship and mātauranga Māori;

- Te Papa in the Community, through National Services, community and iwi partnerships, and sharing the Te Papa experience; and

- Reflected internally in Te Papa's organisational capability, leadership structure, and decision-making and policy development processes.

The three divisions that formed the concept in 1989 and still organise the layout of the exhibitions today are Papatūānuku, tangata whenua and tangata tiriti; that means that the Museum space is divided into natural environment, Māori and non-Māori exhibitions. The fact that the chosen terms are in te reo Māori, like the name of the museum 'Te Papa Tongarewa' meaning 'treasure box', ${ }^{49}$ are further evidence of the will to integrate Māoridom. Whiting reminds us that although inscribing the philosophy into policies is very important, it is people who act on it: "It's all very well writing a whole lot of policies, but if you don't have people to make those things work, it's a pointless exercise,

\footnotetext{
48 Museum of New Zealand Te Papa Tongarewa Bicultural Policy, Kupenga - Te Papa Intranet (accessed 1 December 2010).

49 TP's full name is Museum of New Zealand Te Papa Tongarewa often shortened to the brand name Te Papa. The Māori word Papa refers to Papatūānuku, Mother Earth as well as to Papahou, a carved treasure box, while Tongarewa is rare type of precious greenstone, but refers to any kind of treasure. Therefore the name can be translated to 'our container of treasured things and people that spring from Mother Earth here in New Zealand' or simply 'treasure box'. http://tepapa.govt.nz/AboutUs/history/Pages/MeaningofTePapaTongarewa.aspx (accessed 1 December 2011); personal observation on several TP introduction tours in 2010.
} 
so things like staff relationships, you know the human resource area, is absolutely vital to our work".

\section{Taonga, Mana Taonga and Mātauranga Māori}

A major shift for the relationship of Māori and museums in NZ was adopting the Māori concept of taonga for museum objects. According to Mead (1986:77f) taonga have a 'religious quality' as they present a 'mythical link to the past'. For Māori they are not just inert artifacts representing the ancestors, they are the ancestors and therefore are treated with love and respect, talked to, sung to, embraced and wept over. Taonga embody mana intrinsically through spiritual power and age, as well as contributing mana to the group who owns it. With this animistic belief comes a duty to perform certain protocols and rituals which must be carried out properly to control the spiritual powers that can endanger visitors and museum staff (see Tapsell 1998). Failure to do so might have serious consequences: "people become sick, they have accidents or they may die" (Mead 1986:78).

The Te Maori exhibition (see earlier in this chapter) was a watershed for NZ museums to acknowledge Māori concepts and change their practices accordingly. ${ }^{50} \mathrm{~A}$ paradigm shift in NZ museums saw the concept of taonga central to how Māori artefacts are treated, handled, accessed and displayed. Taonga, often translated as 'treasures', comprises an array of meanings that cannot be described with one English word; taonga can be man-made objects but also oral traditions like waiata and te reo Māori. ${ }^{51}$ Taonga have a spirit, they are alive and therefore need to be nourished; they link the past, present and future; they are ancestors or relatives of living Māori; and they have mana and mauri. McCarthy (2007a; 2011) documents how the notion of taonga changed over time from describing 'goods' or 'property' in the 19th century to the current understanding of them as a 'highly prized object' (Mead 2003), and in Anne Salmond's

\footnotetext{
${ }^{50}$ However, it was by no means the first or only recognition of Māori in the New Zealand museum sector (see McCarthy 2007a, 2007b).

51 In 1985 the Waitangi Tribunal acknowledged that te reo Māori is a taonga and therefore the Government is obliged to protect it, consequently te reo Māori became an official language in New Zealand in 1987, http://www.nzhistory.net.nz/culture/tereo-introduction (accessed 12 June 2012). 
words a "fixed point in the tribal network of names, histories, and relationships' (Mead 1984:118).

The principle of mana taonga acknowledges the authority of people who are connected to TP through collection items or taonga (Annual Report 1995:16), passing the authority that is usually held by the local iwi Te Âti Awa who are the rightful tangata whenua of the land that TP stands on, to all people who have a connection to objects in the TP collection, regardless of their ethnicity. TP explains this principle as follows: ${ }^{2}$

That 'Te Papa Acknowledges Mana Taonga' is one of six corporate principles informing the philosophy of Te Papa. Mana Taonga is a recognition of the power of taonga to communicate deep truths about our people. Te Papa also 'recognises the role of communities in enhancing the care and understanding of collections and taonga.' Taonga in this sense embraces any cultural items of significance or value. The Mana Taonga principle guides our direction and approach to access and research.

The mana taonga principle is crucial at TP as it defines the relationship with the source communities as well as museum practice in the collection storeroom and is recognised by TP in numerous ways: people have privileges such as access to their taonga, the right to stand on Te Marae, and are consulted before treatments, loan agreements or photography is carried out. In the exhibition E Tu Ake - Standing Strong' (2011) a caption explains TP's acknowledgment of taonga Māori and the mana taonga principle:

At the heart of Te Papa's national collections - of art, history, natural history, and Pacific cultures - is its collection of customary and contemporary taonga Māori (Māori cultural treasures). For Mãori, these taonga are more than objects. They are sacred links with the past - a past that is alive in the present and guides Mãori towards the future.

Acknowledging this, Te Papa practises the principle of mana taonga: the museum holds taonga on behalf of iwi (tribes) and Māori communities, who actively contribute to their research, care, management and presentation. Te Papa is thus a place in which Māori can exercise tino rangatiratanga.

Lastly, at TP the concept of mātauranga Māori, meaning the Māori knowledge system or view of the world (Mead 2003; Royal 1998), is considered valid and equal to Western, scientific philosophy.

${ }^{52}$ http://www.tepapa.govt.nz/ResearchAtTePapa/Research/TaongaMaori/Pages/overview.aspx (accessed 6 November 2012). 


\section{Governance}

$\mathrm{TP}$ is an autonomous Crown entity and the only NZ museum that receives state funding. ${ }^{53}$ This makes it very much a Western museum and I argue that the governance structure reflects this. The Museum is governed by the TP Board consisting of eight members who are appointed by the Minister of Culture and Heritage. Because the Board members are selected for their skills and expertise rather than ethnic identity, Māori representation is not structurally guaranteed. Therefore, the Board "didn't totally reflect the huge shift that we made at the management level", former CEO Cheryll Sotheran points out. While Dr Api Mahuika (Board member and head of the Māori advisory group Ngā Kaiwawao) and other Māori representatives were involved in the making of TP and held hui around the country to ensure Māori input for the TP project (McCarthy 2011:96), this high Māori representation at governance level was discontinued after TP opened. Nevertheless, Mahuika (1991:10) confirmed the support TP received at the time from Māori: “Te Papa Tongarewa is seen by Māori as the first physical demonstration of a bicultural approach to taonga and, therefore, a first step towards the recognition of Māori values".

Some are critical that Māori are underrepresented in the governance of TP and the local iwi, Te Āti Awa, does not have a say at the Board table (see Butts 2003 Appendix 1; Tapsell 1998:28; McCarthy 2011:117f). In the past the Board has had up to four Māori trustees, while only two self-identified Māori serve on the current Board. ${ }^{54}$ The lack of Māori representation might be the reason why “[t]he Board doesn't get terribly involved in some of that stuff [tangi; bicultural events]", as former Board member Sue Piper points out, "I mean there's nothing about the way the Board meets that suggests it's a bicultural institution."

\footnotetext{
53 TP is primarily funded by revenue received through the NZ Crown (about 24 million NZD in 2009) but TP generates the other half of its total budget (52 million NZD in 2009) through sponsors and a number of commercial products and revenues, like the TP car park, store, kids store, function venues, tours, rides, image service among others (see Annual Report 2008/ 09). General admission to the Museum is free, but visitors have to pay for some short-term exhibitions and can make donations.

${ }^{54}$ http://tepapa.govt.nz/AboutUs/Pages/organisationstructure.aspx (accessed 13 December 2011).
} 


\section{CEO and Kaihautū}

In contrast to TP's Board, the dual leadership model of CEO and a Kaihautū suggests the sharing of power and resources. 55 This shared leadership between the Māori and Pākehā director expresses the value biculturalism receives at TP not only symbolically but in terms of power. As far as co-management practice in museums goes, TP's dual leadership model is one of the most far reaching, making an attempt to include Māori in all hierarchical levels of the institution, even at the top. ${ }^{56}$

The term Kaihautū refers to the person who makes everyone paddle to the beat in a waka or canoe and is an expression of a Māori world view as former Kaihautū Te Taru White explained:

Kaihautū, when you break it down, means - kai is an action word, hau is the wind and tū is to stand. So conceptually in the journeying of our canoes across the oceans you would see representations of the person standing in the middle going: "Forward, folks!" you know, "Charge! West, kaihautees!" leading, the direction-finder for the tribe. And so in that context I was the direction-finder for bicultural evolution, the cultural evolution of Te Papa.

At TP the Kaihautū is supposedly making all decisions in conjunction with the CEO and ensures that the needs of iwi as source communities and Māori staff are met. Although the positions appeared to be equal until very recently (2012; see chapter five) on TP's organisational structure chart, staff I interviewed often questioned the power balance and sincerity of the partnership between CEO and Kaihautū. Their main point of concern was the fact that the CEO reports directly to the TP Board, whereas the Kaihautū reports to the CEO. As one Pākehā staff member remarked, it is "not really very equal when the other person is actually your boss". I will analyse power-imbalances further in chapter five.

\footnotetext{
55 Models of shared leadership are quite rare in NZ, however the Green Party is run by a male and a female leader, and since 1992 the Anglican Church of Aotearoa, New Zealand and Polynesia acknowledges three strands in its decision-making processes, namely tikanga Māori, tikanga Pākehā and tikanga Pasifika. The fact that the CEO and Kaihautū model in this form is unique to TP brings its challenges "as there is no roadmap" (Michelle Hippolite interview).

${ }^{56}$ Saying that, other New Zealand museums have demonstrated power sharing with iwi in other forms to a great extend. See for example the governance arrangements for the Whanganui Regional Museum and Tairawhiti Museum.
} 
It is crucial to acknowledge that the relationship between the CEO and Kaihautū is by no means just a structural, but also a personal relationship, very much influenced by the personalities and biographies of the people holding these positions. When I talked to Sotheran, she suggested that her upbringing in remote, Māori-dominated communities where her parents were teachers at so called 'native schools' prepared her for her role as first CEO of TP: "I think it absolutely did influence me at that age towards a position where I have never ever seen a partnership with Māori as being any kind of threat". Sotheran consequently wanted to develop a real partnership. It was sometimes difficult to achieve this ideal, when the Māori partner did not engage in a full partnership as Sotheran perceived it: "to be honest I had to sometimes drag Cliff [Whiting; Kaihautū] to the perspective that he was not just dealing with the Māori side of the Museum. That he had a perspective that I valued on everything that the Museum did and that is the kind of partnership that we established". With other people at leadership level Sotheran encountered 'distrust' and 'a sense of losing power' to Māori, something she said she never felt personally.

Whiting remembers their relationship as "a bit like a marriage" in the sense that "you can bring together two people who think they know one another until you live with one another; then you start to know what one another's about and of course there will be differences and of course at times it mightn't work". Kaihautū Michelle Hippolite uses the analogy of 'rally car drivers' to describe the reality of her shared leadership with CEO Bennington. She prefers the term “'co-management' to 'dual-leadership', because the language might assume that everything is the same", which is not the case. The legislative framework makes it very clear that the CEO is the person accountable to the Board. However, in her experience it is possible to have two drivers. CEO and Kaihautū bring different skill sets into the Leadership team and swap the driver's seat from time to time depending on the context, taking turns at steering and reading the map. According to Hippolite, both leaders need to work together and sometimes compromise in order to "find that mutually beneficial pathway" or middle ground (see photo in Appendix 11).

In the case of disagreement, the CEO can override the Kaihautū, but for the sake of the partnership this is not advisable: "Has the CEO the last word? Theoretically: yes. 
Strategically: probably not", says former Kaihautū Te Taru White, who gives an example of Māori resistance. After only three months at TP the CEO tried to restructure the organisation but failed to consult the Kaihautū. In the meeting that was scheduled to wave through the restructuring plans, White challenged CEO Bennington:

\begin{abstract}
I went "taihoa!" Taihoa means hold on. And he looked at me [...] and then I rose and I started doing the haka [...] and when I finished I greeted all the Leadership team, then I turned to him and I said to him: "You have insulted me, you have insulted the partnership, you have insulted my people and I think you have insulted the people of New Zealand to think that you can reach across this table, rip out my Mãori heart and do what you will with it. Sorry, we call that in Maoridom 'you have takahi [dishonoured] my mana'". And when you do that you put my esteem under your feet and you grind it into the dirt.
\end{abstract}

The Kaihautū walked out of the meeting and the CEO decided to put the restructuring on hold and discuss the plans with the other side of the partnership first. White explains: "people were furious. And it wasn't about the restructuring, but he totally ignored our partnership."

While biculturalism is cemented firmly at TP, it has to be seen as an ongoing process of negotiation and a 'work in progress'. Despite its challenges, I agree with Gorbey, that TP has to be applauded for undertaking a large and risky endeavour to achieve a bicultural structure from the top to the bottom. As Gorbey states: "[Whiting and Sotheran] managed to achieve an image for TP at the highest level that was about biculturalism. An organisation being able to be administered on quite revolutionary, almost antimanagement principles." While Sotheran wanted Māori in key positions (something she admits she was only partially successful at), she resisted "having a Māori director and a Māori unit sitting over there, doing Māori stuff. It had to permeate." In the next section I analyse how biculturalism permeates front-of-house and back-of-house.

\title{
Walking Through Te Papa Front-of-House, Exhibitions
}

Visitors to TP will stumble upon bicultural elements when walking through the exhibitions as they are greeted with 'kia ora' by the TP hosts, pass a waharoa (gateway) near the entrance, encounter bilingual signage and exhibition labels in English and 
Māori. ${ }^{57}$ TP's architectural layout lends itself to keeping the tangata whenua exhibitions and tangata tiriti exhibitions separate. On level four, where the exhibitions about NZ culture are located, about half the floor space is dedicated to Māori exhibitions. Having the exhibition Signs of a Nation about the Treaty of Waitangi, NZ's founding document, in the wedge-shaped space in between can be equally interpreted as segregating or uniting the exhibitions around it. While Henare (2004:58) leaves it "to the visitor to judge" this organisation, Goldsmith (2003) sees it as segregation when he criticises the modes of display: Māori displays are dark, mythical and sacred whereas the settlers are portrayed in a profane, fun and quirky way. Signs of a Nation was intended to celebrate the Treaty rather than educate the visitor. As Gorbey observed, "if you mentioned the Treaty to New Zealanders they're uncomfortable", therefore the exhibition space was designed to be a sacred space that invited visitors to contemplate: "I was always on about making this the most comfortable lounge in the whole place".

TP's exhibitions make an attempt - in keeping with its 'new museology' approach - to soften the ethnological and curatorial boundaries by distributing taonga Māori and art throughout the museum. Visitors to the Awesome Forces exhibition for example, find scientific evidence for seismic movements in NZ alongside a film about the Māori creation story. Although criticising TP has been called a 'national sport' (Goldsmith 2003:2) and the list of scholars (Williams 2003; Williams 2006b; Dibley 2007) and journalists (Dalrymple 1999; Keith 2000; McLeod 2013) who have done so is extensive, TP is and always has been very popular with the public, especially with international visitors (Davidson/Sibley 2011). With 1.3 million visitors annually and 20 million through the door from opening until 2012,58 TP is the "most visited museum in Australasia" (Williams 2006b:4). TP's domestic visitors closely match NZ's demographics in regards to age, gender and ethnicity. "In all, visitor statistics are Te Papa's main cause for celebration and the chief weapon in its defense" (Williams 2006b:4). Indeed the evidence suggests TP has been successful in attracting Māori

\footnotetext{
57 TP's language policy states that labels high up in the text hierarchy (like introductory panels) must be bilingual, whereby the te reo part is not a direct translation of the English text. This practice is followed consequently, in order to address Māori visitors and make a bicultural statement, even if the exhibition has no Māori content whatsoever (for example Monet and the Impressionists exhibition). The only exception to this policy was the Mixing Room exhibition, which I will discuss in chapter five.

$58 \mathrm{http}$ ://www.tepapa.govt.nz/AboutUs/history/Pages/default.aspx (accessed 6 November 2012).
} 
visitors, a traditionally under-represented museum audience, who respond positively, especially to the Māori exhibitions which they see as the product of Māori involvement inside and outside the museum. This success with a Māori audience is an important validation of Māori involvement in exhibitions at TP (McCarthy 2013).

As a visitor to TP it struck me that neither was the story of Māori and Pākehā encounter and engagement presented, nor the conflicts and wars between them. Jock Phillips explained to me that TP's main aim at the time was "to make [a visit] a celebratory trip' through NZ history, not a 'guilt trip', so leaving out the dark chapters of history served the purpose to construct a united, yet divided NZ under the bicultural umbrella. In Phillips' opinion it is a 'real failure' of TP that there is

virtually nothing on the New Zealand Wars. There's nothing really about how the two cultures have exchanged ideas and so you have a Māori section that pretty heavily emphasises traditional Māori culture. There's very little expression of Māori in the twentieth century or the twenty-first century in there. The Pākehā exhibitions almost by definition don't treat Māori subjects, so there's this huge great vacuum in the place. I liked the fact that Te Papa had this real bicultural thing, it had a strong Mãori base and a strong Pākehā base, but I thought that it sort of - as if the two cultures remained there and they never engaged. The only place where I really found I enjoyed the engagement with the Mãori team at Te Papa was when we came to do the marae up on the top floor.

Although TP aims to be 'Our Place’59 for all New Zealanders, its bicultural framework is often misunderstood by the general public to exclude immigrants of other cultures who are neither Pākehā nor Māori. This perceptionis incorrect as recent immigrants are included in the definition of tangata tiriti and are well represented in the Museum's Community Gallery that features an exhibition developed with an immigrant community group every third year. ${ }^{60}$

\footnotetext{
${ }^{59}$ Besides its full name Museum of New Zelaland Te Papa Tongarewa exists the brand 'Te Papa - Our Place' which reflects TP's mandate to be a forum for every New Zealander. Though not often called by its latter name, some visitors I spoke to, claimed the museum as 'our place' especially Wellingtonians but also a few Māori.

60 Thus far the small Community Gallery has displayed the following ethnicities, always developing the exhibitions with an advisory group from the community. Exhibition names and opening year in brackets: the Chinese (The Making of a Chinese New Zealander 1998), Dutch (Nieuw Zeeland: Going Dutch 2000), Indians (Aainaa: Reflections through Indian Weddings 2002), Italians (Qui tutto bene - The Italians in New Zealand 2004), Scottish (The Scots in New Zealand 2007) and most recently refugee youth (The Mixing Room: Stories from young refugees in New Zealand 2010)
} 


\section{Iwi Gallery}

The Iwi Gallery (see photo in Appendix 11) receives the greatest Māori input within the exhibition space, because the concept of having iwi exhibitions allows iwi Māori to come in and develop an exhibition about themselves in collaboration with TP. The curators, collection managers and other museum professionals at TP take a backseat in the process of concept development for these exhibitions and let Māori take control over their taonga and representation, as Sotheran explains:

We brought the design skills and the logistical skills and the organisational skills and all those things to the mix. But concepts, narratives, the artefacts come from the iwi and remained in their guardianship for the time that they were in the museum. That's a massive shift.

Developing an iwi exhibition does not only give a particular iwi the opportunity to showcase itself and establish a partnership with TP, it also means that two representatives of that iwi become part of TP's staff as they take up residency for the duration of the exhibition. The kaumātua are respected elders, usually a man and a woman referred to as 'koroua' and 'kuia' with a high standing within their iwi. The iwi in residence concept creates a lasting link for the iwi and the museum, because the iwi kaumātua play a crucial role as spiritual caretakers, ceremonial leaders and guardians of tikanga. Ngāi Tahu kaumātua Kukupa Tirikatene explains that it was his responsibility to cleanse the whole space of 'bad tapu' through karakia: "I try to give a cocoon of spiritual safety [to] everyone who works here". The iwi in residence holds the mana and kawa of the marae according to the protocols of its iwi, which the iwi kaumātua uphold. The iwi kaumātua are also very involved in the Māori activities that are an everyday part of TP's museum practice, as I illustrate in chapter two.

\section{Walking Through Te Papa Back-of-House, Collections}

TP houses about 200,000 objects $^{61}$ from diverse collections including natural environment, history, Pacific cultures, taonga Māori and art. The collections are held at Cable Street with the focus on cultural history and at Tory Street where the natural history collection and waka store is situated.

${ }^{61} \mathrm{http}: / /$ collections.tepapa.govt.nz/ (accessed 2 November 2012). 
Visiting the collection rooms at Tory Street fulfilled my expectations of shelves and drawers cluttered with insects or birds of one species grouped together, whereas the Māori collection stores at Cable St are quite different in its classification system. Central to the grouping of objects there is the understanding that these are 'living taonga' that need to be cared for and nurtured. Similar to Appadurai (1986) who stated that objects have 'social lives', Māori believe that artefacts take on qualities of the people they had contact with in the past and therefore they have special requirements. For instance, weapons used during war are considered tapu and would contaminate objects used for food preparation, which are noa; thus they must be kept separate. These cultural restrictions are followed in the Māori collection rooms.

The use of Māori names for the three collection storerooms for taonga (Tãtau Pounamu for the greenstone room, Ahuru Mōwai for the large carving store and Te Whare Pora o Hine te Iwaiwa for the weaving room) is "a big step in reclaiming cultural ownership" (McCarthy 2011:126) for Māori as is the reorganisation of taonga according to Māori values rather than Western academic practice. However, the classification in iwi groupings has been complicated in practice as provenance is not always known, and some areas have gone back to ethnographic typology (McCarthy 2011:127) or functional solutions where objects of similar shape and dimension are grouped together. Yet, it signifies a paradigm shift that kaitiaki Māori look after the taonga using karakia, waiata and other methods to ensure their spiritual wellbeing. I will discuss the tikanga in the Māori collection room in more detail in chapter four.

\section{Case Study: Building Te Marae - Rongomaraeroa}

If the chapter so far has underlined TP's role as an experiment for the newly adopted state ideology of biculturalism, then the compromises in creating TP's marae further sustain this hypothesis, as the following case study demonstrates. Arguably the most prominent embodiment of TP's commitment to biculturalism is the Museum's newlybuilt marae Rongomaraeroa with the meeting house Te Hono ki Hawaiki. Located on level four, overlooking the Wellington Harbour, Te Marae is both an exhibition space 
open to the public and a 'living marae' used for pōwhiri, functions and tangi. ${ }^{62}$ Cliff Whiting, the first Kaihautū of TP and a master carver, was largely responsible for the marae's modern design using plywood and spray paint to create a contemporary whare whakairo. He had the vision for Te Hono ki Hawaiki as a place where all people, visitors and staff alike can belong. Salmond's (2009:34) statement that "[t]he fact remains that most Europeans never attend a hui, nor do they have much idea of what happens on marae", sadly still holds true today. However, TP attempted to change this and make the marae accessible to all. In order to succeed with this novel concept, Whiting had to come up with something that not only Māori could relate to but Europeans as well:

We needed to find [...] if there's something within Pākehā culture that parallels something on a marae. And that's how we came to the formation of the meeting house itself. The thing that we could see in the history out of England and Europe [...], was the church having a similar role to a marae.

Therefore Te Hono ki Hawaiki features a triptychon shrine (one image featuring a Christian dove) at the back wall and pillars depicting different professions and patterns that are intended to give all people who visit the marae symbols to identify with. When the marae is not in use, visitors can walk right into the house and fill in a whakapapa or genealogy sheet stating their mountain, river, country of origin and name. By putting the completed sheet into a bowl, visitors, regardless of their origin, become part of this marae and can claim it their place to stand. As an exhibition, Te Marae delivers what the rest of the museum lacks, notes Jock Phillips: "in some ways that's the only place where there's a real engagement of Māori and Pākehā."

The fact that TP's marae is supposed to be 'for all people' however, creates a dilemma for its protocols, as each iwi has distinct kawa, yet TP's marae is not only a pan-tribal marae but also one for non-Māori. Therefore its kawa is an artificial construct, rather than the kawa of one particular iwi. Usually marae are Māori domains:

[T] he marae is one major area left in New Zealand where European culture stands at a disadvantage - the rituals are unknown and the speeches unintelligible. [...] So on the

62 It is not uncommon for a NZ institution to have a marae on site. Several NZ universities, polytechnics and Government departments feature pan-tribal marae on their grounds which were established in the mid 1980s as part of a Māori renaissance. For example, initiated by Professor of Māori Studies Hirini Moko Mead, Te Herenga Waka Marae opened in December 1986 at Victoria University of Wellington "creating a place on campus where Māori values can be expressed" (Dr Takirirangi Smith quoted in Vic News 28 November 2011 Victoria University Intranet). 
other hand the insulation works to the advantage of those who use the marae; because one of its most attractive features is that no concessions have to be made to European custom - you can wail, chant, orate, talk Maori and eat Maori food as much as you like, and everyone else will join you. The atmosphere would naturally be hampered if the dominant numbers at hui came to be European and not Maori.

(Salmond 2009 [1975]:34)

However, at TP it is often the case that Māori are in the minority (for example when a conference delegation from overseas is greeted, or even at staff induction), so how does this imbalance impact on the ritual and the kawa of the marae? In practice this causes friction, as Te Herekiekie Herewini (Manager Repatriation Team) explains:

We have a marae, where we can actually do the traditional elements. However, it also recognises that different iwi have different ways of doing things, and that we have to have a tikanga approach that embraces all Māori tribal groups, but [is] also reflective of the non-Mãori part of New Zealand also. So I mean there are compromises that are made, but you have to understand that we're not a totally traditional marae, so you have to embrace new elements.

\section{Watching the documentary Getting to our place (Cottrell/ Preston 1999) it becomes}

visible how much the Māori partners had to bend to deliver on the brief to construct a marae that is 'a place to stand for all New Zealanders'. In a meeting with Sotheran and Whiting, Sir Ronald Trotter (Chairman of the Board 1994-2000) reflects on the marae concept which he wants to be more liberal than traditional marae and a signpost for the new millennium, stressing that the marae should be a place that is "comfortable and warm for any iwi who come here, but [also][...]for any Pākehā". Whiting argues that the customary role of marae in the first place "comes of and comes from tangata whenua, from Māori." Trotter immediately cuts him off, gesturing forcefully:

It is not just for Māori! You must get that: If it is a Māori institution and nothing more this marae has failed. And they must get that idea, because we are bicultural [hits table], biculturalism is about two. And if it's all gonna be totally Māori and driven by Māori protocol without regard to - . Museum is a Pākehā concept. I'd rather be without a marae, if women can't speak on the marae. So we're all gonna be Ngāti Porou, because they let women speak. But we can't have a kawa that says women aren't allowed to speak. I will not chair an institution headed by a woman if she can't stand there in her own right. I know there are sensitivities by some iwi, but we got to be bold enough to say we're gonna make our own kawa! I don't mind if 75 per cent of iwi are a bit irritated that we are more liberal [...]. We want to be able to put a bicultural spin on the ball is what I'm saying. This has to satisfy both cultures. 
Whiting, who during Trotter's exclamation sunk into his chair and became increasingly uncomfortable, replied: "Yes, I would support that, but it has to satisfy both, not be compromised."

From this video sequence it is clear that Te Marae was envisioned as the heart of TP, where the bicultural framework is spatially and tangibly expressed. At the same time the kawa of the marae becomes an instrument of power. Trotter's understanding of biculturalism is that of a Pākehā run museum ('Museum is a Pākehā concept') that tolerates Māori culture to a certain degree, but only if it includes non-Māori and assimilates kawa to TP's requirements. Consequently a Māori run marae as a sovereign space within the building was totally unacceptable to him, as it would challenge Pākehā hegemony and be a potential threat to their white cultural supremacy.

In the next scene Whiting is interviewed, reflecting on the emotional impact the bicultural negotiations surrounding Te Marae have on him personally:

I just have to suppress a lot of inner-feeling, mainly because it's what I do know, my lifelong experience is that [in order] to gain ground forward, at times you have to actually take this sort of crap [laughs]. There were lots of things about that which were, I found, very arrogant and contained a lot of ignorance. And to come in to suggest that, [for] somebody who doesn't know Māori culture, doesn't know Māori fullstop, to come in and to start to want to change a very important part of my culture. [...] It's one of the major threats for instance of the maintenance of Māori culture. It's very fragile! If the museum is about remembering, discovering and all of those high ideals in terms of education etc. it should be able to cope with such an ordinary, what I see as an ordinary, straightforward cultural uniqueness and difference.

One of the reasons TP's marae plans came to fruition was the generosity of the Māori personalities involved who did not insist on their kawa but went to great length in order to include non-Māori. The marae's development was only possible, as Whiting emphasises, because "we really believed in the idea that a national museum was a good idea". Traditionally, women do not speak on marae (with the exception of some iwi, such as Ngāti Porou and Ngāti Kahungunu) and the language of conversation is Māori. The kawa of TP's marae deviates from the kawa of most iwi in that it allows women to speak on the marae and permits speeches in English after a karakia whakawātea is spoken to lift the tapu. These are concessions to the Pākehā partner and follow pragmatism (not everyone can speak Māori) and women rights (as seen in Trotter's 
statement, it was unthinkable that a female CEO is silenced on the marae). How the kawa is enacted in practice and what other strategies Māori use to maintain their tikanga in the museum will be discussed further in chapter two, four, and five.

It was also challenging to run the concept of a 'museum marae' by the local iwi who uphold mana whenua, as Whiting remembers:

Having that agreement with those local people is really, really important, so we said no, you control the ground, the earth Te Papa but our marae is that one sitting up on the front there. And I said," if you really want to be nasty you can stop people from coming across the ground and our marae will have no people!"

Although visually impressive, Rongomaraeroa was not popular with everyone when the museum opened. Pākehā mainly criticised it for its appearance that reminded some of 'Disneyland'; Māori on the other hand struggled with its rooftop position and dubbed it 'the marae in the sky', says Whiting.

The placement of the marae on level four however was deliberately chosen to emphasise that this is a national marae that belongs to TP, not the tangata whenua. Its location was crucial to enable the adoption of a special TP kawa, as Whiting explains:

We didn't want it to become a Te Āti Awa [local tribe] marae, although some Te Āti Awa people think it is and it isn't. We had the agreement from their old people and that's one of the good reasons why it's sitting up on top there. The other good reason is that it sits on isolators. It's not sitting necessarily on the ground and it's quite a hard concept for people to grab hold of and say no, it belongs to the museum. [...] Of course we always consult with the local tangata whenua, but at the same time when it comes to doing major things to it, it's the museum that does it. It's Te Papa that does it.

This raises the question of ownership over the marae and its kawa. The tikanga and marae coordinator as well as the iwi kaumātua dictate the kawa on TP's marae at particular times, yet when claims originate from different iwi, clashes are inevitable. I will elaborate on these issues of power and cultural dominance in chapter five.

The biggest challenge however, was to ensure the marae was 'alive' and 'working' as Whiting points out, "because you can't have a marae without the appropriate people to run it. It was my job to establish that or make it physical and then make it work... So the marae was absolutely central to [the concept of biculturalism]." The marae is a contested 
space with some people unwilling to accept that it is owned by all people and therefore adheres to the mana taonga principle which grants speaking rights (in principle) to everyone who is connected with the collection (including women) and not just tangata whenua and local iwi. Despite this contested nature, the fact that iwi have used it as a venue for the signing of Deeds Settlements when Treaty settlements were achieved, demonstrates that it is generally accepted by Māori.63 Manager Mātauranga Māori, Arapata Hakiwai emphasises that "TP's marae is accepted not by inheritance, but by practice."

I see TP's marae as a national symbol, which to quote Ballantyne (2012:201) makes it sit alongside places like the the national library; "powerful ideological statements of the kind of visions of the nation and its past" that are manifest in the architecture, physical layout and signage. Therefore, the marae sets the scene and fixes the 'rules' within 'which we speak' (Ballantyne 2012:201). In other words, the marae is the centre stage at TP. Sissons (2005:100) stresses the importance of "the creation of spaces - literal and cultural - that are protected from the intrusion of state authorities and within which indigenous self-determination may be pursued". TP's marae to me is one of those spaces. As we will see in the chapters that follow, the marae emerges often as a symbol of, and site for, debate over biculturalism.

\section{Conclusion: Te Papa - A State Experiment or a Stage For the Nation?}

TP was a 'state experiment' (Williams 2006b:1) that was a product of the political climate of the 1970s and 1980s and the 'Māori renaissance'. TP's development was influenced by the triumph of the Te Maori exhibition and the Treaty settlements, economic changes and an evolving Pākehā identity. At the same time, TP’s birth was embedded in a global context of indigenous rights, museum revolutions and 'new museology'. The fact that TP was literally conceptualised and designed from scratch was a rare opportunity that allowed the institution to reinvent itself. The Museum was constructed with the cultural imperative of biculturalism in mind at every step of the way. However, in contrast to this 'top-down' explanation I explored how TP is equally a

\footnotetext{
63 For example, Ngāi Tahu had their signing ceremony at TP's marae on 6 May 2009.
} 
product of 'bottom-up' social forces, practices and personalities. It is often forgotten that individual personalities played a significant role in developing TP, hence I have added this dimension drawing on oral history interviews with key 'TP pioneers'.

Although biculturalism does not feature in the Museum of New Zealand Te Papa Tongarewa Act 1992, it was inscribed into TP's policy, governance, corporate values and translated into its architecture and exhibition spaces. Furthermore, the bicultural concept has strongly influenced the Museum both front-of-house and back-of-house. Revisiting the old museum at Buckle Street illustrates the huge shift that the Museum underwent. Te Marae is TP's boldest bicultural statement as it is set up to include all people and can therefore be read as an extension of the mana taonga principle. I got a glimpse of how difficult the negotiations were looking at the movie Getting to our place (Cottrell/ Preston 1999), which showed Cliff Whiting standing his ground against Sir Ronald Trotter who attempted to 'Pākehā-fy' Māori kawa and thereby make it less threatening. Trotter used biculturalism as a weapon to argue against a Māori-run marae and maintain Pākehā control. Despite or because Rongomaraeroa is a national, pantribal marae, it is not without challenges. However, TP's marae is widely accepted by iwi and used for pōwhiri, tangi and other Māori activities.

The making of TP in this chapter has illustrated that it was indeed a 'bicultural experiment' that can be seen as a model for the NZ nation. Through TP's framework and architecture the state policy of biculturalism was given a stage. This stage was and still is the National Museum that was, to a degree, an artificial environment meant to educate the NZ public. But what about the work going on behind the scenes among staff? What was and is happening as Māori and non-Māori staff work together in offices to manage, interpret and communicate the mission of the Museum through its collections, exhibitions and programmes?

As I have shown, there are many aspects of biculturalism that permeate the institution: the dual leadership model, acknowledging Māori values and concepts (taonga, mana taonga, mātauranga Māori), collaborating with iwi and having iwi in residence. In the next chapter I illustrate how biculturalism is staged and enacted internally through the 
Māori activities and rituals on the 'stage' that is TP, and show how staff position themselves by participating. I argue that Te Marae becomes the centre stage or 'contact zone' within the organisation that creates a sense of belonging for some but not others. 


\section{2 \\ Staging biculturalism}

\section{Introduction}

The previous chapter was concerned with setting the scene for the reader, providing the context of global political movements, paradigm shifts in museology and historical evolutions specific to NZ, such as biculturalism as state policy. Furthermore, by juxtaposing the 'official account' of TP with the oral history of making TP a bicultural institution, I argued that TP was constructed as the 'stage for the nation'. In this chapter I focus on how biculturalism is 'staged' in Māori activities and the pōwhiri ritual, and how staff experience biculturalism through them. 'Staging' seems the appropriate lens to analyse the staff interaction in rituals, because it contains three meanings: a) present a performance of (a play or other show), b) organize and participate in (a public event), and c) cause (something dramatic or unexpected) to happen. ${ }^{64}$ Therefore I understand staging as a conscious act of performing and mise en scène, not simply enacting a scripted show. The ritual theory employed here will help embed the Māori activitities at TP within anthropological discourse. According to David Kertzer (1988:9), ritual is defined as "symbolic behaviour that is socially standardized and repetitive". It has many - sometimes contradictory - functions, including constituting power, reinforcing the status quo, bringing about change, unifying people, positioning groups, defining group boundaries and imagining the future (Kertzer 1988).

The structure of this chapter follows a new (non-Māori) staff member coming into TP, being welcomed, experiencing biculturalism through Māori activities, encountering cultural misunderstandings and finally, feeling either included or excluded. I forgo

${ }^{64}$ Oxford Dictionaries (accessed online 29 April 2013). 
explaining pōwhiri procedure ${ }^{65}$ deliberately in order to give the reader the opportunity to identify with the experience of new staff with limited previous knowledge entering TP. Starting with an analysis of TP staff's cultural make-up, I introduce the 'main actors'. The next section looks at the 'casting and audition' process, where I analyse the 'new staff induction day' as a rite of passage in a case study. I argue that TP aids the process of acculturation, ${ }^{66}$ which means becoming accustomed to a second culture, through the 'induction day' by marking the passage of becoming a member of the 'Te Papa whānau' with the ritual of pōwhiri. Despite the initiation ritual at TP, the successful integration into the bicultural model is left to a great extent to individual staff members and their ability to adapt to the organisational culture. It is up to the individuals whether they take up what is on offer and to what extent they enact biculturalism through Māori activities, such as Māori language classes, waiata sessions and taonga pūoro practice, which are available for staff and could enhance bicultural understanding. Who attends these Māori activities and why? Revealing the politics of participation in the Māori activities, I examine the complex dynamics of access, time, rewards, identity, selfpresentation and status on the ground, and how staff participation is perceived by management. I argue that every Māori activity at TP is a 'staged performance' (but by no means 'inauthentic'); each providing a 'contact zone' (Clifford 1997) where indigenous and non-indigenous staff members interact with each other to a greater or lesser degree. While Māori rituals and sacred spaces create a 'sense of belonging' for some staff members, others feel alienated and excluded.

I then look further into some cultural misunderstandings where people are 'talking past each other' (Metge/ Kinloch 1978), before analysing the pōwhiri as a 'battle ground' for power-struggles, discussing the issues of commercial pōwhiri and speaking English on the marae. Drawing on Goffman's (1959) dramaturgical concept, I utilise theatrical terms for my analysis and particularly look at the stage for the Māori activities, TP's marae, which I propose is a Māori stage for enacting identity and gaining empowerment. The case study of long-term Māori staff member Carolyn RobertsThompson emphasises how working at TP can be interwoven with one's personal life

${ }^{65}$ For a description for the pōwhiri process and protocols see Harawira 1997.

${ }^{66}$ For a discussion of the concept of acculturation see Schwartz et.al. 2010. 
journey, making the marae a place of belonging and personal significance for some staff members.

\section{The 'Actors': Te Papa Staff and Their Cultural Make-Up}

In setting the scene, I introduce TP staff, as these are the main actors in this thesis. Being NZ's national museum TP attracts a wide range of employees in different positions. It is very important to acknowledge that the entire TP staff, often referred to as the 'Te Papa whānau', is by no means a homogenous group, but made up of individuals from diverse cultural backgrounds as well as having different gender and class identities, upbringings, religious beliefs, educational backgrounds, experiences and so on. The complex term identity, particularly national identity, did not naturally emerge, but "was forced into the Lebenswelt of modern men and women - and arrived as a fiction" (Bauman 2004:20). I agree with Angouri and Marra (2011:86) that identity is "not a stable, predefined entity but an ongoing dynamic process which is constantly negotiated and co-constructed between the interactants". Māori and Pākehā identities must therefore be treated as labels created after initial contact in exclusion of 'the other'. Similarly, a 'New Zealand national identity' is a political fiction intended to unite heterogeneous ethnicities under the banner of one nation state. Yet, they are 'real' in the sense that people use and identify strongly with their cultural identities and claim a sense of belonging in NZ. Drawing on Sissons (2005) I understand identity, like indigeneity as a 'project' rather than 'heritage', a fluid rather than static state of being, and even at times fictional as Benedict Anderson suggests in Imagined Communities (2006 [1983]).

Within its bicultural policy framework TP divides people into two groups, tangata whenua and tangata tiriti - or simply Māori and non-Māori - however the cultural make-up of staff is much more complex. Through migration and inter-marriage the NZ population has become more and more interconnected, and it is not uncommon for someone to introduce themselves by stating:

I was born in Australia. My mother is pure Indian, but was raised in South Africa. My father is Scottish and French from New Zealand. And I grew up in New Zealand. 
So for me - I've been struggling with: Do I identify myself as Indian, French, Scottish, New Zealander, Australian or South African? [...] And now my partner is part Mãori, so now I feel connected to that culture as well.

For the purpose of this study I will group TP's staff members into three categories based on self-identification: (1) Māori, (2) Pākehā, and (3) new migrants. ${ }^{67}$ Although I cannot be true to everyone's (often mixed) cultural heritage, I provide their cultural identity wherever necessary. Being aware that these groupings are simplifying the very complex issue of cultural identity and bear the danger of homogenising people, I discuss the three labels in more detail.

Māori identity is very complex; Tracy McIntosh (2005:39) describes it as 'fixed, fluid and forced'. Some Māori staff at TP spoke of diverse iwi affiliations, hybridity and multiple relocations within NZ and internationally. The concept of whakapapa is fundamental to Māori society, connecting the past with the present and future, and humankind with nature, cosmology and mythology (Barlow 2005). Iwi affiliation has become an increasingly important identity marker for Māori, because of the national Census and the Government's Treaty settlements. However, hapū, sub-tribes are the 'building blocks' of tribal development (Royal 1992; Ballara 1998) - meeting houses were built predominantly by and for hapū - and the extended family or whānau is immensely important as the smallest kinship unit. Scholars (Reilly 2004; Winiata 1956; Salmond 2009 [1975]; Mead 2003; Metge 1995) have debated which one of these units is the most influential without agreement.

To complicate Māori identity of TP staff further, there are individuals with mixed heritage, urban Māori who are disconnected from rural and traditional Māoritanga, or non-Māori who are adopted into Māori culture by marriage. Thus, keeping in line with the Census, I rely on self-acclamation. Sissons (2005:155) suggests dividing the postcolonial field into a triangle, consisting of three simplified groups who are interconnected by three binary relationships that are interrupted by a third voice:

\footnotetext{
${ }^{67}$ Pacific Islanders constitute another interesting group, as they often sit somewhere in-between the groups of Māori and new migrants. However, I refrain from adding this group due to small numbers at TP.
} 
Box 17: The post-colonial field (very simplified)

Tribally Indigenous

Ethnically Indigenous

Non-Indigenous

Source: Sissons 2005:155

Although I appreciate this model for its distinction between 'tribally' and 'ethnically' Māori, allowing the inclusion of urbanised Māori who are so often 'the excluded middle' as Wolfe (1994) notes, I withdraw from utilising it to describe the dynamics among TP staff. Most Māori at TP are in fact both tribally and ethnically indigenous to some extent, yet they have in common with other first peoples that they "define themselves in terms of their cultural struggles against foreign cultural forces" (Sissons 2005:13).

New migrants in my definition are people who did not grow up in NZ, immigrated as adults and have lived here less than ten years. As a result of globalisation people's biographies have become individual collages (Beck/ Beck-Gernsheim 1994), and are often narratives of multi-sited lives or consecutive migrations, creating hybrid identities (Bhabha 1994), ethnoscapes (Appadurai 1998), and transnational migrants (Glick Schiller et al. 1992). Many people categorised as 'new migrants' pass through TP each year, some coming on a working holiday or temporary work visa, others with the intention to stay in NZ permanently. Among the group of new migrants people from English-speaking countries, especially from the United Kingdom, seem to fit in easier than others as they are not singled out for having an accent, and share a comparable cultural background with Pākehā. ${ }^{68}$ Similarly, immigrants from the Pacific Islands share many cultural values with Māori and often identify closely with them, especially if they are married to a Māori.

\footnotetext{
68 In fact, historically, there was no distinction between British migrants and New Zealanders: "They were in a very real sense the same people. New Zealand was not a new world, it was a new Britain" (McKinnon 1996:1).
} 
Pākehā is a contested label in NZ that is embraced by few and rejected by many New Zealanders (Pearson/ Sissons 1997; Beddgood 1997), due to the view that it only applies to 'white' New Zealanders of European descent, excluding other ethnic groups (Spoonley 1988:64) and a "widespread and mistaken belief that Pākehā is a Māori term of abuse" (Pearson/ Sissons 1997:69). Therefore, I mostly use non-Māori when I speak of non-indigenous New Zealanders, paying tribute to NZ's ethnic diversity.

To sum up, it is important to keep in mind that TP staff is by no means a homogenous group, as its ethnic diversity shows. Furthermore, there is a vast range of ages, class distinctions, religious beliefs, sexual orientations and so on among staff, which I cannot discuss here. Through the bicultural construct and the front-of-house division of tangata whenua and tangata tiriti exhibitions, TP suggests a binary classification system: you are either Māori or you are not. This division is, of course, due to TP putting the Treaty partnership at the heart of its policy framework. However, as I have demonstrated, this model does not describe the interrelations and overlaps, hybrid and transnational identities of the people who work at TP. Therefore, I added the group of 'new migrants', who think of themselves as neither Pākehā nor Māori. If TP staff is diverse, so are the groupings of non-Māori, Māori and new migrants themselves, with each individual having a rich tapestry of multiple cultural heritages, ancestries and often citizenships and passports. Sissons' (2005:155) model of the post-colonial field helps to reflect the diversity among Māori, avoiding the trap of iwi affiliation that excludes many urban Māori who have lost their tribal links. TP presents a microcosm of NZ society not only symbolically, as the national museum, but also by the ratio of Māori staff which approximates the percentage of Māori in NZ's total population, albeit on the lower end of the scale.

TP management utilises the rhetoric of the TP 'whānau' often to address all staff, whereas occasionally at important pōwhiri staff are referred to as 'te iwi kāinga o Te Papa Tongarewa', that is the host or home tribe of TP, emphasising the tendency to unify the diverse workforce into one 'tribe' or corporate entity. Although I challenge this 
intentional label for ignoring ethnic politics, I group TP's diverse staff in three categories - Māori, non-Māori and new migrants for simplified reading.

\section{Coming into Te Papa - Motivating Factors}

The participants' motivations for working at TP ranged from 'I just needed a job' and 'I was bored in my old job' at one end of the spectrum (push factors), to 'I have always wanted to work at Te Papa' at the other end (pull factor). While most but not all interviewees knew that TP presented itself as a 'bicultural' place before they started in their position, biculturalism was not their main motivation for working at TP. I noted a discrepancy between Māori and non-Māori staff in their motivational factors and entrance into the organisation. Most non-Māori mentioned strong push factors at their previous jobs as their motivation. They followed a linear route - reading a job advertisement, applying for it, having a job interview and starting their position - and envisaged their role at TP as 'just a job' which they would eventually leave. Māori on the other hand, were more likely to state that their employment at TP was a 'calling' or ' $a$ dream come true', as this statement by one Māori woman demonstrates:

I wanted to work here since it opened because I remember standing outside on opening day with my kids and thinking this would be a cool place to work because it's vibrant and exciting. One of my strongest memories is walking up to the marae and looking at it and going, "Wow! This is different." It's brightly coloured and quite different to anything I'd seen before. So I always thought I'd like to work here one day.

Thus, some Māori took an entry level job in the cafe or store to get a 'foot in the door' and often worked their way up, mentored by senior Māori staff members. This indicates that TP can indeed be a place for Māori empowerment.

A number of Māori were drawn to work at TP because a family member already worked there. Consequently, they seem to have quite strong ties to TP through their kinship connection. In contrast to the Western belief that kinship relationships in the workplace are a potential conflict of interest and hence often disadvantage recruitment opportunities, whānau relations are considered advantageous in the kinship-based Māori world (Barlow 2005). I illustrate the 'family connection phenomenon' in more 
detail in the case study of Carolyn Roberts-Thompson later in this chapter. As a result of their passion for the work, family ties and working their way up, Māori staff appeared more loyal to their workplace and had often worked at TP for 20 years or more with no intention of leaving. ${ }^{69}$ Māori staff caring for taonga in the collection or nurturing iwi relationships in particular, perceive their positions as fulfilling, as a young Māori woman asserts:

It was definitely the work [that brought me to Te Papa]. I'd do this work for free if I could survive, so it is the work that drives me to come in every day. I love my job! I love working with iwi all over the country. I love working with taonga and the opportunities we get here for things like taonga pūoro and learning more about waiata, learning more about different iwi's protocols and beliefs. All those things I couldn't get in another job.

This statement, which is representative of other Māori staff, highlights that Māori feel 'at home' in the bicultural workplace, particularly when enhancing their cultural identity through the Māori activities on offer, and that their prime motivation is to make a difference for the wider Māori community through their work. This in turn is a manifestation of the Māori value of manaakitanga and being of 'service to iwi' (Mead 2003:61f.), which is still regarded highly among Māori and seems more important than an individual's career. However, the loyalty of Māori staff to TP also reflects the limited number of 'Māori roles' that match their criteria and skills outside of TP. ${ }^{70}$

\section{Audition and Casting}

Job applicants for new roles at TP are made aware of the bicultural policy by a clause in the job advertisement as this example for 'security shift leader' position shows. Under the rubric of 'generic competencies' it lists:

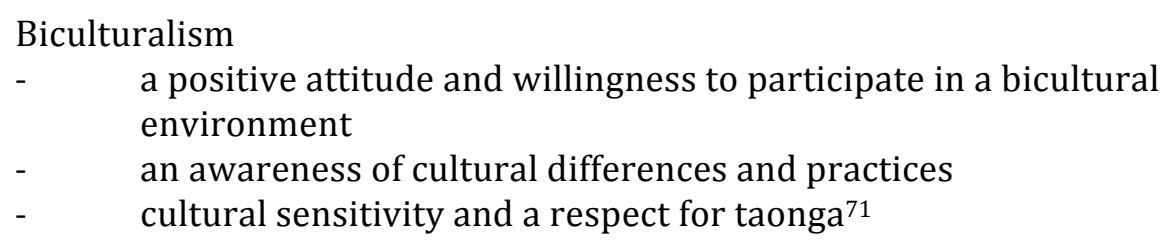

\footnotetext{
${ }^{69}$ Some Pākehā have also worked at TP for a long time; in one case a scientist celebrated his 50 year anniversary at TP. They are, however, the exception.

${ }^{70}$ When Māori staff leave, it is often to work at an organisation that promotes Māori development even further (like Te Puni Kōkiri - the Ministry for Māori Development) or to serve their own iwi (to assist with a Treaty claim, for example).

${ }^{71}$ http://tepapa.govt.nz/AboutUs/JobsAtTePapa/Pages/overview.aspx (accessed 1 October 2011).
} 
If the applicant is shortlisted, the candidate is confronted with biculturalism again at the job interview where a mixed Māori/Pākehā panel asks questions about biculturalism or Māoritanga. The purpose of the interview panel policy, ${ }^{72}$ which states that at least one Māori staff member must be present, is to test the applicant's knowledge of Māori, as well as to put Māori applicants more at ease during the interview process. ${ }^{73}$ However, addressing biculturalism at the job interview can be interpreted as a token gesture, as this comment illustrates:

In the interview I was asked some question and the interviewer [...] said something about biculturalism and then added "we have to ask this question". So I remember asking how seriously it was taken here [...] It had been that often only lip service is paid to it [...] It didn't feature highly in my decision to come here, 'cos I didn't realise how important it is for Te Papa. If I had known that, it would have had a positive impact on my decision actually. (Pākehā woman)

The panel's apologetic phrasing and her past experience in other organisations which did not follow through with their stated bicultural commitment in practice, made her wary of its significance at TP. She interpreted the phrasing in her job interview as a 'negative thing' because the panel said: "'we have to ask this' implying this is a box we have to tick, a necessary evil thing". Even if the question is a mere disclaimer, it has a homogenising effect on TP's workforce as all people working at TP subscribe to biculturalism at least in principle.

\section{Case Study: Induction Day - A Rite of Passage?}

Given that TP is a special workplace because of its bicultural framework, it is important to look at induction procedures for new staff. I use the lens of ritual theory to examine the proceedings of the induction day for new staff members. TP's induction marks a rite of passage (van Gennep 1960 [1909]), but moreover it constitutes an organisational ritual, serving the purpose of "socialis[ing] new members to the values and expectations

\footnotetext{
${ }^{72}$ This 'Day One' policy was abolished in 2010 as it was no longer viable. I will further elaborate on the policy change in chapter five.

${ }^{73}$ During my fieldwork I was allowed to sit-in on three job interviews as an observer; two were for the position of TP host and one was for a school-holiday programme teacher. The latter was not tested for any bicultural competence (because of the temporary and peripheral nature of the job that did not entail interacting with museum visitors but the children of staff members), whereas the prospective hosts were asked to read out loud a list of Māori words and translate them into English, in order to prove their level of pronunciation and understanding.
} 
that make up its culture" (Kertzer 1988:29). Drawing on my own experience of being inducted into TP, I describe the proceedings of the induction day from an autoethnographic perspective. ${ }^{74}$

The ideal start for a new staff member to TP would include a pōwhiri on the marae and induction training soon after joining the bicultural institution. This ideal is underpinned by the Māori belief that people who are not tangata whenua need to be welcomed on to the marae to remove their status as visitors or strangers, therefore a 'ritual of encounter' (Salmond 2009 [1975]) must be conducted. The reality is somewhat different: the practice of having pōwhiri for new staff and induction trainings at three monthly intervals was discontinued (or simply forgotten) and led to a situation where many staff, including myself, had been working at TP for several years without being formally welcomed..$^{75}$

Very seldom the induction coincides with a staff member's first day at TP, or is scheduled for the start date of senior staff (like Board members or the CEO). While the induction pōwhiri for the latter is a form of honouring them and marking their status by 'making an entrance', inducting ordinary staff is intended to increase affiliation and group cohesion (Bergesen 1999; Belliger/Krieger 2008). The importance staff attribute to being formally welcomed is highlighted when staff who have not received a formal welcome voice ill-feelings and express a suspicion that they were purposefully excluded, as this Pākehā manager suggests: “Coming into Te Papa I was never made to feel welcome and participate in those things. I've never been invited to attend anything apart from the general invitations that go out." In some cases staff without their own TP e-mail account, including some hosts, retail workers and casual employees miss out on the inductions because their managers fail to pass on invitations, and new staff

\footnotetext{
${ }^{74}$ I was inducted to TP in late 2008 after already working there for almost two years. When I did my fieldwork I took the opportunity to participate in the induction day again in 2010. I also attended several induction pōwhiri for new staff and Board members, sitting on the tangata whenua side. 75 When I told my TP liaison person that it would be helpful for my research to receive an overview of what the different departments at TP do, she replied: "You know, that's what we used to do in the inductions. We didn't have one in a while, did we?" I assume my remark triggered resuming the forgotten practice of the induction, as soon after this conversation an e-mail was circulated inviting new staff to attend a pōwhiri and day long induction.
} 
members are unaware that they are entitled to attend an induction when they start. ${ }^{76} \mathrm{I}$ discuss in the next section why pōwhiri is an important part of the induction programme and what the briefing session reveals about institutional and personal assumptions.

\section{The Pōwhiri Briefing - Educating Non-Māori}

The fact that the induction pōwhiri was preceded by a 'pōwhiri briefing ' the day before reveals that the organisation did not expect new staff to be familiar with the ritual of pōwhiri in general and TP's marae protocol in particular and consequently required instruction. The briefing took place in the Māori resource room, a meeting room on level three. The six participants (two men and four women), including myself, came together from different teams (Funds Development, Host, Finance, Business and two from the Events team) and were all non-Māori. Some arrived late as they had been in other meetings or front-of-house. We sat around a big table in front of a white board. Without introducing herself, the Māori woman who ran the session (from now on called 'teacher') went straight into business and handed out song sheets for 'E toru nga mea', the waiata we were to sing during the pōwhiri. Her rather abrupt appearance intimidated me and set the tone for the briefing, constructing a class-room situation.

Goffman (1959) suggests that at first encounters individuals try to control the impression they make, thus the Māori woman's entry is by no means coincidental, but strategically chosen to position herself as the Māori expert who must be respected. The following excerpt from my fieldnotes ${ }^{77}$ provides an account of the proceedings at the briefing (all names are pseudonyms):

The teacher tells us that there is a pōwhiri at 6.15pm today for the Telecom Young People walk, she invites us all to come along to learn the tunes of the songs, "have a look and participate". [...] Teacher: "What do you wanna know for Wednesday?" Liz: "What the protocol is. Do we participate or be passive?" Reece: "What is expected of us?" Teacher: "What are your expectations?" Reece: "Welcome ceremony. To welcome us to Te Papa." Liz: "Two way communication, between Te Papa and us." Sandra: "Listening." Teacher: "How would I deal with something that I'm not familiar with? I would have a

${ }^{76}$ I observed one such case on 4 May 2010 when sitting in on the host briefing. The house manager informed everyone of the induction pōwhiri for new staff that was on at the same time and several hosts commented that they would have liked to attend if they had known about their entitlement earlier. ${ }^{77}$ Fieldnotes are in italics and single spaced to set them apart from the text. 
spokesperson. Do you know who your spokesperson is?" Nobody does. [...] The teacher gets up and writes his name down [...] Anybody knows where Te Ara a Hine is." Nobody speaks up. The teacher writes it down and explains where it is and that it is the walkway to the marae for women. The teacher describes the process and writes down 'taonga pūoro' ... When the taonga pūoro [Māori wind instruments] sound, the teacher says we should quieten our minds. "You will experience something. You have to experience that for yourself." She explains how we then enter through the waharoa "one side Captain Cook and on the other side a plane". She thinks we will go up Te Ara a Hine, the internal walk way, "the weather will be awful again, I guess. (laughs) You will go through the puwhara, which is the landing or the deck of the ship. People say to me: 'You mean 'the gateway'. No! I mean waharoa, taonga pūoro (reads list of Māori words and insist that they are used). Your role is to be there and support [the kaikaranga], the men follow [the male leader]. We are hosting you. It's like a phone call: 'Hello?' - 'Hello. Can I come visit you?' You don't do that. You wait till you are invited! It's quite awesome, it's an awesome feeling. That's how pōwhiri happens. But with our external clients it's challenging. That's why I'm down there to suss them out."

This short passage illustrates how TP (here represented by the Māori woman who runs the session) transfers bicultural knowledge to staff, but also what existing knowledge and expectations new staff bring with them: the organisation signals that pōwhiri are (1) open to all staff and participation is encouraged; (2) pōwhiri are occasions to 'learn' the waiata, but also about Māori culture and language more generally; (3) learning by doing (in this case going along to a pōwhiri) is seen as superior to relying on theoretical knowledge; and (4) it is deemed necessary to 'have a look' and experience pōwhiri more than once to grasp the concept. This corresponds with Salmond's (2009 [1975]:121) statement that "the hui itself is by far the best school for its own rituals". Moreover, the teacher's use of Māori terms hints at the importance of the Māori language within the organisational culture, and her insistence that these be used fortifies te reo Māori as a significant element within TP.

The new staff members' questions show that (1) some have pre-existing knowledge and experiences evident by their use of the terms 'protocol' and 'welcome ceremony', (2) they are uncertain of their role at the pōwhiri and are afraid of making mistakes or behaving inappropriately. The teacher responds to participants' anxiety, which can be described as 'Pākehā paralysis' (Tolich 2002), by explaining that the actors performing the ritual are Māori staff members who will act on behalf of the new staff. While this takes the pressure off the new staff, it also limits their role to mere spectators for most of the ritual. This step is taken to ensure the Māori ritual is performed in an appropriate way, 
according to tikanga Māori with knowledgeable Māori people in charge. In contrast, Māori staff and their families are encouraged to actively participate. The e-mail invitation mentioned that new staff should bring their families (or close friends) along for support. Sometimes the whānau of Māori staff perform the karanga and the whaikōrero for the manuhiri, as I observed at another induction pōwhiri, when the parents of a Māori woman who was inducted, fulfilled these crucial roles. I suggest that this practice further contributes to the empowerment of Māori and their strong standing within TP, while non-Māori are treated as apprentices and miss out on this opportunity. ${ }^{78}$

The teacher's explanation of the sequence of events at a pōwhiri familiarised us with the unknown ritual (for a complete description for hui see Salmond 2009 [1975]; for pōwhiri see Mead 2003:117ff.). It is a very simplified structure of a pōwhiri, and no reasons why we were doing it this way were given, the only instruction was for us to 'follow the leaders' of our respective genders. The fact that she points out a male and a female leader implies that there are different roles for males and females on the marae. Indeed, it is women who perform the karanga and men who do whaikōrero. The teacher specifies our supporting role as being present, yet passive and restricted to following the leaders. In other words, we are not 'actors' but 'extras' of the drama. If we fulfil this role, she promises that we will 'experience something' on a emotional level, perhaps a spiritual enlightening. Her definition of the pōwhiri as a 'phone call' emphasises the purpose of the ritual as (1) a ritual of encounter (Salmond 2009 [1975]) between two parties, (2) a means of oral communication and (3) a procedure which follows moral codes and means the actors are entering into a 'social contract' (Rappaport 1999). TP management is aware that conducting rituals of encounter with inexperienced people can be 'challenging', even dangerous, and hence created the role of a knowledgable Māori elder as mediator - to 'suss [the external clients] out' in order to prevent any disturbance of the ritual (see Hüsken 2007).

\footnotetext{
${ }^{78}$ It is not practical to have an induction for each new member of the organisation, yet Māori regard the welcome into TP highly; new Māori staff members receive a so called 'mihi whakatau' on their first day before they actually start work. Interestingly, this practice is broadened in some predominantly Māori teams or teams who are aware of this Māori custom to everyone entering their team, regardless of their ethnicity. I observed one mihi whakatau for a Chinese intern which was held in a meeting room, but had elements of a pōwhiri as the kuia did a karanga and the kaumātua gave a speech in Māori followed by a waiata, hongi and shared lunch.
} 
The pōwhiri briefing continued with a question and answer session where staff could ask specific questions, and the teacher explained the marae protocol, recalling anecdotes of TP's early days. The focal points of discussion were that English is allowed on the marae after a karakia and that women sit in the second row for reasons of 'spiritual safety'. The teacher mentioned the opportunity for one of us to speak on behalf of the group. One Pākehā man, Reece, who had started at TP only three days earlier, after working at museums in the UK, volunteered, but needed reassurance first:

Reece: And that can be done in English?

Teacher: Or Japanese or Chinese or whatever.

Reece: I'd be happy to say something about my three days.

His enthusiasm was met with a mix of surprise and annoyance by the teacher, as another speech on the manuhiri side required a more complex pōwhiri procedure and more work for her, as she made clear: "This means we have to learn the other song now for you! And [a senior Mãori speaker] will have to speak about the house Te Hono ki Hawaiki." The teacher went through the waiata 'e toru ngā mea' with us. She spoke the words and we repeated after her. Then she sung it and we joined half-heartedly as we were unsure if we were supposed to sing with her or not. Again we were reminded to 'follow the leader' during our active part in the ritual, the singing. After asking us about our experiences at TP, Reece started writing his speech and prepared a mihimihi in Māori with the teacher's help. Before we left the hour long briefing, the teacher commented on the novelty of having a Pākehā speak on behalf of the manuhiri: "This is the first time, in all those years that someone actually has asked to speak! Give it a go. If you don't give it a go, you will never know."

It is a balancing act for non-Māori staff to embrace Māori culture without appropriating it, but the teacher's reaction shows that there is room for non-Māori to participate in a Māori ritual and Reece's enthusiasm was welcomed. Usually, non-Māori staff are too shy to speak at a pōwhiri as they fear making mistakes on this public stage and therefore leave the speaking to the Māori staff. Reece, however, having been away from NZ and having only started at TP recently was ignorant of TP politics and consequently may have felt less inhibited. I stayed behind and told the teacher my dilemma that I had been 
inducted into TP already but would like to participate again for fieldwork purposes. I told her that "I wasn't sure if I should sit on the Te Papa side or the manuhiri side, " to which she replied, "You can sit with them. Support Reece. Good on him!"

\section{The Induction Pōwhiri - Sitting on the Manuhiri Side}

Although I had attended many pōwhiri at TP and other marae previously and therefore knew what to expect, I was particularly nervous before this induction pōwhiri; partly, because I had been welcomed before, and therefore felt that it was inappropriate to participate as a researcher, and partly, because I sensed the anxiety in the group of newcomers, identifying with them. We met at TP's main entrance at 8.45am and talked among the 26 new fellow colleagues while waiting for instructions. The museum is not open to the public at that time and a red belt prevents people from walking up to the exhibitions. The new staff members, like the museum visitors, were to stay in the entrance area waiting for the Māori leaders to take us upstairs. Not having the ability to walk freely and being unsure what might happen next, I felt tense and humble at the same time. I was relieved to see our teacher from the pōwhiri briefing, who greeted us saying 'hi!' and gave us instructions. The teacher told us women to stay close behind the female Māori leader for support and distinguished this kawa from the isolation of Western speakers. She explained our route up, what it means to go through the waharoa that recognises all people who came to NZ by ship and plane, the greenstone that 'is the mauri of our complex' (among other mauri), and that each blow with the conch shell is a prayer. The teacher concluded with: “We are adopting the protocol of Te Papa, it's in our policy." Then she went up to the marae to join the tangata whenua for our welcome.

When we heard the blow of the pūtātara, our leader signalled us to follow her up the walkway Te Ara a Hine, outside onto the marae àtea, through the waharoa and the Ranginui doors into the marae where our teacher stood calling us with a karanga, and about 40 TP staff awaited our arrival. The sounds of the wind instruments, the wailing female voices and coming onto the beautiful marae (see Appendix 11 for photos) at a measured step created a spiritual atmosphere that made the hair on my neck stand up. There was a moment when the girl in front of me was not sure if she should go in the second or third row and hesitated. I went ahead into the second row but felt unsure - 
just like everyone else - whether I should remain standing or sit down. We remained standing until a Māori man among our group sat down and we all chuckled relieved.

The other TP staff, including the Kaihautū and several directors, sat in three rows along the paepae opposite us. It felt strange being separated from the colleagues we work with every day and being physically removed by a five-metre gap emphasising the symbolical distance between us. The space between symbolises an invisible boundary between the groups, which is ritually removed through the ceremonial encounter (Salmond 2009 [1975]; Mead 2003). For the staff who had attended a pōwhiri previously, sitting on the manuhiri side opened a new perspective. However, it was an unfamiliar experience for me to be confronted with my colleagues' examining glances from across the paepae. Arapata Hakiwai, a Māori scholar, opened with a speech in Māori on the TP or tangata whenua side, followed by a waiata. I noticed that many staff members did not sing, whether for lack of voice or knowledge of the lyrics was unclear, and it occurred to me that this made a poor impression for biculturalism in practice. Te Arikirangi Mamaku, a younger Māori man, gave the next speech on the TP side and some staff who knew the song on the manuhiri side, including myself, joined in singing 'Ngā kākahu'. A karakia whakawātea was then conducted to 'clear the way' for speeches in English.

Kaihautū Michelle Hippolite stood up, and after a short Māori greeting she said in English: "Because we are a small group today, I will try something different and introduce everyone." She introduced the leadership team on her side by name and then made each team stand up as a group on our side while she read out the names and roles. She started with the hosts: "I am very fond of the hosts. They are the people who make our visitor experience so personal." Going through a list of participants she introduced new staff from almost every team and rank, ranging from barista to business group manager. When it came to the Events team, one colleague and I stood up; I felt a huge relief that my name was on the list and I thereby officially belonged to this induction group.

Welcoming people individually to 'the Te Papa whānau' is not only an opportunity to put names to faces but also to show people that the Kaihautū cares about them 
personally and expects them to do the best job they possibly can. This marks staff as individuals with important roles and certain responsibilities, and strengthens their identification with corporate values. The induction pōwhiri can be seen as an idealised 'socialisation process' (Goffman 1959:30f). Following Emile Durkheim [1976 [1915]) and Alfred Radcliffe-Brown (1964 [1922]), Goffman (1959) argues that performances are ceremonies with the purpose of rejuvenating and reaffirming moral values of society; in this case the corporate values of TP. The rhetoric of TP staff as 'whānau' is one such value that determines that ideally interaction and staff behavior should be guided by respect and care, as in a family unit. After this attempt to instil the 'Te Papa culture' in us, the Kaihautū finished by introducing Reece. In my fieldnotes I recorded the reaction to his speech by staff on the tangata whenua side:

Reece gets up, says "Kia ora!" and does his short mihi in Māori. I hear some people chuckle and laugh on the other side, because he struggles with the correct pronunciation. Then he switches to English, thanks the 'kaihatua' - sic! Mispronouncing it - and tells them that we come from different places in NZ and Germany and the UK.

Again, his mistake is greeted with laughter. I have often observed how staff reacted to the mistakes of non-Māori speakers when trying to speak Māori at a pōwhiri. The 'us' and 'them' distinction seems to run between staff who can pronounce Māori correctly and those who are ignorant to correct pronunciation, rather than between Māori and non-Māori. The two main reactions to what is said in the speeches are either commenting 'kia ora' or 'ka pai' in support or laughing. While the first acknowledges the effort made by the non-Māori person, despite the mistakes, and forgives foreigners their ignorance, the latter is used as a regulative gesture, signalling embarrassment with a person who 'should know better' (see Doerr 2009). In this case the Māori staff laughed not because Reece said something funny, but because he offended Māori speakers (and $\mathrm{TP}$ ) by not knowing the correct pronunciation of one of its most important - and basic words, 'Kaihautū'. Having grown up in NZ and working at TP, he 'should have known better', therefore the laughter was used intentionally to draw attention to his mistake and correct the wrongdoing for everyone to hear. Later in this chapter, I discuss 'laughing' as an example of people 'talking past each other'. 
During the ritual, participants have undergone a phase of separation followed by reintegration (V. Turner 1980; van Gennep 1960 [1909]) through the exchange of welcome speeches (Harawira 1997; Mead 2003; Salmond 2009 [1975]). With the hongi between hosts and guests, the liminal phase of the ritual is completed and the two groups of old staff and new staff have come together as one without a gap between them any longer. ${ }^{79}$ The hongi, the pressing of noses, is quite an intimate gesture, as in Māori culture the head is considered "the most tapu part of a person" (Best 1934:84), and is not usually touched. For non-Māori it is also a trap for accidents, like clashing of foreheads or missing the nose when the other person attempts to kiss the cheek. I noticed that a few people were uncomfortable with this bodily exchange of sharing one's breath on both sides and sensed a big relief that voiced itself in laughter and chitchat after the hongi was done. In order to remove the tapu from all participants at the pōwhiri and bring them back to a noa state, sharing food is a vital part of the pōwhiri ritual. We went down to the café on level one for the so-called kapu tī. Hippolite used the opportunity to talk to some new staff members, whereas most others remained in groups with people they worked with or knew already, defeating the purpose of old and new staff mingling.

The rest of the induction day was held at the meeting room Hinetitama where we introduced ourselves, listened to presentations by senior managers about different areas of TP and socialised over lunch. The presentations gave us 'views from the top' revealing the bigger picture of TP as a national institution, and were aimed at instilling pride in working at this 'unique museum'. Although Hippolite and other managers mentioned that TP is bicultural and 'a great place to foster Mãori', they left open what biculturalism actually means. Hippolite stressed however that staff will pick up "an understanding of biculturalism through their work here", suggesting that staff adapted to biculturalism by osmosis (see Bandura 1986 for learning through partaking in rituals).

At lunch, a young Pākehā woman noted: “Only a few sang along, eh? [My manager] wasn't singing at all." Without my interference, the group discussed that only very few sang, even though, so they assumed, the managers must have heard the waiata many times

\footnotetext{
${ }^{79}$ While this is the case here in the organisational context, Mead (2003) rejects the notion that pōwhiri paves over all differences and make the two parties one.
} 
before. The new staff's comments implied that they had certain expectations - staff working at TP should know the waiata and sing along - and when they noticed discrepancies with the reality at TP, they voiced their disapproval of it. The discrepancy between the official projection of biculturalism and the reality at TP can create an 'embarrassing wedge' (Goffman 1959:45) between the two. When the audience observes that high ranking staff are not singing the waiata at pōwhiri, then they will read this unintended gesture as a disruption of the general impression. Ritual as a 'sacred occasion' (Goffman 1959:45) requires consistency, because any inconsistencies destroy the carefully orchestrated mystification of the event (Hüsken 2007).

The last team-building exercise was a scavenger hunt through the exhibitions that fulfilled multiple purposes: an initiation rite (Eliade 1958) for new staff to enhance group cohesion, familiarise them with the exhibits and increase appreciation for the staff working front-of-house. After a short debriefing the induction day finished at $5 \mathrm{pm}$. The day was packed with information, yet we had only scratched the surface of the organisation. However, TP management had achieved its goal as we had bonded with our colleagues and felt a strong sense of belonging to TP as a result of the induction day.

Although the ritualised entry into TP eases the 'culture shock' experienced by some who are completely new to a bicultural work environment, the induction cannot replace the lengthy process of 'acculturation' that sometimes takes years. The Māori activities are an opportunity for staff to become accustomed to the bicultural organisational culture, and ultimately become bicultural workers. Seeing the Māori activities as smaller 'contact zones' within the contact zone of the museum, I examine how staff utilise them (or not), what barriers are in place, and who enacts the roles of the stage managers, actors and spectators. By doing so I reveal the politics of participation of such productions of biculturalism. 


\section{The Politics of Participation in Māori Activities}

Looking at TP's everyday museum practice, Māori components feature highly as Māori activities, such as Māori language classes, waiata sessions and taonga pūoro practices, are weekly affairs and Māori rituals including exhibition blessings, mihi whakatau and pōwhiri, occur on a regular basis. However, are these Māori activities really genuine cultural expressions or 'add-ons' to an otherwise Western organisation? Avril Bell (1996:149) notes that Pākehā 'culture' is not seen as such, but as 'normal' or unmarked, whereas other 'cultures' are marked as 'strange':

This mix results in the irony of Pakeha New Zealanders, in a situation where the national culture must be displayed through song, costume, dance, etc. turning to Maori culture to represent 'New Zealand'. Pakeha culture may be the national culture in terms of providing the pervasive, commonsense underpinnings for the ordering of social life, but Maori culture is the national culture when distinctiveness and ethnic exoticism is called for.

Although the Māori elements mentioned above are part of the mainstream at TP (McCarthy 2011:123), it is obvious that some Māori and non-Māori staff are more involved in their production and performance than others. There are complex issues at stake that influence participation, however often these are not in people's consciousness, let alone talked about. As people 'vote with their feet' as I was sometimes reminded in interviews, I argue that participation is an indicator for how successful the bicultural model works in practice. While some staff embrace these occasions as part of the 'Te Papa culture', others are almost always absent. What are the motivation factors to get involved with the Māori activities? And what are the barriers that prevent staff from participating?

The degree of participation ranges from passive attendance at pōwhiri or blessings to actively performing as part of the kapa haka or taonga pūoro group (see photos in Appendix 11). Often entry to the latter is through observing pōwhiri and blessings, then signing up for Māori classes and finally becoming part of the performing groups. Although some staff understand biculturalism better through participation, more often participation is a result of understanding as Hippolite points out: "Participation in pōwhiri and taonga pūoro and blessings is usually the outcome of an understanding, not the start to the understanding." I contest this assumption, because in my case 
participation triggered a curiosity about Māori culture that led to an understanding. This suggests individual variations or perhaps it works both ways.

It seems that time, support from managers, and feeling 'culturally safe' are the key issues for all staff. However, I observed curious differences in motivation between Māori, Pākehā and new migrants. While Māori generally felt obliged to 'support' their colleagues at an occasion, Pākehā were caught in paralysis (not part of their job, interested, yet not wanting to appropriate Māori culture), while new migrants attended somewhat naively for their own enjoyment and to experience 'the exotic', rather than supporting Māori. During interviews I asked staff whether they attended the Māori activities and why. The majority of Pākehā staff answered that they had attended a few or all of them at some stage, but often found themselves 'too busy' to go. Many would say that they are participating, yet I had never seen them at any Māori activity. This discrepancy shows that people actively control their image to their advantage (Goffman 1959), by presenting themselves as 'bicultural players' while in reality this was not so. Through participant observation I was able to validate whether their actions mirrored their verbal statements in interviews. Often they had good intentions to attend, but were not 'walking the talk'. The kaiako, Joan Costello, observes that the student numbers drop off every term as the novelty wears off and workloads increase:

When I first came here and started teaching te reo it was a huge uptake of who did classes and things which was really neat. That's fallen off a lot. Te Papa does have a high turnover so that does mean there's a lot of fresh blood that comes in and fresh blood's always like, 'yes, yes, yes, yes, yes' and really keen and then I wait for it and then they get stressed at work, and then I watch it fall over again.

On the other hand, staff are unsure about what level of participation and work time spent at these activities is acceptable for the organisation, having inner conflicts:

Well, I feel that it's okay for me to go to te reo every week. I think I don't go to the waiata because to me that's perceived as just another hour and you've already been to te reo. So for me, I suppose I feel an hour out of the week is okay, but to say I want two hours just is possibly not quite the way you should be doing things. And possibly a pow whiri every month would be okay but if they were every week, it might be a bit much. (new migrant woman)

Staff appeared to find it difficult to justify the time spent away from their desks when participation is voluntary and not recognised or rewarded in any way by the organisation. Front-of-house staff in particular struggle to attend any Māori activities 
during their work hours when they are expected to walk the floor or teach. In the past, attending some of the activities was part of the performance agreement (PA) that outlines what is expected of each staff member, as this Pākehā woman recalls: "It used to be that I attend so many pōwhiri, I attend te reo Māori blablabla, which gave credence to me going 'I'm not teaching' or 'block me out that day because I'm gonna go pōwhiri for my [PA]'. So that helped, but now that's all gone which is a bit weird." However, she is aware that the past practice could be abused "as token as well: attend five pōwhiri, tick, go to te reo Māori, tick. That doesn't stop somebody ticking those little boxes and then saying a couple of racist things around the corner."

At present, staff attending pōwhiri or other Māori activities outside their work hours are not paid or offered time in lieu; staff interpret this as a sign that their participation is not valued 'from the top' and therefore not important. These double standards were criticised harshly:

Te Papa as an institution as a whole doesn't recognise input as in offering time in lieu for people who do the early or the late pōwhiri or the weekend pōwhiri or that kind of stuff. And people go 'you do it of the goodness of your heart', when it still has to be recognised by the institution for having importance enough for us to go and be recognised for it! It's important that I take a tour and I get time in lieu for it, but it's not important that I attend a pōwhiri and get recognised for that - and it's not the only reason why I go to a pōwhiri at all just to get time in lieu, like it isn't the only reason why I do a tour - but it's not important enough by the institution. (Pākehā woman)

Making participation compulsory, on the other hand is not favourable with Hippolite: "I'm an advocate for voluntary participation. I think it elicits a different attitude towards what is taking place, and that will mean it has some trade-offs about the extent to which all staff participate in the process." Staff adopt this view that Māori activities are voluntary and something 'extra, rather than inherent', and given the choice, they might stay away. While this is a fact that the institution may need to accept, given the Māori/Pākehā ratio and the busy work schedules of staff members, being a bicultural organisation, it surprised me that more emphasis was not placed on encouraging staff participation in the Māori activities.

Celine Carlisle (2003) argues the managers' behaviour is crucial to the staff's perception of biculturalism at TP. If the manager buys in, then their staff is much more likely to do 
so, whereas if the manager is not supportive of biculturalism, staff also mirror that. Hippolite knows about the impact of managers' behaviour on their staff, stating: “Unless the behaviours are manifest at the leadership level, then there is no way that we should expect staff to participate where not even the leaders are expected to participate." In practice, high ranking staff are often absent from the Māori activities or participate in a passive way, not providing role-models to other staff. Likewise, when a manager is cynical about the usefulness of the language lessons, their staff is unlikely to embrace them fully. Some Managers seriously doubt staff's genuine motivation:

My observation of the te reo [classes] is that a lot of people go to it because it's interesting. But I don't actually see a lot of te reo being spoken by the people who have been to these te reo courses for one, two, three, four years. I don't see any change in their use of language or behaviour, which makes me a little cynical about why people go to it. Is it less to do with learning te reo and more to do with just having an hour break and having a bit of social time during work hours? (Pākehā man)

This assumption - although seldom said aloud - is quite wide spread. The staff who do attend Māori activities are anxious that others might think they are 'just going for the fun of it'. I experienced myself how 'pushy' or domineering managers can be when it comes to paying for their staff's participation in Māori classes. I was told in my job interview that I was allowed to attend the free Māori classes, so I joined up and put the extra hours on my casual employee timesheet. Every fortnight, when the manager had to approve my timesheet he struggled allocating the one extra hour per week and contacted me to enquire. This behaviour - whether an intentional strategy to keep staff from attending or not - can result in staff feeling pressured to withdraw, because they do not want to cause friction. Many other managers however, encourage their staff to go to the Māori classes and value it highly as it enhances their skills and understanding of Māori culture that is often necessary in their roles. Te Herekiekie Herewini, a Māori man and Manager of the Repatriation team, stresses:

I encourage all my team to participate. Because I mean, when we as a repatriation programme go and undertake meetings with iwi around the country we actually have to know how to whaikörero, we need to know how to karanga and we need to know how to waiata, and so those sort of sessions allow us to enhance what we know.

Non-Māori staff often feel out of their comfort zone and fear making mistakes. Many admitted in the interviews that they were 'scared' of one particularly staunch Māori woman. Yet, in the context of marginalisation of indigenous culture it is understandable 
that Māori feel the need to be fierce and loud in order to be heard: "[P] ractice has shown, time and again, that when indigenous voices are in the minority [...,] they need to be loud ones - and people quickly tire of shouting" (Sissons 2005:80). In this regard a Pākehā run Māori language class might be the answer, creating a learning environment where non-Māori feel comfortable. In the next section I therefore introduce all Māori activities at TP and analyse their potential as intercultural contact zones.

\section{Māori Activities as ‘Contact Zones’?}

\section{Māori Language Classes - A Pākehā Production?}

Given that te reo Māori is an official language of NZ (Māori Language Act 1987) and TP's language policy states that "the Museum makes a commitment to the use and promotion of te reo Māori as a language of basic communication" (TP Language Policy 1996), it seems logical that this public institution provides training facilities where staff can learn te reo Māori. The purpose of the lessons is to teach staff basic language skills, and give them an insight into Māori culture rather than make them fluent Māori speakers. Therefore "a commitment to wanting to learn or know Māori language" is expected of staff, as Hippolite points out, "because language and culture are inextricably linked. There are concepts embedded in Māori language that can't be explained in English either." Usually, there are six to twelve people in one class sitting around a group table. The tables are covered in coloured rods, teaching tools of the 'Te Ataarangi method', that the students use for building sentence structures and role-play. The teaching method 'Te Ataarangi' was developed in 1979 as part of the Māori language revitalisation movement to create a safe and supportive learning environment for speaking Māori. ${ }^{80}$ There are no grammar books and work sheets in the classroom (see photo in Appendix 11); instead the classes are based on language immersion with all instructions given in Māori.

Although TP employs a kaiako who runs classes at different levels, and staff are entitled to a one hour lesson per week during work hours, only about ten percent of TP's staff make use of the classes regularly. Invitations to all classes (except the advanced

\footnotetext{
${ }^{80} \mathrm{http://www.teataarangi.org.nz/} \mathrm{(accessed} 5$ November 2012).
} 
conversation classes) are sent via TP wide meeting requests that allow staff to sign up for the appropriate class with one mouse-click and automatically block the time in their electronic calendars. The barriers to participating seem very low, so why are not more staff attending the free classes? And why are the majority of students non-Māori with a high number of new migrants and only a few Māori among them? I argue that the answer lies in the 'framing' (Goffman 1974) of the classes which are run by a Pākehā teacher, and are held on Pākehā 'stages', and therefore perceived as being mainly for Pākehā.

It might seem paradoxical to hire a Pākehā as a Māori language teacher, a position that is usually considered a 'Māori job', but the decision was not taken lightly and seemed the right step at the time. Karl Johnstone, former interpreter at TP, explains what brought him and the then kaumātua, Te Ikanui Kapa, to this decision:

To me it's not really an issue about whether you're Māori or not. It's about Māori capability. We said, 'Okay, this woman's not Māori. Who is the audience? The audience isn't actually largely Māori, it's non-Māori. What's safe for them? Who had the best competency? Actually it was this non-Māori, who'd taught in Kura Kaupapa and had the right āhua [style], and the wairua [spirit]. (McCarthy 2011:123)

The Pākehā woman was very surprised herself that she got the job and needed some convincing from her Māori friends to take up the position, "because it would just be too scary" teaching Māori language and culture as a non-Māori under the surveillance of Māori staff at TP. From the beginning, some influential Māori staff have made it very clear that they did not approve of the decision to hire a Pākehā teacher and therefore would not support the kaiako in her role. Putting the kaiako position into the HR team instead of in Te Roopu Whakamana Māori contributed to the divide. Carolyn RobertsThompson considers this a mistake in hindsight: "In actual fact the te reo position should have been in that team, but at the time it was decided that it should sit in HR, from a training and development perspective." While having a Pākehā teacher has lowered the barrier for Pākehā staff and new migrants to attend, as they find the class room atmosphere less intimidating than other Māori activities, it has raised the barrier for some Māori staff, who struggle to learn from a non-native speaker. Attending class has become a political matter for Māori staff who might be seen as disloyal to 'their people'. Joan Costello is very aware of her controversial role: 
I did hear a comment that sometimes the odd Māori staff member feels they can't come and learn off me because I'm Pākehā. [...] But I do think being Pākehā [has] meant that it's opened the world up to Pākehà to share an experience of Mãoridom with an open heart and appreciation, and I'm really glad that I've been able to do that. But perhaps some Māori staff are feeling that it hasn't met their needs.

The absence of Māori staff from beginners' Māori classes could simply mean that they already have a good command of Māori, but this is not necessarily the case. ${ }^{81}$ I interpret the lack of Māori participation as "defensive and protective practices [...] to safeguard the impression fostered by an individual during his presence before others" (Goffman 1959:12). Māori staff have a reputation to uphold and protect their mana which could be weakened if they admit to not 'having the reo' by attending the beginners' classes, as the kaiako, Joan Costello, suggests:

And it's also big for Mãori to come into a class, [...] when the Pākehā students are grasping things and maybe they're not and it's huge because it's your language, y'know... What I have found at Te Papa is that some Māori staff don't have a lot of te reo but people think that they have a lot. And so there's perhaps pressure to keep letting people think they have a lot and people expect that they do, yeah.

It can be a humiliating experience for Māori to see Pākehā or new migrants pick up the Māori language easier than they do, even if it is simply due to the non-Māori staff 'having an ear for languages' or their privilege to have learnt several other languages previously. Some Māori may feel it is 'their language' that others are appropriating, while others realise that for the survival of the Māori language a significant uptake by non-Māori is necessary. ${ }^{82}$

However, there is a small number of Māori staff who do attend the classes at TP and speak very positively of the Pākehā teacher. For them it is often the beginning of their personal journey into Māoritanga as they sometimes sign up for Māori-run night classes

\footnotetext{
${ }^{81}$ According to Statistics New Zealand (2006) 23.2 per cent of the Māori population are able to converse in the Māori language.

http://www.stats.govt.nz/browse for_stats/environment/sustainable_development/key-findings2010/preserving-resources.aspx\#speakers (accessed 12 April 2013).

82 In the past, particularly the 1980s, there used to be more concern among Māori about other people appropriating their language. Joan Costello observed that this attitude has changed radically to the extent that all learners are welcomed. This view was discussed and widely accepted at the 2008 'Te Ataarangi Hui and First Indigenous Language Revitalisation and Teaching Conference' held at Mangatu Marae near Gisborne, which I attended.
} 
or immersion courses as a result of getting a taste of re-learning their language at TP; this was the case for a young Māori woman who grew up in Australia:

[I was] doing the weekly classes here with Joan [Costello, the kaiako] and she encouraged me to do night classes, so I was at Te Ataarangi three, six hours of classes a week and then tutorials on top of that and studying. It really pushed me in my reo to a level where I feel really confident in listening and understanding reo and also speaking it. So yeah, that's something I'll be forever grateful for.

If Māori do attend the classes, it is a compliment for Joan Costello: "It's so humbling, I love it when Māori are in the class and it's a total honour for me."

Interestingly, despite having a Pākehā teacher, the uptake among Pākehā staff is not significant either. Why is that? Pākehā seem to still struggle with their collective past as colonisers and have not quite arrived at a stage yet where embracing 'things Māori' comes naturally (Belich 2001b:543; King 1988). The relationship to Māori is influenced by 'Pākehā paralysis' (Tolich 2002) which stems from colonial guilt and anxiety to engage with Māori culture. Being Pākehā, Joan Costello had to deal with this 'baggage of guilt' herself. Her 'journey', as she calls it, started in 1990: "I came back from overseas at 27 years old. I came back very aware that I was really ignorant. I'd grown up in North Canterbury [South Island] and to be honest, I didn't really even know there was a [Māori] language still being spoken!" When she got invited to a marae she went out of curiosity: "I'd never been to a marae, never invited, didn't know how you went to such places." When she did the hongi for the first time, she had a life-changing experience ' $a$ bit like magic' that made her want to find out more about the Māori world. She then lived with Māori and went on a two year immersion course. She describes her time there as "pretty tough - being Pākehā", thus she can relate to her Pākehā students for whom it is a big step out of their comfort zone to learn Māori or stay on marae.

New migrants, like myself, on the other hand, are very keen participants in the Māori lessons, as in other Māori activities. I argue that new migrants are more open-minded towards Māori activities, because they see themselves outside the tangata whenua tangata tiriti binary. When they arrive in NZ, migrants start afresh from a neutral position; without the cultural baggage of guilt they can walk onto the 'minefield' of race relations (Tolich 2002), as Jonathan Mane-Wheoki (1995:20) asserts: “In my 
observation, outsiders have often succeeded in getting to grips with the issue of cultural relativity in New Zealand sooner, and more effectively, than their Pākehā counterparts". The kaiako's experience backs this argument: “Overseas people do it [attend Mâori lessons] far easier than those of us that have grown up here with all our past history, and our past embarrassments and shames and scariness." A woman who immigrated to NZ from England shares this view:

My observation would be that immigrants to varying degrees want to fit in [...] It's been an active decision to come and live here and I think that applies an appreciation of New Zealanders and New Zealand lifestyle and everything about New Zealand, part of which is biculturalism. So I think we tend to embrace or be more open to learning than people who have been brought up here. And we haven't got any of the prejudice and the baggage, which I sometimes see exhibited by people who have been born here.

An indication of this is that although the kaiako invites all her students to come along to marae stays "it's only the foreigners that have the strength to come". Perhaps being uninformed and ignorant towards the delicacies of NZ race relations means the new arrivals face fewer barriers towards participating in Māori activities.

I also noticed during my fieldwork that the uptake was greater among staff working front-of-house than back-of-house. I attributed this discrepancy to the need for conversational language skills when interacting with Māori audiences and presenting the bicultural Museum to the public. Back-of-house staff have more flexible timetables than the front-of-house staff, but nevertheless, they are more likely to drop-out because of tight deadlines and meetings getting in the way. Furthermore, if they have little Māori exposure in their team or with clients they do not see any professional benefit from attending. If they do attend, it is often out of personal interest in the culture as well as a sign of good-will:

I don't know that it actually is important for my work. I can't think of any instances where I've actually used the very small amount of te reo that I know in the work situation. However the broader aspects of the te reo lessons start to give me an inkling of Mâori world views and Māori thinking on things, which I'm enjoying learning more of and as time will go I think it will figure more in what I do and how I approach the research [...]. I try and put my macrons over Māori words when I'm typing things, because I think it's important; for me it's important to demonstrate that I am trying. (Pākehā woman) 
Again, this emphasises Goffman's sociology of interaction (1961) and selfrepresentation theory (1959) of people manipulating how others' view them, by presenting themselves in the way they want to be perceived.

Managers are largely absent from the classes which seem to attract more staff from the lower ranks. The managers' tight time schedules are one explanation for this, but it might also be due to the egalitarian classroom setting that makes them students and therefore bears the risk of them 'losing face' in front of their subordinates, as the Joan Costello suspects: “Oh, I hardly ever get managers. [...] Because y'know, they've got a position to hold and they don't want to show that they feel really out of place." If Māori staff are anxious to uphold their mana, managers are anxious to uphold their status according to hierarchical rank; therefore their non-participation can be interpreted as a protection mechanism as the possibility of losing prestige is too high for them.

\section{Māori Language Classes as Contact Zone}

The classes and mini-courses are very useful for the everyday use of greetings and phrases at TP as well as in e-mails and on the telephone. Many staff who attend the classes reported that it was their entrance to understanding Māori concepts and world views and they cherished the opportunity to stay on a marae outside of TP as a firsthand Māori experience. ${ }^{83}$ They provide an important insight into te ao Māori that non-Māori staff would not have otherwise, unless through personal contacts. Although the fact that the current kaiako is Pākehā has its own challenges for a group of 'tribal Māori' staff who would rather see a Māori in this position, it has opened a door for some 'ethnically', urban Māori and non-Māori staff to learn about Māori culture in a 'safe environment'. Moreover, the classes offer a space to discuss Māori world views, mediated by the Pākehā teacher, but enacted by the Māori and non-Māori students who engage in a cross-cultural dialogue. For those attending, the classes really are a contact zone.

\footnotetext{
83 Joan Costello invites her students along to regional and national hui organised by the Te Ataarangi network of language schools. These meetings include pōwhiri, staying on a marae overnight, sharing food and attending workshops on Māori language and culture.
} 
In addition, the classes are a chance for staff to meet others they do not usually work with: "It's a good way of connecting with people from around the organisation as well. People I would never come across, like the hosts, because they're all front-of-house." In an organisation with about 500 staff in two different buildings this social aspect is not to be underestimated and knowing staff face-to-face contributes to better work relationships. For one hour the hierarchies give way to the equal relationship that comes with being language learners with the same proficiency, regardless of the rank they hold. For frontof-house staff going to the Māori classes is one of the rare occasions to cross the boundary to back-of-house spaces on level three (most front-of-house desks and the staff room are located on level two) and see 'what the office staff are doing'. The Māori activities are therefore excellent places to build 'communities of practice' (Wenger 1998) across TP where staff can collaborate and learn from each other.

\section{Waiata/ Kapa Haka Practice - A Māori Production?}

If the Māori language class is a Pākehā production, then the waiata sessions are a Māori production, as they are held on the marae, led by Māori and are mainly frequented by Māori. Although a few Pākehā and new migrants take part in the weekly rehearsals, when it comes to 'show time' at haka pōwhiri or kapa haka competitions, it is mainly Māori staff who have the skills and confidence to perform. ${ }^{84}$ Some Māori staff seldom attend the practices, but might perform nevertheless, because they know the songs and actions already. Non-Māori staff on the other hand might go to the practices quite regularly but do not perform in public. Depending on the teacher and the urgency of the practice, between two and 40 people attend. Generally the more enjoyable the sessions and the closer to an important pōwhiri, the more people are likely to participate. On average, a small group of ten people gather, most of them Māori and a few new migrants; Pākehā only take part very occasionally. While some staff commit 'almost religiously' to it and form the 'hard core' of the kapa haka group, others choose not to attend. Since I really enjoyed learning Māori action songs and waiata myself, it initially puzzled me that others seemed to steer well clear of waiata practices.

\footnotetext{
${ }^{84} \mathrm{At}$ a pōwhiri all people in attendance are participating in the ritual. However, to distinguish more active participation (such as doing the haka) from passive reception, I use the term 'perform'; this does not suggest an inauthentic 'show'.
} 
In order to shed light on the complex issues at play, I present three distinct views based on several interviews with members of the kapa haka group, using fictional characters: Susan (a 50 year old Pākehā woman), Stephanie (a 30 year old new migrant) and Tui (a 35 year old Māori woman). ${ }^{85}$ This technique of "[p]utting together these three 'viewsfrom-somewhere' can demonstrate the complexity of the problem and why no single person is capable of tackling it" (Darrouzet/ Wild/ Wilkinson 2009:79).

\section{Perspective 1: Susan (Pākehā woman, 50 years)}

Susan tries to get to the waiata practices on a regular basis "because I actually like singing". She wants to learn the words to the waiata sung at blessings and pōwhiri, as she finds it embarrassing when only a few are singing. However, "often I don't get to the waiata as much as I'd quite like to", she says, because she is too busy at work and thinks she is not entitled to another hour away from her desk. When she attends, she comes prepared with the song sheets she printed off, but finds herself out of her comfort zone very easily when the teacher asks the participants to drop the sheets, as she does not know the lyrics by heart. Action songs are not her thing as they require coordination, and Susan would never perform on stage, being too shy and uncomfortable in a Māori setting. If the waiata at a pōwhiri is changed impromptu, she is lost and feels offended. Susan has also suggested that the waiata sung before all staff meetings be projected onto a screen so that everyone could join in, but nobody has adopted her idea yet. Her enthusiasm has waned significantly, because she often feels excluded when waiata are sung that she does not know. To her, the Māori staff seem a 'closed circle' who fail to acknowledge her efforts. Nevertheless, Susan continues to go as she can see how it positively affects her attitude towards Māoridom: "I've learned so much more about the manner of Māori people because before the only exposure I had was the negative press stuff."

\section{Perspective 2: Stephanie (new migrant, 30 years)}

First, Stephanie attended the waiata sessions out of curiosity, but due to her long-term commitment and her ability to learn the action songs quickly, she became an accepted

\footnotetext{
${ }^{85}$ As the majority of participants are female, it seemed appropriate to chose the characters' gender accordingly.
} 
member of the group, often performing kapa haka in the front row. She embraces all the Māori activities TP offers as she is very aware "you wouldn't have that at any other organisation." She is also a vital part of the taonga pūoro group as she can play different instruments and is a reliable performer.

Coming from Europe originally, Stephanie made a conscious decision to immigrate to " $a$ Pacific Island, called New Zealand" and was fascinated by Māori, the 'first people', whom she supports in every way she can. She was very surprised that not everyone at TP shared her attitude, "especially when it's people who have lived in this country all their life or certainly for a lot longer than I have and they demonstrate a shocking lack of even the most basic knowledge of what it means to be Māori in New Zealand at this time." She admits, "I used to be scared of [the teacher]", but she has since learned to not take her 'growl' personally and nowadays she feels fully included: "We're family here!" Stephanie is grateful for the opportunity to get a glimpse of the Māori world through waiata practice while improving her Māori skills, and speaks fondly of marae stays. A highlight for her was performing at the Kapa Haka Regional Competition: "I will never forget this experience."

\section{Perspective 3: Tui (Māori woman, 35 year)}

For Tui, not attending waiata practice is out of the question; she simply goes every Thursday as "that is the way I was brought up." Similarly, she actively participates in blessings, pōwhiri, plays taonga pūoro and performs in the kapa haka group "to tautoko the kaupapa and support the whānau." Tui's motivation is twofold: "It's a sign of solidarity that when we do have pōwhiri we can all stand up and know the words, know what we're singing... [it also] helps develop my own cultural side." In other words, she feels obliged to go, yet also sees it as a path to Māori emancipation. She gets annoyed with non-Māori staff who do not attend waiata with the excuse that they cannot sing: "Ah, grow some thick skin and practice singing in the shower!"

Tui explains that waiata is not just about singing, but a way of expressing one's emotions and communicating with each other: 
What people don't understand - "oh, but I don't sing. Don't like being on public display", a lot of people say that - but it's actually more than that. What they don't realise is that being able to sing [waiata] is another expression and it does help you to be able to get your tongue around the language.

When it comes to performing Tui notices that the non-Māori withdraw and leave the Māori staff to it; sometimes this obligation weighs like a burden on the shoulders of the Māori staff:

But I think [non-Mãori] see their role in that group as just being temporary. They come and go, whereas there's a hardcore group that goes regardless and it continues to sustain those practices, as long as we're all in the building, y'know. If we're away there's nothing you can do about it. So that has an impact, because then, if there's no succession planning and there's no more people coming through to continue learning those songs [we lose this capability].

Tui criticises the status quo and how it reflects that TP is not a bicultural institution yet: "As much as I love it, waiata has become almost a domain for, again, Māori and sympathetic non-Māori."

\section{Waiata/ Kapa Haka Practice as Contact Zone}

Waiata practice is not just 'singing lessons' as many non-Māori staff assume, giving it little value for their professional roles, but a method of teaching through songs and more importantly a means of preserving Māori intangible heritage (Alivizatou 2012). Moreover, as Barlow (2005:151) stresses, waiata "is a medium through which sacred and profane knowledge is passed from one person to another". Therefore, the sessions are predominantly a Māori technique of empowering their own and are by no means public entertainment, albeit the fact that the practices occur in the public sphere on TP's marae. This is often visible in the group formation facing the stage or forming a closed circle, facing each other while turning their backs to curious museum visitors. In other words, waiata practice is a contact zone by Māori for Māori, where 'urban Māori' engage with 'tribal Māoridom' and ancient Māori culture through waiata. ${ }^{86}$

Although the sessions are open to all staff, what is noticeable is the dominance of Māori who control the lessons as well as select who performs at competitions. Non-Māori who

${ }^{86}$ Saying that, not all Māori staff participate and some urban Māori object to these displays of traditional Māori culture and stay away. 
are uncomfortable with this reversal of power do not attend, and Māori do not go out of their way to include them. However Rhonda Paku, a Māori woman and then Manager Iwi Development for NSTP, notes that "when non-Māori come to waiata, [I] have to resist jumping all over them when what I want to say is, 'Oh yay! Good on you for coming!"' While this might be true of her personal attitude, in my experience and that of some non-Māori colleagues, it is not always the case that non-Māori are welcomed with open arms at waiata; rather they are tolerated but often excluded by not being greeted or talked to. Even the few non-Māori who commit to performing at kapa haka competitions sometimes feel like intruders, as well as disadvantaged, lacking years of experience compared to their Māori counterparts. Being in a Māori domain can be 'scary' for nonMāori, yet the benefits for the ones who 'stick it out' are invaluable: an insight into Māori culture in the form of waiata, tales about the 'olden days', jokes, bonding, absorbing and living all facets of Māori culture.

In this sense, waiata practice is a contact zone very much framed by the indigenous peoples, like the one Clifford (1997) encountered at the Portland Art Museum, where Tlingit people performed for themselves rather than the museum professionals. That Māori are setting the frame marks a step towards indigenous sovereignty, regaining control over their intangible heritage. Singing is particularly suited to create group cohesion, because, as Durkheim (1976 [1915]:230) argues, "it is by uttering the same cry, pronouncing the same word, or performing the same gesture in regard to some object that they become and feel themselves to be in unison". Thus, solidarity is best expressed “by participating as a group in symbolic action” (Kertzer 1988:62).

\section{Taonga Pūoro - A Space for Improvisation}

Looking at the taonga pūoro group with a balanced cast of Māori and non-Māori actors making music with Māori instruments together, the metaphor of contact zone is strikingly apt. The weekly practices are staged on the marae (arguably the Māori stage), opened with karakia, yet the leader is a Pacific Islander, and non-Māori participate to the extent that they sometimes lead the lessons. I argue that a combination of factors makes this possible: Firstly, the art of making and playing Māori instruments was 
almost lost (Flintoff 2004). Secondly, one of the pioneers in NZ to revive taonga pūoro and teach Māori this almost forgotten art, was a Pākehā, Dr. Richard Nunns. ${ }^{87}$ Thirdly, playing the instruments involves musical skill that all participants have to learn. This means the playing field is even, as the ability to participate does not depend on cultural skills, but rather previous musical experience or a willingness to learn.

As the taonga pūoro practice invitations only go out to staff who are already part of the group it can be a mystery for other interested staff how to join. Entry is often granted spontaneously, as was the case with this Pākehā woman: "I heard them play one day, it might have been at a blessing or something, and I asked if I could have a go, and he gave me his pūtātara and I just blew it and he said, 'Right, you're coming to practices.' I used to play the trumpet so that made it a lot easier." Māori and non-Māori can engage in an intercultural dialogue having in common a passion for the Māori instruments. As nobody in the group can claim to be an expert at playing taonga pūoro, the sessions are improvisation acts, leaving room for experimentation as well as exchange of ideas between staff of diverse backgrounds.

The non-Māori are a crucial part of the small group of about ten staff members who are constantly in demand to play at pōwhiri, blessings, staff anniversaries and concerts. A highlight for all members are wānanga held at a marae outside TP every couple of years, where during the three days of workshops participants are immersed in Māori culture, eating, sleeping and making music together (see photos in Appendix 11). Given the mixed ethnicities of the members, the notion of improvisation and the intercultural exchange between people, I suggest that this staff initiative is the best example of a contact zone within TP, albeit small and intimate in nature.

\footnotetext{
${ }^{87}$ http://apra.co.nz/apra-awards/new-zealand-music-hall-of-fame/hirini-melbourne-richard-nunns.aspx (accessed 10 July 2009). Hirini Melbourne and Brian Flintoff also played keyroles in revitalising Māori musical instruments. See also Paul Wolffram (forthcoming) Nga Reo O Te Whenua: Voices of the Land. Documentary Feature about Richard Nunns and traditional Maori Instruments.
} 


\section{Whaikōrero and Karanga Workshops}

In contrast, the whaikōrero and karanga workshops are examples of Māori autonomy within the organisation. The purpose of the workshops, which are referred to as wānanga and run by a Māori elder, is to increase the pool of Māori who can be called upon for fulfilling these important roles at pōwhiri on the marae, therefore they are by Māori for Māori. Non-Māori are not only excluded from participating, but also from observing the passing on of knowledge. ${ }^{88}$ Māori are sometimes reluctant to pass on their knowledge to the younger generation, let alone non-Māori, which can be understood in the light of mātauranga Māori, which is believed to be a prized possession, "first brought down from heaven by the god Tane in the kete tuauri, one of three 'kits of knowledge', and has been tapu ever since" (Salmond 2009 [1975]:121). When an elder dies without having passed on the knowledge, it is lost, but if the knowledge was openly shared, it loses its mana and can be commercialised. Hence I respect deeply the Māori quest for knowledge transfer and practice in secrecy, protecting a 'Māori only' space within TP that can enhance Māori empowerment. The format of these wānanga does not fulfil the criteria of contact zone as it goes beyond 'Pākehā engagement with Māori' towards Māori self-determination.

\section{Talking Past Each Other - Intercultural Misunderstandings}

As is visible from the analysis of the participation in Māori activities at TP, it seems that often staff are 'talking past each other' (Metge/Kinloch 1978), unable to see beyond their cultural bias in order to open up a cross-cultural dialogue. I use the examples of Māori laughing at people who mispronounce Māori words, Pākehā criticising the commercialisation of Māori culture, and the misinterpretation of changing the selected waiata as Māori 'purposefully excluding' non-Māori. These incidents might look like 'innocent every day interactions' (Kincheloe and Steinberg 1997) at first glance, yet hegemonic practices at the micro-level are often overlooked and as Doerr (2009:169) argues, it is in this arena that "oppression accomplishes its hurtful work".

\footnotetext{
${ }^{88}$ I asked the facilitator if I could observe the workshops, but was told that this was for Māori only and that my presence would disturb the proceedings.
} 


\section{Laughing - A Corrective Device}

When Māori speakers publically laugh at mistakes by non-Māori trying to speak Māori, it is often perceived as nasty or rude behaviour, yet here I suggest laughing is utilised by Māori strategically to make a statement. Māori pronunciation rules are easy to learn, so why do so many Pākehā mispronounce Māori words? For Māori it becomes a matter of disrespect for Māori culture and they feel rightly offended by it (Mead 1997; Ballara 1986; Kāretu 1995). Ignorance is by no means innocent in the light of NZ claiming to be a bicultural nation, hence "public mispronunciation/ anglicization of Te Reo words indexes tokenism of the bicultural nationhood" (Doerr 2009:163). Joan Metge and Patricia Kinloch (1978:34) stress that although they appear to "laugh it off, Māori resent mispronunciation as a 'sign of unwillingness to make the effort'". Analysing the phenomenon of Māori students laughing at teachers who mispronounce Māori words, Doerr (2009) observes that by this 'shaming exercise' Māori students demanded respect for the Māori language, marking their authority over it. However as a result of being laughed at, Pākehā teachers avoided speaking Māori in the presence of Māori students.

The fact that mispronouncing Māori is a political issue can only be understood against the background of te reo Māori being a significant part of the orally-based Māori culture: te reo Māori is a taonga and "the very essence of all things Māori. Without it, all else becomes meaningless and pointless" (Kāretu 1995:214; also see Mead 1997). In the words of one of the founders of the Kōhanga Reo movement, Sir James Henare, "the language is like a cloak which clothes, envelopes, and adorns the myriad of one's thoughts" (Ko te reo te kākahu o te whakaaro te huarahi i te ao turoa o te hinengaro; Nepe 1991:15). Consequently, Māori perceive mispronouncing their language as an insult to Māori culture and Māori in general.

Laughter can be used as a powerful "political weapon" (Meredith 1956:39); carnivalistic laughter, for example, “corrects men’s manners” (Bergson 1956:71) and socially unapproved behaviour. Ultimately, in NZ concern about language is often a substitute for concerns regarding race relations (J. Hill 2001; Woolard 1998; Doerr 2009). Michael Schröter (2002) examining an unpublished 'Essay on Laughter' by Norbert Elias, asserts that laughter, although sometimes perceived as aggressive, is never a physical attack, as 
“who laughs, can't bite". However, Elias concludes that laughing at somebody generates group-solidarity while excluding the object of the laughter.

While the person being laughed at criticises the Māori behaviour as rude and disrespectful, Māori strategically use it to demonstrate their rejection of 'playing along' and more broadly, the hierarchical 'regime of difference' (Doerr 2009). What is really at stake is a quest for power and authority: by laughing, Māori are acknowledging a person's authority (the person should know better), while at the same time denying them authority (persons who do not know should not have authority), as Doerr (2009:166) suggests: "By revealing [...] ignorance of Te Reo, the [...] laughter challenged the token use of Te Reo in Aotearoa/New Zealand's bicultural national imagining". Thus, laughter becomes a corrective and assertive device for Māori.

\section{Māori Teaching Style}

As I have shown examining the waiata practices, non-Māori struggle with a 'Māori teaching style' and are easily out of their comfort zone. Unlike the Māori language lessons, waiata sessions are largely unstructured and seem chaotic and arbitrary to outsiders who are used to Western choir rehearsals. Often there are no song sheets, accompanying music or voice warm-up, and participants burst into song randomly following the lead of the Māori leader. Some non-Māori criticise the sessions as 'nonprofessional' and the core Māori group as 'exclusive', but instead I see the non-existence of a set structure as applying the Māori pedagogy of immersion. Although weekly practices might happen on local marae, waiata are mostly practised informally while waiting, cooking or on a long bus trip (Salmond 2009 [1975]). ${ }^{89}$

The Māori pedagogy practised on marae is immersion, and "there are always children and young adults about" (Salmond 2009 [1975]:122) who soak up the rituals by watching and listening without being formally taught. Likewise, language learning happens around everyday tasks in a Māori setting, rather than in the classroom, as a Māori staff member told me: “Waiata, mōteatea are the best way - karanga, whaikōrero

\footnotetext{
${ }^{89}$ I experienced this practice several times myself on the bus to Te Ataarangi hui.
} 
- you will pick it up constantly. It's the way to learn the language." However, some Māori can relate to staff feeling out of their comfort zone at practice due to the way the sessions are run:

It all needs to be a bit more coordinated and helpful, especially when you feel like you're going to get your head bitten off if you stand up at the wrong time or whatever. It can be intimidating and it's not just for non-Mãori. There's a lot of Māori that have been shot down in front of everybody at the wrong time.

Therefore one Māori woman suggests that the format of the waiata sessions should change and receive a more significant status from the TP management as a training tool for all staff, bringing across "that we're not here for the shits and giggles! We are an important staff initiative." While Māori believe that learning is best achieved by being exposed to and immersed in Māori culture, they also conform to a Western framework that favours teaching in a structured way in order to be taken seriously.

It happens often at TP that an e-mail outlines the sequence of events at a pōwhiri or blessing including which waiata is to be sung, yet at the occasion another waiata is chosen on the spot without prior warning. Non-Māori who prepared themselves by printing the waiata and learning the words are understandably frustrated by this sudden change of proceedings. Yet this frustration demonstrates their ignorance of Māori protocols, as it is sometimes appropriate to sing a different waiata in order to complement the previous speech. Underpinning this practice is the principle of ea, meaning "meeting the requirements of the occasion" (Mead 2003:118), by making appropriate adjustments to the ritual. Furthermore, waiata is used as powerful commentary on marae proceedings by women who are traditionally not allowed to speak, as Whiting states: "You see, women can stand and sing on a marae. So interesting ways around [not being allowed to speak], eh?" Māori staff are usually much more understanding of this practice, although they too can get 'caught out' when they do not know the waiata selected. However, they are more likely to adjust and sing along, as "each tribe has its own extensive repertoire for all kinds of situations" (Barlow 2005:151).

Some Pākehā interpret changing the waiata as a deliberate Māori strategy to exclude non-Māori: 
I find some Māori staff not helpful at all! There is an arrogance that I find unnecessary and irritating. One example is that I brought my song sheet to a pōwhiri so I knew what song we'll be singing, I'm prepared, but then they start to sing another waiata. I don't know that one and therefore I'm excluded and can't sing. I don't know why it was changed, there might be a good reason for it, but it doesn't contribute to get more people singing. Then it is only the Māori people singing again! I make an effort, but it seems pointless.

(Pākehā woman)

When people are excluded because they do not know the song, they feel deprived of active participation in the event. Looking at what languages a national anthem is sung in is a strong indicator of who is included in the 'we' of the nation, and who is entitled to 'belonging', as "singing is a plural act, an articulation of plurality" (Butler/ Spivak 2010:59). By changing the selected waiata Māori appear to exclude non-Māori, but I stress that it is not an act of sabotage, but a result of cultural requirements. Clearly this cultural misunderstanding highlights the need for contact zones and intercultural training to mediate those different perspectives, which presently is not being achieved.

\section{Pōwhiri - A ‘Battle Ground’?}

As we have seen at the beginning of this chapter, pōwhiri at TP are utilised as rituals of encounter between groups within TP (like at the induction pōwhiri). More often, however, pōwhiri occur at the interface of TP and the outside world (when external clients or iwi are welcomed), again providing a contact zone. Examining the issues of commercial pōwhiri and of speaking English, I suggest that the marae can become a battle ground, where the power struggle between Māori and non-Māori, as well as differences among Māori themselves surface within the organisation. The metaphor of 'battle ground' corresponds with the Mãori belief that the marae atea is the domain of Tümatauenga, the god of war, therefore the marae is the place to have heated discussions. ${ }^{90}$

One reason that keeps some non-Māori staff from attending pōwhiri is the perception that they 'happen too often' and for 'the wrong reasons'. Some of the interviewees criticised the practice that external clients can request a welcome pōwhiri if they pay for

\footnotetext{
${ }^{90} \mathrm{http}: / /$ www.maoridictionary.co.nz/index.cfm?dictionaryKeywords=tumatauenga\&search=Search (accessed 12 April 2013).
} 
it ${ }^{91}$ as 'dial a pōwhiri'. Interestingly, it is mostly Pākehā who find this practice problematic:

I was like "So people can ring up and book a pōwhiri?" - "Yeah" - "So we are just really selling them a pōwhiri?" - "Yeah". So I was sitting there and I'm thinking it is not too different from any other tourist exhibition, really. And we got into talking about it and I said to [the Māori elder] at the time, "With respect, that actually concerns me that we're actually doing that because in some ways that is devaluing the culture, it's commercialising the culture!" And I think [the Māori elder] was a little bit surprised. But the rationale at the time had been 'we do this because it helps the business group to make money' and all the rest of it. But it's kinda like dial-a-pōwhiri, like dial-a-pizza! (Pākehā woman)

While the criticism is certainly justified, this statement also tells us something about Pākehā assuming that Māori must be authentic and keep their rituals pure and traditional; economic ambitions are out of place with this notion, which Sissons (2005:37) terms 'oppressive authenticity'. That Māori may gain financially from cultural performances without compromising their cultural identity, is not a possibility within the mind frame of some Pākehā. Most Māori staff, in contrast, do not feel paid pōwhiri are any less authentic displays of their culture.

Attending pōwhiri seems to be a choice for non-Māori staff members and they select carefully which ones they support, as this new migrant points out: "If I've no idea who on earth it is and why on earth they're there, then I probably won't. I don't as 'rent a mob'. I don't go just because there's a pōwhiri going on because again it's taking time out from the work which I see I'm here to do." This means that sometimes, particularly at powwhiri for external clients, only a very small group of TP staff is present to welcome the manuhiri, seriously compromising the Māori principle of ea (Mead 2003) as this Māori woman explains:

We have had several occasions where there's just no one here, on the day when some random group turns up, of that seniority and of mana, and suddenly we're all called on to get ready for paepae, to karanga, do whakatau, do mihi, do waiata, whatever they need. We're seriously compromised as an organisation to truly reflect and illustrate our bicultural commitment here. We just couldn't call on any member of staff to jump in here and do a waiata, and you'll need to be equipped. We've got no 'Brownies' in the house to come out! The place is just not that, and yet I think a few of you [non-Māori] could pull it off, but it needs leadership. Y'know, if the likes of [the hard core Māori group] are away, all

${ }^{91}$ This practice is also common on other marae, where families pay a fee if they want to hire the venue for a twenty-first birthday or wedding (see Salmond 2009 [1975]:93). 
out of the office at once, again it compromises our capacity to do that with integrity and to do it correctly.

The few non-Māori who make an effort to attend pōwhiri feel 'embarrassed' about their colleagues' lack of commitment, which they perceive reflects badly on the whole organisation. Paradoxically, this in turn leads to them staying away in the future.

For many Māori staff on the other hand it is an obligation to attend as many pōwhiri as they can, because 'someone needs to do it' and they want to show support to their fellow colleagues. They occasionally see it as a burden, yet they still attend, as this Māori woman states: "Because, it's quite demanding you know, we are expected to be at the pōwhiri, we are expected to be at every blessing, because it's part and parcel of who we are. They are the values that we see out there on the floor and that's the extra mile that we do." Jonathan Mane-Wheoki explains this discrepancy between Māori and Pākehā behaviour in the following words:

Biculturalism in the organisation I suppose is assumed to be a Mãori thing. All Mãori have to be bicultural. It's compulsory, they don't have any option, whereas Pākehà seem to be able to opt in and out of it and given the choice they'll opt out. The playing field there is not level.

Māori staff are often seen as bicultural per se, because for them it is necessary to straddle both the Pākehā and Māori worlds with ease on a daily basis, whereas Pākehā can choose the degree of their involvement with biculturalism. This leads to a feeling among some Māori staff that it is largely left to them to uphold biculturalism by performing Māori activities, and that the organisation does not provide adequate resources and rewards to uphold this important principle:

We [Māori] end up carrying the responsibilities of the organisation: whakatau, pōwhiri, repatriations. If we were truly bicultural it wouldn't be that way, everyone at some stage, like te reo classes, would be expected to go through classes to learn the waiata, repatriations, learn the tikanga, but it's not treated the same way. We don't have a dedicated person who can do that with all the staff here if they sign up to it. It still needs to be optional, but it needs to be pitched in as much the same way as te reo [class] is: dedicated person contracted to provide $X, Y, Z$ to all the staff who sign up, who volunteer to be part of it and if they want to continue doing the Thursday sessions for performance, then they have every opportunity to do that too. (Māori woman) 
While some Māori would like to see more Pākehā actively supporting the Māori rituals, most are not prepared to make concessions to non-Māori such as translating speeches at pōwhiri into English, let alone introduce an English-only policy on the marae.

\section{English at Pōwhiri}

Generally, on tribal marae outside TP all speeches at pōwhiri are entirely in te reo Māori. At TP in contrast, sometimes it is acceptable to speak English or other languages after a karakiawhakawātea; this policy allows non-Māori to make a speech, for example representatives of overseas institutions repatriating kōiwi tangata. Most of the time however, Māori is spoken, and hence people who cannot understand Māori are excluded from the proceedings. How does it feel to experience a pōwhiri without understanding anything that is said? Mark Donovan, Director Experience, was welcomed with a pōwhiri straight after arriving from the United States on his first day at TP; he describes it as a spiritual experience: "It felt, I would say, it was spiritual. It had a spiritual [component], sort of like going to church, it felt a lot like church. It felt a lot like I was back in my Catholic schools days, where I knew Latin [...]. It had that type of spiritual, reverent connotation, emotive presence about it."

It is a widely held notion that restrictions placed upon contact and the maintenance of social distance provide a way in which awe can be generated and sustained in the audience, a way, as Kenneth Burke (1945) has said, in which the audience can be held in a state of mystification in regards to the performer (Goffman 1959:59). When staff experience pōwhiri as a spiritually charged ritual which speaks to them emotionally, it seems they are indeed put into a state of mystification. This effect is certainly aided by alienation as most TP staff cannot understand what is being said in Māori, which emphasises the distance between themselves and the Māori speakers. The stage presence of the Māori actors mastering the act of whaikōrero with verbal and nonverbal vocabulary furthers the mystification process. In this regard, the choice not to translate the speeches into English could be interpreted as a technique to maintain an advantage for Māori speakers, and perhaps even intimidate non-Māori speakers. It is a means to gain and maintain Māori authority on the marae. 
While some staff still "enjoy the spiritual side of it", others prefer the speeches to be translated into English. When I confronted some Māori staff with this request, I noticed that they became very defensive. Their reaction made me realise that the language spoken on the marae was a political matter, as the marae was one last bastion where the Māori language, and consequently Māori, prevail. Some Māori staff believe even nonnative speakers can get a sense of the speeches as they follow a set pattern, and therefore do not need to be translated (which TP does not have the resource to do currently). Additionally it should give staff an incentive to learn Māori, as this Māori woman demands: "For me, it's 'go to your Reo class and get the basics, mate!' Because guess what? Most people will start their whaikōrero with 'hello everybody, this is who I am, greetings to the house up there, greetings to the moana out there, this is my mountain, this is my river, this is who I am." Similarly, another Māori woman believes staff attending pōwhiri can simply learn by exposure:

[Given] the amount of pōwhiri we have on it doesn't matter if you don't understand, but just being there and listening. This is where it all picks up, it's the listening, it's not so much 'oh I don't know and am I doing the right thing?' You watch, you listen and you observe. That's where the learning is. What gets clouded up here (points to head) is that you are too worried about 'well, am I doing the right thing?' That's what clouds all this. So if they can just let it all go [they will learn].

This argument fits with Eric Schwimmer's (1968:18) claim that "it is on the unconscious, symbolic level that genuine biculturalism has its genesis". Therefore when non-Māori are exposed to Māori culture, they might embrace biculturalism subconsciously or, as David P. Gardner, Professor of Education, reportedly stated: "We learn simply by the exposure of living. Much that passes for education is not education at all but ritual. The fact is that we are being educated when we know it least." Māori singing is said to have a 'haunting and compelling' quality to it that immediately touches people and moves them emotionally, as Mead noticed in the enthusiastic, sometimes tearful reactions by the American audience of Te Maori (Mead 1986:38).

However, it is important to acknowledge that Māori are not a homogenous group with the same goals; and a few Māori wholeheartedly support translating the speeches into English, because it would make the ritual 'more comfortable' for non-Māori, especially 
in a bicultural institution: "There should be some sort of interpreter to actually let the staff know what it's all about, I really do [believe that]." Kukupa Tirikatene, the Ngāi Tahu kaumātua, also advocated for translating the whaikōrero into English. From travelling internationally he knows firsthand what it is like to listen to speeches without understanding the language, as he jokingly shares: "The only thing that was responding to me, my blommin' bum was getting sore sitting on the seat!" Although he tried hard to push for bilingual pōwhiri at TP, he had to surrender at the opposition, saying that 'the power game' was too tough from his own people. Still, Tirikatene wonders if this practice follows the principle of 'manaakitanga' and asks: "I know what it is like for people to welcome you and you wouldn't have a clue what the hell they're talking about. Is that fair?"

I suggest that much more is at stake here than simple matters of linguistic comprehension, because the pōwhiri on the marae at TP are spaces of indigenous formation as well as places for constituting and maintaining Māori power, while rejecting Pākehā domination. This corresponds with Clifford's (1997:218) reading of ceremonies as manifesting boundaries and enhancing indigenous identity:

When a community displays itself through spectacular collections and ceremonies, it constitutes an 'inside' and an 'outside'. The message of identity is directed differently to members and to outsiders - the former invited to share in the symbolic wealth, the latter maintained onlookers, or partially integrated, whether connoisseurs or tourists.

During pōwhiri at TP the actors and stage-managers are mainly Māori, whereas most non-Māori are spectators. While the ritual protocol pushes non-Māori to the periphery and rejects hegemonic control, it enhances Māori autonomy. Perhaps then pōwhiri can be interpreted as staged performances that are 'indigenous projects' which "turn the pedagogies of liberation. They are not purely utopian, for they map concrete performances that can lead to positive social transformation. They embody ways of resisting the process of colonization" (Denzin/ Lincoln/ L.T. Smith 2008:12). In consequence, I read the marae space within TP not only as a place for encounter but moreover a model for the "radical utopian spaces [we need to create] within our public institutions" (Denzin/ Lincoln/ L.T. Smith 2008:13). Inside TP, which is still largely dominated by a Western hegemony, Rongomaraeroa is a symbol for Māori selfdetermination, providing a Māori stage where Māori futures can be enacted. 


\section{Marae - The Centre Stage For Biculturalism?}

It is no coincidence that most of the Māori activities at TP are staged by Māori on Te Marae, which in my opinion is not only the 'heart of Te Papa' (Te Papa marae brochure) but also the 'centre stage' for Māori within the organisation. I feel the need to extend and blur the 'back stage' and 'front stage' concept (Goffman 1959) here in order to apply it to TP's marae, because depending on the context (rehearsal, official ritual, workshop, warm up etc.), it can take on both functions. Centre stage seems to me the better term to describe Te Marae which provides the scenery and stage at once, as the embodiment (Fortier 1999) of Māori culture. The concept of the marae is central to Māori culture (Barlow 2005; Salmond 2009 [1975]; Mead 2003), and has increasingly become a 'political symbol' for Māori identity (Sissons 2005:141). Goldsmith (2003:10) contemplates whether Te Marae or Te Hau ki Turanga or "these spaces jointly constitute the sacred centre" within TP, and decides that the latter is 'truly central'. My findings suggest otherwise: for the performance of Māori identity Te Marae clearly is the centre stage.

Although the Māori rituals and activities are staged performances, I argue that they are indeed genuine and 'authentic' cultural expressions for the Māori staff. Therefore, I question Williams' $(2005 ; 2006 a ; 2006 b)$ claim that TP's marae is a symbol of biculturalism, as well as TP's own aspiration for it to be a marae for everybody. From my observation the marae is a strong power base for Māori and 'everyone else' is allowed to view the marae as an exhibit during opening hours, yet during Māori rituals non-Māori are largely onlookers and spectators, not active participants. Furthermore, I argue that without the physical space of Te Marae that embodies Māori culture tangibly, the voice of Māori would not be as strong as it is at TP. According to Bourdieu (1998) physical spaces are manifestations of social spaces. Through social interaction within these spaces, place is constructed and "[t]he question of power, as well as questions of belonging and ownership of places, become important from this angle" (Dietz 2011:30).

In other words, having a marae enables Māori activity which in turn is a catalyst for Māori empowerment, as my analysis of the Māori performances illustrates. This is the 
domain where Māori is spoken, action songs are practised, knowledge is passed on by telling stories and singing songs; this is where visitors are welcomed and the dead are mourned. The marae is also, as the induction pōwhiri and the call for Māori as the dominant language have shown, a contact zone (or battle ground) where tikanga Māori is to be followed and the power balance is reversed during the performance.

Although some Mãori criticise the special tikanga on TP's marae as a concession to Pākehā (women allowed to speak, young people taking on ceremonial roles that are usually reserved for elders, speeches in English), the 'hard core group' of tribal Māori who control the marae tikanga ensure the protocols are followed appropriately. One of the women who are in charge of the marae tikanga has been called "a bit cantankerous at times", yet as Whiting stresses, it is crucial for the positioning of Māori to have strong marae based people. By setting boundaries and excluding others, Māori staff are "participants in the construction of their own otherness as self-identity" (Sissons 2005:30). Looking at the construction of these boundaries it should not be forgotten, that it is necessary for indigenous peoples to "counter the cultural hegemony of settler nationalism" (Sissons 2005:30). Thus, Māori culture must stand apart in the Pākehā hegemony of the museum in order to maintain its autonomy and not be absorbed (see Bishop 1996; Salmond 2009 [1975]; G. Smith 1990). Māori keep tight control over their cultural practices and rituals, as the dynamics at TP demonstrate (see also Doerr 2009 for a similar discussion on bicultural schools).

The question is, however, whether Māori autonomy is limited to the marae or acted out on other stages as well? If the marae is the Māori 'setting' or stage, then the Mãori performance is over as soon as they leave the stage (Goffman 1959:19):

First, there is the 'setting', involving furniture, décor, physical layout, and other background items which supply the scenery and stage props for the spate of human action played out before, within, or upon it. A setting tends to stay put, geographically speaking, so that those who would use a particular setting as part of their performance cannot begin their act until they have brought themselves to the appropriate place and must terminate their performance when they leave it.

If this is true, then the perceived power of Māori at TP would be limited to the ceremonial realm, and their 'symbolic dominance' (Belich 2001b) would only exist 
within the setting of Te Marae. Yet, if the marae is "a symbol of tribal identity and solidarity" (Barlow 2005:73) for Māori in general, asserting shared kinship, a common course and indigeneity as Sissons (2005:141) ${ }^{92}$ argues, then what role does it play for the TP staff and their sense of belonging? Memories of one's ancestors mean someone truly belongs to a place, which explains the close attachment Māori have with the marae. However, in the 'belongingness hypothesis' Roy Baumeister and Mark Leary (1995) stress that in order to generate a sense of belonging for a group, positive relations and frequent physical interaction within a place are necessary.

Vikki Bell (1999) emphasises 'performativity' or the act of 'doing belonging' as crucial. While membership and ownership are key factors for the politics of belonging (Crowley 1999:25), we need to keep in mind that "[e]very politics of belonging involves two opposite sides: the side that claims belonging and the side that has the power of 'granting' belonging" (Antonsich 2010:650). Thus, negotiating, rejecting, violating and transgressing are always in place, yet, as Angelika Dietz (2011:32) states "[o]n the other hand, the biographies of individuals, their lived experiences in places, are intertwined with the social relations in a particular place and with groups and networks that are sustained by one or multiple places".

To link such practices to TP's marae and to demonstrate its significance as a place of belonging, I present the example of a Māori woman and longtime TP staff member, Carolyn Roberts-Thompson, whose life is inseparably intertwined with TP and especially its marae. Although a few other staff members claim a special connection to TP also, her bond with TP is quite extraordinary, as the following story illustrates. ${ }^{93}$

Anyone entering TP in a staff capacity and attending any of the Māori activities will know Carolyn Roberts-Thompson, a Māori woman who is very active and influential in pushing for the inclusion of a Māori perspective at TP. Other staff have recommended her as a 'one-stop-shop of all things Māori' or a mentor for guiding new staff through TP

\footnotetext{
92 Sissons (2005:141) quotes Tame Takao, a Tūhoe elder who expresses what Mataatua means to Tūhoe: "It seems to me that what the Tūhoe people are trying to say is 'we have a right to be here, we have a right to the land here, here is our whakapapa [genealogy], here is our relationship to the land'."

${ }^{93}$ For example, the son of a Pākehā staff member (and Māori father) was baptised on the marae as part of an iwi gallery hand-over ceremony.
} 
as she knows the 'beast' inside and out. In my interview she described herself in the following words: "I'm bicultural. I think I am because I am Māori, I'm also Irish, I'm also Scottish."

For Carolyn working at TP was not a conscious decision but due to a series of coincidences that in hindsight make her think "oh my gosh, maybe this was meant to be." Carolyn believes that she was "actually chosen - it hasn't really been a career for me, it's been a calling. Things have happened to me either by way of chance or I've been fortunate to be in the right place at the right time." When the Te Maori: Te hokinga mai exhibition opened at Buckle Street in 1986 and Ngāti Kahungunu held the paepae, Carolyn was part of the Saint Joseph Māori Girls' College senior concert party that travelled to Wellington to perform in the public programme. This was her first encounter of experiencing "the magic and possibilities within the museum sector, what they could be. It was very new at the time and there weren't many Māori staff." In 1990, at age 20 and studying business at Wellington Polytechnic, Carolyn worked in the café that her mother and grandmother were managing at the museum in Buckle Street. There she was 'spotted' by the Senior Education Officer and she took up an administration role as Education Assistant. Since then Carolyn has continuously worked at TP in various roles and moved through the ranks from her humble beginnings "washing dishes in the café in the museum at Buckle Street" to Exhibition Coordinator for the Day One exhibition Mana Whenua, Exhibition Manager, Manager for Bicultural Operations and Manager Iwi Relationships. After 20 years at TP, Carolyn recently held a senior position in the Vision team.

Carolyn's bond with TP goes much deeper than an ordinary work relationship for two reasons. Firstly, she has family ties to the organisation with her mother working in the enquiry centre and being the niece of the late Te Ikanui Kapa, former kaumātua and Māori writer at TP. Secondly, she was married on TP's marae and later her daughter was baptised there as part of the closing ceremony of the Te Atiawa iwi exhibition. She reflects that "There are a number of significant things that happened to me in my life that this place has had a huge impact on. So for example - we were the first ones to get married on the marae." Before the marae was made available to the public as a wedding venue, 
the then Kaihautū Cliff Whiting wanted one of 'Te Papa's own' to be the first to be married there. Ideally it would have been the marriage of a Māori and a Pākehā to celebrate TP's bicultural concept symbolically, but Carolyn and her fiancé Harley were chosen. Again, it was not a choice:

The Kaihautū at the time just said, "Right, I need - are you getting married? Right, you're it! Your wedding's going to be here at Te Papa. It's going to be the first one because you have an association, a connection to this place." I went "What? I don't want to get married here!" - "You're getting married here. This is a marae for all people and it's a visible expression of what biculturalism looks like or could look like in this place, and you're it."

Hence, her wedding soon after TP's opening on February 14, 1998, was not a small family affair, but a symbolic act of significance with 500 guests in attendance. However, Te Marae seemed the perfect place for the couple as "it was a neutral ground of significance that we could both stand on", despite her fiancé and herself having different religious denominations and iwi affiliations. The wedding ceremony and format was bicultural in nature with Māori and English language and tikanga being observed. Through her wedding and her daughter's christening later, Carolyn's relationship with TP has been deepened, but furthermore her family has become part of Te Iwi Kāinga o Te Papa Tongarewa:

For me that's kind of what biculturalism is about. It is almost like a marriage. It is about coming together of more than one culture actually, of many cultures. It is about that coming together and it's about finding ways in order to be able to move forward into whatever it is that you're trying to achieve.

Carolyn's journey and special connection to TP was celebrated at her 20 year anniversary and Carolyn acknowledges that, "I'll always have a connection with this place, even if I'm not working here, just for that reason."

\section{Conclusion: Te Papa -A Contact Zone? A Place of Belonging?}

In this chapter I have analysed how biculturalism is staged at TP, paying attention to the motivational factors and interviewing process, the induction as a rite of passage and the marae as the centre stage where the scripts are enacted. New staff to TP go through a process of 'acculturation' that is aided by the ritual of powwhiri and the induction day proceedings organised by TP's management to showcase the organisation and create a 
sense of belonging. Rather than seeing the whole of TP as a contact zone (Clifford 1997), I suggested that each Māori activity is in itself a contact zone for Māori and non-Māori staff to interact, engage, negotiate with each other and position themselves. Despite aspirations of inclusion and promoting cross-cultural dialogue the Māori activities only attract a very limited number of staff. By analysing the politics of participation and the factors that staff attribute their involvement to, I have shed light on the complex issues that are at play for staff of different ethnicities. Within these contact zones, which sit outside the usual organisational hierarchy, the distribution of power is crucial to the assignment of roles, the performance and how activities are staged.

Strategies of demonstrating power on the one hand and resisting power on the other are employed by the actors and spectators respectively, and the contact zone can easily shift to a battle ground or no-go zone when staff are 'talking past each other' (Metge/Kinloch 1978). Laughter as a corrective action is a prime example of that, as are different perceptions of the rationale behind changing the preselected waiata, and Pākehā critique of the Māori teaching style and the commercial use of pōwhiri. The function of pōwhiri is usually reduced to 'ritual of encounter' (Salmond 2009 [1975]), yet I add to this reading the political negotiations of whether English translations are provided or not as an example of how power is constituted on TP's marae.

It is often stated that everyone working at TP is part of the 'Te Papa whānau', but in actual fact many people feel excluded; this is particularly salient in the waiata sessions. By portraying three fictional characters and their perception of the waiata practice I discussed the reversal of power relations in this 'Māori performance' towards Māori autonomy within the wider organisation. Pākehā show a general anxiety towards Māori dominance, fearing that biculturalism will change existing power relations (see Sharp 1990). The Māori language classes, in contrast, are considered a Pākehā production by many Māori staff who remain largely absent from this training opportunity. Māori boundaries of Pākehā participation might be seen as a legacy from the 1980s when kaupapa Māori became 'fashionable' and Pākehā were excluded, while Māori regained control over their own culture (L.T. Smith 2006 [1999]; Tolich 2002). Tareta Poananga described the politicisation of the movement for rangatiratanga in the following words: 
"[Māori] redefined the duty of Pākehā who were sympathetic to Māori causes: not to know more about Māori culture, but to confront their own society's (in)tolerance issues" (Mannion 1984:105). In other words, non-Māori should take action for radical social change rather than appropriate Māori culture, despite good intentions. When staff refrain from attending Māori activities they close their eyes to the reality of TP, because, as Goffman (1959:31) suggests “[t]o stay in one’s room away from the place where the party is given, [...] is to stay away from where reality is being performed".

While I note that Māori are indeed empowered actors with agency and authority on TP's marae, repossessing this Māori domain, I stress that their dominant role exists within these 'ceremonial pockets' that are removed from everyday work and disconnected from the business agenda (often outside work hours). Sometimes the Māori activities are criticised for putting the bicultural mandate into special events, isolated from, rather than integrated into, the normal day-to-day operation:

This is the whole vex thing of bicultural and picking out individual things which are specifically Màori such as te reo, waiata, the openings and pōwhiri and saying that these are examples of biculturalism in action, when to my mind they are just little snips that are put in. Yeah, y'know they start and end [...] as discrete events rather than as a whole Te Papa way of being in the world. (Pākehā man)

Thus, I argue that Māori are given symbolic power on the ceremonial stage, however the power relations in other arenas must be looked at separately (see chapters three and four). As most Māori activities are staged on the marae, it becomes the centre stage as well as the scenery for performative actions. Curiously, despite being set up as a 'marae for everyone' it is mainly utilised by Māori who regain their cultural identity by controlling the rituals and 'running the show'. This in turn contributes to empowering Māori staff, bringing their Māori cultural identity to the fore while alienating and excluding other ethnicities. TP might help "the emergence of indigenous urban cultures" (Sissons 2005:28) among Māori staff by allowing for cultural expression at the workplace and identity formation aided by Māori staff initiatives like the karanga and whaikōrero wānanga. Speaking Māori on TP's marae is an act of emancipation for Māori and has potential for radical transformation: "These proactive actions at the grass roots will help transform hegemonic norms from the bottom up, as they empower minoritylanguage speakers as agents of social transformation" (Doerr 2009:172). 
The space of the marae, I argue, is not just a silent backdrop to the scene, but embodies biculturalism and becomes an actor itself. An example of 'belonging to Te Papa' through performative acts was given with the case study of Carolyn Roberts-Thompson, who has a very special connection to TP through family ties and her involvement in rituals on the marae, making her a model for 'living biculturalism'. This chapter therefore shows that through the Māori activities and rituals, TP is much more than just a museum or workplace to the extent that it can change lives under certain circumstances and become a place of belonging. ${ }^{94}$

What the actions of place-making and the intricacies of staging biculturalism do not explain however, is TP's commitment to biculturalism on the level of the professional day-to-day operation. Therefore, in the next chapter, I unveil the intercultural interaction within the organisational culture which is largely set back stage in the office spaces, analysing how the staff perform biculturalism there, because as Colin James (2005) states: "[B]iculturalism is not just about song and dance but about rights and power".

94 'Changing lives' is one of TP's new core values that were introduced by CEO Houlihan in 2013. 


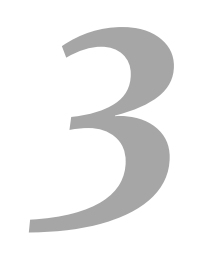

\section{Doing Biculturalism}

\section{Introduction}

The previous chapter presented an analysis of the staging of biculturalism at TP through Māori activities and rituals, examining the factors for participation and the function of these activities for the positioning of Māori staff within the organisation. The findings suggest that the marae is the 'centre-stage' for Māori as a place of belonging. Yet each Māori activity presents a 'contact zone' which in itself exhibits mechanisms of inclusion and exclusion to a varying extent. This chapter in contrast is set 'back stage' at the museum, situated in the offices, meeting rooms and other staff facilities. TP's bicultural policy acknowledges "the unique position of Māori in Aotearoa New Zealand and the need to secure their participation in the governance, management, and operation of the Museum of New Zealand Te Papa Tongarewa". I investigate how the concept of biculturalism is enacted (or not) by staff and management in the day-to-day operation, and how the ideal of a bicultural partnership plays out in practice among staff. By what means do staff learn biculturalism? What bicultural elements are visible in different teams across the organisation? Who is 'doing' biculturalism and why? How does working in a bicultural environment affect the identities and attitudes of staff members? And what do the intercultural interactions of staff mean for the transformative powers of the museum? 
Seeing the museum as a 'site of transformation' (Golding 2009:49), I explore the effects of dialogical interactions between diverse staff and their attempts to 'be themselves', 'set boundaries', 'learn from each other' and 'become one family'. As this chapter focuses mainly on the organisational culture at TP, I should note that I see 'culture as process' (Wright 1994:27) which is negotiated by staff, not as top-down corporate culture. I draw on organisational studies, especially 'organizing as narration' (CzarniawskaJoerges 1997; Czarniawaska/ Gagliardi 2003) and organisational rituals (Wittel 1996; Beyer/Trice 1988; Schwartzman 1989) and how these constitute identity. I argue that identity is constantly constructed and reconstructed through "the constant relationship between the one and many" (Lejeune 1989:34).

Structurally, this chapter consists of five parts. Firstly, I analyse the status quo of 'biculturalism at work'. Here I discuss the disestablishment of the bicultural team which many staff interpret as 'Te Papa is growing up'; I also demonstrate how staff learn bicultural behaviour in the absence of formal training mainly 'by doing' and observing their colleagues, which inevitably leads to making mistakes. Secondly, the case study of the Education team (ET thereafter) further illustrates how bicultural parameters are integrated into the team culture and form the basis for public programmes. Thirdly, I introduce the organisational culture or inner workings of TP in different teams across the organisation and identify indications of biculturalism in the day-to-day routines and interactions. Fourthly, I examine the role of staff farewells and anniversaries to instil the 'Te Papa culture' and perpetuate desired behaviour among staff, as well as position individuals and strengthen group coherence. Finally, I explore the effects of working in a bicultural environment on Māori and non-Māori staff in terms of identity formation, empowerment and attitude change within the Museum and beyond.

\section{Biculturalism at Work: The Status Quo}

A common answer to my question how biculturalism impacts on the work routines of TP staff was 'not very much'. A Pākehā woman's response epitomises this perception: "What does biculturalism mean to me as a person? [...] Going about my day-to-day life? 
Not an awful lot, but if you're talking about me in a work situation, then I'm aware of it." While TP promotes biculturalism on the Museum floor in its exhibitions, public programmes and products quite successfully to visitors (Schorch 2010), behind the scenes it seems some teams and individuals are hardly affected by bicultural principles, which staff perceive as not being communicated explicitly by the organisation.

This results in uncertainty among staff about (1) what is expected of them in applying bicultural principles in their work, and (2) how they can compensate for their lack of knowledge about biculturalism. Nevertheless, as I was assured in informal conversations and formal interviews, all staff are aware of the bicultural policy (see chapter two). The bicultural core value features prominently in people's recollection, as the following story illustrates: in every meeting room TP's corporate principles hang framed on the wall to be omnipresent to staff, often being the only 'decoration' in the room. An interesting incident happened at a team meeting when a director covered up the frame of TP's core values and asked everyone to list them all. A Pākehā man who was present told me: "Nobody could recall all corporate principles, but everyone knew that Te Papa was bicultural!' This confirms that 'Te Papa is bicultural' is carved into the minds of staff as the over-arching ideology, perhaps because it is so dominant in TP's self-representation and management's rhetoric.

My findings suggest that most staff are conscious that 'some consideration' of biculturalism is expected of them, but many are unsure what exactly is required:

We should have also some consideration of bicultural [principles]. But I think in terms of processes and plans, it's not explicit sometimes. You have to kind of ask people, like "So why is it we do it that way?" - "Oh, that's because blah, blah, blah." Because there's maybe an internal understanding of why we do something that way, but it's not explicit. (new migrant woman)

Furthermore, many new staff lack knowledge around 'unwritten protocols' (e.g. how to conduct a meeting in a bicultural way): "I'm not aware of what I should be doing in that area at the moment", says a Pākehā woman. In order to compensate her perceived ignorance, she signed up for the 'understanding tikanga Māori' workshop, but because the workshop's objective is a more general understanding of Māori culture, rather than a specific organisational one, it has not closed her gap in institutional knowledge. There 
is an assumption that in terms of applying bicultural principles to their work 'old staff just do it', almost subconsciously, whereas new staff struggle with it. In the past, the bicultural team assisted new staff transitioning to TP and ensured biculturalism was implemented.

\section{“We used to have a bicultural team...”- Making Meaning of a Team's Disestablishment}

According to a narrative that was often repeated by staff, TP 'used to have a bicultural team' called 'Te Roopu Whakamana Māori' (TRWM thereafter), which 'mysteriously dissolved' in the year 2008. Drawing on the notion that narrating is organizing (Czarniawska 1997), I trace various interpretations of the loss of the bicultural team as 'meaning-making' by staff. The purpose of the bicultural team, consisting of two bicultural advisors, was to implement biculturalism at the workplace through policy making, facilitating workshops (e.g. on the Treaty) and compiling information on tikanga Māori on TP's internal website 'kete' and booklets for staff. The majority of staff found the existence of this team and the resources they provided very helpful as a 'onestop-shop' about anything regarding biculturalism and believed that TRWM were instrumental in ensuring that "policy filters into all areas". However, some found TRWM too pushy and dubbed them 'the bicultural police'. Arguably, in the early days 'policing' was crucial:

Within Te Roopu Whakamana Mãori - even if you just break that word down: 'Te Roopu' the group, 'Whakamana' - to make, Māori - basically it's about giving authority to things Mãori. Back in the day a lot of people thought that we're like policemen, the bicultural policemen that go round and bang about "no, you have to do it this way! You have to do it that way!" Oh my goodness! But at the time that this group was established, that is what was necessary. (Māori woman)

During TP's early days, when the institution was still new and staff had to adapt to significant transformations (see chapter one), it seemed staff required assistance and control, so TRWM was needed. However, ten years on TRWM was deemed no longer necessary by management, as the institution had matured and consequently outgrown the bicultural advisors, like training wheels on a bicycle. Many staff believe that TRWM's disappearance was part of a natural process of TP 'growing up'. There is evidence that 
some managers continue bicultural obligations, despite the absence of TRWM ensuring bicultural principles were adhered to in business plans and implemented in practice:

I still felt that I'd done enough consultation with them to be able to continue that base through the businesses that I look after now. I guess that's partly because I'm quite a strong advocate for [biculturalism], but I can also see how now that that team doesn't exist, that I think there's some areas where probably the bicultural principle isn't perhaps as strong as maybe it was. It seems to come down a bit more now to individual advocacy of people. (Pākehā woman)

On the other hand, the disbandment of TRWM was harshly criticised by many staff, who saw it as an act of sabotage and a sign that TP's overall commitment to biculturalism had weakened:

I think with the disestablishment of having a dedicated group that focuses on biculturalism and the development of that kaupapa and what that means in this organisation, personally I think that was not the right thing to do. I think decentralising it actually provides less commitment, and it's really hard to visibly see what happens and how it happens and how that impacts on the different processes that are set in place to run and manage this organisation from a bicultural perspective. It's really hard when you don't have that core group that are responsible for driving that, for monitoring what it looks like, helping people to develop what they want it to be, for sharing information, educating people; makes it really difficult. (Mãori woman)

Although some individuals continue working in the spirit of TRWM within their means, many bicultural efforts have since fallen by the wayside, and staff generally feel a sense of loss since TRWM vanished, saying that "when [the bicultural team] left, it all stopped."

If the responsibility for implementing biculturalism has shifted from the institution to the individual, the risk is that biculturalism is treated as an option that staff can voluntarily make use of - or not. Without a dedicated team emphasising the importance of biculturalism at TP "it really depends on the staff who are working in those areas [...] and their understanding as to how much importance they place on that principle in their work practice." Similarly, former Kaihautū White warns against weakening the structural commitment to biculturalism:

The honesty of a bicultural relationship is the true sharing of power, including in the structural [sense]! So when we [individuals] leave, it can be sustained. The weakness of it at the moment is that it is dependent upon the personality and the capability of individuals, rather than [structural mechanisms] - and that's ideal when you've got strong people. But the system has to accommodate and the way you accommodate for different changes is to structurally have it arranged: so you are obliged to, you have to! 
Some staff members appreciate having more freedom, whereas others are concerned for bicultural commitment and the 'health' of the organisation when it is left up to the individual to apply bicultural principles, especially seeing that there is little formal training for 'learning biculturalism'.

\section{Learning Biculturalism}

Extending the concept that museums are 'places of learning' for visitors (Hein/Alexander 1998; Lord 2007), I argue that they are also 'classrooms' for staff through interactions with each other. As I discussed in chapter two, TP offers Māori language courses, waiata and taonga pūoro practice for staff, which I interpret as Māori activities rather than bicultural training. They offer an insight into Māori culture, but more in the context of rituals than organisational practice, and are only frequented by a small percentage of staff. So how do staff learn bicultural competence in absence of 'proper' bicultural training? 'Learning by doing' features highly in the minds of managers and staff alike. This might be a legacy from Day One, when TP opened in 1998, as Sotheran argues that 'doing biculturalism' was the best means of conveying the new philosophy to staff, and ultimately transforming TP:

A huge amount of talking [was necessary to change the culture]. Talking and workshops and talking and workshops and talking [...] Just leading by example, doing it, designing the experience in a way that said "this is what drives us". Just doing it. It's true, it took awhile and the shift of that balance I'm talking about didn't happen in five minutes. It did take years, but it didn't take a lot of years; one or two years, not twenty years.

The advice interviewees would give to new staff joining TP, would be something along the lines of "the first six months just let everything wash over you, keep asking questions, meet as many people as you can and don't be afraid of doing something wrong. If you do something wrong, it's because you don't know. And someone will put you right, especially with the tikanga and kawa." Occasionally, appropriate bicultural behaviour is spelled out explicitly, as in this e-mail excerpt: "Please remember that you cannot bring food through Mana Whenua on Level 4, please ensure that you bring your kai either discreetly via the glass lift on Level 2 up to the marae, or via Oceania kitchen and up the 
back stairs to Level 4."95 Typically, no explanation about the underlying tikanga was given. ${ }^{96}$ In Māori culture knowledge is passed on from generation to generation by immersion: "Some of this knowledge is learnt as we go along and participate in the activities of everyday living and join in a cycle of ceremonies that is part of life" (Mead 2003:305) ${ }^{97}$, which perhaps explains why Māori do not see the need to teach what is already 'normal' to them (see also chapter two).

Who needs to learn biculturalism? Most Māori are already living a bicultural life surrounded by the dominant culture and thus have an advantage over their non-Māori counterparts (Carlise 2003). In contrast Pākehā staff and new migrants are not only expected to pick up TP's organisational culture quickly, but might also be exposed to Māori culture in a work setting for the first time. There is an assumption among nonMāori staff that a willingness to do things 'the Mãori way' is expected, as this male Pākehā staff member commented: "It's recognised that [biculturalism is] a Māori thing, which we [Pākehā] have to learn as we go." McCarthy (2011:121) argues that "[m]uch of the effort in bicultural development at TP has gone into training non-Māori staff in Māori values, language, and practices to equip them to operate in a 'bicultural environment'”. The hiring of a Pākehā woman as kaiako (see chapter two) manifests the view that bicultural initiatives at TP are targeted at non-Māori staff, despite the fact that Māori who are ethnic but not tribal Māori also need to regain their own language and culture. This poses the question: what really is the purpose of biculturalism in a museum? This crucial issue is not yet solved: "Is it for Pākehā to learn about things Māori to serve the goal of 'Māorifying' state institutions, or is it to support the ultimate goal of Māori self-determination, which means Māori taking control of Māori heritage?" (McCarthy 2011:124). I shed light on these conflicting notions by exploring the reactions and resistances of staff to these agendas.

\footnotetext{
95 Kupenga (TP Intranet) 'news daily digest' available to all TP staff on 30 March 2012.

96 The reason for not bringing food through the Mana Whenua exhibition is that in Mãori culture cooked food is considered noa or inferior and should be kept separate from highly valued taonga like Te Hau ki Turanga which are tapu (Tamarapa 1996a:165).

97 Saying that, Māori selected young students who were formally instructed to learn mātauranga Māori in wānanga by a tohunga (Mead 2003:308f).
} 
While the expectation to do things in a Māori way as part of the 'Te Papa culture' is accepted by almost all staff, some non-Māori staff contest it, seeing it as a reversal of Pākehā hegemony. As a Pākehā manager stated: "There seems to be a stream - it is about Pākehā learning about Māori, as opposed to the other way round. [...] Pākehā culture has dominated and so therefore you have to let the Māori culture through. But in some way that's just reversing the argument." The push to recognise Māori culture as equal to Pākehā culture at TP was met with resistance by some Pākehā staff, especially when it required them to give up privileges or share resources. This reflects precisely the distinction between 'symbolic biculturalism', which is embraced by most New Zealanders (like singing the National anthem in Māori), and 'resource based biculturalism' (like returning land rights to iwi), which many New Zealanders oppose as undermining egalitarianism (Sibley/ Liu 2004). However it also corresponds with Sharp's (1997:230) notion that biculturalism is divided into 'bicultural reformism' (institutions adapt to meet Māori needs) and 'distributive biculturalism' (develop Māori institutions and share power). In addition to those interpretations, I suggest non-Māori overlook the dominance of their own culture within TP, because to them it is not visible. Unlike Māori culture, Pākehā culture being the 'mainstream' culture of NZ is largely taken for granted: "In reflecting on who we are, those of us who are Pākeha often miss the important dimension of ancestry and culture, partly because we are members of the majority, so surrounded by people like ourselves that we are not conscious of having a culture of our own" (Metge 2010:2).

A common strategy for new non-Māori staff attempting to fill their gap in knowledge is to find someone more experienced and knowledgeable than themselves to support them in a mentor role. Admitting their deficiencies in 'bicultural things' (meaning Māori aspects), they turn to senior Māori staff members, like the kaumātua for guidance, but in the first instance generally they approached the Māori language teacher who is herself Pākehā. I observed that newcomers often stayed close to the kaiako in unfamiliar situations like pōwhiri, in which they felt out of their 'comfort zone', in order to rely on her knowledge; she would translate for them and introduce them to tikanga. Thus, the kaiako has an important role in bringing people together and mediating the cultural gap by providing cross-cultural mediation and knowledge transfer. Having mentors and 
role-models is crucial for newcomers to grasp biculturalism quickly and adapt to the bicultural environment, but as I have demonstrated, TP managers sometimes do not make good role-models themselves and lack bicultural understanding (see also Carlisle 2003). Ignorance of Māori protocol inevitably leads to making mistakes, another avenue for learning at TP.

\section{Learning By 'Making Cultural Mistakes'}

The underlying principle for new staff to learn the ropes seems to be 'learning by doing' as a Māori man put it: "a lot of it is really just experiencing trial and error, like learning [by] doing and stuff like that". Management assumes that new staff already have a 'repertoire' of performances and experiences they can draw on. This corresponds with Goffman's (1959:63) statement:

When the individual does move into a new position in society and obtains a new part to perform, he is not likely to be told in full detail how to conduct himself [...] Ordinarily he will be given only a few cues, hints, and stage directions, and it will be assumed that he already has in his repertoire a large number of bits and pieces of performances that will be required in the new setting.

In order to work in a bicultural environment successfully and adapt to constant shifts, TP staff are required to learn a new skill-set, but most importantly act in good faith, as Gorbey suggests:

They have to learn listening skills, negotiating skills, they have to be accepting of change. They have to understand that their strongly held point of view based on a particular thing or understanding is different from the one across here, which is equally based on a strong understanding. [...] You'll go nowhere unless you are acting in good faith.

Nevertheless, making cultural mistakes is a common experience for non-Māori staff, as the following interview excerpt illustrates:

me: And so was there any example of "ooh, I shouldn't have done that!" $y$ 'know? "I wasn't thinking of the Mãori side" or something like that? (laughs)

new migrant: Oh, well, it wasn't just regarding me, but just when we were pushing out Kura Pounamu [Greenstone exhibition, Appendix 9] there was one of the greenstone images. And we initially liked the look of - I forgot what it's called - but just one of the greenstones. It's kind of like a little weapon image and we liked the way it looked with the handle facing up. Because we're [the] marketing [team], of course we were just going for the way it looked on paper, and then we took it to [the Mâori team for approval] (laughs) and they told us "No, you can't do it that way because it's upside down!" And we were like "Oops", y'know. That's just a clear example of: although it may look nice, [...] it makes no 
sense because it was upside down! And she was saying the way it's held is the butt end down. So that was a big no, no! (laughs)

Another Pākehā staff member experienced a 'telling-off' when she asked a question regarding biculturalism, suggesting that open dialogue is not appreciated by some Māori staff, perhaps to have an advantage in knowledge over others or maintain their power:

Sometimes, I suppose you feel - you just don't know whether what you're doing - or by just making an inquiry, whether this is seen as right or wrong. I have done something recently that raised a really interesting point. There was an event happening and people were asking questions, 'cause they didn't understand or didn't know or the information hadn't been provided about what was going to happen. So I approached somebody and asked. And basically, I was told that I was rude and offensive for asking the question [...] by a senior Mãori person, and it was to do with a pōwhiri. [...] that's not exactly creating an environment for people to learn.

Such negative experiences are embarrassing for both sides and result in silences and avoidance of intercultural engagement between Māori and non-Māori staff.

Several times I observed another 'cultural mistake': non-Māori staff skipped the 'kapu tī' ritual after a pōwhiri, in order to get back to their desks more quickly. It is considered "very poor manners" to leave a hui before the hākari (Salmond 2009 [1975]:107), as in Māori culture eating is a means of transforming the tapu state people receive from attending pōwhiri into the noa state (Mead 2003:347). While some staff were completely oblivious that they made a mistake with their early departure, one Pākehā woman was made aware of her wrongdoing by a subordinate, a Māori elder:

[He] spoke to me a bit firmly one day, and it was an interesting example [...] There was a pōwhiri - I can't remember what it was for or who it was for - but I had so much work to do that day. I wanted to welcome the manuhiri and show the Museum support to our visitors, but I slipped away after the proceedings and I didn't go and have a cup of tea. And he noticed and he took me aside and very nicely just reminded me about this sacred state and that I had broken protocol. So I've never done that again! So you make up your own compromises: either you go to pōwhiri and do it properly, or you don't. [...] It was time pressure and I guess in a Pākehā way I thought, "oh, it doesn't really matter," but it does.

Ute Hüsken (2007) points out in her book When rituals go wrong, that deviations from the norm are only 'mistakes' if someone judges them as such and thereby makes the tacit rules of rituals visible to outsiders. It is through those mistakes, when staff (unintentionally) step over boundaries and are informed about the breach, that the 
rules and practices which are usually invisible are revealed. Staff thus become aware of the appropriate 'Te Papa way' of interactions and learn 'biculturalism' as respecting other cultures, particularly Māori. What follows is the case study of the ET, which highlights some of the issues already raised as well as giving an example of 'biculturalism in practice'.

\section{Case Study: A Week with the Education Team}

I chose the ET for this case study because its bicultural orientation was quite prominent in the staffing, everyday practice and programming, and my fieldnotes provided rich material. The team's history reaches back to 'Buckle Street' times and is intertwined with the Taonga Maori exhibition (1989-90) when the museum hired Māori students from Victoria University of Wellington as tour-guides, paying Māori to work with their own taonga for the first time (Temara/Mason 1994:11). Conal McCarthy, who was part of ET 1988-92, states that “[t]he museum's education department was perceived to be making rapid progress towards the bicultural ideal" (2011:84), while Karen Mason, then senior education officer goes a step further, suggesting that "it was a 'living reality' of biculturalism in practice" (Mason in McCarthy 2011:86). During my own fieldwork members of other teams frequently recommended ET to me as a 'good example of biculturalism at Te Papa'. This in itself is interesting, because it shows that staff perceive a team, which mainly works front-of-house in the museum and interacts with the public, as being more bicultural than their own teams which are based back-of-house and do not interact with the public on a daily basis. ${ }^{98}$ At the same time, their recommendation to 'look over there' may have been intended to divert attention from what they perceived as a lack of 'anything bicultural happening' in their own teams.

Before I was allowed to observe the team of mixed ethnicities, however, the manager asked me to propose my research to all team members at their weekly team meeting. It struck me that the meeting followed a 'Western agenda' and lacked any Māori component. Just before I left the meeting, the manager commented, "usually we open

${ }_{98}$ Another team which was often recommended for my fieldwork was the host team which is also a team of mixed ethnicities that operates front-of-house. 
and close with a karakia", as if to reassure me that they did work biculturally, normally. Nevertheless, this incident highlighted a discrepancy between 'the walk and the talk', which the manager picked up on by apologising for the deficit of bicultural aspects at that particular meeting. A study on meeting structures in NZ workplaces (Holmes/Marra/Vine 2011) has found that Māori-run meetings typically followed a standard structure which included karakia and exhibited elements of 'the ritual of encounter' (Salmond 2009 [1975]), and I often witnessed this as part of the 'normal procedure' at TP in Māori or mixed teams.

Since nobody objected to my research I spent one week with ET in March 2010, attending meetings, shadowing individual staff members and participating in several tours they offered for school groups. In addition, I conducted semi-structured interviews with five of six team members - one Pākehā man, two Pākehā women and two Māori women - including the manager. At the next team meeting that I attended now as an official ethnographer - I observed that karakia was an item on the agenda, and indeed a young Māori woman recited a prayer in Māori to mark the official start of the meeting (for prayers as meeting frames, see Schwartzman 1989:285). As I was uncertain what to make of these two contradicting incidents, wondering whether my presence had any impact on the proceedings or whether it was just 'business as usual', later I asked a Māori woman if karakia is an integral part of all ET meetings she attends. She classified karakia as an arbitrary element, very much depending on Māori personnel who had the mana to do karakia:

Some meetings I go to we say karakia before we start, other meetings we go to we don't. Whether or not that is just personal preference I'm not sure. But when we had Kukupa [Tirikatene; Ngāi Tahu kaumātua] in the house, and he was always in a meeting, he would start with a karakia. Now that he is not here, we don't start with a karakia. It's kind of sad, because if we are being bicultural then taking those little things, little but significant things, into account is what matters and what provides a basis for us to be bicultural.

At the time of my fieldwork the short-term exhibition A Day in Pompeii (see Appendix 9) was on and ET guided several school groups a day through the exhibition. I participated in three tours shadowing three different guides, two Māori women and one Pākehā man. Although all tours were slightly different in the delivery, depending on the age of the children and the personality of the tour guide, some bicultural elements were 
always present. When the children arrived, the tour guides greeted them with the words 'Nau mai, haere mai ki Te Papa Tongarewa'. While the Pākehā guide stuck to this minimal Māori greeting, the Māori guides elaborated further in Māori, introducing themselves with a mihi and using commands like 'e tu' (stand up), 'whaiwhai mai' (follow me) and phrases like 'ka pai' (well done). The attempt to link the ancient Roman culture to Māori culture demonstrated the strong bicultural agenda of the guides: they compared the eruption of Mount Vesuvius with the Mount Tarawera eruption that buried a Māori village in 1886, or the Roman fermenting practices to Māori ones. Furthermore, one Māori guide mentioned Māori beliefs around death and the custom of cleansing oneself with water after visiting the room of body casts from Pompeii. She encouraged the teenagers to use the water bowl provided and some sprinkled water over their heads (and some joked around and made a mess).

When I interviewed the team members later, I asked whether introducing Māori culture was a routine procedure for tours in every exhibition. Pākehā and Māori team members insisted that they only included it if it matched the theme and 'felt right', as opposed to every exhibition regardless of content, which they perceived as tokenism. The following statement by a Māori team member contrasted the Pompeii exhibition with its forerunner Formula One (see Appendix 9):

So far Formula One was my most difficult one, because it is about something that doesn't really fit in Māori culture. The idea of, you know, every car is made from scratch from materials, wasting petrol and people loving it, doesn't fit with our cultural values of looking after Papatūānuku and renewable resources or sustainability in any way [therefore no Māori component was added]. Pompeii was a relatively easy one actually. Even though the history wasn't ours the concepts are; of many gods, the belief in Vulcan is similar to the belief in Rüaumoko, who is the god of volcanoes and earthquakes.

In fact, ET purposefully presents mātauranga Māori, which encompasses "philosophy, astronomy, mathemetics, language, history, education and so on" (Mead 2003:305), and Western scientific knowledge side by side. For example, a Pākehā woman in the team told me how she incorporated both cultures in her tours; I cite from my field notes:

When looking at the geographic outline of New Zealand on the large floor map in Our Space [see Appendix 9] with a school group, she asks them what the two islands resemble and if one looks like a fish. The children usually shake their heads, but when she walks them over to the sting-ray model in Mountains to Sea [see Appendix 9] they agree that it is a similar shape to the North Island, and 
she tells them the Mãori legend of Mãui fishing up the Te Ika a Māui [the North Island], exposing the students to different world views and explanations of how Aotearoa New Zealand came to be. 99

Being one of the few teams at TP that crosses the boundary between front-of-house and back-of-house on a daily basis, ET is very aware of their exposure to different audiences, including Māori, which keeps them connected with the need to deliver on the principle of biculturalism. On the other hand, they are critical that other staff working mainly back-of-house are disconnected from the Museum and argue that biculturalism for those becomes a mere box to tick: "People forget that we work in a museum. There are some people who just don't go front-of-house! They have no idea! Man, you work in a museum! [...] It should never ever be forgotten, ever!" Under CEO Sotheran every staff member at TP was required to work some shifts within the Museum exhibitions in order to understand the visitor needs better. However, this practice was discarded because it compromised TP's high standard of customer service, as Māori host Richard Wright recalls:

It was fantastic having those [back-of-house] guys on the floor but at the same time [...] some of them were fantastic and some of them had no people skills. [It was good to see they were] not afraid to come out and get their hands dirty and work with people. They don't just sit in ivory towers ordering people around. They're working side by side and that's what I miss about that initiative of having back-of-house people coming to work front-ofhouse. But then you got people, who didn't want to come at all and of course rather do other things, do some research and read some books.

Many front-of-house staff wish the programme was reintroduced as they believe it contributes to positive relations between otherwise segregated teams, and as this Pākehā woman suggests: "it stops the snobbiness as well, it hopefully ups the respect levels for people who work front-of-house." Similar biases are spatially constructed between the Tory Street and Cable Street buildings as well as staff on level two and level three.

Given that ET's purpose is to deliver bicultural programmes to school groups that range from mainstream to kaupapa Māori schools, I wondered what mechanisms were in place to ensure it delivered on the bicultural targets. The manager, a Pākehā woman,

${ }^{99}$ This is not to say that New Zealand schools' do not teach Māori legends as part of the curriculum. However, Te Papa's educators shared anecdotes of classes 'knowing more about James Cook than Kupe!' Kupe was a great navigator from the Pacific - suggesting a gap in Māori history in the curriculum. 
explained to me that the bicultural goals used to be embedded in the business plan, which were then integrated into the performance agreements of team members and reported on, ensuring that the bicultural principle 'cascades down' to the individual. Although the bicultural targets have 'disappeared' from ET's business plan, around the same time as the bicultural team was disestablished (discussed earlier in this chapter), the manager continued including them, because she felt personally obliged to do so: "We've got a culture of doing that [including a Mãori perspective] in the team [...]. In the Education team it's probably just more a practice that's been handed on and on and on". Thus, she proposed biculturalism as a tradition in her team, to be continued and passed on by the team members, despite a lack of formal obligation.

In addition, the Pākehā manager tried to have Māori capability by making sure "that we have a really decent whack of Màori ethnicity on the team", who are able to deliver on the bicultural targets. Although the manager's ambition is admirable, it implies that biculturalism is the responsibility of the Māori staff, an assumption that is highly problematic. While including a Māori world view in the programmes was not imposed on the team members, it was implicitly expected of all team members, regardless of their ethnicity. The instrument for implementing bicultural components was not so much the requirement of reporting to the manager but peer pressure among team members as well as interactions with visitors in the Museum space. Moreover, it was an integral part of their 'team culture'.

All team members stated that they felt obliged to include bicultural elements in their work, but some lack the skills and confidence to incorporate them into their teachings, as several non-Māori staff told me. Similar to my analysis of the Māori activities (see chapter two), this imbalance in Māori competency among staff results in Māori staff taking primary responsibility in delivering biculturalism, which potentially becomes a burden on them. While this brief case study of ET provided an insight into one TP team and its bicultural aspects, what follows is the search for bicultural indicators across TP's organisational culture, drawing on my fieldwork with 17 teams. 


\section{Organisational Culture: Indications of Biculturalism Across Teams}

The great differences between teams in their daily practice revealed in this research suggested a bicultural continuum from 'soft' to 'hard' akin to that proposed by Fleras and Spoonley (1999:238); yet the lack of bicultural commitment in some teams overshadowed my overall impression of biculturalism at TP. While some teams were very committed in their everyday work, in other teams I could not find any evidence of bicultural practice. The key to understanding this phenomenon is that some teams are crucial to TP as a museum and contribute to its bicultural undertaking, such as National Services Te Paerangi (NSTP), Iwi Relationships, Karanga Aotearoa and Mātauranga Māori, whereas other teams could easily 'be lifted and dropped' into another organisation, such as Human Resources, Marketing and Finance. Ironically, by definition the former are the least bicultural in terms of staffing, having Māori staff only (except NSTP). My findings suggest the following markers for how bicultural a team was: the percentage of Māori staff in the team; the team's exposure to visitors; how closely it was involved with the collection; and whether it collaborated with iwi stakeholders or not (see also McCarthy 2011).

Although biculturalism was not discussed on a daily basis - to my amazement it was hardly ever talked about - some bicultural aspects featured in the 'organisational culture' in varying degrees from team to team. My findings show that despite TP following a Western business model in its day-to-day operation, Māori values are part of the work life, but only in particular circumstances, and situated outside 'business-asusual'. The 'Te Papa culture' was not so much structured by organisational hierarchy or professional identities, but often along ethnic identities and social prestige; that is to say that in many cases the Māori staff constructed a distinct culture which at times stood side-by-side to the Pākehā culture and at times dominated.

It is often emphasised that Māori and Pākehā have different cultural values (Mead 2003; Salmond 2009 [1975]; Metge 1976 [1967]), and one such value at the heart of Māori culture - as well as most other indigenous cultures (Sissons 2005:33) - is the concept of kinship or whanaungatanga which is not limited to human relations, but entails 
cosmology, attachment to the land and the natural environment. As Sissons (2005:33) argues, it is critical to understand kinship if we want to understand cultural resistance of indigenous peoples. He goes on to draw a distinction between bureaucracy and kinship, arguing that "kinship cosmologies and kin-based polities do not sit easily with systems based on bureaucratic rationality. [...] [I]n bureaucratic cosmologies the head rules the heart - generosity, love, hatred and honour have no recognized place." Contrary to this statement, TP, certainly a bureaucratic entity, acknowledges mana taonga among its corporate principles (Annual Report 2007/08:14) and values manaakitanga and whanaungatanga highly. I have to ask then, how this incorporation of potentially conflicting interests functions in practice.

TP's bicultural policy document states that in order to build organisational capability TP will, “[a]s an employer, actively endorse, validate and respect cultural values, knowledge and diversity through organisational practices", and furthermore, "actively enhance Te Papa's bicultural capability through training and development, and recruitment and retention strategies". Next, I examine these 'organisational practices' and look closely at how they are enacted in the everyday life of TP in the workplace.

\section{Sharing Kai - The Meaning of Food at Te Papa}

I did not intend to write this section at the beginning of my research, but reading my extensive fieldnotes which were full of rich descriptions of who ate what and with whom, inspired me to include the distinct practices around food consumption existent at TP and interpret food rituals as distinction (Bourdieu 1984) of ethnicity, rather than class. Eating is a form of social action as well as a cultural system that can be decoded and analysed, according to Ulrich Tolksdorf (2001:240). Social scientists agree that the meal is the central unit of this system (see Simmel 1957; Lévi-Strauss 1973; Teuteberg/ Wiegelmann 1986) and according to Mary Douglas (1972:69) "[e]ach meal is a structured social event which structures others in its image". Thus, eating and drinking habits reflect society at large and can therefore be called a 'total social phenomenon' (Neuloh/ Teuteberg 1976:397). 
Wittel (1996:51) interprets drinking coffee as a means of 'liquid communication' ('flüssige Kommunikation') revealing the company's intention to strengthen interaction between staff, improve productivity and create an 'organisational culture' by providing coffee-machines. Coffee is indeed important among TP staff, despite the lack of coffeemachines. Back-of-house staff frequent the two in-house cafés so often (for meetings and breaks) that front-of-house staff sometimes wonder somewhat cynically what else they do aside from drinking coffee. At the Tory Street premises there is no in-house café, so the 'cuppa' (cup of tea) replaces the coffee, but sometimes staff gather in small groups to walk to the nearby Havanna coffee roaster for a 'proper coffee'. In some teams 'smokos'100 (smoking breaks) replaced the pilgrimage to the café. I only mention 'smokos' briefly here, because as a non-smoker I did not attend these frequently. Nevertheless, they play an important part in the organisational culture as they are a platform to catch up with others, make jokes, and gossip. When I stood with the smokers on one occasion, a Māori woman told me: "This is the smokers' corner where we meet people. This is where the real decisions are made! You know, just hearing what's going on and talking to people." Doerr (2009) drawing on Goffman (1959), in her ethnography of a rural school remarks that the smokers' den is 'the backstage of the backstage".

Observing the food practices among staff, I was intrigued that there were distinct differences between Māori and non-Māori staff, especially at lunch time. Lunch is a private affair for most non-Māori staff members who eat their left-overs or bought lunch at their desks in a hurry, often multi-tasking or flicking through the newspaper. Some teams, however, celebrate their lunches as institutions of nourishment and exchange, be it by going out for a meal together occasionally or sitting together for breaks on a regular basis. In one Māori team the staff treated themselves to having breakfast at McDonald's together on payday, others went out with their team or friends across teams to celebrate special occasions, like Christmas parties or to farewell team members. For example, at the end of three weeks fieldwork with the Repatriation team,

\footnotetext{
100 Statistics about smoking in New Zealand show that the issue is related to low-income classes and particularly widespread among Māori. According to the Ministry of Health 45.7 per cent of all smokers in New Zealand were Māori compared to 29 per cent European and 19.7 per cent Asian smokers, http://socialreport.msd.govt.nz/health/cigarette-smoking.html (accessed 21 December 2012). It is not surprising then, that Māori and hospitality staff are overrepresented among the smokers at Te Papa. 
they took me out for lunch at a Yum Cha restaurant, where we shared dishes rather than ate individual meals. The choices for social outings ranged from take-aways to high-end restaurants and mark class distinction (Bourdieu 1984).

I found the Māori institution of 'sharing kai' alive in the teams with predominantly Māori staff, and the food distribution went often well beyond the boundaries of the team. Having enough food to feed everyone in the team - including external clients or visiting family - was so important that these teams had small, stocked fridges and a round table with chairs set up in their work areas. Although some other teams (HR, Marketing) also had a 'round table' in their work space, it was not utilised for shared lunches but mainly an extension of their desk space used for piling paper, reading, informal meetings or taking a break. Due to a lack of space in the curators' area of the Mātauranga Māori team, a round table within the staff room on level two was utilised by their team members to catch up with staff who worked on a different floor or in the collection stores. Rank according to the organisational hierarchy is overridden in this context and replaced by a structure of kinship relations and status expressed by mana.

Although most of the time Māori staff members bring their own lunch, the food is almost always offered to everyone present and sharing is expected; often colleagues who walk past are invited to join in (mostly Māori, but also selected non-Māori). This practice is aligned with the Māori concept of manaakitanga, as food is not only offered out of courtesy but to nourish and sustain people (for an account of the importance of feasting at hui see Salmond 2009 [1975]:106f.). The Iwi Relationships team's round table in particular, is a hub for Māori staff from all over the organisation to gather. The Māori elder in the team keeps a close eye on the wellbeing of everyone in the group, rounding up people in a motherly fashion to sit down for a proper meal. Working at one's desk during lunch time is unacceptable in this team, as I found out myself, and is considered rude behaviour. Once a Māori woman commented laughing that she was sometimes 'forced to eat' by the Māori elder between meetings as she would otherwise forget to eat. 
The choices we make regarding food are embedded in our biography (Tolksdorf 2001) as we tend to prefer food items and recipes we grew up with, but what we eat also forms and manifests our cultural identity (Teuteberg 1997). What comes to the table reflects ethnic diversity (see Rey Vasquez 2012 for a study of the ethnic diversity of school lunch boxes), and indicates whether the food is to be consumed by one person or intended for sharing. While the non-Māori staff who ate at their desks usually had leftover dinner, soup or readymade sandwiches for lunch which are convenient to eat, but do not lend themselves for sharing very well, the Māori teams would either shop together or bring food items that are easy to share and distribute: bread rolls, mayonnaise, salad greens and ham, for example, to make sandwiches. Kaimoana (seafood) and some Māori delicacies featured occasionally, like kānga pirau (fermented corn), pūhā (sow thistle 'spinach') and rēwena (leavened bread). Occasionally, when someone went diving on the weekend the Māori team had crayfish. A special treat every couple of months was the hāngī that had to be ordered and paid for in advance. The hāngī came in individual boxes delivered by Victoria University's marae team and was then eaten by the recipients sitting together. As shared meals were always accompanied by conversations, I argue, that 'communities of practice' are formed here, building capabilities on "shared repertoire of communal resources (routines, sensibilities, artefacts, vocabulary, styles, etc.)" (Wenger 1998:73); in this case through the sharing of food. The networks formed here became more important than the team connections and lasted beyond the tenure of contracts at TP, facilitating long term connections between Māori. Such informal networks around a communal activity recreate village structures, as Hilke Thode-Arora (2009:263) demonstrated with the Niuean community of weavers in Auckland.

William Robertson Smith (1995 [1889]) suggested that eating and drinking together is the most archetypical rite of mankind. Among Māori, kai is considered 'social glue', a symbol of reconciliation and peace, as Kukupa Tirikatene told me, recalling an incident when he stayed on a marae with some Pākehā 'trouble-makers'. After a few days he sensed that the relationship had improved dramatically and when he asked one Pākehā man why he thought that was, he replied, "because we slept together". Yet, Tirikatene thought to himself, "more than that, we ate together". Thus, a common strategy for him 
to reconcile conflict, is to invite the person for 'tea' [dinner]: "never underestimate the power of food! [...] because when the puku is full, problems get smaller". This belief corresponds with Mead (1986:35): "Undoubtedly, the act of sharing food together [...] is an effective way of encouraging understanding between cultures". When Māori and non-Māori eat together, food is "acting as a mediator" in the context of rituals (Mead 1986:37), suggesting that eating with 'the other' constitutes a contact zone.

By sitting and eating together, strong, family-like bonds are created as everyone takes on a role in preparing the table, distributing the food and cleaning up. This closely resembles the operation of the marae where the ringawera carry the responsibility of running the kitchen and looking after the guests (Mead 2003). Furthermore, these occasions provide a structure for the day and a framework for conversation. I noticed that during lunch family life was the main topic, and people talked openly about sensitive affairs like family members being sick or passing away as they found empathy and emotional support in the group. I suggest that this helps the (mostly mixed or Māori) teams to come closer together and create a kinship-like bond which they can fall back on in times of crisis at work or in their private lives. When Māori staff in particular represent themselves as a close-knit community sharing their food, according to Goffman (1959:24), “[t]he front becomes a 'collective representation' and a fact in its own right", and Māori identity is strengthened.

Gathering and sharing food are symbolic acts that have the power to promote and enforce social cohesion by including people in the circle - or around the table -, but at the same time this means excluding others. Drawing on Sergej Alexandrovič Tokarev (1971:299) who states that food either unites or separates people, I argue that food rituals can be a means of communication on the one hand and segregation on the other hand. This hypothesis has been proven in studies of immigrants, where cooking familiar recipes stabilised their cultural identity while alienating others from the host community (see Bönisch-Brednich 2002:334-374; Kalinke/Roth/Weger 2010). During my fieldwork having leftovers at my desk like so many of my non-Māori colleagues, I was often unsure whether it was appropriate to join the shared lunches or wait until I was invited. I decided on the latter, and usually I would be asked to join in and eat, 
according to the protocol of manaakitanga, regardless of how little and what food items I could contribute. In these cases, I felt like a full member at the 'round table lunches', although I would make sure to fulfil the expectation of reciprocity that is attached to gifting (Mauss 2000 [1922]). At other times, however, I felt excluded, when I was not asked to participate.

Multiple purposes and meanings are attached to sharing food, as I have demonstrated. Based on the evidence presented here, I argue that by distributing food and controlling who is invited to the table and who is not, Māori construct a closed group that sometimes is perceived as 'separatist' by excluded colleagues. Given that identity construction is a multi-directional process, "[c]oncepts of inclusion (and/or exclusion) become relevant in this process" (Angouri/ Marra 2011:86). Through the collective consumption of food, Māori strengthen their in-group relations, thus creating a powerful, yet separate unit, while ignoring others who are thereby reminded that they do not belong to this group.

\section{'Kia ora' or 'Hi'? - The Politics of Greetings at TP}

Drawing on the notion that using and promoting te reo Māori is an expression of biculturalism (Ministry of Education), ${ }^{101}$ I paid close attention to the languages spoken in the workplace, particularly the greetings that staff utilised in their everyday interactions. I agree with Marra and Angouri (2011) that identity is enacted through the 'linguistic choices' we make, thus language use constructs an image of self. I noticed that in the office spaces Māori was rarely spoken, but used extensively in greetings both in verbal and e-mail communication. Interestingly, Pākehā and new migrants said 'kia ora' or 'mōrena' within the TP building or to greet Māori staff, while Māori often replied with the English equivalents 'good morning' or 'hi'. Which language is used, potentially is a political statement (Heller 1985:80). If Māori used Māori greetings, they were more likely to say 'ata mārie' for good morning, and 'pō mārie' for goodbye, than the English

\footnotetext{
${ }^{101} \underline{\mathrm{http}}$ ///www.educate.ece.govt.nz/learning/exploringPractice/BiculturalPractice/BiculturalismTeWhari ki.aspx (accessed 17 December 2012).
} 
transliterations 'mōrena' and 'ka kite'.102 Perhaps this was a strategy used by Māori staff to reject the appropriation of their language by non-Māori, as Metge (2010:2) points out: "Those of us who identify as Māori or members of other ethnic minorities and those of mixed ancestry sometimes allow ourselves to be defined by the majority, or react against domination by retreating to exclusivity." It is also a rejection of the perceived tokenism, as Māori often told me that for them "biculturalism is a lot more than just throwing in some Māori words!"

Furthermore, being greeted in your native tongue by someone belonging to a different ethnic group - although well-meant - is often seen as a form of 'othering' (Pickering 2001), where being different is synonymous with inferiority; in this case the speaker emphasises that 'the other' is different by not using the standard English greeting. Being German, I was often greeted with 'Guten Tag' ('good day') or other German phrases, said jokingly and often mispronounced. I did not comprehend why it made me feel agitated, until it occurred to me that by this strategy language became a hegemonic device that underlined that I am not one of 'them'. On one occasion a Māori man, a Pākehā woman and I met randomly in the kitchen and according to my fieldnotes the following greetings were exchanged: "He greets me with 'Guten Morgen', I greet her with 'good morning' and she greets him with 'kia ora'. Within seconds we had subconsciously picked up on the ethnicity of the respective other person and addressed them accordingly."

For non-Māori staff using Māori greetings and sign-offs in e-mails became a habit that new staff copied from their colleagues and quickly followed systematically as the 'bicultural Te Papa way'. This development was more likely assisted by the 'business te reo' module providing employees with practical phrases, than the 'language policy document' that most of the participants did not know existed. An analysis of 50 out-ofoffice notifications by TP staff showed that 42 used Māori in the opening address and sign-off, which demonstrates that Māori greetings have become part of the mainstream at TP. However, I argue that non-Māori staff used Māori greetings in order to appear bicultural, thereby maintaining their 'front' (Goffman 1959) and their status in their

102 For example, Māori of the older generation do not approve of the wide use of 'kia ora' as in their time it was only used to say 'cheers' when drinking, now it is used for 'hello' and 'thank you' extensively and has become part of NZ's mainstream. (Joan Costello retelling what linguistic change Kukupa Tirikatene witnessed, TP Māori language lesson 28 November 2012). 
professional persona, yet this does not necessarily mean their take on biculturalism extends beyond using Māori phrases. For the non-Māori staff using Māori phrases and greetings was largely limited to their working hours at TP and after work they would switch back to their private identities, suggesting that most TP staff embody an institutional persona at work that is not identical with their usual self-representation (Goffman 1959). This observation backs up what one of Carlisle's (2003:29) interviewees said about working at TP: “I think it's a totally artificial environment because it's been totally created [...] it's almost like when we walk in the door we put that hat on, and then we go out again. We're in a big bubble here."

Although TP's language policy demands staff to say 'kia ora, welcome to Te Papa, [name] speaking' when answering the phone, according to my observations staff do not always comply with this. In one instance, I was present when someone who usually sticks to English greetings, answered the phone with 'kia ora' to impress the Māori teacher who was standing beside him. This illustrates that choosing an appropriate greeting is not only determined by the addressee but also by other people within earshot. Whether staff used 'kia ora' or 'hi' also depended upon whom they were addressing. I observed that they were more likely to use 'kia ora' if the person addressed was either Māori or a learner of te reo Māori, in which case the greeting was often followed by 'kei te pēhea koe?' ('how are you?'), engaging in a dialogue among students. In the Events team, a mixed team of Māori and Pākehā, 'mōrena' was the default greeting when all team members were present. If, however, the Māori colleagues were absent, this would noticeably change and immediately be replaced by 'good morning'.

While I never observed any rebuke in regards to breaching the language policy in the office spaces, I encountered some TP staff's disapproval of the hosts' greeting practices at the front door of the museum several times. It seems that staff interpreted the language policy as being far more applicable to the front-of-house staff than to themselves, reasoning this with the need to 'educate the public'. When they observed that the hosts did not comply with saying 'kia ora' to visitors, they either interfered or informed higher management about the host's failure to deliver on the bicultural objective. 
English was the uncontested, default language of communication by all staff, but sometimes staff conversed in their native tongue (i.e. Māori, German, French, Samoan etc.) among each other. I did not hear Māori being spoken very often outside the marae, which is probably due to the small number of fluent speakers. ${ }^{103}$ Although speaking Māori around non-Māori speakers is sometimes perceived as 'rude' or 'exclusive', some non-Māori speakers were very supportive of Māori being spoken around them:

I thought it was cool! I loved it! I'm from Invercargill and grew up [in the South Island], [...] so you very very rarely hear Māori spoken in ordinary situations down there, like something you just don't hear. Yes, I thought it was fabulous! Couldn't be more supportive of that. Still quite whakamaa [embarrassed] about using Māori myself (laughs), but people are supportive of that. I grew to understand a lot more by the time I left. (Pākehā woman)

It is indeed very important for the Māori language to be spoken regularly. Barlow (2005:115) argues that in order to survive:

[A] language must be spoken all the time - in church, in the work-place, in trade and commerce, in factories, and in the playgrounds at schools - then the language will flourish. Unfortunately, there are only a few places where Māori is spoken: principally on the marae during special ceremonial occasions and in some schools and churches.

Surprisingly, this is no different at TP, despite a significant Māori workforce, where speaking Māori is largely limited to the marae and ceremonial occasions (see chapter 2).

I conclude that the use of Māori greetings by non-Māori is a presentation of their bicultural awareness, whereas Māori often see it as a token gesture and appropriation of their language, thus rejecting it by replying in English. While TP has an official language policy to greet the public with 'kia ora', this is sometimes undermined by using English instead. The role-model of colleagues is more influential than the language policy, and evidence of the extensive use of Māori greetings in e-mails confirms that there is an accepted 'Te Papa culture' reflected in greetings.

103 According to the 2006 Census 24 cent of the Māori population stated "they could hold a conversation in Māori about everyday things", http://socialreport.msd.govt.nz/cultural-identity/maori-languagespeakers.html (accessed 21 December 2012). I estimate that only a handful of Māori staff at Te Papa are fluent Māori speakers. 


\section{Manaakitanga and Tikanga - Death and Grieving at Te Papa}

During my research I witnessed how TP deals with death as sadly four staff members and one museum visitor died. In Māori culture, when a person dies their status changes immediately to "being very tapu and being classified as a tūpāpaku” (Mead 2003:134). Thus, the occurrence of death contaminates the space spiritually, causing danger to anyone present so that a cleansing ritual, usually involving water (Mead 2003:143), is necessary to lift the tapu of death and make the space safe for everyone (see Barlow 2005:122f; Mead 2003:143). When a visitor died from a heart attack inside the TP building, the area was immediately closed to the public, and all staff were informed about the death and asked to stay away from the area until further notice. Only after the kaumātua acting as tohunga had performed karakia for spiritual cleansing, was the exhibition space declared safe again.

Grieving is considered a community affair in Māori culture, rather than something individuals deal with in privacy. Grief in Western society where the norm is to 'keep it all in', tends to be a private affair, but due to interaction with indigenous or immigrant cultures who express their grief more openly, society changes towards seeing mourning as healing (Raphael 2000). Although TP’s staff is predominantly non-Māori, it was striking that the Māori staff became key figures in orchestrating the grieving process and funeral arrangements, which can be explained by Mead (2003:133), who argues that "[t]he tangihanga ceremony is a vital part of Māori culture today [...] No other ceremony can mobilise Māori people quite as effectively as the tangihanga". In two cases where staff members died tragically, the institution acknowledged the need for staff to grieve and consequently turned a meeting room into a place where people could contemplate, cry, remember the deceased and get support. A photo of the deceased adorned with flowers and a condolence book was arranged, and there was a constant flow of coffee and tea, as well as supplies of finger-food to nurture the grieving staff. This reflects the Māori concept of manaakitanga, meaning "nurturing relationships, looking after people, and being careful about how others are treated" (Mead 2003:29).

The interviewees often commented on this practice as an example of biculturalism that benefitted the organisation as a whole, in bringing people closer together in what was 
often referred to as the 'Te Papa whānau' (for a discussion of the concept of whānau see L. T. Smith 2006 [1999]:187). In times of crisis, so staff argued, biculturalism ${ }^{104}$ comes to the fore and the otherwise fragmented organisation transforms into one organism "pulling through the difficult times". This reveals that TP's management deems Māori cultural rituals as more appropriate to deal with death than Pākehā culture within the bicultural Museum. Māori culture seems to provide a ritual template for dealing with grief, "because we have tikanga to guide us and help us through a crisis" (Mead 2003:148) accepting death as a life event. Despite the sad occasions, staff actually enjoyed the process of collective grieving, feeling well supported by their colleagues and experiencing an unknown closeness through the grieving rituals. Staff identification with TP grew stronger through the shared grieving process, expressed in kinship terms as 'we are family here'. Non-Māori staff became so accustomed to the 'Te Papa way' of dealing with death, that when a colleague had passed away, one Pākehā staff member posted her regret of not being at work that day on facebook: "O Te Papa whanau, so strange not to be there with you today. So very sad. Look after each other xx [hugs]" to which another colleague replied: "It's days like this that I actually want to be at work...".

TP often arranges transport for a staff delegation to attend the funeral or tangihanga (see Mead 2003:137) of a former staff member, wherever it is held in NZ. The organisation also accommodates for the need to leave work for several days to attend tangi when a family member passes away. Often colleagues inform all staff about the sad news, ask for a donation to the family or to sign a condolence card. The fact that colleagues commiserate in these major life events is seen very positively by staff, as one Māori woman's response to my condolense e-mail, after her father died, demonstrates: "I am really humbled by the support and words of comfort from many people at Te Papa. At least there are people who still care about other people! I think that's an important aspect of success of an organisation, that people are 'number one'."

\footnotetext{
104 I am using the term biculturalism here, because this is the term my interviewees used in this context. When looking at the rituals that are conducted at TP following death, however, it is apparent that these are based on tikanga Māori rather than combining or fusing elements of both cultures. Therefore, the use of 'biculturalism' in this context is questionable. I will discuss the notion of biculturalism and the multiple understandings that Te Papa staff associate with this term in chapter five.
} 
These examples are evidence that Māori cultural values shape the organisational culture within the bicultural framework at TP, emphasise interpersonal relationships and become part of the mainstream TP culture. The concepts of manaakitanga and whanaungatanga are not empty phrases but part of TP's everyday life behind the scenes, as the sharing of kai and grieving practices illustrate. In fact, TP management actively encourages staff to value these principles, and join the 'Te Papa whānau'. Thereby, TP fulfils the claim to "honor the experiences of indigenous persons and build on these experiences to construct empowering cultures of compassion and care (Darder et al., 2003, p.11)" (Denzin/ Lincoln/ L.T. Smith 2008:8). However, it is important to realise that the 'Te Papa whānau' is a construct that projects a 'pseudo-community', which is used strategically by TP management to achieve cohesion among staff. 105 I now turn to analyse organisational rituals for individual staff members as another means of perpetuating 'Te Papa culture' in the next section.

\section{Organisational Rituals: A Means to Promote Biculturalism}

Celebrating special occasions such as staff birthdays, anniversaries and farewells, play an important part within most organisations (Lukes 1975; Wittel 1996; Beyer/Trice 1988). Despite their significance within the organisational culture, these rituals have been neglected by researchers, with the rich analyses of organisational rituals by Michael Rosen (see 1985 for breakfast celebration; 2000 for Christmas party) and Andreas Wittel (1996; 'picnic', 'coronation ceremony' and 'birthday party') being the exceptions.

The 'frame' of the situation determines the ritual, its setting, actions and actors (Giddens 1984); for example, an informal picnic constitutes a very different frame to that of an official ceremony (Wittel 1996:234). Having attended 43 social functions at TP (including Christmas functions, staff anniversaries, birthdays, farewells and other parties), I have observed their various framings that are expressed in the venue, who organises it, who partakes, what food is served and what is said in the speeches. Here in

\footnotetext{
105 This issue is further complicated by Māori staff becoming 'Te iwi kāinga o Te Papa' (McCarthy 2011:122) and Pākehā feeling the concept should apply to all staff.
} 
this section, I focus on staff anniversaries and farewells which I call 'social rituals'. I develop the argument that social rituals at TP are vehicles for passing on institutional knowledge, enforcing bicultural behaviour, but most importantly, positioning the individual staff member, as well as the group he or she belongs to, within the organisation.

When long-time staff members leave TP they are usually farewelled with an official gathering with shared food, a photo show, speeches, music and presents. The same applies for celebrating milestones such as 20 years employment anniversaries, which I classify as 'rites of enhancement' (see Edgar Schein's table in Beyer/Trice 1988:147). The protocol of the ritual follows a bicultural procedure as it contains elements of Western organisational rituals as well as tikanga Māori that closely resembles the ritual of pōwhiri (see also chapter two) or hui (Salmond 2009 [1975]), with elements like karanga, karakia, whaikōrero, hongi, hākari and koha. The typical ritual order of most staff celebrations I attended was as follows: welcome by the Master of Ceremony (usually a higher rank staff member, often of Māori descent if the person celebrated was Māori), blessing the food, take a plate, taonga pūoro group performance, speeches followed by waiata (if a Māori speaker and well perceived), gifting present (caricature, card etc.), speech by the 'main actor', waiata, the 'main actor' kisses all members in appreciation (hongi), karakia/ prayer, last waiata, and pack out.

According to Gideon Kunda (1992:93) organisational rituals are gatherings "where the organizational ideology [...] is dramatized and brought to life". This was the case at Kaihautū Hippolite's farewell in late 2012, which constituted a 'bicultural showcase', with the values of manaakitanga, kaitiakitanga and whanaungatanga being stressed repeatedly by many speakers, stating the biggest asset of the institution was 'its people'. In the face of the re-structuring process and the threat of redundancy, this was a timely reminder aimed at the Leadership team of what staff think is the most important feature of TP: the people. TP was held up as 'the realisation of biculturalism' and an institution for 'healing and reconciliation', emphasising its bicultural obligation and wider purpose for NZ society. Thus, in the speeches the shared values of the organisation were revealed and reinforced. Influential staff members who had left TP were remembered in 
speeches and photographs, and some were present in person as living reminders of days gone by, adding to the mana of the Kaihautū. By addressing some colleagues with epithets like 'aunty' and 'nana', fictional kinship was constructed and TP staff were shown in the compilation of family and work photographs as an extension of Hippolite's family.

Social rituals give feedback to the person celebrated by the number of colleagues who attend, who speaks and what is said in the speeches, and the number of songs that are performed; these are indicators of the person's popularity. Conversely, such functions send messages back to management: poor attendance is a clear warning of detachment, disagreement and disenchantment with the running of the organisation. Drawing on Goffman (1974) and Giddens (1984), Wittel (1996:234) stresses that rituals have a double function in constituting power and authority on the one hand, while all participants actively shape the ritual on the other hand; without the staff participation it is impossible to conduct organisational rituals.

Within the 'frame' (Goffman 1974) of social rituals, rules that usually apply (like 'facesaving' or honouring higher ranks or elders) are suspended for the duration of the gathering; in their performances staff take on the role of 'court jesters' holding up a mirror to the authorities. Although management also uses these occasions strategically to convey institutional knowledge, reinforce their vision for TP and instill organisational values in staff, they often take a backseat leaving the running of these events to the lower rank staff and administrators, whose role in organisational ritual is that of 'informal holders of power' ('informelle Machthalterinnen', Wittel 1996:266). This marks social rituals as extraordinary events which allow a reversal of the normal power structure; they function 'bottom up' rather than 'top down' as they are produced mainly by and for staff, and clearly situated back stage: "[H]ere poor members of the team, who are expressively inept, can be schooled or dropped from the performance. Here the performer can relax; he can drop his front, forgo speaking lines, and step out of character" (Goffman 1959:115f.). For instance, at one Māori staff member's farewell a personalised version of the song 'I will survive' was performed by colleagues. Although 
it was tongue-in-cheek and evoked lots of laughter, the lyrics critisised the person's often rude behavior quite openly, as the first verse of the song sheet demonstrates:

First we were afraid, we were petrified

Kept thinkin [she] was really scary, then she came on side

Oh how we spent so many nights, wond'ring what we had done wrong

But we grew stronger, and we learned how to get along!

Later, the leaving staff member showed her 'other side' in his own speech, when she cried and fondly remembered the ones who have passed away.

Criticism of a person's behaviour is usually either passed on explicitly in the speeches (often dressed as a joke) or subtly conveyed in poor attendance as 'people vote with their feet', as the interviewees often mentioned. I argue that praise and reprimand in the speeches are not only aimed at the individual, but at all staff present to the effect that they 'search their hearts' and adapt their behaviour according to what conforms with the organisational culture. Thus, the social ritual for individual staff members acts as a social control mechanism for the wider staff in an organisation, setting the standards and limits of acceptable behaviour and appealing to the collective conscience of staff to adapt their behaviour accordingly. Therefore, these rituals are organisational tools to 'shape the behaviours' of staff and "to perpetuate their own values" (Beyer/Trice 1988:148); moreover, they are "mechanism[s] through which certain organizational members influence how other members are to think and feel - what they want, what they fear, what they should regard as proper and possible, and ultimately, perhaps, who they are" (van Maanen/Kunda 1989:49).

Although, the ritual is mainly conducted to celebrate the individual's achievement or loyalty to TP, on a different level, the speeches address all staff in attendance collectively, often acknowledging them as 'Te Papa whānau' or 'Te Iwi Kāinga o Te Papa'. While Wittel (1996:268) suggests that staff celebrations emphasise the 'human and private side' of a staff member, I argue that at TP the person's position and contribution to the institution is highlighted and valued. In their speeches people shared not only their relationship with the individual, but also passed on institutional knowledge to newer staff and reminded staff of events in the past worth remembering, 
such as the restructure, organisational changes, overcoming crisis (such as the 'mummy case', see chapter four), office space arrangements, as well as mentioning influential staff members who have moved on or passed away. The purpose of those narratives is to keep the institutional memory alive and make it part of the staff members' collective memory while reinforcing the status quo and "recreat[ing] the lived order" (Rosen 1985:32). They also position the person within an ethnic group (e.g. Māori) and make him or her part of the fabric of TP, weaving stories that draw on the personal and institutional biography. These tales play a crucial role in the life of an organisation:

Anecdotes from the past - real, embroidered, or fictitious - are told and retold, detailing disruptions which occurred, almost occurred and were admirably resolved. There seems to be no grouping which does not have a ready supply of these games, and cautionary tales, to be used as a source of humour, a catharsis for anxiety, and a sanction for inducing individuals to be modest in their claims and reasonable in their projected expectations. (Goffman 1959:12f.)

Thus ultimately, social rituals are utilised as a stage by the actors to manipulate the official record of the institution by making jokes, singing waiata and telling tales which often constitute a different story to the 'official' history of TP. Thus, the staged performances and speeches comprise forms of utopian theatre mocking the status quo and enacting politics of possibility, as Denzin/ Lincoln/ L.T.Smith (2008:7) suggest:

These performances reflexively use historical restagings, masquerade, ventriloquism, and doubtly inverted performances involving male and female impersonators to create a subversive theatre that undermines colonial racial representations (see Gilbert, 2003; Kondo, 2000, p. 83). This theatre takes up key diasporic concerns, including those of memory, cultural loss, disorientation, violence, and exploitation (Balme \& Carstensen, 2001, p. 45).

In considering this data, I believe that social rituals at TP have aspirational qualities, where even marginalised groups can stage themselves and perform their vision for the future. Māori staff in particular utilise social rituals in this way. In the next section I move on to examine the long-term effects of working in a bicultural organisation on staff. 


\title{
Intercultural Work Relationships
}

An international trend in museums is to diversify staff in order to reflect a pluralistic society and celebrate difference, but "[m]atters of difference can be complicated stuff" (Early 1995:16). Quite contradictory to the rhetoric of a united 'Te Papa whānau', an often-heard accusation made by some Pākehā staff is that the institution is split into a Māori and a non-Māori group because separatism is at play. Both Māori and Pākehā staff used the idiom of 'us and them', and when issues arose in the workplace they were often interpreted as cultural differences. Objecting to the politics of difference manifests itself in "the claim of separatism" (Doerr 2009:116). Separatism can be a negative side effect of biculturalism, which causes division and can even 'promote racism' or at least racist thinking (Spoonley 1988; Doerr 2009). I see the intercultural relationships within $\mathrm{TP}$ as a microcosm for relationships between indigenous and non-indigenous peoples in NZ more generally.

One Pākehā manager found it challenging sometimes to work with Māori staff, who she perceived as separating themselves from the rest of TP staff, thereby excluding nonMāori:
And there have been instances where it has been a struggle to try and actually work with for example the Māori staff. And they view themselves as being quite different and separate to the rest of the staff which I find really interesting as well. They refer to themselves as 'the Māori staff'. [...] We've just been brickwalled. Just a complete lack of cooperation around it, or an unwillingness to sit down and talk about what it is we're trying to do and how they can actually work with us to do that.

In contrast, another Pākehā woman who worked in a team among Māori did not feel excluded at all:

\begin{abstract}
me: And was there a real sense of acceptance of a Pākehā woman?
Pākehā: Yeah, everyone [outside the team] was worried about me. It wasn't an issue at all. Probably [...] it helped that I was aware of my own ignorance on a lot of things and I didn't come in saying 'I'm a big expert on Mãori stuff', 'cos I wasn't at all (laughs). And I knew that and I was really there to help translate Mãori stuff, bicultural stuff to the general population of Te Papa. And as an outsider I was able to do that more effectively than someone who was an expert in that. So no, nobody ever [rejected me]. Everyone was very supportive and I never had any resistance, that I was aware of anyway. [...] As my boss once said, I was 'the white girl doing brown stuff!' (laughs)
\end{abstract}

The fact that other staff members were worried about how a Pākehā woman would fare among Māori staff shows that anxiety of cultural difference and the projection of 
confrontations, tensions, ill-feelings and exclusion are wide-spread in people's minds, perhaps hindering an intercultural dialogue. However, if staff are open to cultural differences at work, it can improve their own practices:

You'd just be aware about different networks within the Museum [...]. Mãori society works very much along - it's a big network, there is the kümara vine and things like that. When we did things, we needed to be aware of the connections that people had and their different iwi connections, personal connections, tribal connections. So quite often you would involve people that wouldn't otherwise have been involved on paper; they might have such and such job description, but because they had this iwi connection or they knew this person they would be more involved. (Pākehà woman)

Being exposed to a different world view, she developed a more holistic perspective of the employee as a person rather than just someone doing a job: "Something that I'd try to remember for future jobs is actually that kind of inclusiveness and remembering about people's connections outside of work and not just their job title in work."

Sometimes the similarities between Māori and Pākehā culture in contemporary NZ are overlooked for a desire to highlight the differences; Charles Taylor (1995:70-71) thus calls for an active politics to recognise both similarities and differences between dominant cultures and minority groups. I assumed, for example, that Māori preferred face-to-face communication following the principle of 'kanohi ki te kanohi', but this was not the case at TP. Māori staff were no different from non-Māori staff in this regard, as one Pākehā assured me: "I think the Māori that work at Te Papa e-mail just as much as anyone (laughs)."

I also encountered double standards: while all staff acknowledged the merit of Māori rituals for TP, sometimes Māori staff were criticised for being separatist, and the wider society of being ethnically divided. "The underlying presumption of this approach is to incorporate 'them' into what is already going on with no fundamental change" (Early 1995:17), by accepting a 'cosmetic' approach while rejecting efforts to radically change the status quo. In accordance with Doerr (2009) I believe that their criticism was actually aimed at the NZ Government rather than TP, and called for national unity without 'special concessions'. Thus, I interpret the notion of 'Māori separatism' not so much as an act of separation initiated by Māori (although that can be the case sometimes), but as a Pākehā understanding of biculturalism: Pākehā are fine with 
Māorifying TP, but are not prepared to give up cultural control. This raises the question: what strategies do Māori employ in order to survive being absorbed into the 'mainstream institution'?

\section{Māori 'survival' strategies}

Being a minority in the TP workforce, Māori staff sometimes feel the need to utilise drastic measures in order to protect their culture, set boundaries on the hegemony of the dominant culture, and ultimately 'survive' as a people. I have mentioned earlier in this chapter that the Māori staff maintain group cohesion by informally sharing kai. A more organised strategy to mobilise Māori and raise awareness of Māori issues in the workplace is the formation of a 'Māori body' called 'Ngā Whetū Ririki' which meets regularly and serves as a forum for Māori staff, a 'union sub-division' and a kapa haka group. Yet, Rhonda Paku, who is also an active member of Ngā Whetū Ririki, stresses that this group is not about homogenising Māori:

There were between twenty and thirty members of Ngā Whetū. It was a get together to share kai and different people would speak about topical issues or things that were important in our respective areas of work and other matters, raising issues such as what was coming up and how these might impact on us as Mãori. We did not always agree with each other-and it's wrong to think that Māori should be homogenous on any issue, because we're human beings and we all have our own perspectives on everything - it was more about being together and supporting each other, maintaining our culture and whanaungatanga - relationships - in the workplace.

While the diversity among Māori (urban, traditional, different iwi, various dialects etc.) makes for an interesting mix and fruitful discussions, it can weaken the Māori voice in a mainstream setting as it further fragments the minority group. It seems that appearing as one Māori group rather than diverse iwi groups is a strategy to generate a strong Māori representation within the mainstream institution.

Another strategy Māori use to protect cultural integrity is resisting requests that go against their cultural values. For example, one kaitiaki Māori told me that she was asked to take a group of 'VIPs' through the Māori collection after hours, which she refused to do in order to protect the taonga who are asleep at night: 
There is no way I am going to do that! Y'know what I mean, it's that sort of thing but at the same time it's respecting these fellas [taonga]. We are with them all day and it's their time to go to moe [sleep]. [...] They [management] don't sort of see, they see it as a collection. It's not a collection, it's taonga that belongs to the people who are connected and it's their whakapapa and it's reconnecting our values back to that realm. That's what it's all about, if you believe in it.

This statement demonstrates that kaitiaki Māori take their role as guardians of the taonga very seriously and see themselves as the voice of the taonga. Management follows a different agenda with dissimilar objectives from the kaitiaki Māori; for TP, a customer focus and financial gain are high priorities, which in this case clash with the Māori belief that taonga have mauri and mana, and therefore their needs must be respected. In this scenario the Māori staff might be seen as uncooperative and inflexible, yet they are committed to fulfilling their roles, which they define as guardians of taonga and upholding their cultural beliefs. At the same time, Māori set boundaries and regain control over museum practice by refusing to 'play their roles' (Czarniawska-Joerges 1997:38). This example illustrates that the cultural minority is also protecting its rights and mana, as this Māori woman emphasised: "[I'm] not a robot who runs around 24/7."

If this strategy of resistance fails, the last resort is 'walking out', as an incident told by iwi kaumātua Kukupa Tirikatene illustrates:

\begin{abstract}
We went into a meeting the kuia and I, Seddon [Bennington] was there and I said: "Who are all these people?" There were three strangers in there. Seddon must have noticed I was looking at these people. He said "Oh perhaps we better introduce ourselves." That one said, "I'm so and so, lawyer." "I'm so and so, lawyer." I said to the kuia, "I'm getting out of here." Somebody said, "Hey, hey, the meeting hasn't started yet." I said, "I'm not coming into a place where I'm being scrutinized by a legal eagle, where I make the right move or the wrong move, or say the wrong thing," I said, "That's not a meeting as far as I'm concerned!" So I walked out.
\end{abstract}

While 'walking out' is a passive strategy of avoiding confrontation, 'doing the haka' is much more aggressive way of expressing disagreement. This only occurs during exceptional situations where the principle of mana has been severely breached. Te Taru White, then Kaihautū, performed a haka (see chapter one for more details) before walking out of a meeting to show his utter disagreement with the CEO's restructuring plans about which he had not been consulted. The haka was thus utilised as a means of challenging the CEO, pointing out his failure to consult the iwi partner and regaining the mana of the Kaihautū after this shameful incident. As a consequence, the restructuring 
process was delayed and the Kaihautū consulted properly. These examples of Māori survival and resistance strategies demonstrate that Māori demand full power sharing in the bicultural partnership in the workplace, by any means necessary. But what happens to their own identity, and that of their non-Māori colleagues, as a result of working at TP?

\section{Effects of Working in a Bicultural Organisation}

Taylor (1994:70-71) drawing on Gadamer, suggests that the individual is perpetually transformed by encounters with 'the other' resulting in 'fusion of horizons'. In this section I make the point that within the workplace at TP, staff come in contact with a culturally diverse mix of people, and are exposed to bicultural policies, which has longterm effects on the identity formation and cultural values of staff. In general, non-Māori report an appreciation for Māori culture and a new-found interest in their own cultural roots, whereas Māori tend to become more empowered as Māori.

\section{Non-Māori Staff}

Non-Māori staff who have worked at TP for a number of years report that they have 'internalised' a bicultural attitude that is respectful of Māori culture, to the extent that they say it is 'in our DNA'. Coming from 'monocultural Christchurch', writer Liz Grant said working at TP "has been good for me, because it's certainly led to another level of appreciation" of Māori culture but also of cultural diversity. For some biculturalism becomes 'second nature' after a while:

I've worked here for so long, I guess I take some aspects of our biculturalism at Te Papa for granted. It's not until you get out into the community and go and visit other museums that you find out just how special Te Papa is. [...] We're very, very lucky at Te Papa because it surrounds us, it's in the bones of the place, it's the essence of the place. And I don't know if you've had people who have found it hard to express what biculturalism is, and I guess the closer - y'know working here and having it seep into your bones - when you try to enunciate something like that it can be quite difficult. (Pākehā woman)

In fact a bicultural attitude is so engraved in some non-Māori staff that they struggle to make explicit what a bicultural attitude entails. Nevertheless, two effects - appreciating one's own culture more and automatically adhering to Māori protocols - were mentioned frequently: 
Pākehā woman: I'm much more appreciative of my own history and culture now and I think that to a certain extent (pause) having that bicultural nature in Te Papa encourages people to think and investigate themselves and find out where they fit. [...] I guess there are Māori values and tikanga that are just now part of me, so yeah.

me: Can you make an example?

Pākehà woman: Ah, I don't sit on tables. ${ }^{106}$ It's a really good question and all I can say is because of living it, [...] it's hard to try and tease those bits out.

A few non-Māori staff members only realised how much they had internalised the Māori viewpoint on not displaying human remains, when they were confronted with mummies at a museum overseas:

to the extent that when I went to the British Museum last year, I was actually quite horrified (laughs in horror)! That was just - oh they just shove them all out there! There was one guy, he was completely unwrapped - he might have been a sand mummy, one of the earlier ones - so he was in the foetal position and he was just there and you could see him. For me - I love mummies, I think the whole practice of it is very interesting and I'm glad I could see it - but all those people taking photographs, I found revolting, it upset me. (pause) I've been Te Papa-ised! (Pākehā woman)

I get a bit shocked when I see human remains in other museums around the place in Europe or within South America. I went to some tombs which were open, had skeletons of people. And I think it's probably now because knowing how tapu that is from a Māori perspective, that actually that value is part of me now. (Pākehā woman)

These statements confirm a 'bicultural transformation' through working at TP for nonMāori. This is one step towards becoming a 'bicultural person':

Everybody learns one culture in his childhood and owes it primary allegiance. The bicultural person, in addition, accepts as legitimate the values of a second culture, is to some extent familiar with these values, and can turn to them if necessary, for subsidiary relationships [...] Any degree of familiarity with a second culture will soon lead to a contradictory situation where there are two alternative correct ways of acting [...] in such a situation, we have to make a choice; and we can be called bicultural only if we have made such a choice while aware of the value conflict involved in it. (Schwimmer 1968:11)

The non-Māori participants often talked about an attitude or behaviour change that they explained with being exposed to Māori culture within TP. Damian Skinner, a curator and writer, suggests that biculturalism is a "kind of operating procedure that develops out of cross-cultural dialogue", engaging people with diverse cultural backgrounds through which "their own sense of self is transformed" (Skinner 2005; see

106 Sitting on tables used for food preparations is taboo in Māori culture for hygiene reasons (Mead 2003:49). 
also McCarthy 2011:238f). At TP this is true especially for Pākehā who grew up in the South Island with little exposure to Māori culture; they reported a steep learning curve during their career at TP leading to a more open-minded, positive attitude towards Māori than the stereotypical, sometimes negative image they had previously. In many cases their assumptions about Māoridom were skewed by the media (see Walker 1990b), but were quickly replaced by the (often positive) first-hand experiences they had with Māori at TP.

The Pākehā woman who teaches te reo Māori at TP could see a real change in her personality through becoming bicultural:

It means your heart being open to accept the two different worlds, two different ways and being touched and being open to letting a bit of a merge happen and taking on board bits and letting them have more flow, backwards and forwards, yeah. I feel that I live like that. I feel that my whole being is like that. I'm very Pākehā. I know that and I've learnt that through being bicultural (pause). But my soul is very bicultural, and I think that it makes the world more expansive. And it allows (pause)[...] I think it's really related to spirituality as well, I think it's living biculturally [that] has helped me open spiritually. And I'm not saying Māori have spirituality and Pākehā don't. I don't agree with that at all. I just think the world got bigger and I've really gained from that.

In addition, many staff from diverse cultural backgrounds told me that being confronted with a rich Māori culture and staunch Māori identity at TP inspired them to research their own cultural heritage and as a result they became more appreciative of who they are. One Pākehā participant told me that he likes taking part in TP's repatriation pōwhiri because "I find those really connecting. You know I feel like a bicultural New Zealander", whereas outside TP he did not experience that feeling. Subscribing to bicultural principles at work challenges 'Pākehā thinking' and makes one's own culture more visible:

It helps us as human beings to become aware culturally definitely. I remember my first awakening was - apart from travel - during the Treaty course. We examined our own cultural roots and it became very clear to me that my background was culture bound, whereas I tend to think that was just the way it was. I became very aware that it was a context that was learned. And so being here, [...], I may have received that sort of insight working here, realising that the way I operated was not the truth or the way things are done, but coming from a particular cultural context and that there are other ways of being, and so it's really good. It's really advantageous for people here to be exposed to that, whether you're a Mãori [or Pākehā]. If you are Mãori you may not have been brought up with Mãori culture, you may be quite disengaged from it, but it's an advantage for Mãori people as well and for Pākehā to be exposed to Mãori culture, realising that it's not 
necessarily scary and to see the cultures coexisting, definitely. So I think personally, organisationally and outwardly, it's definitely an advantage. It's something that we should promote and be very proud of! (Pākehā woman)

While many staff share this positive outlook on biculturalism, I should add that not everyone subscribes to an attitude change; on the contrary, a few Pākehā staff objected quite vehemently to the notion that they should have to change in any way. In their opinion, biculturalism should be accepting of who people are:

[I am] probably blasé about [biculturalism]. I guess I didn't come in here [thinking] "oh, it's a bicultural organisation, there's quite a lot of importance given to Māoridom, therefore I'll have to change my ways to fit in". Maybe that's my idea of biculturalism: I shouldn't have to change! I should still get to be me and Mãori can be Māori. That's fine. I don't need to change the way that I do things, as long as it's not pissing anybody off. (Päkehā man)

Whiting also emphasises the need to co-exist separately, rather than trying to achieve a mixing of the two distinct cultures under a bicultural umbrella:

[Biculturalism] is understanding the separation, yeah, that at times that bunch of Mãoris over there just want to be themselves and that bunch of Pākehās over there, just leave the buggers alone. Don't go and interfere with them. Don't suggest that "hey, you fellas, you need to be bicultural" or anything like that. And it's understanding what the separation is about.

Having in mind Whiting's idea that TP could be a place for Māori to 'be themselves', I turn to explore the effects of working at TP on Māori staff in the next section.

\section{Māori Staff}

For Māori staff working in a bicultural organisation means that there is an opportunity to explore their heritage further and strengthen their identity. This is true especially for urban Māori who did not grow up in a marae-based community and were estranged from the Māori language and culture. Working in close proximity to other Māori staff, who are culturally competent in Māoritanga, and having the opportunity to improve their language skills within TP (see chapter two), boosts their confidence and aids Māori empowerment. Of special importance to ignite the 'journey of cultural re-discovery' for Māori are physical spaces such as the Māori collection room, which make Māori culture tangible, as a kaitiaki Māori stresses: "Coming in here [...] is all about nurturing, growing and reconnecting. Because it's quite a special place to be." 
Richard Wright, a person of mixed Māori and Pākehā descent, who has been working as a host at TP from 'Day One' and at the 'Old Museum' in Buckle Street before that, recalls an epiphany that sent him on a 'journey' to discover his Māori side by learning te reo Māori at university:

I wasn't brought up with my taha Mãori, so I was brought up in a very Westernised way [...]. So when I worked in the Museum, I didn't have a great desire to be around Mãori treasures. I didn't speak te reo. I didn't know a lot about my culture or the tikanga or the protocols, didn't know any waiata, didn't know anything about taonga pūoro or any of these wonderful, beautiful arts that I know today. So what I knew about being Māori, you could write on the back of a stamp, very little, and I thought that was okay. I worked in the finance department, so I thought that's fine because I'm working in an area where I don't need to use it. So I can still be who I am and I don't have to drop any of my Pākehà identity. Until one day when we had a special welcome ceremony for the Queen of the Netherlands [who] came to visit, Queen Beatrix. That was about 1992. We were all up in the Mãori Hall [at Buckle Street] in those days and we had a welcoming ceremony. We had a pōwhiri for her and then most of the Mãori staff left and went to prepare for the morning tea and I was left there standing looking around the Mãori Hall. And I remember our director turning around and Queen Beatrix asked her "What is the Māori word for cloak?" Our director at the time, Jenny Harper, she turned around, saw me [thinking] "there's a Māori guy, he will know, [I] should go and ask him". And it was probably one of the most embarrassing times of my life, because the cameras were on me and she asked me this question, and I had no idea! I had no idea! Just didn't know. And at that time I'd been working for the Museum for two years. I thought to myself that will never happen again! I'll never be put in that position again. And a year later [...] we found out my wife was expecting a baby, so one of the first things we did was we enrolled our baby in a Kōhanga Reo. I knew that [when my daughter is] in Kōhanga Reo, I'll have to go and learn te reo. And that's when I started to learn te reo and started to use it more and more often at work.

This example illustrates that working at TP can be a catalyst for people of Māori descent to explore their Māori identity. Māori staff at TP are confronted with the assumption by non-Māori staff as well as visitors that because they appear to be Māori, they must consequently express Māori culture in all its facets: "Indigenous people are expected to be essentially 'other' and to manifest this otherness in natural and visible ways" (Sissons 2005:39). When they fall short of this ideal, some Māori staff compensate by brushing up their skills and using the resources provided by TP to develop their own cultural identity, in a way arguably conforming to the existing racial stereotype. TP's management endorses their initiative as part of professional development and provides resources through in-house training or funding courses outside TP (see chapter two).

Giving staff the skills to communicate in Māori has proved successful in some cases where non-Māori staff utilise it in their day-to-day work with visitors or colleagues: 
I remember the first day I started here I freaked out, because an Indian man came up and spoke Māori to me! [...] He was one of our hosts, straight away it just changed the way that I thought. You could not just presume that people can't understand Māori. So that was the first thing I noticed at Te Papa. (Māori woman)

Thus, TP also challenges the preconceived ideas and stereotypes that Māori have of 'the other', often triggering an attitude change.

So, we can see that being exposed to a binary concept that highlights 'culture' as the most important marker for identity, generally tends to reinforce the differences between cultures and pushes staff to express either a Māori or non-Māori identity, even those with mixed heritage. However, exposure to biculturalism also produces hybridity, for example, when non-Māori staff become fluent in Māori and carry out Māori performances (but these are exceptions). Being exposed to diverse cultures at TP and engaging in a cross-cultural dialogue promotes attitude and behaviour changes in many staff. Young urban Māori find role models among TP's staff that 'live and breathe Māoridom' and often discover their Māori side on a deeper level by doing courses in tikanga, karanga, whaikōrero, te reo Māori and learning to embrace Māori culture from their mentors.

\section{Conclusion: Te Papa - A Forum For the Nation But Not For Staff?}

As I have shown in this chapter, the role that biculturalism plays at work is very much dependent on an array of factors: the mix of ethnicities in the team, its exposure to Māori audiences and taonga Māori, and its interaction with iwi. Above all however, the extent of bicultural commitment within a team is driven by individual team members and their personal 'buy-in' which is influenced by their biography, attitudes, previous experiences and pre-existing knowledge of biculturalism. As a result, the picture of biculturalism that emerges from this research is quite different to much of the literature, something that is assembled from below by different actors in an ongoing, fluid and dialogic performance.

The disestablishment of the bicultural team was seen by many staff as an act to weaken biculturalism. However, it can also be interpreted as an indication that TP has grown up 
and made the 'bicultural police' redundant. Shifting the responsibility for implementing biculturalism in operation from the institution to individual managers poses the risk that TP in the long-term could lose its bicultural commitment as staff members leave and take with them the institutional knowledge.

Paradoxically, though TP presents itself as a 'Forum for the Nation' to the public, it actually offers very little formal training to build bicultural capability and does not provide a platform for its staff to discuss biculturalism. Staff suggested that establishing a forum as a 'safe space' and format to facilitate debate around biculturalism, could promote and improve intercultural understanding, as this Māori woman suggests:

You need to have more workshops. Where staff can - quite open workshops - something I was involved with trying to advocate for as well. Open forums, in particular with our nonMàori staff to allow them - no matter how dumb the questions or how terrible they may think it is - that you have the opportunity to ask the question that you need to ask. Which is probably why I would have a non-Māori staff (amused) just come and ask me something sometimes. Ah, it's trying to find a non-threatening environment where people do understand each other. That is what Te Papa still has not provided. It's an environment where all staff can come together, it's not going to be threatening, I mean we provide it for the public and schools. We don't quite provide it for our own staff and just to understand about the whole bicultural thing.

An analysis of the status quo showed that staff learn biculturalism mainly 'by doing', including making mistakes. Despite some staff members arguing that the Māori staff separate themselves, I have seen some fruitful collaboration between Māori and Pākehā staff in the Education team where both mātauranga Māori and a Western scientific knowledge system are integrated equally and implemented by everyone in the team.

Although staff described biculturalism sometimes as an ideological or philosophical mindset that did not play a major role in their actual work practice, the evidence demonstrates that in some circumstances Māori values and protocols come to the fore, especially at times of crisis and grieving. I have analysed the organisational culture among different teams at TP that manifests itself in greetings and food consumption rituals as well as how death is dealt with. In these extraordinary situations, that again (see chapter two) are removed from the business routine, Māori culture has a greater influence to the extent that it dominates the orchestration of procedures when death occurs. The most significant factor for an attitude change for TP staff is not staff training 
or everyday work, but the rituals and times of crisis when staff experience the bicultural concept on an emotional level and learn from their colleagues' behaviour.

In this chapter I also identified the staff celebrations, particularly farewell parties, as one vehicle to pass on institutional knowledge and retain the bicultural 'Te Papa culture', utilising speeches and songs to ingrain the desired behaviour in staff. This can be seen as a subtle and informal, yet quite effective way of passing on corporate values and creating an organisational culture in contrast to formal training initiatives. The problem with this kind of 'alternative training' however, is that only staff who partake can be addressed, and it is only a small percentage of staff present at these staff celebrations. More importantly, social rituals are a stage for performing identity and positioning ethnic groups as a form of 'utopian theatre', especially for Māori.

It seems that the daily work routines follow 'normal', Pākehā-led business protocols whereas Māori culture exists in some 'pockets' that are usually marked by extraordinary events or outside-of-work practices, almost like a parallel universe that is based in the marae and collection room. However, these pockets are crucial for individual identity formation, which Giddens (1991) sees as a typical institution of high modernity. This chapter shows how the effects of working in a bicultural environment can be understood as a 'contact zone' or 'cross-cultural mediator' for staff within TP, that is a microcosm of NZ society.

In the next chapter, I examine how the bicultural framework affects museum practices in the Māori collection room and exhibition spaces of TP, the Museum's interface with the public and source communities. Staff at TP 'grapple' with biculturalism particularly when the different world views are incompatible, yet for the organisation to function, they need to be reconciled. I demonstrate how solutions to bridge "competing theoretical perspectives'” (Marsden 1994:48) are negotiated and decisions are made, arguing that the challenges of being a bicultural institution illustrate the position and power of Māori within the Museum. 


\section{4 \\ 'Grappling' With Biculturalism}

\section{Introduction}

In the previous chapter I examined how staff learn biculturalism as part of TP's organisational culture and illustrated how 'doing biculturalism' in the workplace affects identity formation of Māori and non-Māori staff. While the Māori networks facilitate Māori empowerment, non-Māori staff report they have been transformed by being exposed to Māori culture at TP which acts as a contact zone or cultural mediator. I concluded that bicultural practices are perceived as 'Māori things' that only exist in 'pockets' outside the 'business as usual', i.e. in lunchtime rituals, greetings and times of grief.

In this chapter I discuss how the bicultural framework, which values Western and Māori world views equally, influences museum practices such as collection management, conservation and exhibition concepts. I move away from TP's offices and further into the Museum's core, demonstrating how tikanga Māori guides museum practice in different spaces, namely the Māori collection rooms and the public exhibition gallery during the Egypt: Beyond the Tomb exhibition (thereafter EBT) that was on show at TP from 9 December 2006 till 29 April 2007. The concepts of taonga, mana taonga and tikanga are crucial to the way TP manages its relationships with source communities and their access to collection items. Drawing on interviews with kaitiaki Māori as well as my own impressions while working in the Māori collection rooms and observing back-of-house visitors, I explore some of the issues at stake in this Māori realm, particularly the discourse around menstruating and pregnant women. How taonga are cared for at TP epitomises what Dean Sully (2007) calls 'decolonising conservation', 
where Māori reclaim control over the care of their taonga. By referring to the case study of a non-Māori conservator working with taonga Māori, I examine the challenges and benefits of adhering to multiple values under a bicultural umbrella.

Management constructs TP as a 'unique model for biculturalism internationally' and 'cutting-edge in collaborating with indigenous communities' ${ }^{107}$ I challenge this official image, suggesting that while this is certainly true in many cases, in reality the institution and staff grapple with the bicultural concept when cultural values contradict one another, yet pragmatic decisions need to be made. By reconstructing the case of Keku, a 2700-year-old mummy that went on display at TP in the EBT exhibition in 2006/07, I illustrate the conflicting views staff and management held, and show how the issues arising were negotiated behind the scenes. My argument is that the Māori objection to displaying human remains can only be understood in the light of TP's Karanga Aotearoa Repatriation Programme and its effort in repatriating Māori human remains. Therefore, I introduce this programme and share my personal experience at a repatriation pōwhiri in order to contextualise the 'social drama' with the mummy. Lastly, I analyse the making of EBT from various angles.

\section{Caring for taonga at Te Papa}

\section{Who Owns Taonga Māori?}

Although many taonga have found their way into collections through legal transactions between Māori communities and collectors, the perception that 'museums have stolen our taonga' resonates with some Māori even today (see McCarthy 2011:31). The often complicated pathways of museum objects reveal 'entangled histories' (Macdonald 2013; see also Thomas 1991). For many Māori, museums still represent a Western institution and in recent years some Māori communities have regained full control over their taonga by establishing their own iwi-run cultural centres (McCarthy 2011:240f.). TP has responded ambiguously to this challenge; some staff welcome these initiatives as Māori

\footnotetext{
107 Michelle Hippolite used these phrases at several 'all staff meetings' and museum conferences I
} attended in 2011 and 2012. 
empowerment and exciting additional opportunities in the museum landscape, while others fear TP might have to return taonga from its collections and displays to suboptimal storage conditions, as most of these cultural centres do not have the resources and expertise to create the same high conservation standards that TP deploys.

Te Hau ki Türanga, the whare whakairo on public display in the Mana Whenua exhibition, may well be returned to the Rongowhakaata tribe in the Gisborne area, as a result of being a feature of their Treaty settlement claim that confirmed it was "forcibly taken by the Crown" (McCarthy 2011:218). Positive outcomes may result when taonga is returned to the original owners, with the relationships between museums and Māori strengthened through these transactions (see Tapsell 2004, for Auckland Museum and Ngāti Whakaue; see Tamarapa 1996a, for TP and Rongowhakaata; see also Kreps 2003:72f. for positive museum/iwi initiatives at TP). While the ultimate destiny of taonga in museums remains unresolved, TP makes an effort to be a culturally appropriate guardian by employing kaitiaki Māori (see M. Kawharu 2004 for a definition of kaitiakitanga) who ensure the spiritual and physical wellbeing of taonga and allowing the Māori descendents full access to their taonga wherever possible. In many cases the legal ownership of the taonga lies with iwi and TP is merely the caretaker. Although this approach is quite novel in the museum sector, it is not limited to TP or NZ. Kreps (2003), who researched an Indonesian museum, discovered that the museum staff had a very different attitude towards the museum objects than museum professionals in the Western world. Rather than being separated from the course of everyday life, the objects sometimes crossed the physical boundaries of the museum to be used for their original purposes, a very similar practice to the use of taonga by Māori at TP.

Not all Māori aspire to recover their taonga; some are satisfied with it being kept at TP, mainly because they lack the resources to care for them appropriately. Ngāi Tahu kaumātua Kukupa Tirikātene is an advocate for depositing family heirlooms in museums, because he could not provide the right conditions at home: "I'd hang [the feather cloak] up on a hanger, just like a coat. I couldn't give it the decency it deserved". Thus, he decided TP was the ideal storage space for his own taonga, a cloak gifted to his 
father Eruera Tirikātene by Tahupōtiki Wiremu Rātana, the founder of the Rātana movement, when Eruera became the first of the Rātana faith to be elected to the NZ Parliament in 1932 (Ballara 2012). ${ }^{108}$ Kukupa Tirikātene told me how he felt when his sister, the Honorable Tini Whetū Tirikātene-Sullivan (1932-2011), a long-serving Labour Parliamentarian, presented the cloak to him:

When I came down here [to serve as kaumātua at TP] my sister gave me the cloak that Dad was given from Rātana pā, Te Māngai ['the mouth piece' of god, referring to Tahupōtiki Wiremu Rātana]. He gave it to Dad. Dad left it with Whetū and Whetū gave it to me to wear. Oh gee, I need to look after it! This is our family treasure! I come here. The experts are looking after things. They've got the climate right, repair it, replacing the feathers. So I said to Whetū: "I would like the cloak to be left here. If we need it we can apply for it. If there's a graduation, mokopuna can come along and say: 'I'm his mokopuna. May I borrow it?' They can have it for a couple of days for the graduation, bring it back. These people look after it". The only thing that the museum needs to make in that case for me is to write an agreement who the korowai belongs to and I think that's the most important thing, that a museum acknowledges who gave them the things.

Acknowledging the relationship between Māori and taonga is paramount at TP and allows the occasional use of collection items for ceremonial purposes. Descendents can borrow taonga for graduation ceremonies and other occasions; likewise TP uses feather cloaks at repatriation pōwhiri to drape the wooden crates containing kōiwi tangata or caskets at tangi to keep the dead body inside it warm (Salmond 2009 [1975]:104). The cloaks are appropriately chosen from the same iwi as the koiiwi tangata, whereas unprovenanced cloaks are avoided, because they could have originated from a hostile tribe. Informing this unconventional approach to museum objects is the Māori principle of taonga.

\section{Te Papa's Approach to Taonga}

TP fully embraces the Māori concept of taonga as living entities (Tapsell 1997, 2006; Henare 2007) and the implications that has for museum practice. Moreover, TP has broadened the indigenous lens by applying it to all source communities whose artefacts are cared for by TP under the 'mana taonga principle'. Furthermore, conceding rights (such as borrowing a cloak for a family member's graduation ceremony) and control (such as determining the care of a cloak and keeping its oral history intact) to the source

108 See also: 'The Tirikatene Family Cloak - A Political Heritage'. Story and Video available online at: http://collections.tepapa.govt.nz/theme.aspx?irn=3665 (accessed 30 April 2013). 
communities means the Museum is giving up some of its jurisdiction, authority and privilege of interpretation. Hippolite explained the mana taonga principle with the following diagram as a reciprocal cycle that enhances everyone's mana: the mana of the taonga, the people involved and ultimately, the museum.

\section{Box 18: Mana Taonga Principle at TP109}

\section{Mana Taonga}

accordance with tikanga

right to Rongomaraeroa

mana to care, speak and determine use

iwi relationships

creator of taonga

koroua, kuia/

exhibition

traditions and memory

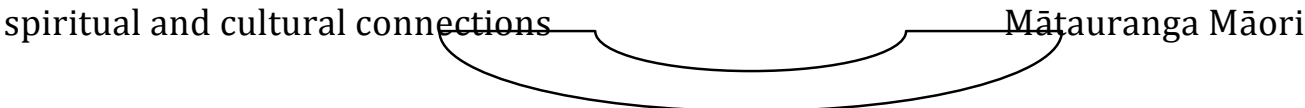

Taonga Māori at TP are housed separately from other collection items in three collection store rooms at Cable Street, as well as the waka store at Tory Street. The Māori store rooms were given Māori names: Ahuru Mōwai houses the large carvings, greenstone taonga are stored in Tātau Pounamu, and Hine Te Iwaiwa, the goddess of weaving, watches over the cloaks in Te Whare Pora o Hine Te Iwaiwa. This act of renaming marked a paradigm shift in recognising cultural ownership as well as "moving away from Western academic practice" towards embracing a Māori cultural framework (Dougal Austin in McCarthy 2011:127). Renaming processes also reverse acts of 'symbolized invasion' by the settlers and are therefore "fundamental to indigenous politics" (Sissons 2005:14).

Furthermore, taonga at TP are looked after by kaitiaki Māori who are of Māori descent. ${ }^{110}$ Although their job title might be 'collection manager Māori', their role

109 This diagram is copied from Michelle Hippolite's key note at the Museums Aotearoa Conference held at TP on 18 April 2012. 
comprises much more than just 'managing' objects as they are the spiritual caretakers of the taonga; "we are their eyes, ears and voice", Moana Parata told me. The protocols are expected to be taken seriously by everyone entering the realm of the collection rooms, staff and visitors alike. Tikanga is applied in an orthodox way, which deviates from the past when tikanga was much more fluid and contingent as anthropologist Annette Weiner (1992:48) suggests.

In the Conservation and Tikanga Policy111 (thereafter CT policy) TP spells out the expected standards for conservators working on taonga. Hereby TP recognises that taonga need 'spiritual care' in addition to 'physical care', emphasising that

[m]any of these standards have their origins in conservators' concern for the physical safety of objects in their care, but following these standards a conservator will also be following behaviours that are culturally appropriate when working with taonga.

Some standards in the CT policy - including "don't eat or drink around taonga", "don't stand over or step over any taonga" and 'wash hands' - follow best practice in international museology and are accepted as 'common sense' for museum professionals worldwide, thus seen as not negotiable, because they would put the taonga at a physical risk of being damaged. In contrast, TP's CT policy frames the following tikanga as recommendations:

There are certain things a conservator may choose to do or not to do for their own personal safety. These are seen as personal choice, and vary from person to person.

A few examples:

- To say prayers/karakia

- Not to work on carvings

- Not to work on koiwi

- Not to use certain treatments, e.g. saliva for surface cleaning a Maori portrait

- Not to work on taonga while menstruating

The last point is the most controversial, because Western and Māori world views collide over what women should or should not be doing while menstruating. I analyse the conflicting discourses around this issue in the Māori collection store in the next section,

110 It is assumed that only Māori can appropriately fulfill this role and this notion is not contested at TP. However, some Pākehā who are fluent in te reo and knowledgeable in tikanga have questioned the assumption (Ashley MacKenzie-White in McCarthy 2011:123).

111 Conservation Policy_Conservation and Tikanga SPAT October 1999. 
using participant observation, an interview with a kaitiaki Māori, media reports and autoethnography.

\section{Case Study: Experiencing Tikanga Taonga in the Māori Collection}

Having anticipated doing fieldwork in the Māori collection for some time, I was very excited at the prospect of working in the store rooms. I followed collection manager Māori, Moana Parata throughout the day, spending most of the time in the carving store Ahuru Mōwai, where I assisted hands-on with putting registration numbers on taonga and observed tikanga in practice, such as the ritual of cleansing oneself with water when leaving the collection room (see Eliade 1958:194 for water as purification agent). Parata explained that it is a very different realm inside the collection room compared to the rest of the museum or the offices and that just being in this special space with the wairua can be very draining and tiring. She advised me with the following words:

[If you are] getting tired, get up and move on out. Always, if anything's worrying you, always grab the water that just releases [the tapu], so [the spirits] are not hanging on to you. Because they do hang on, I tell ya! You don't know they are, but they do it in their own funny little way. But the best thing to do is to go to the water and sprinkle yourself. Water just disconnects everything.

Curiously, I did get tired quickly working in the Māori collection and found it difficult to concentrate. Whether this was due to the wairua or the quiet atmosphere that was so different from the rest of TP, I am not sure. Frequently, I left the store room for a 'breather' on my own. I always had to remind myself of the practice of cleansing with water and often forgot, only to realise my mistake half-way down the corridor, which had me running back to the sink in a hurry. I clearly had not yet internalised the tikanga. On my third day I sat down for an interview with Parata who shared her personal journey and understanding of taonga with me.

Parata started employment at 'Buckle Street' in 1994 (her sister-in-law already worked there) "cataloguing all the Mãori inventory of taonga". She told me she could not enter 
the Māori collection at first, because the spiritual force in there was so overwhelming: ${ }^{112}$

I didn't realise what I was walking into. It took me a long time to be amongst taonga so big and so - it's just a big experience. It took me a good couple of months just to go in and sit in the collection area, they called it the basement. But it took me a while to really be amongst it all, because of the wairua, the spirituality of the room. The rooms in those days were quite unreal; it's just something very different that I have never experienced before. So yeah it took me a good couple of months to actually work with them. More or less be accepted [...] in that realm.

Under the guidance of 'the two nannies', Aunty Bessie (Irihāpeti Walters) and Aunty Betty Rewi, as well as liaising with iwi, Parata grew very fond of looking after the taonga in TP's collection. The move from Buckle Street to Cable Street was an ambiguous time for the toanga, as Parata recalls:

It was great and it was not so great. It was sad leaving Buckle Street because a lot of the taonga had been living up there for over sixty years. It's a long time, [and not easy] to move taonga from a place that they have got so used to. Because in the old Buckle Street galleries they were alive, especially at night time. You would hear footsteps; you would hear wailing, all those sorts of things. Lots used to happen, it was really busy. It was a busy museum by day but very busy by night. I noticed that when we did make the big move everything was quite peaceful but it sort of shut off. You know, the wairua isn't as full on as it used to be. It's like a place they have come to rest.

Having grown up immersed in Māori culture, for Parata adhering to tikanga is not a conscious decision or obeying a strict set of arbitrary rules, but second nature: "Well, I live it, eat it and breathe it." In fact, karakia helps her to clear her mind, be open and move through the day - and ultimately, she says, "do my job the best I can". Thus, for Parata it is a 'no-brainer' that 'wahine mate, wahine hapü', menstruating and pregnant women do not work with taonga. Respecting the tikanga “we [kaitiaki Māori] don't work in the realm during that time. We stay out of those rooms until we are ready to come back in." The collection managers simply do desk-based work during that time that does not require physical contact with taonga.

However it is more difficult, according to Parata, to ensure that the tikanga is complied with when back-of-house tour groups come in. The visitors receive a list with the tikanga two weeks prior to the tour and are reminded verbally of the protocols immediately before they enter the collection, as I observed at several back-of-house

112 See also McCarthy 2011:129. 
tours, but whether or not people comply with them fully cannot be monitored: "Because you cannot in reality go out and say 'well, have you got your period?"' Parata reports that sometimes people question the protocols, or women get very upset when they are asked not to enter the collection room when menstruating. In Māori culture women are considered the source of life and the 'house' for future generations, because they have wombs or whare tangata (Higgins/ Meredith 2012:1); during menstruation women in traditional Māori society were in a tapu state associated with the tapu of blood (Douglas 1966; Brook 2013) and had to adhere to restrictions in order to protect themselves and others from 'dire consequences' (Higgins/ Meredith 2012:2).

One Pākehā staff member told me of her inner conflict with respecting Māori protocol and at the same time being true to her own values:

I'm not particularly comfortable with the protocols, because I don't believe in them personally. [...]There are certain things - menstruating women can't go places - that I find quite confronting. So my approach is to acknowledge that [...] there is a difference in belief there, but I will respect it.

I have not encountered any non-Māori women on TP's staff, who openly criticised the tikanga practiced in the Māori collection - perhaps because their jobs did not require their presence in this realm - but I heard about two scenarios where Māori women challenged the protocol. In both cases Māori women who were pregnant, requested to be allowed to work in the Māori collection, claiming that their elders had given them permission. Although tikanga in fact varies from iwi to iwi, and is a guideline rather than the law, some kaitiaki Māori were very concerned for the women's well-being and tried to dissuade them. Mane-Wheoki, then Director Art and Collection Services, himself Māori, was appalled that one of his employees was told "that a demon might jump onto her and affect her baby in the womb". He believed that incompatible world views "caused things to be said that I just don't think belong in a professional situation."

Parata found this situation very challenging personally, as the following interview excerpt illustrates: 
me: What other scenarios were there, where you sort of felt you are compromising because it is a bicultural organisation?

Parata: [...] We had a kaitaki Mãori that came down from another institution and she was hapū as and not realising how hapū she was-

me: (interrupting) What does that mean, sorry?

Parata: Oh, carrying a baby. And it was more of a health and safety perspective than saying 'no you can't'. There is no such thing as saying' no you can't come in here', becauseit's not like that. And depending on where you are from, what iwi you are from, they all have their own [tikanga], we've got to respect their values and their ways too because it's all different, everyone's different. Well her [request] was an exception into the whare taonga there, because her kaumätua allows her to work in the realm of taonga, while she was carrying her babies. And so they had cleared her to work in that environment where she felt quite comfortable and they were fine, $y^{\prime}$ know they okayed it. But when she came down here [to TP] she said the same thing that she had been cleared and of course I was like 'oh ok'. But it's a different scenario: we house and hold and look after the different treasures of the nation. And it's not just one iwi that you are looking after, you are looking after the motu [New Zealand]. So anyway that was an exception but not a nice exception, because we are so used to not having that. Another one was a conservator who worked here who was hapu and felt it was right for her to come and go while she was hapū. Again that was a challenge for us. We sat around a table and sort of nutted this out. Women menstruating was another one because you had men that allowed [it] and women that didn't allow it. So you came up with all these challenges and it was interesting because these people were going to in-house kaumātua, [...] who you should go and confide to, that is the right way. Again, it's a different iwi from your own. So you've got all those challenges.

In this dialogue Parata raises three main points: (1) the personal safety of staff versus employee rights, (2) the risk for the spiritual safety of taonga, and (3) the challenge for TP to care for national treasures from diverse iwi with different tikanga. Applying tikanga taonga is further complicated at TP by frequently-changing iwi kaumātua, that make it necessary to discuss the implications of tikanga today and decide on a case-bycase basis, as it is not clear who should be the authority: should TP construct a pantribal tikanga, apply the tikanga of the iwi kaumātua, the local iwi or the iwi a particular staff member identifies with? While Parata accepts tikanga variations between iwi, she insisted that breaking tikanga restrictions has tangible consequences for the spiritual realm of the collection room, as well as the people working in it:

We have had someone in here menstruating, this whole place went crazy. Just things, our körero, nothing, just nothing, nothing sort of tallied up. Things just weren't happening. So yeah [...] you get signs alright, you get signs, y'know they [the taonga and their wairua] either like it or they don't basically. And they'll tell you if you're welcome or not.

However, not everyone might be affected in the same way or notice the imbalances, depending on - according to Parata - whether you have a 'connection' to the taonga and 
the spiritual world in general: "If you haven't got that you don't see nothing, you don't feel nothing, you just don't. It happens in other ways."

After the interview I went to the bathroom and was shocked to notice that my period had set in. For a moment I considered pretending nothing had happened and going back in to continue my fieldwork. All sorts of thoughts went through my mind: "Does the tikanga even apply to me as a non-Mãori? If the tikanga was for my own safety, surely I wouldn't put anyone else at risk if I went back in? But after everything Parata had told me how could I not respect the tikanga?" In the end, I decided to respect the tikanga, so I knocked on the door of the collection room to let Parata know that I could not continue today. I was relieved that she understood and simply said, "these things happen". Yet, having anticipated my fieldwork in the Māori collection room so much, I felt utterly disappointed and also a bit embarrassed that my period had come so inconveniently and cut my fieldwork short. ${ }^{113}$ Nevertheless, I told myself that it was much better to be honest and respectful rather than being found out or worse, falling victim to 'bad spirits'. ${ }^{114}$ This experience made me realise, that while it is easy to agree to tikanga restrictions in principle, it feels quite uncomfortable to be actually in a situation where it has tangible consequences for oneself.

Given the importance that is placed on tikanga Māori in the collection room by kaitiaki Māori insisting that everyone, regardless of ethnicity, cultural and spiritual beliefs obeys the 'rules', I argue that Māori staff demonstrate and maintain their power by setting these boundaries. According to Linda T. Smith (2006 [1999]:74) "[c]oncepts of spirituality [...] are critical sites of resistance for indigenous peoples. [...] It is one of the few parts of ourselves which the West cannot decipher, cannot understand and cannot control... yet." This perhaps explains why Māori are so anxious that their tikanga is adhered to in the collection room; for them it is a sacred space and a site where Māori

\footnotetext{
113 I did continue my fieldwork in the Māori collection a couple of days later, yet missed several planned fieldwork days in the Māori collection.

114 Serious consequences of not adhering to Māori protocol or breaching tapu have been reported, including sickness and death (Mead 1986:78). Remarkable events occurred in the making of the meeting house Rauru, when tapu was breached by Te Waru (Garbutt 2007:112; see also Tischner 1971; Neich 2001), who subsequently lost three wives and one (or two) sons (Pomare/ Cowan 1930:260). Parts of Rauru are today exhibited at the Museum für Völkerkunde Hamburg, Germany. I owe thanks to Dr Steven Engelsmann, then director of the Museum Volkenkunde, Leiden, Netherlands and Dr Ingrid Heermann, curator oceania at the Linden Museum, Stuttgart, Germany, for alerting me to Rauru.
} 
culture prevails. At the same time, the restricted access and narrative of a spiritual connection of Māori to their taonga can be read with Goffman (1959:59) as a strategy to 'mystify' Māori culture and maintain a social distance to non-Māori by establishing Māori as authority in this realm. However it seems to me that the power of Māori staff is symbolic, as in practice it is impossible to control and enforce the tikanga, as visitors to the Māori collection determine whether or not they subscribe to the rules. The media uproar about this issue that follows, demonstrates this.

\section{Public Outcry over Te Papa's Ban For Pregnant and Menstruating}

\section{Women}

Not long after my fieldwork in the Māori collection, TP made newspaper headlines for 'warning off' pregnant and menstruating women from a back-of-house tour. In October 2010, a group of museum professionals from regional museums requested to visit TP's Māori collection. TP scheduled the back-of-house tour for 5 November 2010 and sent out a confirmation letter including the clause that "wahine [women] who are either hapu [pregnant] or mate wahine [menstruating] are welcome to visit at another time that is convenient for them" (Ash 2010:5). Reading this clause the women in the group felt discriminated against and informed the media. In the subsequent media coverage ${ }^{115}$ there was an outrage by some members of the public, women and men, who called TP's policy 'stupid', 'bloody ridiculous', 'sexist' and 'too PC'.116 Māori were also divided about the issue, with some commending TP for upholding Māori values (DigitalMaori 2010), while others criticised the custom as outdated or suggested that TP should find a middle-ground. ${ }^{117}$ Feminist blogger 'Boganette' was quoted in several articles: "It's disgusting that in this day and age women can be told they're 'forbidden' for

\footnotetext{
115 See for example http://www.stuff.co.nz/dominion-post/news/wellington/4221940/Te-Papadefends-request-to-pregnant-women; http://www.stuff.co.nz/national/4221890/Pregnant-womenwarned-off-Te-Papa-tour; http://tvnz.co.nz/national-news/te-papa-warning-pregnant-womendownplayed-3831711 (all accessed 11 January 2013).

116 See discussions on these blogs: http://pundit.co.nz/content/why-does-te-papa-hate-women-so-muchand-other-outraged-thoughts; http://readingthemaps.blogspot.com/2010/10/voltaires-bastards-and-tepapas-tapu.html (accessed 20 October 2010).

117 http://tvnz.co.nz/national-news/te-papa-warning-pregnant-women-downplayed-3831711 (accessed 11 January 2013).
} 
menstruating or being pregnant. It's a completely archaic belief that is oppressive to all women." 118

This comment links to the feminist tradition of revealing restrictions placed on women as patriarchal oppression, arguing that "one is not born, but rather becomes, a woman" (Beauvoir 1973:301). Mary Douglas argues in her book Purity and Danger (1966) that everything that cannot be classified is abnormal and considered dirt; being out of place it threatens the natural order. Menstruation blood is a prime "symbol of power and of danger" (Douglas 1966:124) to mankind, which therefore needs to be controlled and encapsulated from 'normal' people. In this context, the body becomes political, as Tiffany Jenkins (2011:116) asserts, even a site of resistance and domination, as well as the focal point for the state to exercise disciplinary power (Foucault 1973; 1977). Feminists critiqued how women's bodies were dominated and oppressed, re-gaining individual control by campaigning for women rights such as abortion, birth-control and sexual autonomy (Shilling 2003; Twigg 2006). Thus, the feminist outcry against TP's policy is unsurprising, as it curtails women's hard-earned equality. Non-Māori women felt excluded from entering areas containing taonga, and fought against what they perceive as discrimination, that - in their view - stems from a patriarchal angst of the natural powers of women (Butler 1990).

What is the Māori rationale for this restriction? In a Māori world view taonga embody the ancestors, being mediators between the past and the present (Hooper-Greenhill 2000:52); they are tapu and can pass on the good or evil 'spirits' of the people who used them to the living, especially when the person handling them is in a vulnerable state, such as menstruating or being pregnant (Higgins/ Meredith 2012:2; Kaeppler 1994:28). Most Māori women would therefore not go into the collection store, let alone touch taonga under these circumstances, not - as some Pākehā assume - because the women would contaminate the taonga, but to ensure their own personal safety.

In the public debate the issue was not just one of women's rights versus indigenous rights, or superstitious beliefs versus enlightenment, but one of cultural dominance and

118 http://www.stuff.co.nz/national/4221890/Pregnant-women-warned-off-Te-Papa-tour (accessed 11 January 2013). 
ideology within a public institution. Deborah Russell, in her blog 'The Hand Mirror' deemed it inappropriate for TP as a public entity to force tikanga Māori on visitors, saying: "I don't understand why a secular institution, funded by public money in a secular state, is imposing religious and cultural values on people."119 TP stood by its policy, yet Hippolite added "[i]t's your choice, it's not a ban",120 and TP spokesperson Jane Keig explained the underlying reasons:

There are items within that collection that have been used in sacred rituals. That rule is in place with consideration for both the safety of the taonga and the women. [...] Pregnant women are sacred and the policy is in place to protect women from these objects. ${ }^{121}$

The Arts, Culture and Heritage Minister Chris Finlayson downplayed concerns in his response to a complaint to the Human Rights Commission: "It's an advisory requested by the iwi, but it's for people to make up their own minds".122 Thus, the policy is not legally binding - or even an instruction - as Finlayson emphasised, and can therefore be ignored.

I suggest that the public outrage over TP's policy to exclude menstruating women from visiting the Māori collection can be read as a 'hegemonic project', where "state and public figures trumpet the national shame of allowing such practices of [...] ignorance and superstition, to take place within its borders" (Povinelli 2002:27). Povinelli continues, that nation states often focus their attention on 'inhuman practices' of a minority culture which they deem unacceptable, yet the motivation is rather their anxiety of 'the other' who they would rather exclude altogether; thus, national will is constructed "through passionate dramas and experiences of intimate community", maintaining an 'utopian image' of a national culture. Perhaps then, the media attention attempted to construct a NZ identity in contrast to 'backward Māori customs'? Douglas (1966:124) on the other hand, suggests "that when rituals express anxiety about the

$119 \mathrm{http://tvnz.co.nz/national-news/te-papa-warning-pregnant-women-downplayed-3831711} \mathrm{(accessed}$ 11 January 2013).

${ }^{120} \mathrm{http}: / /$ tvnz.co.nz/national-news/te-papa-warning-pregnant-women-downplayed-3831711 (accessed 11 January 2013.

${ }^{121} \mathrm{http://www.stuff.co.nz/national/4221890/Pregnant-women-warned-off-Te-Papa-tour} \mathrm{(accessed} 11$ January 2013).

122 http://www.stuff.co.nz/national/politics/4225775/Te-Papa-tapu-advice-can-be-ignored (accessed 11 January 2013). See also: http://www.nzherald.co.nz/nz/news/article.cfm?c id=1\&objectid=10680016 (accessed 11 January 2013). 
body's orifices the sociological counterpart [...] is a care to protect the political and cultural unity of a minority group." The role of the press to contribute to a negative perception of Māori should not be overlooked (Walker 1990b).

My findings suggest that having a Māori enclave with its own rules regarding tikanga around pregnant and menstruating women functions within TP, and moreover asserts Māori authority. However, the public uproar against banning menstruating women from visiting the Mãori collection suggests otherwise: at the public interface of the Museum as contact zone, Māori dictating the rules within a Crown entity is unacceptable. The different reactions to tikanga by TP staff, who mostly embrace it, and the public, who contest it, suggests to me that engaging in genuine biculturalism is limited to the physical boundaries of TP where staff are indoctrinated to tolerate cultural differences, whereas wider NZ society rejects biculturalism if it conflicts with a Western world view. This was an example of tikanga polarising people. In the next section, I demonstrate how museum conservation can act as a contact zone, bridging cultural gaps and reconciling conflicting agendas.

\section{Case Study: Conservator Nirmala Balram}

Nirmala Balram, who identifies as Fijian-Indian, has been working as a conservator at TP since 2005, being responsible for the Māori and Pacific collections. At first she was shocked when she encountered Māori visitors interacting physically with taonga, and the practice of sprinkling them with water appalled her, as she feared major damage. Since then, her thinking has changed dramatically to being "100 per cent accepting" of tikanga Māori. Balram stresses that "while it causes a little damage, it adds a lot of cultural value" to the taonga.

Balram is supportive of descendents borrowing taonga from TP's collection for ceremonies (e.g. graduation), but from a conservation point-of-view she cannot deny that every use deteriorates the already brittle condition of the cloaks. Commissioning cloaks for ceremonial purposes at TP (e.g. repatriation ceremonies) is not a viable option. She was informed that new cloaks 'can't communicate' with the ancestors. When 
I confronted Balram with the notion that taonga pūoro should be played to keep the bindings moist, a statement that I had heard often from museum staff, to my surprise she shook her head laughing: "We don't need that kind of moisture! People who talk like that don't know their science." As often, she is in two minds about it, but she advised against it, for her 'scientific mind' is concerned for the fragile taonga, while her 'spiritual mind' is conscious of the risks of breaking tapu.

Although the Conservation and Tikanga Policy states that "[i]n most cases there is no conflict between the requirements for the physical care and the spiritual care of taonga", Balram stresses that sometimes beliefs are incompatible and challenge traditional Western conservation concepts at TP. A prominent example is the display of Uenuku in the iwi exhibition Tai timu, tai pari, Tainui: Journey of a people. ${ }^{123}$ The striking wooden sculpture called Uenuku is believed to be a Māori atua, known as the rainbow god, who protects the Waikato people. ${ }^{124}$ Balram had been told that he was hidden in a swamp, when the Christian missionaries discouraged Māori from worshipping their gods, and was later recovered partially burnt, after a Māori woman had a vision of him. ${ }^{125}$ Having Uenuku - at an estimated age of 600 years believed to be one of the oldest Māori carvings ${ }^{126}$ - on loan from Tainui required special arrangements for the installation and display, as Balram points out: "He was in darkness in the swamp, therefore he cannot be left in the dark anymore. He always needs a light on him, even in the van he was transported in." Māori visitors paid tribute to Uenuku by placing fresh kawakawa leaves at his feet causing a conservator's worst nightmare: a spider infestation in the Museum! While the conservators had major concerns for the entire collection, some Māori interpreted the cobweb as a sign of Uenuku's wellbeing, saying "Uenuku likes them", as Balram recalls.

\footnotetext{
123 This iwi exhibition was developed in conjunction with five Tainui iwi - Hauraki, Ngāti Maniapoto, Ngāti Raukawa, Te Kawerau-a-Maki, and Waikato - and opened on 3 September 2011 (see Appendix 9). 124 See Simmons/ McGredie 1984:183.

125 "Uenuku was lost during the battle of Hingakākā, between Ngāti Toa and Waikato tribes about 1780, and was rediscovered near Lake Ngāroto many years later." Swarbrick 2012, Te Ara Website (accessed 13 January 2013).

126 "Traditional information would suggest it was made about 1400, when the art styles of the Maori were still East Polynesian in form" (Simmons/ McCredie 1984:183)
} 
Nevertheless, Balram does not want the practice of laying down leaves to stop, valuing its potential to make a lasting impression of "Mãori as a living culture" on international visitors to the Museum: "It makes them realise how important [taonga] are for Mâori". Instead, she pleaded with TP to inform visitors about the potential risks for the collection and provide sprayed or frozen leaves, in order to prevent pests entering the Museum. In her own attempt to educate the people around her, she has refrained from reciting scientific facts and rather uses analogies that are meaningful to Māori, comparing the precious taonga to "a very old and sick relative" or "a newborn baby" that is to be handled with care. That is not to say that Māori reject scientific explanations, but to emphasise how Balram's own understanding has adapted to the Māori belief of taonga having wairua, mauri and mana.

Working alongside Māori at TP, Balram has learned about tikanga, but sometimes her curious questions were rejected. Consequently, she had to teach herself in many instances. She explained that Māori are taking a defensive stance in order to protect their culture after almost losing it through colonisation: "Like it or not, Māori no longer compromise." Balram admires the staunch Māori culture and noticed that "learning about Māori made me more proud of my own culture". After seven years at TP she has formed a relationship of trust with the Māori communities whose taonga she works with, and embraces taonga Māori as living and breathing entities.

In Balram's view museum conservation and allowing Māori cultural practices can complement and enrich each other. Conservators working in a bicultural environment must take various aspects of historical, scientific and spiritual nature into consideration, balance the diverse values attached to taonga, and make their judgments on a 'cultural basis'; thereby they are transformed into bicultural persons. Cultural values in this regard can sometimes override conservation values. She admitted that it took her some time to adjust her view-point to the Māori tikanga associated with taonga, but she realised that these practices "make [the taonga] more living and meaningful"; something she misses when visiting "sterile museums overseas." Balram concludes with "taonga are family", revealing her metamorphosis from scientific conservator to bicultural 
facilitator. ${ }^{127}$ Having discussed the great importance TP places on providing appropriate care for taonga and promoting tikanga, I turn to TP's treatment of human remains in the context of repatriations and exhibitions.

\section{Conflicting World Views About Human Remains}

In this section, I provide an insight into how TP grapples with the issue of human remains in the Museum, on the one hand making efforts to repatriate human remains of Māori and Moriori origin for reburial on their ancestral lands, and on the other hand displaying the body of an Egyptian mummy, Keku, in an exhibition. I suggest that what might look like a blatant contradiction at first glance, is a highly complex issue when examined in greater detail. I present a puzzle pieced together with information from different sources, including interviews, policy documents, meeting minutes and exhibition labels (see Appendix 10, Sequence of Events Regarding the Display of Keku for an overview). I juxtapose these with my own experiences and observations in the Repatriation team and at repatriation pōwhiri. Firstly however, I introduce TP's international repatriation efforts.

\section{Karanga Aotearoa Repatriation Programme}

The main purpose of the Karanga Aotearoa Repatriation Programme (KARP thereafter) is to repatriate Māori and Moriori human remains from overseas collections to their iwi of origin. ${ }^{128}$ KARP has been responsible for repatriating over 230 ancestral remains from overseas institutions, but an estimated 550 kōiwi tangata (430 in Europe and 85 in the USA) are 'still to come home'. ${ }^{129}$ According to the Kōiwi Tangata policy, Māori human remains include tattooed heads, skeletal remains and human tissues. However, human bones that have been transformed into musical instruments, for example, are considered artefacts and exempt from the moral imperative to be repatriated.

\footnotetext{
127 Another example of reconciling science and tikanga Māori at TP is Hokimate Harwood, a Māori woman and bicultural science researcher who uses scientific methods to identify feathers on Māori cloaks in conjunction with mātauranga Māori. http://collections.tepapa.govt.nz/Theme.aspx?irn=3657 (accessed 4 January 2013.

128 Simon Jean's PhD thesis “The Heritage Value of Toi Moko in Their Community of Origin”. PhD Thesis, Ecoles des Hautes Etudes en Sciences Sociales, Paris and Victoria University of Wellington, examines the relationships of iwi to their ancestral remains (forthcoming).

129 Te Herekiekie Herewini, e-mail communication 14 January 2013. 
The quest to repatriate human remains to their indigenous source communities corresponds with the notion that things have 'social lives' (Appaduarai 1986) and agency (Gell 1994), but also how the 'cultural biography of things' (Kopytoff 1986) can change their value over time. Toi moko and kōiwi tangata became commodities that were traded and sold as curiosities to collectors and museums worldwide.

The trading started in the 1770 s with James Cook's voyage ${ }^{130}$ and was practiced until the 1830 s, when it slowly decreased. ${ }^{131}$ Many toi moko were exhibited in museums (even in NZ; see McCarthy 2011), but taken off display when it was no longer a culturally acceptable practice, however auctioning mokamokai continued until 1988 (Fforde 2004:71). During the 'Māori renaissance' in the 1970s Māori requested their ancestors' human remains to be repatriated, but it was not before the 1990s that concrete repatriation plans were put in place. ${ }^{132} \mathrm{TP}$ has recognised the importance of this issue by setting up KARP, a separate Government-funded unit within the institution in 2003. ${ }^{133}$ The programme's foundation is spelled out in the Kōiwi Tangata policy which was approved by the TP Board in February 2001 and authorised by a Government mandate in 2003. The policy statement makes it very clear that the human remains are treated as Māori ancestors, tūpuna, who deserve to rest in eternal peace:

The Museum of New Zealand Te Papa Tongarewa [...] regards the kōiwi tangata in its guardianship as tūpuna to be cared for in a consistent and culturally appropriate manner until such time as the kōiwi tangata are returned to their place of provenance or to an appropriate final resting place." (Draft Kōiwi Tangata Policy 1 October 2010:2; my emphasis)

In practice this means that once the human remains are back on NZ soil they are treated with the utmost respect. Firstly, they are welcomed back in a tangi ceremony on TP's marae, then they are transferred to a separate room, the wāhi tapu, which is seen as their temporary resting place. Sometimes research is carried out to determine their

\footnotetext{
${ }^{130} \mathrm{http}: / /$ www.tepapa.govt.nz/AboutUs/Repatriation/toimoko/trade/Pages/HowwereCaptainCooksvoy agesinvolved.aspx (accessed 4 January 2013).

${ }^{131}$ Some Māori played an active role in trading toi moko (of their enemies rather than their own ancestors) for muskets. Recently this historical fact has sparked a controversial debate with New Zealand historian Paul Moon - a controversial figure himself - calling publicly for "the protocols around preserved heads to be relaxed" and forgo repatriation ceremonies (tv one news 9 June 2012).

132 Similarly, in the USA American Indians also requested the bones of their ancestors to be handed over from museum collections. In the Native Graves Protection and Repatriation Act 1990 their demand was given legal action.

133 This information is based on presentations about repatriation by TP staff on 7 December 2009 .
} 
final resting place on the land where they originated from. TP uses a variety of equally important methods to find out the origin of each toi moko, namely historical records, Waitangi Tribunal reports, donor information, oral history including waiata and whakapapa; but no destructive scientific methods are undertaken. The ultimate goal, however, is domestic repatriation with their original iwi, as "Te Papa does not regard the kōiwi tangata in its guardianship to be collection items, and as such recognises the key role of iwi in their management and return". ${ }^{134}$ Access to the wāhi tapu is very restricted, as it is considered an urupā and therefore follows strict protocols.

During my fieldwork with KARP I witnessed a heated debate between two representatives from a museum in Britain and three Māori museum professionals. One of the British delegates, a scientist, expressed his regret that no further research will be undertaken on the human remains once they are returned, arguing that DNA-analysis could give insights into the Māori diet and lifestyle of the $19^{\text {th }}$ century, which is still largely unknown and perhaps even provide answers to treating Māori health issues today, such as diabetes. He said: "We have an interest - as you have an interest; we are part of the culture of scientists - to have access to them [human remains]." This Western approach was met with disapproval and disgust by the Māori staff, who protested that these were their relatives and therefore off-limits: how would he feel if someone dug up his own grandmother?

The Māori staff explained their indigenous framework further, emphasising that the benefits of scientific research on the bones did not justify or outweigh the damage and pain that comes with it. ${ }^{135}$ The KARP manager Te Herekiekie Herewini said: "There is a destructive aspect to [DNA-analysis] and Māori reject that, fullstop." He clarified that "Māori principles overwrite these intrusive procedures. The priority is to put them to rest rather than finding their original iwi." Nevertheless, the visiting scientists emphasised the 'medical value' that researching the ancient bones could have for indigenous communities today; they wanted to ensure that with handing over the human remains

\footnotetext{
134 Domestic Repatriation Policy approved 23 January 2002.

135 Recently some Māori scholars seem to have opened up to archaeological research on Māori human remains, mixing mātauranga Māori with a scientific approach. Amber Aranui's PhD thesis (in progress) $A$ Māori View of Repatriation and Scientific Testing of Human Remains (working title) is an example of this new development.
} 
they were also handing over the "responsibility to make informed decisions" for the future as one of the scientists phrased it. Despite their disagreement on how to treat human remains once they leave the realm of the museum, both parties agreed that through this act of transfer during repatriation they established a long-term partnership between their institutions (see 0'Hara 2012 for repatriation as relationship building). This can be seen as a result of the reciprocity of gifting (Mauss 2000 [1922]) or the Māori principle of utu (Walker 1990a:69), as both concepts require that the receiver reciprocates the gift at a later stage.

Although in this particular case the European museum representatives were sympathetic to KARP's request to repatriate the Māori human remains they hold in their collection, they did not fully ' $g e t$ it', as one Māori woman told me later; ${ }^{136}$ from their body language during the discussion I was given the impression that the delegates interpreted Māori as sentimental. I must admit that for a long time I did not fully understand the passionate Māori position on human remains either, having grown up in Germany, where it is not uncommon to see skeletons (e.g. the 'Celtic Prince of Hochdorf' $)^{137}$ and mummies on display in museums. However, my understanding of this issue changed completely during my time at $\mathrm{TP}$, mainly due to experiencing several repatriation ceremonies first hand, which were my personal 'moment of understanding', as Mead (1986:9) defined the precise moment when Te Maori opened at the Metropolitan Museum of Art with a dawn ceremony and the 'taha wairua' spilled over many people present. I give a personal account of one of these occasions, a repatriation pōwhiri for twenty toi moko from ten French institutions, in the next section with an excerpt from my field journal.

\section{Story: Experiencing a repatriation ceremony}

It is 3.30pm on Thursday 26 January 2012. I'm standing among TP's kapa haka group going over the haka for the tenth time or so, practising endlessly, stomping my feet until they hurt, waiting for the manuhiri to come up to the marae. Then the kuia spreads the message in te reo Māori. I only get bits of it: strong wind, plane, kōiwi, coming, apopo tomorrow. A Māori woman, seeing me struggle to understand, comes over and tells me in English that the haka pōwhiri for the tattooed Mãori heads from France is postponed as

\footnotetext{
136 The underlying notion is that non-Māori cannot comprehend Māori culture and that one must be born into Māoridom to fully understand.

137 http://www.keltenmuseum.de/index.php/en/the-celtic-museum (accessed 18 January 2013). 
the plane couldn't land in Wellington's galeforce and is now headed for Palmerston North. Some Mãori joke that the ancestors wanted to see a bit of the landscape before they come to rest at TP. We laugh. We take off our skirts that are reserved for special occasions and I head out of the marae to nurse my baby. Then I don on another uniform, the Events shirt as I work on the 'Treaty debate' the same night. The honorary guests along with TP staff present share the meal that was prepared for the occasion; it would be a shame to waste it. When the public lecture is finished at $8 \mathrm{pm}$, I hear singing and realise that the Tainui people who have come down from Waikato to the repatriation pow whiri are still in the Museum and sing waiata to the taonga in their exhibition Tai timu, tai pari, Tainui: Journey of a people. It seems they take TP's sobriquet 'Our Place' literally. Good on them, I think and leave the Museum through the main entrance; dockway is off-limits the security guard told me in the lift, as the crates with the human remains spend the night there when they arrive.

Friday 27 January 2012 at 7 o'clock in the morning. I'm back at TP. This time I use the staff entrance as the Museum is still shut, and while walking through the exhibitions to the marae I breathe in the smell of cleaning products that linger at that time of day. I'm immensely tired, but also wired because I'm excited to be part of the repatriation ceremony that has been so long in the making and is so important that several local and international tv stations are filming it. I collect my skirt, number 34, and hearing rhythmical chanting of 'te waka' above me I head up to the marae green room where the rest of the kapa haka group is already practising the haka all over again. A Māori staff member and opera singer is doing voice exercises with us and the atmosphere is tense but fun. We are ready. The Ranginui doors open, reminding us of the Māori creation myth. Standing in the second row among the kapa haka group facing out to the Wellington harbour, I hear the blow of the pütätara signaling the manuhiri to climb up the stairs. As the taonga pūoro group rushes back inside to take their places amid us, the manuhiri reach the waharoa, we do the haka supported by Tainui, the iwi in residence. The marae is filling up with about 200 people, among them French officials and Māori elders. After our haka contribution we retreat to the edge of the stage where the pallbearers place the crates very carefully on woven mats and the kaitiaki Màori cover them with feather cloaks. The sharp edges of the wooden boxes are covered under the cloaks which transforms them into organic forms, looking like the body of a big, furry creature. Tainui women squat next to the tūpāpaku, protecting them, keeping them warm. All the while the kuia, female elders, cry and wail, tears streaming down their faces. It is strange: although clearly part of the staged ritual, the sadness and grief feels raw and spreads among the participants. For the first time at a pōwhiri I feel really upset and close to tears myself. I realise on an emotional level what the technical term 'human remains' fully means: these are the bones of people, - real people! - dead bodies, kōiwi tangata, tūpuna, ancestors, family! They are not my ancestors, but still, I feel awful thinking about what happened to them: they had been taken overseas, put on display in foreign countries, separated from their homeland, stared at, examined, lying under glass, naked and vulnerable. And now they have come back to be reunited with their families. I cry. The wailing doesn't stop. It becomes almost unbearable. The kuia indicates our group through gestures to go sit with the crates. I am wondering for a split-second: is it appropriate for me, a non-Māori, a German with blonde hair to sit among them? But this is not the time to hesitate, so I do as I am told and sit next to the caskets. It feels right. As a Tainui elder rises to speak the wailing continues, then fades away. A wave of peace fulfills me: the tūpuna are home at last. 


\section{Social Drama around Keku: "Is it right to display an Egyptian mummy at TP?"}

The display of human remains poses a dilemma for museums, which aim to educate the public through exhibits and at the same time respect the cultural values of their source communities. The debates around displaying 'Lindow man' and the subsequent decision temporarily to 'cover up the mummies' at the Manchester Museum are a good example of this discourse (Jenkins 2011). ${ }^{138}$ The story of my experience at a repatriation pōwhiri shall form a backdrop to the debate surrounding the displaying of human remains at TP.

In this section I reconstruct the story of hosting the Egypt: Beyond the Tomb exhibition (thereafter EBT) at TP, which included the display of an Egyptian mummy called Keku. As at 2006, TP's Collection Development Policy (2001:7) states: "It is Te Papa's policy that no human remains will be placed on public display." This policy came under close scrutiny when this travelling exhibition - developed by the National Antiquities Museum in Leiden, Netherlands (who provided most of the artefacts) and toured by the Australian Museum (who provided the narrative) - was going to open at TP in December 2006. I argue that the uproar among staff regarding displaying the mummy at TP can only be understood in the light of the efforts made to repatriate tūpuna from overseas collections (see previous section) and TP's commitment to a bicultural framework that acknowledges Māori cultural beliefs. Putting a dead body on display even if it was Egyptian not Māori - seemed cynical and hypocritical to many staff members, thus provoking protests internally as well as tensions with external stakeholders.

Two world views collided because in a Western framework a mummy is objectified as a relict of ancient times, whereas Māori see a mummy as a (dead) person. In Western societies, there has been a shift in the perception of mummies over time, from 'dead

\footnotetext{
138 I owe thanks to Malcolm Chapman, then head of collection development at the Manchester Museum, for bringing this to my attention.
} 
body' to 'anatomical object' falling outside social relations (Hallam/ Hockey/ Howarth 1999). For Māori, however, "it is a human life we see, we don't see an item, we don't see an object. We see some person whose life was real and who still lives on in our minds", as White explains. TP grappled squarely with the issue of whether it was appropriate or not to display a mummy, but in the end Keku was put on display, against the will of most Māori staff. However, it was Māori protocol that assisted in making her display possible. EBT was the ultimate test for biculturalism at TP to date. I suggest that the events surrounding the exhibition can be interpreted using Victor Turner's (1980:150) concept of 'social drama' with its four phases (1) breach, (2) crisis, (3) redressive action, and (4) reintegration.

At the time $E B T$ was on show I was already working at TP, but had not yet started on my $\mathrm{PhD}$. I experienced the exhibition from a front-of-house perspective - visiting it myself several times and conducting exit interviews with visitors for my job - but I was largely oblivious to the internal struggles going on behind the scenes. Therefore, I rely on the narratives that participants used in interviews. In the following section I group the events into the aforementioned stages of the social drama, letting the participants' voices retell the story, which not only divided TP staff but also threatened the bicultural partnership. White summarises what happened from a Māori perspective:

There was lots of tension. In the end, they showed the mummy, the tribes were ready to walk out. But the tribes said: "Okay, we let that one [go]. But we will not show our face in this exhibition. We will pull our support for it. We won't pull out of Te Papa" - that's how close it got! [...] Needless to say, it caused quite a lot of disruption. Our Māori staff weren't happy. They boycotted that particular exhibition. We did a few things to help mitigate the risks, like we provided water for people to purify themselves. So our protocols were still present, but we did not like that one. So there were tense moments.

\section{Breach}

Displaying a mummy breached TP's own policy to not display human remains (Collection Development Policy 2001:7). Māori were particularly offended as they projected their own cultural beliefs onto Keku, seeing her as one of their ancestors. The Kaihautū at the time canvassed the opinions of iwi around NZ; Carolyn RobertsThompson recalls their reasoning: 
All of them came back and said, "if you look at your own policy, why would you do something that contravenes that?" - "But she's not ours." - "Yes, but you don't look at her like that, do you? You don't see her as being an Egyptian mummy. You look at her as being tūpāpaku!"

Moreover, as White argued, displaying human remains also breached the tikanga of tangata whenua, the protocol of the people of the land that TP stands on:

Māori feel as guardians of the landscape, they have a responsibility that their own tikanga or protocols aren't breached either. You know, it's all good with one family saying "Yes, we will display the remains". But you are displaying it in territory that has protocol.

Many saw the clashing of different imperatives in the Museum as a 'classic case' where biculturalism proves difficult in practice. Management decided to display Keku against strong opposition, thus breaching its own policy and precipitating a crisis.

\section{Crisis}

The interviewees used the words 'drama' and 'power struggle' to describe the internal friction, remembering the atmosphere at work as being 'tense', 'distressful' and 'not very pleasant'. The institution realised how serious the crisis was when the iwi in residence (Ngāi Tahu at the time), represented by the kaumātua, considered taking their taonga out of the Museum and even pulling out of the partnership with TP altogether. One Māori staff member emphasised the effect of the crisis on the Māori activities at TP: "Basically Ngāi Tahu stepped away from the pae for that period of time, so we did nothing with the marae, nothing official with them at the helm while she [Keku] was in the house. Basically the marae became out of bounds."

Keku's presence at TP however, was not limited to the exhibition space; a few Māori staff reported that her spirit had visited them, turning the issue into a personal crisis for them. They were disturbed by those 'visits', but found it hard to talk to others about it:

She [Keku] decided to come visit a few people, back-of-house... It's very challenging and it did push me, because people [would] go "well, what was your problem?" I said, "well you don't really want to know because if I told you, you wouldn't believe me anyway", so it's best just not to say anything or just keep moving on. But it did happen, that's the thing. (Mãori woman) 
Consequently, she blamed the CEO for making an irresponsible decision, saying to him: "You don't believe in that! So it's easy for you to be able to make that decision on behalf of all of us, but you're not the one [whom Keku visits]. You don't experience it, mate." The 'mummy affair' greatly damaged the bicultural partnership between TP and iwi stakeholders, and almost ended in separation:

So from the other partner's side of this marriage with [TP], it was not good and we were looking at having a divorce! What really scared me, was that they [Ngāi Tahu] were forced to even consider withdrawing, from taking all their taonga out of Mō Tàtou, a year before it was due to close and just leave it, with a media disaster on our hands. (Māori woman)

In the build-up of EBT Ngā Whetū Ririki (see chapter three), an assembly of Māori staff, became 'very active' and extended their network within the Museum and beyond; many Māori staff suggested that the crisis unified Māori staff. Conversely, not all Māori staff shared the opinion that Keku should not be displayed, and some fell out over this disagreement, which divided TP's staff into EBT opponents and advocates. The divide cut across ethnic lines; however, while some Māori staff worked in or visited EBT, the majority boycotted it. Mane-Wheoki explains how the Māori resistance to the mummy meant disobeying a Māori elder, and left Māori staff in an uneasy dilemma:

So Ngāi Tahu just drew back in anger, nothing further to say, nothing to do with that exhibition. Te Ikanui [Kapa; a Māori elder] chanced his arm and provided a ritual clearance for that mummy. But I would say that I was one of a majority of Māori staff who didn't attend that blessing, even to support Te Ikanui, and who didn't go to that exhibition at all, didn't go into the Tower Gallery while that ancestor was there. (Pause) Out of respect, you just would not go in.

In contrast, some staff - mainly of non-Māori descent - did not understand 'what the fuss was all about' and argued that TP should not be 'too PC' or shy away from controversial exhibitions. This attitude, however, undermined the bicultural partnership TP is built on: 
People would say Te Papa has had exhibitions that people don't like before, like the 'virgin in the condom'139 thing. But it's like Te Papa is not built on a partnership with the Catholic Church! If they were that would be fair enough. But Te Papa, the institution is built on a partnership with Māori. When one partner says we don't want this [...] I think you have to listen to that. (Pākehā woman)

\title{
Redressive action
}

TP reacted to the crisis by calling a 'staff forum' to discuss the issues at stake and allow leeway for staff who did not wish to work in the exhibition. One Māori staff member summarised the staff forum in the following words:

\begin{abstract}
Basically we held a meeting with Te Taru [White, then Kaihautū] and Seddon [Bennington, then CEO], and Seddon put the case forward and said "This is a commercially rational decision. We realise it may upset some of you. We're going to put some processes in place to help you deal with the cultural unsafety of it, but for this purpose in this particular instance, and because the people of Egypt and the Egyptian government have said, 'We're all good with this', we are going to make a special case and we're going to bring her here." So that was a biggie and you could hear people physically inhale, I mean they just went "hooh", like that, y'know, so things happened.
\end{abstract}

The staff forum was an attempt by management to pacify staff and reassure them that their opinions were valued, but staff felt it was too late for their input. Kertzer (1988:42) stresses the symbolic meaning of seemingly democratic decision-making where transparency and participation is pretended while the decision is made elsewhere:

Since all participants theoretically have the right to say what they want, such meetings give people the impression that the decisions that are taken result from a process in which they [...] are involved. Yet we know that in most cases the subsequent political course has little or nothing to do with the content of the meeting.

Interestingly, some staff were well aware of the theatrical staging that had no real impact on the decision at all, as this cynical comment by a Pākehā woman illustrates: "Everyone was technically able to have their say, even though it was actually I think three

\footnotetext{
139 When the TP opened in 1998 Tania Kovac's artwork 'virgin in a condom', a statue of the Virgin Mary in a transparent condom, was exhibited as part of the Pictura Britannica: Art from Britain exhibition, causing an outcry among Christian and Muslim groups who were offended. In an article published in Christianity Today TP is criticised for its double standards that privilege Māori values over Christian values: "Christian Heritage Party leader Graham Capill says the museum took great care to observe Māori spiritual mores but ran roughshod over Christian values. 'It's increasingly clear that any faith or belief is acceptable in New Zealand, except for the Christian faith,' Capill says. 'Te Papa needs to be not only culturally sensitive, but also spiritually sensitive."'

http://www.christianitytoday.com/ct/1998/june15/8t719b.html (accessed 29 June 2012); see also King 2003:517; and http://www.filmarchive.org.nz/the-catalogue/media/tv3-news-virgin-in-a-condom-tepapa-debate-f34860?option $=$ com events\&task=view_detail\&agid=2010 (accessed 17 January 2013).
} 
days before the mummy was about to arrive in Te Papa. So it was a little bit late to actually talk about it."

Many Pākehā thought that "the Māoris were over-reacting", asking "why should Māori be able to put the kibosh on this exhibition? What happens next?" This reveals the Pākehā angst of creating a precedent if they gave in to the Māori request, fearing to lose their cultural dominance and superiority of power to the 'junior partner' (O'Sullivan 2007) in the bicultural partnership. A Pākehā woman who supported Māori on this issue, rejected this concern as a Pākehā fantasy, because, "as far as I know, Māori haven't tried to can any of the other exhibitions and everything goes along quite well. That was an exceptional case."

In fact, some Māori staff engaged in the 'redressive action' and worked towards a compromise - knowing that the exhibition could not be stopped - that would reconcile the different world views and make viewing the exhibition culturally and spiritually safe for Māori. Mane-Wheoki remembers some "really tense meetings" of the leadership team, where he suggested to compromise: "A separate structure could be built within the [...] Gallery, that would be designated a tapu place and where the protocols of the urupa would [operate] so people could, if they wanted to, wash their hands as they went in." Consequently, it was agreed to put Keku in a separate room and provide water for cleansing.

As I mentioned before, opposition against displaying Keku did not strictly follow ethnic lines, but had followers among both Māori and Pākehā. According to Rhonda Paku, Māori were just louder in their protest:

Some staff put together plans to help their teams deal with it;Māori and non-Māori who felt uncomfortable about it as well, because they also believed that we should be sticking to our policy here on not showing human remains. So it wasn't just Màori, but I think we were the most proactive in terms of voicing our opinion regarding the inclusion of it in the exhibition.

Since the kaumātua had withdrawn themselves from carrying out any ceremonial acts for or during this exhibition, other Māori felt pressured to pick up those duties to ensure cultural safety, as a sympathetic Pākehā woman stated: 
I think some of the Māori staff felt like they had to - since the decision was made and the mummy was coming and it was gonna be displayed - they felt for their own cultural values they had to protect the staff that actually happened to work on the exhibition. They did end up having to buy into it by doing the ceremonies and all those cultural things because they felt "oh what if we don't? They aren't protected." It was very sad.

A Māori woman explained why she felt obliged to work in the exhibition, even though staff were given a choice:

I was one of the few Māori staff who decided to go and work in there, because I thought about some other Māori concepts and in particular I thought about our children. And who was going to tell our children these stories? [That] is why I went to work in the exhibition. At the same time I didn't agree with the display of human remains.

For those few Māori staff, the Māori concepts of manaakitanga and kaitiakitanga overrode their unease at exhibiting human remains. Applying tikanga Māori within EBT became paramount as a measure of respect for Keku and to provide cultural safety for Māori staff and visitors. Not only Māori but also some Pākehā staff observed the tikanga and established a personal relationship with Keku, as Jeff Fox, Concept Developer, remarks: ${ }^{140}$

On a personal note, I regularly brought in fresh kawakawa leaves to locate with Keku while she was on display, it became a morning ritual for me. Just doing that really helped to 'humanise' Keku for me, and after a while there was a growing number of staff who would go into the exhibition before it was open to the public and perhaps lay down some kawakawa leaves, or just talk to her. It felt very much to me that we had done something extraordinary, and were somehow making death a more accessible thing for ourselves and our visitors in a museum display context.

In this regard, applying tikanga Māori to Keku served two purposes; firstly, it was a remedy for making the exhibition safe for any Māori staff or visitors, and secondly, it transformed EBT into a contact zone, where people engaged with Māori beliefs. Ultimately, this reconciling gesture by Māori staff prevented the bicultural marriage ending in divorce and facilitated reintegration. 


\section{Reintegration}

After the travelling exhibition, including the mummy, had left the building, life at TP went back to normal and the iwi kaumātua resumed their ceremonial roles. Having to witness the controversial exhibition go ahead diminished trust in the bicultural partnership of many staff. Disillusioned, some drew the conclusion that "at the end of the day, [management] are going to do what they want to do, aren't they?" and "it's people's jobs. Are you gonna walk out over it? Nobody walked out, but [it got close]." Pushing through EBT without the Māori partner's consent left behind a bitter taste and staff called the drama behind the scenes 'a disgrace'.

Moreover, for many staff the 'mummy case' was an example that the bicultural partnership takes a backseat when financial gains are at stake:

There was a repatriation advisory panel composed of some very eminent Māori scholars and other people who said: "No, you should not be displaying these remains!" And Te Papa [management] went ahead and did it for its own selfish reasons and I think that was probably quite damaging. And that was a very good case study of how the decision-making partnership just wasn't there. I mean, the chief executive and most of the leadership team wanted that for financial reasons and because they like to see mummies (laughs) and it's a cool exhibition or whatever. But - from what I could see - most of the Māori side of the partnership were saying no, but weren't being listened to. (Pākehā woman)

The staff that I talked to agreed that the benefits of EBT (such as visitation numbers and financial revenues) did not outweigh the hurt and damage it caused to the bicultural relationship:

Te Papa is supposed to be a museum for New Zealanders and an exhibition about ancient Egypt isn't really something that we should be walking all over our iwi partners and our indigenous people for. It's not that important. (Pākehā woman)

On the upside, the debate around the issue of displaying human remains was also fruitful as it had implications for future exhibitions, for example A Day in Pompeii (see Appendix 9). Within this travelling exhibition, replicas of the body casts of Pompeians caught in the Mount Vesuvius eruption were shown in the very position in which they died. Even though these replicas did not contain any human remains, some staff were concerned that showing them would upset visitors, especially Māori. It was therefore decided by Museum management to exhibit the replicas in the same way as the Egyptian mummy: in a separate room with a sign at the entry warning visitors of what 
they were about to see and having a water bowl for cleansing at the exit. This procedure was welcomed by both staff and visitors. Kaihautū Michelle Hippolite who started her role at TP after $E B T$, saw some positive outcomes from this exhibition, which in her view:

provoked a lot of discussion about [the] presentation of human remains and the issues associated with a Mãori world view [...] I thought that that would enrich staff's understanding of the various perspectives, which I think that did achieve.

Overall, many staff interpreted the social drama surrounding Keku as evidence that biculturalism is not (yet) working in practice, and that TP missed the opportunity to engage in a bicultural dialogue:

Te Papa is not walking the talk yet. I think the classic, the proof of that was the controversy about the display of the mummy. She was essentially an old dead Egyptian mummy who had no say in coming here or being dug up anyway. There was an opportunity to have a bicultural dialogue there but the two positions just from my observation were so staunch in their belief that, nah it just fell over. I think that still taints Te Papa's biculturalism, $y^{\prime}$ know the dead mummy non-discussion. [...] Well it wasn't a discussion. It was two positions and one decision was made and one decision wasn't made. I don't call that a discussion, I don't call that biculturalism! (Pākehā man)

From a Māori perspective, EBT was the ultimate challenge for the bicultural partnership and some believe that it was only due to the generosity of Māori that the partnership did not break apart:

We clashed, in that case with human remains, with the ideals of the other partner. And, like most times, the [Māori] partner has capitulated in a way of being very generous, this is how I put it, [...] in the context of partnership. And fortunately for the Museum, they were generous, because if they chose not to be in that circumstance, they would have put huge pressure on the collections of the institution. And those are areas where we don't want to go through, because we genuinely seek partnership. (Te Taru White)

Regarding the 'reintegration phase' of the social drama William Beeman (2000) asserts that, "[it] eliminates the original breach that precipitated the crisis. This can be done in two ways - by creating a permanent split in society, or by healing." In the case of displaying an Egyptian mummy at TP, I suggest that the crisis did neither; instead it left a scar that is a reminder of this past injury to the bicultural partnership: seemingly healed on the surface, it is covering up a deeper wound, in the form of an insult to the Māori partner that can easily be ripped open again. The fact that the 'mummy episode' is 
frequently mentioned at staff gatherings (see chapter three) is evidence that it is not forgotten.

\section{Decision-Making Process}

In the previous section, I examined the 'social drama' of EBT coming to TP, examining how staff narrated the events and made meaning of them. What most of these individual statements lack, however, is the' bigger picture' of the decision-making process. Who made the decision to include the mummy in the exhibition? The majority of staff I talked to believed that CEO Bennington, 'wanted' the exhibition and 'put his foot down' in favour of showing the mummy. This confirms that even within TP the governance structure and decision-making processes are not transparent or fully understood by staff. In this section, I illuminate the preliminary considerations and debates that led to the ultimate decision to include the mummy, using internal papers, meeting minutes and organisational documents. ${ }^{141}$

Although a proposal for this touring exhibition was initially declined in 2004 due to the 'blanket policy' that TP does not display human remains, ${ }^{142}$ a 'more detailed evaluation' was undertaken in May 2006 by concept developer Jeff Fox, and management decided to show EBT at TP later that year. At the very first Leadership team meeting discussing $E B T$, the focus was on 'hard facts', such as projected profit and visitation numbers, with the parameter that the exhibition "must at the very least break even, and in reality make a profit" - with or without the display of the mummy. ${ }^{143}$

This shows that the imperative that TP "is commercially positive" (TP's corporate values) has high priority in an institution that is also a commercial enterprise and must therefore consider financial implications carefully. Although the paper mentioned that displaying Keku would be a policy breach, it also stressed that “[a] 'mummies' exhibition without real mummies would erode our credibility as far as producing a high quality,

\footnotetext{
${ }^{141}$ I am very grateful that Jeff Fox, concept developer for $E B T$, shared these documents with me. 142 Similarly, 'Bodyworlds', Gunter von Hagen's controversial exhibition displaying preserved, 'plastinated' human bodies, was declined by TP several times for 'consent issues'.

${ }^{143}$ All quotes that follow are taken from Leadership paper, Life beyond the Tomb - Fiscal considerations 3 June 2006, unless stated otherwise.
} 
authentic visitor experience". This assumption was underpinned with 'hard facts' regarding costs and predicted visitation numbers by the Visitor Market Research Team. At other venues in Australia the mummy and sarcophagus had been the key "visitor attractor" to the exhibition, suggesting Keku should be included, especially given that $E B T$ is "perhaps the least spectacular [of all touring exhibitions on ancient Egypt] in terms of objects or overall visitor experience".

There was also concern that potential visitors may not visit the exhibition at TP if the mummy was not displayed here, but could instead see the mummy at Auckland War Memorial Museum and Otago Museum, which had no reservations about showing it. Furthermore, pragmatic reasons for having this exhibition were emphasised: sponsors "are extremely interested"144 in this exhibition and it "is the most affordable Egyptian exhibition by a long stretch, and it is available for when we want it". Early on the paradigms of making profit and attracting large numbers of visitors by providing a spectacular and authentic experience were paramount, while the Māori resistance and the bicultural partnership took a back seat.

In July 2006 another paper was presented to the CEO and Kaihautū recommending a \$9.50 mid-price adult ticket which translated into this compelling financial scenario: “On paper, with the preferred ticketing option of \$9.50, Te Papa would make a net loss of around \$39,000 without the mummy (@15\% penetration), and a net profit of around $\$ 65,000$ with the mummy (@18\% penetration)."145 At this point it had not been decided yet whether the mummy would be included in the exhibition or not; however, I argue that the compelling financial figures, and equating the inclusion of the mummy with 'profit', paved the way for displaying Keku.

The next paper presented to the Leadership Team addressed TP's dilemma: “[T]here is a significant risk that Te Papa would lose credibility with key institutional stakeholders and / or the New Zealand public if Keku's remains were displayed, and possibly if she

\footnotetext{
${ }^{144}$ Leadership paper, Life beyond the Tomb - Fiscal considerations 3 June 2006.
}

145 Exbn update 050706.doc; my emphasis. 
was not."146 The paper mentioned that iwi stakeholders had made it "abundantly clear" that they condemn the display of any human remains. Furthermore, the display of a mummy from an overseas museum could be perceived "hypocritical” as TP's own mummy Mehit-em-Wesekht was taken off display at Buckle Street in the early 1990s (albeit for conservation purposes, not cultural sensitivity). TP's commitment to the mana taonga principle was then utilised to argue that the source community - in this case contemporary Egyptians - as the guardians of Keku should be consulted. This shift in argument meant that the Māori view became largely irrelevant for the decision, which was passed on to the Egyptian authorities who 'own' the mummy.

While the ancient Egyptians clearly did not want their mummies seen by others, Keku was legitimately acquired, has no living descendants and her display did not offend the current Egyptian Government; therefore in a cultural relativist framework Keku's display could be justified with permission from her culture of origin. Furthermore, the paper stressed that 'authentic' objects have the power to communicate ideas that facsimiles cannot facilitate, an advantage of the museum experience over other popular media. Keku's display was not "a curiosity for mere entertainment", but for "educational purposes" within the context of the exhibition to convey ancient Egyptian beliefs of the afterlife. A draft strategy of display was proposed already including warning signs to alert visitors of the presence of human remains, a separate room for Keku, no photography allowed and no images of Keku in promotional material. Other recommendations included that visitors can share their views on a mini-website, a public symposium discussing human remains in museums, 147 "staff feelings are expressed and taken into consideration", 148 and working in the exhibition should be voluntarily with full briefing for the hosts.

\footnotetext{
146 All quotes that follow are taken from Eternal Life_Keku's mummy_130806.doc, unless stated otherwise.

${ }^{147}$ Although a symposium was not held, TP organised a debate with two scholars as part of its 'Science Express' series for the public on the topic 'Mummies in Museums - Preservation or Denigration?' on 1 March 2007.

148 Eternal Life_Keku's mummy_130806.doc
} 
Although the paper argued that the display of a mummy meets international museological standards - namely Article 4.3 of the ICOM Code of Ethics (2006) ${ }^{149}$ for the exhibition of sensitive material and the World Archeological Congress Code of Ethics $^{150}$ - and conforms with the Egyptian Government's guidelines, it also stated that “the display of Keku's mummy would run counter to the wishes of the culture from which she came" as well as TP's existing policy. Thus, it concluded - somewhat surprisingly - with the recommendation

that Keku's remains are not displayed, as the threat to Te Papa's credibility in a key area of operations (Repatriation of Kōiwi tangata) outweighs the value of displaying Keku in a short-term exhibition that should prove to be a strong attractor for visitors with or without the presence of her physical remains. ${ }^{151}$

No consensus was reached at this Leadership meeting, because "some [directors] were for it and others dead against it", ${ }^{152}$ and the decision was consequently passed on to the CEO and Kaihautū. However, they held strong, polarised views on the display of Keku; CEO Bennington supporting Keku's display and Kaihautū White vehemently rejecting it. ${ }^{153}$ Without a final decision being made, the exhibition team chose a pragmatic approach, as Fox remembers: "We had to design the exhibition assuming that Keku would be included - simply for logistical reasons. The yes / no seesaw was amazing, before a final decision was made."154 The minutes noted that the CEO and Kaihautū provide a decision by 14 September 2006; but failing to reach an agreement, the matter was passed on to TP's Board.

An extraordinary meeting of TP's Board was called for two reasons; firstly "this was a Governance issue with regard to the policy on Human remains" and secondly, "the CEO and Kaihautū simply did not and were never going to, agree with each other on this

\footnotetext{
149 4.3 Exhibition of Sensitive Materials Human remains and materials of sacred significance must be displayed in a manner consistent with professional standards and, where known, taking into account the interests and beliefs of members of the community, ethnic or religious groups from whom the objects originated. They must be presented with great tact and respect for the feelings of human dignity held by all peoples. http://icom.museum/thevision/code-of-ethics/4-museums-provide-opportunities-for-the-appreciation-understanding-andpromotion-of-the-natural-an/\#sommairecontent (accessed 3 July 2012).

150 http://www.worldarchaeologicalcongress.org/site/about ethi.php\#code3 (accessed 3 July 2012).

151 Eternal Life_Keku's mummy_130806.doc

152 Jeff Fox e-mail communication 28 June 2012.

153 See http://www.tepapa.govt.nz/Egypt/podcasts.htm (accessed 3 July 2012).

154 Jeff Fox e-mail communication 28 June 2012.
} 
matter". 155 On 6 November 2006 - only four weeks before the exhibition opened - the TP Board spent 80 minutes discussing by teleconference whether the mummy would be displayed or not. The meeting minutes ${ }^{156}$ allow a reconstruction of what led to the final decision to include the mummy. At the start of the meeting the temporary deputy chairperson, Glenys Coughlan, noted that at a previous Board meeting in October 2006 "the majority of the Board were of the view that Keku should not be displayed, taking into account Te Papa's policy to not display human remains [...] and its commitment to being a bicultural organisation". Nevertheless, given the timing pressure, a final decision had to be made at this meeting, by vote if a consensus could not be reached. Coughlan reminded the trustees that "the role of the Board is to make a decision that is in the best interests of Te Papa" and proposed three options:

(a) To adhere to Te Papa's policy, as written, that no human remains will be placed on display.

(b) To adhere to, and affirm the policy of not displaying human remains consistent with Te Papa's commitment to biculturalism, and taking into account the views expressed by iwi and Māori partners against the display of any human remains.

(c) In the spirit of biculturalism, and recognising that there are differing views on the display of human remains, and taking into account the nature of the exhibition and context in which Keku will be presented, making an exception to the policy and offering visitors the choice about whether to view her or not.

Interestingly, options (b) and (c) both instrumentalise/ utilise biculturalism to argue for and against the display of human remains respectively. This shows the ambiguity of biculturalism, which is here presented as a partnership allowing Māori the right to veto (option b), and a parallel universe that expects the Māori partner to tolerate different views (option c).

The minutes reveal that the Board was split into two factions: supporters and opponents of displaying Keku. The supporters upheld the museum visitors, who apparently wanted to see the mummy and TP's mandate to be a museum for all New Zealanders, implying that the obligation to serve a multicultural population rated higher than the bicultural paradigm. In addition, giving visitors a choice was important to the supporters, while they recognised that

\footnotetext{
155 Jeff Fox e-mail communication 28 June 2012.

${ }^{156}$ All quotes are taken from the Draft unapproved minutes of a special meeting of the Museum of New Zealand Te Papa Tongarewa Board, unless stated otherwise.
} 
there are differing views within New Zealand society on matters relating to human remains, including different cultural perspectives, that there is strong public support for including a mummy in the exhibition, and that as the national museum Te Papa has a responsibility to endeavour to uphold the values of all New Zealanders.

The supporters proposed extending tikanga Māori to Keku's display as "the best compromise" to reconcile the different world views.

Drawing on the bicultural partnership, the opponents on the Board stressed that "as a bicultural organisation, Te Papa must respect the views expressed by iwi partner, Ngāi Tahu, who holds the pae pae, and those who have mana whenua status", and that to not take the advice of the Māori partner was "inconsistent with the spirit of partnership and biculturalism, and may be detrimental to Te Papa's relationships with iwi and Māori". The opponents also raised the risk of 'spiritual contamination' of other areas of TP, such as the marae, as there was 'no guarantee' that visitors would cleanse themselves after viewing Keku. ${ }^{157}$ Again, consensus was not reached and the matter was put to a vote with the result that "the majority of members present agreed that an exception be made to Te Papa's policy on the display of human remains to enable the inclusion of Keku in the exhibition". Thus, on 6 November 2006 the Board made the final decision to display Keku.

Although the minutes do not throw light on the issue of how the vote was won, it is telling that the only two Māori Board members at the time, Josie Karanga and Mark Solomon, "expressed a dissenting view to the majority decision and wished this to be recorded". As there is no parity on the Board, Māori were in the minority (at the time only two out of eight Board members were Māori) - and although they are supposed to be an equal partner in TP's bicultural partnership - Māori were simply outnumbered. Enhancing the visitor experience - and ultimately making a profit - as well as the approval from the Egyptian Supreme Council of Antiquities to present Keku outweighed the Māori partner's veto. This demonstrates that ultimately majority rules at TP. It is a problem inherent in majoritarian systems that "no democracy based on majority voting can ever fully represent indigenous interests" (Sissons 2005:137). In his critique of the contact zone Robin Boast (2011:63) asserts that "[a]lthough all contact zone

${ }^{157}$ See chapter three on tikanga Māori around death and cleansing rituals. 
engagements are incommensurable in this way, what matters is that in an

incommensurable context, dominance wins. This is the real lesson of the contact zone".

In this light, the staff forum on 20 November 2006 (very close to the the exhibition opening on 9 December 2006) was merely to inform staff about the Board's final decision to include Keku; with the exception of a few staff in key positions, TP staff were not consulted or part of the decision-making process. The casual tone of the following email invitation suggests that it was a low-key event meant to gloss over differing views rather than discuss them in-depth:

Tēnā koutou,

We would like to invite all interested staff to a forum to discuss the upcoming exhibition: Egypt:Beyond The Tomb, and in particular to address any concerns or questions staff may have in relation to Keku, the mummy, who is an important focus of the exhibition. The forum will be in .... [venue tba] at $3 \mathrm{pm}$, Friday 17 November. ${ }^{158}$ Look forward to seeing you there, Seddon and Te Taru159

Fox confirmed the suspicion that the 'staff forum' was in fact more a 'staged show' than a genuine dialogue:

So staff are right in thinking that the forum wasn't an opportunity to change minds - it was more a presentation to outline Te Papa's Leadership Team response and process to coming to that decision, and the display strategy to mitigate as far as is possible the cultural sensitivity towards the display of human remains. 160

It is unsurprising then, that staff perceived that their personal views were ignored and resented management for denying them more input. But more importantly, staff felt that the bicultural partnership TP was founded on was strained and out of balance, according to Jeff Fox:

Several staff regarded the impasse between the CE and Kaihautū as a Governance issue, to test the validity of the idea that the CE and Kaihautū positions were in fact 'equal', that Te Papa 'walked the talk' when it came to biculturalism. There was a perception by some that Seddon's 'win' and Te Taru's 'loss' in terms of the inclusion of Keku's mummy reflected a situation whereby the CE was the one that actually wielded the power and that the concept of Kaihautū as a parallel position was merely paying lip service to the concept of

\footnotetext{
158 The staff forum was postponed to 20 November 2006 as Te Taru White was fog-bound in Rotorua (Jeff Fox e-mail communication 3 July 2012).

${ }^{159}$ E-mail invitation sent to staff on 14 November 2006 (Jeff Fox, e-mail communication 3 July 2012).

160 Jeff Fox e-mail communication 3 July 2012
} 
biculturalism. It was an unbelievably tense time for Te Papa - the presence or not of Keku ultimately perceived by some as a test for biculturalism. ${ }^{161}$

The majority of staff viewed the mummy case as a 'battle' between the CEO and Kaihautū, revealing the power struggle of their partnership, yet they overlooked the actual decision-maker: the TP Boad. I have illustrated the lengthy and complex decisionmaking process driven by commercial considerations and the approval of the Egyptian source community, in which the Board had the final say. I analyse the phenomenon of 'humanising' Keku for staff and visitors through Māori customs in the next section.

\section{'Humanising' Keku}

Paradoxically, Māori who largely opposed Keku's display played a key role in the efforts to humanise her. Once the decision was made to display Keku, "protocols associated with welcoming her and making her comfortable (manaakitanga) became paramount, separate from strategic issues." 162 Measures needed to be put in place to a) dignify the mummy, b) ensure staff and visitors were safe in her presence and c) prepare TP for potential criticism. In absence of the Ngāi Tahu kaumātua who abandoned their cultural and ceremonial responsibilities for the duration of the exhibition, "[t]hree senior Mäori staff then discussed in what form the protocols and rituals should be performed so that Keku could be appropriately welcomed, cared for while she was on display, and farewelled", and who would provide the spiritual safety and ensure Keku "was welcomed and regarded with respect, warmth and love". 163

Thanks to Te Ikanui Kapa, a respected Māori elder, tikanga was carried out without damaging TP's integrity. Although Kapa was also challenged by the long-term display of the mummy (as opposed to the short-term display of corpses at tangi), he justified his involvement adhering to the Māori principles of manaakitanga (caring) and ahuatanga (flexibility), as Fox recalls:

The idea that made him [Te Ikanui Kapa] comfortable with the whole thing was that many Mäori are buried in Egypt, from WWII, and their grave sites tendered with care by Egyptian authorities - the authorities were kaitiaki for Mäori servicemen whose remains were interred in Egypt. Should we not then observe Manaakitanga, and regard Keku the

\footnotetext{
161 Jeff Fox e-mail communication 28 June 2012.

162 Kekus display_image caption 5.doc

163 Kekus display_image caption 5.doc
} 
same way; is it not our responsibility to ensure that she is accorded the same respect and care that those Mäori servicemen are treated with in Egypt?164

Through a series of Māori rituals Keku was treated as a tupuna and 'adopted' for the duration of EBT. Her welcome followed tangi protocol, "similar in nature to repatriation ceremonies"165 which was deliberately kept low-key, given the controversy surrounding her coming to TP. This adoption was absolutely necessary from a Māori perspective and thus Keku was treated "with the utmost respect and we say that she was looked after by our ancestors while she was with us and that when she left us we returned her back to her own". A series of ceremonial acts ensured Keku "became part of the Museum's 'living' taonga." 166 A kawakawa wreath, a symbol of death in Māori culture and said to remove tapu ${ }^{167}$, was placed on top of her covered crate. Museum staff replaced the kawakawa leaves with fresh ones every couple of days following Māori tikanga:

Before disposal the old stems were gently rubbed against the new, so that the mauri (life force) of the people conducting the initial ceremonies was communicated and present with Keku for the duration of her time in the exhibition. The old stems were then taken outside to the living exhibition 'Bush City', and placed under living kawakawa plants, to return to the soil and help nourish the living plants. ${ }^{168}$

This practice played a key part in 'humanising' Keku, because it enabled staff to engage with the mummy, "spend time with Keku and communicate with her if they so desired. Effectively Keku became part of the living Museum, and was very much treated and regarded as a person, rather than as a museum object presented as a curiosity". ${ }^{169}$

Keku's adoption by Māori could however be deemed 'Māori-centrism', projecting Māori values onto another culture. I argue that the notion of 'adoption' is ambiguous here, because while it can be interpreted as an altruistic, generous act of embracing the mummy, it can also be seen as an act of appropriation and exploitation. 'Whose remains?' is a question of affiliation and ownership that determines the consultation process (Teague 2007). Claims to authority are thus claims to power (Foucault 1980). When I interviewed Hippolite, who joined TP after EBT, she stressed retrospectively to

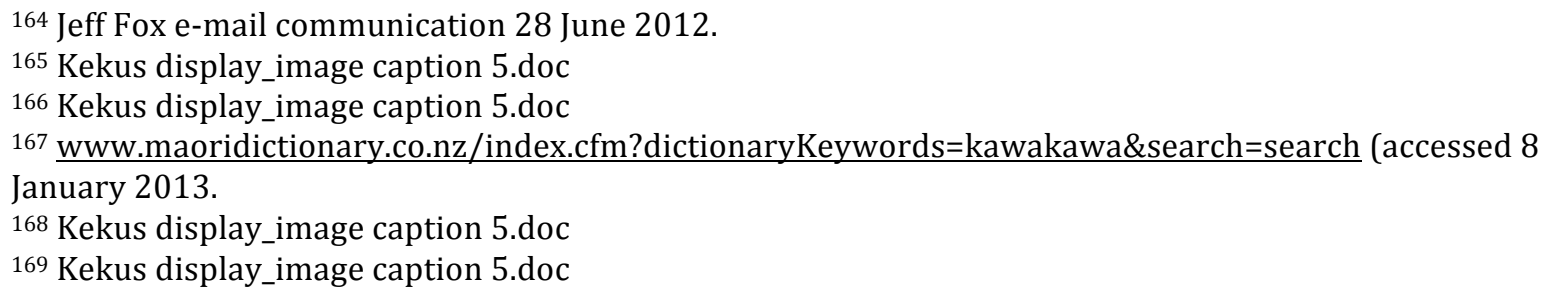


be cautious of this line of argument, which she rated little better than colonial imperialism:

While there may be a construct that is presented around a Mäori world view, I think that if we are to presume that the same construct should apply to other cultures, then in many respects we are doing what the museum was doing to Mãori, in its early phases. From my perspective, if it was appropriate within the Egyptian culture - and goodness knows how we would have found out about whether that was appropriate or not - if it was appropriate within their context, then I couldn't see that we could justifiably say it's inconsistent with our culture and so you shouldn't do it.

For visitors, Keku's placement within the exhibition space contributed to a 'deobjectification' process, as she was accommodated in a separate room at the centre of the exhibition. Signs at the exhibition entrance and immediately before entering Keku's room alerted visitors of the presence of human remains, and sensitised them to the Māori perspective:

\section{Display of Human Remains}

Te Papa acknowledges and respects that some Māori and people of other cultures have strong beliefs and feelings about the display of human remains.

For this reason, the mummy of Keku - who plays a central role in this exhibition - has been displayed in a separate room, allowing visitors to choose to view her if they wish.

We ask that people who choose to view Keku respect her presence and the feelings that others may have regarding this. We have provided water for those who wish to ritually cleanse themselves when leaving the exhibition. ${ }^{170}$

In addition hosts informed visitors about Keku's presence and also played an “extremely important role" in explaining TP’s stance on displaying human remains, answering questions and encouraging visitors to 'have their say' on the Egypt mini website. ${ }^{171}$ A specially commissioned water bowl was provided and a label explained the Māori custom, making EBT a bicultural exhibition and underlining Keku's status as tūpāpaku.

This section stresses the importance of tikanga Māori for humanising Keku which contributed to EBT becoming a bicultural exhibition and being popular with visitors, despite the internal turmoil that preceded it. In fact, I demonstrate that displaying Keku at TP was only possible, because some Māori staff provided the rituals to 'naturalise'

\footnotetext{
170 Kekus display_image caption 5. doc

171 http://www.tepapa.govt.nz/Egypt/default.htm (accessed 4 July 2012.)
} 
Keku as a 'tūpuna'. However, was EBT really a successful exhibition, as TP management stated? And what were the consequences for the bicultural partnership?

\section{Egypt: Beyond the Tomb - A successful exhibition?}

According to the host wrap report the exhibition was "a huge success: the public expressed their appreciation to the exhibition staff all the time with their positive comments." ${ }^{172}$ With 120,385 visitors, ${ }^{173}$ EBT exceeded expectations and was the "second highest visited charged-exhibition that Te Papa has hosted, behind Lord of the Rings 1 (219,539)", as of May 2007. As predicted, seeing a 'real mummy' was a key motivator to visit EBT. Given the visitors' feedback and financial profit that TP made with $E B T$, it was indeed a successful exhibition, but are these parameters adequate to measure the success of an exhibition? From a staff perspective the exhibition was very challenging. The hosts noted that

The implications of allowing staff to choose to be associated/interact with Keku were at times problematic. Some minor issues arose around the cleaning of Keku's case, which resulted in Hosts cleaning Keku's case when other departments were unavailable. ${ }^{174}$

For many Māori staff EBT was a disaster. Ngā Whētu Ririki (thereafter NWR), the formal representation of Māori staff at TP, presented a paper ${ }^{175}$ in February 2007, long after the exhibition had opened, responding to the presence of Keku in EBT. It pointed out the negative implications that the exhibition had for the bicultural partnership internally and externally, the risks for the repatriation programme, the commercialisation of Keku and the risks for staff. NWR criticised the consultation process - or lack thereof:

Early consultation should have occurred internally through Te Rōpu Whakamana Māori [...] and the Repatriation Advisory Panel, and externally with Ngāi Tahu iwi. Whilst this did eventually occur, it was extremely late, and their advice was not implemented. NWR believes a timely and robust bicultural process could have mitigated the concerns expressed by Māori and other staff.

\footnotetext{
172 Egypt host report.doc

173 All quotes and figures are taken from Egypt: beyond the tomb - visitation and satisfaction prepared by Michael Harvey May 2007, unless stated otherwise.

174 Egypt host report.doc

175 All quotes that follow are taken from 'Nga Whetu Ririki response to the presence of Keku in Egypt Beyond The Tomb', unless stated otherwise.
} 
In regards to the visitor survey that the Visitor and Market Research team conducted prior to EBT and which had a large impact on the Board's decision, NWR suggested that the "survey was inappropriate", because it lacked kaupapa Māori methods and neither Te Roopu Whakamana Māori nor NRW had any input into its development. Moreover, NWR accused TP of deliberately ignoring Māori beliefs: "There is a perception that the advice of Māori staff was avoided." Given that Ngāi Tahu, the iwi in residence, opposed the inclusion of Keku from the outset, NWR asked what is "the importance Te Papa places on iwi opinion?"

The 'burden' placed on Māori staff and the fact that "Ngāi Tahu was forced to consider the appropriateness of their kuia/ kaumātua remaining on site to support the exhibition" has permanently 'stained' TP's relationship with that iwi, according to NWR. In addition, TP's reputation "domestically and internationally" has suffered, because with this exhibition TP is "not only charging to view human remains, but doing so in the face of opposition from the indigenous group on whose behalf Te Papa's repatriation programme is operating". In NWR's opinion the Board used the ICOM Code of Ethics opportunistically, as it "was not intended to support the overriding of internal policy of an organisation and opposition from an indigenous group". Above all, Māori staff were put in a difficult position, as NRW stresses:

- Keku's presence is in conflict with tikanga Māori.

- Māori ceremonial processes have been requested for the exhibition, such as blessings, however it places our experts under pressure as to whether they will conduct these ceremonies under such conflict.

- There are no safe-guards in place to protect the taha wairua of staff during the exhibition.

NRW's outlook on the decision-making process and exhibition from a staff perspective thus underlines the destructive impact EBT had on the bicultural relationship and Mãori personally. Overall, NWR insisted that in the future a better communication and consultation process with staff be followed, and most importantly, that "no human remains are displayed" at TP, and the Kōiwi Tangata Policy is adjusted accordingly.

The scenario of including Keku despite TP's policy of not displaying human remains, demonstrates that policies, unlike religious doctrine, are guidelines that can be exempt 
under certain circumstances. Although making an exception to this policy has decreased the trust people (especially Māori) had in them, it has also sparked an interesting discussion about the role of policies, as a result of EBT. In the aftermath of the exhibition, there was consensus at TP that "[p]olicies are not unchanging, permanent documents. They need to change to reflect the times, and in many cases change for an institution to survive." 176 In the paper prepared for the Leadership meeting in August 2006 a formal review of TP's policy on displaying human remains was advised, as "[ $t$ ]he current blanket policy does not take into consideration the wishes of all of our potential audience and potentially does compromise the integrity of the presentation of other narratives where 'being human' is fundamental". ${ }^{177}$ After the review, the Kōiwi Tangata Policy ${ }^{178}$ states that TP does not display human remains "of Māori or Moriori origin", a distinction allowing decision-making leeway for future exhibitions.

To sum up, I suggest that TP's positive evaluation of EBT and NWR's critique of the process confirm that the success of an exhibition depends on the parameters it is measured against. 'The end justifies the means' seems to be at odds with the threat EBT posed to the bicultural partnership in its development phase. Nevertheless, the wider discussion about the role of policies at TP can be seen as a positive side-effect of EBT.

\section{Conclusion}

In this chapter I examined the bicultural museum practices at the 'heart of the Museum', in the collection room, at repatriation ceremonies on the marae and within the exhibition space of EBT. Considering Māori objects as taonga, living and breathing beings that link the present with the past and the future, is a fundamental principle for the care they receive at TP through kaitiaki Māori applying tikanga in the realm of the collection store rooms. This understanding of taonga in turn informs the mana taonga principle which is TP's guiding principle for acknowledging all cultures with a link to TP's collections. I emphasised how the dominance of tikanga in the Māori collection marks an important step in Māori empowerment in NZ museums and aids the

\footnotetext{
176 Jeff Fox, e-mail communication 28 June 2012

177 Eternal Life_Keku's mummy_130806.doc

178 Draft Kōiwi Tangata Policy dated 1 October 2010.
} 
decolonisation of museum conservation, as well as giving weight to the bicultural partnership at TP. The case of conservator Nirmala Balram illustrated how tikanga Māori and conservation values can complement each other. Working in a bicultural environment has immensely enriched her own understanding of conservation and opened up new pathways of collaboration with source communities. Nevertheless, there are also scenarios where pluralistic world views can clash, especially in a bicultural environment that is supposed to place equal value on Western and mātauranga Māori beliefs.

This 'grappling' with biculturalism has been demonstrated using the example of menstruating and pregnant women, who - following Māori protocols - should not enter the Māori collection. In a Māori framework the underlying reason is the women's own safety from the mauri of the taonga, whereas feminists contest the concept as being oppressive and out-dated, calling for a 'secular' museum. Having experienced the 'balancing act' of adhering to cultural protocols myself, being true to my own beliefs and being productive at work, I realised the full impact that this Māori practice can have on individuals. I conclude that Māori constitute and maintain control by defining the tikanga in this realm, but ultimately, as the 'media debacle' has shown, they do not have the backup or power to reinforce it. Within TP, the Māori controlled cell that is the collection room is not contested by Pākehā, and tikanga is taken for granted as part of its bicultural framework. In contrast, I suggest that in this particular case the contact zone at the periphery or public interface of TP did not work in support of a Māori world view, because it collided with feminist, postmodern values and was interpreted as limiting women's rights. Whenever biculturalism is posing a threat to (Pākehā) privileges, the 'state philosophy' is abandoned and declared 'symbolic' (Sibley/ Liu 2004).

I presented the internal struggle that occurred when Keku's remains were displayed in $E B T$, in contrast to TP's repatriation efforts of Māori and Moriori tūpuna from overseas collections, because it appeared contradictory to me. The social drama that unfolded around this exhibition was the biggest test for TP's bicultural relationship to date, as the institution breached its own policy not to display human remains. This case illustrated 
not only how the prospect of high visitation numbers and financial gain outweighed the cultural concerns by Māori staff and stakeholders, but also the power-struggle between the CEO and Kaihautū, a governance issue, rooted in TP's dual leadership model. Through document analysis I dissected the lengthy and complex decision-making process that ended ultimately with a majority vote by TP Board members in favour of exhibiting the mummy (and supporting the CEO's request), outvoting the Māori minority on the Board.

Although the iwi in residence, Ngāi Tahu, suspended their ceremonial responsibilities during EBT, Keku was 'humanised' through several ceremonial procedures that followed tikanga Māori, emphasising the need to 'adopt' Keku in order to display her at TP. The narratives staff contributed from this tense time for TP speak a different language to the reports prepared to measure the success of the exhibition; the reports indicate that in terms of visitor numbers and satisfaction EBT was a 'huge success', whereas staff (especially Māori) recall an incredibly stressful and tense atmosphere in the workplace due to the bicultural 'marriage' almost falling apart over the display of human remains. While the practice of tikanga Māori in the collection room portrayed Māori in a powerful position, the making of EBT proved that the ultimate power lies with the hegemonic in-built decision-making mechanisms. Ultimately, source communities are absorbed into the 'centre' of the museum:

Thus, always, is the contact zone an asymmetric space where the periphery comes to win some small, momentary, and strategic advantage, but where the center ultimately gains. This asymmetry is built, literally and figuratively, into our institutions. (Boast 2011:66)

The examples are evidence of an imbalance in the supposedly equal bicultural partnership, and underline TP's many - sometimes contradictory - mandates; profit was valued over cultural protocol and bicultural partnership with the financial success of this blockbuster show appearing to justify the means. If nothing else, there was one lesson learned from this exhibition that could be described as a positive outcome, seeing that TP's approach regarding its policies became the subject of debate. In the past TP had adhered to its policies in an orthodox way that came close to religious doctrine and was therefore criticised for being 'token' by many. Following the EBT exhibition, TP has made exceptions to existing policies (i.e. language policy, interview panel policy). Rather 
than applying a 'blanket policy' regardless of the context, the institution nowadays takes the circumstances, staff capability and capacity into consideration to make a decision on a case-by-case basis. Perhaps this is a sign that TP is indeed 'growing up', as dissolving the Bicultural team (chapter three) suggested.

Overall this chapter demonstrated that despite the challenges a bicultural concept poses to museum practices, it adds value and enriches the museum experience. In the next chapter, I discuss how staff make meaning of the concept of biculturalism. Juxtaposing staff's diverse understandings and imaginations of biculturalism with academic discourse, I reveal the ambiguities of the concept and offer a prospect for the future of biculturalism. 


\section{5 \\ Understanding and Imagining Biculturalism}

\section{Introduction}

In the previous chapters I discussed how biculturalism at TP was constructed, how it is staged and experienced by TP staff, how it is translated into everyday operation. I also examined how the institution grapples with the concept in museum practice. In this chapter I look deeper into how biculturalism is understood and imagined at TP. It is appropriate to explore these questions in this final chapter as TP staff's understanding of biculturalism is usually the result of working in a bicultural environment. The verb 'imagine' has three implications that I find fitting to describe biculturalism: 1) form a mental image or concept of, 2) believe (something unreal or untrue) to exist or be so, and 3) suppose or assume. ${ }^{179}$ Applied to the topic examined in this research, the first meaning might imply that the concept of biculturalism is not a fait accompli but a work in progress; the second, that biculturalism has an aspirational component that allows for thinking beyond the boundaries of reality, but also pretends to be 'true biculturalism'; the third meaning suggests that many assumptions exist about what biculturalism at TP is or should be. The following two statements exemplify 'imaginings' that surround biculturalism at TP:

Te Papa is a place to dream and aspire (Pākehā man and TP Board member)

Biculturalism is almost a living entity in itself and it moves and it changes. It's different for everyone. (Pākehā woman)

In this chapter I analyse the diverse 'imaginings' that TP staff attach to the notion of biculturalism. Ballantyne (2012:201) calls biculturalism a 'national imaginary' which

179 Oxford Dictionaries, accessed online 29 April 2013. 
supports a certain vision of the past and, likewise, of the future. I argue that biculturalism is a 'messy' term that is difficult to grasp, yet allows for a range of interpretations, imaginings and aspirations. Although the concept of biculturalism seems to be defined within TP's statutes and policies quite concretely, my research shows it is constantly contested, negotiated, imagined and re-imagined by TP's staff. I suggest in this chapter that biculturalism is constructed within the dynamics of a simultaneous process combining a 'top-down ideological prescription' and 'bottom-up practices' within TP, making it a complex and paradoxical assemblage. What are the different 'imaginings' that Māori and Pākehā staff attach to biculturalism and what are the imagined outcomes of it? How does this in turn shape staff's evaluation of TP 'walking the talk'? I highlight unresolved issues that stem from contested imaginings of biculturalism using two examples - the power-balance between CEO and Kaihautū, and TP's marae protocol - which are often targeted by the staff's critique. The term biculturalism itself is contested at TP and within academic discourse, and the search for a new term to replace it shows the ongoing struggle with its connotations.

Overall, this last chapter sets out to argue that, despite the challenges a bicultural concept poses to museum practices, it adds value and enriches the museum experience. I put special emphasis on the question of how staff actively make meaning around the notion of biculturalism. Juxtaposing staff's diverse understandings and imaginings of biculturalism with academic discourse, I reveal the ambiguities of the concept and outline some prospects for the future of biculturalism. Official rhetoric at TP as well as participants of this study often referred to TP as a person that is growing up. At 15 years old in 2013, TP is an adolescent now: it wants to push the boundaries and at times discard the 'bicultural corset'. To begin with, I illustrate this 'teenage rebellion' in some recent policy changes.

\section{The Coming-of-Age of Te Papa?}

Remembering how TP was created, Sotheran, Whiting, Phillips and Gorbey agree that the concept of biculturalism had to be formative, prescriptive, reductive and tied down structurally in order to create a robust framework that would be able to withstand 
pressure from critics inside and outside TP. In Sotheran's view the bicultural partnership was very fragile and needed protection against opposition from "diluting conversations" where people argued "we're actually monocultural, and what that was code for almost every time, was [...] we're actually white and if we can divide and rule, we can stay the dominant power". It was necessary in those early days to have biculturalism reflected in the management structure as well as written down in the policies which were to be followed religiously. Gorbey called this process "driving stakes in the ground" in order to establish the bicultural field. As TP is growing up and is in its 'teens' after 15 years of operation on $14^{\text {th }}$ February 2013, following the original policies blindly for the sake of bureaucracy has been challenged by TP staff on the grounds that they felt the policies to be inconvenient and inappropriate in certain circumstances. Could this change towards a more relaxed handling of policies be judged as a sign of maturity that the institution can give effect to the bicultural partnership without the 'training wheels' or, does it indicate that the bicultural commitment has become a hollow phrase because it is felt less important than in the early days?

Two examples of recent policy changes illustrate the 'coming of age' of TP: the language policy and the interview panel policy. According to TP's language policy every introductory panel has to be bilingual (te reo Māori and English), regardless of the exhibition content. However, when developing The Mixing Room (Appendix 9) in collaboration with refugee youth, this blanket policy felt tokenist to the Exhibition Development team. They argued that English was the common language for the refugees of the exhibition who spoke 28 different languages; the purpose of the exhibition was that "the young refugees [are] telling their stories their way, [...] their voice isn't that bicultural voice" as a Pākehā woman explained. In addition, the exhibition space is very small and the developers were anxious the panel would appear too cluttered with text if they included te reo Māori. Consequently, with approval from the Kaihautū, an exception was made for this particular exhibition to use nine languages of the refugee communities alongside English and Braille, and forgo te reo Māori in the introduction panels. The other example that supports the argument of TP wanting to remove the 'bicultural corset', was the policy that every panel for job interviews must include at least one staff member of Māori descent (and be gender-balanced). This 
policy was abolished in 2010, because Māori staff in particular criticised as a token gesture the requirement to have a 'brown face' on the panel, regardless of the role or candidate (or the - sometimes limited - Māori capability of the Māori staff member); furthermore the policy proved a burden for Māori staff who were called upon "all the time". Management felt that "you don't have to be Māori to assess biculturalism in a candidate" and changed the policy accordingly: in the new policy a Māori person must only be on the panel for any "managerial or supervisory role".

These examples of recent policy changes demonstrate several developments at TP. Firstly, that policy making is not a linear, top-down procedure, but rather a dynamic process that is strongly influenced by staff on the ground. Secondly, pragmatic reasons play a significant role in policy changes, such as space constraints in The Mixing Room or a limited pool of Māori staff to call on for interview panels. Finally, the more relaxed treatment of policies - making exceptions or abolishing them - confirms that TP management and staff do not feel they have to stick to an orthodox set of rules, instead preferring to make decisions on a case-by-case basis that reflects the requirements and circumstances of each occasion. On balance I would argue that TP has indeed grown up in interpreting its bicultural framework as a guideline rather than a tight structure. Moreover, 'growing up' was used by one interviewee as a metaphor for abandoning biculturalism, in a rather sarcastic comment: "I think the country is matured enough to go beyond [biculturalism] now. I feel [Māori] are no longer an endangered species as such" (Pākehā man).

\section{What is Biculturalism for TP Staff? Making Sense of Biculturalism}

The participants in my sample believed that staff held various definitions and understandings of biculturalism depending on their cultural background and the team they were assigned to work in. "I'm sure that everyone who you ask 'what does biculturalism mean to you?' will come up with a different answer", stated a Pākehā woman in the interview, expressing a view that is shared by many TP staff. Interestingly, their individual definitions of biculturalism that followed during the 
interviews were strikingly similar and in many cases their answers were almost identical, stating that biculturalism is:

- A relationship between the Crown and Māori as established by the signing of the Treaty of Waitangi

- A partnership that acknowledges Māori as tangata whenua here by right of first discovery and everyone else as tangata tiriti here by virtue of the Treaty

- An agreement to respect cultural differences and work together

In my view this research finding demonstrates that staff align their understanding of biculturalism closely with TP's definition and are to a certain extent institutionalised, repeating the 'official' definition of biculturalism:

Biculturalism at Te Papa is the partnership between Tangata Whenua and Tangata Tiriti recognising the legislative, conceptual and Treaty framework within which the Museum operates as well as reflecting international developments. This framework provides the mandate for the Museum to express and celebrate the natural and cultural diversity of New Zealand. It acknowledges the unique position of Māori in Aotearoa New Zealand and the need to secure their participation in the governance, management, and operation of the Museum of New Zealand Te Papa Tongarewa. 180

Carlisle (2003) was similarly struck, when she interviewed TP staff, by the discrepancy between the informants' perception that bicultural definitions vary and the uniform answers they gave. One Pākehā man in my sample called the 'official' definition that TP staff reiterate the 'easy answer', which is sometimes used to cover up a lack of understanding the concept on a deeper level.

\section{Interpretations}

In contrast, when I asked staff members what biculturalism meant to them personally, the differences in their understandings of the concept were vast. Staff members were well aware of the variety saying things like "biculturalism has various meanings to various people". In a nutshell, from the interviews conducted as part of this research three distinct imaginings emerged of what biculturalism is or should be: a token gesture

180 Museum of New Zealand Te Papa Tongarewa Bicultural Policy, Kupenga - Te Papa Intranet (accessed 1 September 2010). 
towards Māori inclusion, a process to achieve an equal partnership between Māori and Pākehā, and a tool for Māori development with the goal of self-determination. Each one of them entails different ideas about merging or separating cultural values, maintaining or sharing power, and aspirations for the future. The following statements by TP staff demonstrate the diversity of imaginings on the bicultural spectrum:

Biculturalism to me means an equal partnership. [...] It's not giving preferential treatment for one over the other. It's recognising and respecting both values, like both languages, both customs, both cultures. (Mãori man)

It's a matter of being aware of and advocating for and raising people's awareness of tikanga Māori. (Pākehā woman)

It's not just having two things side-by-side all the time, it's intertwining those two and respecting each side individually. (Māori woman)

It's a bit of a cliché but there is two cultures coexisting and getting along, appreciating and acknowledging two different [...] cultures and trying to merge them into a happy coexistence. (new migrant, man)

Ngā tikanga rua [...] tangata whenua and tangata tiriti which is not just Pākehā but Polynesian as well. (explains biculturalism showing me a carving he made using Māori and European patterns that intertwine) See, they don't actually melt together, they [are] two distinct patterns and they tend to butt heads sometimes [...]. It's not balanced, it's not fiftyfifty. (Pacific Islander, man)

For me biculturalism is - as a Mãori - practising all of those things that make you Mãori and for non-Māori it's practising those things and actually appreciating the different side. (Mãori woman)

Biculturalism for me is [...] to reconcile yourself as a product of a Māori and a non-Māori heritage and find a way to walk a middle path that acknowledges and gives meaning to both. (Māori man)

Incorporating aspects of more than one culture and [making it] inclusive. (Pākehā woman)

The bicultural aspect for me is about empowering Māori. (Māori woman)

[I]t's understanding the separation [...] It's having respect for the cultural difference. (Māori woman)

We are talking about biculturalism, but really, it's Māori we're talking about! (Pākehā man)

I think the term biculturalism is an attempt to satisfy indigenous cultures. (Pākehā man)

It's based on the respect of each party and understanding what notions of control and authority we give each other. (Māori woman) 
[Biculturalism] has a tendency to turn into a dial up pōwhiri situation where Māori are only called upon to toot horns and dong bells and murmur karakia before and after an exhibition for instance. It could go there, in this place Te Papa if it's not careful. (Māori woman)

Biculturalism is something that is at the comfortable end of interacting with Mãori [...]. It usually up-skills Pākehā people [...]. Māori people are far more concerned with power sharing than biculturalism [...]. I would say that a lot of Mãori, including myself, would see biculturalism at the soft end of race relations in that it doesn't address core issues around Treaty of Waitangi inequities and justices, real power sharing in decision-making. (Māori woman)

Within these imaginings of biculturalism that TP staff currently hold, the whole spectrum of Durie's (1998b:102f) bicultural continuum as well as Fleras and Spoonley's (1999:238) model of bicultural commitment from 'soft' to 'hard' is reflected. The main difference between the statements above is that some see biculturalism as an attempt to create a cultural fusion of the two cultural streams into one, whereas others interpret biculturalism as the capacity for each culture to be different and stay separate. The first strives for amalgamation or assimilation of some sort, while the latter strives for selfdetermination and parallel institutions. The Māori participants tended to be more focused on issues of power and control than the non-Māori participants, who generally thought of biculturalism as including a Māori perspective and applying 'soft' measures like learning the Māori language. It is particularly interesting that several participants suggested that biculturalism should have different implications for Māori and nonMāori (empowering and strengthening Māori versus up-skilling non-Māori to be more appreciative of Māori culture). We can see from the diverse statements above that staff imagine completely different levels of intercultural interaction, extents of cooperation and outcomes from the bicultural concept. While many Māori and non-Māori accept some degree of learning from each other's cultures, a few Pākehā (men in particular) believed that biculturalism is solely the responsibility of the Māori staff. With the exception of a few scholars who work at TP, most staff seemed largely unaware of the academic discourse about biculturalism and often struggle with the term, an issue which I shall discuss in the following section.

\section{Struggling with Biculturalism}

Staff often emphasised that the bicultural concept to them seemed 'muddy', or 'confusing' and admitted to struggling with it, as these two Pākehā managers described: 
We don't really know what [biculturalism] means, as an organisation. (Pākehā woman)

I'm not so sure that any organisation in New Zealand has really got to grips with what it means, biculturalism. [...]I don't think anyone knows what that means. I don't know what it means! [...] I recognise the fact that I don't know and I've not encountered anybody who can tell me what it means. (Pākehā man)

Others remarked that biculturalism "is a hard one", "it's not clear", "it makes my head hurt", and "it scares the pants off me". ${ }^{181}$ I suggest revisiting TP's conception before Day One in order to find the roots of this uncertainty about biculturalism. When TP was conceived, biculturalism was not spelled out, recalls Gorbey, so the Project Team "had to find out what [biculturalism] was". In hindsight, Gorbey asserts that biculturalism at TP "wasn't being discussed enough by the institution as a whole". Paradoxically, in Gorbey's view, the bicultural concept was formalised too quickly in a simplistic way and quite literally set in stone in the institutional framework. Therefore it took on a prescriptive character where bicultural principles were formulated a priori. It was a mistake, according to Gorbey, to try and bring the fluid concept of biculturalism into a solid form, "as though it could somehow be tied down to something concrete that could be defined, when in fact for me biculturalism is a constant redefinition through negotiation of a current situation". This institutional struggle with the bicultural concept is mirrored by the confusion staff feel in this regard or perhaps is projected on to them. Staff often have a lack of understanding of biculturalism, and when "push comes to shove" at TP, Māori values can easily be overridden by other paradigms, as I have demonstrated with the Egypt Beyond the Tomb exhibition (see chapter four). Staff who witnessed decisions that they perceived as paying 'lip-service' to the bicultural mandate become disillusioned and even more uncertain of the status of the bicultural commitment on the scale of organisational priorities.

In addition professional development by the Museum is narrowly focused on technical skills (McCarthy 2011:239) and there is a notable absence of thorough critical debate at TP of what biculturalism means, leaving a vacuum that staff fill with their own

181 This corresponds with Jennifer Shannon's (2009:233) research at the National Museum of the American Indian, that "around the time after the opening, there was no consensus about what Native voice is"; suggesting that the struggle represents part of a negotiation process in the relationship between museums and indigenous peoples. 
imaginations and misconceptions. For Rhonda Paku the confusion lies in the term biculturalism:

It can be a very confusing term, because as an example, inherent in that term is that it only involves two cultures and that the relationship is therefore between two parties onlyMāori and British. But actually the interpretation of biculturalism here is that the Treaty relationship is between Māori and all cultures and traditions that have made their home in New Zealand.

The binary in this term implies that there are two cultures - Māori and Pākehā in popular opinion - which in turn implies that the diversity of ethnic groups in NZ is not reflected and that some people are included but not others. Hence a number of staff, especially in leading positions request and actively search for a new term. However, the question remains what term could replace biculturalism, and how would that change the power balance between Māori and non-Māori at TP? What needs to follow here is a dissection of each proposed term, its implications and the underlying thinking.

\section{Quest For a New Term}

Biculturalism in NZ is commonly contrasted with multiculturalism, and a popular opinion (by ordinary New Zealanders and some academics) is that the concept of biculturalism is out of date (or fashion) and should therefore be replaced by the concept of multiculturalism. Critics of biculturalism argue that NZ's demographics have changed dramatically in the last twenty years to the extent that Māori are outnumbered by the increasingly diverse group of immigrants from various ethnicities, particularly Asians and Pacific Islanders, who are excluded within the bicultural model, which they believe, only reflects Māori and European heritage. Ballantyne (2012:54) writes that many Asian New Zealanders "long to belong to the nation, but feel excluded by the authority of biculturalism and the assumption that New Zealanders are either Pākehā or Māori".

This view overlooks the fact that the counterpart to tangata whenua is tangata tiriti (Museum of New Zealand Te Papa Tongarewa Act 1992), in which all non-Māori regardless of their ethnicity are included. Therefore Sharp (1995:120) emphasises that biculturalism is not incompatible with multiculturalism (see also Vasil 2000 [1988]). In my opinion it is a common misconception for New Zealanders to see multiculturalism as more inclusive than biculturalism, revealing that its promoters - among them some TP 
staff - either have limited knowledge of biculturalism or reject the notion of sharing power and resources with Māori that a bicultural partnership implies. While both these assumptions are valid, I focus on the latter to demonstrate the political agenda of the 'multiculturalism rhetoric'.

What the critics of biculturalism really resist is not so much a perceived exclusion of Asian immigrants for example, but the centrality of Māori within the partnership, which signals a reversal of the previous marginalisation of Māori. The promoters of multiculturalism often stress that the demographics make Māori a minority group (14.6 per cent of the NZ population identified as Māori in the 2006 Census; in 2010 about 12 per cent of TP staff were Māori), whereas the bicultural model privileges Māori. This line of argument subtly undermines the responsibility to protect Māori culture that stems from the Treaty. Mane-Wheoki states that the seemingly innocent question "why are we still talking about biculturalism? We're a multicultural society now!" is in fact "a very neat way of stepping out of any obligation for or responsibility to the Treaty. Very neat." Thus the quest for multiculturalism can be read as an attack on Māori power in disguise, an attempt for Pākehā to maintain their cultural hegemony.

Interestingly, Pacific Islanders in NZ seem to be generally in favour of a bicultural framework as they see potential for their own cultural development, if 'Māori get it right'. Samoan born New Zealander, Maualaivao Albert Wendt, former professor of Pacific Studies at Auckland University, said in his keynote at the Museums Aotearoa conference 2012:

If Māori come to terms with the Crown, then all other ethnicities, including Pacific Islanders will benefit from it. Multiculturalism denies Māori [culture's place in New Zealand as the indigenous culture]. Let's get biculturalism well established first and then move on!

Similarly, Senior Curator Pacific Cultures at TP Sean Mallon (2011:249) sees biculturalism as a "catalyst for transformation", creating "the space for more nuanced multicultural voices to be expressed", including the Pacific voice. Despite the support for the bicultural partnership model by Pacific Islanders, the mana taonga principle is becoming more popular at TP as the following section demonstrates. 


\section{Mana Taonga Principle}

Under Kaihautū and acting CEO Michelle Hippolite the term 'mana taonga principle' has replaced biculturalism on many occasions in 2010/2011. Hippolite doubts that the "value-laden term" biculturalism brings across what TP's philosophy is really about and finds "the concept of mana taonga to be more foundational [...] and easier to explain than that of being bicultural." 182 According to Hippolite a new term will be needed in the future:

I think the intellectual challenge is to find, to evolve and develop a concept that is embracing of what's happened in the past, but allows for a dynamic change in the future to come, because [biculturalism] is a value-laden term from lots of perspectives, from a government Crown perspective to an iwi tribal perspective to academics' points of view of the word 'bicultural'. And in some respects [biculturalism] may be a misnomer for a country that is reconciling its past with many tribes, not just one tribe. So not just 'he iwi kotahi tâtou', we are one, rather with a lot of sovereigns, who are seeking recognition and compensation for the past. Now that reality, I think, has a different way [or] language of expressing itself. And I'm not confident that bicultural is what that is, but nor am I an advocate for being multicultural, because it introduces some other complexities, again a value-laden term. So [...] certainly my vision for the future is to find a theoretical basis in which to explore and express this diverse reality.

While mana taonga being a Māori term implies a Māori perspective, it does not acknowledge Māori as the indigenous culture or Treaty partner. Time will tell whether the terminology will change persistently or not, and what implications for the future of the Māori/Pākehā relationship at TP this paradigm shift will bring. In the meantime the appealing rhetoric of mana taonga, with its suggestion of empowering all source communities to be included in the care of their collections, provides a model for "how we move this organisation forward under the banner of mana taonga, how it can be inclusive across a raft of different cultures, collections, peoples, products, the whole gamut," as a Māori staff member put it.

\section{What is Wrong with Biculturalism?183}

After dissecting the term biculturalism and the quest for a replacement, I now turn to biculturalism as a concept, which at TP is constructed as an 'equal partnership'. The

\footnotetext{
182 CEO Michael Houlihan also shared this view in the interview; see Epilogue. 183 I borrow this heading from McCarthy (2011:230) as it seems to use the right words to summarise a 'feeling' of discontent many museum professionals who are affected by a bicultural concept share in NZ.
} 
very nature of acknowledging Māori as an equal partner in a bicultural relationship seems to give Māori privileges that other minority groups do not have; this leads to the perception that is clear in the research that there is "too much focus" on Māori who are perceived 'superior' to other ethnic minorities in the bicultural construct. The value of egalitarianism is still highly regarded in NZ society despite neo-liberal changes to the Welfare State model since the 1960s (Kelsey 1996), but the egalitarian ethos clashes with the values of treasuring the indigenous culture and compensating for the wrongdoings of the past. The perceived favouritism of Māori under the bicultural policy goes against people's belief that everyone should be treated equally, regardless of their cultural heritage. Using the metaphor of a 'seesaw' that is out of balance, tipped towards the Māori side, a Māori man expresses his discontent:

There [is] some very, very pro-Māori stuff in the organisation - processes and things like that - that could get perceived as receiving preferential treatment over the other, and so that's not really the foundations of biculturalism. It's almost like it's contradictory to it, giving preference to one over the other.

Mane-Wheoki's concern for biculturalism is that the secular institution of the museum opens itself up for a religious component inherent in Māoridom:

I think one of the problems with bicultural[ism] is that a Māori world view brings with it a belief system that a Pākehā world view doesn't. A museum within the Western museum system is a secular institution. [...] So whether Māori religion and Māori theology has any place within a secular museum [and] just what the place of it is within a bicultural relationship, I don't know.

I demonstrated in previous chapters that at TP indigenous and Western epistemologies are considered valid, yet sometimes contradict each other (see chapter four), in which case Māori epistemologies might be limited to certain spheres or overridden. That 'religious' aspect of Māoritanga, which is in fact often a fusion of Māori spirituality and Christian tradition (Morrison 2012; Royal n.d.), can be observed in the Māori collection room as well as in pōwhiri on the marae where the Lord's prayer may be spoken and sometimes a hymn sung (both in Māori) using bible verses and tunes of old church chorals. This intermingling poses the problem that non-Christians sometimes feel alienated. Moreover, the orthodoxy of the Māori belief system in Māori domains within TP often excludes non-Māori from full participation, because Māori believe "they don't get it"; customary spiritual elements such as mauri, wairua, mana and tapu are 
particularly difficult for non-Māori to grasp, and ignorance or a sense of exclusion provokes resistance.

These two aspects, perceived favouritism towards Māori and the spiritual elements of Māoritanga, fuel the impression that biculturalism at TP is a 'Māori thing'. Non-Māori often feel alienated and inadequately skilled to participate fully and consequently 'opt out'. This in turn increases the pressure on Māori staff to carry biculturalism on their shoulders, as the examples of the Māori activities (see chapter two) and the interview panel policy (before the review) illustrated. As a result I suggest that notions of authority, power and responsibility present unresolved issues at TP which reveal themselves in two prominent features of TP's bicultural commitment: the dual governance model and the marae protocols.

\section{Does a Bicultural Partnership Imply Equality in Dual Governance?}

When TP was developed, a dual leadership model was created to express the bicultural partnership that was envisioned to permeate through the whole organisation. Sotheran asserts: "[...] it was not a matter of consultation, it was a genuine matter of shared power in a partnership. [...] It certainly wasn't a soft, politically correct relationship, [...] it wasn't warm and fuzzy. It was tough stuff." Thus, TP's bicultural vision then was to establish a 'strong' bicultural institution, which was advancing towards the self determination pole or tino rangatiratanga on Fleras and Spoonley's (1999:238) bicultural diagram and almost at the end of Durie's (1998b:102f.) 'bicultural continuum', with separate leaders at the top. This was nothing less than the attempt to enshrine a genuine bicultural partnership in a structure substantially different from the Western-type museum where one culture is imposed onto another culture. The equation expressed not only the inclusion of Māori at TP, but positioned them at the centre of decision-making power. Sotheran regrets that the TP Board "although it did have Māori representation on it, didn't totally reflect the huge shift that we made at the management level", making it difficult to follow through with bicultural decision-making processes (see chapter four). Nevertheless, the positions of the CEO and the Kaihautū were created "sitting alongside each other on a par, equal", as Gorbey stresses, seeing biculturalism as "a statement 
about positioning in terms of sovereignty. [...] Cheryll [Sotheran] related to the Crown, Cliff [Whiting] related to the iwi".

While both Sotheran and Whiting saw themselves as equals and put much effort into negotiating their bicultural 'marriage', the power balance between the two positions has not always been even, and the role of the Kaihautū in particular has changed significantly since TP opened. Staff interpret this power imbalance as an indication that $\mathrm{TP}$ is not yet a truly bicultural institution and see the changes as a means to "water down the bicultural concept little by little", as a Pākehā woman suggests. The reason for staff's criticism lies in the fact that the Kaihautū is subordinate to the CEO, thus their power and responsibilities are not equally distributed. The underlying assumption is that bicultural partnership means parity or cutting the institution into two equal halves, one run by Māori and one run by Pākehā reflecting the Treaty, regardless of the demographics within TP or NZ society as a whole. Interestingly, nobody in my sample questioned the assumption that the CEO and Kaihautū should be on a par, or suggested that the leadership should be distributed according to democratic majority correlations.

When I asked a member of the human resources team for the rationale behind this perceived power-imbalance, she told me that this was "for a very good reason" as "[f]rom an organisational perspective there has to be one leader. There has to be one person who has the casting vote". However, some staff expressed their disagreement with the current disparity, such as a Pākehā woman who commented: "So it's not really very equal when the other person is actually your boss!" Richard Wright humorously sums up the perception that the CEO is 'boss':

There's a big disparity between what the chief executive does and what the Kaihautü's role is. The Kaihautū today has more of a role whereby they support the chief executive. The chief executive makes all the big decisions. Chief executive gets the big money. The chief executive has the better office.

During the restructuring process in 2008 the responsibilities of the Kaihautū changed to the effect that the Kaihautū manages the Ngā Manu Atarau group consisting of the Iwi Relationships Team, National Services and Repatriation while the CEO has no such managerial duties. This change made some staff suspicious of the degree of power- 
sharing. Many staff believe that the CEO-Kaihautū-relationship after the restructure was more that of a "strong consultation process" than a true partnership:

And I understand now that the Kaihautū is no longer a sort of a joint CEO really, because they have people reporting to them, they have operational responsibilities basically, they're not just a leadership role. (Pākehā man)

This inherent power imbalance of the dual leadership model creates tensions between the two leaders and, at times, outright disagreement (see EBT chapter four) and leaves too much up to their individual preferences rather than relying on structural arrangements. Therefore many of my participants wanted to see this power struggle resolved in order to become a "truly bicultural institution":

[W] hen you [...] create a manager role of the Kaihautū [role] you deconstruct it. [... ] So I'm a dial-up Mâori. My role, the mana of the role has to be beside you [the CEO], not down like this. [...] It wasn't a money role, this was about valuing respectful partnership. [...] The honesty of a bicultural relationship is the true sharing of power, including the structural [sense]! So when we leave, it can be sustained. The weakness of it at the moment is that it is dependent upon the personality and the capability of individuals, rather than [the structure] - and that's ideal when you've got strong people! But the system has to accommodate and the way you accommodate for different changes is to structurally have it arranged. So you are obliged to, you have to [be bicultural]. (Te Taru White)

At a TP Board meeting held in Waitangi (where the Treaty was signed) the position of Kaihautū was discussed in-depth, however, the position was not pushed up to CEO level, rather it lost some of its mana:

[The Te Papa Board] talked about restructure and [Te Taru White] wanted the Kaihautū and the CEO position to be on equal footing. Well, what really happened in the end was that the Kaihautū became more of a director's position. The Kaihautū was responsible for Karanga Aotearoa and Te Roopu [Whakamana Māori]. It's more a hands-on position, not up there with the CEO, so it got separated, those roles, rather than making them closer together on parity; it became more of a distinct line between the two, so that was a shame really. I think it went in the wrong direction personally. (Shane Pasene)

When the co-leader is subordinate to the CEO, the Kaihautū role is diminished to a representational role at Māori rituals, and its symbolic status and mana are reduced to a "dial up Mãori" as White states. Nevertheless, White feels that the relationship between CEO Bennington and himself was genuine:

Let's put it this way: in principle it was equal. In principal we worked hard to ensure that the Māori voice, through the Kaihautū, was heard. In practice I opened every exhibition, but it was more about my ability to speak and present as opposed to (giggles) equal partnership. My partner, in all honesty, wasn't - (giggles), that wasn't his drink. So I opened 
it and was able to do that in most occasions. So we were always present [...]. I never ever felt it was token. If I felt it was token I wouldn't have been there! It wasn't an attachment. It was a genuine desire to filter Mäori perspectives through the whole organisation, in response of the partnership. So, on the face of it, the equality was largely dependent often upon the personality and strength of the Kaihautu. Because it is that fragile, even at Te Papa.[...] Because in reality, the chief executive was the employer of all people, including the Kaihautū, which was always an anomaly that we tried to fix. (Te Taru White)

As long as this power struggle between CEO and Kaihautū is unresolved, it will come up again and again, because it seems to me that Māori do not want to settle for symbolic power, but are striving for yet-to-be granted power sharing as equal partners. Whiting interprets the disparity as a Pākehā means of holding on to control and cultural dominance:

[I]t's just the Pākehā thing. They like that control and they think that if they're not in control, then it's all going to fall to bits. Yeah, it's as simple as that. [...] But it's surprising how that kind of thinking [is popular] with people who think they are bicultural and they're nowhere near it. The other thing is most of them have little understanding of how Mäoris operate. It's [got] to do with this governance idea that 'if [...] we're not in control, it's just not going to work', or 'we're not going to be included'. They [Pākehā] get very concerned about that.

The current model of dual leadership at TP, whereby the CEO is senior to the Kaihautū, affirms a bicultural relationship that sees Māori as the 'junior partner' (O'Sullivan 2007). The changes made during the restructuring under Bennington in 2008 and Houlihan in 2012 seem to have enlarged the inequality between CEO and Kaihautū. While the visible power relation of CEO and Kaihautū on the front stage (e.g. at exhibition openings) suggest equality, back stage their different responsibilities reveal Pākehā hegemony though these displays of power are rather subtle and largely invisible. In the next section I go on to examine the marae as centre stage, employing the contact zone theory to analyse what disagreements over marae kawa say about power, identity and the relationship of Māori among each other and in relation to the institution as a whole.

\section{Does the Bicultural Framework at Te Papa Advance the 'Museum as Contact Zone'?}

While I have demonstrated that within TP there certainly are contact zones of different kinds (see chapters two and three for contact zones within the Māori activities and the organisational culture), the question remains to what extent a contact zone is possible in any 'Western museum'. One of the first critiques of the 'museum as contact zone' 
concept was that while it creates a space for cross-cultural dialogue, it is nevertheless still situated in the museum and therefore merely extending governmentality (Bennett 1998:213). When Boast (2011) revisited the New Guinean Sculpture Garden at Stanford University - one of the examples Clifford (1997) used to illustrate contact zones - he realised that it failed as a successful model for contact zones because it lacked an ongoing exchange with the artists and did not fulfil their expectations. Thus, he warns against a "rosy portrait of the contact zone" (2011:57) as it seldom lives up to the ideal of "equal reciprocity and mutual benefit" (2011:63), and ultimately "[n]o matter how much we try to make the spaces accommodating, they remain sites where the Others come to perform for us, not with us". That leads him to the realisation "that the contact zone is a clinical collaboration, a consultation that is designed from the outset to appropriate the resources necessary for the academy and to be silent about those that were not necessary" (Boast 2011:66). I use TP's marae and the negotiations regarding the protocol that is adhered to in order to illustrate that TP goes beyond this 'clinical collaboration' and is in fact a re-appropriation of the marae by Māori. Thus, TP's marae is not a contact zone in Boast's sense, where Māori perform for non-Māori, but is a contact zone framed in indigenous terms where Māori themselves 'run the show'.

That TP, the national museum, has a marae built into it with the custom-made meeting house Te Hono ki Hawaiki indicates that the bicultural framework has visibly and physically become part of the institution. TP's pamphlet Welcome to Te Marae, states that "[o]ur Marae represents the essence of Te Papa - a place where everybody can have a sense of belonging. Our kawa, the way we host people, reflects this." In my view, TP's marae is in fact an embodiment of biculturalism. Here, biculturalism can be discussed and defined from a Māori perspective. I have already discussed the negotiation processes in developing a national marae 'for all New Zealanders' in chapter one. However, the marae kawa continues to be a contested issue among Māori and nonMāori within TP and beyond as well as between Māori staff of differing backgrounds, generations and iwi affiliations. As I demonstrate below, these debates among Māori move beyond the 'us and them' dynamics of the contact zone, as they constitute an intra-indigenous dynamic where Māori speak to Māori, albeit within the context of TP. 
Usually marae 'belong' to a hapū who owns the land the marae stands on and are recognised as tangata whenua by virtue of descent, bestowing rights to land and "privileges in its use" (Metge 1976 [1967]:236). For the tangata whenua the marae is their tūrangawaewae, where "Maori is king", as Metge (1976 [1967]:236) stresses, and "no-one can order him around". The issue at stake is that unlike other marae around NZ, TP's marae is not owned by one hapū, who sets the rules, but a pan-tribal marae that is supposedly inclusive of everybody, Māori or non-Māori. Hence, it is not clear who the tangata whenua of Rongomaraeroa are: the local tribe, Māori staff at TP, the iwi kaumātua, the marae coordinator, all TP staff, or the people of NZ? It is sometimes argued at TP that 'te iwi kāinga o Te Papa' is the rightful host of the marae, but with changing staff and iwi kaumātua this arrangement also has its pitfalls.

When TP opened to the public in 1998 and Māori leaders saw the colourful, modern meeting house for the first time it was met with 'mixed feelings'; many disapproved as it was too far removed from the appearance of a traditional meeting house and looked like a 'Disney-version' of a whare whakairo. Nevertheless, TP's marae is indeed a functioning marae which, says White, "runs according to the protocols of the tribe [in residence], not the protocols of TP. And [...] it's the second nationally recognised marae in the country, ${ }^{184}$ which is a real bang". Despite the hesitation in the beginning it is now widely accepted as a 'proper' marae:

And [Mãori] vote with their feet, right? (I laugh in sympathy) If they come, they come, if they don't come: (imitates Mãori visitor) "You're not national!" If they don't come and recognise it as a marae or as some sort of (imitates Mãori visitor) "Disney-looking thing", they'll just walk away. [...] Well the years gone by, thousands and thousands of Māori feet, and non-Māori feet have been through that marae. We've laid bodies in state there. [...] So, it's been richly used and recognised by virtue of its practice. So I could proudly say: Yes, it is the second national marae of New Zealand! (meaningful pause). And for an institution to be able to claim that, that says something! That says something. That's practice at work. That's the best diploma! Not one that the king, queen, the sultan, whoever can match, but the collective strength of people. (Te Taru White)

This certainly is a significant achievement for the only marae in NZ that was purposebuilt within a museum. However, the fact that Rongomaraeroa is a pan-tribal marae, and

184 The other nationally recognised marae is in Waitangi, where the Treaty was signed in 1840 . Some argue that the third national marae is $N g \bar{a} \mathrm{Hau} E$ Whā, which was opened in 1990 as NZ's largest urban marae in Christchurch (Meredith n.d. 'Te Ara Website) or Tūrangawaewae Marae in the Waikato which represents the headquarters of the Kingitanga movement (TP tour guide, personal communication). 
does not belong to one hapū as is common in Māori culture (Sissons 2010), creates tensions and poses the question whose kawa will be practiced.

Although urbanisation has led to the development of a pan-Māori identity, multi-tribal marae are strongly contested by Māori, as Kawharu (2008:56) states: "Even as a concept, a multi-tribal marae is a contradiction in terms." Metge (1976 [1967]:238f) discusses the formation of urban marae or community centres in the city, such as Ngāti Pōneke in Wellington, and their challenges. Marae at universities or high schools would be another example for marae that are not run by a descent group. Where kinship ties and tribal loyalties are absent, differences in kawa present problems, and compromises, uncertainty and competition are the results, as Kawharu pointed out (Schwimmer 1968:174f.). Despite their challenges, urban marae are "true marae in ways that matter most, that is, in function" (Metge 1976 [1967]:244). Paul Tapsell's (1998:81f.) distinction between two urban marae models is helpful: non-tribal marae for all 'immigrant Māori', and visitor-tribal marae where manuhiri set the protocols (such as at Mataatua in Rotorua, where Tūhoe kawa prevails outside their rohe). According to Tapsell TP's marae falls under the non-tribal or 'nationalised Māori [...] rights' category. This framework presents problems of intercultural nature, as not only are urban Māori of different iwi affiliations (or none) included, but also non-Māori. Salmond (2009 [1975]:90) is sceptical about such intercultural marae:

Marae with inter-tribal and inter-racial governing bodies do not appear to succeed. Factionalism and struggles for leadership mark their history, and it is dubious whether the ideal of integration should ever be applied to the marae. The marae requires some sort of a tāngata whenua group, which cannot be replaced by a European-style Board with diverse membership. Wherever pākeha are placed in positions of leadership in urban marae, resentment inevitably results. The marae is a Māori institution, and Europeans should have the grace to leave it that way.

The desire at TP to include non-Māori as much as possible can result in concessions to them that Māori perceive as going too far and compromising proper marae protocol. Consequently, not all Māori staff accept TP's marae as equivalent to their marae. The following excerpt from an interview with a Māori staff member manifests why some Māori object to TP's marae: 
Māori woman: [M]ost Mãori will not take their people there, 'cos for us that's not our marae. The other thing is some of the things that they do at Te Papa with regards to pōwhiri and Mãori traditions we'd never do on our marae, never do that.

me: Like what?

Mãori woman:That's the Te Papa way. What they do at Te Papa is the Te Papa way. But on each of our maraes we do different things. Every tribe does different things. We don't do what they do over there [in another iwi], anyway.

me:What's an example for that? I don't know enough about marae protocol -

Māori woman:Well, on our marae we definitely don't have anyone speaking English, on it! You want to speak in English you go to the outside of the meeting house. But there are a number of things that they do at Te Papa that we would not do on our marae, so I mean it's the Te Papa way. We have Te Papa who is trying to change the face of how Mãori should be anyway, so I mean what they're trying to do is what we call Pākehā-fy our Mãori traditions and no, that's why we don't like to have too many of our traditions in there. It's because that's not our place! It's a museum!

In the view of this Māori woman the 'Te Papa way' of conducting rituals on the marae, including speeches in English (after a karakia whakawātea; see chapter one and two), is a Pākehā invasion of the space that is the very "heart of Māori community" (Te Hono ki Hawaiki Pamphlet). While speaking English occasionally in order to include non-Māori could be seen as an attempt to make biculturalism inclusive, some Māori interpret it as the exact opposite, a way for Pākehā to control Māori and appropriate or 'Pākehā-fy' this Māori domain: "When a museum says to a tribe what you should be doing on the marae...hello? That's not bicultural!"

Challenges arise on TP's marae over who is in charge. Even though most non-Māori staff at TP do not interfere with the marae protocols and disagreement is expressed by absence from Māori rituals (see chapter two) rather than open criticism, the Māori staff themselves sometimes quarrel over the 'right kawa'. A dilemma for some Māori staff at TP is that the kawa for TP's marae over the years has taken on an institutionalised form that mainly adheres to Tūhoe kawa (due to the iwi affiliation of the person overseeing the marae proceedings) that might be at odds with the kawa they were brought up with. It is often forgotten that Māori are not a homogenous group, but identify themselves as iwi, hapū and whānau that can have very distinct cultural expressions, dialects, tikanga and kawa (Barlow 2005; Mead 2003). The issue is further complicated by the Māori custom that younger generations respect the older generation, so open criticism of the elders is not acceptable, thus Māori in disagreement with the conservative traditions tend to avoid participating in the rituals. The personal element in these 'acts of sabotage' should not be underestimated, as this comment by a young Māori shows, who 
despises the fact that 'Te Papa kawa' is considered superior to the kawa of other iwi and therefore overrides their protocols on the marae:

which is in some ways why I steer away from a lot of the events and things here [at Te Papa], because it becomes less about the event and rather more about individuals. And once again it's not right, because you're Māori, you're not an individual, you're part of a bigger picture. And I suppose because at Te Papa nobody else has stood up and said, "okay, this is what I think", we're all like lambs sometimes following the leader that's not necessarily a leader of the best way to do things. So it's quite hard [...]. I'm not the kind of person that tries to paint a picture that this is the perfect example of biculturalism. It's the best that we can do. [But at] times it's really hard to try to stick with the old ways today.

TP's policy states clearly that the iwi in residence dictates the marae kawa: "As part of the iwi exhibition programme, kawa (protocols) of the iwi in residence are observed on Te Papa's marae." (Annual Report 2011/2012: 28). In reality however, there is an expectation that "things are done the Te Papa way" which has evolved over the years and has become the norm, that could be called 'Te Papatanga'. Given that the iwi kaumātua take up temporary residence at TP for the duration of the iwi exhibition of two to three years - or sometimes, as with Tainui (composed of five iwi), take short stints of six months to represent the diverse composition of the confederation of tribes a permanent position to maintain the integrity and continuity of the Māori rituals is provided by TP. Different personalities, rivalry between iwi and contesting marae kawa can be an explosive mixture.

After waiata practice on 19 January 2012 I observed a heated discussion between the marae co-ordinator and the kuia from the iwi in residence, concerning the kawa for the upcoming repatriation pōwhiri. The kuia asked the kapa haka group to stand in front of the paepae for the haka facing the manuhiri, as is the custom in the Waikato, but her request was refused on the grounds that at TP they always perform in front of the stage. At a staff member's $20^{\text {th }}$ employment anniversary later that year the Tainui kuia told this story in her speech recalling that the 'debate' challenged the kawa she was brought up with and made her feel pressured to align herself with the 'Te Papa way' instantly. This example shows that the monopoly of the staunch, permanent guardian of TP's marae over its kawa - although necessary to ensure continuity and integrity - is challenged by the concept of constantly changing short-term iwi in residence, which creates tensions and power struggles among Māori staff. 
For TP's Māori staff this situation sometimes leads to fragmentation when they feel obliged to take sides. This demonstrates that although TP's marae is supposedly a 'contact zone' for Māori and non-Māori, and intended to be a place of belonging for everyone, in fact it becomes a 'battle-ground' at times where Māori personalities and opinions on marae kawa clash. However, considering that "it is often said: 'Ko Tū a waho, ko Rongo a roto'" (Metge 1976 [1967]:231), meaning that the marae atea is the realm of Tümatauenga, the god of war, while inside the meeting house Rongo, the god of peace, reigns; so both, disputes and harmony, have their rightful place within the marae in Māori epistemology. The mahau links the two spheres and is an 'intermediate area' (Metge 1976 [1967]:231), where women might be allowed to speak or the coffin might be placed at tangi. Regardless of the quarrelling behind the scenes, Rongomaraeroa provides an important physical space for Māori empowerment and a stage for Māori within the national museum. Is it a contact zone for Māori and non-Māori staff though?

Metge (1976 [1967]:244) states that "Pakeha sometimes raise objections to the building of marae in urban areas, on the grounds that they foster 'separatism' on the part of Maoris". While I did not find that opinion voiced in my sample, non-Māori perceived and acknowledged that the marae is a Māori domain, where they felt as guests at best and excluded at worst. It seems that Metge's vision of urban marae contributing to developing a "truly multi-cultural society" has not yet been realised and is perhaps utopian nowadays. TP's marae might at least have achieved one of Metge's (1976 [1967]:245) goals, namely to

provide a meeting-ground where people of different cultures, but especially Pakehas and Maoris, can get to know each other more readily than in situations ordered according to Pakeha rules, because there Maoris no longer feel at a disadvantage and on the defensive. On a marae Maoris walk tall, sure of the ground beneath their feet, organizers instead of organized, givers instead of receivers, hosts instead of immigrants in an alien world.

Therefore, I suggest that TP's marae is indeed a contact zone in the sense that Pākehā are exposed to Māori in a physical space that is framed on Māori terms. Moreover it is also a stage for Māori to form their identities by disputing issues at the heart of their culture, such as kawa variations in different iwi. On the marae they perform not for 'the 
other', but for themselves. Having experienced a repatriation pōwhiri at TP, most people get a sense of the physical display of Māori power in front of them that culminates in the dramatic performance of the haka - this is not a staged show for tourists, in my view, it is Māori people marking their territory and constituting their power and identity. After looking at the microcosm of Rongomaraeroa within TP, I now examine the whole of TP, attempting to answer the central question of this thesis: is TP walking the talk? Firstly, I discuss the (often negative) evaluation by outsiders of TP; secondly, I provide the viewpoints of TP staff and their parameters, and thirdly, I demonstrate how TP's bicultural commitment fares internationally.

\section{Walking the Talk -How Bicultural is Te Papa?}

McCarthy (2011:230) writes that criticising TP has become "virtually an industry in its own right". Joining the chorus of TP critics, Paul Williams (2003:305) states that "[b]y presenting biculturalism as an achieved postcolonial state, Te Papa overlooks not only a history of colonialism, but also the continuing inequality between Maori and Pakeha that made biculturalism a necessary state response in the first place". He argues that biculturalism has a "limited shelf life", and that TP is the representation of what a group of professionals sees as 'our times', rather than being 'Our Place' to New Zealanders (Williams 2003:306). Analysing TP's Day One exhibitions, Williams (2003) concludes that TP is best seen as a 'pedagogic symbol' of biculturalism. While some of the criticism might be justified, I disagree with this simplistic view that overlooks the deep levels of engagement that go on between TP staff which, in my view, make TP a meaningful contact zone in real terms. In contrast to the critical voices of outsiders, I present a view from within, letting the staff members themselves evaluate how bicultural they think TP is.

They walk the talk [at Te Papa] as opposed to other institutions where they go 'oh yes, we're bicultural, we've got a Māori name. (Pākehā woman)

As an organisation, it's at a place where it's still growing into its biculturalism clothes, but it's kind of fitting in and it's looking better. (Māori man)

Te Papa is definitely more advanced than [the universities] in a bicultural approach. But [...] Te Papa is not walking the talk yet. (Päkehä man) 
The above statements show the spectrum of opinion held by staff and the tendency to compare TP with other institutions. Comments were usually positive if the person was new to TP and had little exposure to Māori culture before or when the person had worked at TP for over ten years. In contrast, people who had worked at TP between five and ten years often became cynical as they drew on discrepancies between the aspiration and the reality of biculturalism. If we read TP's commitment to biculturalism as a 'dramatical performance' as Goffman (1959) has defined it, the audience doubts the sincerity of the act when the performance is no longer believed to be reality and the acting becomes visible.

At TP sometimes the practices contradict expectations of 'true biculturalism' and consequently staff consider TP's bicultural commitment as token. The 'one-size-fits all' approach, for example that TP opens all exhibitions with a Māori blessing regardless of the exhibition content, is met with scepticism by some Pākehā and Māori alike who do not subscribe to this practice. Pōwhiri for external clients who pay money for this service (chapter two), is another example. When staff realise that pōwhiri are not only performed at what are perceived as 'appropriate occasions' (for example to welcome new staff, repatriate human remains or hold funerals), but also for commercial reasons, staff criticise the practice as 'dial a Māori' and tokenism. This seems to upset some Pākehā staff more than Māori staff, suggesting that Pākehā generally have an essentialised and perhaps even antiquated view of what ('traditional') Māori culture should be, whereas most Māori staff do not see commercial use of pōwhiri as necessarily compromising their culture.

It appears that staff's high expectations of biculturalism in practice are not met entirely at TP, so staff take on cynical and critical positions, especially when they witnessed the kinds of difficult issues I described as 'grappling with biculturalism' (see chapter four); staff get the impression that Māori culture is an 'add on' and at the end of the day 'majority rules'. This critical view presents a stark contrast to the meaningful engagement with iwi that TP curatorial staff acclaim (Hakiwai 1999; Tamarapa 1996a; Evans 1996), and TP's international reputation as being one of the most advanced models of the museum as 'contact zone' with indigenous peoples and source 
communities (Kreps 2003; Message 2006; Simpson 2001 [1996]; Dyson 2005).

Interestingly, staff who travel to museums and conferences overseas on a regular basis evaluate TP's bicultural commitment more positively than their colleagues who are confined to the 'Te Papa bubble', as they can look beyond the details and see the bigger picture. Perhaps staff are harsh critics because they suffer from 'organisational blindness' and lose perspective. Many former staff members told me that it was not until they had left TP that they realised how bicultural it really was compared to the organisation they worked for afterwards.

\section{Comparison with other Organisations}

Asking TP staff the question 'is Te Papa a truly bicultural institution?' provoked very different, yet strongly held responses ranging from 'hell no!' to 'it's as close as you can get' to a bicultural institution. The variation in evaluating TP's degree of bicultural commitment is understandable considering my participants' diverse cultural backgrounds, aspirations for a bicultural institution and previous experiences at other organisations. Keeping in mind the 'bicultural continuum' (Durie 1998b, 102-3) and the 'model of bicultural commitment' (Fleras/ Spoonley 1999, Table 7.2, 238) helps to evaluate and visualise where TP stands in this moment of time.

Comparison of TP to other purportedly bicultural institutions in NZ and overseas enabled my participants to make a judgement of how bicultural TP really is. A good 75 per cent of my participants have worked in the public sector or Government departments previously and used these experiences as a template/matrix to draw a distinction. Most participants confirmed that TP stood out against other organisations and was indeed making an effort to be bicultural in many regards, in contrast to their previous work environments within NZ where biculturalism to them felt predominantly superficial, shallow, added on and token. Saying that, two participants who had worked for the Ministry of Education (MoE) before they came to TP perceived MoE as more bicultural on a day-to-day basis than TP. The NZ education system in parts is arguably a model for biculturalism with a range of initiatives on the spectrum from bicultural classes within mainstream schools to kura kaupapa that are fully Māori run (Penetito 
2010; Bishop 2008). Another sector that has been leading bicultural developments until recently is the healthcare sector (Ramsden/Spoonley 1994; Ministry of Health 2006).

A typical impression from those informants who had worked at other Government agencies was that only 'lip-service' was paid there to biculturalism which existed in written documents, but was not implemented in practice. A new migrant stated that at her first workplace in NZ biculturalism was token: "At the very worst case scenario [...] the baseline [was] 'Oh well, we'll pop that in there, so you've signed up for it [and] therefore you must agree with the principles of the Treaty of Waitangi because it's in your contract'. But it doesn't actually mean anything, on a day-to-day basis."

A very different view among staff is that biculturalism is so ingrained into the organisation that it becomes almost invisible. Contrary to the popular opinion held by staff that TP is not bicultural enough, these people think that the bicultural concept is taken for granted by the institution and therefore no longer noticed as it has become part of the subconscious psyche of $\mathrm{TP}$, as White suspects: "I like to think that we practice biculturalism, [we] just don't talk about it." The danger with the fact that at TP biculturalism is not much talked about is that newcomers 'don't get it at all' as the TP culture is not spelled out to them and sometimes so foreign that they are 'scared' of it and suffer from 'culture shock' (see chapter two). The view that biculturalism at TP is 'ingrained' and consequently does not need discussion anymore, suggests that biculturalism was a goal that has already been achieved and implies that 'we can move on now'.

\section{International Comparison: Bicultural Partnership Makes Te Papa a World Leader}

Carolyn Roberts-Thompson sees a discrepancy between the internal view of biculturalism and the international interest: “We don't talk a lot about it. Although in a global sense it is absolutely the fundamental thing that people find unique about this place." Although people working at TP are often quite critical of the institution's degree of bicultural commitment and very apprehensive to praise it internally, there is mutual agreement among staff that compared with museums worldwide TP is a 'world leader' in facilitating a bicultural partnership with indigenous communities. Stories of the huge 
interest from international museum practitioners when TP first opened as well as at museum conferences are recited at official staff meetings and informal get-togethers (see chapter three). As I mentioned before, staff who have travelled overseas on behalf of TP come back 'shocked' by the often poor relations between museums and indigenous peoples, but at the same time impressed by the admiration for TP from museum practitioners, perpetuating the perception that TP is 'unique' in its bicultural framework and an international role model for the museum sector.

\section{Better Ways of Walking the Talk?}

In this section I summarise what TP staff think would move TP further along the bicultural continuum. Many suggested that as long as the CEO is above the Kaihautū in the organisational hierarchy TP is not yet a truly bicultural institution. In White's opinion, TP is:

about as close as you get, for any institution, it's certainly a leader to where it's gone to. But the day that it puts that last brick in the wall [and makes CEO and Kaihautū truly equal], is the day that they can truly proclaim, it's let go of all control. So there is a little bit of a fudge-factor here, and that's the fudge.

According to many critics TP is a world leader in terms of transforming the role and self-image of the museum, because it gave up curatorial control and at the same time empowered indigenous and non-indigenous communities:

[I]t's about letting go, letting loose of control. Our museums are so good at control. They control memory of our peoples. And when you control memory obviously you have a great deal of power. I think [...] that the way forward for biculturalism as we pursued it at Te Papa, was about letting go of control, letting the tribal people come in and tell their stories the way they wanted to and we simply became the facilitators, provided the infrastructure in which that could happen, but allowed their voice to be heard. It's like most things: Who created the treasures? Whose treasures are they? Whose stories are being told? Who are we to demand that we tell it in our way? So, the tribal people come in, [...], when you're asking people to share their ideas in a way you are consulting with them, you are sharing power. And most museums do find that difficult. And when you are in a position to share power, when you can see partners, like tribal peoples, coming in, freely of their own volition and freely giving up their knowledge to you [...] they are beginning to trust you. [Then] you know that you are getting somewhere close to being a bicultural institution! (Te Taru White)

Acknowledging the expertise of communities and following their lead is not an easy task for a museum, but TP has successfully endorsed this ethos with its mana taonga principle (see chapter four), and within the exhibition spaces dedicated to Māori in the 
Iwi Gallery and other NZ communities in the Community Gallery (see photos in Appendix 11). Clifford (1997:210) states that successful "[c]ontact work in the museum thus goes beyond consultation and sensitivity [...] It becomes active collaboration and a sharing of authority". This is certainly true for TP, despite exceptional cases where world views collide (chapter four).

Although TP is 15 years old in 2013, its bicultural model is still ground breaking in an international context, as it shares power and authority to a degree that poses a threat to the Western museum concept:

[M] useum personnel, personalities are still worried by the concept [because it] threatens their power base [...]. When I was in Europe people feared Te Papa. They feared it because they thought it was a fun park. They also feared it because it seemed to be a model of a big national museum giving away much of its authority. (Ken Gorbey)

Thinking about how far TP has come in moving away from a Western museum approach to a bicultural partnership and dual leadership approach, Sotheran emphasises: "I think we got further than anyone else in the world in those terms". What stands out for White are some 'magic moments' when the bicultural framework opened new pathways and enabled Māori to take control, for example at the opening of iwi exhibitions:

When the tribal exhibitions happened [...], you know we had two and a half thousand Mãori coming in. You got all the staff, both Mãori and non-Māori coming in. The place is vibrant. You know, life beating, the heart-beat is huge and everybody is bathing in that and that loving and that glowing! To some in the museum world, they might feel a little bit afraid (smiled), because they are outnumbered on that occasion (laughs, I join in). You got all these Mãoris (laughs) roaming around, so they own the place and to Mãoris, they feel they do. And when people feel they own the place - it's nice!

Perhaps TP's biggest achievement for NZ society was that it 'has made biculturalism safe', as Gorbey elaborates:

I personally would say that one of the successes of Te Papa is that people see it as a safe place where biculturalism is part of the fabric. So this threatening thing called biculturalism which fills our newspapers with headlines about Treaty deals and what the radicals are doing at [the] Waitangi Treaty [grounds] on Waitangi Day, that generates a lot of fear, but Te Papa doesn't and yet it's based on the same principles. So to me personally, the great success, one of the great successes of Te Papa, has been that it has made biculturalism safe. It's given it a safe face.

In doing so, TP as an institution seems to fulfil Elaine Heumann Gurian's (2006a:99; 2006b:12) aspiration to turn museums into "safe places for unsafe ideas". Seeing 
biculturalism as a continuing process not an achieved status, I ponder what comes next at TP; will it move beyond biculturalism or revert back to white supremacy? Staff's reimaginings of biculturalism surface when they consider TP without a bicultural framework.

\section{Re-imagining Biculturalism: What would Te Papa be without Biculturalism?}

At this point in time we cannot be sure what the future will hold for TP's commitment to the bicultural concept. As the institutional rhetoric shifts from 'biculturalism' to 'mana taonga' and TP undergoes a major restructuring process at the time of writing this thesis, it is not clear what implications this will have for the interaction of Māori and non-Māori staff. While it seems that the term biculturalism over the 15 years of TP's operation has become less important, a terminology change does not necessary mean less commitment in the partnership with Mãori. Although some staff fear that the bicultural concept will be less and less important in TP's future, it is highly unlikely that the institution will 'get rid' of biculturalism altogether. Former CEOs and Kaihautū in particular were hopeful that the bicultural concept will persist as it is too ingrained in TP to be aborted. White likens taking biculturalism out of TP to breaking its backbone:

Just by virtue of the practice of biculturalism and getting some things done in operations, it has, I believe, produced this situation where there is no turning back. You know, you have garnered it so much, over ten years, with its imperfections, you got it to a situation now where people are used to it. People now want to see it, people feel the value of it, even though it is not perfect. You try reversing that! It's very difficult. [...] If Te Papa wanted to revert back and trying to peel itself back from any bicultural commitment: you watch it go! You watch it go flat! You watch it lose its value!

Backing this view up, Whiting asserts: "[Biculturalism] is absolutely essential to TP to maintain a really high standard of bicultural process, so that it can continue to develop the sorts of exhibitions and services to the rest of New Zealand, which is its responsibility." Furthermore, "when I look back [...] what's been resilient about Te Papa", emphasises Sotheran, "it's that [bicultural] model". 
What would TP be without its bicultural partnership? The participants spoke of TP as 'just an ordinary museum' and more dramatically 'a monocultural shell'. Biculturalism is now so much part of all of TP but the highest management structures (e.g. TP Board) that it would require a major and very public restructuring process to remove it, and this would be against the overall national commitment to develop ongoing relationships and conversation with Māori. Therefore it would be counterproductive to the national imaging of Māori-Pākehā relations. Another reason that makes it very unlikely for TP to drop its bicultural commitment completely is the Museum's successful marriage with the TP brand. In terms of marketing, commercial outlets, tours and attracting overseas visitors, biculturalism is a big selling factor. Essentially, this museological concept that is translated into the staffing on the floor front-of-house as well as exhibition design, the range of products in the gift shops, the menu in the cafes and the events held for the public, such as Matariki, the Māori new year festival held every June, help TP generate revenue. Taking this innovative and distinctive component out of TP would leave a vacuum that could not easily be filled with something else.

However, almost all participants agreed that TP still has some way to go before it can proclaim to be 'truly bicultural'. The benchmark for some is making the CEO and Kaihautū positions completely equal structurally, whereas for others it is up-skilling non-Māori so they can help carry the 'bicultural load' that largely rests on Māori shoulders at the moment:

If we had one leader who did both jobs it would be even cooler because that would be to me true biculturalism. It's not just having two things side by side all the time, it's intertwining those two and respecting each side individually. That's what I would like to see happen [...] I still understand the need to have a Mãori representation but [...] if there wasn't a need to have Mãori representation because it was already there anyway that would be even cooler. (Māori woman)

Perhaps biculturalism is a historical stage of development, and as the Treaty's significance will change after Treaty settlements, NZ may become a very different place. Māori identity as well as identity politics and what is considered Māori culture is changing constantly (McCarthy/ Cobley 2009; Kukutai 2011; McIntosh 2005). Biculturalism can perhaps provide a framework for an ongoing conversation for a partnership between Māori and non-Māori, as well as Māori and the Crown that needs 
constant nurturing. However, other models have been proposed, including postbiculturalism (Durie 1994) and bi-nationalism (Fleras/Spoonley 1999; Rata 2005) which move beyond biculturalism towards a 'two sovereigns' or 'nation within a nation' model. Quests for tino rangatiratanga demand constitutional arrangements for a NZ society that takes Māori and the Treaty seriously (Maaka/Fleras 2005). Perhaps then a multicultural model (not to be confused with the old conservative multi-culturalism of the 1980s) that acknowledges the Treaty and an 'ongoing partnership' with Māori would be possible (Fleras/ Spoonley 1999:250).

Critiquing the 'us/them' dichotomy that biculturalism evokes in its binary, Paul Meredith (1998:1) promotes a "far more critical perspective of bicultural politics in New Zealand", which he stresses "must acknowledge and negotiate not only difference but also affinity". Thus Meredith (1998) proposes reinventing identity politics in NZ, drawing on Homi Bhabha's (1994) concepts of third space and hybridity which offer a multi-faceted and inclusionary approach. While intercultural dialogue does not necessarily result in hybridity, as Skinner remarks, in the process of engagement "your own sense of self is transformed" (McCarthy 2011:239). Bhabha's concepts are useful, because they imply constant change and fluidity. Biculturalism therefore should be imagined as a process not a goal, as Whiting stresses, "it has to be worked on all the time!" Thus, biculturalism at TP is best seen as a fluid, elusive, aspirational and interactional process rather than a solid base. At the end of the day, the bicultural environment that TP created is an artificial environment, where biculturalism is set up as an experiment; although the bicultural principles are prominent in the organisational structure, the partnership between Māori and Pākehā is an ideal that is very fragile in reality.

\section{Conclusion}

In this chapter I have discussed the cloud of imaginings that TP staff associate with biculturalism. Being exposed to an officially bicultural environment at TP results in staff trying to 'make meaning' of the concept and reaching some sort of understanding. While most staff were unaware of the academic discourse of biculturalism (except curatorial 
staff, some scholars and activists), their statements reflect the (sometimes contradictory) positions and aspirations of the bicultural discourse in NZ. Juxtaposition of academic views with findings from the ground revealed that biculturalism allows for various aspirations and political agendas, however, achieving them is limited by the organisational frame. Exploring staff's interpretations and struggle with biculturalism as well as the changes in policy and the quest for a new term, I have demonstrated that the bicultural concept is ambiguous and unsatisfactory for many.

TP staff (myself included) often struggle to capture biculturalism at the organisation: are pōwhiri a genuine bicultural expression, a concession to including Māori culture or a display of Māori power? Some non-Māori participants argued that the Māori activities are not enhancing the 'bicultural aspect' of the institution, on the contrary, they are making them "more aware of the 'other"'. Thus, they separate staff along the bicultural binary, rather than bridging cultural gaps and aiding the understanding of each others' cultures.

The persisting inequalities in TP's dual leadership reveal that TP has some way to go to become a 'truly bicultural' organisation. On the other hand, looking at the marae and how it is utilised by Māori as a zone to debate and enact Māori identity suggests that Māori claim it as their own space to exercise self-determination (despite some criticism of 'Pākehā-fying' Māori protocols). Although many staff are critical that TP is not walking the talk yet, compared with other organisations in NZ and museums overseas, on balance it is clear that TP was and still is a leader in fostering a partnership between Māori and the museum. Although TP's future in terms of the model that informs its practice is uncertain, studying the complexities of bicultural interactions and discourses within the microcosm of the museum is a valuable exercise, according to Ames (1986:36):

By studying museums in their social and historical settings we can study the making of culture in its concrete reality. [...] The challenging environment of modern museums provides opportunities for creative innovations in the theories and methods of anthropology. 


\section{Conclusion}

\section{Closing story: Seddon Bennington's tangi}

When CEO Bennington (thereafter Seddon ${ }^{185}$ ) died suddenly in 2009, his tangi was a powerful expression of biculturalism at TP and resulted in a deeper appreciation of Māori cultural values among staff. The fact that Seddon's tangi is still talked about on occasions five years later and that many staff who attended this sad event in TP's life still have the service order ${ }^{186}$ on their desks shows just how emotionally affected staff were. Carolyn Roberts-Thompson comments: "I think Seddon's passing had a huge impact on this organisation. [...], and that now is part of the historic fabric of this place." The following story about Seddon's tangi and funeral at TP is related through interviews conducted in this research to encapsulate the themes that have emerged: participation, appropriation, Pākehā paralysis, Māori dominance in exceptional circumstances, positioning through performance, sense of belonging, the creation of a 'Te Papa whānau' and the value of biculturalism within the organisational culture at TP.

After his tragic death, management considered it very important to bring the CEO back into the Museum to send him off 'the Mãori way' in order to give staff the opportunity to say goodbye and bring closure to the sudden loss, but also to give effect to biculturalism and follow Māori protocol:

One of the worst things that can happen to an organisation is a senior manager dying in situ as it were. It can be incredibly destabilising. So Seddon coming here, there was a chance for Te Papa to come together. (Sue Piper)

[Seddon was] our leader and this is our place and if anyone deserves and warrants to have a tangi on their marae, it's him and that's his marae and we need to make it happen. [...] I think that if we hadn't have been able to have him there, it would have destroyed many people and their belief in what this place is about, particularly around the expression of biculturalism and how it is enacted, how it's implemented across this beast of a place [...], because it was befitting. (Carolyn Roberts-Thompson)

\footnotetext{
185 I use Seddon Bennington's first name here, because he was referred to as Seddon by TP staff.
} ${ }^{186}$ A booklet with the programme of the funeral service and photos of the deceased. 
The differences in thoughts and feelings between new migrants, Pākehā and Māori staff at the Museum was immense, as these statements demonstrate:

He was the rangatira for Te Papa and not only does [having his tangi at TP] uplift his mana, but it uplifts the mana of Te Papa as well as a whānau, as iwi I suppose [...]. We all just pitched in as a whānau I think it was more than as part of my job, just because our rangatira, our CEO had passed away and so we all gathered together to pay our respects, like any other tangi. (Māori man)

My concern at the time was around the desire to go and get his body and I was like 'back off, let the family [deal with it first]!' There were three scenarios here: one, yes we have a tangi; two, we have a memorial without the body; three, that we have a more traditional Pākehà style memorial of some kind. (Pākehā woman)

He wasn't Mãori, his family wasn't Mãori, yet they have a tangi for him. Who knows if he would have wanted it? And that whole notion of "Seddon is coming home" - it was not his home, it was his work for goodness sake! (new migrant, woman)

Although it is not unheard of in NZ to have a tangi for a Pākehā who was respected by the Mãori community, the fact that Seddon's casket stayed on the marae overnight surrounded by some staff (not his family however) was somewhat extraordinary. ${ }^{187}$ However, the fact that very few non-Māori stayed the night reveals that a commitment to biculturalism is considered a Māori responsibility whereas Pākehā staff opt out quickly:

There's hundreds of people working in this organisation, but they weren't there! [..] The food for thought that it gave me, was that the commitment to biculturalism when the tough gets going is clearly the Māori staff demonstrate it and the Pākehā staff don't. I just thought there would have been more [people]. [...]I think that the events around Seddon's death demonstrated that the commitment to biculturalism in Te Papa is a bit shallow when it comes to a significant number of the staff [...] I'm a liberal and even sometimes this notion of biculturalism, it scares the pants off me too! (Sue Piper)

In the time of grieving, Māori staff took the lead and created an environment of unity, that many participants called fondly 'Te Papa whānau':

I mean we're a family here. [...] It's one of the most humbling experiences, because you know (chooses words very carefully) that you're in this amazing organisation that has awhi and aroha at its heart. [...] I don't know if that would happen at a non-bicultural organisation. (Pākehā woman)

187 When Roger Duff, director of the Canterbury Museum in Christchurch, passed away in 1978 his body lay in state in the museum in a similar fashion (Conal McCarthy, personal communication 7 January 2013). 
The TP hosts performed a spontaneous haka for their rangatira at TP's main entrance, when Seddon's casket was carried out to the waiting hearse. Standing at the exit one Māori woman said to her Pākehā colleague "If they don't get the bicultural thing at Te Papa today, they'll never get it!"

\section{Concluding Comments}

The aim of this thesis was to explore how biculturalism works behind the scenes at TP. Asking how biculturalism affects TP staff and how they enacted it in diverse Museum spaces, how they position themselves within the framework through organisational rituals and whether or not TP is walking the talk, I set out to reveal the inner workings of a national museum in an avowedly bicultural nation. This thesis has shed light on the dynamics of biculturalism in practice within an organisation and revealed how staff enact the museum's bicultural concept in their day-to-day work through interacting with each other. By 'living with' 18 different teams for a year and working at TP over seven years I have tried to gain an insider's perspective and understand the opportunities and challenges that a bicultural framework entails; or in other words, make sense of the 'messiness' and complexities of biculturalism in a museum context.

Being mindful that TP's institutional culture depends on local and historical circumstances as well as personalities and projects, I believe that this in-depth study of the organisational culture of a bicultural museum can be a useful lesson for other museums or cultural institutions in NZ and overseas. The thesis makes a contribution to the anthropology of organisations as well as the field of museum studies and bicultural literature in NZ by addressing the gap in the research on biculturalism on the ground. The value of this ethnography lies in looking across and beyond TP as an exhibition space that mirrors NZ society, instead dissecting TP as a living entity that is the sum of diverse groups of people working together under a bicultural umbrella.

What happens behind the scenes at TP is an exemplary case study of the problem of applying the bicultural concept in organisational practice: biculturalism is thus best seen as a process rather than a result, a journey with an unknown destination, which is 
constantly negotiated, reworked and reimagined. The notion of biculturalism is not as black and white as the common academic critique of TP suggests. While the concept implies a dichotomy between Māori and Pākehā, my findings stress that it is more nuanced; there are very 'politicised' Pākehā as well as 'uncritical' Māori. Thus, understandings of biculturalism is more a matter of whether people are aware of the academic discourse and whether they are sensitised to the Māori quest for selfdetermination, than a question of ethnicity. In future, we need more in-depth studies of organisations like this thesis, where researchers immerse themselves long-term, rather than shallow criticisms of TP that focus on museum products, processes and formal selfrepresentations. Instead, further studies should look at everyday cultural practices and performances.

The thesis structure has reflected my own journey through TP in many regards; not only did I experience the Māori activities before I had much understanding of biculturalism, but I also underwent the 'TP cycle', like so many participants: I had a very positive - certainly naive - first impression of biculturalism as harmonious co-existence, but when I began participating I was confronted with the sometimes ugly 'power games' back-of-house at the Museum, thus my view became more and more negative and cynical, fuelled by all the criticisms I heard constantly from insiders. After leaving the field, I had to revise this negative image, as it dawned on me how exceptional TP really was - despite its many shortcomings - when I visited museums elsewhere and saw museum professionals' eyes light up when I mentioned TP. Now, I am much more critical towards the concept of biculturalism as state-prescribed ideology, yet full of admiration for staff at TP taking the concept further, pursuing their own agendas (including Māori empowerment or advancing their skills), growing to understand 'the other'. Regardless of the setbacks, they continue to walk the high rope of biculturalism with resilience. The international interest in TP remains undiminished as I have observed assisting with several visits of high-profile museum practitioners, academics and 'celebritities' to the national museum. In March 2013 alone there were delegations from Chile, Myanmar, USA, an Aboriginal delegation from Australia and three delegations from Germany, including representatives of the prestigious HumboldtForum. 
It is all too understandable that staff, who are bogged down in their busy schedules and tight deadlines, do not have time to reflect on the values of biculturalism, seeing it through the lens of the continuous struggle in their work lives. By making transparent the (sometimes unconscious) boundaries to participation for individuals, for example attendance at waiata sessions, but also the organisational decision-making processes that are obscure to many staff, such as the justifications for displaying human remains, I brought the underlying anxieties, misunderstandings and political agendas into the light. I hope that through my contribution museum professionals will be alerted to the unique opportunity a bicultural framework creates and how profoundly it can affect people's lives. In March 2013, I took a group of German academics on a back-of-house tour through the Māori collection at TP where they received a traditional welcome (mihi whakatau) by the Māori elders. Even though the ritual only lasted about 20 minutes the participants commented that they had been touched in a way they had never thought possible before. For me, it was moments such as this ,when I 'felt' biculturalism rather than tried to analyse it, that I realised how Māori rituals can sometimes affect people emotionally, creating a contact zone for in-depth dialogues and encounters right in front of your eyes.

This thesis shows the value of Māori rituals within TP on different levels: for new staff to connect with their colleagues and feel part of the institution (chapter two), for Māori staff to express their identity in the workplace (chapter three), as a means of healing frictions (chapter four), to understand biculturalism on a deeper level (chapter five), and lastly, to provide an outlet for grief and strengthen group cohesion in times of crisis (closing story). In my opinion, Māori rituals are much more than 'staged shows', they are powerful instruments to build Māori unity through participation, displays of power through performance, demonstrations of resistances against colonial suppression, and a strategic means to sensitise and awe non-Māori.

Chapter one demonstrated that TP was constructed as a bicultural experiment to express NZ's increasingly bicultural political agenda and a place to celebrate diversity while still holding on to the Western idea of a museum. TP's commitment to 
biculturalism was a logical response to the social and political climate of the 1980s in NZ, heralding the 'Māori renaissance' and a new era for the relationship of Māori and museums that began with the Te Mãori exhibition. An exceptional situation created a holistic bicultural institution in a new building where biculturalism is 'breathed' in every facet from architecture to governance, from policy to practice, from top to bottom; yet some organisational structures became hurdles which limited the bicultural relationship and Māori power (such as the Board, dual leadership), and created issues that are still not resolved today (such as who is in charge of the marae). Overall, I argued that the development of TP as a bicultural institution was an experiment for NZ society or as Sotheran stated "a glimpse of what New Zealand could be".

TP's attempts to raise bicultural awareness among staff through te reo classes, waiata sessions and taonga pūoro practice are viewed ambivalently by staff, as I explained in chapter two. Staff's hesitant uptake of these opportunities and some managers' cynicism suggest that there is uncertainty of the usefulness and importance of Māori activities. Although these classes could be catalysts for social inclusion, Pākehā staff perceive them as quite the opposite: exclusive clubs with obscure initiation of some privileged, predominantly Māori staff. In contrast, Māori staff feel obliged to attend the practices to 'tautoko the kaupapa' and complain about having to bear the burden without much Pākehā support. Access to and participation in the Māori activities are sometimes obscure, thus only a small percentage of staff (mainly Māori or staff from overseas) participate, with the exception of the te reo Māori classes which I argue are a 'Pākehā production' run by a Pākehā teacher. Management largely fails to acknowledge the Māori activities as an important part of their staff's work, degrading the activities to the realm of voluntary, 'just-for-fun' options. However, I argued that observing, and better even, actively participating in the Māori activities and rituals is crucial for staff to feel and experience biculturalism on an emotional and spiritual level; this can mark the beginning of a profound transformation into biculturally competent beings.

In chapter three, my findings suggested that although biculturalism is supposed to be evident throughout the organisation, it is stronger in some teams than others. The simplified formula goes like this: the more Māori staff, exposure to Māori stakeholders 
or Māori content and contact with audiences, the more bicultural the team.

Paradoxically, the teams consisting of only Māori staff are the most bicultural in the way they work, yet per definition are monocultural. The assumption that biculturalism filters through from top management to the ground has not been confirmed. Rather the bicultural efforts at TP are grounded in practice and often bottom-up rather than topdown. Although it is important that management 'walks the talk' for their employees' buy-in, some of the best examples of 'living biculturalism' are found in the lower ranks, e.g. Education team. In the day-to-day operation I found little evidence for biculturalism, Māori greetings and sharing kai being two exceptions. Not only do staff have little time for thinking about the overarching ideology, but they are also largely oblivious of academic discourse - except scholars at TP - and most struggle with what biculturalism means. Social rituals are an instrument to enforce bicultural behaviour in staff and manifest the 'Te Papa culture' and the 'Te Papa whānau' through narrating stories, but Māori staff also utilise them to form their identity and uphold their status within TP.

In chapter four, I demonstrated that biculturalism can mediate between cultures (Case Study: Conservator Nirmala Balram) as well as widen the cultural gap (Māori collection and $E B T$ ) between Māori and Western perspectives. With a bicultural concept that allows for different but equally valid world views under the roof of one institution, conflicts surface when cultural beliefs are incompatible. My analysis of the cultural clash over the issue of 'banning' pregnant and menstruating women from the Māori collection room revealed two agendas: on the one hand Māori attempts to protect tikanga and constitute power, on the other the media's attack on 'archaic' Māori customs which fuels the racial divide, and at the same time strengthens a national Pākehā identity by portraying Māori as the 'barbaric other'. The display of human remains in EBT suggests that a bicultural framework has the potential to split an organisation when one partner feels disrespected and threatens the other with 'divorce'. Moreover, the social drama that unfolded over the display of the mummy Keku highlighted three points; firstly, that TP as a museum for all New Zealanders in a public neoliberal environment must reconcile several, sometimes contradictory mandates (such as acknowledge Māori as tangata whenua and be commercially positive); secondly, it showed that the final decision was made by the TP Board by majority vote simply overriding the Māori 
minority; and thirdly, that despite the Māori opposition to the mummy, Māori rituals were utilised as a remedy to heal the frictions. This chapter revealed the limits of the Māori voice within the Western institution of a museum as well as the limits of biculturalism: although Māori are an integral part of the ceremonial life at TP, financial parameters outweigh cultural ones and, ultimately, Pākehā hegemony prevails. This underlined the mainly symbolic power of Māori within the 'bicultural bubble' at TP, which bursts under pressures from the dominant culture outside.

Chapter five illustrated that staff still struggle with understanding biculturalism. The research showed the ambiguous ideas many still have on this topic, resulting in a plethora of 'imaginings'. Although the vagueness of the term biculturalism creates space for a great variety of valid understandings that can be attached to it, it also fuels misconceptions and a silent uncomfortableness. TP falls somewhat short of the 'forum of the nation' it claims to be, at least behind the scenes. My observation - that biculturalism is hardly ever talked about at TP - can be interpreted in two ways. Firstly, I suggest that many staff - particularly staff who have been in the organisation for a long time - take biculturalism for granted and have made themselves comfortable within this framework. Secondly, new staff members avoid the topic out of fear of revealing their ignorance. My analysis of the imbalances in the dual leadership of TP reveals that the bicultural partnership lacks equal power-sharing and has therefore not yet reached the 'hard' end of the bicultural continuum. Despite some criticism that TP pays lip-service to a truly bicultural partnership or that a 'national bicultural museum' is a contradiction in terms, as it still represents a museum and inevitably a Western idea (Peter Adds, discussion at "Representation, Reconciliation and Indigeneity" conference 23 March 2013, Victoria University of Wellington), I have found an organisation that tries very hard to incorporate bicultural principles and make space for cross-cultural encounters. Compared with other organisations, which claim to be bicultural, TP comes out on top according to the interviewees, and working at TP often contributes to a mindset that Sean Mallon calls ‘bicultural fluency’ (Mallon 2011:252). 


\section{Te Papa - A Contact Zone?}

At the time TP was conceived it was necessary to formulate biculturalism in policy but, 15 years on, the 'sacred' policies have become mere guidelines that are applied or altered on a case-by-case basis. In 2008, management felt that a dedicated bicultural development team was no longer needed as the 'bicultural police'. As I have argued this assumption might have been wrong as the disestablishment left a vacuum for "bicultural ignorance' to florish that made it difficult to sustain organisational practices, especially with a high staff turn over and new staff lacking the institutional knowledge. Slackening the reins is seen as appropriate now that TP has 'grown up', but it should not be overlooked that at the same time it weakens the bicultural policy and makes space for other philosophies. Biculturalism is a 'messy business' and challenges an organisation on an intellectual level as well as in practical terms. Not only is the term biculturalism unsatisfactory for many but it also makes museum practice much more complicated and time-consuming: just imagine having to consult 'the other side' of the bicultural partnership before any decision can be made. So why should TP be bicultural?

This thesis stressed that biculturalism promotes close and personal encounters and relationships between staff of different ethnicities at work. Therefore I argued that behind the scenes the museum is indeed a 'contact zone' in James Clifford's sense as Pākehā (the colonisers) and Māori (the colonised) work together and have meaningful encounters they might not have otherwise. The unity across the organisation often referred to as the 'Te Papa whānau' is a strength that can be observed in times of crisis, a safety net staff can fall back on. The Māori values of manaakitanga and whanaungatanga shape the interpersonal relationships between staff and make for a supportive and mostly friendly work environment where people are supposedly acknowledged for who they are, not just their professional rank. These Māori concepts have transformational powers for the organisation and the individual. The tragic death of CEO Seddon Bennington and his funeral held on Te Marae will be remembered for the 'bicultural' spirit it sparked throughout the organisation. Most importantly, biculturalism enriches the workplace culture and the staff experience - at least for Pākehā - and empowers Māori staff by giving them a voice and a place to stand. Therefore, I argue that biculturalism is a necessary phase on the journey moving away 
from monocultural institutions towards indigenous empowerment, a journey bound ultimately for Māori self-determination.

Seeing the museum as a "safe place for unsafe ideas" (Gurian 2006a:99; 2006b:12), TP has been an ideal location for the 'experiment' of advancing race relations based on Treaty principles. Does TP walk the talk? I agree with the participants who think that TP is quite advanced on the bicultural continuum, yet I hope it progresses further in order to become truly bicultural. However, I believe that TP's commitment to biculturalism makes it a more dynamic and inclusive Museum and workplace. Studying the impact of biculturalism on the microcosm that is TP might have implications for other organisations or museums worldwide thinking of adopting a bicultural framework or establishing collaborations with indigenous peoples or ethnic minorities. It is unfortunate and misleading that the term biculturalism suggests a Māori/ Pākehā divide that many think excludes all other cultures and should therefore be replaced with multiculturalism, when indeed biculturalism includes all New Zealanders while acknowledging Māori as the indigenous people and honouring the Treaty. Perhaps a new terminology might help resolve this misunderstanding. The mana taonga principle offers a blueprint for managing relationships with diverse source communities and the museum. However, despite its Māori name, it might have negative consequences for Māori, as it challenges the strong position Māori hold within TP in the bicultural framework and might level their influence to minority rights, rather than advancing their striving for self-determination.

\section{Te Papa - A Space for Māori Empowerment?}

Throughout this thesis I have illustrated under what circumstances Māori values and rituals are accepted within TP and I concluded that the occurrence of extraordinary events outside of the norm bring bicultural principles and Māori tikanga to the fore, e.g. when rituals are performed on the marae or when a staff member has passed away. It seems TP sees these out-of-the-ordinary situations as the rightful place for Māori culture within TP, and Māori staff accept dealing with them according to tikanga Māori. In contrast, in the arena of day-to-day operations within the office spaces, Māori culture 
is largely invisible or not utilised as most teams follow a Western business model to operate the Museum in a manner indistinguishable from other organisations. To include a Māori perspective is a voluntary option for most staff that I observed, an add-on not a requirement, and therefore is often shifted to certain places like the Māori collection room, the marae and linked to times such as lunch-time rituals or staff anniversaries. Within these domains a reversal of the norm can be observed: hierarchical ranks are overridden by kinship relationships and social status within the Māori world becomes the point of reference, Māori tikanga is used to set the rules, showing emotions is encouraged, and the collective replaces the individual's interest. Drawing on Goffman's front stage/ back stage model, I suggest that at TP there are two stages: a 'Pākehā stage' and a 'Māori stage', co-existing simultaneously. Yet, these stages are largely separate and do not overlap much, creating a parallel model.

Box 19: Biculturalism at TP as Pākehā stage and Māori stage

\begin{tabular}{|l|l|l|}
\hline & Pākehā stage & Māori stage \\
\hline events & ordinary & extraordinary, special \\
\hline physical space & offices, labs & Māori collection, marae \\
\hline situation & day-to-day operation & special events \\
\hline mode & rational, secular & emotional, spiritual \\
\hline time & during work hours & $\begin{array}{l}\text { often outside work hours, lunch } \\
\text { time }\end{array}$ \\
\hline work & paid & voluntary, often unpaid \\
\hline hierarchy & organisational hierarchy & kinship relationships, mana \\
\hline organising principle & rank & social status \\
\hline interest & individual & collective \\
\hline behavior & not-ritualised & ritualised \\
\hline belief system & Western, European thinking & mātauranga Māori \\
\hline
\end{tabular}

This dichotomy is grounded in the bicultural model and seems to push Māori and nonMāori staff apart, rather than bring them closer together. Nevertheless, by having these two parallel worlds co-exist at TP, staff are exposed to world views that are different to their own, which aids their transformation into bicultural beings. Thus, I propose that TP is neither a perfect exemplar of a bicultural museum nor a bicultural failure as a whole, but a Western museum, which within its building provides stages for performing Pākehā and Māori culture. Rather than seeing TP as one bicultural entity, I see biculturalism acted out there on multiple stages. Almost presenting a 'bicultural fair' with simultaneous stages and performances, TP - especially behind the scenes - is 
much more diverse and complex than what has been reflected by academics arguing TP is a state beacon of biculturalism or a mere symbol of it. This emphasises the value of ethnographic fieldwork in museums, resulting in understandings that are significantly more in-depth than 'reading-off' exhibition displays or policy documents.

If TP was a theatre, then biculturalism is the play that is performed on several stages with an ever changing cast and crew who switch roles with performing and observing, yet all participants are somehow transformed by participating in the production. Although for me the concept of biculturalism is problematic with its tendencies of appropriating Māori culture, mainstreaming it and ultimately preventing selfdetermination, I see its potential as bridging a liminal phase in NZ's journey moving towards a post-Treaty arrangement. At TP the bicultural concept enables Māori to express themselves, advance their skills and goals, while non-Māori benefit from the challenges of collaborating with Māori and re-thinking their Western world view. Māori grow stronger within this framework, whereas non-Māori are confronted with the 'indigenous other', which results in alienation and/or appreciation for Māori culture. This means TP's role within the nation is that of a contact zone where Māori and nonMāori can interact in a safe environment and create pockets that are bicultural (such as the Education team or the taonga pūoro group) as well as Māori domains (such as the Māori collection rooms or karanga workshops) which could become the seedbed or nucleus for tino rangatiratanga. As a whole I view TP as a contact zone for staff, yet in my study I found that within this one contact zone several smaller contact zones are at play, acted out in pōwhiri and Māori activities but also in the everyday encounters between Māori and non-Māori staff. These contact zones can be arranged on a bicultural continuum, taking into consideration their script, stage manager and actors.

Box 20: Contact zones within TP

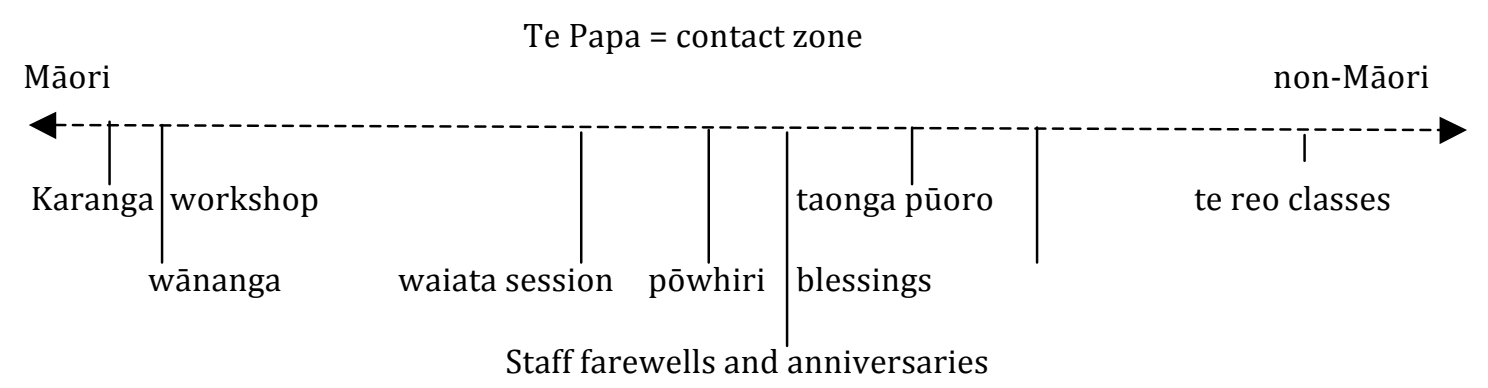


The importance of Te Marae as a physical space for belonging, showcasing Māori rituals and organisational rituals of encounter cannot be over-emphasised, as it has significant implications for revitalising Māori culture as well as educating non-Māori. Having a dedicated space is conditional to making these rituals happen, and in turn the rituals create spaces and help revitalise Māori culture and affirm its strong and powerful position at TP and beyond. However, certain occasions also call for rituals and the 'invention of tradition', including a staged wedding or baptism ceremonies arranged by Māori elders. The - sometimes involuntary - protagonists and participants have a special bond to TP that goes far beyond an employment relationship and consequently affirms their sense of belonging to TP.

Biculturalism, as the case study of TP shows, is much more complex and 'muddy' than academic discourse suggests. Academic critiques fall short in describing TP in all its facets, as they are not grounded in museum or organisational practice, whereas museum professionals tend to not see the bigger picture in which TP and bicultural discourse are embedded, or gloss over frictions in order to appear loyal to the organisation. My study contributes a more refined and nuanced view to the literature on biculturalism, thus adding a valuable perspective to museum studies by providing an ethnographical insight into TP using anthropological frameworks to interpret the internal encounters and conflicts. Biculturalism in my eyes is not a state but a process that needs constant debate and negotiation, because the moment we proclaim 'we are bicultural' is probably the moment when the concept collapses.

This study has been limited by the areas of TP that I was not allowed to access because of confidentiality issues (e.g. the Leadership team or Board meetings) and cultural issues (e.g. karanga and whaikōrero workshops for Māori staff). I am also aware that as a German woman I was often perceived as an outsider and that my view was biased by those markers; a male or Māori researcher certainly would have provoked different reactions and drawn different conclusions. Nevertheless, the significance of this research lies in overcoming the initial hurdles and immersing myself in both the Pākehā 
and Māori world at TP as much as possible, perhaps having an advantage in being neither 'the coloniser' nor the 'colonised' but an empathetic foreigner.

I hope that this thesis about a particular museum, at a particular moment in time, in a far away corner of the world is useful not only for TP staff, who seldom have the time to stand still and reflect upon their everyday practices, but also other museums and organisations in other parts of the world, where redressive action is sought to heal historical injustices and the wounds of colonisation. I argue that TP provides a farreaching model of biculturalism in action; despite its limitations I believe that adopting a bicultural framework has the potential to turn an organisation or museum into a contact zone. This ethnography provides an in-depth understanding of Māori/nonMāori relations at TP, contributing an anthropological analysis of organisational culture within a museum to the fields of museum studies, anthropology of organisations, intercultural communication and studies of cultural politics and identity in NZ. I believe that the lessons learned will be valuable for academics and museum professionals and help advance genuine collaborations of indigenous and non-indigenous people in museums in NZ and overseas. If others picked up the strands of my research and continued to weave the cloak of biculturalism at TP, a taonga could come out of this kaupapa. I would like to end with a whakatāuki (Museum of New Zealand Te Papa Tongarewa 2012):

E kore e taea e te whenu kotahi ki te raranga ki te whāriki, kia mōhio ai tātou ki a tātou. Mā te mahi tahi o ngā whenu. Mā te mahi tahi o ngā kairaranga, ka oti tēnei whāriki.

I te otinga, me titiro tātou ki ngā pai ka puta mai. $\bar{A}$ tana wā hoki, titiro ki ngā raranga kua makere. Nā te mea, ne kōrero anō kei reira.
The tapestry of understanding cannot be woven by just one strand alone. It takes the working together of strands, the working together of weavers to complete such a tapestry. When it is complete let us look at the good that comes from it. In time, look at those dropped stitches, for there is a message there also. 


\section{Epilogue}

What will the future for biculturalism at TP hold? Under CEO Michael Houlihan TP has profoundly changed its shape and structure. A major restructuring resulted in staff redundancies but also the split into two museums, the 'museum of living cultures' and the 'museum of the future'; a matrix structure was introduced to ensure staff are working across teams, and office spaces were reshuffled to give emphasis to the new way of working together. But what will those changes mean for the relationship of Māori and non-Māori in the museum and the future of biculturalism? Will the favoured term, mana taonga principle, resolve the perceived exclusivity of biculturalism or undermine Māori control? Will breaking up teams really break up 'silos' or destroy whānau structures and diminish Māori unity? Is a new organisation chart that shows the CEO clearly superior to the Kaihautū just giving effect to the status quo or a major caesura and turning point to the spirit of equal partners in a bicultural partnership? Future research is needed to document these changes and see how they shape the meaning of biculturalism and the future of Māori-Pākehā relationships in the Museum. 


\section{Glossary}

ahuatanga

Ahuru Mōwai

Aotearoa

aroha

ata mārie

ātea

atua

E toru ngā mea

ea

haka

haka pōwhiri

hākari

hāngī

hapū

harakeke

Hinetitama

hongi

hui

ihonui

iwi

kai

kaiako

Kaihautū

kaimoana flexibility

name of TP's collection store room for large carvings; literally: calm, settled

North Island, whole of New Zealand

love, respect, pity, passion, show approval

good morning

space, clear, untrammelled, blank

god, supernatural being, guardian or spiritual powers of the natural world

name of a waiata/ song, (see dedication of this thesis)

paid for, avenged, done

posture dance

welcome haka - ceremonial dance performed to welcome visitors. Sometimes leaves are waved by the performers as a symbol of death.

feast; gift

earth oven, food from earth oven

extended family group, subtribe or section of a large tribe; pregnancy

native flax plant, Phormium tenax

meeting room at TP named after a mythical figure, daughter of Tāne and Hineahuone

salute or greet by pressing noses together, sharing breath

gather, meeting, appointment, seminar, conference

corner and floor space on the right on entering a wharenui; at TP name for 'the Void' or core of the building

tribe, race, people, nation, strength; bones

food, eat, dine, nutrient

teacher

Māori director at TP; leader, representative, controller, steersman, host seafood 
kaitiaki

kākahu

ka kite

kānga pirau

kapa haka

kapu tī

karakia

karakia whakawātea

karanga

Karanga Aotearoa

kaupapa

kaupapa Māori

kaumātua/ iwi kaumātua

kawa (marae)

kei te pēhea koe?

kete

kia ora

'ko Tū a waho, ko Rongo a roto'

kōauau

koha

Kōhanga Reo

kōiwi (tangata)

kōrero

korowai

kuia

kūmara guard, caretaker; Māori museum staff caring for taonga (literally 'one who cares')

cloak/s, garnment, clothes

see you later

fermented corn

group performing Māori action songs

literally: 'cup of tea', refreshments and snacks after pōwhiri (to remove tapu)

prayer, chant, incantation

prayer to remove tapu so that English can be spoken at pōwhiri

call of welcome to visitor in pōwhiri ceremony

Team for Repatriation of human remains at TP;

literally: 'calling back to $\mathrm{NZ}$ '

plan, proposal, policy, reason; philosophy

modern term referring to Māori-driven project or issue, self-determination

old man, elder; iwi representatives for duration of iwi exhibition at TP

marae protocol, custom of a particular marae

how are you?

flax basket

hello; cheers, thank you; literally: 'be well'

'god of war outside, god of peace inside' (Māori saying regarding marae protocol)

cross-blown flute - smaller than a pūtōrino, this instrument was traditionally made of wood, bone or a species of kelp.

present, donation, contribution; gift given at pōwhiri

Māori language pre-schools

human bone(s) or skeletal remains

say, speak, talk, conversation, story

cloak for chief ornamented with black tassles

female Māori elder who accompany the iwi exhibition at TP; old lady, matron

sweet potatoe, Ipomoea batatas 
Kupe

Kura Pounamu

Kura Kaupapa Māori

mahau

mana

manaakitanga

mana taonga

Mana Whenua

manuhiri

Māori

Māoritanga

marae

marae ātea

Matariki

mātauranga

mātauranga Māori

Māui

mauri

mihi

mihi whakatau

mihimihi

moana according to Māori narratives Kupe was the first Polynesian to discover NZ

name of exhibition at TP (see Appendix 9); meaning 'school of greenstone'

Māori-language school

porch of the marae, neutral space where women are allowed to speak

integrity, charisma, prestige, formal, status, jurisdiction, power, control, authority; closely related to tapu

hospitality, kindness

prestige, authority and responsibility associated with the possession of taonga (treasures); principle that influences museum practices at TP

exhibition at TP (see Appendix 9); Māori concept: the power and responsibility arising from the possession of lands

guest, visitor (as opposed to tangata whenua)

person of Māori descent, indigenous to NZ; ordinary, natural, fresh (water), native people

Māori culture, practices and beliefs

courtyard - the open area in front of the wharenui, where formal greetings and discussions take place. Often also used to include the complex of buildings around the marae.

courtyard, public forum - open area in front of the wharenui where formal welcomes to visitors takes place and issues are debated. The marae àtea is the domain of Tūmatauenga, the atua of war and people, and is thus the appropriate place to raise contentious issues.

Pleiades, The Seven Sisters - an open cluster of many stars in the constellation Taurus, with at least six stars visible to the naked eye. The brightest star is aso known as Matariki (Alcyone). First appearance before sunrise of Matariki in the north-eastern sky indicates the beginning of the Māori year - about the middle of June

knowledge

modern term referring to the Māori system of knowledge or world view wonderboy of legend

spark of life, essence of life

greet, admire, respect, congratulate, sigh for, acknowledge

short welcome ceremony at TP; speech of greeting

speech of greetings, tribute

sea, ocean, large lake 
moe

mokamokai

moko

mokopuna

mōrena

motu

Ngā Kākahu

Ngā Tamatoa

ngā tikanga rua

Ngā Whetū Ririki

Ngāi Tahu

Ngāti Kahungunu

Ngāti Pōneke

Ngāti Porou

Ngāti Whātua

noa

noho marae

pā

paepae

Pākehā

Papatūānuku

pō mārie

pōwhiri/ pōhiri

pūhā

pūkaea sleep

dried human head often tattooed, now often referred to as toi moko

Māori tattooing designs on the face or body

grandchild (also: moko)

good morning

literally 'island', but used as a synonym for NZ

exhibition at TP (see Appendix 9); cloaks

'The Young Warriors', Māori activist group founded in 1971

biculturalism; literally: two protocols

informal network of Māori staff at TP, also recruits TP's kapa haka competition group

Māori tribe on the South Island

tribal group of the southern North Island east of the ranges from the area of Nūhaka and Wairoa to southern Wairarapa; women of mana perform whaikōrero (usually only performed by men)

A pan-tribal, urban Māori network in Wellington (Port Nicholson) that was formed in 1937 as the 'Ngāti Pōneke Young Māori Club'

tribal group of East Coast area north of Gisborne to Tihirau; women of mana perform whaikōrero (usually only performed by men)

Māori tribe located from Kaipara to Tāmaki-makau-rau (Northland to Auckland)

free from tapu, 'ordinary, normal, safe (balance, neutrality, Mead 2003)

staying at a marae overnight

fortified village, fort

line of kaumātua at welcome ceremony; orator's bench, panel, threshold

non-Māori, European, Caucasian; as opposed to Māori

mother earth and wife of Ranginui. All living things originate from them.

good bye, good night

welcome ceremony on a marae

prickly sow thistle, sonchus; when cooked it is a spinach-like Māori delicacy

a long trumpet made of wood and bound with vine 


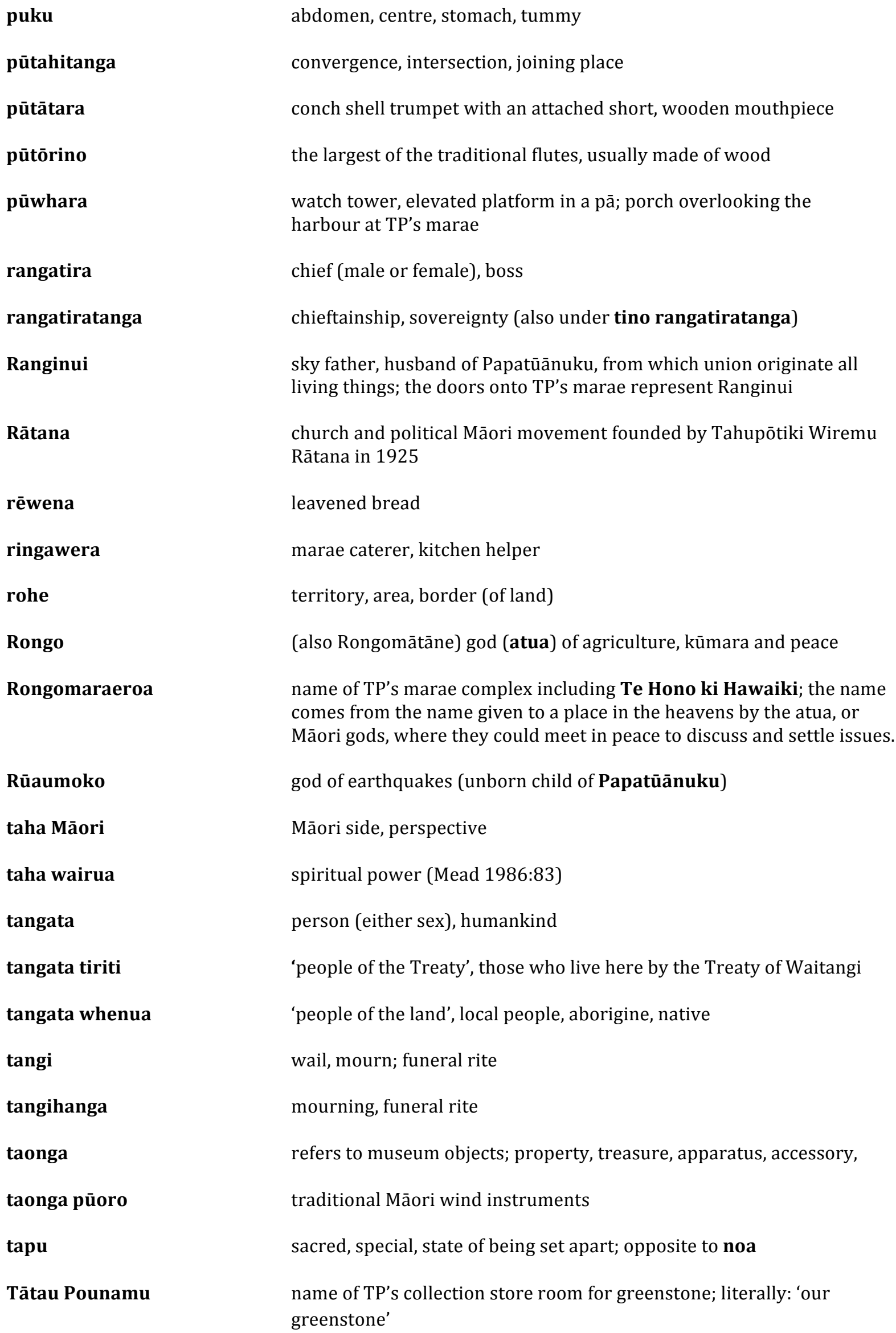

Tātau Pounamu

convergence, intersection, joining place

conch shell trumpet with an attached short, wooden mouthpiece the largest of the traditional flutes, usually made of wood watch tower, elevated platform in a pā; porch overlooking the harbour at TP's marae

chief (male or female), boss

chieftainship, sovereignty (also under tino rangatiratanga)

sky father, husband of Papatūānuku, from which union originate all living things; the doors onto TP's marae represent Ranginui

church and political Māori movement founded by Tahupōtiki Wiremu Rātana in 1925

leavened bread

marae caterer, kitchen helper

territory, area, border (of land)

(also Rongomātāne) god (atua) of agriculture, kūmara and peace

name of TP's marae complex including Te Hono ki Hawaiki; the name comes from the name given to a place in the heavens by the atua, or Māori gods, where they could meet in peace to discuss and settle issues.

god of earthquakes (unborn child of Papatūānuku)

Māori side, perspective

spiritual power (Mead 1986:83)

person (either sex), humankind

'people of the Treaty', those who live here by the Treaty of Waitangi

'people of the land', local people, aborigine, native

wail, mourn; funeral rite

mourning, funeral rite

refers to museum objects; property, treasure, apparatus, accessory,

traditional Māori wind instruments

sacred, special, state of being set apart; opposite to noa

name of TP's collection store room for greenstone; literally: 'our greenstone' 
'tautoko the kaupapa'

te ao Māori

Te Ara a Hine

Te Ataarangi

Te Āti Awa

Te Hono ki Hawaiki

'te iwi kotahi tātau'

'te iwi kāinga o Te Papa'

Te Māngai

Te Marae

tēnā koe

Te Papa

Te Puni Kōkiri

te reo Māori

Te Roopu Whakamana Māori

Te Wānanga o Raukawa

Te Whare Pora o Hine te Iwaiwa

tikanga

tikanga Māori

tikanga taonga

tino rangatiratanga

tipuna

tohunga to support a philosophy or 'good cause'

the Māori world

gateway at TP to the marae, walkway for women

a revitalisation of the Māori language movement that developed a particular teaching style which is offered around NZ, including at TP, providing a safe, oral-based learning environment

iwi located in the Taranaki and Wellington region

name of TP's modern meeting house, 'Link to Hawaiki' (the ancestral home of Māori)

'we are one iwi' (contested notion of Māori being a homogenous group)

local people, host; home crowd of TP

Tahupōtiki Wiremu Rātana (founder of the Rātana church) referred to himself as 'the mouth piece' (Te Māngai) of god

refers to the exhibition and space at TP that includes the marae complex greeting or acknowledging one person directly; thank you

an abbreviation of 'Te Papa Tongarewa', literally meaning 'container of treasures'

Ministry for Māori Development

the Māori language

name of bicultural team at TP; literally: group for enhancing Māoritanga

Māori-run tertiary education institute in Ōtaki opened in 1981

name of TP's collection store room for weaving; literally: the house of the goddess of weaving

meaning, custom, obligations and conditions (legal), provisions (legal), criterion, convention, protocol

Māori custom or protocol

customary Māori cultural practices employed in caring for taonga in museum collections, Māori collection care

phrase in the Māori text of the Treaty meaning absolute chieftainship or authority; today generally refers to the aspiration for Māori selfdetermination

ancestor, grandparent (see also tupuna)

expert, specialist, priest, artist 
toi moko

Tongarewa

Tūhoe

Tūmatauenga

tūpāpaku

tupuna

tūrangawaewae

urupā

utu

waharoa

wāhi tapu

waiata

wai māori

wairua

waka

waka tūpāpaku

wānanga

whaikōrero

whakanoa

whakapapa

whakataukī

whānau

whanaungatanga

whare

wharenui

whenua

whare tapere tattooed preserved human head

variety of greenstone, something precious

Māori tribe located in the isolated Urewera ranges in the central eastern North Island, who did not sign the Treaty and are known for their resistance

god (atua) of war and people

corpse, cadaver

(pl. tūpuna) ancestor, grandparent (see also tipuna)

a place to stand

cemetery, burial ground, tomb

compensation, revenge

gateway to pā or marae

special repositories for human remains; cemetery, reserved ground

sing, chant, song

blessed water, placed outside rooms where taonga is stored in museums and used to remove tapu

soul, spirit, spirituality

canoe, vessel or container

burial chest for bones and human remains

learning, seminar, series of discussions

oration, formal speech

tapu-reducing ritual

genealogy, cultural identity, family tree, recite genealogy

proverb, saying

extended family; delivery, give birth

relationship, kinship group dynamics

house

meeting house, large house - main building of a marae where guests are accommodated

land; placenta

house of amusement, theatre (arts), community centre 


\section{Appendix 1: Floor Maps of TP}

(source: n.d. Te Papa Pamphlet 'Map'; collected January 2014)

\section{Level 1}

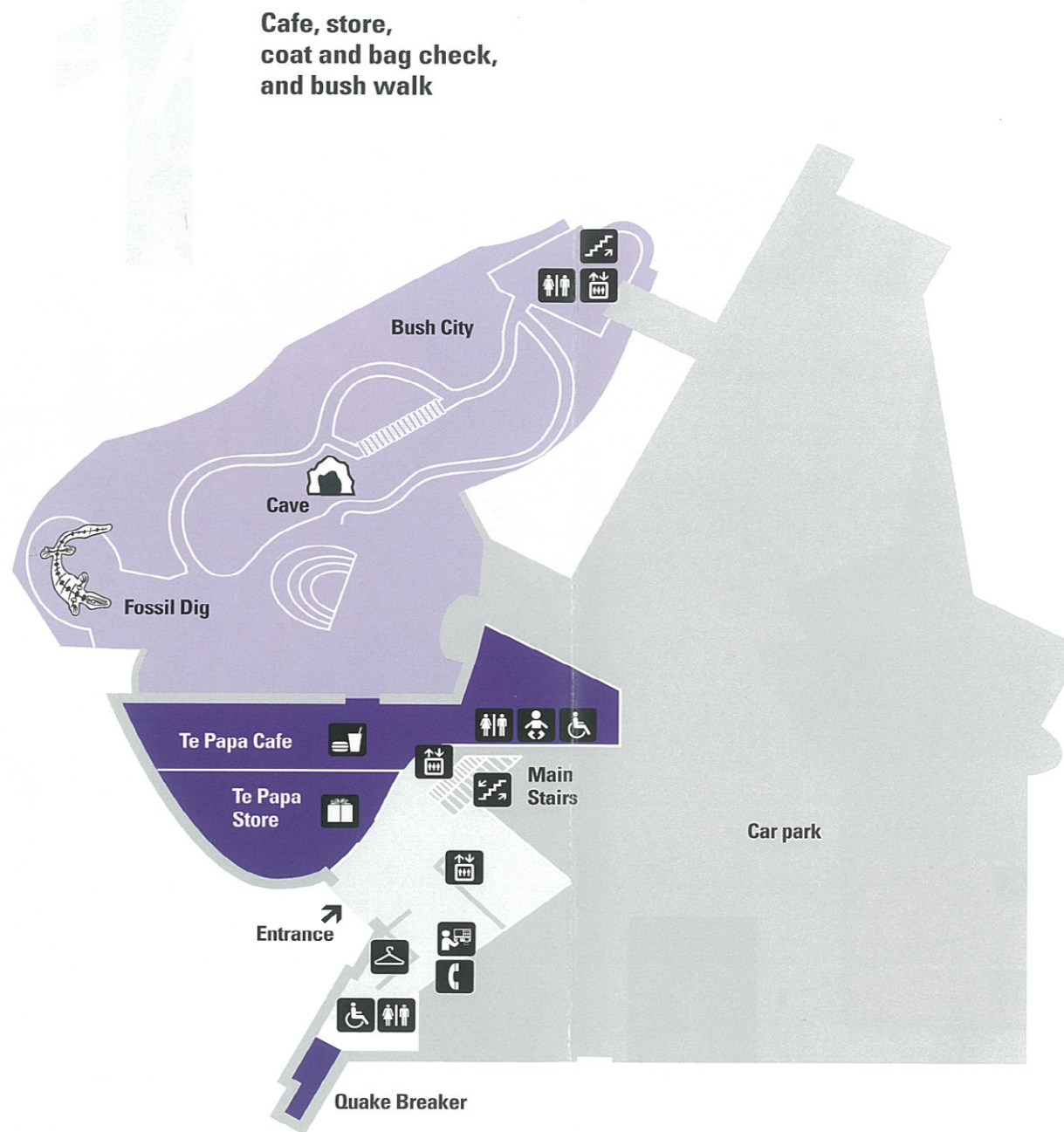




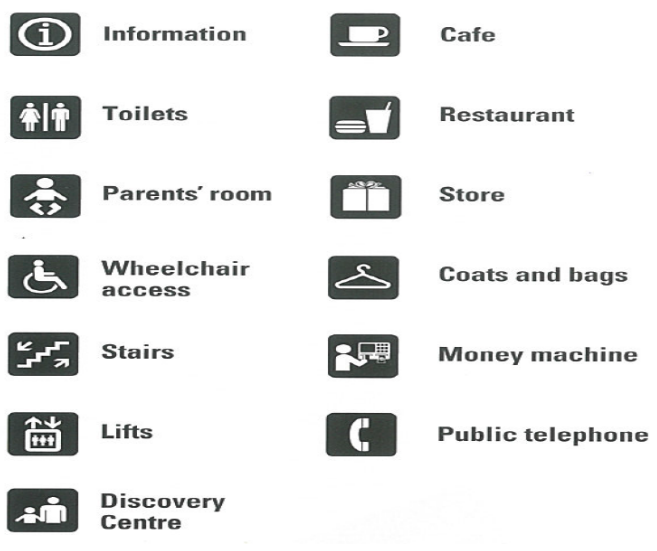

\section{Level 2}

Natural environment, digital playground, and kids' store
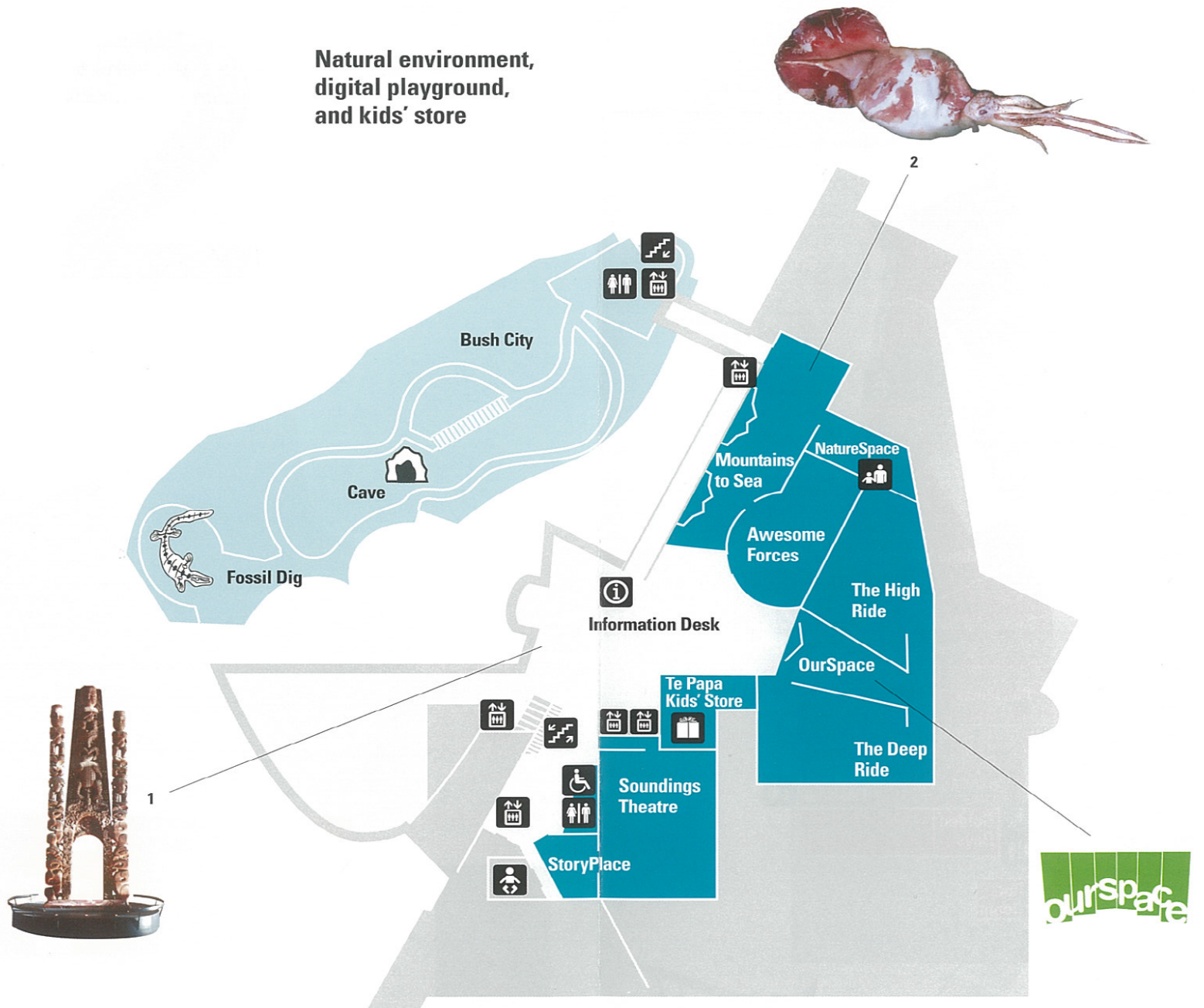


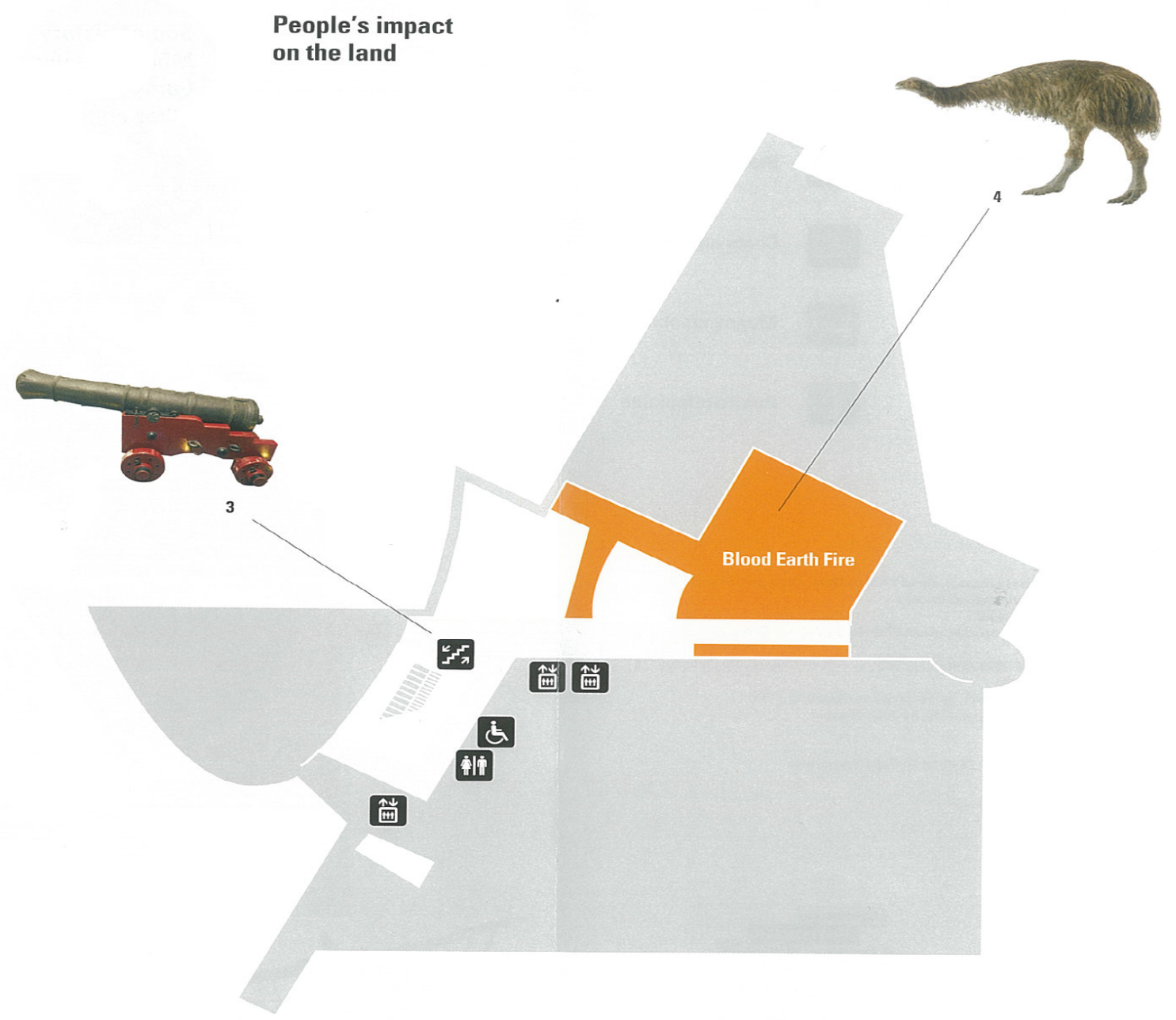

Note: Most of the grey area on level 2 and 3 towards the bottom of the map is office space or houses TP's collections. 
Social history Mãori, Pacific,

European, and other communities

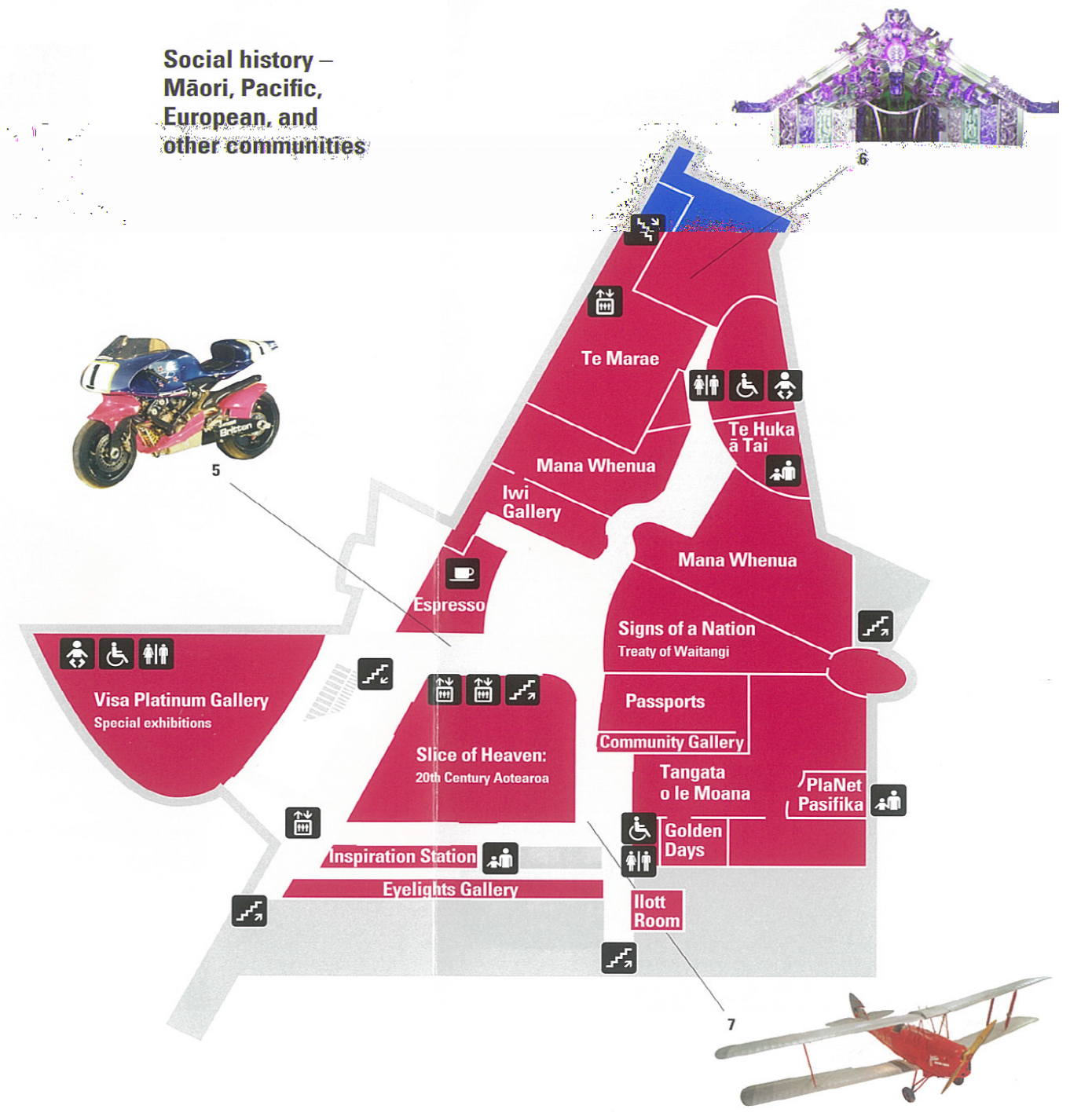

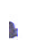




\section{Level 6}

The arts - and a great harbour view on Level 6!

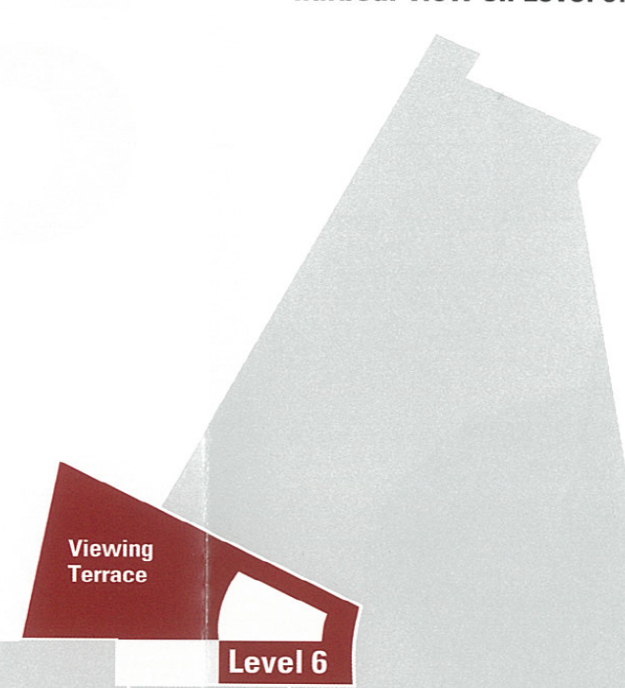

啚鲾

Fe

\section{베i 베연}

Level 5 Arts Te Papa

\section{Images}

1. Waharoa (gateway), about 1905 , by Neke, Tene, and Eramiha Kapua, Ngāti Tarawhai iwi (tribe)

2. Colossal Squid

3. Endeavour cannon, about 1750-1760, by Joseph Christopher

4. Moa

5. Britten V-1000 motorbike, 1992 , by Britten Motorcycle Company Ltd

6. The Marae

7. Tiger Moth, 1941, by de Havilland (NZ) Aircraft Co

8. Poedua [Poetua], 1785, by John Webber 
Appendix 2: TP's Organisational Structure 2007/ 08

(based on Annual Report 2007/08, as of 30 June 2008)

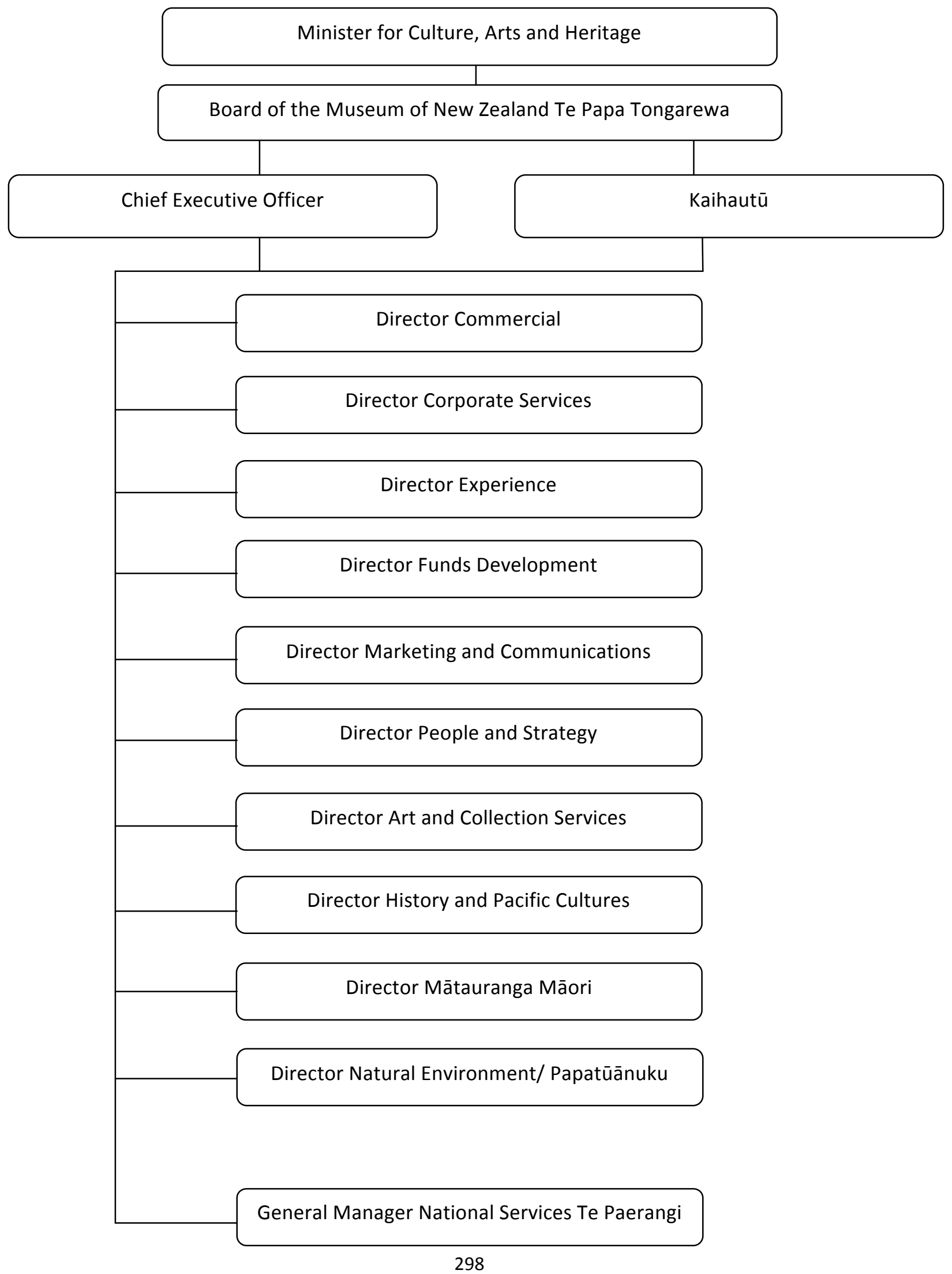


Appendix 3: TP's Organisational Structure2008/ 09

(based on Annual Report 2008/09, as of 30 June 2009)

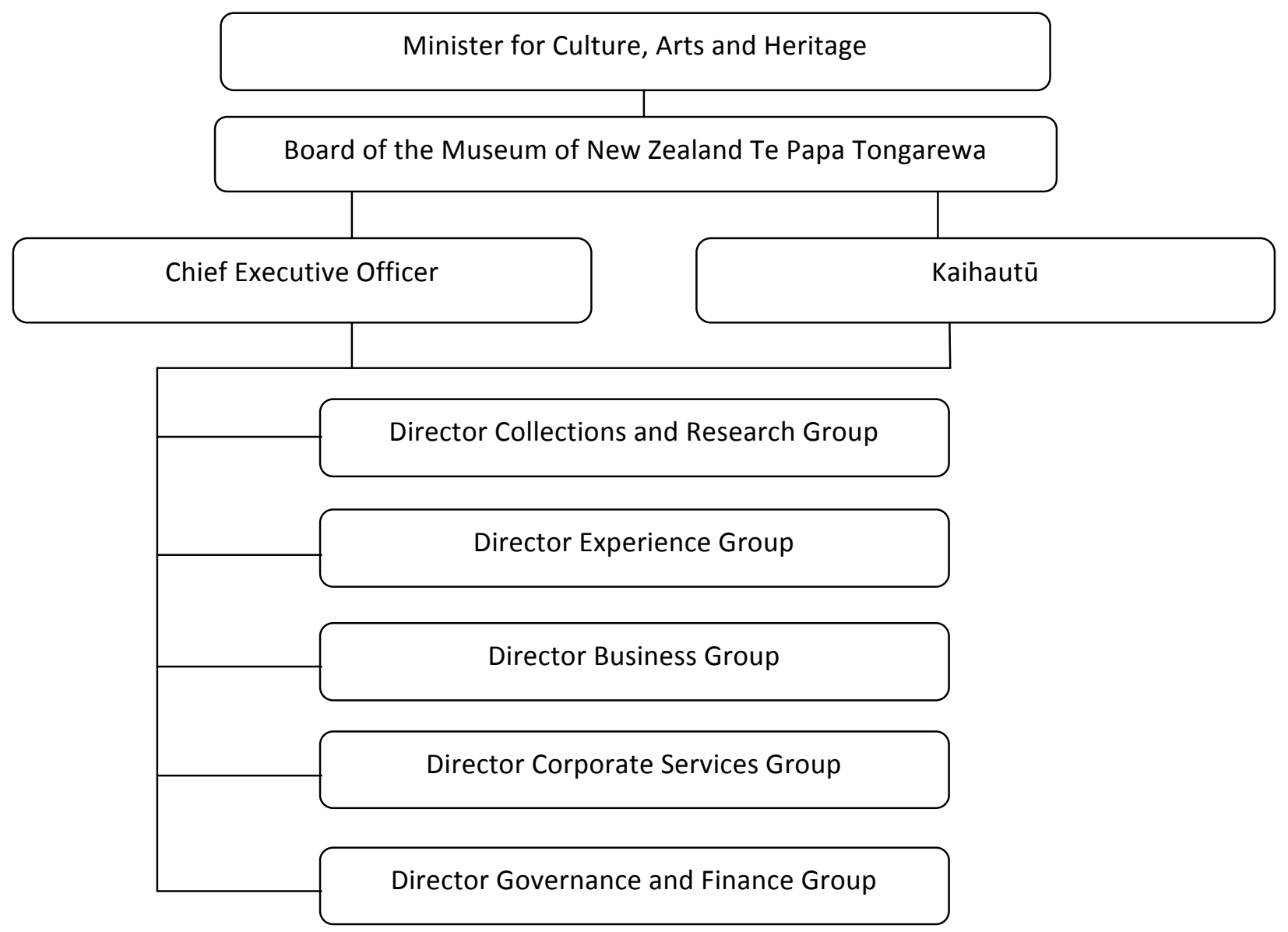




\section{Appendix 4: TP Organisational Chart 2008 (Māori staff highlighted yellow)}
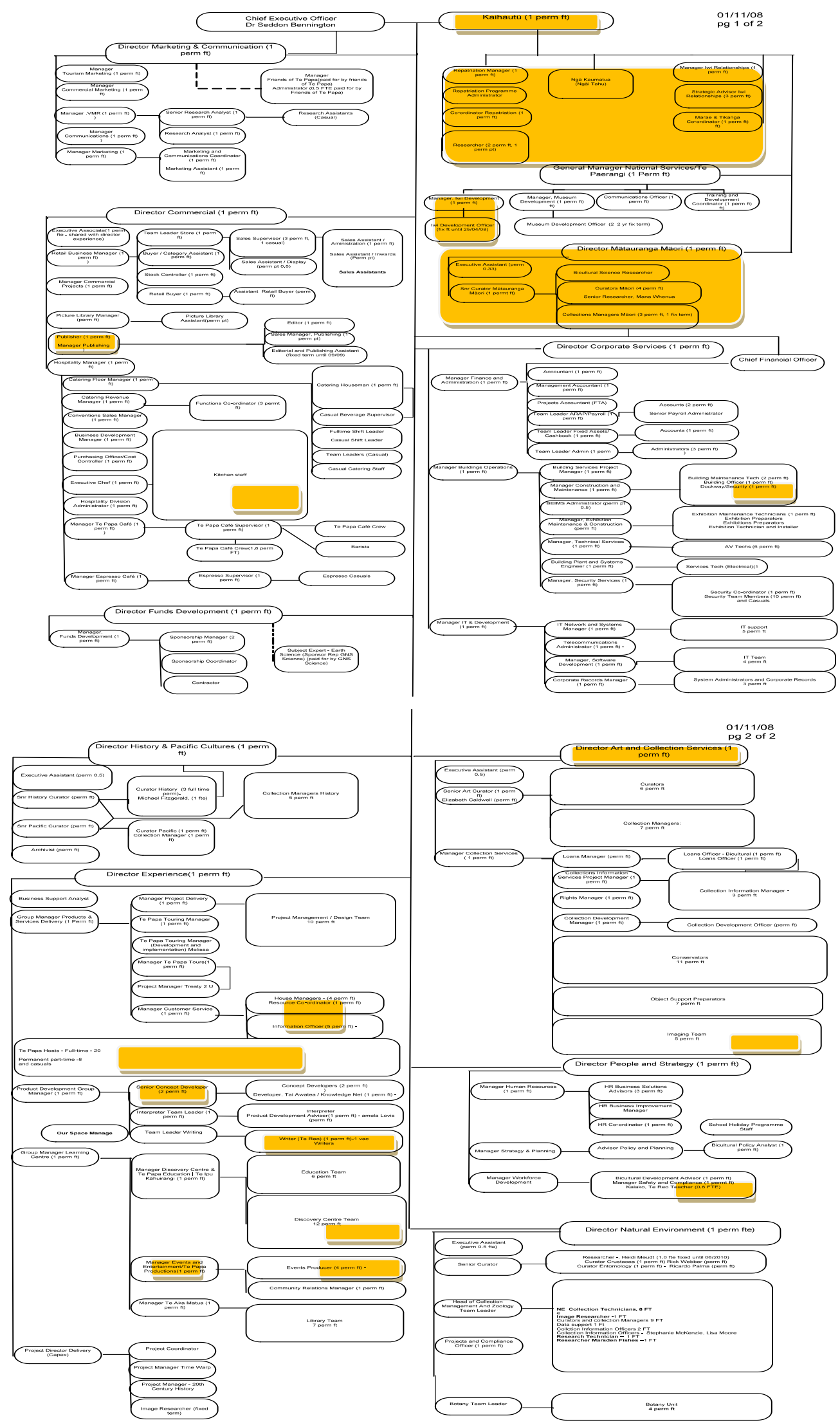


\section{Appendix 5: Interview Questions for Current TP Staff}

Could you give me a brief overview of your career path so far and tell me what your role at Te Papa involves?

What expectations did you have of Te Papa before you came here?

For you personally, what does biculturalism mean? What do you think of Te Papa's bicultural model?

How is biculturalism at Te Papa incorporated and reinforced (or not) in the everyday work life?

Can you give me an example?

How are cultural sensitivities dealt with? How is biculturalism negotiated behind the scenes?

Do you make use of te reo and waiata sessions?

Do you think staff has enough training and knowledge in terms of bicultural principles?

Has working at Te Papa changed your world view in any way?

How inclusive is Te Papa? What efforts are being made to be an inclusive museum?

What is the power-balance at Te Papa like (Māori, Pākehā, immigrants)?

To what extent do the Government, the Board, the staff and the visitors influence Te Papa?

In your opinion what should be improved at Te Papa?

What needs to be done to turn Te Papa into a "truly bicultural institution"?

What is your opinion on the Te Papa management?

What do you think of the restructuring of the leadership team?

What changes have you seen in your time at Te Papa?

Do you know any other bicultual institutions (in NZ or overseas) or museums that are compareable with Te Papa?

Who do you recommend to talk to at Te Papa (or former staff)? 


\section{Appendix 6: Overview of Participant Observation in Teams at TP}

\begin{tabular}{|c|c|c|c|c|}
\hline Team name & $\begin{array}{l}\text { stay } \\
\text { (days) }\end{array}$ & $\begin{array}{l}\text { staff } \\
\text { observed }\end{array}$ & Type of work I did & Events attended \\
\hline Events & 10 & 6 & filing & $\begin{array}{l}\text { Team meetings and other } \\
\text { meetings; farewell } \\
\text { morning tea }\end{array}$ \\
\hline $\begin{array}{l}\text { National } \\
\text { Services Te } \\
\text { Paerangi } \\
\end{array}$ & 10 & 6 & $\begin{array}{l}\text { Updating museum } \\
\text { database on phone and } \\
\text { online }\end{array}$ & $\begin{array}{l}\text { Team meetings; Christmas } \\
\text { dinner }\end{array}$ \\
\hline Repatriation & 10 & 4 & $\begin{array}{l}\text { Organising tours and } \\
\text { talks for visiting } \\
\text { scholars; translations of } \\
\text { correspondence into } \\
\text { German }\end{array}$ & $\begin{array}{l}\text { All talks and tours for and } \\
\text { by visiting scholars; FOH } \\
\text { tour; repatriation } \\
\text { ceremony; farewell lunch }\end{array}$ \\
\hline $\begin{array}{l}\text { Workforce } \\
\text { Development }\end{array}$ & 5 & 2 & Update Excell sheets & $\begin{array}{l}\text { Farewell dinner for } \\
\text { leaving team member at } \\
\text { director's house }\end{array}$ \\
\hline $\begin{array}{l}\text { Visitor Market } \\
\text { Research }\end{array}$ & 5 & 2 & Data entry & - \\
\hline Marketing & 6 & 7 & - & $\begin{array}{l}\text { Team meetings; meetings } \\
\text { with external clients }\end{array}$ \\
\hline Māori collection & 3 & 2 & Register taonga & $\begin{array}{l}\text { Māori collection BOH tour } \\
\text { for external group }\end{array}$ \\
\hline Interpreters & 8 & 4 & $\begin{array}{l}\text { Edit subtitles for film } \\
\text { clip }\end{array}$ & Visit Weta Cave \\
\hline Writers & 1 & 3 & - & - \\
\hline $\begin{array}{l}\text { Human } \\
\text { Resources }\end{array}$ & 5 & 5 & Update excel sheets & Team meetings \\
\hline Education & 5 & 5 & - & $\begin{array}{l}\text { Daily team meetings; FOH } \\
\text { tours for school groups }\end{array}$ \\
\hline $\begin{array}{l}\text { Discovery } \\
\text { Centres }\end{array}$ & 5 & 8 & Help with clean up & $\begin{array}{l}\text { Daily team meetings; } \\
\text { Storyplace sessions; some } \\
\text { kids' activities }\end{array}$ \\
\hline $\begin{array}{l}\text { Mātauranga } \\
\text { Māori }\end{array}$ & 5 & 5 & - & Team meetings; BOH tours \\
\hline $\begin{array}{l}\text { Strategy and } \\
\text { Planning }\end{array}$ & 3 & 2 & - & $\begin{array}{l}\text { Meeting with external } \\
\text { client }\end{array}$ \\
\hline Host team & 5 & 5 & - & $\begin{array}{l}\text { Daily team briefings, } \\
\text { Several FOH tour }\end{array}$ \\
\hline $\begin{array}{l}\text { Conservation } \\
\text { (Cable and Tory } \\
\text { Street) }\end{array}$ & 1 & 2 & - & $\begin{array}{l}\text { Tour through Tory Street } \\
\text { office spaces and } \\
\text { collection rooms }\end{array}$ \\
\hline $\begin{array}{l}\text { Natural } \\
\text { Environment } \\
\text { (Tory Street) }\end{array}$ & 2 & 2 & - & $\begin{array}{l}\text { Tour through Tory Street } \\
\text { office spaces and } \\
\text { collection rooms }\end{array}$ \\
\hline $\begin{array}{l}\text { Iwi } \\
\text { Relationships }\end{array}$ & 15 & 4 & $\begin{array}{l}\text { Prepare Matariki staff } \\
\text { breakfast }\end{array}$ & $\begin{array}{l}\text { Matariki gala; Matariki } \\
\text { Dawn ceremony and staff } \\
\text { breakfast }\end{array}$ \\
\hline Total & 104 & 74 & & \\
\hline
\end{tabular}




\section{Appendix 7: Interview Sample and Dates}

\begin{tabular}{|c|c|c|c|c|}
\hline No & Name & Ethnicity & Gender & \begin{tabular}{|l|} 
Date of \\
Interview
\end{tabular} \\
\hline 1 & Jock Phillips & Pākehā & Male & 09.11 .2008 \\
\hline 2 & Kukupa Tirikatene & Māori & Male & 02.02 .2009 \\
\hline 3 & Ken Gorbey & Pākehā & Male & 02.02 .2009 \\
\hline 4 & Jonathan Mane-Wheoki & Māori \& Pākehā & Male & 15.05.2009 \\
\hline 5 & Rhonda Paku & Māori & Female & 11.12 .2009 \\
\hline 6 & Richard Wright & Māori & Male & 04.03 .2010 \\
\hline 7 & Cliff Whiting & Māori \& Pākehā & Male & 16.03 .2010 \\
\hline 8 & Arapata Hakiwai & Māori & Male & 19.04 .2010 \\
\hline 9 & Sue Piper & Pākehā & Female & 06.05 .2010 \\
\hline 10 & Shane Pasene & Pacific Islander & Male & 21.05 .2010 \\
\hline 11 & Carolyn Roberts-Thompson & Māori \& Pākehā & Female & 01.06 .2010 \\
\hline 12 & Cheryll Sotheran & Pākehā & Female & 16.06 .2010 \\
\hline 13 & Michelle Hippolite & Māori & Female & 13.08 .2010 \\
\hline 14 & Te Taru White & Māori & Male & 26.08 .2010 \\
\hline 15 & Michael Houlihan & new migrant & Male & 05.09 .2012 \\
\hline 16 & Nirmala Balram & Fijian-Indian (immigrant) & Female & 26.04 .2012 \\
\hline 17 & Joan Costello & Pākehā & Female & 13.01.2010 \\
\hline 18 & Anonymous & Pākehā & Male & 30.04 .2009 \\
\hline 19 & Anonymous & Pākehā & Female & 09.09 .2009 \\
\hline 20 & Anonymous & Pākehā & Female & 10.09 .2009 \\
\hline 21 & Anonymous & Pākehā & Female & 11.09.2009 \\
\hline 22 & Anonymous & new migrant & Female & 22.10 .2009 \\
\hline 23 & Anonymous & Māori & Female & 08.12 .2009 \\
\hline 24 & Anonymous & Māori & Female & 08.12 .2009 \\
\hline 25 & Anonymous & Māori & Male & 10.12.2009 \\
\hline 26 & Anonymous & Māori & Male & 10.12.2009 \\
\hline 27 & Anonymous & Pākehā & Male & 13.12 .2009 \\
\hline 28 & Anonymous & Pākehā & Female & 13.12.2009 \\
\hline 29 & Anonymous & Pākehā & Male & 26.01 .2010 \\
\hline 30 & Anonymous & new migrant & Female & 01.02.2010 \\
\hline 31 & Anonymous & new migrant & Female & \begin{tabular}{|l|l}
01.02 .2010 \\
\end{tabular} \\
\hline 32 & Anonymous & new migrant & Female & 01.02.2010 \\
\hline 33 & Anonymous & Pākehā & Female & 02.02.2010 \\
\hline 34 & Anonymous & Pākehā & Female & 02.02 .2010 \\
\hline 35 & Anonymous & Pākehā & Male & 02.02.2010 \\
\hline 36 & Anonymous & Pākehā & Female & 12.02.2010 \\
\hline 37 & Anonymous & Māori & Male & 17.02.2010 \\
\hline 38 & Anonymous & Pākehā & Female & 18.03 .2010 \\
\hline 39 & Anonymous & Māori & Female & 19.03.2010 \\
\hline 40 & Anonymous & Māori & Female & 26.02.2010 \\
\hline 41 & Anonymous & Pākehā & Female & 05.03 .2010 \\
\hline 42 & Anonymous & Pākehā & Female & 09.03.2010 \\
\hline
\end{tabular}




\begin{tabular}{|l|l|l|l|l|}
\hline 43 & Anonymous & Māori & Female & 30.03 .2010 \\
\hline 44 & Anonymous & Pākehā & Female & 30.03 .2010 \\
\hline 45 & Anonymous & Pākehā & Male & 31.03 .2010 \\
\hline 46 & Anonymous & Pākehā & Female & 01.04 .2010 \\
\hline 47 & Anonymous & Pākehā & Male & 05.04 .2010 \\
\hline 48 & Anonymous & new migrant & Female & 09.04 .2010 \\
\hline 49 & Anonymous & Pākehā & Female & 12.04 .2010 \\
\hline 50 & Anonymous & Māori & Female & 12.04 .2010 \\
\hline 51 & Anonymous & Māori \& Pākehā & Female & 13.04 .2010 \\
\hline 52 & Anonymous & Pākehā & Female & 13.04 .2010 \\
\hline 53 & Anonymous & Māori \& Pākehā & Female & 22.05 .2010 \\
\hline 54 & Anonymous & Māori & Male & 23.04 .2010 \\
\hline 55 & Anonymous & Māori \& Pākehā & Male & 23.04 .2010 \\
\hline 56 & Anonymous & Pākehā & Female & 27.04 .2010 \\
\hline 57 & Anonymous & Pākehā & Male & 28.04 .2010 \\
\hline 58 & Anonymous & new migrant & Male & 29.04 .2010 \\
\hline 59 & Anonymous & Pākehā & Female & 28.04 .2010 \\
\hline 60 & Anonymous & Pākehā & Female & 07.05 .2010 \\
\hline 61 & Anonymous & Pākehā & Female & 18.05 .2010 \\
\hline 62 & Anonymous & Pākehā & Male & 20.05 .2010 \\
\hline 63 & Anonymous & new migrant & Female & 27.05 .2010 \\
\hline 64 & Anonymous & Māori & Female & 04.06 .2010 \\
\hline 65 & Anonymous & new migrant & Female & 07.06 .2010 \\
\hline 66 & Anonymous & Pākehā & Female & 26.08 .2010 \\
\hline 67 & Anonymous & Māori & Female & 02.09 .2010 \\
\hline 68 & Anonymous & Pākehāa & Female & 25.05 .2011 \\
\hline & & & \\
\hline
\end{tabular}




\section{Appendix 8: Who is Who of People Named}

\begin{tabular}{|c|c|}
\hline Name & Role at Te Papa and Beyond \\
\hline $\begin{array}{l}\text { Dr Seddon } \\
\text { Bennington ( ) }\end{array}$ & $\begin{array}{l}\text { Pākehā } \\
\text { CEO (2003-2009) }\end{array}$ \\
\hline Dr Jock Phillips & $\begin{array}{l}\text { Pākehā; Conceptual Leader (history) for TP (1994-98); } \\
\text { Chief Historian (1989-1997; and 2000-2002) at Department of Internal } \\
\text { Affairs; currently general editor 'Te Ara' }\end{array}$ \\
\hline Kukupa Tirikatene & $\begin{array}{l}\text { Māori of Ngāi Tahu descent } \\
\text { Iwi kaumātua during the Ngāi Tahu exhibition (2006-2009) }\end{array}$ \\
\hline Ken Gorbey & $\begin{array}{l}\text { Pākehā } \\
\text { Director of Museum Project (1992-1999), museum consultant }\end{array}$ \\
\hline $\begin{array}{l}\text { Jonathan Mane- } \\
\text { Wheoki }\end{array}$ & $\begin{array}{l}\text { Māori and Pākehā descent } \\
\text { Director Art and Collection Services(2004-2009) }\end{array}$ \\
\hline Rhonda Paku & $\begin{array}{l}\text { Māori of Ngāti Kahungunu, Tūhoe and Ngāti Ruapani descent } \\
\text { Several roles at TP and its predessor, such as Manager Iwi Development, } \\
\text { Senior Curator Māori, Manager Mātauranga Māori, acting Kaihautū } \\
\text { (late 1980s; 2005-ongoing) }\end{array}$ \\
\hline Richard Wright & $\begin{array}{l}\text { Several roles at TP and its predessor, such as Manager visitor } \\
\text { centre museum project (1994-1998), host, tourguide, kaitiaki Māori }\end{array}$ \\
\hline Cliff Whiting & $\begin{array}{l}\text { Māori of Te Whānau-ā-Apanui descent } \\
\text { Conceptualised and carved TP's marae; } \\
\text { kaihautū (1995-2000) }\end{array}$ \\
\hline Arapata Hakiwai & $\begin{array}{l}\text { Māori of Ngāti Kahungunu, Rongowhakaata, Ngāti Porou and Ngāi Tahu } \\
\text { Several roles at TP and its predessor, such as Manager Mātauranga Māori, } \\
\text { scholar Mātauranga Māori and Acting kaihautū (early 1990s-ongoing) }\end{array}$ \\
\hline Sue Piper & $\begin{array}{l}\text { Pākehā } \\
\text { TP Board member (2008-2010) }\end{array}$ \\
\hline Shane Pasene & $\begin{array}{l}\text { Cook Island and Niuean descent } \\
\text { Several roles at TP and its predessor, such as Conservation technician } \\
\text { (early 1990s-ongoing), facilitator taonga pūoro group }\end{array}$ \\
\hline $\begin{array}{l}\text { Carolyn Roberts- } \\
\text { Thompson }\end{array}$ & $\begin{array}{l}\text { Māori, Irish, Scottish } \\
\text { Several roles at TP and its predessor, such as café staff, Manager Iwi } \\
\text { Relationships, Vision Team (1991-ongoing) }\end{array}$ \\
\hline Cheryll Sotheran & $\begin{array}{l}\text { Pākehā } \\
\text { CEO (1993-2002) }\end{array}$ \\
\hline Michelle Hippolite & $\begin{array}{l}\text { Māori of Waikato, Rongowhakaata and Te Aitanga-a-Mahaki } \\
\text { Several roles at TP, such as Kaihautū (2008-2012), acting business group } \\
\text { Director (2011-2012) and Acting CEO (2009-2010); currently CEO of Te } \\
\text { Puni Kōkiri (Ministry of Māori Development) }\end{array}$ \\
\hline
\end{tabular}




\begin{tabular}{|l|l|}
\hline Te Taru White & $\begin{array}{l}\text { Māori of Te Arawa, Ngāti Porou, Tainui descent } \\
\text { Kaihautū (2000-2007); CEO 'Te Puia' in Rotorua (2007-2010); currently } \\
\text { consultant }\end{array}$ \\
\hline Michael Houlihan & $\begin{array}{l}\text { Welsh descent (new migrant) } \\
\text { CEO since 2010 }\end{array}$ \\
\hline Nirmala Balram & $\begin{array}{l}\text { Fijian-Indian } \\
\text { Conservator ethnographic objects and sculptures }\end{array}$ \\
\hline Mark Donovan & $\begin{array}{l}\text { American (new migrant) } \\
\text { Experience Group Director (2009-2013) }\end{array}$ \\
\hline Moana Parata & $\begin{array}{l}\text { Māori } \\
\text { Kaitiaki Māori, collections manager (early 1990-ongoing) }\end{array}$ \\
\hline Liz Grant & $\begin{array}{l}\text { Pākehā } \\
\text { Team Leader writing team (2008-2011) }\end{array}$ \\
\hline Joan Costello & $\begin{array}{l}\text { Pākehā } \\
\text { Kaiako/ Māori language teacher (2004-ongoing) }\end{array}$ \\
\hline
\end{tabular}




\section{Appendix 9: Current and Past Exhibitions Relevant to Thesis}

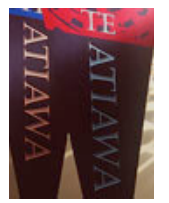

\section{Te Ātiawa iwi exhibition}

February 1998 - August 1999

Te Ātiawa discussed the legends of the very early people named Te Kāhui Maunga (the Assembly of Mountains) and their association with Te Upoko o Te Ika a Māui (the south of the North Island).

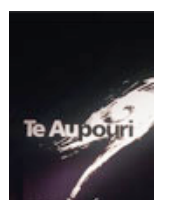

\section{Te Aupouri Iwi: People of smoke and flame}

August 1999 - October 2001

Te Aupouri Iwi: People of smoke and flame was the iwi exhibition of the tenacious Te Aupouri tribe from the far north of Aotearoa New Zealand.

\section{Tūhoe: Children of the mist}

November 2001 - November 2003

Ngāi Tūhoe contributed to the exhibition content, narratives, and taonga.

\section{Mō Tātou: The Ngāi Tahu Whānui exhibition}

8 July 2006 - 9 August 2009

Ngāi Tahu Whānui invite you to celebrate their past and present, their values, and their vision for the future. Mō Tātou celebrates the distinct and dynamic culture of the South Island's Ngāi Tahu people.

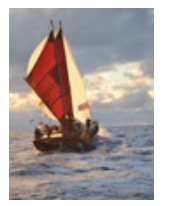

Tai timu, tai pari, Tainui: Journey of a people

3 September 2011 - May 2014

Tai timu, tai pari, Tainui: Journey of a people tells the epic story of Tainui - New Zealand's largest tribal grouping. This iwi exhibition was developed in conjunction with five Tainui iwi - Hauraki, Ngāti Maniapoto, Ngāti Raukawa, Te Kawerau-a-Maki, and Waikato.

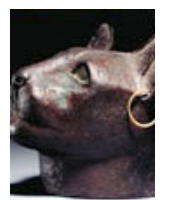

\section{Egypt: Beyond the tomb}

9 December 2006 - 29 April 2007

See the 2700-year-old mummy of Keku, and explore the mysteries of ancient Egyptian rituals for journeying to the afterlife.

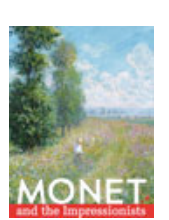

\section{Monet and the Impressionists}

14 February - 17 May 2009

This is a rare chance to see some of the world's most famous and best-loved Impressionist paintings, including Claude Monet's Water lilies, Haystacks, and Meadow with poplars.

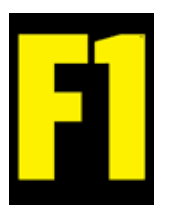

\section{Formula One ${ }^{\mathrm{Tm}}$ : The great design race}

15 July - 1 November 2009

Thrilling, seductive, and addictive! Follow the incredible technology, see iconic cars, and discover New Zealand's Formula One heroes.

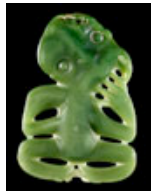

Kura Pounamu: Treasured stone of Aotearoa New Zealand

17 October 2009 - 10 July 2011

Pounamu is a stone of exceptional beauty, strength, and spiritual presence. This evocative exhibition explores pounamu's enduring value. 

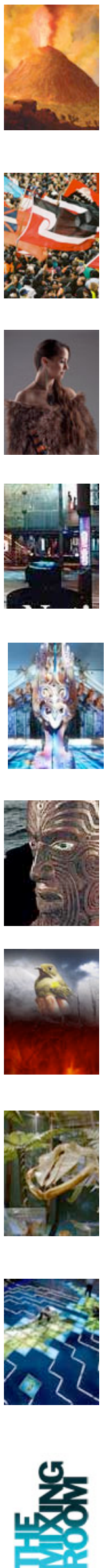

\section{A Day in Pompeii}

19 December 2009 - 25 April 2010

Unearth the story of daily life in Pompeii in this blockbuster exhibition featuring more than 250 priceless treasures. This travelling exhibition from Soprintendenza Speciale per i Beni Archeologici di Napoli e Pompei was developed in association with the Melbourne Museum.

\section{E Tū Ake: Standing Strong}

9 April - 26 June 2011

Here, ancestral Māori treasures from Aotearoa New Zealand stand alongside contemporary works to show the artistic depth and political aspirations of this vibrant indigenous culture.

\section{Kahu Ora Living Cloaks}

8 June 2012 - 22 October 2012

Explore the world's largest collection of Māori cloaks and experience cloak-making as a living art form.

\section{Signs of a Nation / Ngā Tohu Kotahitanga}

Long-term exhibition (Day One)

An exploration of the Treaty signed in 1840 between the British Crown and Māori - its history and place in New Zealand today.

\section{Te Marae}

Long-term exhibition (Day One)

Te Papa's Marae (meeting place) - focal point for pōwhiri (welcomes) and many other special events - is an outstanding example of contemporary Māori art.

\section{Mana Whenua}

Long-term exhibition (Day One)

Beautiful taonga (treasures) and fascinating stories combine to create a stunning picture of Māori, the tangata whenua (original people) of Aotearoa New Zealand.

\section{Blood Earth Fire / Whāngai Whenua Ahi Kā}

Long-term exhibition

How was this land turned from forests and wetlands to farms and settlements? Why were thousands of 'alien' plants and animals introduced and why did others become extinct? Experience the transformation with Blood, Earth, Fire!

\section{Mountains to Sea}

Long-term exhibition (Day One)

Explore New Zealand's diverse range of plants and animals and their living places - mountains, fresh waters, forests, coasts, and the surrounding seas. This Day One natural history exhibition shows New Zealand's fauna and flora in diorama displays and features models of sea creatures.

\section{Our Space}

Long-term exhibition (28 September 2008 and is scheduled to close in 2018) Te Papa's spectacular multimedia experience. It comprises a high-resolution gigantic map of New Zealand that visitors can walk on, 'the wall' where the audience can upload photos to make their own exhibition and two rides. Our Space is targeted at teenagers and young adults.

\section{The Mixing Room: Stories from young refugees in New Zealand}

10 April 2010 - April 2013

Young refugees to New Zealand invite you to share their extraordinary stories - told through art, film, poetry, performance, and digital media. 


\section{Appendix 10: Sequence of Events Regarding the Display of Keku}

\begin{tabular}{|c|c|c|c|}
\hline Date & Who/ what & Rationale/ Outcome & $\begin{array}{l}\text { Keku } \\
\text { included? }\end{array}$ \\
\hline November 2004 & $\begin{array}{l}\text { Concept developer } \\
\text { reviews proposal of } \\
\text { touring exhibition }\end{array}$ & $\begin{array}{l}\text { Declined on the grounds } \\
\text { of Te Papa's policy not } \\
\text { to display human } \\
\text { remains }\end{array}$ & \\
\hline May 2006 & $\begin{array}{l}\text { Concept developer } \\
\text { reviews proposal } \\
\text { again }\end{array}$ & $\begin{array}{l}\text { Management decides } \\
\text { that } E B T \text { will be shown } \\
\text { at Te Papa }\end{array}$ & Unsure \\
\hline June 2006 & $\begin{array}{l}\text { Leadership Team } \\
\text { discusses budget, } \\
\text { timing, pricing and } \\
\text { potential visitation }\end{array}$ & $\begin{array}{l}\text { Financial reports and } \\
\text { visitor research projects } \\
\text { profit and higher } \\
\text { visitation if mummy is } \\
\text { included }\end{array}$ & $\begin{array}{l}\text { Unsure, but } \\
\text { more yes }\end{array}$ \\
\hline July 2006 & $\begin{array}{l}\text { Paper presented to } \\
\text { CEO and Kaihautū }\end{array}$ & $\begin{array}{l}\text { Financial loss without } \\
\text { mummy, profit with } \\
\text { mummy }\end{array}$ & $\begin{array}{l}\text { Unsure; design } \\
\text { prepared for } \\
\text { both scenarios } \\
\end{array}$ \\
\hline August 2006 & $\begin{array}{l}\text { Leadership Team } \\
\text { discusses possible } \\
\text { display of Keku }\end{array}$ & $\begin{array}{l}\text { Māori opposition versus } \\
\text { Egyptian approval to } \\
\text { display; draft strategy } \\
\text { for display proposed; } \\
\text { recommended not to } \\
\text { display mummy }\end{array}$ & $\begin{array}{l}\text { No consensus } \\
\text { reached; } \\
\text { unsure, but } \\
\text { more no }\end{array}$ \\
\hline 1 September 2006 & $\begin{array}{l}\text { Concept developer } \\
\text { presents 'display } \\
\text { strategy' (incl. } \\
\text { ceremonial } \\
\text { requirements) to } \\
\text { Core Projects } \\
\text { Approvals Team, } \\
\text { exhibition team, CEO } \\
\text { and Kaihautū }\end{array}$ & $\begin{array}{l}\text { CEO and Kaihautū to } \\
\text { make final decision }\end{array}$ & $\begin{array}{l}\text { Unsure; } \\
\text { CEO - yes } \\
\text { Kaihautū - no }\end{array}$ \\
\hline 6 November 2006 & $\begin{array}{l}\text { Extraordinary Te } \\
\text { Papa Board meeting } \\
\text { (teleconference); } 3 \\
\text { options are put } \\
\text { forward }\end{array}$ & $\begin{array}{l}\text { No consensus reached, } \\
\text { majority vote decides }\end{array}$ & $\begin{array}{l}\text { Final decision: } \\
\text { yes }\end{array}$ \\
\hline $\begin{array}{l}16 \text { November } \\
2006\end{array}$ & $\begin{array}{l}\text { CEO and Kaihautū } \\
\text { record podcast }\end{array}$ & $\begin{array}{l}\text { Make different views } \\
\text { accessible for public }\end{array}$ & \\
\hline $\begin{array}{l}20 \text { November } \\
2006\end{array}$ & Staff forum & $\begin{array}{l}\text { Inform staff; have their } \\
\text { say }\end{array}$ & \\
\hline 9 December 2006 & EBT opens & & $\begin{array}{l}\text { Yes, in separate } \\
\text { room }\end{array}$ \\
\hline
\end{tabular}




\section{Appendix 11: Photos}

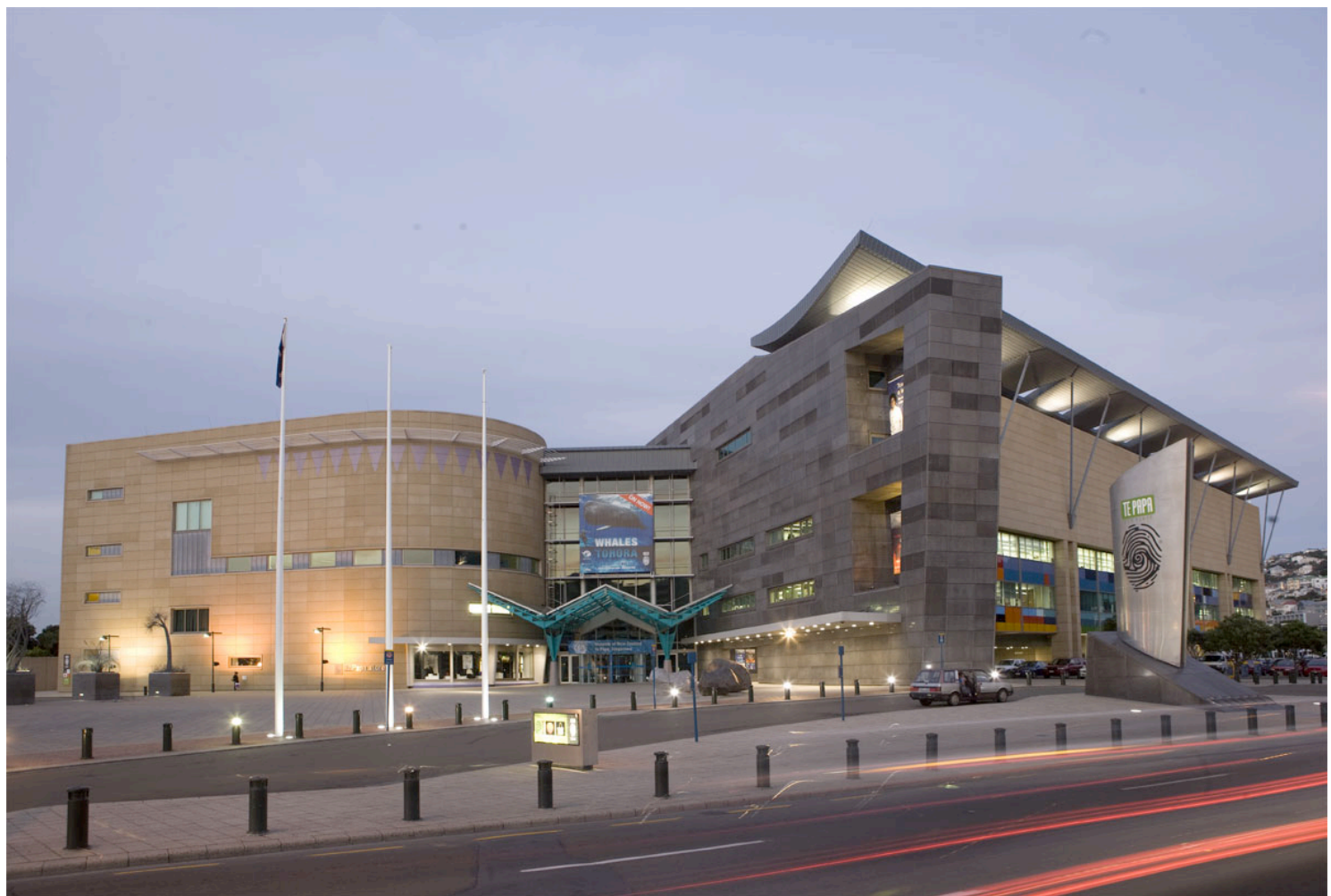

Photo 1: Te Papa building with the front entrance, taken from the city-side (Photograph by: Te Papa)



Photo 2: Te Papa from the harbour-side (Photograph by: Tanja Schubert-McArthur) 


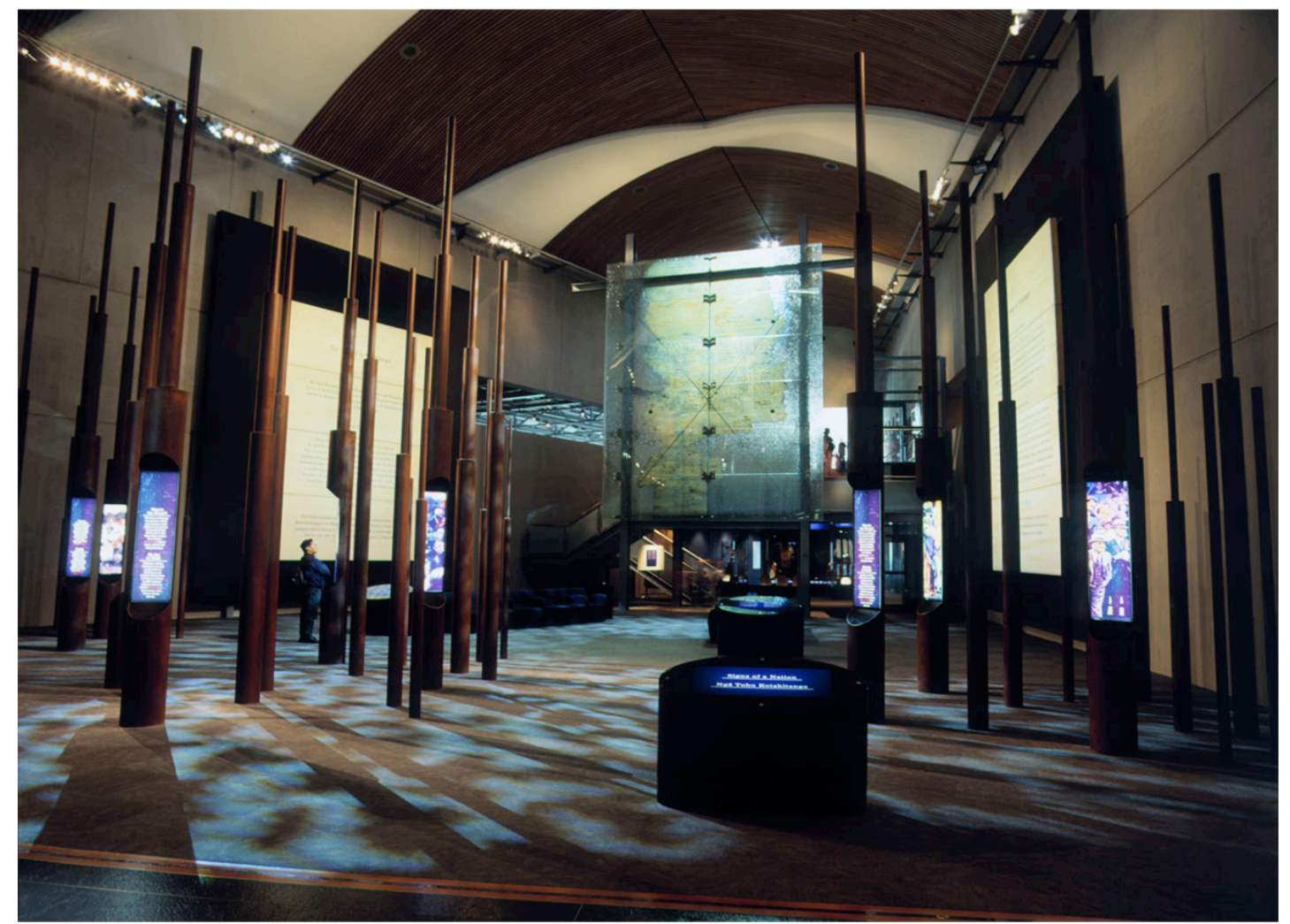

Photo 3: Signs of a Nation exhibition - The Treaty of Waitangi is positioned at the centre of Te Papa.

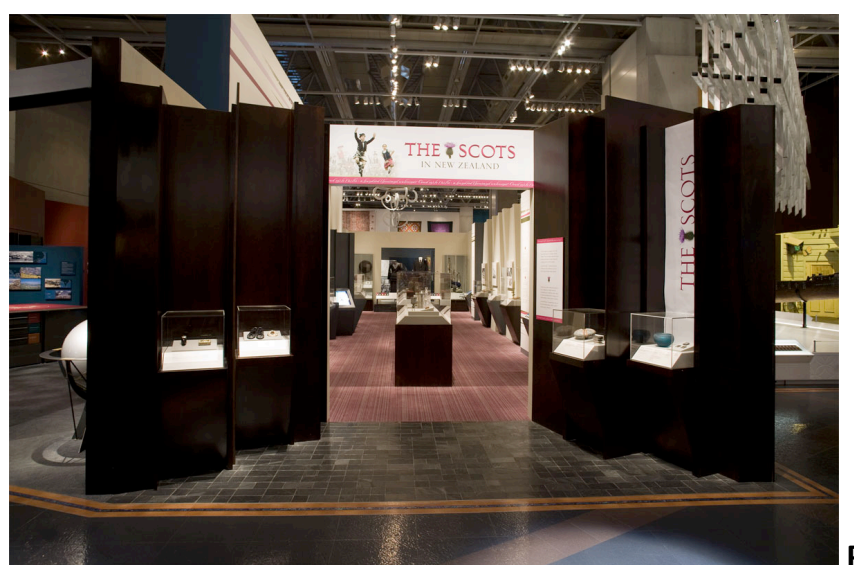

Photo 4 and 5: Community Gallery and Iwi Gallery exhibitions are developed by the source communities themselves. (Photographs by: Te Papa)

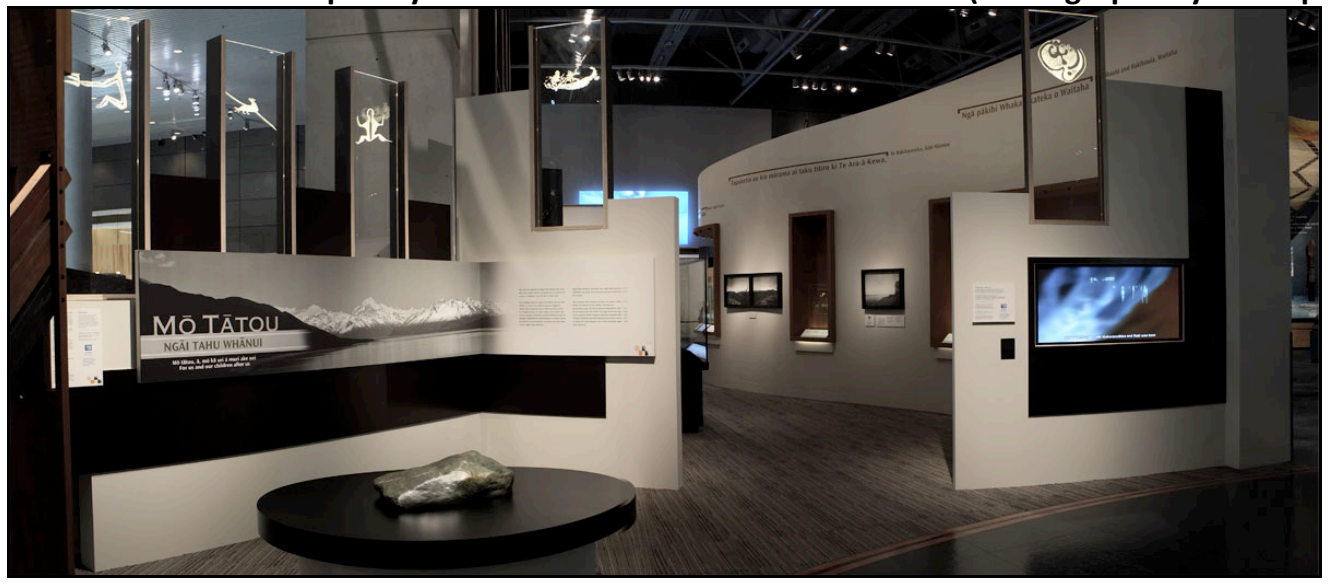




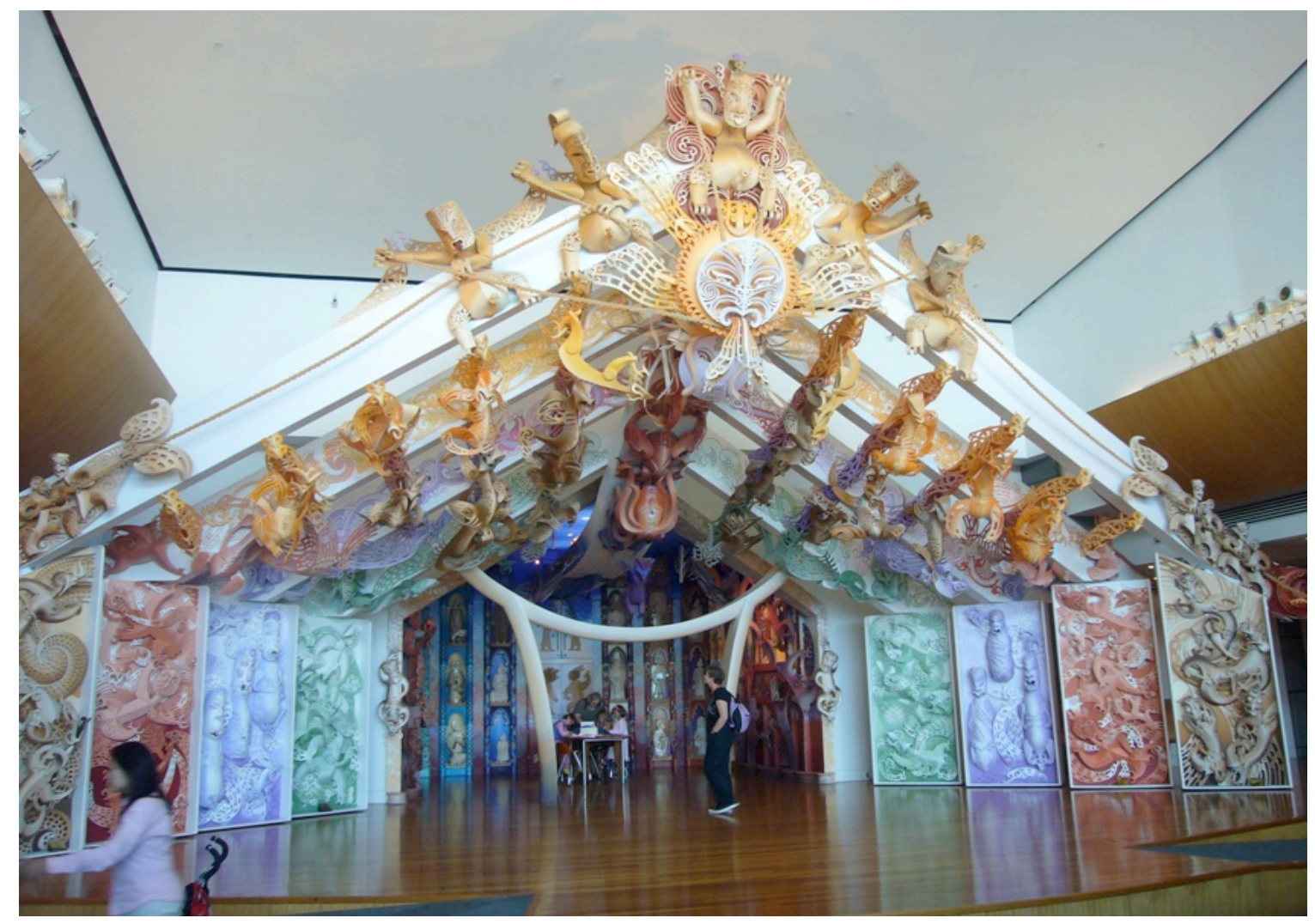

Photo 6: Te Papa's marae features the contemporary meeting house Te Hono ki Hawaiki, conceptualised by Cliff Whiting. (Photograph by: Tanja Schubert-McArthur)

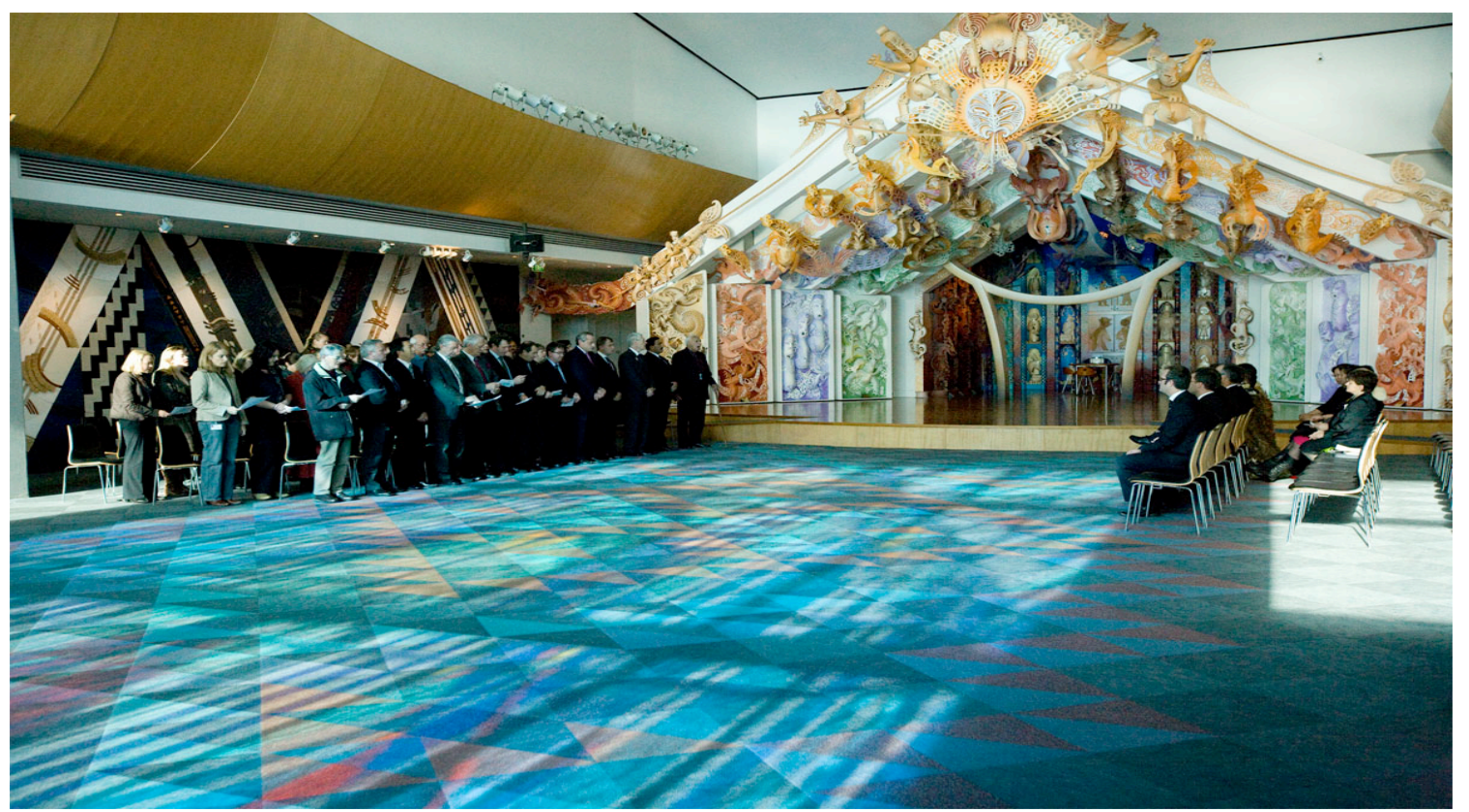

Photo 7: Te Papa's marae during a pōwhiri (Photograph by: Te Papa) 


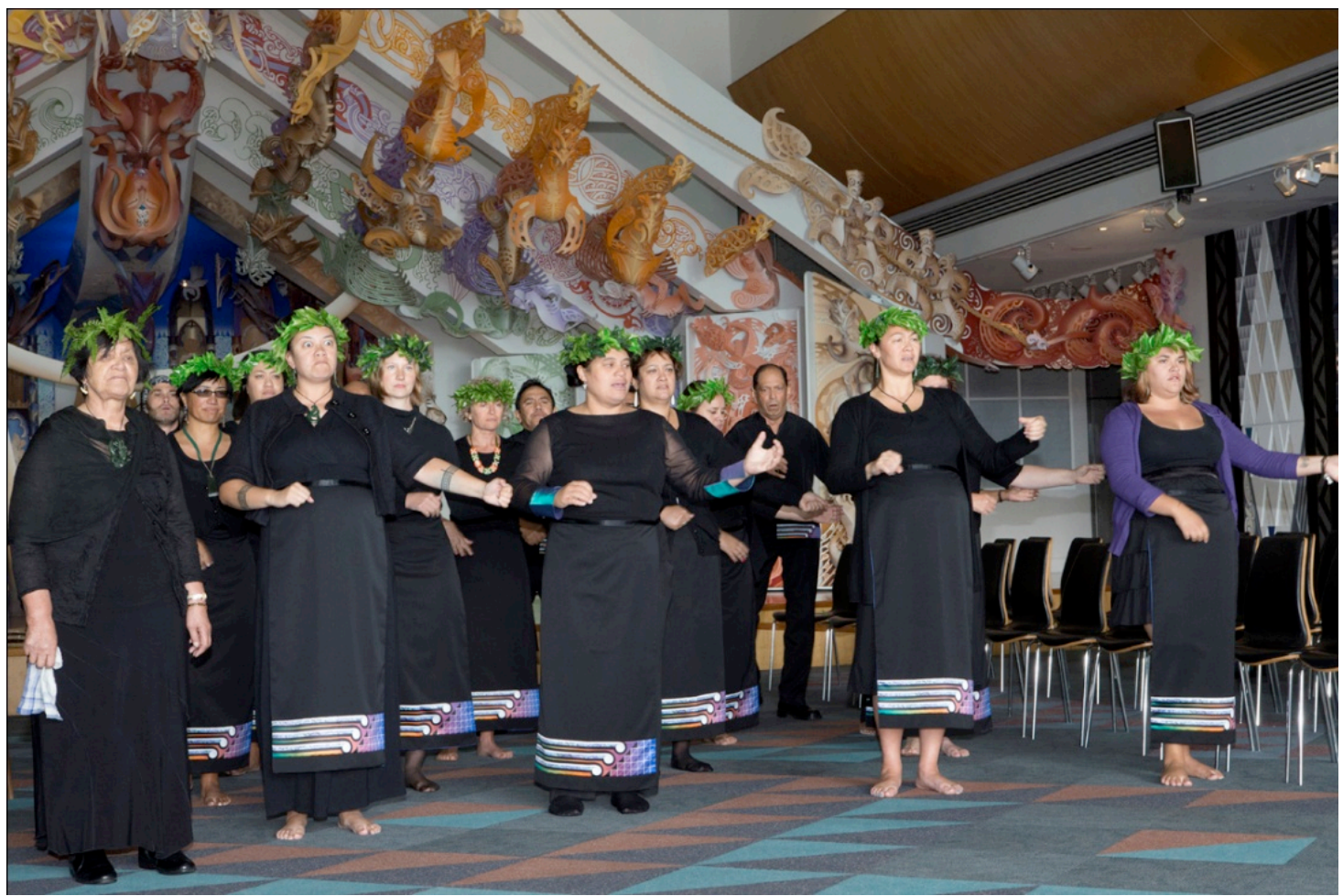

Photo 8: L-R front row kuia Nancye ('Nan') Gage, Sonya Davis, Jay Houpapa, Kylie Ngaropo, Khali PhilipBarbara; L-R second row Awhina Tamarapa, Waitangi Teepa, Tanja Schubert-McArthur, Joan Costello, Hokimate Harwood, Amber Aranui, Chrissie Locke.

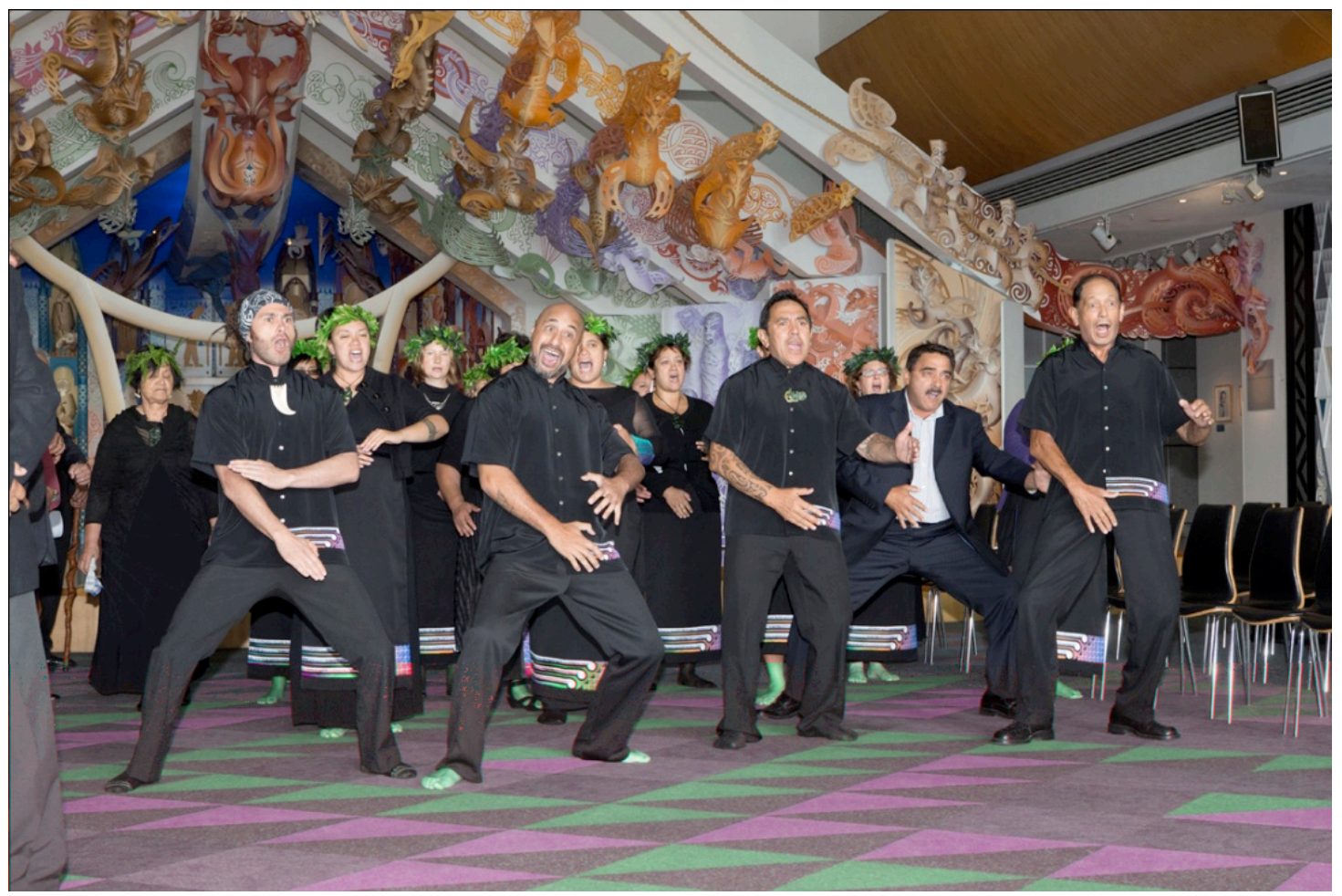

Photo 9: L-R front row Shane James, Shane Pasene, Mark Skyles, Arapata Hakiwai, Tom Ward (Photographs by: Norm Heke) 


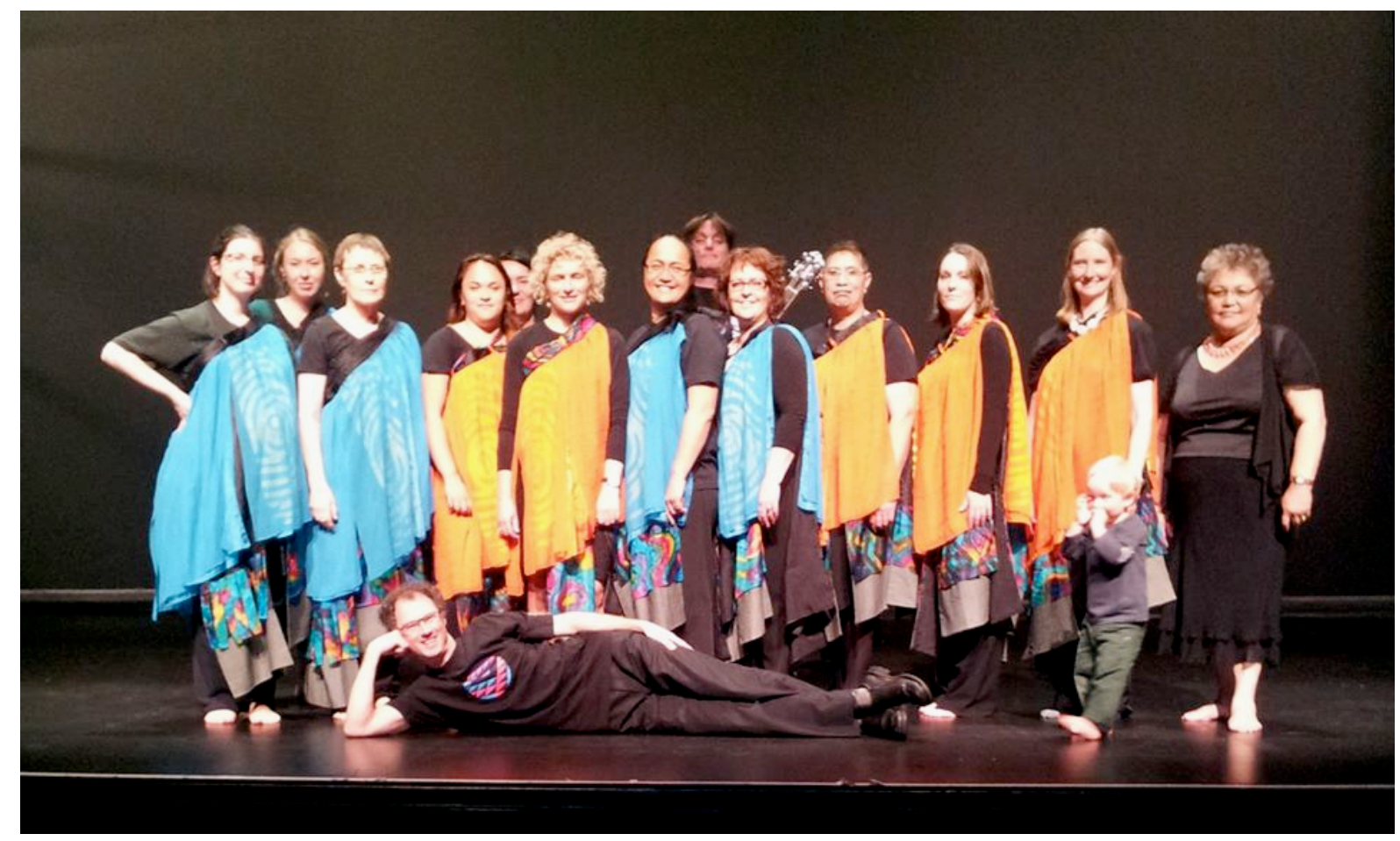

Photo 10: L-R Florence Liger, Kim Gustavsson, Judith Jones, Khali Philip-Barbara, Gillian Appleby, Joan Costello, Carolyn Roberts-Thompson, Alan Baird-Smith, Chrissie Locke, Bev Teinaki, Malinda Aikman, Tanja Schubert-McArthur, Maximilian McArthur, Pera Rangitaawa, Leroy Holmes (lying).

(Photograph by: Hema Temara)

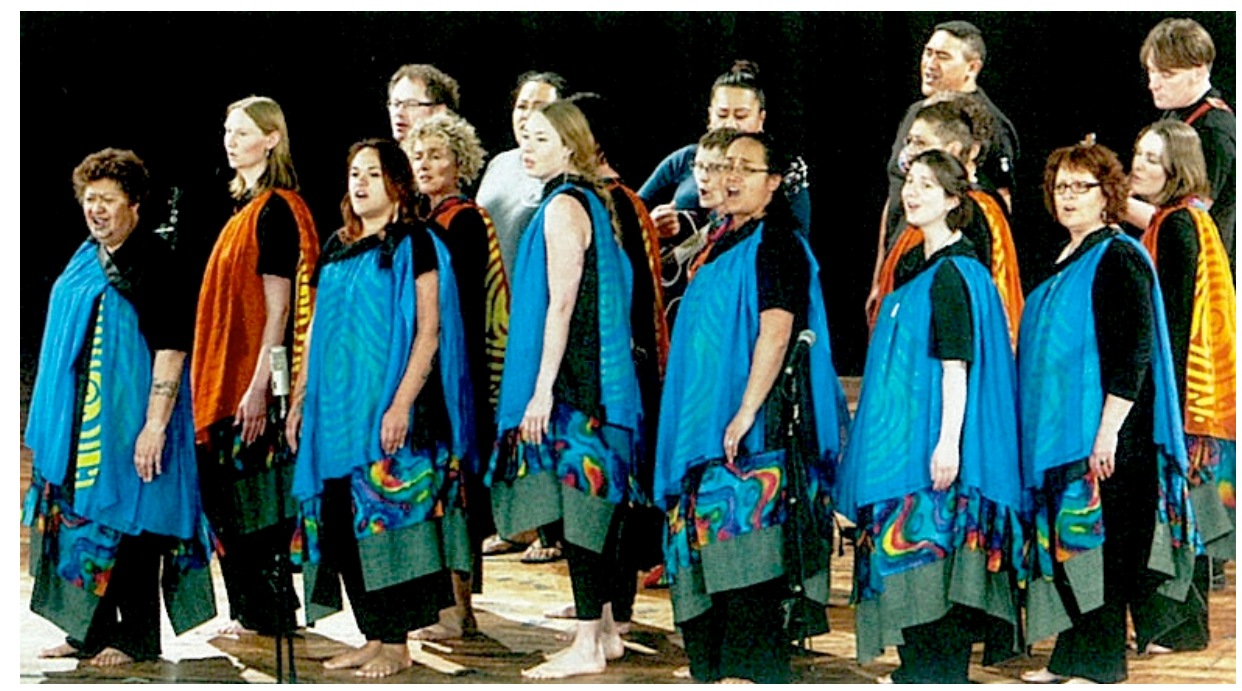

Photo 11: Te Papa's Kapa Haka group performs at Te Kōnohete, the Wellington Interagency Kapa Haka showcase in November 2013. (Photograph by: Te Puni Kōkiri) 


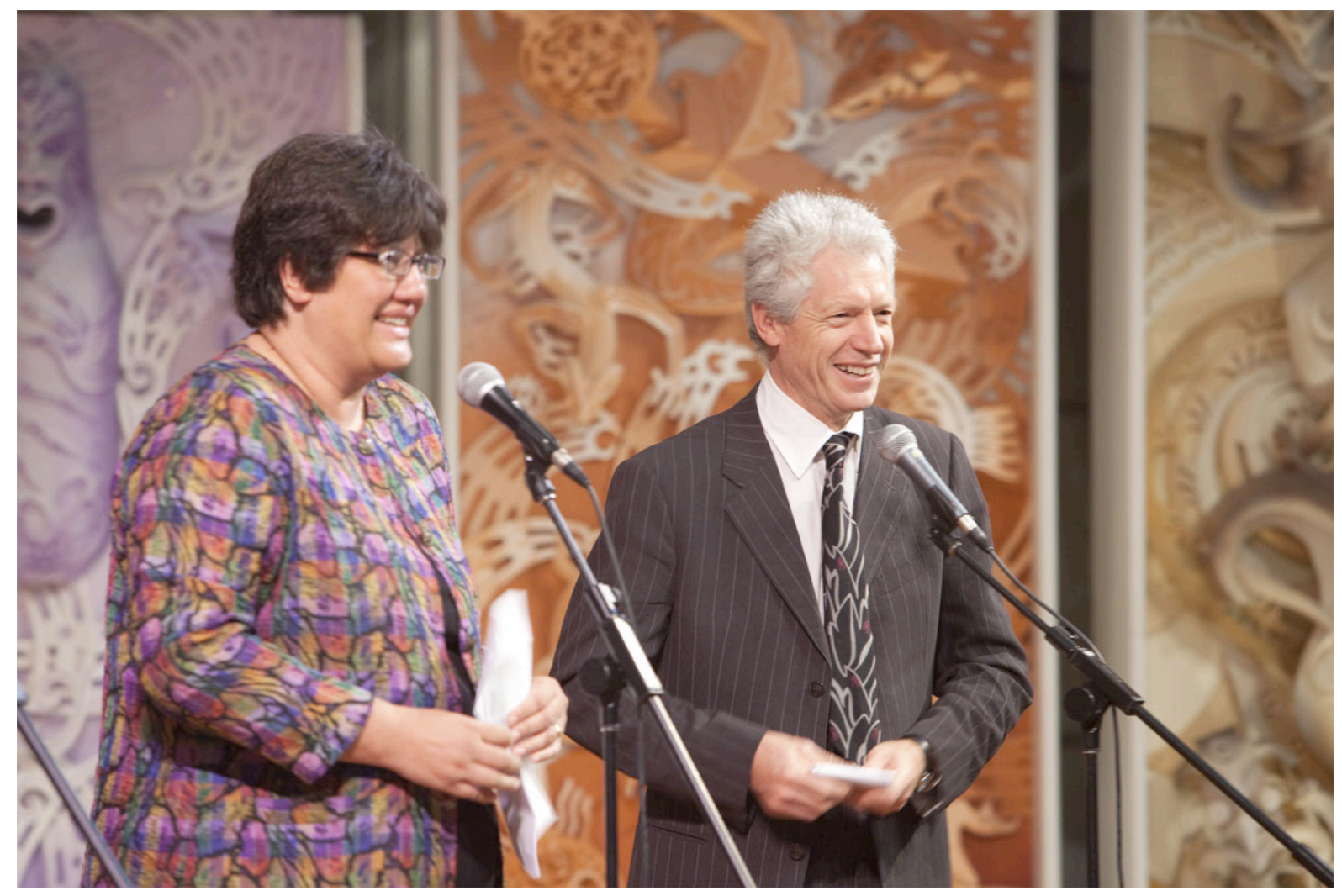

Photo 12: Kaihautū Michelle Hippolite and CEO Seddon Bennington at the Matariki Dawn Ceremony in 2009.

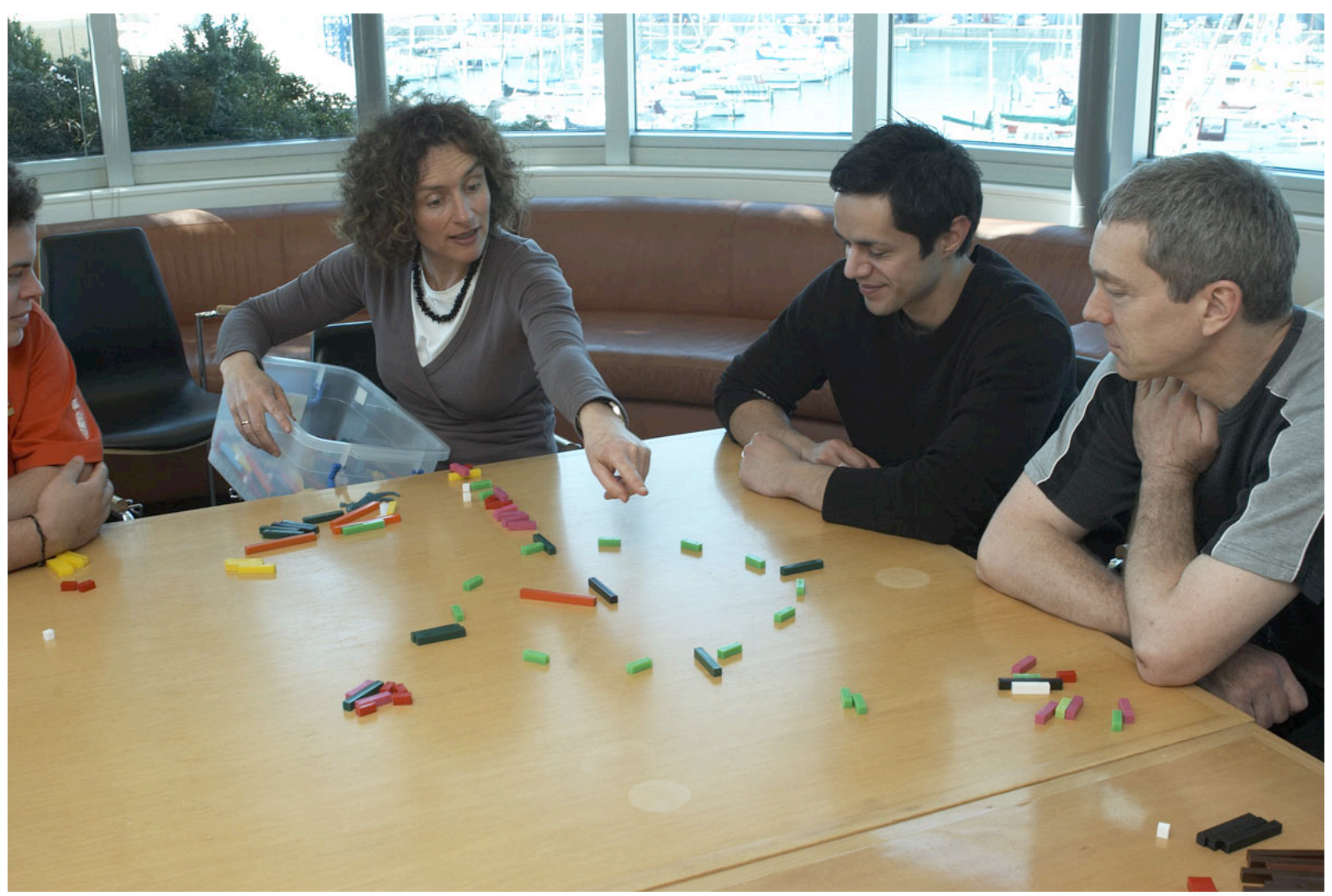

Photo 13: Kaiako Joan Costello teaching students during a te reo Māori class. (Photographs by: Te Papa) 


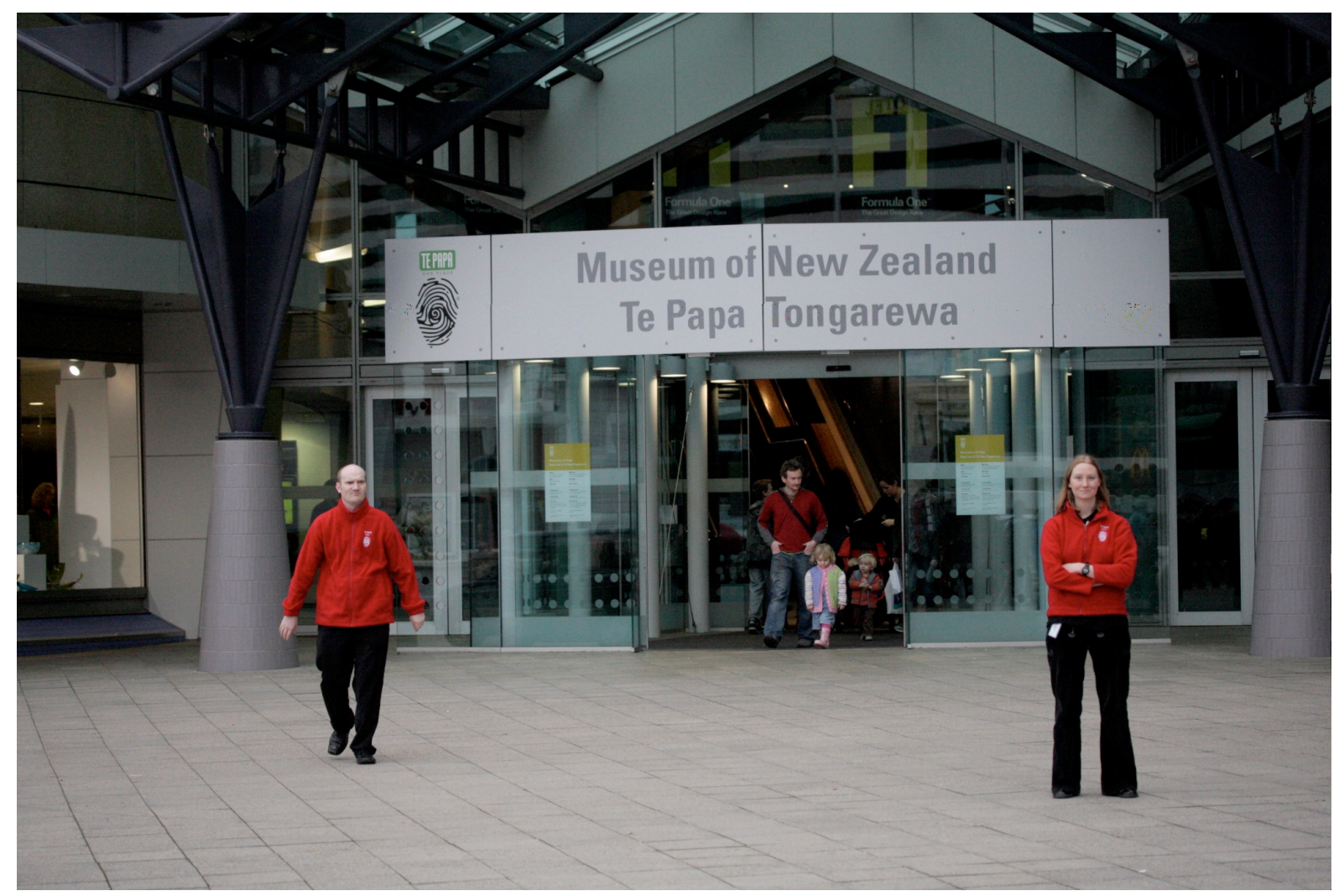

Photo 14: Working at Te Papa as an Events supervisor with host Chris Reed (left). (Photograph by: Ryan McArthur)

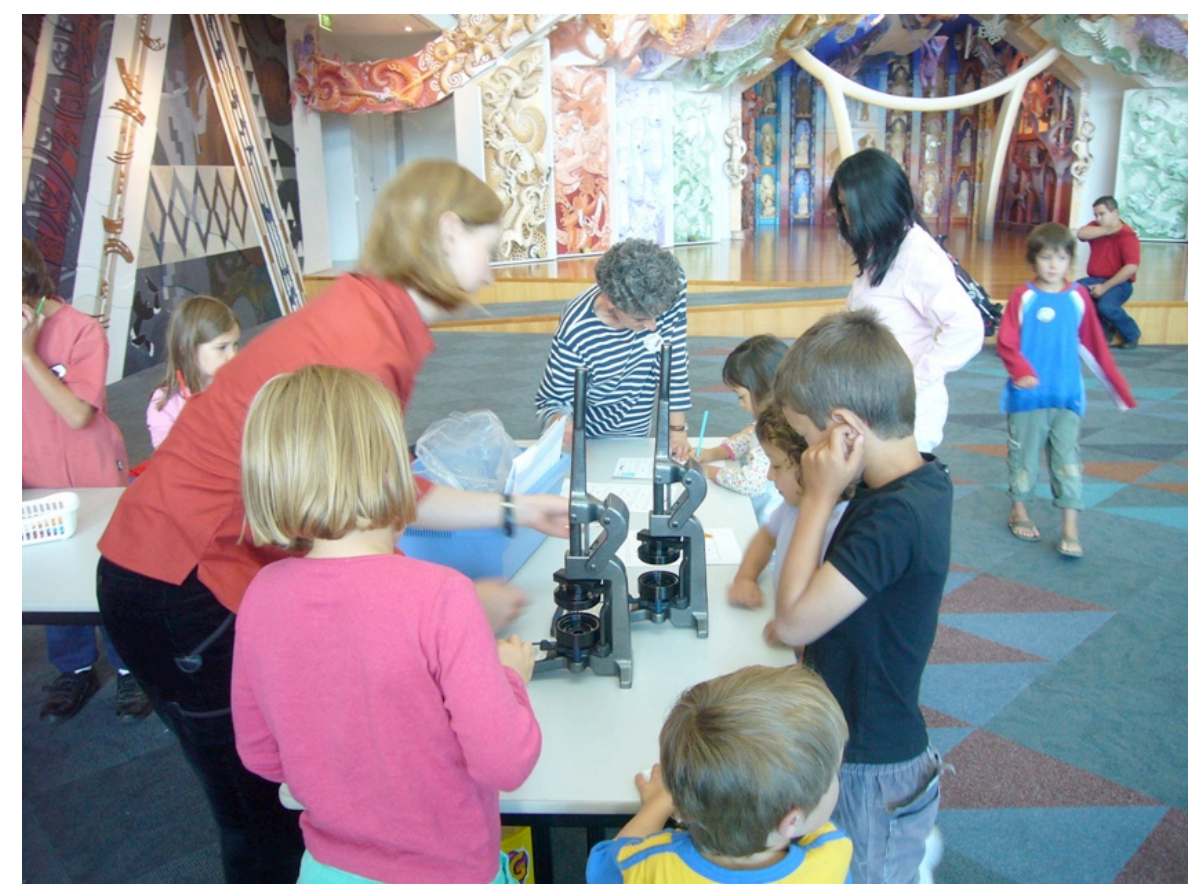

Photo 15: Hands-on - Making name badges with children at a French language programme for the Monet and the Impressionists exhibition. (Photograph by: Jude Turner)

Photo 16: Taoga Pūoro Wānanga at Hongoeka Marae 2011, group photo (Photograph by: Norm Heke) 


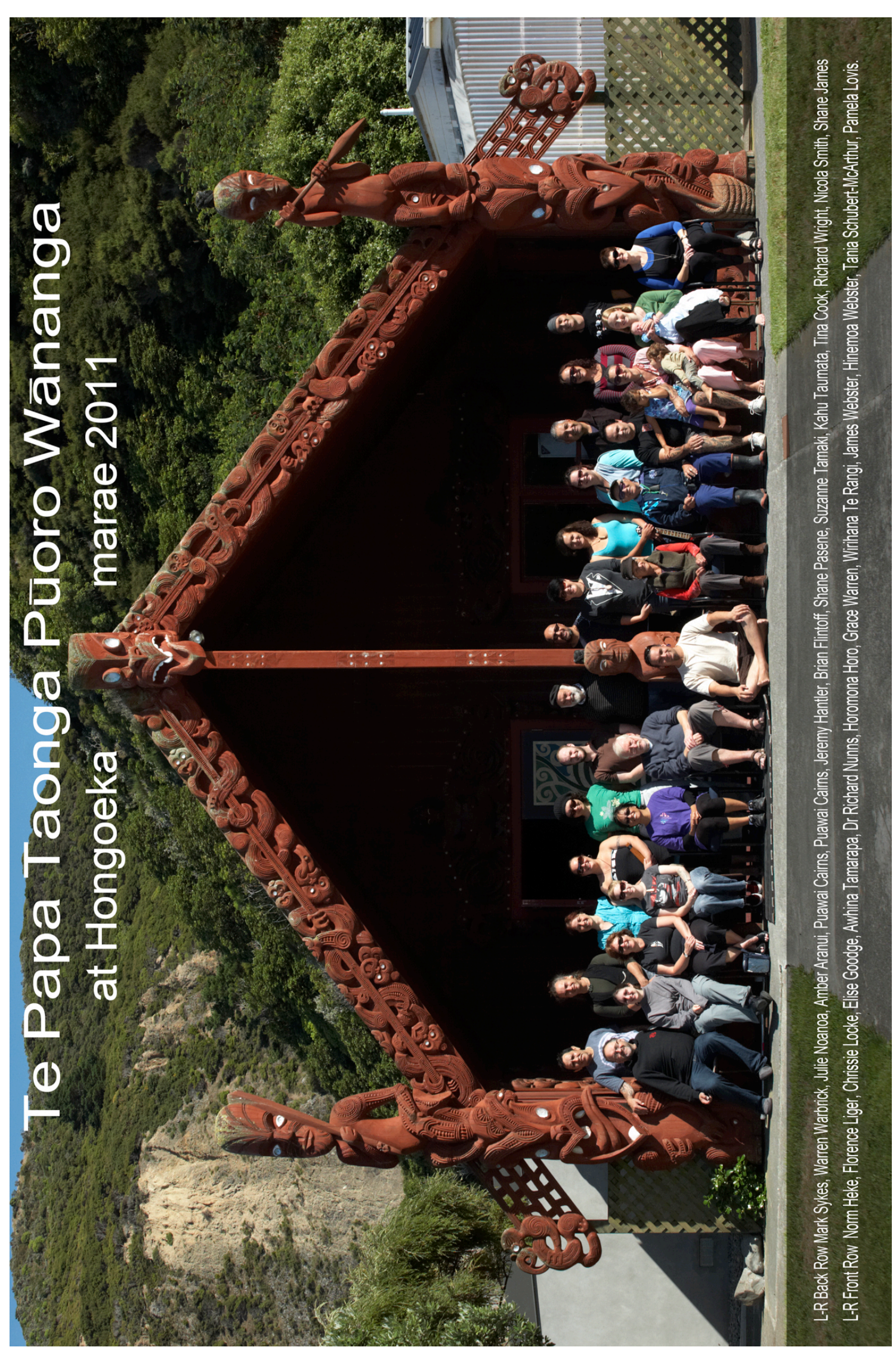




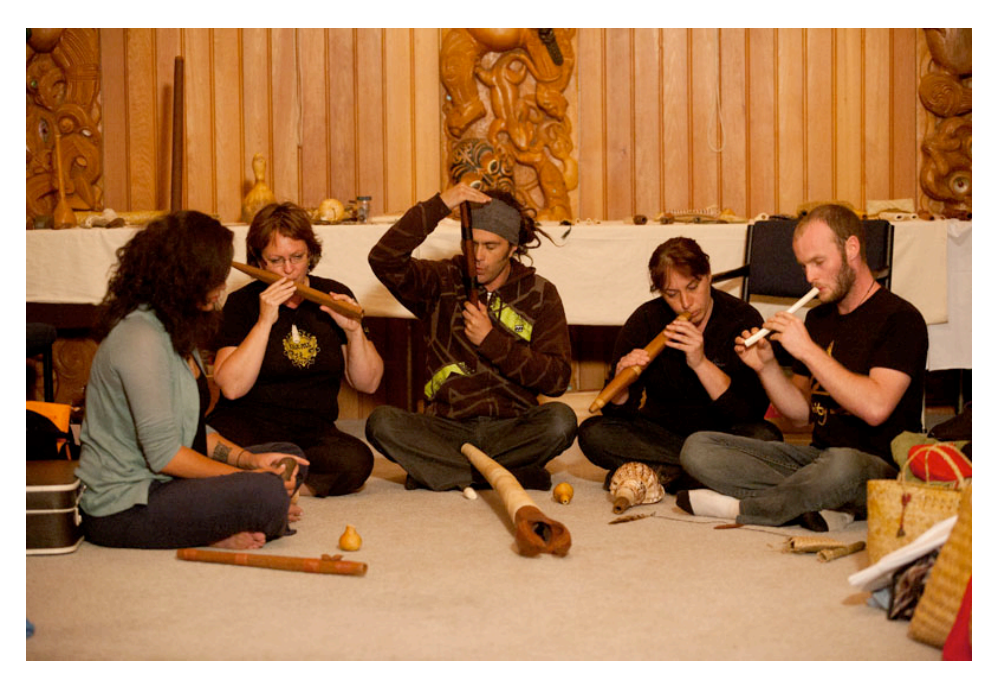

Photo 17: L-R Kahu Taumata, Chrissie Locke, Shane James, Julie Noanoa, Jeremy Hantler presenting a soundscape they developed together.

Photo 18: Dr Richard Nunns playing pūtōrino with Horomona Horo in the background.
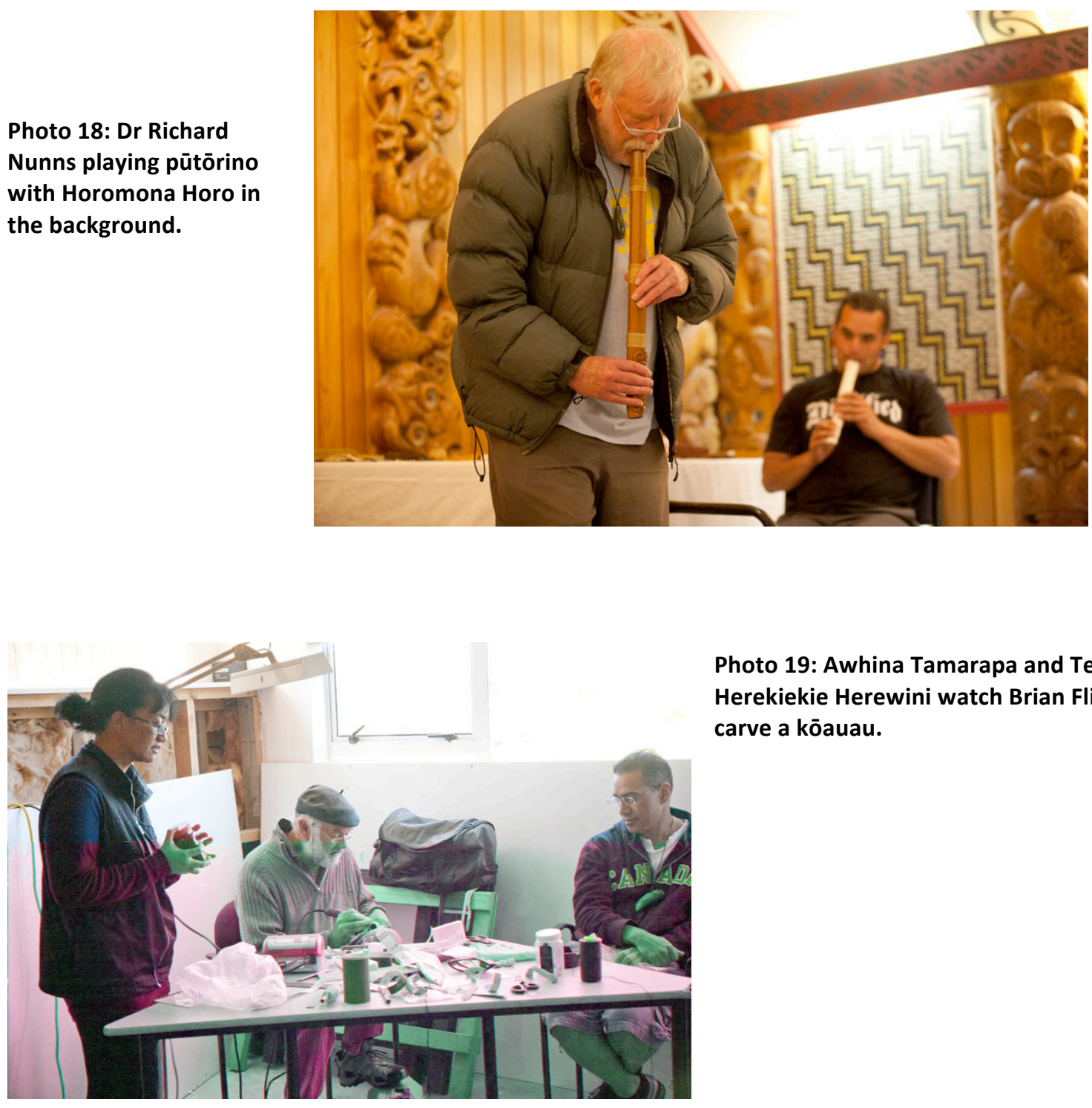

Photo 19: Awhina Tamarapa and Te Herekiekie Herewini watch Brian Flintoff carve a kōauau. 
Photo 20: Tanja Schubert-McArthur and son Maximilian listen to Amber Aranui playing pūkaea. (Photograph by: Marita Schubert)
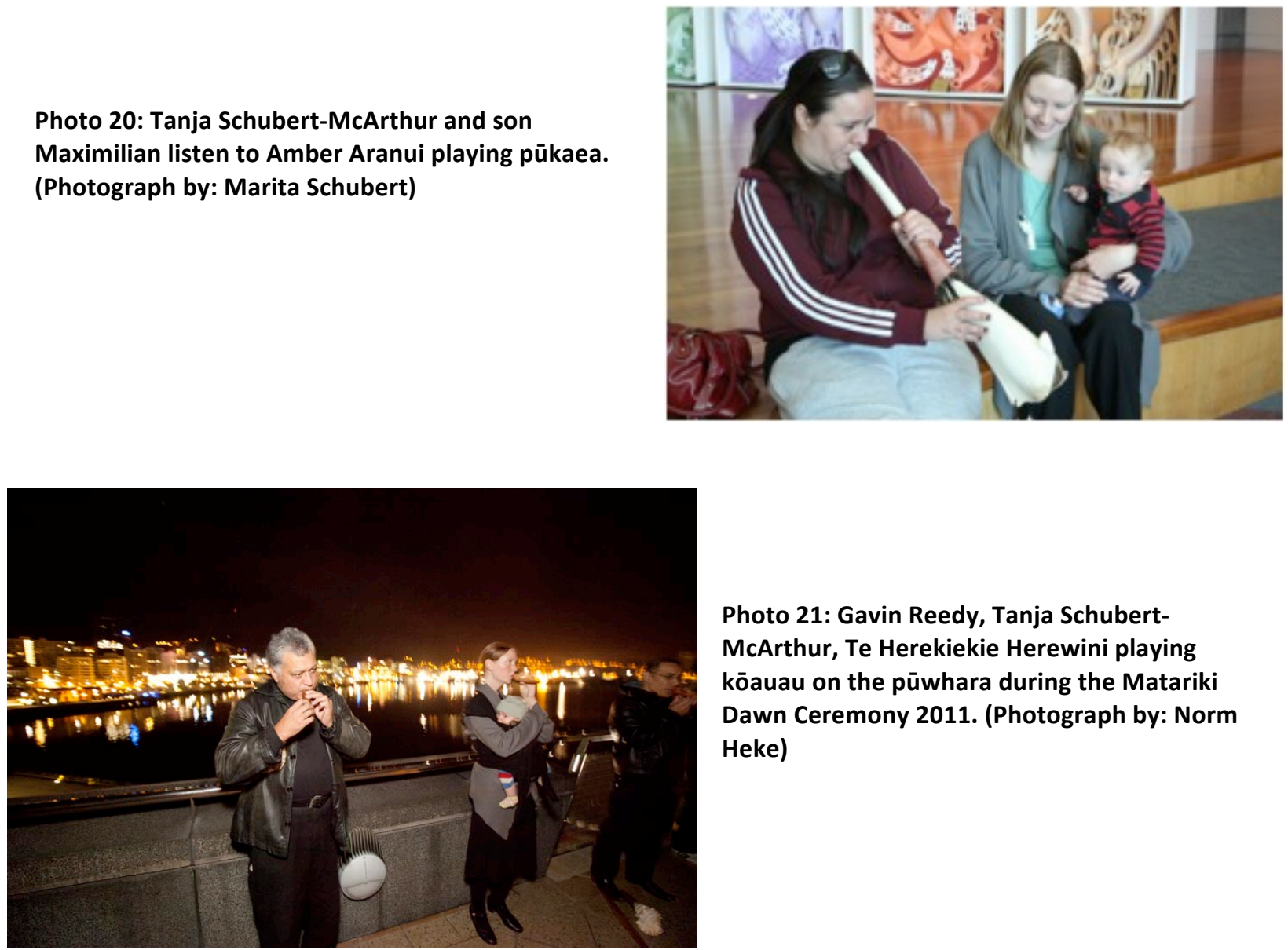

Photo 21: Gavin Reedy, Tanja SchubertMcArthur, Te Herekiekie Herewini playing kōauau on the pūwhara during the Matariki Dawn Ceremony 2011. (Photograph by: Norm Heke)

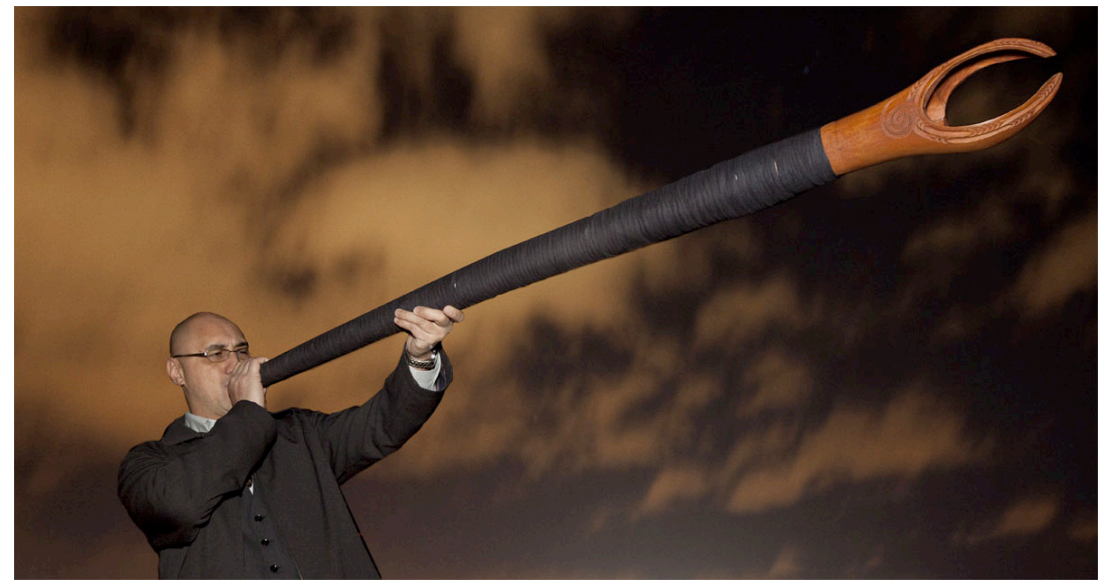

Photo 22: Shane Pasene playing pūkaea. (Photograph by: Te Papa) 


\section{Bibliography}

Abasa, Susan F.

1995 Careers in Museums: A Directory. North Fitzroy Victoria: Museums Australia.

Adorno, Theodor W.

1983 Prisms [by] Theodor W. Adorno. S. Weber and S. Weber, transl. London: Spearman.

Alivizatou, Marilena

2012 Intangible Heritage and the Museum: New Perspectives on Cultural

Preservation. Walnut Creek: Left Coast Press.

Allan, Lynne Carmichael

2008 Giving and Receiving: A Case Study of the Stowaways Exhibit in Blood, Earth, Fire - Whāngai, Whenua, Ahi Kā at the Museum of New Zealand Te Papa Tongarewa. BA Hons Thesis, Museum and Heritage Studies, Victoria University of Wellington.

Ames, Michael M.

1979 Applied Anthropology in Our Backyards. Practicing Anthropology 2 (1)(7):23-

24.

- 1986 Museums, the Public, and Anthropology: A Study in the Anthropology of Anthropology. Vancouver: University of British Columbia Press.

- 1988 The Democratization of Anthropology and Museums. AGMANZ Journal 19(2):3335.

- 1991 Biculturalism in Exhibitions. Museum Anthropology 15(2):7-15.

- 1992 Cannibal Tours and Glass Boxes: The Anthropology of Museums. Vancouver: UBC Press.

- 1996 'Rapporteurs' Summary Comments'. In Curatorship: Indigenous Perspectives in Post-Colonial Societies: Proceedings of Conference, May 1994. M.M. Ames and M. McKenzie, eds. Pp. 208. Ottawa: Canadian Museum of Civilization.

Amstutz, Mark R.

2005 The Healing of Nations: The Promise and Limits of Political Forgiveness. Lanham, MD: Rowman and Littlefield Publishers. 
Anderson, Benedict

2006 [1983] Imagined Communities: Reflections on the Origin and Spread of Nationalism. London: Verso.

Angouri, Jo, and Meredith Marra

2011 "OK one last thing for today then": Constructing Identities in Corporate Meeting Talk. In Constructing Identities at Work. J. Angouri and M. Marra, eds. Pp. 85-100. New York: Palgrave Macmillan.

Antonsich, Marco

2010 Searching for Belonging: An Analytical Framework. Geography Compass 4(6):644-659.

Appadurai, Arjun

1998 Globale ethnische Räume. [Global Ethnic Areas]. In Perspektiven der Weltgesellschaft. U. Beck, ed. Pp. 11-40. Frankfurt am Main: Suhrkamp.

—, ed. 1986 The Social Life of Things: Commodities in Cultural Perspective. Cambridge: Cambridge University Press.

Archibald, Lindsay

2007 Museums, Nations, Communities: Historicising the Late 20th Century Redevelopment Projects at the Canadian Museum of Civilization and the Museum of New Zealand Te Papa Tongarewa. Master's Thesis (applied), Museum and Heritage Studies, Victoria University of Wellington.

Armada, Bernard

2010 Place Politics: Material Transformation and Community Identity at the National Civil Rights Museum. Journal of Black Studies 40(5):897-914.

Armstrong, Kerry Raymond

2002 Issues Regarding Museum Evaluation and the Visitor Experience: A Case Study of "Signs of a Nation" in the Museum of New Zealand Te Papa Tongarewa. Master's Thesis, Tourism Management, Victoria University of Wellington.

Arnoldi, Mary Jo

1992 A Distorted Mirror: The Exhibition of the Herbert Ward Collection of Africana. In Museums and Communities: The Politics of Public Culture. I. Karp, C. Mullen Kreamer, and S.D. Lavine, eds. Pp. 428-457. Washington: Smithonian Institution Press.

Ash, Julie

2010 Tapu Advice Can Be Ignored, Says Minister. Dominion Post, 13 October. 
Ashley, Susan

2005 First Nations on View: Canadian Museums and Hybrid Representations of Culture. In Hybrid Entities, Annual Graduate Conference Hosted by the York/ Ryerson Pogramme in Communication and Culture. March 18-10, 2005. Pp. 32-40. Rogers Communication Centre, York University, Canada.

Augustynek, Marta, and Gunter Hirschfelder

2010 Integrationsmechanismen und Esskultur: Zur Akkulturation Polnischer und Moldawisch-Gagausischer Migranten [Mechanisms of Integration and Food Culture: About the Acculturation of Gagauz Moldovan Migrants]. In Esskultur und Kulturelle Identität: Ethnologische Nahrungsforschung im Östlichen Europa. H.M. Kalinke, K. Roth, and T. Weger, eds. Pp. 157-174. Oldenburg: Bundesinstitut für Kultur und Geschichte der Deutschen im Östlichen Europa.

Awatere, Donna

1984 Maori Sovereignty. Auckland: Broadsheet.

Ballantyne, Tony

2012 Webs of Empire: Locating New Zealand's Colonial Past. Wellington: Bridget Williams Books.

Ballara, Angela

1986 Proud to be White? A Survey of Pakeha Prejudice in New Zealand. Auckland: Heinemann.

- 1998 Iwi: The Dynamics of Māori Tribal Organisation from c.1769 to c.1945.

Wellington: Victoria University Press.

- 2012 Tirikatene, Eruera Tihema Te Aika. In Dictionary of New Zealand Biography: Te Ara - The Encyclopedia of New Zealand.

Bandura, Albert

1986 Social Foundations of Thought and Action: A Social Cognitive Theory. Englewood Cliff, NJ: Prentice-Hall.

Barcham, Manuhuia

2000 (De)Constructing the Politics of Indigeneity. In Political Theory and the Rights of Indigenous Peoples. D. Ivison, P. Patton, and W. Sanders, eds. Pp. 137-151. Cambridge: Cambrige University Press.

Barclay, Kelly

2005 Rethinking Inclusion and Biculturalism: Towards a More Relational Practice of Democratic Justice. In New Zealand Identities: Departures and Destinations. J.H. Liu, T. McCreanor, T. McIntosh, and T. Teaiwa, eds. Pp. 118-139. Wellington: Victoria University Press. 
Bargh, Maria, ed.

2007 Resistance: An Indigenous Response to Neoliberalism. Wellington: Huia.

Barlow, Cleve

2005 Tikanga Whakaaro: Key Concepts in Māori Culture. South Melbourne: Oxford University Press.

Barni, Mary, and Anita Herle

1998 Collaborative Projects on Torres Strait Collections. Journal of Museum Ethnography 10:115-120.

Bataille, Georges

2005 [1929] Museum [The Museum]. In Kritisches Wörterbuch. R.M. Kiesow and H. Schmidgen, eds. Pp. 64-66. Berlin: Merve.

Bauman, Zygmunt

2004 Identity: Conversations with Benedetto Vecchi. Cambridge: Polity Press.

Baumeister, Roy, and Mark Leary

1995 The Need to Belong: Desire for Interpersonal Attachments as a Fundamental Human Motivation. Psychological Bulletin 117(3):497-529.

Baur, Joachim, ed.

2010 Museumsanalyse: Methoden und Konturen eines Neuen Forschungsfeldes [Museum Analysis: Methods and Contours of a New Field of Enquiry]. Bielefeld: Transcript Verlag.

Beauvoir, Simone de

1973 The Second Sex. New York: Vintage Books.

Beck, Ulrich, and Elisabeth Beck-Gernsheim

1994 Riskante Freiheiten: Zur Individualisierung der Lebensformen in der Moderne [Risky Freedom: Individualisation of Lifestyles in Modernity]. Frankfurt am Main: Suhrkamp.

Beddgood, Janet

1997 Pakeha Ethnicity? SITES: A Journal of Social Anthropology and Cultural Studies 35:81-100.

Bedeian, Arthur G.

1984 Organizations: Theory and Analysis: Text and Cases. Hinsdale: Dryden Press. 
Beeman, William 0.

2000 The American Social Drama. Available online at:

ww.brown.edu/Administration/News_Bureau/2000-01/00-062.html (accessed 1 April 2013).

Belgrave, Michael

2005 Historical Frictions: Maori Claims and Reinvented Histories. Auckland: Auckland University Press.

Belich, James

1986 The New Zealand Wars and the Victorian Interpretation of Racial Conflict. Auckland: Auckland University Press.

- $\quad 1996$ Making Peoples: A History of the New Zealanders: From Polynesian Settlement to the End of the Nineteenth Century. Auckland: Allen Lane/Penguin.

- 2001a Foreword. In Civilising Mission? Perceptions and Representations of the New Zealand Native Schools System. J. Simon and L.T. Smith, eds. Pp. ix-xi. Auckland: Auckland University Press.

- 2001b Paradise Reforged: A History of the New Zealanders from the 1880s to the Year 2000. Auckland: Penguin.

Bell, Avril

1996 "We are Just New Zealanders": Pakeha Identity Politics. In Nga Patai: Racism and Ethnic Relations in Aotearoa/New Zealand. P. Spoonley, C. Macpherson, and D. Pearson, eds. Pp. 144-158. Palmerston North: Dunmore Press.

Bell, Claudia , and Steve Matthewman, eds.

2004 Cultural Studies in Aotearoa New Zealand: Identity, Space and Place. South Melbourne: Oxford University Press.

Bell, Vikki

1999 Performativity and Belonging: An Introduction. Theory, Culture and Society 16(2):1-10.

Belliger, Andréa, and David J. Krieger

2008 Ritualtheorien: Ein Einführendes Handbuch [Ritual Theory: An Introductory Handbook]. $4^{\text {th }}$ edition. Wiesbaden: VS Verlag für Sozialwissenschaften. 
Bendix, Regina, and Gisela Welz

2002 Kulturvermittlung und 'Public Folklore': Formen des Volkskundlichen Wissenstransfer in Deutschland und den USA [Forms of Anthropological Knowledge Transfer in Germany and the USA]. In Kulturwissenschaft und Öffentlichkeit: Amerikanische und Deutschsprachige Volkskunde im Gespräch. R. Bendix and G. Welz, eds. Pp. 15-29. Frankfurt am Main: Institut für Kulturanthropologie und Europäische Ethnologie der Johann Wolfgang Goethe-Universtität.

Bennett, Tony

1995 The Birth of the Museum: History, Theory, Politics. London: Routledge.

- 1998 Culture: A Reformer's Science. London: Sage.

- 2013 Making Culture, Changing Society. Abingdon, Oxon: Routledge.

Bennington, Seddon

2004 Te Papa: Product, and Agent, of Change. Te Ara - Journal of Museums Aotearoa 29(1):9-11.

- 2007 The National Museum: Whose History? In The National Museums in a Globalised World: A Conference on the Bicentenary of the National Museum of Denmark, Copenhagen May 21-22 2007. P.K. Madsen and L. Jorgensen, eds. Pp. 78-83. Gylling: Narayana Press.

Benton, Richard, Alex Frame and Paul Meredith, eds.

2013 Te Mātāpunenga: A Compendium of References to the Concepts and Institutions of Māori Customary Law. Te Mātāhauariki Research Institute, University of Waikato. Wellington: Victoria University Press.

Bergesen, Albert

1999 The Ritual Order. Humboldt Journal of Social Relations (25):157-197.

Bergson, Henri

1956 Laughter. In Comedy. S. Wylie, ed. Pp. 61-190. Garden City, N.Y.: Doubleday Anchor Books.

Bernard, H. Russell, ed.

1998 Handbook of Methods in Cultural Anthropology. Walnut Creek: Altamira Press.

Bernard, H. Russell, and Gery Wayne Ryan

2010 Analyzing Qualitative Data: Systematic Approaches. Los Angeles: Sage. 
Bertram, Geoff

2009 The New Zealand Economy 1900-2000. In The New Oxford History of New Zealand. G. Byrnes, ed. Pp. 537-572. Oxford: Oxford University Press.

Best, Elsdon

1934 The Maori as he was: A Brief Account of Maori Life as it was in Pre-European Days. Wellington: Dominion Museum.

Beyer, Janice M., and Harrison M. Trice

1988 The Communication of Power Relations in Organizations Through Cultural Rites. In Inside Organizations: Understanding the Human Dimension. M.O. Jones, M.D. Moore, and R.C. Snyder, eds. Pp. 141-163. London: Sage.

Bhabha, Homi K.

1994 The Location of Culture. London: Routledge.

Binney, Judith

1987 Maori Oral Narratives, Pakeha Written Texts: Two Forms of Telling History. NZJH 21(1):16-28.

Bishop, Russell

1994 Initiating Empowering Research? New Zealand Journal of Educational Studies 29(1):175-188.

- 1996 Collaborative Research Stories: Whakawhanaungatanga. Palmerston North: Dunmore Press.

- 2008 Te Kotahitanga: Kaupapa Māori in Mainstream Classrooms. In Handbook of Critical and Indigenous Methodologies. N.K. Denzin, Y.S. Lincoln, and L.T. Smith, eds. Pp. 439-458. Thousand Oaks, CA: Sage.

Bishop, Russell, and Ted Glynn

1999 Culture Counts: Changing Power Relations in Education. Palmerston North: Dunmore Press.

Boast, Robin

2011 Neocolonial Collaboration: Museum as Contact Zone Revisited. Museum Anthropology 34(1):56-70.

Boast, Richard, and Richard S. Hill, eds.

2009 Raupatu: The Confiscation of Māori Land. Wellington: Victoria University Press. 
Bönisch-Brednich, Brigitte

2002 Auswandern: Destination Neuseeland [Emigrating: Destination New Zealand]. Berlin: Mana Verlag.

- 2012 Autoethnographie: Neue Ansätze zur Subjektivität in Kulturanthropologischer Forschung [Autoethnography: New Approaches of Subjectivity in Anthropological Research]. Zeitschrift für Volkskunde 108(2012/ I):47-63.

Bönisch-Brednich, Brigitte, and Richard S. Hill

2002 From Monoculturalism to Biculturalism in Twentieth-Century New

Zealand/Aotearoa. Cultures of the Commonwealth 8(Spring):29-47.

Borman, Kathryn, et al.

2007 Observing a Workplace. In Doing cultural Anthropology. 2nd edition. M.v. Angrosino, ed. Pp. 83-90. Longrove, Illinois: Wavepress.

Bossley, Pete

1998 Te Papa: An Architectural Adventure. Wellington: Te Papa Press.

- 2008 Interview with Te Papa Architect Pete Bossley. 'Te Papa at ten', architecturenz (6) 2008:90-92.

Bouquet, Mary

2001 Introduction: Academic Anthropology and the Museum: Back to the Future. In Academic Anthropology and the Museum: Back to the Future. M. Bouquet, ed. Pp. 1-16. New York: Berghahn.

Bourdieu, Pierre

1984 Distinction: A Social Critique of the Judgement of Taste. R. Nice, transl. London: Routledge and Kegan Paul.

- 1991 Language and Symbolic Power. G. Raymond and M. Adamson, transl. Cambridge: Harvard University Press.

- 1998 Ortseffekte [Effects of Spaces]. In Kultur in der Stadt: Stadtsoziologische Analysen zur Kultur. Albrecht Göschel/ Volker Kirchberg, eds. Pp. 17-25. Opladen: Leske und Budrich.

Boylan, Patrick, ed.

1992 Museums 2000: Politics, People, Professionals, and Profit. London: Museums Association in conjunction with Routledge.

Boylan, Patrick

2006 The Museum Profession. In A Companion to Museum Studies. S. Macdonald, ed. Pp. 415-430. Oxford: Blackwell Publishing. 
Bozic-Vrbancic, Senka

2003 One Nation, Two Peoples, Many Cultures: Exhibiting Identity at Te Papa

Tongarewa. Journal of the Polynesian Society 112(3):295-313.

Brady, Miranda J.

2009 A Dialogic Response to the Problematized Past: The National Museum of the American Indian. In Contesting Knowledge: Museums and Indigenous Perspectives. S. Sleeper-Smith, ed. Pp. 133-155. Lincoln: University of Nebraska Press.

Brednich, Rolf W., ed.

2001 Grundriss der Volkskunde: Einführung in die Forschungsfelder der

Europäischen Ethnologie. Berlin: Dietrich Reimer Verlag.

Brettell, Caroline B.

1998 Fieldwork in the Archives: Methods and Sources in Historical Anthropology. In Handbook of Methods in Cultural Anthropology. H.R. Bernard, ed. Pp. 513-546. Walnut Creek: Altamira Press.

Brook, Andrew et al.

2013 Taboo. The Rocks: Museum of Contemporary Art Australia.

Brooks, Mary M., and Claire Rumsey

2007 'Who Knows the Fate of His Bones?' Rethinking the Body on Display: Object, Art or Human Remains? In Museum Revolutions: How Museums Change and are Changed.

S.J. Knell, S. MacLeod, and S. Watson, eds. Pp. 343-354. New York: Routledge.

Brosnahan, Sean

2009 Review: Watersheds - Ngā Waipupū: A History of Tairāwhiti, Tairāwhiti

Museum. New Zealand Journal of History 43(2):235-236.

Buchanan, D., D. Boddy and J. Mc Calman

1988 Getting In, Getting On, Getting Out, Getting Back. In Doing Research in

Organisations. A. Bryman, ed. Pp. 53-67. London: Routledge.

Burke, Kenneth

1945 Grammar of Motives. New York: Prentice-Hall.

Butler, Judith

1990 Gender Trouble: Feminism and the Subversion of Identity. New York: Routledge. 
Butler, Judith, and Gayatri Chakravorty Spivak

2010 Who Sings the Nation-State? Language, Politics, Belonging. London: Seagull Books.

Butler, Philippa

1996 Te Māori Past and Present: Stories of Te Māori, Social Anthropology, Massey University.

Butler, Shelley Ruth

1999 Contested Representations: Revisiting Into the Heart of Africa. New York: Routledge.

Butt, Danny

2005 Biculturalism as Multiculturalism? In Biculturalism or Multiculturalism? Christchurch: University of Canterbury.

Butts, David

1994 The Orthodoxy of Bi-Culturalism. New Zealand Museums Journal 24(2):32-34.

- 2002 Māori and Museums: The Politics of Indigenous Recognition. In Museums, Society, Inequality. R. Sandell, ed. Pp. 225-243. London and New York: Routledge.

- 2003 Māori and Museum: The Politics of Indigenous Recognition, PhD Thesis, Museum Studies. Palmerston North, Massey University.

- 2006 Museum Governance, Indigenous Recognition and (In)Tolerant Multiculturalism. New Zealand Sociology 21(1):89-107.

- 2007 Māori, Museum, and the Treaty of Waitangi: The Changing Politics of Representation and Control. In Museum Revolutions: How Museums Change and Are Changed. S.J. Knell, S. MacLeod, and S.E.R. Watson, eds. Pp. 215-227. London: Routledge.

Butts, David, Sharon Dell, and Rangi Wills

2002 Recent Constitutional Changes at Whanganui Regional Museum. Te Ara - Journal of Museums Aotearoa 27(2):37-40.

Byrnes, Giselle

2004 The Waitangi Tribunal and New Zealand History. Auckland: Oxford University Press.

—, ed. 2009 The New Oxford History of New Zealand. South Melbourne: Oxford University Press Australia and New Zealand. 
Cameron, Duncan

2004 The Museum, a Temple or Forum. In Reinventing the Museum: Historical and Contemporary Perspectives on the Paradigm Shift. G. Anderson, ed. Pp. 61-73. Walnut Creek: Altamira Press.

Campbell, Marie L.

2006 Institutional Ethnography and Experience as Data. In Institutional Ethnography as Practice. D.E. Smith, ed. Pp. 91-107. Lanham, MD: Rowman and Littlefield.

Carlisle, Celine

2003 A Working Model of Biculturalism in Action: A Qualitative Analysis of Biculturalism Within an Organisational Context. Honours Research Essay, Psychology. Wellington: Victoria University of Wellington.

Carsten, Janet

2012 Fieldwork Since the 1980s: Total Immersion and its Discontents. In The Sage Handbook of Social Anthropology. R. Fardon and John Gledhill, eds. Pp. 7-18. Los Angeles: Sage.

Cassells, Richard

1994 Otago Museum: The Wharenui Mataatua and the Waitangi Tribunal. New Zealand Museums Journal 24(2):28-31.

Cefkin, Melissa, ed.

2010 Ethnography and the Corporate Encounter: Reflections on Research in and of Corporations. New York: Berghahn Books.

Chapman, Malcolm

2001 Social Anthropology and Business Studies: Some Considerations of Method. In Inside Organizations: Anthroplogists at Work. D.N. Gellner and E. Hirsch, eds. Pp. 19-33. Oxford: Berg.

Chapple, Simon

2000 Maori Socio-Economic Disparity: A Paper for the Ministry of Social Policy.

Clarke, Chanel Victoire

1998 Mai i Te Poi Ki Te Ao Marama: Māori and Museums: Past, Present and Future Aspirations, History, University of Waikato.

- 2003 Selected Bibliographie of Resource Information for Iwi and Bicultural Development with Regard to Museums and Cultural Heritage. Wellington: Museum of New Zealand Te Papa Tongarewa. 
Clifford, James

1988 The Predicament of Culture: Twentieth-century Ethnography, Literature, and Art. Cambridge: Harvard University Press.

- 1997 Routes: Travel and Translation in the Late Twentieth Century. Cambridge: Harvard University Press.

Clifford, James, and George E. Marcus, eds.

1986 Writing Culture: The Poetics and Politics of Ethnography: A School of American Research Advanced Seminar. Berkeley: University of California Press.

Coates, Ken S.

2004 A Global Histroy of Indigenous Peoples: Struggle and Survival. Basingstoke, Hampshire: Palgrave Macmillan.

Cole, Catherine

1996 'Round-Table Responses'. In Curatorship: Indigenous Perspectives in PostColonial Societies: Proceedings of Conference, May 1994. M.M. Ames and M. McKenzie, eds. Pp. 174. Ottawa: Canadian Museum of Civilization.

Corsane, Gerard

2005 Heritage, Museums and Galleries: An Introductory Reader. London and New York: Routledge.

Cottrell, Anna, and Gaylene Preston, dirs.

1999 Getting to Our Place. 80 min. Wellington: Gaylene Preston Productions in association with NZ on Air and TVNZ.

Cowley, J.

1999 The Politics of Belonging: Some Theoretical Considerations. In The Politics of Belonging: Migrants and Minorities in Contemporary Europe. A. Geddes and A. Favell, eds. Pp. 15-41. Aldershot, England: Ashgate.

Cram, Fiona

1997 Developing Partnerships in Research: Pakeha Researchers and Māori Research. SITES: A Journal of Social Anthropology and Cultural Studies 35:44-63.

- 2001 Rangahau Mãori: Tona Tika, Tona Pono. In Research Ethics in Aotearoa. M. Tolich, ed. Pp. 35-52. Auckland: Longman.

Crane, Susan A.

1997 Memory, Distortion, and History in the Museum. History and Theory 36(4):4463. 
Czarniawska, Barbara

2004 On Time, Space, and Action Nets. Organization 11:773-91.

Czarniawska, Barbara, and Pasquale Gagliardi, eds.

2003 Narratives We Organize By. Amsterdam and Philadelphia: John Benjamins Pub Co.

Czarniawska-Joerges, Barbara

1997 Narrating the Organization: Dramas of Institutional Identity. Chicago: University of Chicago Press.

Dalrymple, Theodore

1999 An Amusement Arcade Masquerading as a Museum. In New Statesman. Pp. 3233, Vol. 12.

Darrouzet, Christopher, Helga Wild, and Susann Wilkinson

2009 Participatory Ethnography at Work: Practicing in the Puzzle Palaces of a Large, Complex Healthcare Organization. In Ethnography and the Corporate Encounter:

Reflections on Research in and of Corporations. M. Cefkin, ed. Pp. 61-94. New York: Berghahn.

Dart, William

1998 New Zealand: A Bicultural Meeting Place. UNESCO Sources 105:5-6.

Davidson, Lee, and Pamela Sibley

2011 Audiences at the New Museum: A Profile of Visitors to the Museum of New Zealand Te Papa Tongarewa. Visitor Studies 14(2):176-194.

Davies, Charlotte Aull

2008 Reflexive Ethnography. New York: Routledge.

Davies, Christine. S.

2008 A Funeral Liturgy: Death Rituals as Symbolic Communication. Journal of Loss and Trauma 13(5):406-421.

Davison, Patricia

1999 Museums and the Reshaping of Memory. In Negotiating the Past: Making of Memory in South Africa. S. Nuttal and C. Coetzee, eds. Pp. 143-160. Oxford and New York: Oxford University Press. 
Day, Jasmine

2006 The Mummy's Curse: Mummymania in the English-speaking World. London: Routledge.

Denzin, Norman K.

1997 Interpretive Ethnography: Ethnographic Practices for the 21st Century. Thousand Oaks: Sage Publications.

- 2003 Performance Ethnography: Critical Pedagogy and the Politics of Culture. Thousand Oaks: Sage.

Denzin, Norman K., Yvonna S. Lincoln, and Linda Tuhiwai Smith, eds.

2008 Handbook of Critical and Indigenous Methodologies. Los Angeles: Sage.

Department of Justice

1989 Principles for Crown Action on the Treaty of Waitangi.

Devereux, George

1968 From Anxiety to Method in the Behavioral Sciences. The Hague: Mouton.

DeWalt, Kathleen M., and Billie R. DeWalt

2002 Participant Observation: A Guide for Fieldworkers. Walnut Creek: Altamira Press.

Diamond, Timothy

2006 "Where did you get the fur coat, Fern?": Participant Observation in Institutional Ethnography. In Institutional Ethnography as Practice. D.E. Smith, ed. Pp. 45-63. Lanham, MD: Rowman and Littlefield.

Dibley, Ben

1996 Museum, Native, Nation: Museological Narrative and Postcolonial National Identity Formation. Master's Thesis, Sociology. Auckland: University of Auckland.

- 1997 Museum, Nation, Narration: The Museum of New Zealand - Te Papa Tongarewa: 'Telling New Zealand's Story'. Culture and Policy 8(3):97-119.

- 2005 The Museum's Redemption: Contact Zones, Government and the Limits of Reform. International Journal of Cultural Studies 8(1):5-27.

- 2007 Antipodean Aesthetics, Public Policy and the Museum: The Papa, for Example. Cultural Studies Review 13(1):129-149. 
Dickinson, George E., and Michael R. Leming

2010 Understanding Dying, Death, and Bereavement. Belmont, CA: Wadsworth.

Dietz, Angelika

2011 Dimensions of Belonging and Migrants by Choice: Contemporary Movements Between Italy and Northern Ireland. Münster: Waxmann.

DigitalMaori

2010 Te Papa Bans Pregnant Women From Exhibit TV3 Reports. Tangata Whenua website, October 12. Available online at:

http://news.tangatawhenua.com/archives/7279 (accessed 20 October 2010).

Dodd, Jocelyn, and Richard Sandell, eds.

2001 Including Museums: Perspectives on Museums, Galleries, and Social Inclusion. Leicester: Research Centre for Museums and Galleries, University of Leicester.

Doerr, Neriko Musha

2009 Meaningful Inconsistencies: Bicultural Nationhood, the Free Market, and Schooling in Aotearoa/New Zealand. New York: Berghahn Books.

Douglas, Mary

1966 Purity and Danger: An Analysis of Concepts of Pollution and Taboo. London: Routledge and Kegan Paul.

- 1972 Deciphering a Meal. Daedalus: Journal of the American Academy of Arts and Sciences (Winter):61-81.

- 1984 [1973] Standard Social Uses of Food: Introduction. In Food in the Social Order: Studies of Food and Festivities in Three American Communities. M. Douglas, ed. Pp. 1-39. New York: Russell Sage Foundation.

- 1986 How Institutions Think. Syracuse: Syracuse University Press.

Duff, Roger

1978 Repatriation of the Ortiz Maori Lintel. AGMANZ News 9(4):15-18.

Durie, Mason

1994 Understanding Biculturalism. Paper presented at Kokiri Nga Tahi Hui - Side by Side Seminar: Maori and Pakeha working together. Sponsored by the Race Relations Office. Gisborne.

- 1995 Beyond 1852: Maori, the State, and a New Zealand Constitution. SITES: A Journal of Social Anthropology and Cultural Studies 30:31-47. 
- $\quad$ 1998a Te Mana, Te Kāwanatanga: The Politics of Māori Self-determination. Auckland: Oxford University Press.

- 1998b Whaiora: Maori Health Development. $2^{\text {nd }}$ edition. Auckland: Oxford Univeristy Press.

- 2005 Tino Rangatiratanga. In Waitangi Revisited. M. Belgrave, M. Kawharu, and D. Williams, eds. Pp. 3-19. Melbourne: Oxford University Press.

Durkheim, Emile

1976 [1915] The Elementary Forms of the Religious Life. J.W. Swain, transl. London: Allen and Unwin.

Dyson, Lynda

2005 Reinventing the Nation: British Heritage and the Bicultural Settlement in New Zealand. In The Politics of Heritage: The Legacies of 'Race'. J. Littler and R. Naidoo, eds. Pp. 115-130. London: Routledge.

Early, James

1995 Creating Safe Environments in the Museum Profession. The Journal of Museum Education 20(3):16-19.

Eliade, Mircea

1958 Patterns in Comparative Religion. R. Sheed, transl. New York: Sheed and Ward.

Ellis, Ngarino

2000/2001 Restoring Spirits: The Auckland Museum's Māori Collection. Art New Zealand 97(Summer 2000/2001):92-94.

Ember, Carol R., and Melvin Ember

1998 Cross-cultural Research. In Handbook of Methods in Cultural Anthropology. H.R. Bernard, ed. Pp. 647-687. Walnut Creek: Altamira Press.

- 2001 Cross-cultural Research Methods. Lanham, MD: Altamira Press.

Enfield, N.Y.

2009 Everyday Ritual in the Residential World. In Ritual Communication. G. Senft, and E.B. Basso, eds. Pp. 51-80. Oxford: Berg.

Evans, Rose

1996 Conservation in a Changing Museum Context: A Case Study at the Museum of New Zealand Te Papa Tongarewa. New Zealand Museums Journal 26(1):39-41. 
- $\quad 1999$ Tribal Involvement in Exhibition Planning and Conservation Treatment: A New Institutional Approach. ICOM Ethnographic Conservation Newsletter 19:13-16.

Fforde, Cressida

2004 Collecting the Dead: Archaeology and the Reburial Issue. London: Duckworth.

Fitz Gibbon, Kate, ed.

2005 Who Owns the Past? Cultural Policy, Cultural Property, and the Law. New Brunswick, N.J.: Rutgers University Press in Association with The American Council for Cultural Policy.

Fitzgerald, Michael

2009 Te Papa's Community Gallery: Presenting Migrant Stories at 'Our Place'. New Zealand Journal of History 43(2):198-207.

Fleras, Augie

1999 Politicising Indigeneity: Ethno-Politics in White Settler Dominions. In Indigenous People's Rights in Australia. P. Havermann, ed. Pp. 187-234. Auckland: Oxford University Press.

Fleras, Augie, and Paul Spoonley

1999 Recalling Aotearoa: Indigenous Politics and Ethnic Relations in New Zealand. Auckland: Oxford University Press.

Flintoff, Brian

2004 Taonga Pūoro = Singing Treasures: The Musical Instruments of the Māori. Nelson: Craig Potton Publishing.

Forsyth, Jenny

2000 'It's Our Place and We're Proud of It'. New Zealand Herald, January 30, p.7.

Foucault, Michel

1973 The Birth of the Clinic: An Archaeology of Medical Perception. A.M.S. Smith, transl. New York: Pantheon Books.

- 1977 Discipline and Punish: The Birth of the Prison. A. Sheridan, transl. New York: Pantheon Books.

- $\quad 1980 \quad$ Power/Knowledge: Selected Interviews and Other Writings, 1972-1977. C. Gordon, transl. Brighton: Harvester Press. 
Fraser, Jem

2007 Museums: Drama, Ritual, and Power. In Museum Revolutions: How Museums Change and are Changed. S.J. Knell, S. MacLeod, and S. Watson, eds. Pp. 291-302. New York: Routledge.

Friebertshäuser, Barbara

1997 Feldforschung und teilnehmende Beobachtung [Fieldwork and Participant Observation]. In Handbuch Qualitative Forschungsmethoden in der

Erziehungswissenschaft. B. Friebertshäuser and A. Prengel eds. Pp. 503-534. Weinheim: Juventa.

Gagné, Natacha

2013 Being Māori in the City: Indigenous Everyday Life in Auckland. Toronto: Toronto University Press.

2009 The Political Dimensions of Coexistence. Anthropological Theory 9(1):33-58.

Galla, Amareswar

1996 Indigenous Peoples, Museums and Frameworks for Effective Change. In Curatorship: Indigenous Perspectives in Post-Colonial Societies. Proceedings. Mercury Series. E. Arinze and A. Cummins, eds. Pp. 82-95: Canadian Museum of Civilization with the Commonwealth Association of Museums and the University of Victoria, British Columbia.

Garbutt, Eva

2007 The Care of Living Objects: Conserving Rauru and Te Wharepuni A Maui in Germany. In Decolonizing Conservation: Caring for Maori Meeting Houses Outside New Zealand. D. Sully, ed. Pp. 111-126. Walnut Creek: Left Coast Press.

Gardiner, Wira

2012 Speech given in the panel discussion 'Taonga to Taonga' with Willie Jackson, Jenny Harper, Albert Wendt, and Ripeka Evans at the Museums Aotearoa Conference: Collaboration in Practice. Wellington 18-20 April: Te Papa.

Geddis, Andrew

2010 Why Does Te Papa Hate Women so Much (and Other Outraged Thoughts). Pundit website, 12 October. Available online at: http://www.pundit.co.nz/content/why-doeste-papa-hate-women-so-much-and-other-outraged-thoughts (accessed 20 October 2010).

Geertz, Clifford

1973 The Interpretation of Cultures: Selected Essays. New York: Basic Books. 
Gell, Alfred

1994 The Technology of Enchantment and the Enchantment of Technology. In Anthropology, Art, and Aesthetics. J. Coote and A. Shelton, eds. Pp. 40-66. Oxford: Oxford University Press.

Gellner, David N., and Eric Hirsch, eds.

2001 Inside Organizations: Anthropologists at Work. Oxford: Berg.

Gibson, Stephanie

2003 Te Papa and New Zealand's Indian Communities: A Case Study About Exhibition Development. Tuhinga 14:61-75.

Giddens, Anthony

1984 The Constitution of Society: Outline of the Theory of Structuration. Cambridge: Polity Press.

- 1991 Modernity and Self-identity. Cambridge: Polity Press.

Girtler, Roland

2001 Methoden der Feldforschung [Methods of Fieldwork]. Wien: LIT Verlag.

Glaser, Barney G. and Anselm Strauss

1967 The Discovery of Grounded Theory: Strategies for Qualitative Research. Chicago, IL: Aldine Publishing.

Glick Schiller, Nina, Linda Basch, and Christina Blanc-Szanton

1992 Transnationalism: A New Analytic Framework for Understanding Migration. In Towards a Transnational Perspective on Migration, Race, Class, Ethnicity and Nationalism Reconsidered. N. Glick Schiller, L. Basch, and C. Blanc-Szanton, eds. Pp. 1-24. New York: New York Academy of Sciences.

Goffman, Erving

1959 The Presentation of Self in Everyday Life. Garden City: Doubleday.

- 1961 Encounters: Two Studies in the Sociology of Interaction. Indianapolis: BobbsMerrill.

- 1974 Frame Analysis: An Essay on the Organization of Experience. Cambridge: Harvard University Press.

Golding, Vivien

2007 Learning at the Museum Frontiers: Democracy, Identity, and Difference. In Museum Revolutions: How Museums Change and are Changed. S.J. Knell, S. MacLeod, and S. Watson, eds. Pp. 315-329. New York: Routledge. 
- 2009 Learning at the Museum Frontiers: Identity, Race and Power. Farnham: Ashgate.

Goldsmith, Michael

2001 Te Papa/Our Place and the Grammar of New Zealand Museumhood. In Annual Conference of Social Anthropologists of Aotearoa New Zealand, 24-25 November 2001. Palmerston North: Massey University.

- 2003 'Our Place' in New Zealand Culture: How the Museum of New Zealand Constructs Biculturalism Ethnologies Comparée 6(Printemps):1-14.

Goldsmith, Michael, and Toon Van Meijl

2003 Introduction: Recognition, Redistribution and Reconciliation in Postcolonial Settler Societies. Journal of the Polynesian Society 112(3):205-218.

Gorbey, Ken

1991 The Challenge of Creating a Bicultural Museum. Museum Anthropology 15(4):78.

- $2006 \quad$ 'Driving Stakes Into the Ground': Michael Blumenthal's Vision for a Museum of German Jewish History. In Die Ersten Achtzig Jahre/The First Eighty Years: W. Michael Blumenthal zum Geburtstag. Pp. 155-163. Berlin: Society of Friends of the Jewish Museum Berlin.

Gore, James Michael

2002 Representations of History and Nation in Museums in Australia and Aotearoa New Zealand: The National Museum of Australia and the Museum of New Zealand Te Papa Tongarewa. PhD Thesis, Department of History, University of Melbourne.

- 2003 Representations of Non-Indigenous History and Identity in the National Museum of Australia and Museum of New Zealand Te Papa Tongarewa.

Götz, Irene

1997 Unternehmenskultur: Die Arbeitswelt einer Grossbäckerei aus

Kulturwissenschaftlicher Sicht. Münster: Waxmann.

Graham, Douglas

1997 Trick or Treaty? Wellington: Institute of Policy Studies.

Greenland, Hauraki

1991 Maori Ethnicity as Ideology. In Nga Take: Ethnic Relations and Racism in Aotearoa/New Zealand. P. Spoonley, D. Pearson, and C. Macpherson, eds. Pp. 90-107.

Palmerston North: Dunmore Press. 
Griffin, Janette , et.al.

2007 Optimizing Learning Opportunities in Museums: The Role of Organizational Culture. In In Principle, in Practice: Museums as Learning Institutions. J.H. Falk, L.D. Dierking, and S. Foutz, eds. Pp. 153-165. Plymouth: Altamira Press.

Groys, Boris

1997 Logik der Sammlung: Am Ende des musealen Zeitalters [Logic of Collection: At the End of the Museological Era]. München: Hanser.

Gurian, Elaine Heumann

1995a Offering Safer Public Spaces. The Journal of Museum Education 20(3):14-16.

—, ed. 1995b Institutional Trauma: The Effect of Major Change on Museum Staff. Washington, DC: American Association of Museums.

- $\quad 1998$ A Ray of Hope. Architecture New Zealand February (Special Edition 'The Designing of Te Papa'. Pp. 74-79.

- 2004 Singing and Dancing at Night. In Stewards of the Sacred. L.E. Sullivan and A. Edward, eds. Pp. 89-96. Washington: American Association of Museums.

- 2006a Civilizing the Museum: The Collected Writings of Elaine Heumann Gurian. London: Routledge.

- 2006b Along the Continuum, Museums and Possibilities. Open Museum Journal, available online from http://hosting.collectionsaustralia.net/omj/vol8/pdfs/egurianpaper.pdf. Retrieved 14 September 2010.

Hakiwai, Arapata

1990 Once Again the Light of Day? Museums and Maori Culture in New Zealand. Museum 42(1):35-38.

- 1995 Ruatepupuke: Working Together, Understanding One Another. New Zealand Museums Journal 25(1):42-44.

- $\quad 1999$ Kaitiakitanga - Looking After the Culture: Insights from "Within" - Two Curatorial Perspectives. ICOM Ethnographic Conservation Newsletter 19:10-12.

- 2005 The Search for Legitimacy: Museum in Aotearoa, New Zealand - A Maori Viewpoint. In Heritage, Museums and Galleries: An Introduction Reader. G. Corsane, ed. London: Routledge.

Hall, Edward

1976 Beyond Culture. Garden City, N.Y.: Anchor Press.

Hallam, Elizabeth, Jenny Hockey and Glennys Howarth

1999 Beyond the Body: Death and Social Identity. London and New York: Routledge. 
Halpin, Marjorie

1978 Review of "The 12,000 Year Gap: Archeology in British Columbia" at the British Columbia Museum. Canadian Museums Association Gazette 11(1):40-48.

Handler, Richard, and Eric Gable

1997 The New History in an Old Museum: Creating the Past at Colonial Williamsburg. Durham: Duke University Press.

Hanham, Stacey

2000 The Te Maori Exhibition: An Examination of Its Organisation and Impacts as Seen by Those Closely Involved with It. Master's Thesis, Museum and Heritage Studies, Victoria University of Wellington.

Harawira, Wena

1997 Te kawa o te marae: A Guide For All Marae Visitors. Auckland: Reed.

Harré Hindmarsh, Jennie

2000 Biculturalism (and Antiracism) in Education in New Zealand: An Overview. In Systems of Education: Theories, Policies and Implicit Values. M. Leicester, C. Mogdil, and S. Mogdil, eds. Pp. 126-143. London and New York: Falmer Press.

- $\quad 2007$ A Way Forward: The Remaking of New Zealand Museums. Museums and Social Issues 2(1):89-102.

Harris, Aroha

1993 Crown Acquisition of Confiscated and Maori Land in Taranaki, 1872-1881.

Wellington: Waitangi Tribunal Division, Dept. of Justice.

- $2004 \quad$ Hīkoi: Forty Years of Māori Protest. Wellington: Huia.

Harrison, Julia D.

2005a Ideas of Museums in the 1990s. In Heritage, Museums and Galleries: An Introductory Reader. G. Corsane, ed. Pp. 38-53. London: Routledge.

- 2005b Shaping Collaboration: Considering Institutional Culture. Museum Management and Curatorship 20(3):195-212.

Hauenschild, Andrea

1988 Claims and Reality of New Museology: Case Studies in Canada, the United States and Mexico. Washington, DC: Center for Museum Studies, Smithsonian Institution.

Healy, Chris, and Andrea Witcomb, eds.

2006 South Pacific Museums: Experiments in Culture. Melbourne: Monash University ePress. 
Hein, George E., and Mary Alexander

1998 Museums: Places of Learning. Washington: American Association of Museums, Education Committee.

Heller, Monica

1985 Ethnic Relations and Language Use in Montréal. In Language of Inequality. N. Wolfson and J. Manes, eds. Pp. 75-90. Berlin: Walter de Gruyter and Co.

Henare, Amiria

2004 Rewriting the Script: Te Papa Tongarewa the Museum of New Zealand. Social Analysis 48(1):55-63.

- 2005 Museums, Anthropology and Imperial Exchange. New York: Cambridge University Press.

- $\quad 2007$ Taonga Maori: Encompassing Rights and Property in New Zealand. In Thinking Through Things: Theorising Artefacts Ethnographically. A. Henare, M. Holbraad, and S. Wastell, eds. Pp. 47-67. London and New York: Routledge.

Hendry, Joy

2005 Reclaiming Indigenous Culture: Indigenous People and Self-Representation. New York: Palgrave Macmillan.

Higgins, Rawinia, and Paul Meredith

2012 Te Mana o te Wāhine - Māori Women - Tapu and Peacemaking. Te Ara - The Encyclopedia of New Zealand (updated 11 June 2013).

http://www.TeAra.govt.nz/en/te-mana-o-te-wahine-maori-women/page-2 (accessed 16 September 2012).

Hilden, Patricia Penn, and Shari Huhndorf

1999 Performing 'Indian' in the National Museum of the American Indian. Social Identities 5:161-183.

Hill, Richard S.

2004 State Authority, Indigenous Autonomy: Crown-Māori Relations in New Zealand/Aotearoa 1900-1950. Wellington: Victoria University Press.

- 2009 Māori and the State: Crown-Māori Relations in New Zealand/Aotearoa, 1950-2000. Wellington: Victoria University Press.

Hill, Richard S., and Brigitte Bönisch-Brednich

2007 Politicizing the Past: Indigenous Scholarship and Crown-Maori Reparations Processes in New Zealand. Social and Legal Studies: An International Journal 16(2):163181. 
- 2009 Fitting Aotearoa into New Zealand: Politico-Cultural Change in a Modern Bicultural Nation. In Historical Justice in International Perspective. M. Berg and B. Schaefer, eds. Pp. 239-263. Washington and Cambridge: German Historical Institute and Cambridge University Press.

Hill, Richard S., and Vincent O’Malley

2000 The Māori Quest for Rangatiratanga/Autonomy, 1840-2000. Wellington: Treaty of Waitangi Research Unit, Stout Research Centre, Victoria University of Wellington.

Hill, Jane H.

2001 The Radicalizing Function of Language Panics. In Language Ideologies: Critical Perspectives on the Official English Movement, vol. 2: History, Theory, and Policy. R. Duenas Gonzales and I. Melis. Mahwah, NJ: Lawrence Erlbaum.

Hirsch, Joanne S., and Lois H. Silverman, eds.

2000 Transforming Practice: Selections from the Journal of Museum Education, 19921999. Washington: MER.

Holmes, Janet, Meredith Marra, and Bernadette Vine

2011 Leadership, Discourse and Ethnicity. Oxford: Oxford University Press.

Hooper-Greenhill, Eilean

2000 Museums and the Interpretation of Visual Culture. New York: Routledge.

—, ed. 1994 The Educational Role of the Museum. London: Routledge.

Howe, Paora

2005 Biculturalism: The New "Cool". People and Performance 13(3):10-14.

Hudson, Kenneth

2004 The Museum Refuses to Stand Still. In Museum Studies: An Anthology of

Contexts. B.M. Carbonell, ed. Pp. 85-91. Malden, MA: Blackwell Publishing.

Hüsken, Ute

2007 Ritual Dynamics and Ritual Failure. In When Rituals Go Wrong. U. Hüsken, ed. Pp. 337-366. Leiden: Brill.

Ihaka, Kingi

1989 Biculturalism and Museums from a Maori Point of View. AGMANZ Journal 20(2):12-13.

International Council of Museums (ICOM)

2004 ICOM Code of Ethics for Museums. Revised. Available online at: http://archives.icom.museum/ethics.html (accessed 1 April 2009). 
- 2007 Museum Definition. According to the ICOM Statutes, adopted during the 21st General Conference in Vienna, Austria. Available online:

http://icom.museum/the-vision/museum-definition/ (accesses 1 April 2009).

Irwin, K.

1994 Maori Research Methods and Practices. SITES: A Journal of Social Anthropology and Cultural Studies 28(Autumn):25-43.

Jackson, Anthony, and Jenny Kidd, eds.

2011 Performing Heritage: Research, Practice and Innovation in Museum Theatre and Live Interpretation. Manchester and New York: Manchester University Press.

Jackson, Moana

1988 The Maori and the Criminal Justice System: A New Perspective: He Whaipaanga

Hou. Part 2. Wellington: Policy and Research Division, Department of Justice.

James, Colin

2005 Unifying a Divided Country is the Next PM's Big Challenge. New Zealand Herald, 5 September 2005.

Janes, Robert R., and Gerald T. Conaty, eds.

2005 Looking Reality in the Eye: Museums and Social Responsibility. Calgary:

University of Calgary Press.

Janesick, Valerie J.

2010 Oral History for the Qualitative Researcher: Choreographing the Story. New York: Guilford Press.

Jenkins, Tiffany

2011 Contesting Human Remains in Museum Collections: The Crisis of Cultural Authority. New York: Routledge.

Jimenez, Alberto Corsin, ed.

2007 The Anthropology of Organisations. Aldershot, England: Ashgate.

Johnstone, Karl

2006 Mātauranga Māori and Museum Practice. National Services Te Paerangi.

Jones, Michael O., Michael D. Moore, and Christopher S. Richard, eds.

1988 Inside Organizations: Understanding the Human Dimension. Newbury Park:

Sage. 
Kaeppler, Adrienne L.

1991 Taonga Maori and the Evolution of the Presentation of the "Other". In Taonga Maori Conference, New Zealand, 18-27 November 1990. M. Lindsay, ed. Wellington: Cultural Conservation Advisory Council, Department of Internal Affaris.

- $1994 \quad$ Paradise Regained: The Role of Pacific Museums in Forging National Identity. In Museums and the Making of 'Ourselves': The Role of Objects in National Identity. F.E.S. Kaplan, ed. Pp. 19-44. London: Leicester University Press.

Kalinke, Heinke M., Klaus Roth and Tobias Weger

2010 Esskultur und kulturelle Identität: Ethnologische Nahrnungsforschung im östlichen Europa [Eating Habits and Cultural Identity: Ethnological Nutrition Research in Eastern Europe]. Oldenbourg Wissenschaftsverlag.

Kaplan, Flora E.S., ed.

1996 Museum and the Making of 'Ourselves': The Role of Objects in National Identity. London: Leicester University Press.

Kāretu, Timoti S.

1995 "Māori Language Rights in New Zealand." In Linguistic Human Rights: Overcoming Linguistic Discrimination. T. Skutnabb-Kangas and R. Phillipson, eds. Pp. 209-218.

Berlin: Moutou de Gruyter.

Karp, Ivan, Gustavo Buntinx, Barbara Kirshenblatt-Gimblett, and Ciraj Rassool, eds.

2006 Museum Frictions: Public Cultures/Global Transformations. Durham: Duke University Press.

Karp, Ivan, and Steven D. Lavine, eds.

1991 Exhibiting Cultures: The Poetics and Politics of Museum Display. Washington: Smithsonian Institution Press.

Karp, Ivan, Christine Mullen Kreamer, and Steven D. Lavine, eds.

1992 Museums and Communities: The Politics of Public Culture. Washington: Smithsonian Institution Press.

Kawharu, Ian H.

2008 Biculturalism and Inclusion in New Zealand: The Case of Orakei. Anthropologica 50(1):49-56.

Kawharu, Merata

2004 Indigenous Governance in Museums: A Case Study: The Auckland War Memorial Museum. In The Dead and Their Possessions: Repatriation in Principle, Policy and Practice. C. Fforde, J. Hubert, and P. Turnbull, eds. Pp. 293-302. New York: Routledge. 
Kaye, Michael

Myth-makers and Story-tellers: How to Unleash the Power of Myths, Stories and Metaphors to Understand the Past, Envisage the Future, and Create Lasting and Positive Cultural Change in Your Organisation. Chatswood, N.S.W.: Business and Professional Publishing.

Keith, Hamish

1984 Letter to Editor. New Zealand Listener, 27 October 1984.

- $2000 \quad$ Let's Have More Museum and Less McDonald's. New Zealand Herald, 31 January: A19.

Kelsey, Jane

1996 From Flagpoles to Pine Trees: Tino Rangatiratanga and Treaty Policy Today. In Nga Patai: Racism and Ethnic Relations in Aotearoa/New Zealand. P. Spoonley, D. Pearsom, and C. Macpherson, eds. Pp. 177-201. Palmerston North: Dunmore Press.

Kertzer, David I.

1988 Ritual, Politics and Power. Yale: Yale University.

Kincheloe, Joe L., and Shirley R. Steinberg

1997 Changing Multiculturalism. Philadelphia: Open University Press.

King, Michael

1983 Whina: A Biography of Whina Cooper. Auckland: Hodder and Stoughton.

- 1988 Being Pakeha: An Encounter with New Zealand and the Maori Renaissance. Auckland: Hodder and Stoughton.

- $\quad 2000$ Allegiance to One's Origins: The Consequences of Belief. Paper delivered to Sea of Faith Network (NZ) Conference: Beyond Belief-Putting Faith Into Practice. Havelock North. Available online at: http://www.sof.org.nz/origins.htm (accessed 1 February 2012).

- $\quad 2003$ The Penguin History of New Zealand. Auckland: Penguin.

Kirshenblatt-Gimblett, Barbara

1998a Destination Culture: Tourism, Museums, and Heritage. Berkeley: University of California Press.

- $\quad 1998$ b quoted in 'No Shame in Being So Popular'. The Australian, July 10, p.14.

- 2004 Refugium für Utopien? Das Museum: Einleitung [Refugium for Utopias? The Museum: Introduction]. In Die Unruhe der Kultur: Potentiale des Utopischen. J. Rüsen, M. Fehr, and A. Ramsbock, eds. Pp. 187-196. Weilerswist: Velbrück Wissenschaft. 
Knell, Simon J., Suzanne Macleod, and Sheila Watson, eds.

2007 Museum Revolutions: How Museums Change and Are Changed. London and New York: Routledge.

Knell, Simon J. et al., eds.

2010 National Museums: New Studies From Around the World. New York: Routledge.

Knoblauch, Hubert

2003 Qualitative Religionsforschung: Religionsethnographie in der eigenen

Gesellschaft [Qualitative Religion Research: Ethnography of Religion in one's own

Society]. Paderborn: Schöninghausen.

König, René

1974 Das Interview: Formen, Technik, Auswertung [The Interview: Forms,

Techniques, Analysis]. Köln.

Kopytoff, Igor

1986 The Cultural Biography of Things: Commoditization as Process. In The Social Life of Things: Commodities in Cultural Perspective. A. Appadurai, ed. Pp. 64-91. Cambridge: Cambridge University Press.

Korff, Gottfried

2002 Speicher und/ oder Generator: Zum Verhältnis von Deponieren und Exponieren im Museum [Depot and/ or Generator: About the Relation of Depositing and Exhibiting in Museums]. In Museumsdinge: Deponieren - Exponieren. G. Korff, ed. Pp. 167-178.

Köln: Böhlau.

Korff, Gottfried, and Martin Roth

1990 Das Historische Museum: Labor - Schaubühne - Identitätsfabrik [The Historic Museum: Laboratory - Playhouse - Identity Factory]. Frankfurt am Main: Campus.

Kreps, Christina

2003 Liberating Culture: Cross-Cultural Perspectives on Museums, Curation, and Heritage Preservation. London and New York: Routledge.

- 2006 Non-Western Models of Museums and Curation in Cross-Cultural Perspective. In A Companion to Museum Studies. S. Macdonald, ed. Pp. 457-472. Oxford: Blackwell Publishing.

Krmpotich, Cara, and Laura L. Peers

2011 The Scholar Practitioner Expanded: An Indigenous and Museum Research Network. Museum Management and Curatorship 26(5):421-440. 
Kukutai, Tahu

2009 In Search of Ethnic New Zealanders: National Naming in the 2006 Census. Social Policy Journal of New Zealand (36):46-62.

- 2011 Contemporary Issues in Māori Demography. In Māori and Social Issues. T. McIntosh and M. Mulholland, eds. Pp. 11-48. Wellington: Huia.

Kumoll, Karsten

2005 'From the Native's Point of View'? Kulturelle Globalisierung nach Clifford Geertz und Pierre Bourdieu [Cultural Globalisation After Clifford Geertz and Pierre Bourdieu]. Bielefeld: Transcript.

Kunda, Gideon

1992 Engineering Culture: Control and Commitment in a High-Tech Corporation. Philadelphia: Temple University Press.

Kuper, Adam

2003 The Return of the Native. Current Anthropology 44(3):389-402.

Labrum, Bronwyn, and Conal McCarthy

2005 Museum Studies and Museums: Bringing Together Theory and Practice. Special Issue - New Reserach in Museum Studies. Te Ara - Journal of Museums Aotearoa 30(2):4-11.

Larner, Wendy

1997 'A Means to an End': Neoliberalism and State Processes in New Zealand. Studies in Political Economy 52(Spring):7-38.

Leavy, Patricia

2011 Oral History. Oxford: Oxford University Press.

Legget, Jane

1995 Biculturalism in Action. Museum Journal 95(12):22-23.

Lejeune, Philippe

1989 On Autobiography. K. Leary, transl. Minneapolis: University of Minnesota Press.

Lévi-Strauss, Claude

1973 Der Ursprung der Tischsitten [The Origin of Table Manners]. In Mythologica III.

C. Lévi-Strauss, ed. Pp. 504-532. Frankfurt am Main: Suhrkamp. 
Lindner, Rolf

1981 Die Angst des Forschers vor dem Feld: Überlegungen zur teilnehmenden Beobachtung als Interaktionsprozeß - The Researcher's Fear of the Field; Reflections on Participant Observation as an Interactional Process. Zeitschrift für Volkskunde 77(H1):51-66.

Liu, James H.

2005 History and Identity: A System of Checks and Balances for Aotearoa/New Zealand. In New Zealand Identities: Departures and Destinations. J.H. Liu, T.M.

McCreanor, Tracey, and T. Teaiwa, eds. Pp. 69-87. Wellington: Victoria University Press.

Liu, James H., Tim McGreanor, Tracey MacIntosh, and Teresia Teaiwa., eds.

2005 New Zealand Identities: Departures and Destinations. Wellington: Victoria University Press.

Liu, James H., and Chris Sibley

2004 Attitudes Towards Biculturalism in New Zealand: Social Dominance and Pakeha Attitudes Towards the General Principles and Resource-Specific Aspects of

Biculturalism Policy. New Zealand Journal of Psychology 33(2).

Lonetree, Amy

2006 Missed Opportunities: Reflections on the NMAI. American Indian Quarterly 30(3-4):632-645.

- 2009 Museums as Sites of Decolonization: Truth Telling in the National and Tribal Museum. In Contesting Knowledge: Museums and Indigenous Perspectives. S. SleeperSmith, ed. Pp. 322-337. Lincoln: University of Nebraska.

Lord, Barry, ed.

2007 The Manual of Museum Learning. Lanham, MD: Rowman and Littlefield.

Lukes, Steven

1975 Political Ritual and Social Integration. Sociology 9:289-308.

Maaka, Roger, and Augie Fleras

1997 Politicising Property Rights: Tino Rangatiratanga as Constructive Engagement. SITES: A Journal of Social Anthropology and Cultural Studies (35):20-43.

- 2005 The Politics of Indigeneity: Challenging the State in Canada and Aotearoa New Zealand. Dunedin: University of Otago Press. 
Macdonald, Charlotte J.

2009 Two Peoples, One Museum: Biculturalism and Visitor "Experience" at Te Papa"Our Place", New Zealand's New National Museum. In Contested Histories in Public Space: Memory, Race, and Nation. D.J. Walkowitz and L.M. Knauer, eds. Pp. 31-48. Durham: Duke University Press.

Macdonald, Sharon

1995 Consuming Science: Public Knowledge and the Dispersed Politics of Reception Among Museum Visitors. Media, Culture and Society 17:13-29.

- $\quad$ 1997a The Museum as Mirror: Ethnographic Reflections. In After Writing Culture: Epistemology and Praxis in Contemporary Anthropology. A. James, J. Hockey, and A. Dawson, eds. Pp. 161-176. London: Routledge.

- $\quad$ 1997b Reimagining Culture: Histories, Identities, and the Gaelic Renaissance. Oxford and New York: Berg.

- 2001 Ethnography in the Science Museum, London. In Inside Organizations: Anthropologists at Work. D.N. Gellner and E. Hirsch, eds. Pp. 77-96. Oxford: Berg.

- 2002 Behind the Scenes at the Science Museum. Oxford: Berg.

- $\quad 2010 \quad$ Museen Erforschen: Für eine Museumswissenschaft in der Erweiterung [Researching Museums: For Expanding Museum Studies]. In Museumsanalyse. J. Baur, ed. Pp. 49-69. Bielefeld: Transcript.

- 2013 Memorylands: Heritage and Identity in Europe Today. Abingdon, Oxon: Routledge.

—, ed. 2006 A Companion to Museum Studies. Malden, MA: Blackwell Publishing.

Macdonald, Sharon, and Gordon Fyfe, eds.

1996 Theorizing Museums: Representing Identity and Diversity in a Changing World. Oxford: Blackwell Publishing/ The Sociological Review.

Mahuika, Apirana T.

1991 Maori Culture and the New Museum. Museum Anthropology 15(4):9-11.

- 1996 Kawa and the Marae o Te Papa Tongarewa/Museum of New Zealand. Appendix to Paper for the Board. Wellington: Museum of New Zealand Te Papa Tongarewa.

Malaro, Marie C.

1994 Museum Governance: Mission, Ethics, Policy. Washington: Smithsonian Institution Press.

Malinowski, Bronislaw

1954 [1925] Magic, Science and Religion, and Other Essays. Garden City: Doubleday. 
Mallon, Sean

2011 Afterword: Pacific Voices in the Bicultural Museum. In Museums and Māori: Heritage Proefessionals, Indigenous Collections, Current Practice. C. McCarthy. Pp.248253. Wellington: Te Papa Press.

Mane-Wheoki, Jonathan

1995 Imag(in)ing Our Heritage: Museums and People in Aotearoa. AGMANZ Conference 1992. New Zealand Museums Journal 25(1):2-8.

Mannion, Robert

1984 A Pakeha Writer Meets the Maori Renaissance. Metro (October):100-106.

Māori Dictionary

Online version of Te Aka Māori-English, English-Māori Dictionary and Index. http://www.maoridictionary.co.nz/ (accessed 12 April 2013).

Māori Language Act

1987 Available online:

http://www.legislation.govt.nz/act/public/1987/0176/latest/DLM124116.html

(accessed 7 January 2014).

Marcus, George E.

1995 Ethnography in/of the World System: The Emergece of Mulit-Sited Ethnography. Annual Review of Anthropology 24:95-117.

- 2010 Notes from within a Laboratory for the Reinvention of Anthropological Method. In Ethnographic Practice in the Present. M. Melhuus, J.P. Mitchell, and H. Wulff, eds. Pp. 69-79. New York: Berghahn.

Marcus, George E., and Michael M.J. Fischer

1986 Anthropology as Cultural Critique: An Experimental Moment in the Human Sciences. Chicago: Chicago University Press.

Markham, Sydney

1933 A Report on the Museums and Art Galleries of Australia and New Zealand. London: The Museums Association.

Marra, Meredith, and Jo Angouri

2011 Investigating the Negotiation of Identity: A View from the Field of Workplace Discourse. In Constructing Identities at Work. J. Angouri and M. Marra, eds. Pp. 1-14. Houndmills, Basingstoke, Hampshire, and New York Palgrave Macmillan. 
Marra, Meredith, and Janet Holmes

2002 Laughing on the Inside: Humour and Internal Politics in the Workplace. Wellington: Language in the Workplace, School of Linguistics and Applied Language Studies, Victoria University of Wellington.

Marsden, David

1994 Indigenous Knowledge Management and the Management of Indigenous Knowledge. In Anthropology of Organizations. S. Wright, ed. Pp. 41-67. London: Routledge.

Marshall, James, et al., eds.

2000 Politics, Policy, Pedagogy: Education in Aotearoa/New Zealand. Palmerston North: Dunmore Press.

Marshall, R., and P. Sutherland

2008 The Social Relations of Bereavement in the Carribean. Omega 57(1):21-34.

Mason, Rhiannon

2006 Cultural Theory and Museum Studies. In A Companion to Museum Studies. S. Macdonald, ed. Pp. 17-32. Oxford: Blackwell Publishing.

Mauss, Marcel

2000 The Gift: The Form and Reason for Exchange in Archaic Societies. W.D. Halls, transl. London and New York: W.W. Norton.

Maxwell, Anne

1998 Ethnicity and Education: Biculturalism in New Zealand. In Multicultural States: Rethinking Difference and Identity. D. Bennet, ed. London: Routledge.

McCarthy, Conal

2007a Exhibiting Maori: A History of Colonial Cultures of Display. Oxford and New York: Berg.

- 2007b Before 'Te Maori': A Revolution Deconstructed. In Museum Revolutions: How Museums Change and are Changed. S.J. Knell, S. Macleod, and S.E.R. Watson, eds. Pp. 117133. New York: Routledge.

- 2011 Museums and Māori: Heritage Professionals, Indigenous Collections, Current Practice. Wellington: Te Papa Press.

- 2013 The Rules of (Maori) Art: Bourdieu's Cultural Sociology and Maori Visitors in New Zealand Museums. Journal of Sociology 49:2-3. 
McCarthy, Conal, and Joanna Cobley

2009 Museums and Museum Studies in New Zealand: A Survey of Historical Developments. History Compass, 7, (2):395-413.

McCreanor, Tim

2005 'Sticks and Stones May Break My Bones...': Talking Pakeha Identities. In New Zealand Identities: Departures and Destinations. J.H. Liu, T. McCreanor, T. McIntosh, and T. Teaiwa, eds. Pp. 52-68. Wellington: Victoria University Press.

McIntosh, Tracey

2005 Maori Identities: Fixed, Fluid, Forced. In New Zealand Identities: Departures ad Destinations. J.H. Liu, T. McCreanor, T. McIntosh, and T. Teaiwa, eds. Pp. 39-51.

Wellington: Victoria University Press.

McIntosh, Tracey, and Malcolm Mulholland, eds.

2011 Māori and Social Issues. Wellington: Huia.

McKinnon, Malcolm

1996 Immigrants and Citizens: New Zealanders and Asian Immigration in Historical Context. Wellington: Institute of Policy Studies, Victoria University of Wellington.

McLean, Fiona

2007 Museums and the Construction of National Identity: A Review. In The Political Nature of Cultural Heritage and Tourism: Critical Essays. T.J. Dallen, ed. Pp. 329-337. Aldershot, England: Ashgate.

McLeod, Rosemary

2013 Te Papa to Turn into Twins. The Press, 31 January 2013. Available online at: http://www.stuff.co.nz/the-press/opinion/columnists/rosemary-mcleod/8243991/TePapa-to-turn-into-twins (accessed 1 February 2013).

McManus, Greg

1992 The "Te Maori" Exhibition: A Turning Point in New Zealand Museology. In Museums and Europe: New Research in Museum Studies. S.M. Pearce, ed. Pp. 192-199. London: Athlone Press.

McQuire, Scott, and Natalia Radywyl

2010 From Object to Platform: Art, Digital Technology and Time. Time and Society 19(1):5-27.

Mead, (Sidney) Hirini Moko

1984 Te Maori: Maori Art from New Zealand Collections. New York: Heinemann, American Federation of Arts. 
- 1986 Magnificent Te Maori - Te Maori whakahirahira: he korero whakanui i Te Maori. Auckland: Heinemann.

- $\quad 1991$ The Nature of Taonga. In Taonga Maori Conference, New Zealand, 18-27 November 1990. M. Lindsay, ed. Wellington: Department of Internal Affairs.

- 1997 Maori Participation in Museums. Pu Kaea (December 1997c):10-11.

- $2003 \quad$ Tikanga Māori: Living by Māori Values. Wellington: Huia Publishers.

Meaning of Te Papa Tongarewa, Te Papa website:

n. d. http://tepapa.govt.nz/AboutUs/history/Pages/MeaningofTePapaTongarewa.aspx (accessed 1 December 2011).

Melhuus, Marit, Jon P. Mitchell, and Helena Wulff, eds.

2010 Ethnographic Practice in the Present. New York: Berghahn Books.

Meredith, George

1956 An Essay on Comedy. In Comedy S. Wylie, ed. Pp. 3-57. Garden City, N.Y.: Doubleday Anchor Books.

Meredith, Paul

1998 Hybridity in the Third Space: Rethinking Bi-cultural Politics in Aotearoa/New Zealand. Paper presented to Te Oru Rangahau Maori Research and Development Conference, School of Maori Studies, Massey University, Palmerston North. Available online at: http://lianz.waikato.ac.nz/PAPERS/paul/hybridity.pdf (accessed 10 March 2009).

- 1999 Going Beyond the Bi-Cultural vs Multi-Cultural Debate. Tu Mai: Offering an Indigenous New Zealand Perspective 5:24-25.

- n.d. Urban Māori - Urban Marae. Te Ara - the Encyclopedia of New Zealand (updated 22 September 2012). http://www.TeAra.govt.nz/en/urban-maori/page-4 (accessed 30 September 2013).

Message, Kylie

2005 Representing Cultural Diversity in a Global Context: The Museum of New Zealand Te Papa Tongarewa and the National Museum of Australia. International Journal of Cultural Studies 8(4):465-485.

- $2006 \quad$ New Museums and the Making of Culture. Oxford: Berg.

Metge, Joan

1967 Alternative Policy Patterns in Multi-racial Societies. In Administration in New Zealand's Multi-racial Society. R.H. Brookes and I.H. Kawharu, eds. Wellington.

- 1976 [1967] The Maoris of New Zealand: Rautahi. London: Routledge and K. Paul. 
- 1995 New Growth from Old: The Whānau in the Modern World. Wellington: Victoria University Press.

- 2010 Tuamaka: The Challenge of Difference in Aotearoa New Zealand. Auckland: Auckland University Press.

Metge, Joan, and Patricia Kinloch

1978 Talking Past Each Other: Problems of Cross Cultural Communications. Wellington: Victoria University Press.

Meyerhoff, Barbara, and Jay Ruby

1982 Introduction. In A Crack in the Mirror: Reflexive Perspectives in Anthropology. J. Ruby, ed. Pp. 1-35.

Miles, Matthew, and A. Michael Huberman

1994 Qualitative Data Analysis: An Expanded Sourcebook. 2nd edition. Thousand Oaks: Sage.

Ministry of Education Website

http://www.educate.ece.govt.nz/learning/exploringPractice/BiculturalPractice/Bicultu ralismTeWhariki.aspx (accessed 17 December 2012).

Ministry for Culture and Heritage

n.d. The Treaty in Brief (updated 23 January 2014).

http://www.nzhistory.net.nz/politics/treaty/the-treaty-in-brief (accessed 27 January 2014).

Ministry of Health (NZ)

2006 Taonga tuku iho Treasures of Our Heritage: Rongoā Development Plan.

Wellington: Ministry of Health.

Ministry of Maori Development / Te Puni Kōkiri

1993 The Benefits of Kura Kaupapa Maori. Wellington: Ministry of Maori Development.

- $1994 \quad$ Mana Tangata: Draft Declaration on the Rights of Indigenous Peoples 1993:

Background and Discussion on Key Issues: An Explanatory Document. Wellington:

Ministry of Maori Development.

Moore, Kevin, ed.

1998 Management in Museums. New Brunswick, NJ: Athlone Press.

Morrison, Hugh

2012 Mana Māori and Christianity. Wellington: Huia. 
Mosse, David

2004 Is Good Policy Unimplementable? Reflections on the Ethnography of Aid Policy and Practice. Development and Change 35:639-71.

- 2005 Cultivating Development: An Ethnography of Aid Policy and Practice. London: Pluto Press.

Mulholland, Malcolm, ed.

2006 State of the Māori Nation: Twenty-first-century Issues in Aotearoa. Auckland:

Reed.

Munz, Peter

2000 Te Papa and the Problem of Historical Truth. History Now 6(1):13-16.

Murchie, M. M.

2001 The Whanganui Regional Museum and Maori, 1895-1995: A Study of the Relationship Between a Museum with a Notable Maori Collection and Regional Iwi. BA Hons Thesis, History, Palmerston North, Massey University.

Murphy, Hineihaea

1999 Bicultural Developments in Museums of Aotearoa: A Way Forward. Te Kaupapa Tikanga-a-rua ki Roto i Nga WhareTaonga o Aotearoa: Anei ko te Huarahi. Wellington: National Services Te Paerangi, Museum of New Zealand Te Papa Tongarewa.

Museums Aotearoa Website

www.museums-aotearoa.org.nz (accessed 1 April 2013).

Museum of New Zealand Project Development Board

1989 A Concept for the Museum of New Zealand Te Papa Tongarewa.

Museum of New Zealand Te Papa Tongarewa

1995 Annual Report of the Museum of New Zealand Te Papa Tongarewa.

- 1996 Language Policy, (internal document).

- 2001 Collection Development Policy, Approved by Board 87 August 2001 (includes revisions to May 2005), (internal document).

- 2002 Domestic Repatriation Policy, approved 23 January, (internal document).

— 2004 Mātauranga Māori Strategy: He Ara Whainga, (internal document).

- 2005 Kete: Intranet Resources for Understanding Biculturalism at Te Papa. Vertical file: Biculturalism. Wellington: Te Aka Matua Library. 
- 2005/06 Annual Report of the Museum of New Zealand Te Papa Tongarewa.

- 2005/08 Statement of Intent.

- 2008/09 Annual Report of the Museum of New Zealand Te Papa Tongarewa.

- 2009-12 Statement of Intent.

- 2010 Draft Kōiwi Tangata Policy, dated 1 October. Available online: http://www.tepapa.govt.nz/SiteCollectionDocuments/AboutTePapa/Repatriation/Draf tKoiwiTangataPolicy10ctober2010.pdf (accessed 8 January 2014).

- 2011/12 Annual Report of the Museum of New Zealand Te Papa Tongarewa.

- 2012 The Tirikatene Family Cloak - A Political Heritage. Story and Video available online at: http://collections.tepapa.govt.nz/theme.aspx?irn=3665 (accessed 30 April 2013).

- n.d. Bicultural Policy, (internal document).

- n.d. Conservation and Tikanga Policy, (internal document).

- $\quad$ n.d. Te Hono ki Hawaiki. Brochure for Visitors.

- n.d. Te Marae ō Te Papa Tongarewa. Brochure for Visitors.

- $\quad$ n.d. Website: www.tepapa.govt.nz (accessed 1 April 2013).

- $\quad$ n.d. Welcome to the Marae. Brochure for Visitors.

Museum of New Zealand Te Papa Tongarewa Act

1992 Available online:

http://www.legislation.govt.nz/act/public/1992/0019/latest/dlm260204.html (accessed 1 July 2008).

Nader, Laura

1972 Up the Anthropologist - Perspectives Gained From Studying Up. In Reinventing Anthropology. D. Hymes, ed. Pp. 285-311. New York: Random House.

National Services Te Paerangi

1999 Wānanga on Bicultural Development in Museums/He Wānanga Tirohanga Rangapū mō Te Kaupapa Tikanga-ā-rua i Roto i Ngā Whare Taonga. Wellington: National Service Te Paerangi at Museum of New Zealand Te Papa Tongarewa.

- 2000 Wānanga on Bicultural Governance and Leadership in Museums. Wellington: National Services Te Paerangi at Museum of New Zealand Te Papa Tongarewa.

- 2003 Taking Care of Taonga. Tātai Kōrero: National Services Te Paerangi Newslink 28 (June): 6. 
- $2004 \quad$ Bicultural Governance. He Rauemi: Resource Guides Issue No. 22.

_ 2005 Regional Partnership for 2005/6. Tātai Kōrero: National Services Te Paerangi Newslink 34 (July):6.

- Website: www.tepapa.govt.nz/nationalservicePages/National_Services.aspx (accessed 1 April 2013).

Neich, Roger

2001 Carved Histories: Rotorua Ngāti Tarawhai Woodcarving. Auckland: Auckland University Press.

Nepe, Tukana

1991 E Hao Nei e Tenei Reanga: Te Toi Huarewa Tipuna, Kaupapa Maori, an Educational Intervention System. Master's Thesis, Education Department, University of Auckland.

Nesus, Cath

2004 Making the Connection - Biculturalism at Work. Te Ara - Journal of Museums Aotearoa 29(1):12-15.

Neuloh, Otto, and Hans J. Teuteberg.

1976 Psychosoziale Ursachen des Fehlverhaltens in der Ernährung [Psycho-Social Reasons for Eating Disorders]. Ernährungsbericht 1976. Deutsche Gesellschaft für Ernährung, Pp. 395-445. Frankfurt am Main.

New Zealand 1990 Commission

1989 The Treaty of Waitangi: The Symbol of Our Life Together as a Nation. Wellington: New Zealand 1990 Commission.

Neyland, Daniel

2008 Organizational Ethnography. Los Angeles and London: Sage.

Ngata, Apirana

1986-8 Apirana Ngata to Te Rangi Hiroa. In Na to Hoa Aroha, from Your Dear Friend:

The Correspondence of Sir Apirana Ngata and Sir Peter Buck, 1925-50. M.P.K. Sorrenson, ed. Auckland: Auckland University Press in association with the Alexander Turnbull Library Endowment Trust and the Maori Purposes Fund Board.

Nicks, Trudy

2003 Introduction. In Museums and Source Communities: A Routledge Reader. L.L. Peers and A.K. Brown, eds. Pp. 19-27. London: Routledge. 
O'Biso, Carol

1987 First Light. Auckland: Heinemann.

O'Hara, Coralie J.

2012 Repatriation in Practice: A Critical Analysis of the Repatriation of Human Remains in New Zealand Museums. Master's Thesis, Museum and Heritage Studies, Victoria University of Wellington.

Okely, Judith

1996 [1975] The Self and Scientism. In Own and Other Culture. J. Okely, ed. London: Routledge.

Oliver, W. H.

2001 Future Behind Us: The Waitangi Tribunal's Retrospective Utopia. In Histories, Power and Loss: Uses of the Past - A New Zealand Commentary. P. McHugh and A. Sharp, eds. Pp. 9-30. Wellington: Bridget Williams Books.

O'Malley, Vincent

2012 The Meeting Place: Māori and Pākehā Encounters, 1642-1840. Auckland: Auckland University Press.

Omura, Keiichi

2003 Comments [on Kuper's 'The Return of the Native']. Current Anthropology 44(3):395-396.

O'Neill, Martin

2001 Participation or Observation? Some Practical and Ethical Dilemmas. In Inside Organizations: Anthropologists at work. D.N.a.E.H. Gellner, ed. Pp. 221-230. Oxford Berg.

Orange, Claudia

2011 [1987] The Treaty of Waitangi. $2^{\text {nd }}$ edition. Wellington: Bridget Williams Books.

O'Regan, Gerard

1995 Bicultural Developments in Museums of Aotearoa: Obtaining a Maori Perspective. Wellington: Taonga o Aotearoa National Services of the Museums of New Zealand, Museums Association of Aotearoa New Zealand.

- $\quad 1997$ Biculturalism, the Treaty and the Spirit of Partnership. New Zealand Museums Journal 26(2):28-30.

O'Regan, Gerard, and David Russell

2003 To Bury or Not to Bury: The Future of our Kōiwi Tangata. Te Karaka (Raumati/Summer 2003):n.p. 
O'Reilly, T., and D. Wood

1991 Biculturalism and the Public Sector. In Reshaping the State: New Zealand's Bureaucratic Revolution. J. Boston et al., eds. Pp. 320-342. Auckland: Oxford University Press.

O'Sullivan, Dominic

2007 Beyond Biculturalism: The Politics of an Indigenous Minority. Wellington: Huia.

Oxford Dictionaries

Available online: http://www.oxforddictionaries.com (accessed 29 April 2013).

Paku, Rhonda

2009 Biculturalism at Te Papa Tongarewa. Paper delivered at 'Raise Your Voice':

Fourth National Public Galleries Summit. Townsville.

Palmer, Matthew S. R.

2008 The Treaty of Waitangi in New Zealand's Law and Constitution. Wellington: Victoria University Press.

Parkinson, Robin

1998 Design in Exhibits. Architecture New Zealand February (Special Edition 'The Designing of Te Papa'):61-62.

Pearson, David

1989 Pakeha Ethnicity: Concept or Conundrum. SITES: A Journal of Social Anthropology and Cultural Studies 18:61-72.

Pearson, David, and Jeffrey Sissons

1997 Pakeha and Never Pakeha. SITES: A Journal of Social Anthropology and Cultural Studies 35:64-80.

Peers, Laura L. and Alison K. Brown, eds.

2003 Museums and Source Communities: A Routledge Reader. New York: Routledge.

Penetito, Wally

2010 What's Māori About Māori Education?: The Struggle for a Meaningful Context. Wellington: Victoria University Press.

Phillips, Ruth

2005 Replacing Objects: Historical Practices for the Second Museum Age. Canadian Historical Review 86(1):83-110. 
Pickering, Michael

2001 Stereotyping: The Politics of Representation. Basingstoke, Hampshire: Palgrave.

Pickering, Michael, and Paul Turnbull, eds.

2010 The Long Way Home: The Meanings and Values of Repatriation. New York: Berghahn Books.

Pipi, Kataraina, Fiona Cram, Rene Hawke, Sharon Hawke, Te Miringa Huriwai, Tania Mataki, Moe Milne, Karen Morgan, Huhana Tuhaka, and Colleen Tuuta, eds.

2004 A Research Ethic for Studying Maori and Iwi Provider Success. Social Policy Journal of New Zealand (23):141-153.

Poata-Smith, Evan S. Te Ahu

1996 'He Pokeke Uenuku i Tu Ai: The Evolution of Contemporary Maori Protest. In Ngā Patai: Racism and Ethnic Relations in Aotearoa/New Zealand. P. Spoonley, D. Pearson, and C. Macpherson, eds. Palmerston North: Dunmore Press.

Pomare, Maui, and James Cowan

1930 Legends of the Maori. Wellington: Fine Arts.

Pomian, Krzysztof

1992 Museum, Nation, Nationalmuseum [Museum, Nation, National Museum]. In Die Nation und ihre Museen. M.-L.v. Plessen, ed. Pp. 19-32. Frankfurt am Main: Campus.

- $\quad 2007$ Was macht ein Museum erfolgreich? [What Makes a Museum Successful?]. Museumskunde 72(7):16-25.

Pommier, Edouard

2006 Wien 1780 - Paris 1793: Welches der beiden Museen war wohl das revolutionärste? [Vienna 1780 - Paris 1793: Which of the Two Museums was the Most Revolutionary?] In Tempel der Kunst: Die Geburt des öffentlichen Museums in Deutschland 1701-1815. B. Savoy, ed. Pp. 55-65. Mainz am Rhein: von Zabern.

Potts, Grant

2012 Negotiating the Social in the Ritual Theory of Victor Turner and Roy Rappaport. In Negotiating Rites. U.H.a.F. Neubert, ed. Pp. 277-290. Oxford: Oxford University Press.

Povinelli, Elizabeth A.

2002 The Cunning of Recognition: Indigenous Alterities and the Making of Australian Multiculturalism. Durham [N.C.]: Duke University Press. 
Prakash, Gyan

2012 [2004] Museum Matters. In Museum Studies: An Anthology of Contexts. $2^{\text {nd }}$ edition. B.M. Carbonell, ed. Pp. 317-323. Chichester, West Sussex: Wiley-Blackwell.

Pratt, Mary Louise

1992 Imperial Eyes: Travel Writing and Transculturation. London: Routledge.

Puketapu Hetet, Erenora

1989 Māori Museum Training Programme. AGMANZ Journal 20(1):26-27.

Puklowski, Tracy

2011 Gateways, not Gate-keepers: Exploring the Waharoa as a Model for Working in Partnership. In The Radical Museum: Democracy, Dialogue and Debate. G. Chamberlain, ed. Pp. 79-91: Museum Identity.

Radcliffe-Brown, A. R.

1964 [1922] The Andaman Islander. New York: Free Press.

Raffler, Marlies

2008 Museum - Der Spiegel der Nation? Zugänge zur Historischen Museologie am Beispiel der Genese von Landes- und Nationalmuseen in der Habsburgermonarchie [Museum - The Mirror of the Nation? Approaches Towards Historic Museology in the Example of the Development of Regional- and National Museums in the Habsburg Monarchy]. Wien: Böhlau.

Ramsden, Irihapeti, and Paul Spoonley

1994 The Cultural Safety Debate in Nursing Education in Aotearoa. New Zealand Annual Review of Education 3:161-174.

Raphael, Beverly

2000 Grief and Loss in Australian Society. In Death and Dying in Australia. A. Kellehear, ed. Pp. 116-129. Oxford: Oxford University Press.

Rappaport, Roy

1999 Ritual and Religion in the Making of Humanity. Cambridge: Cambridge University Press.

Rata, Elizabeth

2005 Rethinking Biculturalism. Anthropological Theory 5(3):267-285. 
Reilly, Michael P. J.

2004 Whanaungatanga. In Ki te Whaiao: Introduction to Maori Society. Ka'ai, T. M., Moorfield, J. C., Reilly, M.P. J., and S. Mosley, eds. Pp. 61-72. Auckland: Pearson Education New Zealand Ltd.

Rey Vasquez, Carla

2012 "What's in a lunchbox?" A Story about New Zeland Ideals of Health, Social Class and Ethicity Told Through Sandwiches and the Children Who Eat Them. Master's Thesis, Cultural Anthropology, Victoria University of Wellington.

Richards, Trevor Lawson

1999 Dancing on Our Bones: New Zealand, South Africa, Rugby and Racism. Wellington: Bridget Williams Books.

Riseborough, Hazel

1989 Days of Darkness: Taranaki, 1878-1884. Wellington: Allen and Unwin Historical Branch.

Ritchie, James E.

1992 Becoming Bicultural. Wellington: Huia Publishers, Daphne Brasell Associates Press.

Roper, Brian

1990 Contested Terrain: From Arbitration and Conciliation to Enterprise Bargaining and Company Unionism. New Zealand Monthly Review 325:6-13.

- $\quad 1993 \quad$ The End of the Golden Weather: New Zealand's Economic Crisis. In State and Economy in New Zealand. B. Roper and C. Rudd, eds. Pp. 1-25. Auckland: Auckland University Press.

Rosen, Michael

1985 Breakfast at Spiro's: Dramaturgy and Dominance. Journal of Management 11(2):31-48.

- 2000 Turning Words, Spinning Words: Chapters in Organizational Ethnography. Amsterdam: Harwood Academic Publishers.

Roth, Juliana and Klaus Roth

2001 Interkulturelle Kommunikation [Intercultural Communication]. In Grundriss der Volkskunde: Einführung in die Forschungsfelder der Europäischen Ethnologie. 3. überarbeitete und erweiterte Auflage. R.W. Brednich, ed. Pp. 391-422. Berlin: Dietrich Reimer Verlag. 
Royal, Te Ahukaramū Charles

n.d. 'Māori Creation Traditions - Different Creation Traditions'. In Te Ara - the Encyclopedia of New Zealand (updated 9 November 2012).

http://www.TeAra.govt.nz/en/maori-creation-traditions (accessed 1 December 2013).

- $\quad 1992$ Te Haurapa: An Introduction to Researching Tribal Histories and Traditions. Wellington: Bridget Williams Books and Historical Branch, Dept. of Internal Affairs.

- 1998 Te Whare Tapere: Towards a Model for Māori Performance Art. PhD thesis, Theatre and Film, Victoria University of Wellington.

Ryan, P.M

2008 [1995] The Raupō Dictionary of Modern Māori. 2nd rev. edition. North Shore, N.Z.: Penguin.

Salmond, Anne

2009 [1975] Hui: A Study of Maori Ceremonial Gatherings. 3rd edition. North Shore, N.Z.: Raupo/ Penguin Group.

Sandell, Richard, and Jocelyn Dodd, eds.

2001 Including Museums: Perspectives on Museums, Galleries and Social Inclusion. Leicester: Research Centre for Museums and Galleries, Department of Museum Studies, University of Leicester.

Sandell, Richard, and Eithne Nightingale

2012 Museums, Equality, and Social Justice. Abingdon, Oxon: Routledge.

Schechner, Richard

1993 The Future of Ritual: Writings on Culture and Performance. London: Routledge.

Schorch, Philipp

2010 Te Papa, a Forum for the World? A Narrative Exploration of a Global Public Sphere. PhD Thesis, Museum and Heritage Studies, Victoria University of Wellington.

Schröter, Michael

2002 Wer lacht, kann nicht beissen [Who Laughs Cannot Bite]. Merkur - Deutsche Zeitschrift für europäisches Denken 9/10(56):860-873.

Schubert-McArthur, Tanja

2007 Mit Sack und Pack nach Neuseeland: Zum Gepäck deutscher Auswanderer heute [Everything but the Kitchen Sink: About the Luggage of German Immigrants to New Zealand Today]. Berlin: MANA Verlag. 
- $\quad 2009 \quad$ "Ich hab noch einen Koffer in Berlin": Die Grauzone zwischen Tourismus und Migration am Beispiel des Gepäcks von Neuseelandauswanderern ["I still have a suitcase in Berlin": The Greyzone Between Tourism and Migration Using the Example of the Luggage of Emigrants to New Zealand]. In Dinge auf Reisen: Materielle Kultur und Tourismus. J. Moser und D. Seidl, eds. Pp. 179-195. Münchner Beiträge zur Volkskunde. Münster: Waxmann.

- $\quad$ (in press) Bikulturalität in der Museumspraxis [Biculturalism in Museum Practice]. In: Die neuen 'Wilden'. Zentrum für Interkulturelle Studien (ZIS), ed. Mainz: Zentrum für Interkulturelle Studien (ZIS).

Schwartz, S. J., J.B. Unger, B.L. Zamboanga, and J. Szapocznik

2010 Rethinking the Concept of Acculturation: Implications for Theory and Research. American Psychologist (65):237-251.

Schwartzman, Helen B.

1989 The Meeting: Gatherings in Organizations and Communities. New York: Plenum Press.

- 1993 Ethnography in Organizations. Newbury Park, CA.: Sage.

Schwimmer, Eric, ed.

1968 The Maori People in the Nineteen-Sixties: A Symposium. With the co-operation of John Forster, William Parker and James E. Ritchie. Hamilton: Blackwood and Janet Paul.

Sciascia, Ana

2012 Iwi Exhibitions at Te Papa: A Ngāi Tahu Perspective. Master's Thesis, Museum and Heritage Studies, Victoria University of Wellington.

Selby, Rachael, and Laurie Alison J., eds.

2005 Māori and Oral History: A Collection. Wellington: National Oral History Association of New Zealand (NOHANZ).

Shannon, Jennifer

2009 The Construction of Native Voice at the National Museum of the American Indian. In Contesting Knowledge: Museums and Indigenous Perspectives. S. SleeperSmith, ed. Pp. 218-247. Lincoln: University of Nebraska Press.

- (in press) An Ethnography of 'Our Lives': Collaboration, Native Voice, and the Making of the National Museum of the American Indian. Santa Fe, NM: SAR Press.

Sharp, Andrew

1990 Justice and the Māori: Mãori Claims in New Zealand Political Argument in the 1980s. Auckland: Oxford University Press. 
- 1995 Why Be Bicultural? In Justice and Identity: Antipodean Practices. M. Wilson and A. Yeatman, eds. Pp. 116-133. Wellington: Bridget Williams Books.

- 1997 Justice and the Māori: The Philosophy and Practice of Māori Claims in New Zealand since the 1970s. $2^{\text {nd }}$ edition. Auckland: Oxford University Press.

Shelton, Anthony A.

2006 Museums and Anthropologies: Practices and Narratives. In A Companion to Museum Studies. S. Macdonald, ed. Pp. 64-80. Malden, MA: Blackwell Publishing.

Sherman, Daniel J., ed.

2008 Museums and Difference. Bloomington: Indiana University Press.

Shilling, Chris

2003 The Body and Social Theory. London: Sage.

Shore, Cris, and Susan Wright, eds.

1997 Anthropology of Policy: Critical Perspectives on Governance and Power. London: Routledge.

Shore, Cris, and Susan Wright

2011 Conceptualising Policy: Technologies of Governance and the Politics of Visibility. In Policy Worlds: Anthropology and the Analysis of Contemporary Power . C. Shore, S. Wright and D. Però, eds. Pp. 1-25. New York: Berghahn.

Shore, Cris, Susan Wright, and Davide Però, eds.

2011 Policy Worlds: Anthropology and the Analysis of Contemporary Power. New York: Berghahn.

Sibley, Chris J., and James Liu

2004 Attitudes Towards Biculturalism in New Zealand: Social Dominance Orientation and Pakeha Attitudes Towards the General Principles and Resource-specific Aspects of Bicultural Policy. New Zealand Journal of Psychology 33:88-99.

Simmel, Georg

1957 Soziologie der Mahlzeit [Sociology of the Meal]. In Brücke und Tür: Essays der Philosophen zur Geschichte, Religion, Kunst und Gesellschaft. G. Simmel, ed. Pp. 243250. Stuttgart: Koehler.

Simmons, David R., and Athol McCredie

1984 Te Rarangi Toanga: Catalogue. In Te Maori: Maori Art From New Zealand Collections. S.H.M. Mead, ed. Pp. 175-235. Auckland: Heinemann Publishers. 
Simon, Judith

1989 Aspirations and Ideology: Biculturalism and Multiculturalism in New Zealand Education. SITES: A Journal of Radical Perspectives on Culture 18:23-34.

Simon, Judith, Linda Tuhiwai Smith and Fiona Cram et.al.

2001 Civilising Mission? Perceptions and Representations of the New

Zealand Native Schools System. Auckland: Auckland University Press.

Simpson, Moira

2001 [1996] Making Representations: Museums in the Post-Colonial Era. London: Routledge.

- $\quad 2007 \quad$ Charting the Boundaries: Indigenous Models and Parallel Practices in the Development of the Post-Museum. In Museum Revolutions: How Museums Change and are Changed. S.J. Knell, S. MacLeod, and S. Watson, eds. Pp. 235-249. New York: Routledge.

Sissons, Jeffrey

1989 The Future of Biculturalism in Aotearoa/New Zealand. In Social Science and the Future of New Zealand: A Series of Public Lectures. Pp. 15-24. Dunedin: University of Otago.

- $\quad 1992$ What Did the Shark Say to the Kahawai? Metaphors of Culture Within Ethnic Relations Discourse in New Zealand. New Zealand Sociology 7(1):20-35.

- $2000 \quad$ The Post-Assimilationist Thought of Sir Apirana Ngata: Towards a Genealogy of New Zealand Biculturalism. New Zealand Journal of History 34(1):47-59.

- 2005 First Peoples: Indigenous Cultures and Their Futures. London: Reaktion Books.

- $\quad 2010 \quad$ Building a House Society: The Reorganization of Maori Communities Around Meeting Houses. Journal of the Anthropological Institute 16(1):372-386.

SITES: A Journal of Social Anthropology and Cultural Studies

1989 Being Pakeha. 18 (Special Issue).

Skinner, Damian

2005 Parallel Practices: Biculturalism in Contemporary Art. Hastings: Hawke's Bay Cultural Trust Ruawharo Ta-u-rangi.

Sleeper-Smith, Susan

2009 Contesting Knowledge: Museums and Indigenous Perspectives. In Contesting Knowledge: Museums and Indigenous Perspectives. S. Sleeper-Smith, ed. Pp. 1-5.

Lincoln: University of Nebraska. 
—, ed. 2009 Contesting Knowledge: Museums and Indigenous Perspectives. Lincoln and London: University of Nebraska Press.

Smircich, Linda

1983 Concepts of Culture and Organizational Analysis. Administrative Science Quarterly 28:339-58.

Smith, Dorothy E.

1987 The Everyday World as Problematic: A Feminist Sociology. Boston: Northeastern University Press.

—, ed. 2006 Institutional Ethnography as Practice. Lanham, MD: Rowman and Littlefield.

Smith, Graham Hingangaroa

1990 Research Issues Related to Maori Education. Paper presented at NZARE Special Interests Conference. Education Department, University of Auckland.

Smith, Huhana

2006 The Museum of New Zealand Te Papa Tongarewa. In South Pacific Museums. C. Healy and A. Witcomb, eds. Pp. 10.1-10.3. Melbourne: Monash University ePress.

- 2009 Mana Taonga and the Micro World of Intricate Research and Findings around Taonga Maori at the Museum of New Zealand Te Papa Tongarewa. Special Issue: Matter in Place. SITES: A Journal of Social Anthropology and Cultural Studies 6(2):7-31.

Smith, Linda Tuhiwai, Graham Hingangaroa Smith, and Trudie McNaughton

1999 Working with Maori =Te mahi tahi ki te Maori: A Beginner's Guide for Employers. Auckland: Equal Opportunities Trust.

Smith, Linda Tuhiwai

2006 [1999] Decolonizing Methodologies: Research and Indigenous Peoples. Dunedin: University of Otago Press.

Smith, Vicki

2005 Ethnographies of Work and the Work of Ethnographers. In Handbook of Ethnography. P. Atkinson, ed. Pp. 220-232. London: Sage.

Smith, William Robertson

1995 [1889] Lectures on the Religion of the Semites: Second and Third Series; edited with an introduction and appendix by John Day. Sheffield: Sheffield Academic.

Sola, Tomislav

1992 Museum Professionals: The Endangered Species. In Museums 2000: Politics, People, Professionals, and Profit. P. Boylan, ed. Pp. 101-122. London: Routledge. 
Sorrenson, M.P.K.

1982 Polynesian Corpuscles and Pacific Anthropology: The Home-Made Anthropology of Sir Apirana Ngata and Sir Peter Buck. Journal of the Polynesian Society 91(1):7-28.

Soutar, Monty

1996 Speaking with Authority: Scholarship and Mātauranga at the Museum of New Zealand Te Papa Tongarewa: A Strategy. Wellington: Museum of New Zealand Te Papa Tongarewa.

Soutar, Monty, and Mike Spedding

2000 Improving Bicultural Relationships: A Case Study: The C Company 28 Maori Battalion Collection and Exhibition at Gisborne Museum and Arts Centre. Wellington: Museum of New Zealand Te Papa Tongarewa and National Services Te Paerangi.

Spoonley, Paul

1986 Introduction: Being Pakeha - In Search of Ethnicity. SITES: A Journal of Social Anthropology and Cultural Studies 13:1-13.

- 1988 Racism and Ethnicity. Auckland: Oxford University Press.

- 1991 Pakeha Ethnicity: A Response to Maori Sovereignty. In Nga Take: Ethnic Relations and Racism in Aotearoa/ New Zealand. P. Spoonley, D. Pearson, and C. Macpherson, eds. Palmerston North: Dunmore Press.

- 1995 Constructing Ourselves: The Post-Colonial Politics of Pakeha. In Antipodean Practices. M. Wilson and A. Yeatman, eds. Pp. 96-115. Wellington: Bridget Williams Books.

Spoonley, Paul, David G. Pearson, and Cluny Macpherson, eds.

1996 Ngā Patai: Racism and Ethnic Relations in Aotearoa/New Zealand. Palmerston North: Dunmore Press.

Stam, Deidre C.

2005 The Informed Muse: The Implications of "the New Museology" for Museum Practice. In Heritage, Museums and Galleries: An Introductory Reader. G. Corsane, ed. London: Routledge.

Stanley, Nick, ed.

2007 The Future of Indigenous Museums: Perspectives from the Southwest Pacific. Oxford: Berghahn.

Stanton, John E.

2003 Snapshots on the Dreaming: Photographs of the Past and Present. L.L. Peers and A.K. Brown, eds. Pp. 136-151. London: Routledge. 
Statistics New Zealand for the New Zealand Statistical Association

1986 Maori Statistical Profile 1961-86. Cat No. 04.019

Stefano, Michelle L., Peter Davis, and Corsane Gerard, eds.

2012 Safeguarding Intangible Cultural Heritage. Woodbridge, Suffolk: Boyell Press.

Strathern, Marilyn

1987 The Limits of Auto-Anthropology. In Anthropology at Home. A. Jackson, ed. Pp. 16-37. ASA Monographs. London: Travistock.

- $\quad 2000 \quad$ The Tyranny of Transperancy. British Educational Research Journal 26:309-21.

Sullivan, Keith

2000 Values, Policy and Practice in the Education of Maori in Aotearoa/New Zealand. In Education, Culture and Values. M. Leicester, C. Modgil, and S. Modgil, eds. Pp. 179-193. London and New York: Falmer Press.

Sully, Dean, ed.

2007 Decolonising Conservation: Caring for Maori Meeting Houses Outside New Zealand. Walnut Creek, CA: Left Coast Press.

Swarbrick, Nancy

2012 'Waikato Region - Māori Settlement', Te Ara - the Encyclopedia of New Zealand. Available online at: www.TeAra.govt.nz/en/waikato-region/page-4 (accessed 13 January 2013).

Tahi, Brenda

1995 Biculturalism: The Model of Te Ohu Whakatapu. In Justice and Identity: Antipodean Practices. M. Wilson and A. Yeatman, eds. Pp. 61-77. Wellington: Bridget Williams Books.

Tamaira, A. Marata

2009a Making Myth, Making Nation: Māori Symbols and the Construction of Bicultural Identity in Aotearoa New Zealand. Master's Thesis, Pacific Island Studies, University of Hawai'i.

—, ed. 2009b The Space Between: Negotiating Culture, Place, and Identity in the Pacific. Honolulu: Center for Pacific Islands Studies, School of Hawaiian, Asian and Pacific Studies, University of Hawai i at Mānoa. 
Tamarapa, Awhina

1996a Museum Kaitiaki: Maori Perspectives on the Presentation and Management of Maori Treasures and Relationships with Museums. In Curatorship: Indigenous Perspectives in Post-Colonial Societies: Proceedings of Conference, May 1994. M.M. Ames and M. McKenzie, eds. Pp. 160-169. Ottawa: Canadian Museum of Civilization.

- $\quad$ 1996b Redefining the Keeping Place: Symposium Presentation and Roundtable Discussion. In Curatorship: Indigenous Perspectives in Post-Colonial Societies: Proceedings of Conference, May 1994. M.M. Ames and M. McKenzie, eds. Pp. 170-172, 74-76. Ottawa: Canadian Museum of Civilization.

- 2007 Weaving a Journey: The Story of a Unique Cloak. In Looking Flash: Clothing in Aotearoa New Zealand. B. Labrum, F. McKergow, and S. Gibson, eds. Pp. 94-111. Auckland: Auckland University Press.

Tambiah, Stanley J.

1990 Magic, Science and Religion and the Scope of Rationality. Cambridge: Cambridge University Press.

Tapsell, Paul

1998 Taonga: A Tribal Response to Museums. PhD Thesis, School of Museum Ethnography, University of Oxford.

- 2001 Taonga, Marae, Whenua: Negotiating Custodianship: A Maori Tribal Response to the Museum of New Zealand. In Negotiating Histories: National Museum: Conference Proceedings. D. McIntyre and K. Wehner, eds. Pp. 112-121. Canberra: National Museum of Australia.

- $2004 \quad$ Partnership in Museums: A Tribal Response to Repatriation. In The Dead and Their Possessions: Repatriation in Principle, Policy and Practice. C. Fforde, J. Hubert, and P. Turnbull, eds. Pp. 284-292. New York: Routledge.

- 2006 Ko Tawa: Maori Treasures of New Zealand. Auckland: David Bateman.

Taylor, Charles

1994 The Politics of Recognition. In Multiculturalism. C. Taylor and A. Gutman, eds. Pp. 25-73. New Jersey: Princeton University Press.

Te Ataarangi Website

n.d. $\quad$ http://www.teataarangi.org.nz/ (accessed 5 November 2012).

Te Awekotuku, Ngahuia

1988 He Whare Taonga, He Whare Korero: Are Museums Really Necessary? AGMANZ Journal 19(2):36-37. 
Te Heesen, Anke

2012 Theorien des Museum: Zur Einführung [Museum Theories: An Introduction]. Hamburg: Junius Verlag.

Te Puni Kokiri

1993 The Benefits of Kura Kaupapa Māori. Wellington: Te Puni Kokiri.

Te Runanganui o Tahu

1993 Koiwi Tangata: Te Wawata o Ngai Tahu e pa ana Ki Nga Taoka Koiwi o Nga Tupuna. Christchurch.

Teague, Lynn S.

2007 Respect for the Dead, Respect for the Living. In Human Remains: Guide for Museums and Academic Institutions. V. Cassman, N. Odegaard, and J. Powell, eds. Pp. 245-259. Lanham, MD: Altamira Press.

Temara, Hema, and Karen Mason

1994 Projecting an Image or a Living Reality: The Application of Biculturalism to Museum Education. Museum National 2(4):9-11.

Temm, Paul

1990 The Waitangi Tribunal: The Conscience of the Nation. Auckland: Random Century.

Ten, C.L.

1993 Multiculturalism and the Value of Diversity. In Multicultural Citizens: The Philosopy and Politics of Identity. C. Kukathas, ed. Pp. 7-16. St. Leonhards, NSW:

Multicultural Research Program, Centre for Independent Studies.

Teuteberg, Hans Jürgen ed.

1997 Essen und kulturelle Identität: Europäische Perspektiven [Eating and Cultural Identity: European Perspectives]. Volume 2. Berlin: Akademie Verlag.

Teuteberg, Hans Jürgen, and Günter Wiegelmann

1986 Unsere tägliche Kost: Geschichte und Regionale Prägung [Our Daily Food:

History and Regional Characteristics]. Münster: Coppenrath.

Thode-Arora, Hilke

2009 Weavers of Men and Women: Niuean Weaving and its Social Implications. Berlin: Reimer. 
Thomas, Nicholas

1991 Entangled Objects: Exchange, Material Culture, and Colonialism in the Pacific. Cambridge, MA.: Harvard University Press.

Thompson Rand, Jacki

2009 Museums and Indigenous Perspectives on Curatorial Practices. In Contesting Knowledge: Museums and Indigenous Perspectives. S. Sleeper-Smith, ed. Pp. 129-132. Lincoln: Nebraska University Press.

Thomson, Keith

1981 Art Galleries and Museums of New Zealand. Wellington: Reed.

Tischner, Herbert

1971 Rauru: Ein Versammlungshaus von Neuseeland in der alten Kultur der Maori [Rauru: A Meeting House from New Zealand in the Old Culure of the Maori]. Volume 11. Hamburg: Hamburgisches Museum für Völkerkunde und Vorgeschichte.

Tokarev, Sergej A.

1971 Zur Methodik der ethnographischen Erforschung der Nahrung [Ethnographic Methods of Researching Food]. In Studia Ethnographica et Folkloristica in Honorem Béla Gunda. Pp. 297-302. Debrecen: Kossuth Lajos Tudomanyegyetem.

Tolich, Martin

2002 Pakeha Paralysis: Cultural Safety for Those Researching the General Population of Aotearoa. Social Policy Journal of New Zealand 19:164-178.

Tolksdorf, Ulrich

2001 Nahrungsforschung [The Study of Food]. In Grundriss der Volkskunde:

Einführung in die Forschungsfelder der Europäischen Ethnologie, R.W. Brednich, ed. Pp. 239-254. Berlin: Dietrich Reimer Verlag.

Trotter, Robert T. and Jean J. Schensul

1998 Methods in Applied Anthropology. In Handbook of Methods in Cultural Anthropology. H.R. Bernard, ed. Pp. 691-735. Walnut Creek, California: Altamira Press.

Tschernokoshewa, Elka und Marija Jurić Pahor, eds.

2005 Auf der Suche nach hybriden Lebensgeschichten: Theorie, Feldforschung, Praxis [Searching Hybrid Biographies: Theory, Fieldwork, Practice]. Volume 3. Münster:

Waxmann.

Turner, Victor

1980 Social Dramas and Stories About Them. Critical Inquiry 7(1):141-168. 
Turner, Kaye

1995 The April Report of the Royal Commission on Social Policy: Treaty Partnership as a Framework for a Politics of Difference? In Justice and Identity: Antipodean Practices. M. Wilson and A. Yeatman, eds. Pp. 78-95. Wellington: Bridget Williams Books.

Twigg, Julia

2006 The Body in Health and Social Care. Hampshire: Palgrave Macmillan.

van Gennep, Arnold

1960 [1909] The Rites of Passage. M. B. Vizedom and G. L. Caffee, transl.. Introduction by Solon T. Kimball. London: Routledge and Kegan Paul.

van Maanen, John

1988 Tales of the Field: On Writing Ethnography. Chicago: Chicago University Press.

- 2001 Afterword: Natives 'R' Us: Some Notes on the Ethnography of Organizations. In Inside Organizations: Anthropologists at Work. David Gellner and Eric Hirsch, eds. Pp. 231-261. Oxford: Berg.

- $\quad 2007$ [1979] The Fact of Fiction in Organizational Ethnography. In The Anthropology of Organisations. A.C. Jimenez, ed. Pp. 293-304. Aldershot, England: Ashgate.

van Maanen, John, and Ai-Yen Chen, eds.

1999 The Reflective Spin: Case Studies of Teachers in Higher Education Transforming Action Singapore: World Scientific.

van Maanen, John, and Gideon Kunda

1989 Real Feelings: Emotional Expression and Organizational Culture. In L. L. Cummings and B. M. Staw, eds. Research in Organizational Behavior. Volume 11. Pp. 43-103. Greenwich, CT: JAI Press.

Varine, Hugues de (Varine-Bohan)

1976 Le musee modern: conditions et problemes d'un renovation [The Modern Museum: Conditions and Problems of Renewal]. Museum 28(3):126-139.

1985 Notes en forme d'avant-propos [Notes in the Form of a Forward]. In Nouvelles Muséologies. A. Nicolas, ed. Pp. 3-4. Marseille: Association Museologie Nouvelle et Experimentation Sociale.

Vasil, Raj

2000 [1988] Biculturalism: Reconciling Aotearoa with New Zealand. Wellington: Victoria University Press for the Institute of Policy Studies. 


\section{Veracini, Lorenzo}

2001 Negotiating a Bicultural Past: An Historiographical "Revolution" in 1980 Aotearoa/New Zealand. Wellington: Treaty of Waitangi Research Unit, Stout Research Centre, Victoria University of Wellington.

Vergo, Peter, ed.

1989 The New Museology. London: Reaktion Books.

Wade, Amelia

2010a Anger at Te Papa Ban on Pregnant Women. New Zealand Herald, 12 October.

- $\quad$ 2010b Te Papa Ban on Pregnant Women 'Just Advisory'. New Zealand Herald, 12 October.

- $\quad$ 2010c Te Papa Says Pregnant Women Can Ignore Ban. New Zealand Herald, 13 October.

Waite, Julia

2009 Under Construction: National Identity and the Display of Colonial History at the National Museum of Singapore and the Museum of New Zealand Te Papa Tongarewa. Master's Thesis, Museum and Heritage Studies, Victoria University of Wellington.

Walker, Ranginui

1990a Ka Whawhai Tonu Mātou = Struggle Without End. Auckland: Penguin.

- $\quad$ 1990b The Role of the Press in Defining Pakeha Perceptions of Maori. In Between the Lines: Racism and the New Zealand Media. P. Spoonley and W. Hirsh, eds. Pp. 38-46. Auckland: Heinemann Press.

Walker, Tim

1989 This Thing Called Biculturalism. AGMANZ Journal 20(2):4-5.

Ward, Alan

1995 [1974] A Show of Justice: Racial 'Amalgamation' in Nineteenth Century New Zealand. New edition, corrected and updated. Auckland: Auckland University Press.

- 1999 An Unsettled History: Treaty Claims in New Zealand Today. Wellington: Bridget Williams Books.

Warneken, Bernd Jürgen, and Andreas Wittel

1997 Die neue Angst vor dem Feld. Ethnographisches research up am Beispiel der Unternehmensforschung. Zeitschrift für Volkskunde 93(1):1-16.

Weil, Stephen E.

2002 Making Museums Matter. Washington, D.C.: Smithsonian Institution Press. 
Weiner, Annette

1992 Inalienable Possessions: The Paradox of Keeping-while-giving. Berkeley: University of California Press.

Wellington, Shannon

2013 Building GLAMour: Converging Practice between Gallery, Library, Archive and Museum Entities in New Zealand Memory Institutions. PhD Thesis, Museum and Heritage Studies, Victoria University of Wellington.

Welz, Gisela

1998 Moving Targets: Feldforschung unter Mobilitätsdruck [Moving Targets:

Fieldwork Under the Pressure of Mobility]. Zeitschrift für Volkskunde (94):177-194.

Wendt, Maualaivao Albert

2012 Speech given at the Museums Aotearoa Conference: Collaboration in Practice. Wellington 18-20 April: Te Papa.

Wenger, Etienne

1998 Communities of Practice: Learning as a Social System. Systems Thinker 9(5):210.

White, Richard

1991 The Middle Ground: Indians, Empires, and Republics in the Great Lakes Region, 1650-1815. Cambridge: Cambridge University Press.

- 2006 Creative Misunderstandings and New Understandings. The William and Mary Quarterly 63(1):12-13.

Whiting, Cliff

1998 Setting Standards: Biculturalism - Interview with Cliff Whiting. Architecture New Zealand February (Special Edition 'The Designing of Te Papa'):68-73.

Williams, Henry

1971 A Dictionary of the Maori Language. Wellington: GP Books.

Williams, Paul

2003 New Zealand's Identity Complex: A Critique of Cultural Practices at the Museum of New Zealand Te Papa Tongarewa. PhD Thesis, Cultural Studies, University of Melbourne.

- $\quad 2005 \quad$ A Breach on the Beach: Te Papa and the Fraying of Biculturalism. Museums and Society 3(2):81-97. 
- 2006a Bicultural Space in the Museum: The Case of Te Marae. Fabrications: Journal of the Society of Architectural Historians of Australia and New Zealand (June):91-104.

- 2006b Reforming Nationhood: The Intersection of the Free Market and Biculturalism at the Museum of New Zealand Te Papa Tongarewa. In South Pacific Museums:

Experiments in Culture. C. Healy and A. Whitcomb, eds. Pp. 2.1-2.16. Melbourne: Monash University epress.

Winiata, Maharaia

1956 Leadership in Pre-European Society. Journal of the Polynesian Society 65(3):212-231.

Witcomb, Andrea

2003 Re-imagining the Museum: Beyond the Mausoleum. London: Routledge.

- 2006 Interactivity: Thinking Beyond. In A Companion to Museum Studies. S. Macdonald, ed. Pp. 353-361. Malden, MA: Blackwell Publishing.

Wittel, Andreas

1996 Belegschaftskultur im Schatten der Firmenideologie: Eine ethnographische Fallstudie [Corporate Culture in the Shadow of Institutional Ideology: An Ethnographic Case Study]. Berlin: Rainer Bohn Verlag.

Wolfe, Patrick

1994 Nation and Miscenegation: Discursive Continuity in the Post-Mabo Era. Social Analysis 36(October):93-151.

Woolard, Kathryn

1998 Introduction: Language Ideology as a Field of Inquiry. In Language Ideologies: Practice and Theory. B. Schieffelin, K. Woolard, and P. Kroskrity, eds. Pp. 3-47. New York: Oxford University Press.

Wright, Susan, ed.

1994 The Anthropology of Organizations. London: Routledge.

Wright, Anthony

2000 'Rebirth of the Museum'. Christchurch Press, March 25, p.6.

Ybema, Sierk, Dvora Yanow, Harry Wels and Frans Kamsteeg, eds.

2009 Organizational Ethnography: Studying the Complexities of Everyday Life. London: Sage. 